\title{
Universiteit
}

Leiden

The Netherlands

\section{Bending Opinion : Essays on Persuasion in the Public Domain}

Haaften, Ton van; Jansen, Henrike; Jong, Jaap de; Koetsenruijter, Willem

\section{Citation}

Haaften, T. van, Jansen, H., Jong, J. de, \& Koetsenruijter, W. (Eds.). (2011). Bending Opinion : Essays on Persuasion in the Public Domain. Leiden University Press. Retrieved from https://hdl.handle.net/1887/21371

Version: $\quad$ Not Applicable (or Unknown)

License: $\quad$ Creative Commons CC BY-NC-ND 4.0 license

Downloaded from: https://hdl.handle.net/1887/21371

Note: To cite this publication please use the final published version (if applicable). 


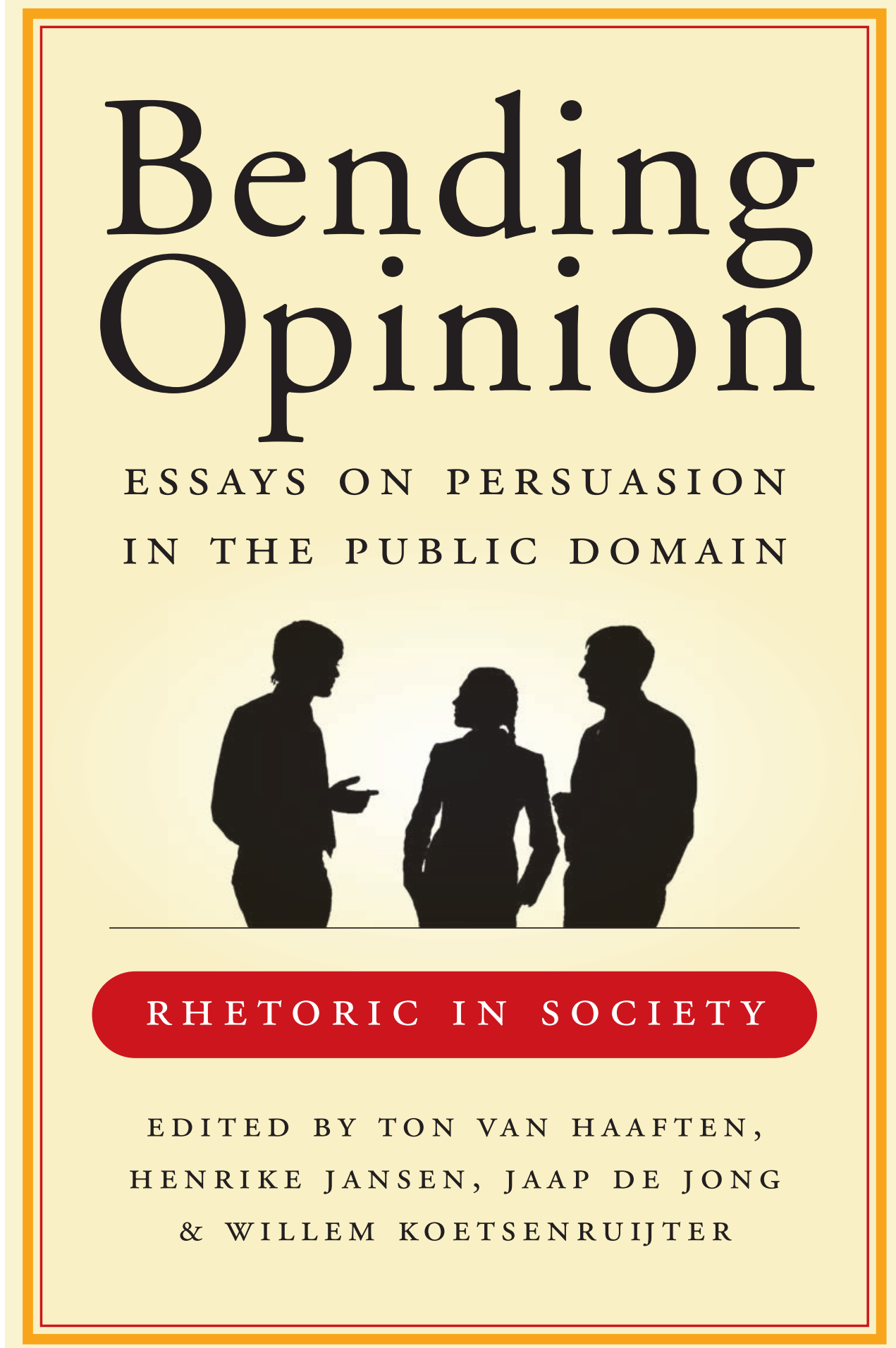

LEI D E U N IVERSITY PRESS 
Bending

Opinion 


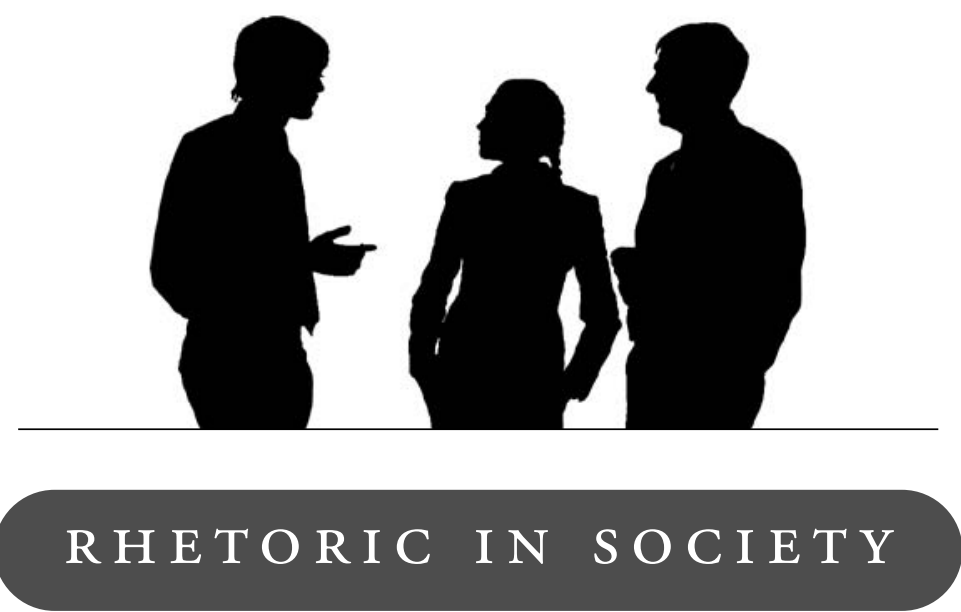




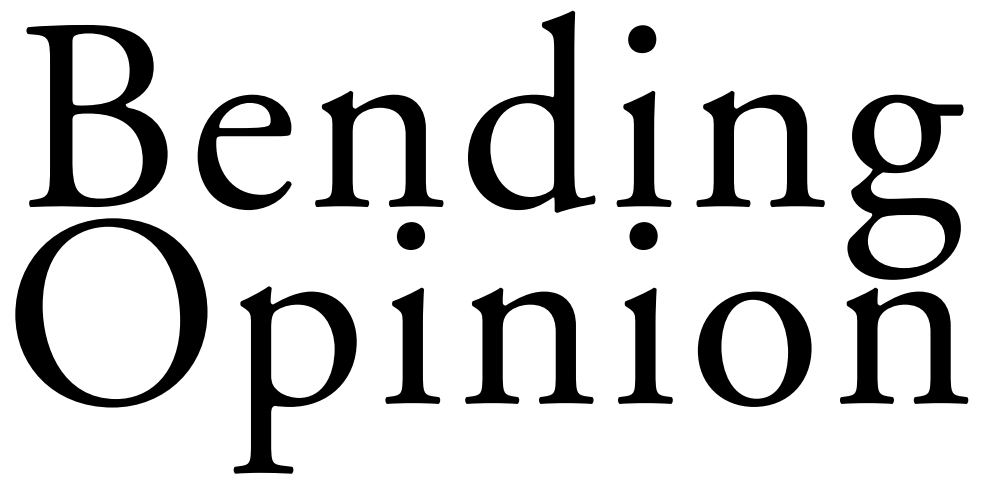

ESSAYS ON PERSUASION IN THE PUBLIC DOMAIN

EDITED BY TON VAN HAAFTEN, HENRIKE JANSEN, JAAP DE JONG $\&$ WILLEM KOETSENRUIJTER

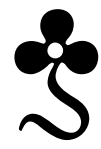


Cover design and lay-out: Mulder van Meurs, Amsterdam

ISBN 9789087280994

e-ISBN 978940060 O2O I

NUR 616

(C) Leiden University Press, 20II

All rights reserved. Without limiting the rights under copyright reserved above, no part of this book may be reproduced, stored in or introduced into a retrieval system, or transmitted, in any form or by any means (electronic, mechanical, photocopying, recording or otherwise) without the written permission of both the copyright owner and the author of the book.

Every effort has been made to obtain permission to use all copyrighted illustrations reproduced in this book. Nonetheless, whosoever believes to have rights to this material is advised to contact the publisher. 


\section{Contents}

\section{Introduction}

TON VAN HAAFTEN, HENRIKE JANSEN, JAAP DE JONG

AND WILLEM KOETSENRUIJTER 9

\section{PART I Fundamentals of Rhetoric}

I Deliberation, Free Speech and the Marketplace of Ideas INEKE SLUITER 25

2 Rhetoric, Classicism and Democracy: The Conveyance of Moral and Political Values in Late Antique Rhetorical Education MANFRED KRAUS 49

3 Melody and Rhythm in Ancient Political Discourse.

On How Emotions Induce Persuasion MARIE FORMARIER 6I

4 Generalizing Stasis Theory for Everyday Use CHRISTIAN KOCK 8I

5 Rhetoric and Argumentation

J. ANTHONY BLAIR 95

PART II The Rhetoric of Verbal Presentation

6 Generalizing about the Persuasive Effects of Message Variations: The Case of Gain-Framed and Loss-Framed Appeals DANIEL J. O'KEEFE II 7

7 The Contribution of Praeteritio to Arguers' Strategic Maneuvering in the Argumentation Stage of a Discussion A. FRANCISCA SNOECK HENKEMANS I33

8 Limits and Effects of Reductio ad Absurdum Argumentation HENRIKE JANSEN, MARIANNE DINGEMANSE AND INGRID PERSOON I43

9 Professionalizing Speech Production. Changes in Is Years of Ministerial Speeches JAAP DE JONG AND BAS ANDEWEG I59 
Io The Correlation between Style and Argument in Newspaper Columns

HILDE VAN BELLE I85

PART III Rhetoric and the Media

II If This Goes On...: The Rhetorical Construction of Future Problems

JOEL BEST 203

I2 Exploring Everyday Ethos. Ethos Techniques in

Online Discussions about Extraordinary Experiences

PETER BURGER AND LOTTE ANEMAET 219

I3 The Popular Virgin and the Wolf in Sheep's Clothing:

A Case Study of the Imaging of Victims and Offenders

WILLEM KOETSENRUIJTER AND GABRY VANDERVEEN 24I

I4 "Conceptual and Fanciful" or "a Depiction of Reality":

Exploiting Visual Modality to Claim Environmental Ethos in uK Advertizements for Automotive and Energy Companies (2007-2008) SUSAN HOGBEN 27I

\section{PART IV Rhetoric and Politics}

Is Rhetoric and the (Re)Constitution of Collective Identity:

The Example of Poland

CEZAR M. ORNATOWSKI 29I

I6 Symbolic Power: Political Rhetoric in a State of Exception

BART VAN KLINK, OLIVIER LEMBCKE AND

PABLO LEANDRO CIOCCHINI 307

I7 Do New Parties Bring Personalization, a Narrow Issue Agenda and Populist Rhetoric? Evidence from Dutch Election

Campaign Coverage from 1998 to 2006

JANET TAKENS, ANITA VAN HOOF,

JAN KLEINNIJENHUIS AND WOUTER ATtEVELDT 327

I8 Parliamentary Debate and Political Culture: The Dutch Case

TON VAN HAAFTEN 349 
PART V The Rhetoric of Topoi

I9 Talking about Sustainability: Responses to Frames in Persuasive Messages about Sustainable Agriculture and Food

BALDWIN VAN GORP AND MARGOT VAN DER GOOT 373

20 Responding to Expert Arguments

Emerging Lay Topoi in Focus Group Interviews on GM Crops

ANDERS HORSBØL 395

2I Speaking of Terror: Challenging Norms of Rhetorical Citizenship in Danish Public Discourse

LISA STORM VILLADSEN 407

22 Strategic Maneuvering with Linguistic Arguments in the Justification of Judicial Decisions

EVELINE FETERIS 423

Contributors 44I

Index 443 



\section{Introduction}

TON VAN HAAFTEN, HENRIKE JANSEN, JAAP DE JONG AND WILLEM KOETSENRUIJTER

The field of rhetoric - from both a practical and a theoretical perspective is highly relevant, not only for conducting debates in the public domain, but for analyzing and evaluating them as well. The idea of democracy is, after all, closely intertwined with the ideal of making transparent decisions based on high quality open discussions in the public domain. Pericles discusses this close relationship as early as the middle of the 5 th century $\mathrm{BC}$ in his famous funeral oration and panegyric of Athens and the Athenians:

Here each individual is interested not only in his own affairs but in the affairs of the state as well: even those who are mostly occupied with their own business are extremely well-informed on general politics - this is a peculiarity of ours: we do not say that a man who takes no interest in politics is a man who minds his own business; we say that he has no business here at all. We Athenians, in our own persons, take our decisions on policy or submit them to proper discussions: for we do not think that there is an incompatibility between words and deeds; the worst thing is to rush into action before the consequences have been properly debated. ${ }^{\mathrm{I}}$

From classical antiquity until the present time, much attention has been paid to questions like: how should public debate be organized and conducted so that it contributes to decision making? And how - in that light - can public speakers effectively construe their message in order to persuade an audience or - in other words - bend its opinion?

Nowadays, research on rhetoric and its relationship to discussions in the public domain has developed into an important area of interdisciplinary scholarship. Theories, methodologies and insights from different academic disciplines are confronted and combined: fields such as classical

I Thucydides (1972). History of the Peloponnesian War. Translated by R. Warner. London: Penguin Books Ltd., p. I47. 
studies, argumentation theory, philosophy, logic, linguistics, history, law, sociology, political science, public administration, criminology, psychology and media studies. The objective of this current collection of essays on persuasion in the public domain is to give an overview of the state of the art in this field of interdisciplinary scholarship and of the different approaches and methodologies that it contains, explained and illustrated with relevant examples and compelling case studies.

The book is divided in five parts, each with a specific theme: Fundamentals of rhetoric (Part I), The rhetoric of verbal presentation (Part II), Rhetoric and the media (Part III), Rhetoric and politics (Part IV) and The rhetoric of topoi (Part v). The themes are overlapping rather than mutually exclusive which means that the various chapters are organized according to their main perspective, but also that all five themes are - to varying degrees addressed in every chapter.

\section{Fundamentals of rhetoric}

The first part of the book focuses on fundamental aspects of the relationship between persuasion and public debate from both historical and theoretical perspectives.

In Chapter I, Ineke Sluiter explores the metaphor of the 'marketplace of ideas' in debates about freedom of speech and political deliberation. Starting from a study of the legal case against the controversial Dutch politician Geert Wilders, Sluiter takes a look at the archaeology of the concept in ancient Greece, fast-forwards to the United States at the beginning of the 2oth century, analyses the nature of the frame of the 'marketplace' and examines three subsequent theories that take their lead from this metaphor: (I) marketplace mechanisms as a way of eliciting information from a group in order to make the deliberative process more effective, (II) the analysis of the metaphor as a vehicle of social criticism and (III) the consequences of more recent insights into the functioning of the actual economy for ideas about freedom of speech. After a brief return to the Wilders case and the 'rhetoric of free speech', the chapter ends by briefly proposing an alternative model for thinking about free speech: an evolutionary theory of rhetoric.

In Chapter 2, Manfred Kraus studies the relationship between rhetorical exercises and a society's value system. It is argued that class room exercises in rhetoric have always been used, at the same time, for conveying 
moral, social, religious and/or political values which may either be in accordance or at variance with a society's prevailing value system. An interesting case is rhetorical education in late antiquity which, although embedded in the environment of a highly centralist and monarchic form of government, still exhibited a strong classicizing trait, praising the democratic and egalitarian values of classical Athens. Using as an example the 4th century Progymnasmata, a textbook of rhetorical exercises compiled by the Antiochian sophist Aphthonius, which takes a decidedly liberal, democratic, anti-monarchic and legalistic stance in a monarchic society, and a pagan if not entirely secular stance in a basically Christian environment, the chapter poses the question as to how these exercises were implemented in the classroom and what impact they had on society. In comparison with medieval and early modern parallels, raising this question also highlights the contemporary problem of how one chooses appropriate topics for rhetorical exercise in an age of political correctness.

In Chapter 3, Marie Formarier discusses the musical quality of speeches. Rhetoric was extremely powerful in Antiquity as speeches were the only media hat gave information about politics. Consequently ancient speakers such as Aristotle or Cicero knew very well how to be persuasive, to attract and keep people's attention; in other words to communicate efficiently. In fact, they were very well aware of the persuasive power of the musical quality of speeches. This chapter elucidates the fundamental principles that determined the use of melody and rhythm in ancient political discourse and clarifies the formal characteristics that were commonly exploited in both musical and rhetorical melodies and rhythms through a complex mimetic process. Ancient theorists used to believe that rhythm and melody could have an impact on the hearer's feelings, beliefs and decisions. This interaction between emotions and political decision-making obviously raises deep ethical concerns as - even today - it can result in political manipulation. Finally, inspired by these ancient rhetorical theories on melody and rhythm, the chapter opens perspectives for oratory analysis.

In Chapter 4, Christian Kock presents a practical reinterpretation of ancient stasis (status) theories which defined the available strategies, or lines of argument, for criminal cases. Central were the three status rationales: the conjectural, the definitional, and the qualitative, equivalent to the questions: What are the facts? How are the facts to be categorized? What particular circumstances characterize them? While these questions problematize 
the facts at issue, another main component of stasis thinking concerned the status legales, i.e., the questions which problematized the laws by which the facts were to be judged. Some theorists also offered lists of strategies for 'practical issues', i.e., political debates. Kock suggests a way of generalizing and integrating these strategies into one scheme which maps out all the strategies which are available in any kind of social disagreement. More importantly, the scheme may also help clarify, for everyone involved, what a disagreement is about, and what it is not about.

Part I concludes with J. Antony Blair's discussion, in Chapter 5, of the relationship between rhetoric and argumentation. Blair describes four ways in which rhetoric and argument, or argumentation, were thought to have been related, after which he comments on some of the implications of these conceptions. The fact that different theorists understand rhetoric, argument and argumentation differently has to be taken into account. In some views all argument is rhetorical, but not all rhetoric concerns argument. In others, argument and rhetoric overlap but neither one completely encompasses the other. In a third view, the rhetorical is just one perspective to take on argument, among others (namely logic and dialectic). In the fourth understanding of the relationship, rhetoric is the enhancement of argument, sometimes legitimately and sometimes not. In the discussion, problems are found with all four views. The first has a too narrow conception of logic; the second, a conception of the domain of rhetorical argument that is too limited; the third, a tendency to reduce to the fourth; and the fourth, too restricted a conception of rhetoric. The principal culprit behind some of these flaws is said to be an insufficiently expansive understanding of rhetoric's internal commitment to reasonableness.

\section{The rhetoric of verbal presentation}

The second part consists of chapters 6 to Io and focuses on the relationship between a message's form and its persuasiveness. It is concerned with stylistic choices regarding the formulation of a message and the use of tropes and other rhetorical devices.

In Chapter 6, Daniel J. O'Keefe discusses the relative persuasiveness of alternative message forms. Social-scientific experiments that address this matter focus on establishing well-founded generalizations about persuasive effects; generalizations such as these naturally provide corresponding principles of effective rhetorical design. O'Keefe focuses on research examining the rel- 
ative persuasiveness of gain-framed messages (which emphasize the advantages of compliance with the communicator's recommendation) and lossframed messages (which emphasize the disadvantages of noncompliance). There has been considerable speculation about whether these two appeal forms differ in relative persuasiveness, either in general or for particular kinds of advocacy topics. And although a great deal of experimental evidence has accumulated on these matters, it has not been systematically retrieved or analyzed - until recently, in a series of meta-analytic reviews. The findings from these reviews turn out to be instructive, not only about the persuasive effects of gain-loss message variations, but also more generally about how experimental social-scientific research concerning persuasion should be performed, reported and interpreted. In particular, the history of gain-loss message framing research illustrates the continuing challenges embodied in the task of developing dependable generalizations about effective message design.

In Chapter 7, A. Francisca Snoeck Henkemans investigates what role the stylistic device of praeteritio can play in arguers' attempts to reconcile their rhetorical with their dialectical aims in the argumentation stage of a discussion by maneuvering strategically. In her discussion of praeteritio she thus makes use of the theoretical framework of the Extended Pragma-Dialectical approach to argumentation that Frans van Eemeren and Peter Houtlosser developed over the last ten years, which consists of an integration of rhetorical insights in the pragma-dialectical approach to argumentation. First, she pays attention to the ways in which praeteritio can be realized in discourse. Next, she gives an analysis of the general effects that the use of praeteritio may have due to the presentational means that are employed. Finally she focuses on the argumentation stage and discusses the ways in which praeteritio may contribute to arguers' dialectical and rhetorical aims when presenting and criticizing arguments.

In Chapter 8, Henrike Jansen, Marianne Dingemanse and Ingrid Persoon argue that the order of information presented in the antecedent and the consequent of an argument's inference license determines whether an argument is interpreted as either a causal or symptomatic one. This conclusion is drawn on the basis of a reformulation of examples of reductio ad absurdum arguments as arguments presented in the 'standard' way. Arguments which appear causal when they are presented as reductio ad absurdum arguments appear symptomatic when they are reformulated as arguments presented in the standard way. That is not to say that these arguments are, or become, causal or 
symptomatic in essence, but only that their presentation affects the initial perception of an argument type. However, there is a limit to the reformulation of arguments. It is shown that causal arguments that were originally presented in a standard way cannot be reformulated as reductio ad absurdum arguments. A subjunctive if...then-clause cannot contain an information structure which starts with the later event (in the if-part) and is then followed by the earlier event (in the then-part). The same holds for some examples of symptomatic argumentation which also contain a temporal difference in the antecedent and consequent of the inference license.

In Chapter 9, Jaap de Jong and Bas Andeweg discuss some rhetorical developments which have taken place in the way that speeches of Ministers and State Secretaries are written in the Netherlands. Every Dutch Minister and State Secretary presents dozens of speeches every year. Fifteen years ago, most of these speeches were written by civil servants, the policy experts of the departments; over the past ten years, however, all the governmental departments have expanded and now include an agency of specialist speechwriters. What are the main rhetorical differences between the speeches written by the civil servants and the speeches written today? An analysis of 66 speeches reveals the following: the speeches became richer, stylistically spoken, and shorter; they contained more humor, comparisons, anecdotes and examples, and the style became more personal. The introductions of the speeches became longer and the closings fulfilled more rhetorical functions. All these differences indicate more rhetorical care and growing craftsmanship in this type of Dutch speech writing.

In the last chapter of Part II, Chapter Io, Hilde van Belle discusses style and argument in the genre of newspaper columns. Columns are a popular genre, yet it is hard to sum up their basic features. In order to explore this phenomenon, Van Belle first tracks down the intense correlation between style and argument in the history of columns. Second, she looks at old and new theories about rhetorical figures and their argumentative function. Finally, she combines these lines of enquiry in a proposal about the actual function of columns and concludes that they make up for the (necessary) blind spot in journalism, i.e., the fact that transparency (neutrality, normality) is the effect of a very strict and traditional low style of writing. Columns are not so much free spaces for political ideas, it is argued, but rather, they are free spaces away from the very strict style prescriptions and traditions employed in the rest of the paper. 


\section{Rhetoric and the media}

Part III consists of chapters II to I4 and focuses on public debates in, and persuasion through, the media. With regard to bending opinion and the use of rhetorical techniques and devices, the role of the media can hardly be overestimated, especially with respect to public debates on social problems.

In Chapter II, Joel Best discusses the rhetorical construction of a specific type of social problems: future problems. He shows that attempts to draw attention to future social problems are inevitably vulnerable to challenge - how can one claim to know what the future holds? He argues that four issues shape the rhetoric of future claims: prediction (what will occur?); magnitude (how big will the problem be?); probability (how likely is it?); and timing (when will it happen?) and that claims regarding each of these issues can be contested. Uncertainty about what the future holds - as well as the competition for public attention - encourage an adoption of rhetoric that makes the future problem seem as serious as possible.

In Chapter 12, Peter Burger and Lotte Anemaet explore the controversial issue of 'drink spiking': is it a genuine crime problem or an urban legend? They illustrate that most of the online discussions of this topic feature personal accounts of alleged victims. How do these victims establish ethos in the face of widespread skepticism? Conversely, what rhetorical devices do debunkers use to dismantle the victims' credibility? Most previous research efforts in this field were carried out by folklorists and social psychologists who did not employ a rhetorical framework, with the notable exception of Oring. Burger and Anemaet seek to expand Oring's 'rhetoric of truth': an enumeration of credibility-enhancing techniques, gleaned from a collection of orally communicated legends. Their model aims to further the understanding of the way extraordinary experiences are constructed in online environments.

In Chapter 13, Willem Koetsenruijter and Gabry Vanderveen examine the way media construct stereotypical images of victims and offenders by using established sets of characteristics. They call these sets 'frames'. Media use these frames as a rhetorical device to convince the public of the guilt or innocence of the parties involved. By using a series of content analyses, the authors provide empirical evidence for ideas which are then developed in analytical and qualitative research about stereotypical victims and offenders. The case they use to achieve this is the story about the missing American girl Natalee Holloway and her (presumed) offender, the Dutch adolescent Joran 
van der Sloot, published in June 2005. The research reported in this chapter is part of a broader multimedia research project about the way in which Dutch media presented the Van der Sloot/Holloway case visually and verbally. In this chapter the authors focus their attention on the photographs which were published in newspapers, magazines and tabloids.

Part III concludes with Susan Hogben's discussion, in Chapter I4, about how environmental ethos can be built. Demonstrating environmental credentials or being 'green' can accrue important financial and reputational advantages for corporations. Building such an image as this is often a rhetorical matter. Environmental ethos can be built on the judicious and accurate use of practical wisdom, a display of shared virtues or virtuous character, and by demonstrating goodwill. Corporations are routinely using brand and product advertizements to do this. Recently, attention is being drawn to assertions that appear to overstate the environmental benefits claimed by corporations. These address both linguistic and visual argument. However, adjudications by the UK advertising regulatory authority do not treat the text and image with rhetorical equity. On the basis of the analysis of a corpus of complaint-generating advertizements, Hogben reveals that low modality linguistic claims such as 'ecological' or 'low emissions' are consistently rejected as misrepresentative. However, low modality images such as sketches or cartoons are either ignored or deemed to be merely fictions and thus not misrepresentations of alleged environmental impact. Only high modality images, deemed to represent reality, attract critical re-appraisal. Attributing different truth-values to images in this way means - the author argues - that corporations can exploit visual modality to build environmental ethos without rebuke.

\section{Rhetoric and politics}

In Part IV, which consists of chapters I5 to I8, the focus is on several aspects of the most notable type of public discussion: the political debate. How does it work, how is it conducted and how do politicians try to persuade whom?

In Chapter 15, Cezar M. Ornatowski proposes a rhetorical framework for examining collective identity formation and transformation in terms of seven constitutive dimensions: membership (who are we?), origin and history (how did we become who we are?), location (where are we?), internal relations (how are we organized?; how do we relate to each other?), external re- 
lations (who are our others?), shared values (what things do we hold in common?) and shared purpose (what are we striving for?). These dimensions represent topoi of collective identity in the rhetorical sense of loci communis, places of argument (analogous to Kenneth Burke's Pentad of Act, Agent, Agency, Scene and Purpose) within which collective identities are constituted, debated and transformed through a variety of discourses and practices.

\section{In Chapter i6, Bart van Klink, Olivier Lembcke and Pablo Leandro} Ciocchini start off from the observation that, in their fight against terrorism, modern states seem to install a permanent state of exception. They focus on the role that the notions connected to the Rule of Law play in key speeches delivered by two political leaders who had to defend exceptional measures which were taken in reaction to terrorist actions and threats: the former British Prime Minister Tony Blair and the current Prime Minister of Spain, Jose Luis Zapatero. The central research questions they address are: How are the anti-terrorist measures justified in the speeches at hand? Are they, legally speaking, created "from nowhere", or are they still related in some way to positive law?

In Chapter 17, Janet Takens, Anita van Hoof, Jan Kleinnijenhuis and Wouter Atteveldt discuss so-called 'populist rhetoric'. New political parties, which have recently gained extensive popular support in the Netherlands, employ a communication style that attracts media attention. In this chapter, the authors focus on three of the characteristics of this communication style, namely the emphasis on party leaders (personalization), the narrow issue agenda and the use of populist rhetoric. They study the rhetoric used by new parties, while taking into account who is voicing this rhetoric, and which issues they are discussing. Election coverage of two Dutch news broadcasts and five national newspapers in the three months preceding the I998, 2002, 2003, and 2006 Dutch national elections were analysed by using a Semantic Network Analysis. The results indicate that the media depict new parties as voicing rhetoric through their party leaders, while employing a narrow issue agenda, and the established parties as adjusting to that communication style when new parties gain popularity.

In the last chapter of Part IV, Chapter I8, Ton van Haaften discusses the influence of political culture on the way that parliamentary debate is conducted. Contrary to what one sees in, for example, the British or French parliament, the debate in the Dutch parliament can be described as a rather 
formal and clinical discussion which, in ideal form, consists of the rational exchange of arguments. Rhetorical techniques are only used in moderation and are generally not appreciated very much by Dutch members of parliament. Within the framework of the Extended Pragma-Dialectical Argumentation Theory and, on the basis of results of political-historical research, Van Haaften attempts to characterize the nature of Dutch parliamentary debate as a culturally determined, specific type of communicative activity. To achieve this he examines a debate on 'Islamic activism' which was held in the Dutch Lower Chamber in 2007 and, using this case, the author illustrates how the debating style of the controversial Dutch anti-Islam politician Geert Wilders challenges the dominant debate culture in the Dutch Parliament.

\section{The rhetoric of topoi}

The fifth and last part of this book consists of Chapters in to 22 and focuses on topoi as places to find arguments and as techniques of argumentation, for example, the techniques for framing an audience or the types of argument used in a legal discussion. What role do topoi play in public debate and how can they be used persuasively?

In Chapter 19, Baldwin van Gorp and Margot van der Goot investigate how citizens respond to persuasive messages about sustainability. Sustainable agriculture and food production present a complex field in which stakeholders need to look for the most effective arguments to communicate that their production methods, in particular, are sustainable. To study this persuasive communication framing theory, a constructionist perspective is used. From a previous study conducted by the authors, six frames are identified that stakeholders use in their communication about sustainable food and agriculture. In this current study, four focus groups were conducted in Belgium to identify how participants respond to texts that used these six frames. The analysis leads to four main findings about how frames work with respect to the abstract issue of sustainability in the agriculture and food system: simplification, figurative analogy, causation and cultural resonance.

In Chapter 20, Anders Horsbøl challenges the view that attitudes towards genetically modified (GM) crops in agriculture are 'utterly resistant to persuasion', as is suggested in a review of the literature. Methodologically, this is achieved by studying opinions as they emerge in situated interaction, in this case in focus groups interviews with both GM experts and laypersons 
without specific knowledge of GM crops. In this chapter, Horsbøl analyses the laypersons' responses to persuasive expert utterances as inventive contributions to the discussion, not just as reactions showing either support or rejection. More specifically, he analyses the topoi in the sense of argumentative 'places' which are realized by the laypersons in dealing with, and making sense of, the new knowledge presented by the experts.

In Chapter 2I, Lisa Storm Villadsen introduces the notion of 'rhetorical citizenship' and discusses its relevance to rhetorical studies through a reading of a contemporary case of political discourse. An examination of critical reactions to two controversial statements illustrates how disappointed expectations to leading figures' public statements led to criticism of their enactment of citizenship and a questioning of their rhetorical agency. The overall claim is that the case suggests that an underdeveloped understanding and appreciation of rhetoric's role in public deliberation can have detrimental effects to such deliberation, including an active or more indirect exclusion of particular points of view, a deferral of certain discussions, and a less tolerant debate culture. It is suggested that public, political debate would benefit from increased attention to, and tolerance of, various manifestations of rhetorical practice, e.g., by combating essentializing argumentation which equates dissent with otherness and embracing a view of debate as productive, not destabilizing for the community.

Part v, and the book itself, conclude with Eveline Feteris' discussion in Chapter 22 of strategic maneuvering in legal discussions. Participants in a legal process often use linguistic arguments to support their claim. In linguistic argument it is argued that the proposed interpretation of a rule is based on the meaning of the words used in the rule in ordinary or technical language. The reason why linguistic arguments are chosen as supports for a legal claim is that they are considered to have a preferred status in justifying a legal decision and, for this reason, in rhetorical terms, constitute a topos in legal discourse. However, this preferred status can also be misused for rhetorical reasons. In this chapter, the author analyses and evaluates two examples of a form of strategic maneuvering with linguistic arguments that often occurs in discussions about the application of legal rules and explains how the strategic maneuvering derails. It becomes clear that the strategic maneuvering with linguistic arguments in these cases consists of a complex form of strategic maneuvering that constitutes a combination of two maneuvers. 
The ideas expressed in the chapters of this book were presented earlier at the second 'Rhetoric in Society' conference, held in January 2009, at Leiden University in the Netherlands. ${ }^{2}$ We would like to thank Inge van der Bijl, Karin Geurtsen, Maarten van Leeuwen, Kathryn Sedman and Yvonne Twisk for their help and support in preparing this book.

Leiden $201 \mathrm{II}$

${ }^{2}$ For the proceedings of this conference, see: Haaften, T. van, H. Jansen, J. de Jong and W. Koetsenruijter (Eds.) (2009). Rhetoric in Society. Papers Second Conference (CD). Leiden: Rhetoric in Society. The first 'Rhetoric in Society' conference took place at Aalborg University, Denmark, in November 2006. For a collection of papers that arose from this conference, see: Dam, L., L. Holmgreen and J. Strunck (Eds.) (2008). Rhetorical Aspects of Discourses in Present-Day Society. Newcastle upon Tyne: Cambridge Scholars Publishing. 




\section{PART I}

Fundamentals of Rhetoric

s 



\title{
I Deliberation, Free Speech and the Marketplace of Ideas
}

\author{
INEKE SLUITER
}

\section{I.I Introduction}

The controversial Dutch politician Geert Wilders is the leader of a political party running on a single-issue ticket: the self-proclaimed battle against Islam. In the process, one of his main selling points is his self-presentation and selffashioning as a (or maybe "the only") champion of free speech. Freedom of speech is central in the whole discussion surrounding this politician. Wilders himself defends his more extreme statements with an appeal to the right to freedom of speech, while at the same time blandly denying that right to Muslims: in his view, the Qu'ran should be prohibited and banished. He remains perfectly undisturbed by opponents pointing out the inconsistency of this rhetorical strategy, which so far seems to have worked for him. Wilders' opponents, too, appeal to constitutional issues of freedom of speech: they claim that Wilders engages in hate speech and that he incites to violence. At the moment, Wilders is on trial on these charges. ${ }^{\text {I }}$

One issue that keeps surfacing in Wilders' views on freedom of speech is the appeal to the "American model", although obviously the legal playing field is constrained by European legislation. Since at least the beginning of the $2 \mathrm{O}^{\text {th }}$ century, the (more permissive) American model was dominated by one metaphor: the marketplace of ideas. That metaphor has traditionally been used in defences of non-intervention, while recent experiences with the "real" marketplace have accustomed us over the past two years to massive state intervention even in capitalist societies with a strong belief in the free market. How should we see the relationship between the marketplace as a rhetorical frame and the real marketplace?

\footnotetext{
${ }^{\mathrm{I}}$ Initially, after a number of plaintiffs had pressed charges, the public prosecutor declined to prosecute. However, the Amsterdam Court of Appeal ordered that the case should go to trial (LJN: BHo496, Gerechtshof Amsterdam).
} 
In this chapter, I would like to cast my net wide, by first exploring the archaeology of the relationship between free speech, political deliberation and the market in ancient Greece (section 1.2), and then fast-forward to the United States at the beginning of the $20^{\text {th }}$ century (section I.3). Obviously, I will not claim that there is a historical continuity between those periods, but the differences and similarities that emerge may be illuminating. I will then proceed to analyse the "frame" of the market (section I.4), and discuss some of the ramifications of the market metaphor in recent scholarship (sections I.5-I.7). In section I.7, I will also briefly return to the Wilders case, and argue that the contributions of New Institutional Economics to theorizing free speech issues offer us a new basis in theory to understand why politicians should have a special responsibility for protecting access to public debate for all. In section I.8 I discuss the rhetorical phenomenon of the "rhetoric of embattled free speech". In the final section, I will offer a hint to an alternative, not primarily economic, model for thinking about free speech: an evolutionary theory of rhetoric.

\section{I.2 Deliberation and the marketplace of ideas in Athens}

There is an ongoing academic debate over the role of "economy" and "market thinking" in classical antiquity. For us, "the economy" is part of our social imaginary, as Charles Taylor calls it (Taylor 2004): it is one of the frames, concepts or metaphors, through which we conceive of political society. A "social imaginary”, as distinct from a social theory, is defined as (Taylor 2004, p. 22):

the ways people imagine their social existence, how they fit together with others, how things go on between them and their fellows, the expectations that are normally met, and the deeper normative notions and images that underlie these expectations.

Even though there are good arguments to assume that a form of economic thinking emerged in classical Athens (Cohen 1992), "marketplace economy" did not play the same role in the ancient social imaginary as in our present time. ${ }^{2}$ However, verbal exchanges in the marketplace did have a symbolic value. They were associated with openness, as opposed to subversive and clandestine dealings; they stood for an interest in the common good, as opposed to the "quietism", the withdrawal from public affairs of which Athenian ideology did not approve (Carter 1986, e.g., p. 39, Manville 1996, p. 38I); their goal was truth-finding through the testing and exchanging of ideas; there 
were definite links, both positive and negative, to the political arena; and intellectuals also thought about the form and underlying norms in these exchanges. In this respect, the archaeology of the concept of the marketplace of ideas is relevant. Let us look at these aspects in some more depth.

The Athenian marketplace, the public space known as the agora, was a favourite hang-out of Socrates because of its unique opportunities for social engagement. After Socrates had been sentenced to death and executed, his defenders use the fact that he operated in the marketplace to emphasize the openness, the public nature, of that interaction, and the absence of deceit or subversiveness (see, for example, Xenophon). ${ }^{3}$ It is on the agora that he could best test the truth of Apollo's famous oracle stating that no man was wiser than Socrates. ${ }^{4}$ For Socrates, this process is inextricably connected with truthfinding, particularly about moral issues, such as the essence of virtue. That, rather than political deliberation, is the point of his philosophical conversations. 5 Socrates is highly sceptical about the possibility that the masses will have the necessary expert knowledge to know the good of the city. Arguably, for Socrates the things about which it is possible to find the truth in the marketplace are all connected with the expert technical knowledge of, for instance, a shoemaker. The market will discover quickly enough whether somebody is good at that or not: if the shoes that were handed in for cobbling turn out to be falling apart when you pick them up, the cobbler won't last a month, he will lose clientele and starve. ${ }^{6}$

${ }^{2}$ The most famous defender of the idea that ancient Greece had no real concepts of commerce and markets is Finley $\left(1999^{2}\right)$. See Manville (1996) on ancient versus modern conceptualizations of citizenship, especially I996, p. 39I on "economic" versus "non-economic" democratic organizations. Cole (1986, p. 893), points out that the Greek version of the ago$r a$-marketplace (as a place of exchange, without all the economic overtones) may be useful to overcome some of the conceptual weaknesses in the applications of the notion of the marketplace of ideas by the US Supreme Court. See section 3 below.

${ }^{3}$ Xenophon, Memorabilia I.I.Io; in Xenophon, Memorabilia I.I.2 the same point is made about Socratic religion, cf. Gigon (1953), ad loc.

${ }^{4}$ Plato, Apologia I7c8; cf. Gorgias 447a8, with the ingenious reading in Doyle (2006). Testing people in the agora: Plato, Apologia 2ob8ff.

5 Cf. the Pseudo-Platonic dialogue Sisyphus, which deals with "deliberation".

${ }^{6}$ Plato, Meno 9id-e. The Socrates character in Plato is not opposed to the market as such: his sketch for an ideal state leaves room for merchants. 
In the same period, however, there are also people for whom there exists a real marketplace of ideas in Athens, people who literally sell their knowledge and thoughts to anyone who would like to listen. These travelling professors are the sophists, the first professional teachers of rhetoric, and the first to link their rhetorical expertise, for sale on a marketplace of ideas, to expertise in political deliberation. In the same passage in Plato in which Socrates professes his faith in the market to discover bad merchandise, he ironically says that surely if somebody like Protagoras has been on this market selling his lessons for over forty years with his reputation intact, he cannot have been sending his students away in a worse moral condition than he found them. Elsewhere, the sophists are repeatedly called merchants, traders, and retailers (emporoi and kapêloi). ${ }^{7}$ In fact, this turns into a very important point in the self-presentation of Socrates, who makes a great effort to distinguish himself from the sophists (although the sophists otherwise share quite a few of his own intellectual interests). The most obvious difference is that Socrates insists that he never received any money for his teaching, in fact, that he would have had nothing to sell since he does not claim to have any particular kind of knowledge. However that is, the sophists are definitely "in the marketplace of ideas".

Although Plato's treatment of the sophists is hostile, and, moreover, has almost completely overwhelmed any independent evidence about them, it is precisely in their circles that one should look for early theory on the relationship between deliberation and rhetoric - and slightly more indirectly democracy. In Plato's dialogue Protagoras, Socrates and Protagoras engage in a lengthy exchange that ultimately revolves around a complex of questions: can we teach "sound deliberation", "the art of good citizenship" or, in Socratic terms, "virtue"? At some point, Socrates wonders why the Athenians allow only experts to speak in the assembly when the issue is, for example, building houses or ships, whereas anyone can take the floor if the topic of deliberation is the common good of the polis. Protagoras couches his explanation in a famous myth about the origins of human civilization (Plato, Protagoras $320 \mathrm{O}-322 \mathrm{~d}$ ).

The myth tells us that once upon a time, when human beings had first been created and were about to be sent forth over the earth, all abilities and gifts were distributed over the living creatures. However, through a terrible

7 Plato, Protagoras 313b-c; Sophistes 223b-e. 
mistake in the distribution process, humans alone were left naked and helpless, without any means to defend themselves, or keep warm. Then Prometheus came to the rescue: he stole fire from the gods, and gave mankind technical skill - but not political skill, since he would have needed to steal that from Zeus himself. Technique is not useless: with its help man invented religion, speech, housing, clothes, and food. They lived by themselves, rather than in cities, which had the unfortunate effect that they kept being killed by animals. Their protection should lie in forming communities, but whenever they tried that, they would treat each other unjustly, for they lacked political skill, the skill to form poleis or "political communities", that Prometheus had been unable to steal for them: as a result they would disperse again, and once again be eaten by animals. Finally, Zeus took mercy and ordered Hermes to distribute two vital qualities to all human beings, justice, and a sense of respect, of social inhibition. All human beings received a part of those, and that is why all human beings may have a vote and a voice when deliberating about justice, and about political virtue.

This myth may count as a justification of deliberative democracy, whether Protagoras intended it as such or not. By nature, human beings have a moral orientation, a sense of justice (dikê), which makes it possible for them to contribute meaningfully to the political decisions of their community. For discussions about freedom of speech, however, the other divine gift may be even more important: aidôs, a sense of "shame", as it is traditionally translated, or maybe rather of the mutual "respect" that keeps people from harming others (cf. Cairns 1993). It is the social skill that makes actual social interaction, on the basis of a shared sense of justice (the other gift), possible. Aidôs does not incite someone to action; it is an emotion that functions as a restraint only. Interestingly, while this emotion is useful and may even be necessary in social interaction (as opposed to our modern view of provocation, shock and offence as possible and permissible side effects of the exercise of freedom of speech), Socrates values it negatively in philosophical exchanges. Instead he advocates, not bashful inhibition, but brash shamelessness in order to get to the bottom of any philosophical problem (van Raalte 2004). In that connection he uses the term parrhêsia, the ancient concept of "free speech": not a right, as in our time, but a highly valued attribute of the good friend, the earnest philosopher, and the responsible citizen (Sluiter and Rosen 2004).

So Protagoras introduces a normative concept of social interaction for the purpose of deliberation. He is also associated with two other slogans that 
are relevant in the context of deliberation: the claim that there are two logoi, two arguments, to be associated with any cause; and the promise that he could make the weaker logos, the weaker argument, stronger. Traditionally, and in line with the hostile approach by Plato, both phrases have been interpreted as indicative of a lack of morality, and of an approach to rhetoric as a ruthless winner-take-all discipline, with the sophist or intellectual as the devil's advocate. However, two recent papers have argued just the opposite, stating that Protagoras' principles are either morally neutral, or even conducive to optimal decision-making. Jane Day (2007) considers the "two logoi" principle the precursor to a highly valuable liberal principle. And Paul Woodruff (2008) has argued convincingly that "making the weaker argument stronger" should be read as a formal strategy to improve political decision-making: before taking a decision, the counterargument to one's own position should be allowed to appear at maximum strength - making the weaker argument stronger, or as strong as possible - so that the final decision is a result of genuine euboulia, "good judgment", "being well-advised", "having taken good counsel”. "Making the weaker argument stronger" is a rhetorical strategy of using polarized and starkly competing views in the service of deliberative political decision making (Woodruff 2008).

Between Socrates and Protagoras we have already encountered a number of the issues that will play a role in the metaphor of the "marketplace of ideas": in Socrates' case, the notions of openness, public process, truth-finding, and the investigation of ideas and their testing; in Protagoras' case, the relation between morality and political rhetoric through the concept of aidôs, a notion rejected by Socrates in a context of a philosophical search for truth. Protagoras also adds the important formal notion of, not just alternative ideas in a common search for truth, but of opposing and competing ideas, presented in a polarized way and at maximum strength, to improve the quality of political decision-making. For us as students of rhetoric, the other issue that is important in this very early marketplace of ideas, is that Socrates is at least nominally, and notwithstanding the highly rhetorical presentation of his own ideas, virulently opposed to rhetoric, which as a technique lacks the grounding in knowledge that would make it morally acceptable to him (since for Socrates virtue is knowledge). Protagoras and his colleagues, on the other hand, are the champions of rhetoric, and Protagoras is much more optimistic than Socrates about the reliability of decisions taken by large assemblies. 


\section{I.3 The US Supreme Court}

After this quick archaeological exploration, we must move on to an equally quick investigation of the metaphor of the marketplace of ideas in our own times, particularly in the United States, where it is the foundational metaphor and conceptual frame for thinking about the First Amendment, the part of the American Constitution that safeguards freedom of expression.

Obviously, political thought in the United States developed in dialogue and debate with the British tradition. Precursors to the marketplace of ideas have been identified in John Milton's Areopagitica of I644, dealing with liberty of thought and expression, and in John Stuart Mill's I859 classic On Liberty (Cole 1986, pp. 876-877). Both start from the notion of a search for truth. According to Stuart Mill, there are three risks when you suppress any opinion: for one thing, it may have been true; second, it may have contained a portion of the truth, which in combination with other available opinions might have led to the discovery of the whole truth; and third, if the suppressed opinion was false, we may have missed a chance of preventing truth from turning into dogma (since there is no need to argue for it any more).

In the United States, the tradition of the metaphor of the marketplace of ideas starts in 1919, when in the wake of wwI four anti-war cases were heard by the Supreme Court, all resulting from the Espionage Act of 1917: the Espionage Act was a piece of legislature curtailing speech that could damage the interests of a nation at war. Maybe the most famous Justice in the history of the Supreme Court, Oliver Wendell Holmes, wrote a dissenting opinion in the fourth of these cases, Abrams v. United States, ${ }^{8}$ in which, interestingly, he not only dissented from his colleagues on the Supreme Court in that particular case, but also from himself in the unanimous opinions penned by Holmes himself in the previous three cases of protests against the war. ${ }^{9}$ In the three previous cases the Supreme Court had upheld the preceding convictions in lower courts, on the basis of the test of 'clear and present danger': sometimes the speech under discussion brings with it a clear and present danger of an immediate and violent disruption of the deliberative process (for instance because it is so incendiary that no

\footnotetext{
${ }^{8} 250$ U.S. 616 (1919).

${ }^{9}$ For Abrams as an instantiation of dissent, see the analysis by Cole (1986, pp. 885-887). For war as the ultimate test of free speech issues, see Stone (2004).
} 
one is going to be willing to hear out any opposing views). If such clear and present danger is at issue, that was considered a legitimate reason to suspend an individual's right to freedom of expression.

In Abrams, the defendants were five people who had pro-Russian leanings and who had printed and distributed 5000 leaflets protesting US policy towards Russia and calling for a general strike, in particular among munitions workers (see Cole 1986, p. 883). The charge, of which they had been found guilty, was an intention to "incite, provoke and encourage resistance to the United States in [the war with Germany]". The Supreme Court again upheld the conviction, but in his dissent Oliver Wendell Holmes pleads for a more laissez-faire approach. Here is the famous peroration to that dissent (at 630), which starts with a very daring move: in complete irony, Holmes states exactly the opposite of what he means to say (Cole 1986, p. 885):

Persecution for the expression of opinions seems to me perfectly logical. If you have no doubt of your premises or your power and want a certain result with all your heart you naturally express your wishes in law and sweep away all opposition. But when men have realized that time has upset many fighting faiths, they may come to believe even more than they believe the very foundations of their own conduct that the ultimate good desired is better reached by free trade in ideas - that the best test of truth is the power of thought to get itself accepted in the competition of the market, and that truth is the only ground upon which their wishes safely can be carried out. That at any rate is the theory of our Constitution. It is an experiment, as all life is an experiment. Every year if not every day we have to wager our salvation upon some prophecy based upon imperfect knowledge.

"Free trade in ideas", "the power of thought to get itself accepted in the competition of the market": these ideas were taken up later, expanded upon and reinterpreted in that specific combination of reverence for precedence and creativity in the light of new societal developments that is typical for legal thinking (Cole 1986). The actual phrase "the marketplace of ideas" is first found in a concurring opinion by Justice Brennan in $1965,{ }^{10}$ who defends not only the right of free expression of individuals, but also the right of the public to receive ideas. This is what he says:

Io Lamont v. Postmaster General 38I U.S. 30I, 307 (1965) (Brennan, J., concurring). 
The dissemination of ideas can accomplish nothing if otherwise willing addressees are not free to receive and consider them. It would be a barren marketplace of ideas that had only sellers and no buyers. ${ }^{\text {I }}$

In the meantime, a different strand of First Amendment thinking also emerges, which I will introduce here because it is also of vital importance in theories about deliberative democracy. Justice Brandeis introduces the phrase "the freedom to think as you will and to speak as you think" (Dutch readers may have been inclined to attribute these words to exuberant politician Pim Fortuyn but in fact the formulation dates back over seventy years to 1927$).{ }^{12}$ Brandeis moved the focus of his reading of the First Amendment from quasi-economic truth-finding to political considerations of individual freedom and communal political deliberation $^{13}-$ I will return to this later.

\section{I.4 Framing free speech in the Supreme Court}

As students of rhetoric, we recognize clearly that the metaphor of the marketplace of ideas functions as a frame. It directs and helps focus thought about whatever concrete example of free expression is before the court. This particular frame, moreover, is usually invoked in support of authorizing free speech. It is well worth investigating the characteristics of the frame somewhat more precisely.

The model of the marketplace that Holmes had in mind is basically that of neoclassical economics; it assumes a laissez-faire economy, in which individual actors, all pursuing their own rational self-interest, have a free, equal and unimpeded access to the common market on which they compete. Their transactions are supposed to be completely efficient and cost-free - this market knows no friction. And there is the notion of the "invisible hand" that will miraculously promote the common good, although the individual actors act out of purely personal self-interest. Holmes explicitly introduced "truth" as that common good: in his view, as in the tradition of Locke, truth is the goal of this economy.

Now obviously, it is not hard to think of some problems connected with this interpretation of the frame in view of more recent economic in-

\footnotetext{
II 38 I U.S. at 308.

${ }^{12}$ Concurring opinion in Whitney v. California 274 U.S. 357, 372-380 (1927).

${ }^{13}$ Cole (1986, p. 888).
} 
sights - in fact, all aspects of the model can be fairly criticized. If that was still necessary, we were effectively disabused of our trust in the laissez-faire economy and cost-free transactions by the massive state interventions necessitated by the recent economic crisis, and by the disastrous results for small investors of poor access to relevant information. Free, equal and unimpeded access to the market for all? Rational behavior? None of it fits our recent experiences. In fact, as Paul Brietzke had already put it (1997, pp. 962-963): the model seems to ignore "a host of factors that make us human" (and he proceeds to mention altruism, habit, bigotry, panic, genius, luck and peer pressures: "we are after all a social animal").. ${ }^{\text {I4 }}$

So, the frame is not realistic, but that never stopped the Supreme Court from using it, in fact the frequency of its use increased. However, the definitions of "the marketplace of ideas" shifted considerably over time, and in fact the Supreme Court does not work with a monolithic concept of the marketplace, but acknowledges many different smaller and larger "marketplaces" (Hopkins 1996, pp. 40-4I).

But quite apart from its actual use in the judiciary, the frame was also reconsidered by theorists for a number of different purposes. In the next section, we will successively look at a proposal to take the market model literally in order to improve the deliberative decision-making process (Sunstein 2006), and at two critiques of the model; one as a vehicle for social criticism (Ingber 1984), the other a revision of the model in light of recent economic insights, and an attempt to rethink their implications for free speech issues (Blocher 2007-2008).

\section{I.5 Markets and democratic deliberation}

Thinking with the frame of the marketplace of ideas has led to further thought on how market mechanisms can be made productive for political deliberation. In an interesting recent book that appeared right before the 2007 global market crisis, Cass Sunstein takes a fresh look at the decisionmaking process (Sunstein 2006): does deliberation really lead to the best possible decisions, maybe even to "truth"? Or does it just legitimize the democratic process, because it leads to consensus, even though the decision

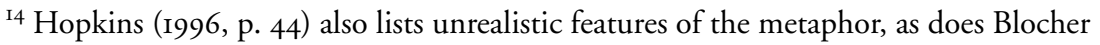
(2007-2008, pp. 832ff), who also discusses a number of features of the economic market that can carry over to the frame of the marketplace of ideas.
} 
itself may be "wrong"? ${ }^{15}$ Under what circumstances does deliberation produce the best results, rather than just forms of group-think?

According to Sunstein it is crucial that the knowledge dispersed in any group be elicited efficiently, because in that case groups spectacularly outperform individuals - something Aristotle also believed. ${ }^{16}$ It has been demonstrated that majority decisions are significantly more reliable than individual decisions, even if taken by experts, as long as the group is big enough and as long as there is a higher statistic probability for each member of the group that they will be right than wrong. Under such conditions, the probability that the group as a whole is right increases steeply, a very important piece of information also for the functioning of juries. ${ }^{17}$ So, for example, if each individual has a $51 \%$ chance of being right, the statistical chance of a group verdict being right may quickly rise to over $70 \%$. Of course, the downside is that if the probability that the individual is wrong exceeds the probability that they are right, the probability of a correct group decision falls rapidly to just about zero. This means that eliciting and sharing knowledge is crucial for a wellfunctioning democracy.

The system recommended by Sunstein to reach this goal of increased availability of knowledge within a group is in fact the price system: following Hayek (1973), he considers prices a superb instrument for aggregating information. Prices are the result of a complex interaction between individual actors and all kinds of factors influencing the market as a whole. Sunstein proposes to use a market system that will allow people to put their money on certain outcomes of political processes. In fact, a number of websites operating on this principle already exist, for example: the Austrian Political Stock market, predicting outcomes of Austrian elections; or the British celeb-

${ }^{\text {Is }} \mathrm{Cf}$. the theory of deliberative democracy as formulated by Gutman and Thompson (2004), who speak about an "Economy of moral disagreement" (2004, p. 7).

${ }^{16}$ Aristotle, Politics 3.II: I28Ia42-bio, 3.I5: I286a22-b22, cf. Manville (1996, p. 382); the assumption that the dêmos will make wiser decisions than any individual is also found in the Attic orators, see Ober (1989, pp. 163-165); Hesk (2000, p. 55 n. 107).

${ }^{17}$ Sunstein (2006, pp. 25-43) on the so-called "Condorcet Jury Theorem". The same principle explains the winning strategy of allowing a game-show candidate to consult the audience in the popular TV show "Who Wants To Be A Millionaire?", recently featured in the movie "Slumdog Millionaire": given the nature of the questions, the majority is highly likely to get the answer right. 
daq, where investors use virtual money to trade shares in celebrities, with amounts paid on the basis of the level of press coverage; or the Hollywood Stock exchange, where one can bet, again with virtual money, on box office successes of actors and movies, an instrument highly valued by movie makers; or the Tech buzz game, in which players can predict the success of new technologies. It is Sunstein's contention that such information markets will encourage people to translate their sometimes hidden knowledge into market activity, and that this will increase the knowledge base of political deliberation. "How many minds produce knowledge" is the subtitle of the book, which we may read as a very literal application of the notion of the marketplace of ideas. Sunstein was aware of the risk of bubbles and manipulation of the information market even before their fatal manifestation in 2007; however, that most recent market failure obviously does not inspire full confidence in his proposal.

\section{I.6 Social critique based on the marketplace of ideas}

One of the presuppositions of Holmes' marketplace of ideas is that of equality of access and opportunity. Again, a comparison with real markets suggests that not only is this quite an unrealistic feature to attribute to real markets, it does not go for the "marketplace of ideas", the arena for free expression, either. Again, then, this is a case where a better look at the real market suggests that this may still be an apposite comparison for the marketplace of ideas, but that expectations about both types of market should be tempered and made more realistic. Not surprisingly given the academic climate at the time, social scientists in the 1980 os pointed out that the marketplace of ideas was overwhelmingly biased in favour of establishment point of views. The whole socialization process of the young, mass communication technology, unequal allocation of resources: all such factors privilege ideas that support "an entrenched power structure or ideology" (Ingber 1984, p. 17). Dissenting ideas should, according to this view, almost be allowed a greater than equal access, given the confirmation bias of most people: most of us are more open to information that confirms what we already think than to what denies or opposes it, and most of us are happier when we can safely agree with the majority (see below, section I.8).

Stanley Ingber (1984) uses this analysis of the relationship between the "real market" and the "marketplace of ideas" to suggest a completely different function for the frame: the marketplace of ideas has the status of a myth 
that serves to legitimize our political system. The kind of conflict that the marketplace of ideas will accommodate does not, according to Ingber, threaten the core values of our society - if it does, those dissident ideas are removed from the marketplace of ideas, for instance by putting them on the other side of the divide between words and action. The "clear and present danger" test is an example of that strategy according to Ingber: as soon as dissenting words have a radically persuasive effect and encourage people to take action, they are no longer protected speech. So, according to Ingber, "free speech is a device by which established interests may both refine their minor differences and promote their commonly held assumptions of truth; it is not a device to change society" ( 1984, p. 76). In this way, the doctrine of free speech also creates a relatively safe and well-circumscribed role for dissidents: their dissent is part of a societal script.

What Ingber does is to appropriate a familiar aspect of political discourse and deconstruct it as a rhetorical ploy, thus turning the frame of the marketplace of ideas into a vehicle for societal critique.

\section{I.7 Tinkering with the model: a New Institutional Economics (NIE) approach to the Wilders case}

Clearly, the notion of a self-regulating non-interventionist marketplace of ideas is contradicted by our real-world experience with actual markets. If one wished to bring the two marketplaces into closer proximity, one could in fact argue that market failures in either market should bring about state intervention. Hate speech, it can be argued, creates a market failure, because it is aimed at shutting up the other party rather than at opening up a discussion. Could this warrant its suppression?

As we saw, one other aspect of the traditional marketplace frame that has come under criticism is that clearly not all individuals and groups have equal access either to the marketplace of ideas, or to the real market. It is not the case that real markets are effortlessly efficient and cost-free. In fact, transactions in the real market come with all kinds of transaction costs, the costs of finding relevant information, evaluating that information, the decisionmaking process, effectuation of the deal etc. But there are also factors in societies that influence those transaction costs, and systematically lower them: a well-functioning press, for instance, makes it easier to get reliable information, and thereby lowers transaction costs. These are economic insights deriving from a line of economic thinking called NIE, or New Institutional 
Economics, of which 1991 Nobel Prize winner Robert Coase was a pioneer. The term "institutional" refers to all the hard and soft norms, rules, regulations and laws of a society: these are the social constructs here called institutions. The press, broadcasting media, and academia are also institutions. But Leiden University, CNN, or the New York Times are called "organizations".

Now, transaction costs can not only be increased or decreased on the real market, but also on the marketplace of ideas. A society that promotes the institution of free accessibility of information lowers transaction costs in its economy. Ancient historian Josiah Ober has argued in a recent book and paper that such economic factors as these, the desired and desirable lowering of transaction costs, may even produce or promote certain values in a society: free speech could be one of those. A society that adopts a principle of free speech thereby structurally lowers transaction costs, and it is therefore in the economic interest of a nation to promote it (Ober 2009 and f.c.).

A recent paper on First Amendment theory by Joseph Blocher (20072008) argued for an "Institutional First Amendment", which theorizes the special status under the First Amendment of certain institutions, e.g., universities, schools, the press. Since these all have the effect of lowering transaction costs, they make it possible for more people to effectively use their First Amendment right to free expression. ${ }^{18}$ Paradoxically, that means that organizations under these institutions (for example individual specific schools or newspapers) should answer to higher standards, and face higher barriers when they wish to restrict certain kinds of speech, for example by removing a certain book from the school library. ${ }^{19}$ Since schools have a special responsibility as a transaction-cost-lowering institution both in the promotion of free speech and the marketplace of ideas, their own handling of free speech issues should be especially sensitive.

This latter way of rethinking the relationship between the economic market and the marketplace of ideas gives us a means to theorize an issue that came to the fore in the Wilders case. According to European jurisdiction, politicians occupy a special position in free speech cases. On the one hand,

\footnotetext{
${ }^{18}$ Hofstadter and Metzger (1955, p. 6I and pp. 403-407) discuss the objection to academic tenure that claims that tenure is an undue protection against market effects resulting from unpopular utterances, since it far exceeds the constitutional protection of other citizens. Within an NIE approach, a defence for this state of affairs can easily be formulated.

I9 Blocher (2007-2008).
} 
their freedom to address issues in ways that others may find provocative, shocking or disturbing is greater than that of the general public, given the political nature of their contribution and the special role they have in public debate and democratic deliberation. On the other hand, the European Court has stated repeatedly that they also carry a special responsibility to protect and enable the exercise of the freedoms of others. We are now in a better position to understand that latter requirement: Parliament is a transaction-costlowering institution. Its members have a particular responsibility to protect the open character of democratic society and not to exclude others from the legitimate exercise of their right. Hate speech, or the call to banish books, constitute violations of this special responsibility by the purposeful and culpable creation of market failures. In this way, we can reconcile recent American First Amendment thinking with the European jurisprudence.

\section{I.8 The rhetoric of embattled free speech}

So far, we have pursued a strand in First Amendment Theory that took its inspiration from the line of thinking of Justice Holmes. This is the moment to recall that second strand in First Amendment Theory, the one not directly related to market thinking, but connected to Justice Brandeis' formulation of "the freedom to think as you will and to speak as you think". What this formulation emphasizes about the importance of free speech is not so much the aspect of truth-finding, or benefit to society as a whole (a more instrumental approach to free speech, that makes it a condition for the functioning of democracy), but rather individual autonomy and self-realization, the right of an individual to express himself or herself. Since being autonomous and independent from the masses and having an opinion of one's own are usually held to be attractive and important character traits that require courage and independence, this view of free speech makes it an appealing topos in political rhetoric.

We may again invoke a comparison with classical Antiquity. In Athens in the fifth and fourth centuries BCE, we see a phenomenon that has been labeled "the rhetoric of rhetoric", or better: the rhetoric of anti-rhetoric, a phenomenon very well analysed by Jon Hesk (2000, pp. 208ff.). The term "rhetoric of anti-rhetoric" refers to the fact that many public speakers, in politics and law courts, self-consciously distance themselves from perverse uses of deceitful rhetoric, while presenting themselves as courageous truth-tellers. They use this topos in their self-presentation to align themselves squarely with public interest, and that would obviously give them an edge in a com- 
petitive environment. Speakers demonstrate in this way that they are aware of the importance of speeches as a vehicle for deliberation and of the dangers posed by deceptive communication (ibid. pp. 4-5). The topos not only functions as a "strategic act of self-authorisation", it is also inherently antagonistic in that one distances oneself from one's adversaries, who are, it is implied, likely to engage in illicit rhetorical maneuvering (ibid. pp.I69, 208). The speaker thus sets up a contrast between truth and sincerity in serving the democratic community versus self-serving deceitfulness. Obviously, this particular rhetoric, as a form of meta-discourse, also plays a genuine role in promoting mass vigilance (ibid. p. 24I).

If we look at the use of the notion of freedom of expression in modern public discourse, we may perceive something similar. Nobody invokes his or her right to freedom of speech when making an uncontroversial point, or a point shared by the majority. Freedom of speech is at issue, precisely when an individual stands out from the group, and when his or her contribution has the potential of being disruptive, shocking, provocative or offensive (to use the language of the European Court of Human Rights). And this is a very uncomfortable position for a speaker to be in: all research, both in evolutionary psychology and modern brain research, indicates that we are hard-wired to be conformists. Our brain gives off frantic error signals whenever we discover that we are in disagreement with the majority, and will flash the warning "social mistake! social mistake!" at us. We experience discomfort and think that we must have been "wrong", when we find out that we are alone in our views, and if given the chance we will quickly "correct" our opinion (Klucharev and others 2009). And yet, our society claims to value independent critical thinking.

The "rhetoric of embattled free speech" helps such dissenting individuals in framing this dilemma. Whenever we hold a point of view that is potentially shocking, provocative or controversial, apart from all intrinsic merits both of free speech itself and of the viewpoints it is supposed to allow, a "rhetoric of free speech", or rather a "rhetoric of embattled free speech" can be a valuable asset in the self-presentation of the speaker, enhancing his or her personal prestige in a competitive environment. From classical antiquity to the present "embattled free speech" carries strong associations with courage (Sluiter and Rosen 2004). Therefore, when speakers present themselves as champions of free speech, as defending a threatened right to free expression, we are at the very least also dealing with a "strategic act of self-authorisation" (Hesk 2000, p. 169). 
This position firmly puts the speaker on the side of democracy and deliberation, and rhetorically, if not in fact, creates the image of a more powerful (or at least more numerous) opponent with whom the speaker does not just disagree, but who threatens the very basis of democratic deliberation. The exercise of free speech is itself performative: democracy, as an egalitarian way of conflict resolution and a system for managing political disagreement, is irrevocably bound up with the use of language. Debating, voting, demonstrating, pronouncing verdict, interpreting the law, legislating: vital functions of democracy consist in the performance of speech acts. The rhetoric of free speech is a performance of democratic behaviour, and it self-reflexively aligns the speaker with this basic aspect of democracy, while it also stimulates mass vigilance over the same issue, as did the "rhetoric of anti-rhetoric" (Hesk 2000, p. 24I).

In Dutch politics we have witnessed a number of debates in recent years, in which issues, which arguably were not, or not primarily "about" speech, were framed as free speech issues by the participants. I am thinking notably of the debate about the position of Islam. Time and again, politicians like Hirsi Ali and Geert Wilders invoked their right to free speech in their statements. Whatever the merits of their positions, this had the additional effect of a self-presentation as beleaguered champions of core values of democracy, but also of automatically framing Islam, their opponent, as inherently anti-democratic; it also often successfully persuaded their political rivals to accept their framing of the debate. When the affair of the Danish Muhammad cartoons was at its peak, and Ayaan Hirsi Ali had invoked a "right to offend" in a speech in Berlin, the Dutch Minister of the Interior at the time, Alexander Pechtold told a group of young liberals that there are limits to freedom of speech, as when somebody incites to hatred or discrimination, and he proceeded as follows: ${ }^{20}$

In the Netherlands the court will judge that. Fortunately, we do not know an absolute "free marketplace of ideas" here, as a free haven for insults and extreme statements with "the last idea standing" as the victor. The court will judge when something goes too far, and that is the way it should be! The exclamation mark especially goes for Ms Hirsi Ali.

\footnotetext{
${ }^{20}$ Speech by Minister Pechtold at the congress of the young liberals (Jovd), I8 March 2006. Source: http://www.minbzk.nl/actueel/toespraken?popup=t...\&ActItmIdt=80797, consulted i9 Jan. 2009.
} 
Notice how Pechtold's acceptance of this free speech frame forces him to take a negative view of the marketplace of ideas. The current trial against Geert Wilders in many ways plays into his hands: he is consistently speaking about a "political trial" that is intended to infringe his right to freedom of speech. Once again, he can pose as the champion of free speech before a court that he accuses of political motives.

The indignation that is apparent in Pechtold's view of the marketplace of ideas as a market with no moral boundaries points out a problem in "markets" and "rhetoric": they are morally blind. Rhetoric (and free speech) is theoretically a morally neutral instrument that can be used for good and bad purposes; the market blindly sorts out competing ideas. However, as soon as we find ourselves in the rhetoric of anti-rhetoric, or the rhetoric of embattled free speech, we are dealing with defences of an allegedly morally responsible use of speech. This issue had worried rhetoricians from the very inception of rhetorical theory, and ancient theory had therefore built in moral safeguards. This is true, for example, of the text that was foundational in rhetorical teaching throughout Roman antiquity and the Western Middle Ages: Cicero's On invention. On invention opens with the then I9-yearold Cicero wondering whether eloquence has brought mankind more harm or more blessings and he comes to the conclusion that wisdom without eloquence is ineffective, but that eloquence without wisdom is positively dangerous. The real orator will need both. Cicero then, like Protagoras, relates his own myth of origin, an origin of mankind and of the emergence of human community and political organization out of an animal-like prehistory. Irrational strength ruled the day. Then, one day a great and wonderful man lifted his fellow-humans out of their state of misery, and taught them culture through a mixture of reason, wisdom and eloquence. They found a political community, but ruthless men of middling ability, but with eloquence, corrupt the young state. They bring disaster on the human community and give eloquence a bad name. As a result, eloquence was ignored by the best, noblest and most talented - wrongly, says Cicero, for they should have put up resistance (in words) and taken better care of their fatherland: their good words should have been used to drive out the bad ones. Cicero ends by pleading earnestly for the study of eloquence as a defence against badness. This founding myth decisively couples morality with the pursuit of eloquence: speech is pitted against speech - not unlike what happens in the marketplace of ideas. It is the responsibility of good individuals to put their 
moral eloquent speech in opposition to the bad speech of ruthless characters pursuing their own self-interest.

There is no ancient rhetorical theory that is not at the same time a theory of ethics. And yet, if there is one aspect that traditionally could hardly be covered in modern legislation about free speech, it is this: laying down the law on moral speech entails risking the direst censorship. But the metaphor of the morally neutral economic market will help no longer: in analyses of the most recent economic crisis, the factors that are mentioned most are only partially market-related; moral condemnation is prominent. Vermeend (2008), for instance, lists as factors, among other things, first of all, neoconservative laissez-faire economics, with maximum freedom for the financial sector without adequate oversight - where clearly laissez-faire has lost its neoclassical lustre. Second, the sub-prime mortgages, related to irresponsible behaviour of American bankers; third, the rating agencies that knowingly gave triple-A ratings to sub-prime investment products; and fourth, incompetence of the boards of trustees of different banks, and the perverse bonus system that determined their actions. The list is not finished, but clearly, the problem was a moral one, and it was called "avarice" and "greed". Marketplaces, of products and ideas, need moral responsibility. And in spite of everything, the least regulation possible (Butler 1997).

\section{I.9 An evolutionary theory of rhetoric}

One last point we need to consider in thinking about the marketplace of ideas, and that is, obviously, whether we should not simply reject and abandon, or rather transcend, the frame. For why would we accept an economic frame if economy is maybe no longer the most powerful explanatory framework for human behaviour available? Admittedly, the economy is still a foundational element in our social imaginary. The attractions of the economic frame are its claims to relate individual behaviour to social interaction on the group level, and the impersonal nature of its explanatory system. As we have already seen, the frame is least popular with those, like Brandeis, who see free speech mostly as the realization of the autonomy of the individual. Others see free speech as a condition for democratic deliberation, as part of the democratic process. There are also combinations of these views. If deliberation may not always work to find truth, it at least legitimizes the democratic process and the decisions punctuating the deliberative process itself, however provisional and open to revision such decisions may be. I have argued that democracy should also be 
considered a performative process: together the citizens produce democracy by the performance of various speech acts and other behaviours (e.g., the abstention of public violence). The question is whether the characteristics of the market are the best explanation for these forms of group interaction, or whether features of the market may themselves be an instantiation of group behaviour that is best explained at an even higher level of abstraction.

Such a higher level of abstraction is on offer now in the theory of evolution. As David Sloan Wilson, the evolutionary biologist, puts it (2007): all roads lead to evolution. As did the marketplace metaphor, evolutionary biology works with a strong notion of scarcity and hence competition, which is after all what explains the need for selection. The question is: what is being selected? Gene? Individual? Group? An increasingly strong case is being made for group selection, a point of view again staunchly defended by David Sloan Wilson, who points out that an individual, one organism, can in fact also be regarded as a group of lower-level entities, that have temporarily solved the problem of within-group conflict. But if the individual develops cancer, for instance, we can see clearly that it is not one whole, but that there is now conflict between groups (healthy cells versus cancer cells) within the group that constitutes the individual. The most convincing theory available at present argues against a forced choice between gene, individual, or group, and for accepting the principle of multiple-level selection (Sloan Wilson \& Wilson 2007).

The differential survival and success of individuals in groups and groups in the larger population may be influenced by factors such as cooperation, equality, exchange, fairness, and reciprocity. ${ }^{21}$ In human beings, speech can play different roles in group selection. Various speech mechanisms, such as gossip, criticism, or ridicule form defences against subversion from within. And, unlikely as it seems at first sight, it may be argued that some cherished concepts, such as the concept of free speech, have a similar regulatory function. "Free speech" and particularly the "rhetoric of embattled free speech" helps police and guard the speech practices that are important to maintain an economy of moral disagreement, and hence contribute to the success of the group. ${ }^{22}$

\footnotetext{
${ }^{2 I}$ The need for reciprocity in addition to their model of deliberative democracy is seen as a weakness in Gutman and Thompson (2004, p. 18): in fact, however, it anchors their theory to evolutionary insights.
}

${ }^{22}$ Ibid. p. 7. 
In other words, concepts that we used to associate with the economic model, are in fact concepts of evolutionary theory that will be visible in various lowerlevel theories: in economy, psychology and the explanation of the function of literature (see Boyd 2009). It is hardly a daring prediction that in the next couple of years, we will increasingly witness a movement within the study of rhetoric, as we already see within the study of language at large, that may be called an evolutionary theory of rhetoric, or even simply "evolutionary rhetoric", which tries to take into account the discoveries made within the strong paradigm of evolutionary theory for our understanding of the societal functioning of rhetoric, deliberation, free speech and the self-reflexive discussion of those issues as a form of meta-rhetoric. The study of rhetoric will be able to profit from this new framing, and to understand that that is what it is.

\section{References}

Blocher, J. (2007-2008). Institutions in the Marketplace of Ideas. Duke Law Journal 57.4, $82 \mathrm{I}-889$.

Boyd, B. (2009). On the Origin of Stories. Evolution, Cognition, and Fiction. Cambridge, Mass.: The Belknap Press of Harvard University Press.

Brietzke, P.H. (1997). How and Why the Marketplace of Ideas Fails. 3 I Valparaiso University Law Review, 95I-969.

Butler, J. (1997). Excitable Speech. A Politics of the Performative. New York/London: Routledge.

Cairns, D. (1993). Aidos. The Psychology and Ethics of Honour and Shame in Ancient Greek Literature. Oxford: Oxford University Press.

Carter, L.B. (1986). The Quiet Athenian. Oxford: Oxford University Press.

Cohen, E. (1992). Athenian Economy and Society. A Banking Perspective. Princeton: Princeton University Press.

Cole, D. (1985-1986). Agon at Agora: Creative Misreadings in the First Amendment Tradition. Yale Law Journal 95, 857-905.

Day, J.M. (2007). Rhetoric and Ethics from the Sophists to Aristotle. In: I. Worthington (Ed.), A Companion to Greek Rhetoric (pp. 378-392). Oxford: Blackwell publishing. Doyle, J. (2006). On the first eight lines of Plato's Gorgias. Classical Quarterly 56.2, 599-602.

Finley, M.I. (1999, second, updated ed. [1973]). The Ancient Economy. Berkeley/Los Angeles: University of California Press.

Gigon, O. (1953). Kommentar zum ersten Buch von Xenophons Memorabilien. Basel: F. Reinhardt. 
Gutman, A. and D. Thompson (2004). Why Deliberative Democracy. Princeton: Princeton University Press.

Hayek, F.A. (1973-1979). Law, Legislation and Liberty. A new statement of the liberal principles of justice and political economy. Vol. I Rules and order (1973); Vol. 2 The mirage of social justice (1976); Vol. 3 The political order of a free people (1979). Chicago: University of Chicago Press.

Hesk, J. (2000). Deception and Democracy in Classical Athens. Cambridge: Cambridge University Press.

Hofstadter, R. and W.P. Metzger (1955). The Development of Academic Freedom in the United States. New York: Columbia University Press.

Hopkins, W.W. (1996). 'The Supreme Court Defines the Marketplace of Ideas', Journalism and Mass Communication Quarterly 73, 40-52.

Ingber, S. (1984). The Marketplace of Ideas: A Legitimizing Myth. Duke Law Journal, I-9I. Klucharev, V., K. Hytönen, M. Rijpkema, A. Smidts and G. Fernández (2009). Reinforcement Learning Signal Predicts Social Conformity. Neuron 6I.I, I4O-I5I.

Mansville, P.B. (1994). Toward a New Paradigm of Athenian Citizenship. In: A.L. Boegehold and A.C. Scafuro (Eds.), Athenian Identity and Civic Ideology (pp. 2I-33). Baltimore/London: The Johns Hopkins University Press.

Mansville, P.B. (1996). Ancient Greek Democracy and the Modern Knowledge-Based Organization: Reflections on the Ideology of Two Revolutions. In: J. Ober and Ch. Hedrick (Eds.), Demokratia. A Conversation on Democracies, Ancient and Modern (pp. 377-399). Princeton: Princeton University Press.

Ober, J. (f.c.). The instrumental value of others and institutional change: an Athenian case study. In: R.M. Rosen and I. Sluiter (Eds.), Valuing Others in Classical Antiquity. Leiden: Brill.

Ober, J. (2008). Democracy and Knowledge: Innovation and Learning in Classical Athens. Princeton: Princeton University Press.

Ober, J. (2002). Political Dissent in Democratic Athens. Intellectual Critics of Popular Rule. Princeton: Princeton University Press.

Ober, J. and C. Hedrick (Eds.) (1996). Demokratia. A Conversation on Democracies, Ancient and Modern. Princeton: Princeton University Press.

Ober, J. (1989). Mass and Elite in Democratic Athens: Rhetoric, Ideology, and the Power of the People. Princeton: Princeton University Press.

Pinker, S. (2007). The Stuff of Thought. Language as a Window into Human Nature. London: Viking.

Sloan Wilson, D. (2007). Evolution for Everyone. How Darwin's Theory Can Change the Way We Think About Our Lives. New York: Delacorte Press. 
Sloan Wilson, D. and E.O. Wilson (2007). Rethinking the Theoretical Foundation of Sociobiology. The Quarterly Review of Biology 82.4, 327-348.

Sluiter, I. and R.M. Rosen (Eds.) (2004), Free Speech in Classical Antiquity. Leiden: Brill.

Stone, G.R. (2004). Perilous Times: Free Speech in Wartime: From the Sedition Act of 1798 to the War on Terrorism. New York: W.W. Norton.

Sunstein, C. (2006). Infotopia. How Many Minds Produce Knowledge. Oxford/New York: Oxford University Press.

Taylor, C. (2004). Modern Social Imaginaries. Durham/London: Duke University Press.

Usher, S. (2007). Symbouleutic Oratory. In: I. Worthington (Ed.), A Companion to Greek Rhetoric. (pp. 220-235) Oxford: Blackwell publishing.

Van Raalte, M. (2004). Socratic parrhêsia and its afterlife in Plato's Laws. In: I. Sluiter and R.M. Rosen (Eds.), Free Speech in Classical Antiquity. (pp. 279-312) Leiden: Brill.

Vermeend, W. (2008). De Kredietcrisis. Amsterdam: Lebowski.

Woodruff, P. (2008). Euboulia: How Might Good Judgment Be Taught? Lampas 4I, $252-262$.

Worthington, I. (Ed.) (2007). A Companion to Greek Rhetoric. Oxford: Blackwell publishing. 



\title{
2 Rhetoric, Classicism and Democracy: The Conveyance of Moral and Political Values in Late Antique Rhetorical Education
}

\author{
MANFRED KRAUS
}

\section{I Introduction}

It is a standard commonplace in rhetoric that perfect eloquence cannot be learned from books alone. Detailed theoretical and technical advice may help to a certain extent, but nothing will ever really be achieved without practical exercise in any of its basic manifestations, be it in reading, writing or speaking. For this reason, at all times, practical exercises have played a vital part in rhetorical education. All ancient handbooks unanimously bear testimony to this truism. The anonymous author of the so-called Rhetoric to Herennius, for instance, makes "exercise" literally the last word of his entire treatise (4.69), and he frequently refers to the importance of exercise throughout his work (e.g., I.I; I.3; I.I2-I3; 2.7; 2.I2; 3.I4; 3.20; 3.27; 3.34; 3.39-4O; 4.7; 4.27; 4.58).

Unsurprisingly, then, as soon as rhetoric became a major subject in the ancient educational system, it developed a detailed program of classroom exercises. An elaborate curriculum of exercises was established in Greek rhetorical schools during the Hellenistic period, i.e., in the last two centuries before the Christian era (Marrou 1955, pp. 252-57 and 297-303, Bonner 1977, pp. 250-5I), a program that was also soon adopted by the Romans (Gwynn I926, pp. 34-4I). The pivotal type of exercise was, of course, the so-called declamation, a fully fledged speech on an imaginary subject assigned by the teacher and elaborated and delivered orally by the student (see Russell 1983). But additionally, as a preparation for this developed stage, and in order to provide a smooth transition from education in grammar to the teaching of rhetoric proper, preliminary exercises were devised called progymnasmata (Clark 1957, pp. 178-212, Bonner 1977, pp. 250-76, Kennedy 1983, pp. 54-73, 
Pernot 2005, pp. I46-5I). While declamation was oral, these were essentially written exercises, which students could use to exercise themselves in individual parts, elements or features of an oration, before they eventually ventured on the declamations proper.

\subsection{Rhetorical exercises and moral education}

Yet rhetoric, as the art of speech, clearly cannot be practised in an abstract and purely formal way, devoid of any specific content. Even a moot speech or debate needs to have a definite subject or topic to develop. The typical subject matter of rhetoric, however, as Aristotle already knew, is the field of human action and behaviour, and thus of ethics and politics which, in Aristotle's eyes, are the disciplines most closely related to rhetoric (cf. Rhetoric I.4-8).

Consequently, rhetorical exercises too, if they are supposed to prepare students for true oratorical practice, cannot help dealing in some way with moral or political matters, even if this is only on an imaginary or fictitious level. If the topics assigned were drawn from some remote myth or legend, or were completely fictitious, as was in fact more often than not the case in ancient declamations and related exercises, even then the arguments employed would nonetheless have to be grounded in the experience of real life, and would have to comply with general moral or political values.

By the same token, both in ancient education and way beyond, rhetorical exercises have always been used deliberately not only for teaching students the formal skills of oratory, but also for conveying to their minds the general values of ethics, politics or even religion, in order to prepare them for their future roles in society. However, these values may, in any particular case, be either in accordance or at variance with the value system prevailing in the relevant society. In the former case, their effect will be an affirmative one and confirm the dominant ideas and values of that society. In the latter case, by contrast, the ideas underlying the argumentation can be subversive as well. The reasons for such subversive tendencies may be manifold. In certain cases, they may result from a deliberate and aggressive seditious or anarchical disposition adopted by a teacher or textbook author. Yet more often than not, the reasons will be much simpler and more straightforward than that. At times, an extreme conservatism will simply have refused to realize that things in the real world have changed over time, and that the prevalent values of a culture or society have also changed. Just imagine the possible case of a present-day reprint of a textbook dating from the fifties or sixties, which still im- 
plicitly takes racial segregation for granted in the choice of topics for its exercises, or considers single mothers and fathers a social anomaly rather than an everyday phenomenon. Since textbooks usually live to see a number of student generations, but society and its values keep changing at an accelerating pace, these are increasingly common experiences nowadays.

In former times, the pace of social and political change may certainly have been less rapid than it is today. Yet nonetheless, changes did occur. In this chapter I intend to focus on a particularly conspicuous historical case of such a change in society and the political and religious setting which brought about an obvious divergence between the values conveyed in classroom education in rhetoric and those from the reality of that society. The case I have in mind concerns the period of late antiquity. I will first try to outline the special historical circumstances which characterized that particular period, and the special conditions under which rhetorical education was practised in those days; I will then substantiate and document this by a particular case study, using as an example a popular classroom textbook of rhetorical exercises from the late fourth century CE. A brief comparison of the results with the very different appearance of corresponding medieval and early modern practices will finally lead to reflections on the present-day problem of how to choose appropriate assignments for rhetorical exercises in an age dominated by political correctness.

Late antiquity (according to the most popular definition ranging roughly from the second to the fifth or sixth century $\mathrm{CE}$ ) was a period which saw not only the transformation of the Roman Empire into a truly absolute monarchy, but also the rise of Christianity from a marginalized, suppressed and persecuted sect to the status of official state religion, to name only the two most fundamental and distinctive changes that took place within that period. Compared to these fundamental changes of a society, however, late ancient rhetorical education, which undoubtedly was the most dominant educational factor in that society, was a thoroughly conservative enterprise and persisted in practically unchanged form for nearly half a millennium. The main reason for this amazing constancy and persistence was arguably the petrifying effect of a stern conservatism and classicism. What kind of classicism was this, and what reasons motivated it?

\subsection{Rhetorical education and classicism}

Everything started with a purely linguistic or stylistic phenomenon. As early as the first century вСE, rhetoricians such as Dionysius of Halicarnassus, 
driven by an open dissatisfaction with the Hellenistic koiné style of the Greek of their times, called for a return to the Greek of the classical period of the fifth and fourth centuries BCE (see Gelzer 1978). They wanted to get back to the plain and sober Attic style which orators such as Lysias, Isocrates or Demosthenes had used, authors who were therefore to be imitated on all accounts.

This movement of Atticism, as it was called, was associated with the predominantly Greek movement known as the Second Sophistic, which had its heyday in the second and third centuries CE (see Anderson 1993 and 2007, Whitmarsh 2005). It was, however, not confined to style only. Stylistic imitation presupposed some close reading of those old Attic authors, and, by way of this process, a natural absorption of the contents and the ideas of their writings and speeches, which thus re-emerged and gained new value. In this way linguistic Atticism resulted in the more general concept of cultural Atticism. In declamations, for instance, topics related to the orator Demosthenes and his fight against King Philip of Macedon were among the most popular. Other popular topics related to the Persian Wars or the Peloponnesian War, in both of which Athens played a decisive role (see Bowie 2004, pp. 70-72 and 82-83). Moreover, themes from Greek myth, mostly taken from Attic tragedy or from the Homeric epics, were frequently used in rhetorical training as well. This obsession with the grand Attic past even infected the Romans, who also developed a certain preference for the same kinds of themes in their own rhetorical schools.

Yet the real world of those times was far different from this idealistic picture. Greece was dominated by Rome, and the Roman Empire was steadily developing into a centralistic and increasingly oppressive system of absolute monarchy. Nonetheless, in their classrooms, the rhetors and sophists of the imperial period continued to glorify the political and moral ideals of classical Athens, such as democracy vs. monarchy, independence vs. subservience, provincialism vs. centralism and the rule of law vs. tyrannic despotism. This repertoire of topics for rhetorical education did not change much throughout the entire imperial period. We find it in Hermogenes of Tarsus in the second century and in Libanius and Aphthonius in the fourth century.

This obvious discrepancy between the idealistic world of the classroom and the hard facts of the real world outside cannot have gone unnoticed by teachers nor by students. It is thus surprising that it seems not to have been theoretically reflected in any way. We do hear complaints from Roman 
authors (such as Quintilian or Tacitus) about the lack of realism in classroom rhetoric, but this is mainly concerned about the employment of completely unrealistic laws in declamations and the fanciful fictitious stories about pirates and raped virgins, war heroes and tyrant slayers, prodigal sons and miserly fathers, jealous stepmothers and covetous doters that were so popular in judicial declamations (the so-called controversiae, as opposed to the more historically-oriented deliberative declamations, known as suasoriae).

The Greeks, on the other hand, apparently relished this rhetorical classicism as a matter of national pride in a situation of political oppression. Atticism was enhanced, if not triggered by the need of the Greeks to define their own identity within the context of the Roman Empire (see Bowie 1970, Swain 1996, Goldhill 200I). It provided them with a kind of cultural identity ("Greekness") that had little to do with ethnicity, but was mainly a construct established by means of rhetoric (see Whitmarsh 2005, pp. 32-37 and 52-54). Yet, amazingly, we do not hear much about any particular impact that this constant inculcation of political and social ideals from a glorious, but distant past would have had on late antique society, although the entire contemporary political and administrative elite must necessarily have passed through this educational process as it provided the essential gateway to prestige and power (see Schmitz 1997).

\subsection{A model case in point: Aphthonius' Progymnasmata}

A particularly instructive example of this classicizing attitude from a very late stage within late antiquity is the short, but highly influential textbook of rhetorical exercises entitled Progymnasmata, written by an author called Aphthonius. Towards the end of the fourth century CE, Aphthonius lived and worked as a rhetor or teacher of rhetoric in the Syrian town of Antioch, which is now Antakya in Southern Turkey, close to the present-day Syrian border. He was a student of the famous rhetor Libanius, who ran a well-established rhetorical school in Antioch (see Cribiore 2007). Aphthonius' writings would seem to adhere fairly closely to the teachings he found in Libanius' school.

The fourth century was a particularly interesting period, since it is that very century which saw the rise of Christianity from its toleration within the Roman Empire by Constantine in 313 to the position of official state religion under Theodosius in 39I (see MacMullen 1984). Moreover, the official political separation of the Eastern and Western parts of the Roman Empire in the year 395 also took place at the very time that Aphthonius most proba- 
bly wrote his little handbook. Furthermore, in that period, Antioch was also a hot spot of religious dissension and debate. By the late fourth century, the town was already about eighty percent Christianized and the see of an important Patriarchate which, according to church tradition, was founded by the Apostle Saint Peter himself (see Sandwell 2007). Antiochian theologians (such as Eustathius of Antioch, Diodorus of Tarsus, Theodore of Mopsuestia, Theodoretus of Cyrus, Ibas of Edessa, and later of Nestorius) battled with their Alexandrian opponents over the divine and human nature of Christ. Yet in the midst of all this, the rhetorical school in particular continued to be a stronghold of Greek pagan culture (see Norman 2000). Libanius himself was a pagan and a close friend and admirer of the last non-Christian emperor Julian the Apostate. Nonetheless he had many Christian students (such as John Chrysostom or Theodore of Mopsuestia) as well as pagan students, one of whom was Aphthonius.

Aphthonius' textbook of progymnasmata was a short primer of fourteen basic rhetorical exercises (viz. fable, narration, chreia, maxim, refutation, confirmation, commonplace, encomium, vituperation, comparison, ethopoeia, description, thesis, and proposal of a law), for each of which he not only provided detailed theoretical instructions, but he also offered an elaborated model example. It is predominantly in these examples (which, by the way, were most probably the main reason for the booklet's popularity) that a very specific set of moral values and political opinions clearly emerges.

As his own example for the exercise of Commonplace, for instance, which is basically an amplificatory, vituperative elaboration on some morally depraved stock character (such as, for instance, a parricide, a traitor, an adulterer, a murderer etc.), Aphthonius chooses the figure of the tyrant (Kennedy 2003, pp. 106-08). Throughout the exercise the stock character of the tyrant is persistently described in opposition to, and against the background of, the ideal of Athenian democracy and the rule of law. The tyrant's disdain for and rescission of the laws is addressed repeatedly, most clearly so in the prooemium: "Since laws have been established and courts of justice are part of our government, let one seeking to annul the laws be subject to the laws for punishment" (Kennedy 2003, p. I06). His thoughts are described as follows: "I shall seize the acropolis and put aside the laws, curse them, and thus I shall be a law to the many, not the many to me" (ibid. p. I07). One major argument against tyranny is that it is unconstitutional (at least with respect to the Athenian constitution). For: "As a benefit to us [our ancestors] in- 
vented a constitution free of domination, and quite rightly so" (ibid. p. Io6). Most strikingly, however, the tyrant is never contrasted, as one might also have expected, with the character of the wise and benevolent king, so that this vituperative accusation could well be interpreted as a critique of monarchy in general. This becomes even more obvious when, in the more individualized assignment of Vituperation, it is King Philip of Macedon who is chosen as the model example (ibid.pp. II2-I3). Here again, the king is clearly described as the stereotype of the barbarian and the tyrant, and he is for his part also depicted - even if less explicitly so - in strong contrast to the ideals of Athenian democracy and freedom, which he was to suppress and annihilate long before the Romans ever appeared on the Greek stage. The basic idea of this model piece, which draws heavily on various motifs from speeches by Demosthenes (see ibid. pp. II2-I3, footnotes 66 and 68) is, of course, perfectly in line with the general tendency of classicism and Athenocentrism that was so prominent in imperial Greek rhetorical training.

The corresponding model example for the exercise of Encomium is - and very fittingly so - a praise of the Athenian historian Thucydides (ibid. pp. I08-IO). Not only does this again strike the right note of Athenian classicism (in the theoretical instructions, Demosthenes is explicitly named as the other principal option and, to distinguish collective from individual praise, Aphthonius refers to the example of a collective encomium of all Athenians vs. an individual encomium of one particular Athenian (ibid. p. Io8); but it also, once more, offers ample opportunity for praising the institutions and benefits of Attic democracy in its finest days, as for instance when Thucydides is said to have been endowed with "the double benefit of a strong ancestry and a democratic constitution," to have been "prevented from being rich unjustly by the equality of law," or to have been "nurtured under a constitution and laws that are by their nature better than others" (ibid. p. I09). Nor does the author miss the opportunity to glorify the great deeds of the Athenians in the Peloponnesian War (ibid. pp. I09-Io). Besides these outstanding examples, there are also various other passages scattered all through Aphthonius' Progymnasmata, which contain hidden or open critiques of monarchy and praise democracy as the better of all constitutions.

Aphthonius' unswerving partisanship for the rule of law without any restrictions is most obvious in the example he devises for the exercise of Proposal of a Law, in which he attacks a proposed law that prescribes that an adulterer may be killed on the spot by the deceived husband (ibid. pp. I24- 
27). In this piece Aphthonius repeatedly states that the law must stand above all other things, that nobody can be exempt from it, and that it must be the prerogative of judges and juries, and no-one else, to administer justice.

Considering that Aphthonius lived and worked in a predominantly Christian community and environment, it is also worth remarking that all his examples are exclusively pagan in character. Narratives of pagan myths are his favourite choices for the illustration of assignments such as Narration (Aphrodite and Adonis, ibid. p. 97), Refutation and Confirmation (Daphne and Apollo, ibid. pp. IOI-03 and I04-05), or Ethopoeia (Niobe, ibid. pp. II617). But most noticeable of all, for the exercise of Description, he offers a detailed description of the magnificent pagan temple and precinct of the god Sarapis, once situated on the "acropolis" of the city of Alexandria (ibid.pp. II8-20), which, however, in Aphthonius' own lifetime, in the year 39I, was burnt down and razed during a riot triggered by the Christian faction in town, at the instigation of the patriarch Theophilus, and with tacit consent of the Christian emperor Theodosius (cf. Eunapius, Lives of the Philosophers and Sophists 472; Sozomenus, Ecclesiastical History 7.I5). The temple was a miracle to visitors, and an imposing example of pagan culture in Alexandria (see McKenzie, Gibson and Reyes 2004). Its selection as a model example in a school textbook is therefore certainly not accidental, but can be interpreted as a deliberate act of assertion of Greek pagan culture and as a protest against its wilful vandalization by a Christian mob. In passages such as this, Aphthonius, like his teacher Libanius, takes an unmistakably pagan stance in the midst of a meanwhile predominantly Christian environment. With respect to other passages, one may even speak of a completely secular tendency, for instance when Aphthonius occasionally remarks that the commonly believed stories about the gods may, after all, just be mere fictions made up by the poets (see e.g., Refutation, Kennedy 2003, pp. IOI-O2, Encomium p. IIO).

All these various features in Aphthonius' work, which was widely used for teaching beginners in rhetoric, were very clearly totally at odds with the real contemporary political world outside the classroom. This raises the question: what kind of impact might those teachings have had on society? Was the interior world of the rhetorical school really so completely insulated from the real world outside that nobody ever noticed the blatant discrepancies? Or were they intentionally ignored? Or did the employment of those themes and topics contribute to the establishment of a kind of liberal-thinking intellectual elite of scholars who were well aware of both the assets and the 
drawbacks of democracy on the one hand, and of their own monarchic and hierarchic society on the other? The mere fact that not even state officials seemed to have taken offence at the kind of ideas that were expounded in rhetorical schools appears to reveal an astonishing amount of liberal thinking.

\subsection{Contrasting practices in medieval and early modern times}

That such liberal-mindedness of the sort described above was far from being a matter of course, can be easily demonstrated by a contrastive glimpse at later periods in the history of Aphthonius' little manual, which was also widely used in the Byzantine and (in multiple Latin translations) in the early modern period (for a survey, see Kraus 2005, pp. I64-65 and I67-83). Basically, the core of its text was transmitted in unaltered form, but a considerable number of additional model examples were composed to adapt the work to contemporary needs and ideas. Byzantine scholars, for instance, added a great number of clearly Christian examples, taken from Scripture, from the lives of the saints, or even from controversial theological debates; these would praise typically Christian virtues and values such as humility or steadfastness in faith, and markedly Christian heroes such as the martyrs (for details, see Hunger 1978, pp. III-I6). There were also explicit commitments made, and subservience shown, to the politics of Byzantine emperors; particularly so in times of internal quarrels or external wars (see ibid. p. III).

In a similar way, in their adaptations of Aphthonius' textbook, Renaissance scholars would also add examples in which they would take a clear stance on the political or religious issues of their day. In the age of the Reformation, in particular, authors from both sides of the denominational divide openly acted as partisans of their respective parties by unconditionally extolling the political and religious commitments of their own side, while at the same time mercilessly and ruthlessly attacking and censoring the opposing party. These model examples were deliberately used for aggressive political and religious indoctrination and argument. While allegedly practising the art of rhetoric, students would thus subconsciously absorb their lessons in controversial theology and party prejudice. One would find refutations of Roman Catholic dogmas, accusations of alleged crimes committed by the "papists", offensive vituperations of Popes and Catholic bishops and corresponding eulogies of pro-reformation princes and potentates on the Protestant side as well as defences of the Catholic creed and religious practices, encomia of saints, and aggressive slanders and vituperations of outstanding re- 
formers and their secular supporters on the Catholic side. This was particularly so in Jesuit circles, which were highly influential in rhetorical education in those times (for details, see Kraus 2008, p. 65). In that period, which was dominated by religious strife, teachers in rhetorical schools were very clearly taking sides, and the model examples presented to students were, as a rule, strongly affirmative of the respective values. Internal criticism was not meant to be. Evidently, the amazing toleration of the huge discrepancy between the values presented in classrooms of rhetorical schools and the reality of the political world outside, which we observed as the result of a long-standing and excessive classicism in the late antique period, had vanished.

\subsection{Conclusion: Lessons to learn for contemporary teaching}

What then can we learn from those ancient stories? In our modern globalized and pluralistic societies, very often we do not even know if any fixed sets of values to agree or disagree with exist at all. Perhaps human or civil rights may be something everyone could (or should) agree on. But basically, the principal commitment is not to make any commitments at all. Everything seems to be dominated by the rule of political correctness, which is often a commitment to non-commitment, and if there is a commitment, the side to be taken is almost mandatory, and the opposing view is strictly banned.

Yet rhetorical exercise will always have to make controversial commitments and to take controversial sides in public deliberation. Otherwise it would not be rhetoric. Strict observation of the rules of political correctness would make any reasonable choice of examples for rhetorical exercises extremely difficult and awkward, if not impossible. Almost any assignment we choose would be open to criticism from some social, religious or other group within society. Consequently, for instance, most of the "contemporary" examples of exercises recently offered by Frank D’Angelo for rhetorical training in the spirit of Aphthonius' Progymnasmata, such as, e.g., Confirmation or Refutation of newspaper stories on a "Man Arrested in Scalding of a Toddler" (D'Angelo 2000, p. I23) or a conflict between two high school students (ibid. p. I27), Praise, Vituperation or Comparison of local public figures, characters from TV soaps, familiar locales or works of art (ibid.pp. I6o and I87), Speeches-in-Character of caring parents sending their son or daughter off to college (ibid. p. 207), or Discussion of a law that would prohibit the taping of TV movies without paying royalties (ibid. p. 24I), are not concerned with top-level political issues, but rather with issues of either more local or 
very general interest. Some hotter potatoes, however, can be found in the book by Crowley and Hawhee (I999, e.g., was George Bush Sr. right to pardon several people connected with the Iran-Contra affair? pp. 333-35, or discussion of a law that permits pornography, pp. 363-64).

Perhaps we not only cannot, but also need not, and even should not, always strictly observe the rules of political correctness when assigning tasks to our students. Otherwise we will implant invisible razors in their heads that will curtail and crop their inventive imagination and fancy. We might learn something from the way earlier periods in history managed to endure and tolerate discrepancies between classroom exercises and social and political reality, namely that rhetorical education will never be able to abstain completely from making explicit or implicit commitments to sets of moral, social or political values, but that these sets of values need not imperatively coincide with any given society's "official" values, and that practical exercises in rhetoric should be regarded as a kind of playground instead (or marketplace, to take up the metaphor of Ineke Sluiter ${ }^{1}$ ) for experimenting freely with various kinds of ideas and values, in order to weigh them up and compare them against one another in open and unrestrained debate, and in this way learn how to make our own independent and well-founded commitments.

\section{References}

Anderson, G. (1993). The Second Sophistic. A Cultural Phenomenon in the Roman Empire. London/New York, NY: Routledge.

Anderson, G. (2007). Rhetoric and the Second Sophistic. In: W. Dominik and J. Hall

(Eds.), A Companion to Roman Rhetoric (pp. 339-53). Oxford: Blackwell.

Bowie, E.L. (1970). Greeks and their past in the Second Sophistic. Past and Present 46, 3-4I. Bowie, E. (2004). The Geography of the Second Sophistic: Cultural variations. In: B.E. Borg (Ed.), Paideia: The World of the Second Sophistic (pp. 65-84). Berlin/New York, NY: Walter de Gruyter.

Bonner, S.F. (1977). Education in Ancient Rome: From the Elder Cato to the Younger Pliny. Berkeley, CA: University of California Press.

Clark, D.L. (1957). Rhetoric in Greco-Roman Education. New York: Columbia University Press.

Cribiore, R. (2007). The School of Libanius in Late Antioch. Princeton, NJ: Princeton University Press.

${ }^{\mathrm{I}}$ In her opening plenary speech of the Second Conference of Rhetoric in Society in Leiden. 
Crowley, S. and D. Hawhee (1999). Ancient Rhetorics for Contemporary Students. 2nd ed.

Boston, MA: Allyn and Bacon.

D'Angelo, F.J. (2000). Composition in the Classical Tradition. Boston, MA: Allyn and Bacon.

Gelzer, T. (1978). Klassizismus, Attizismus und Asianismus. In: H. Flashar (Ed.), Le classicisme à Rome aux Iers siècles avant et après J.-C. (pp. I-4I). Vandœuvres: Fondation Hardt.

Goldhill, S. (Ed.) (200I). Being Greek under Rome: Cultural Identity, the Second Sophistic and the Development of Empire. Cambridge: Cambridge University Press.

Gwynn, A. (1926). Roman Education from Cicero to Quintilian. Oxford: Clarendon Press.

Hunger, H. (1978). Die hochsprachliche profane Literatur der Byzantiner, Vol. I. München: C.H. Beck.

Kennedy, G. (1983). Greek Rhetoric under Christian Emperors. Princeton, NJ: Princeton University Press.

Kennedy, G. (2003). Progymnasmata. Greek Textbooks of Prose Composition and Rhetoric. Trans. with introduction and notes. Atlanta, GA: Society of Biblical Literature.

Kraus, M. (2005). Progymnasmata, Gymnasmata. In: Gert Ueding (Ed.), Historisches Wörterbuch der Rhetorik, Vol. 7 (pp. I59-9I). Tübingen: Niemeyer.

Kraus, M. (2008). Aphthonius and the Progymnasmata in rhetorical theory and practice. In: D. Zarefsky and E. Benacka (Eds.), Sizing Up Rhetoric (pp.52-67). Long Grove, IL: Waveland Press.

MacMullen, R. (1984). Christianizing the Roman Empire (A.D. 100-400). New Haven, CT: Yale University Press.

Marrou, H.-I. (1957). Geschichte der Erziehung im klassischen Altertum. Freiburg: Alber.

McKenzie, J.S., S. Gibson and A.T. Reyes (2004). Reconstructing the Serapeum in Alexandria from the archaeological evidence. Journal of Roman Studies 94, 73-I2I.

Norman, A.F. (2000). Antioch as a Centre of Hellenic Culture as Observed by Libanius.

Liverpool: Liverpool University Press.

Pernot, L. (2005). Rhetoric in Antiquity. Trans. W.E. Higgins. Washington, DC: The Catholic University of America Press.

Russell, D.A. (1983). Greek Declamation. Cambridge: Cambridge University Press.

Sandwell, I. (2007). Religious Identity in Late Antiquity. Greeks, Jews and Christians in Antioch. Cambridge: Cambridge University Press.

Schmitz, T. (1997). Bildung und Macht: Zur sozialen und politischen Funktion der zweiten Sophistik in der griechischen Welt der Kaiserzeit. München: C.H. Beck.

Swain, S. (1996). Hellenism and Empire: Language, Classicism, and Power in the Greek World $A D$ 50-250. Oxford: Oxford University Press.

Whitmarsh, T. (2005). The Second Sophistic. Oxford: Oxford University Press. 


\title{
3 Melody and Rhythm in Ancient Political Discourse
}

\section{On How Emotions Induce Persuasion}

\author{
MARIE FORMARIER
}

\section{I Introduction}

If we admit with G. A. Kennedy that, "all communication involves rhetoric" (Kennedy 1999, p. I), any speaker has to be careful when choosing words and gestures so as to give a persuasive performance. This was especially true in Antiquity. In those days, people who decided to devote themselves to politics had to learn rhetoric during their whole childhood. Skilled speakers were then supposed not only to be able to write discourses and to learn them by heart but also to improvise in front of any audience. Most of all, they had to adapt their speeches to the surroundings and to the hearers' socio-cultural backgrounds (Michel 1996, pp. 20I-209, May 2002, pp. 53-54). Indeed, rhetoric had to be used differently in a tribunal, on the forum (Aldrete 1999, pp. 77-8I, May 2002, pp. 55-59) or in front of the Senate, before judges or ordinary people who were often illiterate (Aldrete 1999, p. 85). Actually, a good speaker was supposed to make a "one-man show" of it (Narducci 2002, p. 439, Hömke 2009, pp. 240255) since the public "entered the forum and listened to a speaker, expecting not only to hear the facts of a case, but also to be entertained while doing so" (May 2002, p. 59). One of the most fundamental rules the ancient speaker had to keep in mind was to adapt and modulate melody and rhythm. Indeed, since Antiquity, musicality in political discourse has been considered as essential for persuasion. Dionysius of Halicarnassus ( $\mathrm{I}^{\mathrm{st}}$ century $\mathrm{BC}$ ) clearly summarised this challenging relationship between rhetoric and music. According to him,

Political eloquence is a sort of music. The difference between eloquence and music either vocal or instrumental - is quantitative not qualitative. Actually, words in speeches follow a melody and a rhythm. (...) Consequently, the difference between music and speech consists of a "more or less". (DH. De Comp. 6, II, 64-66) 
A good speaker has to master music because a proper melody and rhythm actually give him the power to influence the hearers' feelings and decisions. An emblematic example is the case of Antonius. In Cicero's treatise De Oratore ( $\mathrm{I}^{\text {st }}$ century $\left.\mathrm{BC}\right)$, this orator concludes his demonstration with these words: "By moving the judges' emotions more than by providing proof, I triumphed over you, Sulpicius." (Cic. De Or., 2, 20I). This statement suggests that the musical quality of words played a central role in the ancient rhetorical theory as well as in the way speeches were actually delivered. Consequently, speakers had to imitate singers. They accordingly used to train their voices and rehearse their gestures to be able to modulate intonations and to keep up rhythm. This was clearly stated in Quintilian's pedagogy ( $\mathrm{I}^{\text {st }}$ century $\mathrm{AD}$ ) (Quint. Inst., I, IO, 22; I, II, I2; Hömke 2009, pp. 243-244).

Furthermore, melody and rhythm were used in ancient music to play on emotions and to give pleasure; rhetoric in Greece and Rome adapted this process to its specific goal, which was persuasion. Indeed, to obtain the expected feedback from their audience and to follow their strategies of persuasion successfully, speakers had to earn people's goodwill, to sway their feelings and emotions (Solmsen 1938, pp. 390-404; 194I, pp. 35-50; 169-190; Wisse 1989, pp. 65-74, Cooper 1996, pp. 238-257, Leighton 1996, pp. 206-237). Therefore, although the distinction between singing and speaking was a leitmotiv in Cicero's rhetoric and also in Dionysius' and Quintilian's works, political eloquence was nevertheless based on a deep interaction between music, emotions and persuasion. This interaction raises two main questions: how does this process work? And what does it mean as far as the relation between politics and ethics is concerned?

\subsection{Natural music in speech and song}

\subsection{Melodic and rhythmic properties in speech and song}

Linguistic theories in Antiquity were based on the belief that the melodic and rhythmic properties of languages were rooted in nature. For instance, to Cicero, nature had an effect on the stress patterns of Latin:

Nature itself, as if to modulate human speech, has placed an accent, and only one, on every word and never farther from the end of the word than the third syllable.

(Cic. Or. 58) 
According to him, nature supplied melodic modulations to Latin by determining verbal dynamics, while giving to the voice

A marvellous quality, so that from merely three intonations (ascending, descending and also ascending then descending), it produces such a rich variety in song. However, there is in speech too a sort of secret singing. (ibid. 57)

Cicero therefore admitted that speech and song were based on the same melodic properties, characterized here by three types of intonations that were in fact common to Latin and Greek (DH. De Comp., 6, II, 77-79). However, political discourse could not sound like a song. Melody had to remain discreet, somewhat hidden. Dionysius of Halicarnassus added that vocal amplitude in speech was to be narrower than in song - never higher than an interval of one fifth (ibid. 73-74). Actually, to mistake a speech for a song would have meant a loss of dignity for the speaker because it would have given political discourse the same role as musical entertainment. Clearly enough, ancient political discourse was definitely influenced by music since it was based on melody and rhythm. But it was to be plainly distinguished from song at the same time. This difficult compromise was absolutely fundamental since it gave its specificity to the aesthetics of political rhetoric and determined delivery as well.

\subsubsection{Nature in the creation and perception of music}

The great power assigned to nature had a huge impact on the way ancient theorists considered the process of musical creation and perception. First, musical performance, either in song or in speech, had to comply with the demands of nature. Here is the rule given by Cicero: "Therefore let art follow the leadership of nature in pleasing the ear" (Cic. Or., 58). In other words, according to ancient theorists, rhetoric must be based on the gifts granted to the human voice by nature. It is necessary for any speaker to follow this rule so as to deliver a good speech which is to please an audience. Moreover, since rhythm and melody are natural, they are supposed to be intuitively perceived by anyone, even by uneducated people. Indeed, Cicero, Dionysius of Halicarnassus and Quintilian all told short anecdotes in their treatises to illustrate the universality of musical judgement (Cic. De Or., 3, 195; Or., I73; Quint. Inst., 9, 4, II-I2; DH. De Comp., 6, II, 29-52). According to them, illiterate hearers can unanimously notice any mishap in rhythm or in melody. To quote Cicero, it is 
Because in this particular department as in every other, nature has a vast and indeed incredible power (Cic. De Or., 3, I95). Actually, nature itself has placed into our ears the faculty of judging long and short, high and low sounds. (Cic. Or. 173)

For ancient rhetoricians, there is therefore no need for any previous knowledge, for any linguistic skill to perceive melody and rhythm. When untaught people listen to a song or a speech, they can feel and judge what follows the musical rules or not, in spite of knowing nothing about musical and rhetorical theories, notions and techniques.

Consequently, Cicero and Quintilian used to draw a clear distinction between the process of feeling and the process of analysing. According to them, the former is based on emotions, the latter on reason. The ability to assess ideas requires culture and knowledge in many fields such as linguistics, philosophy, law and politics while the ability to appraise melody and rhythm is given to everybody:

While the faculty of assessing facts and words is based on intellectual skills, ears can assess sounds and rhythms. The first assessment is linked with logic, the second one with pleasure. In the former, reason discovers art whereas in the latter, perception does (Cic. Or., I62). That is the reason why cultivated people understand the composition of discourse while uncultivated people can perceive its charm. (Quint. Inst. 9, 4, II6)

A speaker who carefully chose melody and rhythm was consequently sure to exert an influence on the whole audience, even if the argumentation developed in this discourse remained somewhat unclear for a lot of people. This idea may sound rather discriminatory but it was held by people who had received a good education and belonged to the elite. Moreover, this dual system which distinguished rational and emotional assessments was also prompted by a vast experience of rhetoric. Ancient theories, especially Cicero's, were indeed based on empirical observations. Eventually, this distinction has also been proved today by cognitive sciences. Very interesting experiments truly suggest that people who cannot read and who know nothing about music and rhetoric can however be sensitive to musicality (Warren 1994, pp. 4I-52, 69-70). 


\subsection{From emotions to persuasion: The power of pathos}

\subsection{The orator's threefold psychological task}

In ancient rhetoric, melody and rhythm in speech were deemed necessary to have a deep impact on the whole audience. Indeed, musicality was supposed to be emotionally perceived by everybody, but also to provide a speech with a powerful emotional quality. Ancient rhetoricians were indeed clearly aware of the role of emotions in the interaction between performer and audience. Aristotle first clarified the process to follow to play on feelings and emotions (Solmsen 1938, p. 393, Wisse 1989, p. 65):

It is necessary to divide the material about each of the emotions under three heads; for instance, when talking about anger, (I) what state of mind makes people inclined to anger, (2) with whom they usually get angry, (3) and on account of what. For if we knew one or two of these heads, but not all three, it would be impossible to arouse anger; and the same applies to the other emotions. (Arist. Rhet. 1378a 2328)

According to Aristotle, the speaker must follow this tripartite psychological process in order to arouse emotions. For him, oratory success is thus based on accurate psychological knowledge and on appropriateness. Indeed, the most important is to adapt speech to the hearers' moods and to the topic which is to be developed (Hömke 2009, p. 242). Aristotle's analysis is therefore based on the belief that political discourse must have a psychological impact to be persuasive. This implies a close correlation between emotions and persuasion:

Emotions are all those feelings that so change men as to make their judgements different, and that are accompanied by pleasure and pain; such are anger, pity, fear, and the like, as well as their opposites. (Arist. Rhet. 1378a 20-23)

For Aristotle, controlling the hearers' emotions enables the speaker to control their minds and thus to sway their judgements. This is the reason why he considers that playing on emotions plainly contributes to the oratory strategy of persuasion. This use of emotions (pathos) must work together with rational demonstration (apodeixis) and moral characterisation (ethos) (Solmsen I938, pp. 390-397; I94I, p. I78, Wisse I989, p. 5, pp.I5-2I): 
Of the means of persuasion furnished by the speech, there are three kinds, for some depend on the character of the speaker (ethos), some on putting the hearer into a certain emotional state (pathos), and some on the speech itself, brought about by proving or seeming to prove (apodeixis). (Arist. Rhet. 1355b 35-1356a 4)

This threefold division of persuasive material was also used by Cicero as a basis for his rhetoric. However, as he was initially under the influence of the Stoics when writing his treatise De Inventione, the younger Cicero focused on argumentation and a little on moral characterisation rather than on emotions (Wisse 1989, p. 267, Achard 1994, p. 13): for him, persuasion was definitely induced through a well-built series of different kinds of arguments (Cic. De Inv. I, 34-76; 2, 159-I69). Yet, after many oratory experiences, he finally took into account the fundamental role played by emotions in persuasion. More precisely, he correlated each means of persuasion to a specific oratory task. According to him, the speaker must inform his audience and prove what he says in order to achieve success in his demonstration. He must also convince everybody that he is a good citizen and that he defends virtue so as to win them over by earning their goodwill and pleasing them. Finally, he must play on emotions to move the hearers' hearts deeply to make sure his victory is overwhelming (Cic. De Or. 2, II5; 2, I28; 2, 310; 3,IO4; Brut. 185; 276; Or. 69; Solmsen 1938, p. 399). Actually, "to prove is the first necessity, to please is charm, to move is victory; for it is the one thing of all that avails most in winning verdicts" (Cic. Or. 69). This analysis is clearly influenced by Aristotle's theory but it also illustrates a lucid awareness of communication processes. As J. Wisse (1989, p. 6) explains, "arguments seem to be bound up with the message, ethos seems to be bound up with the sender, pathos intends an effect of the message on the receiver."

The role played by melody and rhythm in this threefold psychological task is really crucial. Indeed, in ancient rhetoric, especially in Cicero's, the most powerful rhetorical material to charm and to move is music (Chiron 2008, pp. 27-46):

For as art started from nature, it would certainly be deemed to have failed if it had not a natural power of affecting us and giving us pleasure; but nothing is so akin to our own hearts as rhythms and sounds - these rouse us up to excitement, and smooth and calm us down, and often lead us to mirth and to sorrow. (Cic. De Or. $3,197)$ 
To put it briefly, ideas developed in argumentation supply a demonstration while melody and rhythm alter feelings and emotions. In other words, music in speech has a strong role to play in persuasion since it participates in two of the three psychological oratory goals, as shown below:

FIGURE 3.I

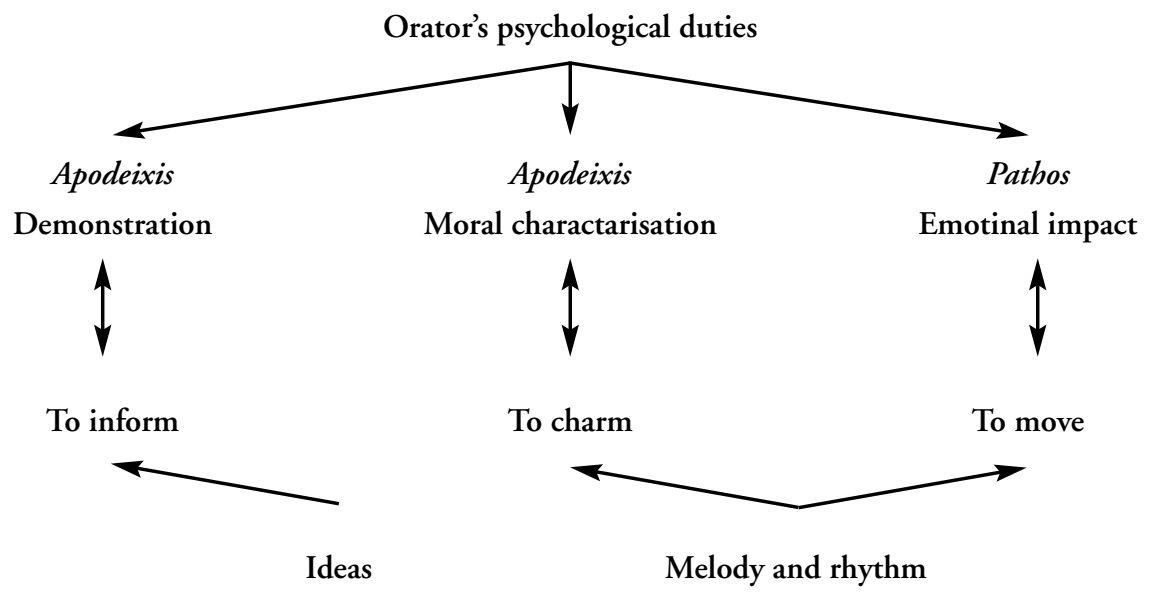

This process was quite fundamental in ancient rhetoric. It also suggests that any strategy of persuasion must take into account the whole subjectivity of both performer and hearer. Since melody and rhythm take part in the shaping of the speaker's morality and the conditioning of the hearer on an emotional level, they are thus definitely essential for persuasion.

\subsubsection{Melody and rhythm in emotional mimesis}

The close interaction between emotions and persuasion unquestionably raises a challenging problem: how can melody and rhythm sway the hearers' emotions and hence induce persuasion? Actually, on this particular point, ancient rhetoric was influenced by music theories first developed by Plato and Aristotle $\left(5^{\text {th }}-4^{\text {th }}\right.$ centuries BC) in Greece and then summarised by Aristides Quintilianus during the Roman Empire ( $3^{\text {rd }}$ century $\left.\mathrm{AD}\right)$. In music as well as in rhetoric, melodies and rhythms were classified according to their character and the emotions this character was supposed to rouse. For instance, a quick rhythm associated with a high-pitched melody can express anxiety or mirth (Cic. Or. 193; A. Quint. De Mus., 2, I5, 34; West 1992, p. 158) whereas a peace- 
ful rhythm and a low-pitched melody can express calm, solemnity or deep sorrow (Plat. Leg., 3, 70ob; Arist. Poet., I459a 8-Io; Quint. Inst., 9, 4, 83; A. Quint. De Mus., 2, 6, I-7; 2, I5, I6-22; Duysinx 1990, p. I22; Mathiesen 1999, p. 62; Dangel 200I, pp. 44-45). Consequently, melody and rhythm themselves were described according to their ethos and their pathos, i.e., their moral characterisation and their emotional impact.

Well-chosen melodies and rhythms thus determine the stylistic and musical properties of speech and contribute to the strategy of persuasion by participating in the oratory ethos and pathos. More precisely, melody and rhythm first mimic real feelings and emotions. Then, out of empathy, the hearers recognise - consciously or not - part of their own subjectivity and are led to feel the same emotions (West 1992, p. 249, Halliwell 2002, p. 53, Zagdoun 2007 , p. 96). This empathy is actually induced by the similarity between what is expressed in the speech and felt in the soul; indeed, after Cicero's words, "nothing is so akin to our own hearts as rhythms and sounds." Consequently, as matched with ideas, melody and rhythm contribute to the strategy of persuasion through a double emotional mimesis (see figure 3.2):

FIGURE 3.2

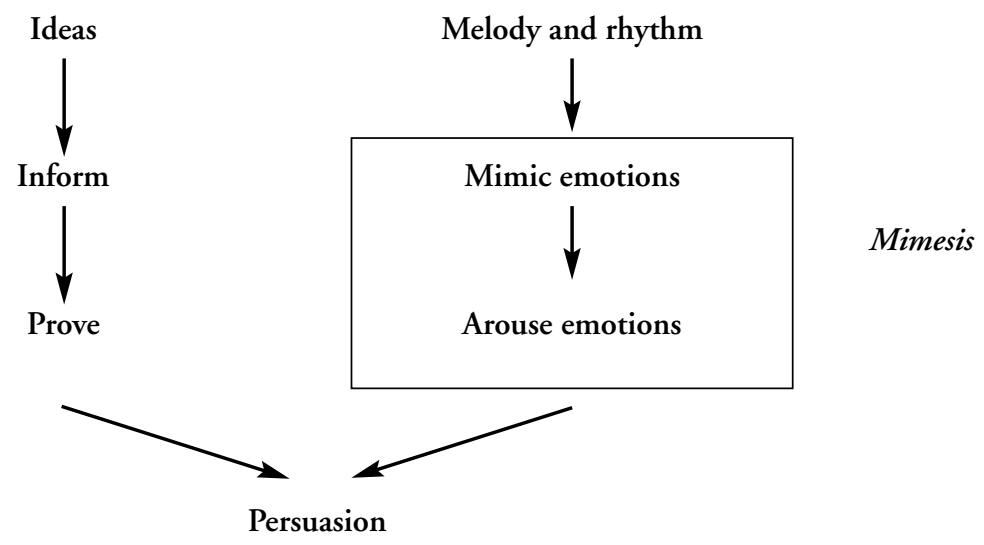

This conception is obviously correlated with the above-mentioned belief that language and the oratory use of language come from nature as Cicero's words read: "art started from nature." Therefore, speech itself is "regarded as a living organism possessing a certain character, by which it can influence the hearers" (Wisse 1989, pp. 6I-62). Melody and rhythm definitely determine this charac- 
ter by providing speech with their own properties. They are part and parcel of the strategy of persuasion in controlling what is irrational in the hearers' subjectivities. This system reveals how much ancient rhetoricians were aware of the psychological impact of delivery itself on persuasion. Indeed, music in speech is expressed by vocal intonations, rhythms of words and gestures (Cic. De Or. 3, 220; Brut. 278; Quint. Inst. I, IO, 22; II, 3, I07-IO8; Aldrete 1999, p. 39): the whole body must be involved in the delivery to communicate melody and rhythm, to arouse emotions and finally to persuade.

\title{
3.4 What about ethics?
}

\subsection{Music and oratory manipulation}

The interaction between emotions and persuasion may raise some deep ethical concern. Indeed, in Aristotle and Cicero's views, the same emotions can be used respecting ethics or not. Thus, "rhetoric is a tool that may be used rightly or wrongly, and it is morally neutral in itself" (Wisse I989, p. 297). Consequently, the speaker who uses them in his strategy of persuasion has a strong moral responsibility. According to Cicero, he must exercise his rhetorical skills to help justice (Cic. De Or. I, 30-34; 2, 33-38; Wisse 1989, p. 397):

\begin{abstract}
If anyone neglects the study of philosophy and moral conduct, which is the highest and most honourable of pursuits, and devotes his whole energy to the practice of oratory, his civic life is nurtured into something useless to himself and harmful to his country; but the man who equips himself with the weapons of eloquence, not to be able to attack the welfare of his country but to defend it, he, I think, will be a citizen most helpful and most devoted both to his own interests and those of his community. (Cic. De Inv. I, I)
\end{abstract}

However, can this ideal be truly reached in reality? Cicero was actually aware of the heuristic function of this introduction: his aim was to describe the perfect speaker in order to provide a model of rhetoric but also to warn against immoral oratory practices. These had already been evoked by Aristotle in ancient Greece:

Appropriate style also makes the fact appear persuasive; for the mind of the hearer is imposed upon under the impression that the speaker is speaking the truth, because, in such circumstances, his feelings are the same, so that he thinks - even if it 
is not the case as the speaker puts it - that things are as he represents them; and the hearer always sympathises with one who speaks emotionally, even though he really says nothing. (Arist. Rhet. I408a 19-24)

An appropriate speech is characterized by a perfect correspondence between formal properties, topic and psychological goals. Melody and rhythm thus determine appropriateness. According to Aristotle, a speaker who perfectly masters the music of words, vocal intonations, tempo and gestures, can achieve persuasion whatever he says. Consequently, persuasion can be exclusively based on emotions. The problem is that formal properties - above all melody and rhythm - do not serve ideas but replace ideas themselves. In other words, the message is deprived of what must be its main component. These practices were clearly inspired by Gorgias' theory of "the dominance of the passive psychè by the active logos" (Wardy 1996, p. 79). Nevertheless, this ethical danger is still real nowadays: emotional manipulation through melody and rhythm is indeed an oratory tool which may be the basis of dictatorship.

\subsubsection{Solutions}

Ancient rhetoricians suggested some solutions against emotional manipulation in political discourse. First, emotions like ideas have to be "permeated by reason" (Wardy I996, p. 62) because reason is necessarily guided by morality and honesty. The "reasonable" speaker can therefore show himself as a wise and trustworthy person. This means that throughout the performance, the emotional mimesis must always be correlated to the argumentation (Arist. Rhet. I356a I4; Garver 2000, p. I7).

Cicero proposed an additional solution. In his view, a good speaker must also feel the very emotions he wants to arouse (Wisse 1989, p. 264, Cooper I996, p. 239) and then express them with appropriate melody and rhythm during the performance. In other words, morality is implied by the genuineness of the emotions to be displayed (Narducci 1997, p. 77). The orator Antonius analyses this process in detail in the second book of De Oratore:

It is impossible for the listener to feel indignation, hatred or ill-will, to be terrified of anything, or reduced to tear of compassion, unless all those emotions, which the advocate would inspire in the judge, are visibly stamped or rather branded on the advocate himself. Now if some feigned indignation had to be depicted, and that the same kind of oratory afforded only what was counterfeit and produced by mimicry, 
some loftier art would perhaps be called for. (...) I give you my word that I never tried, by means of a speech, to arouse either indignation or compassion, either illwill or hatred, in the minds of a tribunal without being really stirred myself, as I worked upon their minds, by the very feelings to which I was seeking to prompt them. (Cic. De Or. 2,189).

This solution thus suggests that genuine emotions are the most persuasive because they imply sincerity and are consequently effective in defending the truth. Actually, these two solutions have to work together, as shown by figure 3.3:

\section{FIGURE $3 \cdot 3$}

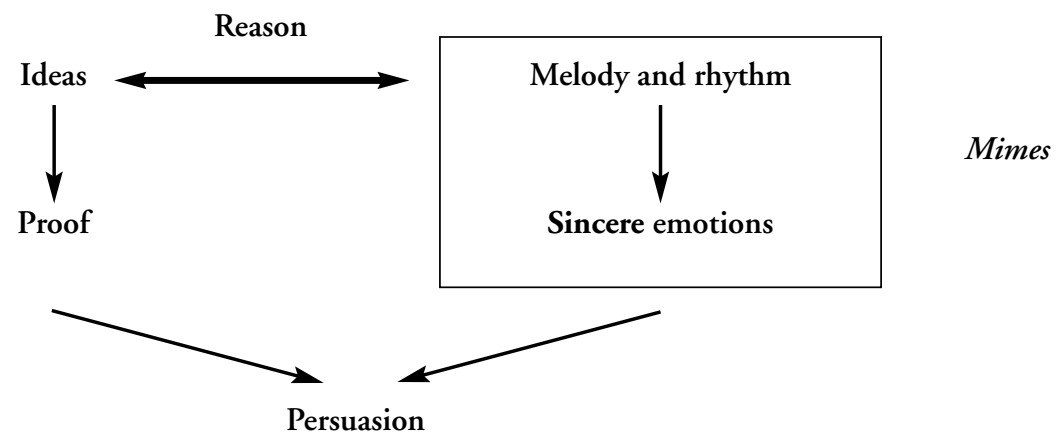

However, Cicero holds an ambiguous position about emotions and ethics. On the one hand, he insists on the fact that good speakers have to be "aflame" before attempting to "inflame" the hearers (Cic. De Or. 2, I89-196, Wisse 1989, pp. 257-258, Narducci 1997, p. 80) - but it is far from easy to tell a good speaker from an actor and thus to draw the line between rhetoric and dramatic eloquence. On the other hand, imitation and pretence can also be part of the strategy of persuasion. In this case, rhythm and melody are regarded as an oratorical trick based on pleasure (Cic. De Or. 197; 208): they secretly coax the hearers into experiencing the emotions that will eventually persuade them. However, Cicero believes that the speaker must keep in mind that "no doubt reality always does better than imitation" (Cic. De Or. 3, 215). Consequently, imitation must never be the last step - it must support truth and virtue (Wisse 1989, p. 262). 


\subsection{From Cicero to Obama: Melody and rhythm in the victory speech (4 $4^{\text {th }}$ Nov. 2008)}

By altering emotions, melody and rhythm play a fundamental part in the strategy of persuasion. This process was interpreted in Antiquity in the light of mimesis. Even though this conception clearly belonged to a specific social, cultural and aesthetic context, it can rightly elucidate aspects of some persuasive process involved in modern political discourses. Many examples could be taken, among which Obama's victory speech on November $4^{\text {th }} 2008$. That day, as soon as the Obama family appeared, people in the audience showed their joy and goodwill. Obama's aim was therefore to reinforce his partisans' support as well as to associate all the American people with his victory, even those who had not voted for him.

\subsection{Anaphora, solemnity and admiration}

His speech followed a clear argumentative progression. Vocal intonations and syntactic rhythm specifically contributed to the whole architecture as they guided the hearers from one idea to another while maintaining an unquestionable emotional tension as well. One of the most striking musical effects was based on anaphora, i.e., the repetition of the same word or expression at the beginning of sentences. This repetitive effect can create a rhythm because it influences perception by inducing anticipation and recognition of a specific pattern. Particular vocal intonations also make it easily perceptible. At the same time, it is clear that it contributes to the argumentative structure of the speech. This process is particularly patent in the introduction:

If there is anyone out there who still doubts that America is a place where all things are possible;

who still wonders if the dream of our founders is alive in our time;

who still questions the power of our democracy, tonight is your answer.

It's the answer told by lines that stretched around schools and churches (...)

It's the answer spoken by young and old, rich and poor, Democrat and Republican, black, white, Hispanic, Asian, Native American, gay, straight, disabled and not disabled (...)

It's the answer that led those who have been told for so long by so many to be cynical, and fearful, and doubtful of what we can achieve (...). 
Rhythm in this extract is based on two very simple ternary anaphoric patterns. The first consists of the repetition of the same syntactic structure: "who still" + verb. Actually, the main musical marker is the adverb "still" as is clearly shown in the sonogram in figure $3 \cdot 4:^{\mathrm{I}}$

\section{FIGURE 3.4}

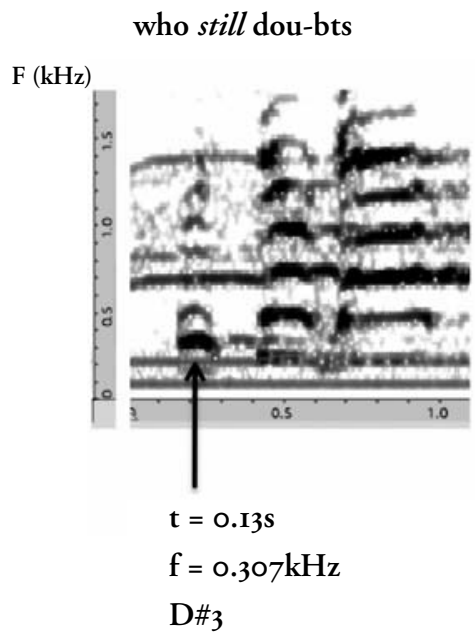

who still won-ders

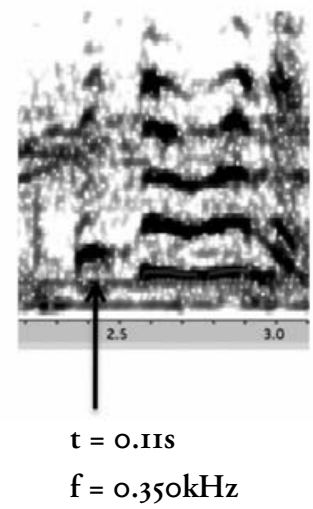

$\mathrm{F}_{3}$ who still ques-tions

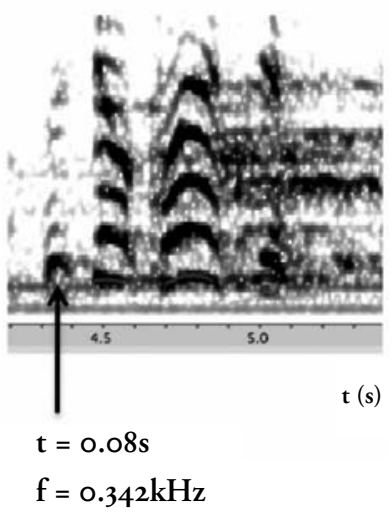

$\mathrm{E}_{3}$

Time (s) is reported on the horizontal axis whereas frequency $(\mathrm{kHz})$ is reported on the vertical one. Each sound corresponds to a series of harmonics, represented here by a stratification of lines. The lowest harmonic constitutes the fundamental tone $-\mathrm{A \# 2}$ in Obama's voice. The blackness of the harmonics corresponding to "still" signals a strong vocal intensity, induced by the harshness of sounds but also by Obama's will to plainly mark the beginning of each segment. Measures of frequency tend to reveal a binary melodic development: first, the voice follows a rising movement and then a falling one. Time spans are also shorter and shorter; this acceleration of tempo creates a tension likely to produce expectancy among the hearers. This ends with the words "tonight is your answer" which corresponds to the first direct address to the audience. The same process is applied to the anaphoric clause "It's your answer." In fact, the use of a ternary rhythm and vocal amplitude - as in an incantation - gives solemnity to the speech and dignity to the speaker. In this specific case, it con-

\footnotetext{
I I employed the software Audiosculpt (IRCAM, Paris).
} 
tributes to encourage goodwill by associating the hearers with political victory and nourishing their collective energy too.

Other musical processes, also based on anaphora, may be observed in the following parts of this speech. They confirm a shift in the oratory strategy. Indeed, after thanking all the people who had been involved in the campaign, Obama exposed the difficult task ahead. Sentences tend to be shorter as if to delineate each step. A good example is this sentence: "There's new energy to harness and new jobs to be created; new schools to build and threats to meet and alliances to repair." Here again rhythm is based on the anaphora of a syntactic group: "new" + noun + infinitive. The first coordinative "and" initially suggests a binary rhythm. However, the addition of the third group "new schools..." actually induces a modulation and thus introduces ternary dynamics.

\section{FIGURE $3 \cdot 5$}

There's new energy and new jobs new schools and threats and alliances to harness to be created; to build to meet

to repair

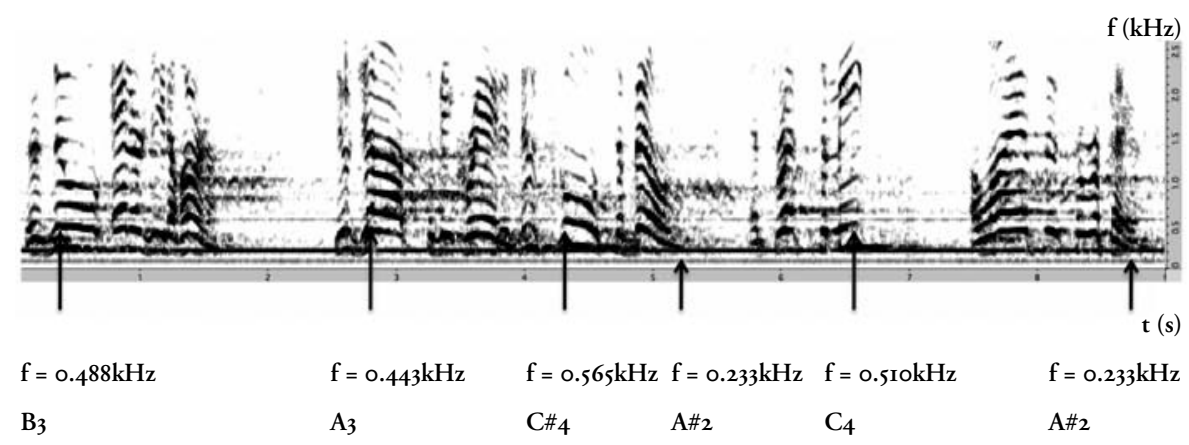

This group "new schools to build" is in fact the pivot of this sentence. Indeed, it marks the end of the first ternary group and the beginning of the second one. This central role is moreover given by melody and rhythm: the adjective "new" corresponds here to the highest vocal tension. It also initiates the second ternary movement which follows a parabolic intonation. Indeed, frequency measures show that the central group "and threats to meet" is characterized by a vocal suspense - the voice does not fall down to the fundamental tone as it usually does to mark punctuation. Therefore, Obama visibly mastered melody and rhythm in this sentence. By choosing short 
sentences and cautiously chunking them, he hinted at each difficult step to be taken in the future task. As he combined binary and ternary rhythms while modulating his voice, he maintained solemnity and in a way built up an atmosphere of epic tension: he and the American people would have to be "heroes" to achieve this renewal.

\subsubsection{The chorus "yes we can" for a collective victory}

The most famous musical effect in this speech must be the repetition of the credo "yes we can." This short phrase really played the role of a chorus when Obama finally told the story of Ann Nixon Cooper, the ro6-year-old woman who voted during this election. The oratory goal was to inflame the audience, to make everybody proud of America and its history that this lady - described by Obama as extraordinary - was supposed to embody. By repeating the chorus, the hearers showed their unity and confirmed it was a successful speech. Then it was time for Obama to conclude:

This is our chance to answer that call.

This is our moment.

This is our time

to put our people back to work and open doors of opportunity for our kids;

to restore prosperity and promote the cause of peace;

to reclaim the American dream and reaffirm that fundamental truth

that out of many, we are one;

that while we breathe, we hope, and where we are met with cynicism and doubt, and those who tell us that we can't,

we will respond with that timeless creed that sums up the spirit of a people: yes, we can.

Here again, ternary anaphoric patterns ("this is our chance (...) this is our moment (...) this is our time (...) to put (...) to restore (...) to reclaim") were used to reinforce the chanting rhythm full of solemnity. Moreover, by employing the pronoun "we," Obama did associate the whole American people with his victory. However, the last sentence is the most interesting as far as melody and rhythm are concerned. The sonogram (see figure 3.6) indeed reveals a very elaborate musical process: 


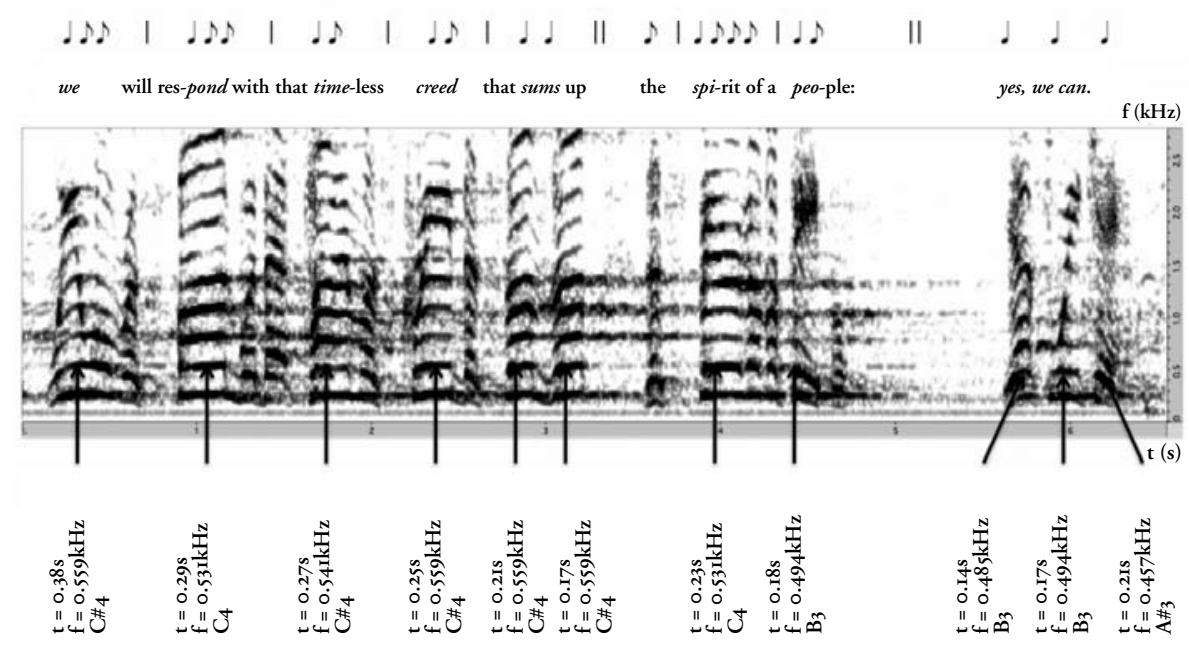

First, this sentence is based on a binary progression: the credo "yes we can" is clearly isolated by a pause (of around Is). In the first part, vocal tension is maintained: the first harmonic higher than the fundamental tone is around $\mathrm{C}$, which truly corresponds to a huge stress in Obama's voice. A descending movement can however be observed on the last word "people", just before the pause. The second part is characterized by a lower tension, as to signal a final punctuation. The most striking effect is the use of specific rhythmic patterns. Indeed, as in Latin, stress in English plays a fundamental role in verbal dynamics. In this sentence, each stress thus marks the beginning of a musical measure. Each measure is clearly distinguished and typified by a rhythmic pattern based on contrasts between long stressed and short unstressed syllables (of around 0.20 s and o.Ios). Moreover, some regularity can be detected. Among the five opening measures, the first and the second are based on a dactylic pattern (one long and two short syllables), the following two on a trochaic one (one long syllable and one short syllable) and the last on a spondaic one (two long syllables). Then a pause occurs as to emphasise the group of words "the spirit of a people." This begins with the unstressed syllable "the" which can be interpreted as an anacrusis, i.e., a preliminary measure after which the beat starts. The two following measures are based on a rhythmic pattern that used to be most appreciated by ancient orators: a peon (one long syllable and three short syllables) and a trochee (one long syl- 
lable and one short syllable). The phrase "yes, we can" can finally be interpreted as a series of three long syllables, which is a moloss. Consequently, melody and rhythm in this last sentence are particularly elaborate. The rhythmic regularity and melodic tension set up an easily perceptible pace and provide the whole speech with a cadence likely to be greeted with cheers of agreement and admiration.

\subsection{Conclusion}

Melody and rhythm can be rightly considered as highly powerful tools to achieve persuasion. It has been experimented since Aristotle and Cicero. During Antiquity, political speeches, as well as songs, were supposed to alter feelings and thus to determine the hearers' behaviours. More exactly, the speakers' duty was to take advantage of the natural gifts of the human voice, i.e., intonations, long and short sounds, contrasts of intensity, etc. Indeed, ancient theorists such as Aristotle and Cicero knew that ideas were not sufficient to impose a point of view, that they were to be reinforced by delivery and most of all, by melody and rhythm. Through a complex mimetic process that involves rational and irrational material, ancient speakers were supposed not only to develop an argumentation and provide evidence on facts but also to adapt rhythm and melody in order to make speeches appropriate, to prove themselves wise and trustworthy and to play on emotions as well - a last step necessary to achieve persuasion. In other words, music in speech was considered as deeply correlated to ethos (moral characterisation) and pathos (emotional impact). The analysis of Obama's victory speech has shown how much this interaction between music, ethos and pathos is definitely and unquestionably fundamental in rhetoric, even today. Consequently, although ancient Greek and Latin differ from our own languages, although those cultures may appear so alien to our daily worries, ancient thought can really provide a good starting point for our reflections on rhetoric. It is particularly true when we deal with the interaction between emotions and persuasion and the ethical concern inferred by the psychological impact of music in political speech.

\section{References}

Achard, G. (1994). Cicéron, De Inventione. Paris: Les Belles Lettres.

Aldrete, G.S. (1999). Gestures and Acclamations in Ancient Rome. Baltimore/London:

J. Hopkins University Press. 
Chiron, P. (2008). Musique des mots et persuasion dans deux traités de rhétorique d'époque hellénistique et romaine (Ps. Démétrios de Phalère, Du Style, Denys d'Halicarnasse, La Composition stylistique). Modèles linguistiques 29, 27-46.

Cooper, J.M. (1996). An Aristotelian Theory on Emotion. In: A. Oksenberg Rorty (Ed.), Essays on Aristotle's Rhetoric (pp. 238-257). Berkeley/Los Angeles: University of California Press.

Dangel, J. (200I). La musique des vers latins déclamés, modulés et chantés: carmen, cantica, carmina. In: J. Foyard (Ed.), Le vers et sa musique (pp. 39-63). Dijon: Université de Bourgogne, Centre de recherches sur le texte et l'édition.

Duysinx, F. (1999). Aristide Quintilien, La Musique. Genève: Duroz.

Garver, E. (2000). La découverte de l'ethos chez Aristote. In: F. Cornilliat and R. Lockwood (Eds.), Ethos et Pathos, le statut du sujet rhétorique (pp. 15-35). Paris: Champion.

Halliwell, S. (2002). Aesthetics of Mimesis. Ancient Texts and Modern Problems.

Princeton/Oxford: Princeton University Press.

Hömke, N. (2009). The Declaimer's One-Man Show. Playing with Role and Rules in the Pseudo-Quintilian Declamationes Minores. Rhetorica 27, 240-255.

Kennedy, G.A. (1999). Classical Rhetoric and its Christian and Secular Tradition from Ancient to Modern Times. Chapel Hill: University of California Press.

Leighton, S.R. (1996). Aristotle and the Emotions. In: A. Oksenberg Rorty (Ed.), Essays on Aristotle's Rhetoric (pp. 206-237). Berkeley/Los Angeles: University of California Press.

Mathiesen, T.J. (1999). Apollo's lyre: Greek music and Music Theory in Antiquity and the Middle Ages. London: University of Nebraska Press.

May, J.M. (2002). Ciceronian Oratory in Context. In: J.M. May (Ed.), Brill's Companion to Cicero, Oratory and Rhetoric (pp. 49-70). Leiden: Brill.

Michel, A. (1996). Rhétorique, philosophie, oralité: Cicéron et les genres littéraires. In:

J. Dangel and C. Moussy (Eds.), Les structures de l'oralité en latin (pp. 20I-209). Paris: Presses Universitaires de France.

Narducci, E. (1997). Cicerone e l'eloquenza romana. Retorica e progetto culturale. Roma: Laterza.

Narducci, E. (2002). Orator and the Definition of the Ideal Orator. In: J.M. May (Ed.), Brill's Companion to Cicero, Oratory and Rhetoric (pp. 427-443). Leiden: Brill.

Solmsen, F. (1938). Aristotle and Cicero on the Orator's Playing upon the Feelings. Classical Philology 33, 390-404.

Solmsen, F. (194I). The Aristotelian Tradition in Ancient Rhetoric. American Journal of Philology 62, 35-50, 169-190. 
Wardy, R. (1996). The Birth of Rhetoric: Gorgias, Plato, and their Successors. London/New York: Routledge.

Warren, R.M. (1994). La perception des séquences acoustiques: intégration globale ou résolution temporelle? In: S. Mc Adams and E. Bigand (Eds.), Penser les sons (pp. 4I-74). Paris : Presses Universitaires de France.

West, M.L. (1992). Ancient Greek Music. Oxford: Clarendon Paperbacks.

Wisse, J. (1989). Ethos and Pathos from Aristotle to Cicero. Amsterdam: A.M. Hakkert.

Zagdoun, M.A. (2007). Ethique et théories de la musique chez les Stö̈ciens. In: F. Malhomme and A.G. Wersinger (Eds.), Mousikè et Aretè : la musique et l'éthique de l'Antiquité à l'Âge Moderne (pp. 87-98). Paris: Vrin. 



\title{
4 Generalizing Stasis Theory for Everyday Use
}

\author{
CHRISTIAN KOCK
}

\section{I Introduction}

When debaters disagree, it is important to understand the exact nature and scope of their disagreement. Each debater has an interest in knowing the precise reasons that make his opponents disagree with him, because if he wants some of his opponents to change their minds, those are the reasons he should try to refute. The onlooker, too, has an interest in knowing them, because they are probably the reasons that will best help him decide for himself.

However, public debaters often misrepresent and widen their disagreements. They distort each other's standpoints and reasons, representing them as either bizarre or toothless (two subtypes of the 'straw man' fallacy). Or they ignore the opponents' real reasons and attribute imaginary reasons to them. They speculate on their opponents' basic, hidden motives. Often they see an opponent as part of a large, monolithic block, so that he is either a member of a conspiracy or at least a "useful idiot". Attacks on the opponent's ethics, intellect and personality often follow. Partisanship and polarization flourish. Debaters see their own standpoint as representing righteousness, while any divergent standpoint is seen as opposite, usually in a dichotomous sense: there are no third positions, no neutral ground. This way, political and social debate may resemble trench warfare as in the First World War. In both, we can see a typical widening of the front zone where the two parties clash.

For onlookers who look to debates for enlightenment to choose a standpoint there is little help. They would be better served if the debate would focus on those smaller sectors of the front where debaters crucially disagree, and where a true breakthrough might most likely occur. Litigation lawyers know the need to focus their argument on potentially decisive points and present a coordinative argumentation rather than a multiple set of unconnected reasons - to use the terminology of Francisca Snoeck Henkemans (2000). Interestingly, an empirical study of televized political debates where 
representative audiences voted on issues before and after each debate showed that here too the coordinative strategy is superior: what we called "single ground" debaters performed significantly better in terms of votes than "multiple ground" debaters (Jørgensen, Kock and Rørbech 1994, 1998). Readers of a famous essay by Orwell (1946) will know that to shoot a mad elephant (as the young Orwell once had to) one should place one bullet in the exact right spot with great force. A similar piece of advice seems to be sound regarding deliberative argument.

\subsection{Status theory as a focusing tool}

Ancient stasis (status) theory was a tool to help forensic debaters focus their case. The central part of the theory was the status rationales: the conjectural, the definitional and the qualitative, equivalent to the questions: What are the facts? How are the facts to be categorized? What particular circumstances characterize them?

These status rationales question the facts at issue, but another main part of status theory were the status legales, which question the laws by which the facts were to be judged. Usually, four types of disagreement are mentioned. In all of them the debater argues that there is no clear one-to-one match between a law and a fact. Ratiocinatio is when there is no norm that meaningfully covers the fact, so we must reason by analogy from existing norms about something else. Ambiguum is where there is one relevant norm that may cover the fact, but it is ambiguous or abstract. In scriptum et voluntas there is also one relevant norm, but this time it is too specific; it may literally cover the fact, but the argument is that we should read the spirit of the law, not the letter. Finally, contrariae leges is where two or more norms which may cover the fact, but they point to different conclusions.

Notice that here we pass logically from cases with no applicable norms, to cases where one norm may apply, which is either too abstract or too specific, to cases with more than one applicable norm.

Ancient status theories also included lists of so-called "practical issues", such as legality, justice, advantage, feasibility, honor and consequence. All these are examples of relevant norms (or norm systems) that may legitimately be invoked in social and political argument, but they are mutually heterogeneous, i.e., the set of relevant norms is 'multidimensional', and hence the norms will necessarily tend to clash. For example, a debater might support a policy as advantageous; another might oppose it as dishonorable. This is the practical par- 
allel to the issue of contrariae leges. But the main components of the status system - the status rationales and the status legales - were intended for legal argument; they presupposed the existence of explicit, formal rules (leges), which were meant to cover the facts of the case, i.e., to correlate ius and factum.

I suggest a way to generalize and integrate all these strategies into one scheme which can help identify and narrow down the decisive reasons not just in legal argument, but in deliberative argument as well, that is, in any social disagreement over action. Such a scheme (see table 4.I) might help clarify, for debaters and onlookers alike, what current disagreements are essentially about, and in particular what they are not about.

We should note that the differences between legal and political argument are not absolute. Legal argument often relies on informal norms used in practical reasoning; political argument often invokes legal considerations. Both kinds are about action - legal argument is about legal action in response to past acts, political argument is mainly about future action but also about evaluating and modifying past acts. In both cases acts are being supported or opposed with reference to norms of right action, which function as 'warrants', to use Toulmin's term (1958). The difference is mainly that legal norms are typically written statutes which are recognized as valid and operative by all; norms underlying political argument are usually informal, unwritten and not always recognized as valid by all, or to the same degree. Also, they are most often implicit rather than explicitly stated, and they are more heterogeneous or 'multidimensional' than legal norms: some may be purely prudential and are perhaps only concerned with economic consequences; others may be virtue-ethical norms about moral conduct, fairness or justice; others again are in fact formal and legal, for example considerations as to whether a policy is constitutional.

\subsection{Applying status theory to social and political argument}

Status theory is a typology of the problems we may meet in correlating norms and facts, and since these problems are analogous in the two fields, I propose we use status theory to consider not just legal argument, but social and political argument as well.

For this purpose, I further propose to integrate the status legales in the status rationales. In the status of definition, we discuss how a fact can be subsumed under a norm. The status legales are about the same kind of discussion, but they start from the other end: the norms. The reason they are useful is that 
TABLE 4.I STATUS SYSTEM FOR PRACTICAL DEBATE

\begin{tabular}{|c|c|c|c|c|c|c|}
\hline $\mathbf{I}$ & Classical terms & $\begin{array}{l}\text { I. Status conjecturae } \\
\text { Conjecture }\end{array}$ & \multicolumn{4}{|c|}{$\begin{array}{l}\text { 2. Status finitionis - Definition } \\
\text { (the status legales are inserted here: } \mathrm{C}_{4}-\mathrm{F}_{4} \text { ) }\end{array}$} \\
\hline 2 & $\begin{array}{l}\text { What are we } \\
\text { debating? }\end{array}$ & What are the facts? & \multicolumn{4}{|c|}{$\begin{array}{l}\text { What norms apply to the facts? } \\
\text { (Legal norms (statutes), ethical norms, ideological norms, } \\
\text { value concepts, "doxai", "common sense", } \\
\text { formal and informal topoi ...) }\end{array}$} \\
\hline 3 & $\begin{array}{l}\text { Counterpart in } \\
\text { argumentation theory }\end{array}$ & $\begin{array}{l}\text { Truth/ } \\
\text { Acceptability }\end{array}$ & \multicolumn{4}{|l|}{ Relevance } \\
\hline 4 & Classical subtypes & & $\begin{array}{l}\text { Assimilation } \\
\text { Ratiocinatio }\end{array}$ & $\begin{array}{l}\text { Ambiguity } \\
\text { Ambiguum }\end{array}$ & $\begin{array}{l}\text { "Letter and } \\
\text { Intent" } \\
\text { Scriptum et } \\
\text { voluntas }\end{array}$ & $\begin{array}{l}\text { Conflict of law } \\
\text { Contrariae leges }\end{array}$ \\
\hline 5 & $\begin{array}{l}\text { Disagreement type } \\
\text { and appropriate } \\
\text { rhetorical strategies }\end{array}$ & $\begin{array}{l}\text { Disagreement about } \\
\text { facts } \\
\text { Give evidence. } \\
\text { Increase probability }\end{array}$ & $\begin{array}{l}\text { No norms } \\
\text { clearly apply } \\
\text { Argue from } \\
\text { either } \\
\text { consequences } \\
\text { or analogy }\end{array}$ & $\begin{array}{l}\text { One disputable } \\
\text { (vague) norm } \\
\text { applies } \\
\text { Argue for } \\
\text { interpretation } \\
\text { of norm to } \\
\text { either include } \\
\text { or exclude facts }\end{array}$ & $\begin{array}{l}\text { One disputable } \\
\text { (strict) norm } \\
\text { applies } \\
\text { Propose } \\
\text { distinction } \\
\text { between } \\
\text { literal and } \\
\text { intended } \\
\text { meaning }\end{array}$ & $\begin{array}{l}\text { Two or more contradictory } \\
\text { norms apply } \\
\text { Argue to show that norms } \\
\text { on own side have more } \\
\text { relevance andlor weight } \\
\text { than those on other side }\end{array}$ \\
\hline 6 & Comments & & $\begin{array}{l}\text { Mostly about } \\
\text { novel } \\
\text { phenomena }\end{array}$ & $\begin{array}{l}\text { Many debates } \\
\text { in politics } \\
\text { and ethics } \\
\text { belong here } \\
\text { (cf. Warnke) }\end{array}$ & $\begin{array}{l}\text { Often a last } \\
\text { resort in } \\
\text { argument }\end{array}$ & $\begin{array}{l}\text { * Many debates in politics } \\
\text { and practical ethics belong } \\
\text { here } \\
\text { * "Conductive reasoning" } \\
\text { (cf. Wellman, Govier) } \\
\text { * "Value pluralism" (cf. } \\
\text { Berlin et al.) } \\
\text { * "Incommensurability" } \\
\text { (cf. Raz et al.) } \\
\text { * "Normative meta- } \\
\text { consensus" (cf. Dryzek) } \\
\text { may apply } \\
\text { * Types of norms invoked } \\
\text { - include: } \\
\text { - legality } \\
\text { - justice } \\
\text { - advantage } \\
\text { - feasibility } \\
\text { - honor } \\
\text { - consequence }\end{array}$ \\
\hline 7 & Examples & & $\begin{array}{l}\text { Cloning, } \\
\text { Stem cell } \\
\text { research, } \\
\text { File-sharing }\end{array}$ & Abortion & $\begin{array}{l}\text { Anti- } \\
\text { abolitionist: } \\
\text { "Black slaves } \\
\text { not intended } \\
\text { by all men to } \\
\text { be created } \\
\text { equal" }\end{array}$ & $\begin{array}{l}\text { Invasion of Iraq: } \\
\text { Spreading democracy, } \\
\text { deposing a tyrant } \\
\text { Self-defense } \\
\text { Vs. } \\
\text { Legality, human and } \\
\text { material costs } \\
\text { Resulting chaos } \\
\text { Muhammad cartoons: } \\
\text { Defense of free speech } \\
\text { internationally } \\
\text { Vs. } \\
\text { Gratuitous offense to } \\
\text { minority locally }\end{array}$ \\
\hline & A & B & $\mathrm{C}$ & $\mathrm{D}$ & $\mathrm{E}$ & $\mathrm{F}$ \\
\hline
\end{tabular}




\section{Status qualitatis - Quality}

What specific features and circumstances of the facts should be considered?

Weight, Strength, "Sufficiency", "Good Grounds" (= gradual and quantitative considerations)

\begin{tabular}{|c|c|c|c|c|c|}
\hline $\begin{array}{l}\text { Counterplea } \\
\text { Antilepsis }\end{array}$ & $\begin{array}{l}\text { Counterstatement } \\
\text { Antistasis }\end{array}$ & $\begin{array}{l}\text { Counteraccusation } \\
\text { Antenklema }\end{array}$ & $\begin{array}{l}\text { Transference } \\
\text { Metastasis }\end{array}$ & $\begin{array}{l}\text { Mitigation } \\
\text { Syngnome }\end{array}$ & Mortification \\
\hline $\begin{array}{l}\text { Norm recognized, } \\
\text { but breach } \\
\text { justified by } \\
\text { extraordinary } \\
\text { circumstances } \\
\text { "It is just" }\end{array}$ & $\begin{array}{l}\text { Norm recognized, } \\
\text { but regretfully } \\
\text { disregarded } \\
\text { "It is necessary" }\end{array}$ & $\begin{array}{l}\text { Norm recognized, } \\
\text { breach blamed } \\
\text { on object of } \\
\text { breach } \\
\text { "They asked for it" }\end{array}$ & $\begin{array}{l}\text { Norm recognized, } \\
\text { breach blamed } \\
\text { on external party } \\
\text { "They made us } \\
\text { do it" }\end{array}$ & $\begin{array}{l}\text { "Mitigating } \\
\text { circumstances" }\end{array}$ & $\begin{array}{l}\text { Norm } \\
\text { recognized, } \\
\text { breach } \\
\text { deplored, } \\
\text { forgiveness } \\
\text { "I apologize" }\end{array}$ \\
\hline
\end{tabular}

All these resemble, or are even identical to, those issues where contradictory norms apply (F5); the difference, if any, is that in the qualitative status (as we are here), one argues for an exception to the strict application of a certain general norm, the relevance of which is not contested.

\begin{tabular}{|l|l|l|l|l|l|}
$\begin{array}{l}\text { Liquidation of } \\
\text { informers under } \\
\text { German } \\
\text { Occupation; } \\
\text { "Whistleblowing" }\end{array}$ & $\begin{array}{l}\text { Torture, } \\
\text { "extraordinary } \\
\text { rendition", } \\
\text { "illegal } \\
\text { combattants" }\end{array}$ & $\begin{array}{l}\text { Retaliation } \\
\text { in war }\end{array}$ & $\begin{array}{l}\text { "We were } \\
\text { under orders" }\end{array}$ & $\begin{array}{l}\text { Victim gets } \\
\text { back } \\
\text { at tormentor }\end{array}$ & $\begin{array}{l}\text { "I misled } \\
\text { people, } \\
\text { including even } \\
\text { my wife. } \\
\text { I deeply } \\
\text { regret that." }\end{array}$ \\
\hline G & H & I & & & \\
\hline
\end{tabular}


they specify the problems raised by the correlation of norms and facts. Finally, I also propose to include the 'practical issues' of political argument among the many norms that are invoked, implicitly or explicitly, in political argument.

So this is how we may integrate and generalize the various components of ancient status thinking into a comprehensive typology of disagreement in social debates: I) We generalize the formal legal concept of 'laws' into a broader, more varied concept of norms; 2) We see the status legales as specifications of the ways in which the correlation between facts and norms may be contentious; and 3) We use the 'practical issues' to specify some of the varied norms that may clash in social debates.

The complete, integrated status system for practical debates is given in the table 4.I. I have named the cells with letters and number, filled in some terms drawn from ancient status theories and supplied examples for the different types of disagreement. We will look at some of these. (Notice that the table also contains examples and comments not cited in the text of this chapter.)

But you may ask: why do all this? Is this meant to be a better interpretation of what ancient rhetoricians meant? No, I propose it as a useful tool for handling current social and political disagreements. If public debaters and audiences would think about disagreements in terms like these, they might better avoid the characteristic widening of disagreements where debaters impute imaginary standpoints, policies, reasons, intentions and personality features to each other. With greater awareness of the specific type of disagreement in a particular case, debaters may be more conscious of the norms that their own argument relies on, and of those on the other side.

Let us look at some of the types of disagreement that our generalized and integrated version of the status system specifies. Those that primarily call for comment are those representing the four status legales, seen as specifications of the status finitionis ( $\mathrm{C}_{5}-\mathrm{F}_{5}$ in the table). This is where the traditional system of status rationales is most notably enriched; the status conjecturae and the status qualitatis, on the other hand, are defined and subdivided by the present scheme in the same way as we find in ancient theory (more specifically that of Hermogenes).

If, for example, the disagreement is one where no pre-existing norm clearly and indisputably applies (cell $\mathrm{C}_{5}$ in the table), then that understanding might be a starting point for a discussion where both parties collaborate to find 
a relevant norm. Issues where such a search for relevant norms is indicated concern such 'new' phenomena as are currently emerging in fields like bioethics and information technology: cloning of higher organisms and stem cell research are activities where there is indeterminacy as to what categories may relevantly apply to the entities in question - and hence there are also quandaries as to what existing norms, if any, may relevantly apply to them. Various forms of digital file sharing are technological phenomena which, at least according to some, fundamentally question existing norms relating to property and intellectual rights, thus necessitating the formulation of new norms.

Disagreeing debaters might also find that they both agree on a certain norm, but that their disagreement is about interpretation, that is, about whether the fact they discuss can indeed be meaningfully subsumed under this norm that they both happen to support (cell D5). The philosopher Georgia Warnke (1999) has written about this sort of 'interpretive' disagreement. The abortion issue in the United States is a prime example; the problem is that the participants in that debate do not realize it. Both sides are surely 'pro life' as well as 'pro choice', but the disagreement is on whether the removal of a new foetus, or fertilized egg, constitutes the taking of a human life, and whether a woman's choice to have a new foetus removed from her body can be seen as her own choice.

Disagreements belonging in cell $\mathrm{E}_{5}$ are those where a strict and literal understanding of a norm (either written or unwritten) is opposed by one that will read a different underlying spirit into that norm. For example, anti-abolitionists in the debate on slavery in the US in the Nineteenth Century were apt to believe that the words in the Declaration of Independence about "all men" being "created equal," when read in the right spirit, did not really apply to black slaves, although they admittedly were, in a certain sense, men.

Again, two disagreeing debaters in the abortion controversy might find that they mutually endorse the other side's interpretation of the norms that are invoked. Then we have a dispute belonging in cell $\mathrm{F}_{5}$ : there is agreement on two relevant norms which in the specific case point to opposite conclusions, and the crucial point is now whether the argument relying on one of these norms can be made to appear weightier than the argument relying on the other.

Column $\mathrm{F}$ in the table is the deliberative counterpart of contrariae leges: cases like those where two or more normative concepts are used as warrants on opposite sides. We face such issues all the time. The invasion of Iraq was 
supported by some with reference to a defence against terrorism, dissemination of democracy and the need to overturn tyrants, but it was opposed by others with reference to its non-compliance with international law, the loss in human and material terms, and the dangerous chaos that would be its likely consequence.

All of these considerations were in some sense potentially relevant to the issue, so we had a case of what Carl Wellman (1971) and Trudy Govier (1987, 2004) called "conductive reasoning", i.e., we must somehow weigh the pros against the cons. Such situations exemplify the "value pluralism" propounded by Isaiah Berlin ( 1998,2002$)$; that is, the understanding that several norms may be relevant to a given issue, but argue for opposite decisions - and this not only between two disagreeing debaters, but also inside the mind of an individual. Other philosophers have recently emphasized the 'incommensurability' that obtains between such norms, which implies that it cannot be objectively determined whether one or the other norm should have priority because the relevant norms belong to different dimensions (see, e.g., Raz 1998, and Kock 2003). In legal argument the status of contrariae leges describes such situations, and if we apply status thinking to social disagreements we are reminded that similar contradictions are common there as well, probably more so.

Besides value pluralism and incommensurability, another concept that may be illuminative in polarized debates about controversial issues is that of normative meta-consensus. The political theorist John Dryzek defines it as "agreement on recognition of the legitimacy of a value, though not extending to agreement on which of two or more values ought to receive priority in a given decision" (see, e.g., Dryzek \& Niemeyer 2006, p. 639). In the Iraq debate, both supporters and opponents of the invasion might probably agree on values such as spreading democracy as well as respecting international law. The dispute would then be narrowed down to one about the priority, in the specific case, of one norm over the other; that is, there would be normative meta-consensus. Normative meta-consensus might also be said to exist between the two sides in the abortion debate. Life and choice are two values that both sides recognize, and their dispute is either one of interpretation because both these notions are vague, or one of priorities.

In proposing to apply status thinking to deliberative disputes I do not suggest that we can expect consensus on issues like the ones I have mentioned. The belief that rational argumentative discourse will necessarily lead to consensus (or towards consensus) has been championed by Habermas in philoso- 
phy and by political theorists such as Elster (1986). In argumentation theory, the pragma-dialectical school builds on the hypothetical assumption that the purpose of all argumentation is for the discussants to resolve their dispute. But as John Rawls and others have maintained, there are reasons why people may not ever agree on issues where values are involved, hence his term "reasonable disagreement" (1989, 1993). One of these reasons is precisely the fact that people may, even within the bounds of reasonableness, interpret values differently; this is the main idea in Georgia Warnke (1999). Another reason that people may prioritize values differently; or, in the terminology of Perelman and Olbrechts-Tyteca (1969), their value hierarchies differ. Nevertheless, although consensus cannot, for these reasons, be expected to emerge, in some cases it actually might, and of course that would be welcome. But in the absence of consensus, to realize that there is normative meta-consensus is also an achievement. It would reveal that a dispute is not always an all-out clash between monolithic blocks that reject each other's values. Thus it would help narrow down the scope of the disagreement, and focus everyone's attention on where it actually is rather than on where it is not. The polarization and the trench warfare we often see in public debates would lose some of its fuel. Moreover, debaters on both sides might find more persuasive arguments for their views. The status system in antiquity had this kind of purpose. The reason it might work like that is that helps us focus on the decisive point of disagreement. If one could change opponents' minds about those, then one might change their minds about the whole issue. Similarly for undecided onlookers. They too would more likely take our side if we were to focus on the decisive point of disagreement and make them accept our case on that precise point.

To complete the picture, let us briefly consider the types of disagreement represented by the cells G5-L5. In G5, we have issues where a norm is recognized, but where the presence of 'exceptional' circumstances is invoked to justify the suspension of that norm. For example, during the Nazi occupation of various European countries, including my own country, Denmark, many individuals known or assumed to be informers against members of the resistance movements were summarily liquidated by resistance men. No law or social norm was invoked to justify these killings or the fact that no legal steps were taken against them after the war, only the completely exceptional nature of the situation.

Cell $\mathrm{H}_{5}$ represents issues of a partly similar nature, including the use of "extraordinary rendition" and physical pressure bordering on torture against 
so-called "illegal combatants" captured in Iraq, Afghanistan, etc. Whereas in G5 cases the basic norm outlawing the liquidation of one individual by another is simply suspended by exceptional circumstances, in $\mathrm{H}_{5}$ cases there is more of a weighing of contradictory norms against each other, with one being regretfully 'bent' because trumped by another, based on self-defence.

Cases represented by cells $\mathrm{I}_{5}$ - $\mathrm{L} 5$ show gradually increasing degrees of recognition of the norm that is being broken: In Is cases, the victim of the norm breach is cited as giving cause for it and deserving retaliation ("they asked for it"). In J5 cases, no degree of mitigation of the norm breach itself is sought, yet the perpetrator seeks acquittal or at least mitigation for himself by seeking to shift the blame to a third party, supposedly so powerful that no alternative was available for the perpetrator ("we were under orders"). In K5 cases the perpetrator admits his transgression and his responsibility for it, yet he seeks mitigation in the fact that, e.g., the victim had long tormented or provoked him - a circumstance that may indeed explain and even mitigate the transgression but never justify it. Finally, in Ls the perpetrator fully recognizes the transgression and his own responsibility, seeking mitigation only as an act of mercy, following his avowal of guilt and contrition. This strategy may be exemplified by former President Clinton's words: "I misled people, including even my wife. I deeply regret that" (words which came after a series of attempts at some of the strategies discussed above).

Let me reiterate that what I see as the most useful feature of this proposal to generalize status theory to everyday disagreements is the integration of the fours status legales as a series of specifications of how we may disagree about the definition or nature of the act we debate. As an example, consider the debate on the Muhammad cartoons published by a Danish newspaper in 2005. In October of 2008, the debate was revived in another newspaper between its editor, Tøger Seidenfaden, a leading critic of the cartoons, and Frederik Stjernfelt, a well-known academic (Mogensen 2008). Seidenfaden argued that the cartoons were an act of gratuitous offence denying due empathy to a domestic minority not deserving such treatment, namely all those Muslims in Denmark who are peaceful and want integration, and thus the cartoons were likely to set back integration. Stjernfelt, a self-declared enlightenment thinker, argued that the cartoons were part of a global struggle for freedom of speech, against special rights for cultural groups, and he rebuked Seidenfaden for wearing "blinkers" and seeing only "the tiny Danish corner" of the issue, ignoring the global aspects. 
As an onlooker, I cannot help wondering why these two debaters, both highly articulate and intelligent men, did not see more clearly the simultaneous relevance of two contradictory norms, both of which they probably both support. In other words, there was normative meta-consensus between them, but they did not realize it. Stjernfelt persisted in assuming that opposing the cartoons constituted a betrayal of the principle of free speech, and rejected the relevance of the 'gratuitous offence' argument as "tiny"; Seidenfaden, on the other hand, appeared similarly insensitive to the global context, where some Muslims in fact acted violently to curtail freedom of speech, and he was unwilling to concede that the cartoons might relevantly be seen in that context - in which the domestically-based criticism of them (and of the Danish government's no-comment attitude to them) might appear as a failure to stand up for free speech. As an onlooker, I find it obvious that the quarrel between the two sides in this debate was not about any one of them betraying one or the other of the norms invoked (empathy with deserving minorities and free speech, respectively), but about how to interpret these norms, how they were relevant to the case, and in particular what relative weight or priority should be assigned to them. In other words, the disagreement was primarily an instance of the deliberative counterpart of contrariae leges (cell F5), with elements of interpretive disagreement (cell D5) - and the debaters should have realized that, or have it pointed out to them. As a general principle, I would argue that onlookers looking for guidance on a controversial issue are let down by a debate where each debater only insists on the exclusive relevance of his 'own' favoured norm. What might have helped onlookers more would be mutual recognition by the opposite sides that contradictory norms are relevant, plus a motivated bid from each side as to why its favoured norm should be given priority in the case at hand.

Even more generally, I suggest that democracies like ours need a greater awareness among debaters, audiences, journalists and educators that social disputes should not be seen as all-out clashes along enormous front lines, but may usually often be narrowed down to focused disagreements on more specific, but also more potentially persuasive points. I suggest that the insights contained in status theory as presented here can help promote such awareness. Let us not be like the two lovers in Matthew Arnold's famous poem "Dover Beach", who feel that "we are here as on a darkling plain, Swept with confused alarms of struggle and flight, Where ignorant armies clash by night." 


\section{References}

Berlin, Isaiah (1998). The Pursuit of the Ideal. In: H. Hardy and R. Hausheer (Eds.), Berlin, The Proper Study of Mankind: An Anthology of Essays (pp. I-I6). New York: Farrar, Straus, and Giroux. (Original publication date: 1988.)

Berlin, Isaiah (2002). Two Concepts of Liberty. In Liberty, Incorporating Four Essays on Liberty (pp. 166-217). Oxford: Oxford University Press. (Original publication date: I958.)

Dryzek, John S., and S.J. Niemeyer (2006). Reconciling Pluralism and Consensus as Political Ideals. American Journal of Political Science 50, 634-649.

Elster, Jon (1986). The Market and the Forum. In: J. Elster and A. Hylland (Eds.), Foundations of Social Choice Theory (pp. I03-I22). Cambridge: Cambridge University Press.

Govier, Trudy (1987). Problems in Argument Analysis and Evaluation (Studies of Argumentation in Pragmatics and Discourse Analysis, Vol. 5). Dordrecht: Foris. Govier, Trudy (2004). A Practical Study of Argument (6 ${ }^{\text {th }}$ Ed.). Florence, KY: Wadsworth. Jørgensen, Charlotte, L. Rørbech and C. Kock (1994). Retorik der flytter stemmer. København: Gyldendal.

Jørgensen, Charlotte, L. Rørbech and C. Kock (1998). Rhetoric that Shifts Votes: A Largescale Exploratory Study of Persuasion in Issue-oriented Public Debates. Political Communication I5, 283-299.

Kock, Christian (2003). Multidimensionality and Non-deductiveness in Deliberative Argumentation. In: F. van Eemeren, J. Anthony Blair, Charles A. Willard and A. Francisca Snoeck Henkemans (Eds.), Anyone Who Has a View: Theoretical Contributions to the Study of Argumentation (pp. I57-I7I). Dordrecht: Kluwer Academic Publishers.

Mogensen, Lars Trier (2008). Interview: frihed for Frederik såvel som for Tøger. Politiken, October 4, section "Debat".

Orwell, George (1946). Shooting an Elephant and Other Essays. London: Secker \& Warburg. Rawls, John (1989). The Domain of the Political and Overlapping Consensus. New York University Law Review 64, 233-255.

Rawls, John (1993). Political Liberalism. New York: Columbia University Press.

Raz, Joseph (1998). Incommensurability and Agency. In: Ruth Chang (Ed.), Incommensurability, Incomparability, and Practical Reason (pp. IIO-I28). Cambridge, Mass.:

Harvard University Press.

Snoeck Henkemans, Francisca. (2000). State-of-the-art: The Structure of Argumentation. Argumentation I4, 447-473.

Toulmin, Stephen (1958). The Uses of Argument. Cambridge: Cambridge University Press. 
Warnke, Georgia (1999). Legitimate Differences. Berkeley: University of California Press.

Wellman, Carl (197I). Challenge and Response: Justification in Ethics. Carbondale: Southern Illinois University Press. 



\title{
5 Rhetoric and Argumentation
}

\author{
J. ANTHONY BLAIR
}

\section{I Introduction}

How is the relationship between rhetoric, on the one hand, and argument and argumentation, on the other, properly understood? That is the question this chapter sets out to answer. Given the historical connections between rhetoric, argument and argumentation, it is fundamental for any understanding of rhetoric.

Why bother with this question? One reason that will become clear is that there are several different, and on the face of it incompatible, conceptions of this relationship in the more or less current literature, so it doesn't seem that they can all be right. Another reason, as will also become clear, is that how we understand rhetoric and how we understand argument and argumentation depend partly on how we understand their relationship, and conversely.

The concepts of rhetoric and of argument have undergone many changes since their articulation by the ancient Greeks. Rhetoric, said to have originated as the art of successful pleading in the courts of Syracuse $\left(5^{\text {th }} \mathrm{c}\right.$. BCE), was extended by the time of Rhetoric to Alexander (see Braet 1996, 2004) and Aristotle's Rhetoric ( $4^{\text {th }} \mathrm{C}$. BCE) to include the art of public persuasion in court, persuasion in political forums and on occasions of public celebration. Cicero ( $\mathrm{I}^{\text {st }} \mathrm{C}$. BCE) introduces the "offices" of the orator: docere (to teach, inform or instruct), delectare (to please) and movere, flectere (to move or "bend"). Following its Ramist ( $\mathrm{I} 6^{\text {th }} \mathrm{c}$.) relegation for a few centuries to the art of style and embellishment, in rhetoric's resurgence in the $20^{\text {th }}$ century it was enlarged to, in Burke's (Burke 1969, p. 43) famous characterization, "the use of language as a symbolic means of inducing cooperation in beings that by nature respond to symbols," and beyond that, to the art of symbolic communication, not just persuasion (e.g., Foss, Foss and Trapp 1985, p. II), and finally expanded to cover the symbolic construction of cultural meaning: "rhetoric usually is seen now as incorporating virtually any humanly created symbols from which audiences derive meaning" (Foss, Foss and Griffin 1999, p. 6). It is possible to see in these changes a progression from the more particular to 
the more general, with the term 'rhetoric' being promoted each time to designate the more general conception. But as Burke (Burke 1969, Section II) has shown, there have traditionally been several strands in the concept of rhetoric, some of which are emphasized more than others in different conceptions.

The concept of argument or illation too has expanded from its early understanding. Aristotle identified argument with two species of relations of probative support, which we might loosely call "deduction" and "induction" (each having a scientific or theoretical variant, and also a public or popular variant). Today theorists would both introduce a narrower concept of deduction than Aristotle's (restricted to necessary implication), and also expand the varieties of induction beyond generalizing from examples, to include, for instance, sample-to-population generalizations and statistical correlations. Moreover, many would add such further species of argument as conduction (Campbell 1776, Wellman 1971, Govier 1999, Hansen 2008), abduction (Peirce 1940, Walton 2002, Woods 2008), and more generally presumptive or plausible arguments (Rescher 1976, Walton 1996), and perhaps most generally of all, defeasible arguments (Pollock 2008).

Argumentation, if understood as the social practice entailing at its heart the delivery and exchanges of arguments (but including much else), has seen its spheres expand and contract. For Aristotle, besides its role in rhetoric, it could occur as a student game called dialectic, and more seriously as a method of building and testing philosophical theory. It was also for Aristotle a tool to be used in speeches addressing various kinds of wider audience. In contemporary theory, some restrict its purview to the resolution of disagreements (Van Eemeren and Grootendorst 2004), whereas others regard it as a way of maintaining dissensus (Willard 1987), as an instrument for negotiating in public spheres (Goodnight 1982), as a method of investigation (Meiland 198I), and/or as a method of decision-making (Rieke and Sillars 200I, Hollihan and Baaske 1994).

This chapter proceeds by classifying some of the current views about the rhetoric-argument or argumentation relationship, followed by a critical discussion of them, and ending with comments about which might be preferable. There are, to be sure, many more views on these topics than those canvassed here, and that implies a restriction in the scope of this chapter.

\subsection{A survey of some current rhetoric-argument conceptions}

I have found four different ways of conceiving the relation between rhetoric and argument. In this section I describe these in turn. 
(I) According to one, the class of arguments is a member of the class of rhetorical entities or processes. All arguments are rhetorical. Argumentation is inherently rhetorical.

However, rhetoric is not restricted to argumentation or arguments. "[W]e affirm," writes Perelman, an advocate of this view, "that every discourse which does not claim an impersonal validity belongs to rhetoric. As soon as a communication tries to influence one or more persons, to orient their thinking, to excite or calm their emotions, to guide their action, it belongs to the realm of rhetoric" (Perelman 1982, p. I62). Unless "argument" is defined to be identical with such discourse, the domain of rhetoric must include other things as well as arguments. The color a room is painted, the background music in a shop, the furnishings and lighting of a restaurant these and countless more examples are clearly rhetorical by Perelman's definition, but they are not arguments unless that term is so stretched that it becomes too flabby to be useful.

According to some versions of this first conception of the rhetoric-argument relation, logical (that is, deductive) or mathematical or scientific demonstrations, which might look like arguments or argumentation, are excluded on the ground that they claim pure rationality and complete independence from the emotions of the audience or the character of the arguer; they claim objectivity; they claim to hold universally without reference to audience, occasion, situation or historical circumstances. Argumentation, in contrast, occurs over matters on which reasonable people may differ, with particular arguers addressing particular audiences, none of which is true of demonstrations. Thus, on Perelman's conception, argumentation is by definition rhetorical, and what might look like an argument insofar as there are grounds adduced in support of a claim, if it qualifies as a demonstration, does not count as an argument.

Besides Perelman and Olbrechts-Tyteca (1958), Meyer (2008) takes this view and Reboul's (199I) position is similar. Meyer defines rhetoric as "the negotiation of the distance between individuals in relation to a given question" (Meyer 2008, p. 2I). I am reminded of once when I was driving in Italy and at a roundabout I inadvertently started to infringe on another driver's right of way. He responded with an angry blast of his horn. I stopped immediately,

\footnotetext{
I "Le rhétorique est la négotiation de la distance entre des individus à propos d'une question donnée."
} 
made an apologetic face and held up my hands in surrender. He responded by smiling magnanimously and signaling me to go ahead of him. We had negotiated the distance between my mistake and his indignation - I, by obsequious apology; he, by magnanimous forgiveness. It was a thoroughly rhetorical exchange, by Meyer's definition, but there was no argument in sight. Yet Meyer affirms that "argumentation traditionally makes up part of the discipline of rhetoric" (Meyer 2008, p. 85). ${ }^{2}$ So Meyer belongs among those who regard argument or argumentation as one vehicle of rhetoric, among others.

Reboul has a narrower definition of rhetoric, namely, the art of persuading by speech (Reboul I99I, p. 4). ${ }^{3}$ Still for him argument is not identified with rhetoric, but included as part of it. He insists on a fundamental distinction between two means of persuasive discourse, the rational and the affective (ibid. p. 7). The means belonging to reason are arguments; those belonging to affect are ethos and pathos (ibid.). To be sure, these are typically combined and not always easy to distinguish (ibid.). For Reboul the point seems to be not so much that rhetoric includes other kinds of activity besides giving arguments, but that the bare bones of rational argument often needs to be, or in any case is, accompanied by various affective aspects and devices. I will call this first view of the rhetoric-argument relation the class-inclusion view.

(2) A second way of conceiving the rhetoric-argument relationship sees the class of arguments overlapping with the class of rhetorical entities or processes, so while some arguments are rhetorical, others are not, and while part of the domain of rhetoric relates to arguments, part has to do with entities or processes other than arguments. According to proponents of this conception, what makes an argument a rhetorical argument is a matter of its domain - the subject matter it is concerned with. In particular, rhetorical arguments on this view are arguments about choices and actions, either directly, or else indirectly by focusing on the values or norms that govern choices and actions. There can be arguments with other subject matters, such as theoretical matters in general, or more particularly philosophy or science, but they are not rhetorical arguments, for their conclusions are about what is true or reasonable to believe, not about what should be done. To be sure, although these ar-

\footnotetext{
2 "L'argumentation fait traditionnellement partie de la rhétorique comme discipline."

3 "Voici donc la définition que nous proposons: la rhétorique est l'art de persuader par le discours. "
} 
guments are not rhetorical, some of the properties that can belong to arguments in the rhetorical domain, such as the intention to persuade, may be found in some of them.

Advocates of this second conception include Hauser (2002) and Kock (2007, 2008). Hauser's definition of rhetoric is strongly Burkean: "Rhetoric, as an area of study, is concerned with how humans use symbols, especially language, to reach agreement that permits coordinated effort of some sort"; or again, "Rhetoric ... is concerned with the use of symbols to induce social action"(Hauser 2002, pp. 2-3). For Hauser, rhetoric is a mode of arguing (ibid. p. 33). Rhetorical arguing is based on opinion, where the objective is persuasion, in the realm of the contingent, aiming at probable solutions (ibid. p. 34). Rhetorical argument is to be contrasted with dialectical argument, which is also a mode of arguing, but a different one from rhetorical arguing. Where rhetorical arguing aims at securing agreement of opinion, dialectical arguing aims at securing a transcendent truth (ibid. p. 33). Dialectical arguing occurs among experts discussing their subjects in technical fashion, typically belonging to a specific discipline or domain of knowledge (ibid. pp. 33-34). The objective of dialectical arguing is criticism, working out the necessary conclusions that follow from initial opinions, with results that "can reach the point of virtual certainty" if no counterarguments can be found to refute the conclusion (ibid. p. 34).

Kock (2008) cites favorably George Campbell's description of rhetoric as being "about that art or talent by which the discourse is adapted to its end." With "the ends of speaking ... reducible to four; every speech being intended to enlighten the understanding, to please the imagination, to move the passions, or to influence the will" (Campbell 1776, 1969). Kock agrees with Campbell that some of what Campbell would call discourse, such as poetry, "so far as it aims to 'please the imagination', would not belong to the subject matter of argumentation theory" (Kock, 2008). Kock concludes:

Clearly, then, argumentation theory does not cover the entire discipline that rhetoricians cultivate; argumentation and rhetoric intersect, but are not coextensive. Not all rhetoric is about argumentation; [and] ... not all argumentation is rhetorical. (ibid.)

Kock (2008) argues that Aristotle also defines rhetoric in terms of the domain of choice and conduct, and Aristotle does seem to allow that there can 
also be non-rhetorical arguments (namely dialectical ones), so there is a case that Aristotle belongs to this group as well. I call this second conception of the relation between rhetoric and argument the class-overlap view.

The class-overlap view might look almost like the class-inclusion view, just lacking its definitional fiat against demonstrations counting as arguments. If that were the only difference there would be not two but one conception, with two terminological variants. But proponents of the class-inclusion view don't see arguments and argumentation - all rhetorical - as restricted to the domain of choice and conduct. Reboul, for instance, insists that while argument can be aimed at getting someone to do something, if it is to be rhetorical argument it must do so by getting that person to believe that it is the right thing to do: "Argumentation always aims at causing belief" (Reboul I99I, p. 5) ${ }^{4}$. And in the Traité de l'Argumentation, Perelman and OlbrechtsTyteca (1958) and Perelman (1982) pretty clearly envisage arguments and argumentation to be about what it is reasonable to believe no less than about what to do. However, for proponents of the class-overlap view even the arguments that are not context-free, definitive demonstrations but are about what is reasonable to believe still do not belong within the realm of rhetoric. For Aristotle, and following him closely, Hauser, dialectic is such a domain and is to be distinguished from rhetoric. So the class-inclusion and class-overlap conceptions, at least as held by these theorists, are distinct.

(3) The third conception of the relation between rhetoric and argument or argumentation seems to understand these concepts in a different way from the first two. According to the class-inclusion conception, arguments and argumentation have features that identify them as rhetorical. According to the class-overlap conception, argument and argumentation can be identified independently of any rhetorical properties, and while some possess rhetorical properties, others do not. According to the third conception, arguments and argumentation are amalgams of three different kinds of properties. They typically have rhetorical properties, dialectical properties and logical properties. These three kinds of properties correlate with three perspectives from which to consider arguments and argumentation. Arguments can be considered as entities or products, in which case their logical properties are salient; or they can be considered from a procedural perspective, in which case their dialec-

4 "[L'argumentation] vis toujours à faire croire." 
tical properties are salient; or they can be considered as processes occurring in time and embedded in historical contexts, in which case their rhetorical properties are salient. To look at just their logical, or just their dialectical, or just their rhetorical features is to abstract from argument and argumentation, to focus on one perspective to the exclusion of the others, and thus to misunderstand the essentially complex nature of arguments and argumentation.

The person most emphatically identified with this third, perspectival, conception of the rhetoric-argument relationship is Wenzel (1980, 1987, 1990). Tindale $(1999,2004)$ may also be associated with this view.

Each places the emphasis slightly differently. Although Wenzel himself is a rhetorician and communication theorist, he regards none of the three perspectives as privileged; each has its legitimate uses and provides its distinctive illumination. Wenzel's conception of rhetoric is quite traditional: "the practical purpose of rhetoric is helping speakers marshal all the available means of persuasion to help people in social groups make wise decisions" (Wenzel 1990, p. 14), for "rhetoric is applied in decision-making situations where people have to make a choice between alternatives and where there may be good reasons on both sides" (ibid. p. 13). His conception of rhetoric seems to line up with that of Kock and Hauser. But he does not, as they do, identify a particular type of argument as rhetorical. "Human judgment," Wenzel writes, "depends upon argumentation, and argumentation depends equally upon the resources of rhetoric, dialectic and logic" (ibid. pp. 25-26).

Tindale, an informal logician initially, has come to see the rhetorical perspective as deserving priority. Rhetoric, for Tindale, "concentrates on the communication process inherent in argumentation, on the means by which arguers make their cases for the adherence of audiences to the claims advanced" (Tindale 1999, pp. 3-4). Quoting Richard Andrews, Tindale understands rhetoric as, "the arts [sic] of discourse' with all the associations of discourse embedded in social contexts" (Andrews 1995, p. 30, as quoted in Tindale 1999, p. I4). Discussing the effect of rhetorical figures such as analogy, praeteritio and prolepsis, Tindale writes, "It is [the] ... rhetorical nature [of arguments drawn from figures] that makes them most effective, not just in persuading an audience, but engaging them at a quite deep, often emotional level, before reason moves in as an organizing force. They relate" he continues, "to a level of engagement that grounds the argumentative situation, and thus" - and this is the point of difference with Wenzel - "they further demonstrate why the rhetorical is the primary, most influential layer in any 
model of argument that seeks to integrate the logical, dialectical, and rhetorical" (Tindale 2004, p. 86).

However, both Tindale and Wenzel regard an argument's or argumentation's rhetorical properties as just one set of properties that coexist with the other two. And both think that any argument put to use in argumentation, and the argumentation itself, will have rhetorical properties. So the perspectival conception of the rhetoric-argument connection shifts the focus from rhetorical vs. non-rhetorical argument to argument as rhetorical or dialectical or logical.

(4) I turn now to the fourth conception of how rhetoric and argumentation relate. According to it, the rhetorical properties of arguments and argumentation consist of the framing, selecting or formulating arguments or argumentation that can make logically and dialectically good arguments more appealing and persuasive, although it can also be mis-used to cover the blemishes of logically or dialectically defective arguments. Thus this fourth conception of how rhetoric is related to argument might be called the cosmetic conception. Rhetoric is enhancement. This view is Platonic in spirit, and also somewhat reminiscent of the $16^{\text {th }}$ century Ramist position that rhetoric is style and presentation that is also expressed by writers such as Blair (1783) in the $18^{\text {th }}$ century belles-lettres tradition.

I regard Johnson (2000) and Van Eemeren and Houtlosser (2000, 2002, 2007 among many others) as contemporary proponents of this view. Johnson thinks a speaker or writer can have different and often incompatible goals. The arguer aims at rational persuasion, the goal of which is to justify truth-claims and in which the logical and dialectical strengths and weakness of the argumentation are made manifest. The rhetor, in contrast, aims simply to persuade the audience of the claim being argued for, where the truth of the premises from which the argument starts and the truth of the conclusion it seeks to establish are not essential and persuasion may consist simply of getting the audience to accept the claim. To be sure, one can try to combine the objectives of arguer and rhetor, but for any arguer, rhetorical dressing should always function as auxiliary to the goal of logical and dialectical manifest rationality.

For Johnson, rhetoric's aim is persuasion and its norm is effectiveness, so arguments used for rhetorical purposes will be designed for success, even if that means glossing over their weaknesses. "The arguer," Johnson writes, 
"cannot ignore objections to his argument, even if it is not known how to forestall them ... The rhetor is under no such constraint: If ignoring the objection will lead to a more effective communication, and if doing so is rational, then the objection can be ignored" (Johnson 2000, p. I63). Argument is thus contrasted with rhetoric; both are potentially rational activities, but argument must be open and transparent, whereas rhetoric can sugar coat or skip over awkward difficulties that argument is required to raise and confront. Johnson thus sees rhetoric as in principle distinct from argument.

For Van Eemeren and Houtlosser, the rhetorical aim is to win; and in the use of arguments to resolve a difference of opinion it is to use arguments to resolve the disagreement in one's own favor:

People engaged in argumentative discourse are characteristically oriented toward resolving a difference of opinion ...- maintaining certain standards of reasonableness ... This does, of course, not mean that they are not interested in resolving the difference in their own favor. Their argumentative speech acts may even be assumed to be designed to achieve primarily this effect. There is, in other words, not only a dialectical, but also a rhetorical dimension to argumentative discourse. (Van Eemeren and Houtlosser 2000, p. 295)

While the arguers can be presumed to maintain ... critical standards, they can at the same time be presumed to be out for an optimal persuasive result. In their efforts to achieve this result, they will resort to what we have called strategic maneuvering, directed at diminishing the potential tension between the simultaneous pursuit of critical and persuasive aims. (Van Eemeren and Houtlosser 2002, p. 290)

On their view, "Rhetoric is the theoretical study of practical persuasion techniques" (Van Eemeren and Houtlosser 2000, p. 297). Since, in their view, argumentation is a dialectical activity, which means that it lies under the constraint of rationality, and since the whole point of argumentation is to use reasons to resolve a difference in a reasonable way or on the merits, it follows that the result can be a conflict between the rhetorical objective of winning and the dialectical constraint of being reasonable. Rhetoric's influence on arguments makes them subject to derailment. "If a party allows its commitment to a critical exchange of argumentative moves to be overruled by the aim of persuading the opponent," they write, "we say that the strategic maneuvering has got 'derailed"' (Van Eemeren and Houtlosser 2002, p. 290): 
The rhetorical aspect of argumentation manifests itself in our view in the strategic attempts to direct the resolution process effectively toward the acceptance of one's own position. As the word goes, effective persuasion must be disciplined by dialectical rationality. (Van Eemeren and Houtlosser 2000, p. 297)

It is dialectic that keeps the rhetorical components of the discussion on the tracks.

Although Johnson's and Van Eemeren and Houtlosser's theories differ in many respects, they both treat rhetorical objectives as in potential conflict with fully manifest rationality. Rhetoric consists of strategies to win or persuade, and while it can thus enhance the attractiveness of a dialectically or logically reasonable argument, there is always the risk that it will mask dialectical or logical subterfuge. So on both views, rhetoric has the properties of a cosmetic designed to make merits more appealing but subject to being used to conceal flaws.

\subsection{Discussion}

\subsection{The class-inclusion position}

My reservation about the class-inclusion conception is its acceptance of the positivist identification of logic with formal deductive logic. This conception of logic is open to challenge.

On Perelman's view, logic is restricted to formal deductive systems. Deductively valid arguments in natural language are relegated to the status of "quasi-logical" arguments. Presumably that would also be the fate of materially valid deductive arguments in natural languages. (Example: Question: "Did Fred have any siblings?" Answer: "Didn't you know that he was Julia's uncle?") It would thus exclude from logic proper what Ryle (1936) termed "informal logic," by which he meant the entailment relations among concepts that map their structure, for example that the concept of fear entails the apprehension of danger. It also relegates to extra-logical or quasi-logical standing the "logic" of presumptive inferences, and in general of defeasible reasoning and arguments. To be sure, one can use terms any way one likes as long as one is consistent, but restricting the scope of logic to formal deductive logic banishes to a conceptual limbo various kinds of reasoning and arguments that don't clearly have a home anywhere else than under the rubric of logic. And if the term 'logic' is to denote the norms of good reasoning or 
good inferring as such reasoning and inferring are exhibited in or invited by arguments used in argumentation, it certainly must include other norms besides deductive validity, let alone formal validity.

If the term 'logic' is given the wider denotation I suggest it ought to have, then it becomes permissible to speak of the logic of arguments in argumentation without relying on the qualifier 'quasi,' and to see logic as a tool of rhetoric. Since logically good arguments in fact tend to be effective arguments (see O'Keefe 2003), the class-inclusion conception of the rhetoric-argument relation, at least as it is defended by the kinds of arguments Perelman makes, seems to restrict unduly the nature of rhetorical argument.

\subsubsection{The class-overlap position}

The class-overlap conception of the rhetoric-argument relationship regards arguments about what is true or reasonable to believe as lying outside the domain of rhetoric. Rhetoric is to be restricted to arguments about what to choose or do. According to Kock, this is because rhetoric deals with what cannot be settled definitively, about issues on which people may reasonably disagree because these issues are decided on the basis of people's values, priorities and weightings, all of which are subjective. Presumably, then, the tools of rhetoric are the only reasonable resource to use to move people to choose or act in a certain way; objective arguments cannot settle disagreements here. For example, there is no way to establish by impersonal argument that everyone should rank liberty more highly than security - that it is true that liberty is preferable to security - should the two conflict, whereas rhetorical arguments stand a chance of getting a person who is willing to sacrifice some liberty in exchange for greater security to shift his perspective.

Kock's reason for confining rhetoric to arguments about choices is a meta-ethical position known as non-cognitivism. According to non-cognitivism, sentences expressing normative judgements of values, prescriptions, and so on have no truth conditions and are not susceptible to knowledge. In taking this position, Kock joins a respectable tradition in philosophy, but it is one that is far from universally shared. The modern debate between cognitivism and noncognitivism arose in earnest in the 1930s, with people like Ayer (1936) and Stevenson (1944, 1963) raising the non-cognitivist banner, but the issue remains undecided in the philosophical literature to this day (see van Roojen 2008). So accepting Kock's rationale requires at the least relying on a promissory note that non-cognitivism will win out over the cognitivism. 
Even if Kock is right that prescriptions cannot have truth conditions, it does not follow that they cannot be objectively evaluated on other grounds; for instance, as being practical or impractical, wise or foolish, short-sighted or far-sighted, and so on. And a good many such judgements are liable to a very high degree of inter-rater reliability. I do not mean to suggest that these properties take arguments about choices out of the realm of rhetoric. On the contrary, my view is that arguments that can have a degree of objectivity should not therefore be excluded from rhetoric. A good deal of what we argue about even when the ideal is to establish the truth of the matter cannot be settled beyond doubt or controversy. For example, predictions constitute a huge class of such arguments. Think of predictions about the weather, or the economy, or the adult traits a child will develop, or the success of a student, or the effects of human actions upon the environment, and so on and on. These are judgements about what we hope to be true and think to be reasonable to believe. Arguments for and against various alternative cognitive positions are thus in many cases no less subject to dispute than are those about prescriptions or commendations. So if disputability is the password of rhetorical arguments, then all of such disputatious topics in which any position is a candidate for knowledge, or reasonable belief will be topics for rhetorical arguments and argumentation no less than decisions or choices. ${ }^{5}$

I conclude from these considerations that the class-overlap view of the relation between rhetoric and argument, at least as defended using the arguments that Kock offers, unduly limits the realm of rhetorical arguments and argumentation. But if matters of belief no less than matters of action can be topics of rhetorical argumentation, then the class-overlap view seems to become the class-inclusion view.

\subsubsection{The cosmetic position}

According to the cosmetic position, rhetoric's inherent objective is persuasion, its overriding norm is effectiveness, and its design and deployment of arguments, although capable of increasing their success and in principle compatible with logic and dialectic, is also liable to conflict with rationality or reasonableness. There is reason to think that this view saddles rhetoric with

\footnotetext{
5 I won't mention another argument that is too controversial to take up here, namely that philosophical claims - those that Kock contends are about truth - are all conceptual - that is, all about how we should conceive of the world - and as such, are all normative.
} 
the reputation cast upon it by those who abuse it, and that seems to subject rhetoric to a double standard. After all, a clever logician or dialectician can use equivocation, vagueness, flawed analogy, improper appeal to authority and other fallacies to trick his audience, but logic and dialectic have managed for the most part to avoid being tarred with the brush of fallacy mongering. It seems unfair that the possibility of rhetorical trickery should be due to the essence of rhetoric any more than logic or dialectic should be deemed guilty by association with those who trade in logical or dialectical fallacies. Braet (1996, 2004) has contended persuasively that from the earliest surviving handbooks rhetoric has included the use of legitimate argument schemes as central to its persuasive devices. In addition, the Roman tradition of forensic rhetoric advised finding and using arguments that would result in rational persuasion. At least part of the aim of rhetoric, traditionally, has been to make rational arguments effective, not to make arguments effective at the expense of rationality.

So it seems that the cosmetic conception of the rhetoric-argument relation relies on an understanding of rhetoric that takes more from its popular reputation than from its historical record, viewing rhetoric as requiring the discipline of logic or of dialectic.

\subsubsection{The perspectival position}

I have left discussion of this position to the end because it seems to avoid the shortcomings of the other three. It leaves open the possibility of arguments that count as logical even if they are not formal demonstrations. It also puts no restriction on the domain of rhetorical argument. And it does not seem to require identifying rhetorical argumentation with the goal of mere persuasion. Yet a question can be raised about it just the same.

Here is the problem. If, from the perspective of rhetoric, the aim of the use of arguments and argumentation were rational persuasion, then, since logic is the custodian of some of the norms of rational arguments, the rhetorical perspective must include the logical perspective. Furthermore, since dialectic is the custodian of the norms of reasonable argumentation, then the rhetorical perspective must include the dialectical perspective. In sum, if rhetoric's use of arguments is to persuade rationally or reasonably, then logic and dialectic must be tools of rhetoric. But if the rhetorical perspective is conceptually distinct and separate from the logical and the dialectical - which is what the perspectival position requires - then the norms of rhetoric would seem to be independent of those of logic and dialectic. And if that is so, then 
it will be possible for an argument to be good rhetorically but weak logically and/or dialectically. Thus the door is opened to the position that rhetoric's telos is after all mere persuasion. In other words, it appears that the perspectival position implies the cosmetic position.

\subsection{The upshot}

If these last speculations are correct, then we seem to be faced with the following dilemma. Either rhetoric as it relates to arguments and argumentation is to have rational persuasion as its goal, in which case the rhetorical commitment to reasonableness means that the norms of rhetoric imply those of logic as applied to arguments and of dialectic as applied to argumentation. Or else, rhetoric represents one analytic and normative perspective on arguments and argumentation independent of those of logic and dialectic, in which case there is no commitment to logical or dialectical norms from the perspective of rhetoric, and the rhetorical reasonableness of arguments and argumentation becomes purely instrumental - whatever works.

It could be that we can talk and think either way. That is, theorists might be free to adopt whichever conception of how rhetoric relates to arguments they prefer. However, there are risks in overlooking the insights of tradition. The class-inclusion and class-overlap views build in no commitment on this matter and so offer us no guidance. The cosmetic view of the relation between rhetoric and argument seems to over-emphasize in its conception of rhetoric the goal of winning over or persuading the audience or interlocutor. Whether the perspectival view shares this defect depends on what conception of the rhetorical perspective one builds into it.

In appealing to the tradition of rhetoric, I am guided by the arguments of Michael Leff in a paper discussing the relation between rhetoric and dialectic, arguments which have a bearing on the rhetoric-argument relationship. Leff draws attention to the fact that historically there was a difference even for Aristotle "between using the art [of rhetoric] properly and achieving a specific outcome" (Leff 2000, p. 244). Leff continues:

Rhetoricians in the Latin tradition make much the same point when they differentiate the end and the duty of the orator. The end is to persuade through speech; the duty is to speak in a manner suited for persuasion. (ibid. p. 245)

The point is that rhetoric is subject to normative standards of its own. 
In the tradition that stretches from Isocrates to Cicero and from there to the Renaissance humanists, content and style, words and thoughts, the aesthetic and the rational are regarded as interconnected parts of eloquence. Rhetorical argument is not simply decoration added to logic. It is a fully embodied expression of reason that is at once accommodated to and also capable of intervening in public situations.

Rhetoric, then, imbricates style and argument to achieve evocative and emotional force, and while rhetorical argumentation often uses dialectical principles, it does not add a linguistic veneer to them so much as it transforms them into instruments for public action. (ibid. p. 246)

If this understanding of rhetoric is correct, then the relation between rhetoric and argument and argumentation is more complex than what has been suggested by the views canvassed above, although three of the four are consistent with it.

The class-inclusion conception, at least with a broadened notion of logic, leaves room for independent and non-instrumental rhetorical norms to apply to arguments as well as to other forms of discourse. The class-overlap conception, if extended to envisage arguments about contentious matters of belief as well as prescriptions, is also consistent with independent rhetorical norms. The perspectivalist too is at liberty to understand the rhetorical perspective as bringing to bear on argument and argumentation standards of suitableness to audience and occasion that go beyond, and thus can override, the goal of winning over the audience.

It is only the cosmetic conception that shortchanges the rhetorical tradition, on Leff's expansive reading of it. For the cosmetic conception of the rhetoric-argument relationship relies on a narrow, merely instrumentalist conception of rhetoric. While it is no doubt a virtue of the cosmetic conception that it emphasizes that the goal of winning the argument or persuading by argument can conflict with dialectical or logical norms, it is also a shortcoming of this view that it leaves out of account in its conception of argument and argumentation the broader rhetorical norms that the rhetorical tradition cited by Leff assigns to them. This broader role allows rhetorical insights about how new possibilities for thought and action can be brought to public consciousness to shape our arguments and our argumentation, while continuing to respect people's capacity for reasoned and reasonable belief and conduct. ${ }^{6}$

\footnotetext{
${ }^{6}$ My thanks to an anonymous reviewer for many corrections and helpful comments.
} 


\section{References}

Andrews, R. (1995). Teaching and Learning Argument. London: Cassell.

Ayer, A.J. (1936). Language, Truth and Logic. London: Gollancz.

Blair, H. (I783). Lectures on Rhetoric and Belles Lettres. London: Strahan and Cadell. Edinburgh: Creech.

Braet, A.C. (1996). On the Origin of Normative Argumentation Theory. Argumentation Io, 347-359.

Braet, A.C. (2004). The Oldest Typology of Argumentation Schemes. Argumentation I8, I27-I48.

Burke, K. (1969). A Rhetoric of Motives. Berkeley: University of California Press. (Original publication date: 1950.)

Campbell, G. (1776). The Philosophy of Rhetoric. L. Bitzer (Ed.). Carbondale, IL: Southern Illinois University Press, 1963.

Eemeren, F.H. van and R. Grootendorst (2004). A Systematic Theory of Argumentation: The Pragma-Dialectical Approach. Cambridge: Cambridge University Press.

Eemeren, F.H. van and P. Houtlosser (2000). Rhetorical Analysis within a PragmaDialectical Framework: The Case of R.J. Reynolds. Argumentation I4, 293-305.

Eemeren, F.H. van and P. Houtlosser (2002). Strategic Maneuvering in Argumentative Discourse: Maintaining a Delicate Balance. In F.H. van Eemeren and P. Houtlosser (Eds.). Dialectic and Rhetoric: The Warp and Woof of Argumentation Analysis (pp. I3II59). Dordrecht: Kluwer Academic Publishers.

Eemeren, F.H. van and P. Houtlosser (2007). Seizing the Occasion: Parameters for Analysing Ways of Strategic Manoeuvring. In F.H. van Eemeren, J.A. Blair, C.A. Willard and B. Garssen (Eds.), Proceedings of the Sixth Conference of the International Society for the Study of Argumentation (pp. 375-380). Amsterdam: SicSat.

Foss, S.J., K.A. Foss and R. Trapp (Eds.) (1985). Contemporary Perspectives on Rhetoric. Prospect Heights, IL: Waveland Press.

Foss, K.A., S.J. Foss and C.L. Griffin (1999). Feminist Rhetorical Theories. Thousand Oaks, CA: Sage Publications.

Goodnight, G.T. (1982). The Personal, Technical and Public Spheres of Argument: A Speculative Inquiry into the Art of Public Deliberation. Journal of the American Forensic Association 4, 214-227.

Govier, T. (1999). Conductive Arguments Revisited. In T. Govier, The Philosophy of Argument (Ch. IO). Newport News: Vale Press.

Hansen, H.V. (2008). Picturing Conductive Arguments. (unpublished article ms.) Hauser, G.A. (2002). Introduction to Rhetoric, $2^{\text {nd }}$ ed. Prospect Heights: Waveland Press. 
Hollihan, T.A. and K.T. Baaske (1994). Arguments and Arguing: The Products and Process of Human Decision Making. Prospect Heights, IL: Waveland Press.

Johnson, R.H. (200o). Manifest Rationality: A Pragmatic Theory of Argument. Mahwah, NJ: Lawrence Erlbaum.

Kock, C. (2007). The Domain of Rhetorical Argumentation. In F.H. van Eemeren, J.A. Blair, C.A. Willard and B. Garssen (Eds.), Proceedings of the Sixth Conference of the International Society for the Study of Argumentation (pp. 785-788). Amsterdam: SicSat.

Kock, C. (2008). Choice is Not True or False: The Domain of Rhetorical Argumentation. Argumentation 22, 4.

Leff, M. (2000). Rhetoric and Dialectic in the Twenty-First Century. Argumentation I4, 24I-254.

Meiland, J.W. (198I). College Thinking. New York: Mentor.

Meyer. M. (2008). Principia Rhetorica, Théorie Général de l'Argumentation. Paris: Fayard. O'Keefe, D.J. (2003). The Potential Conflict between Normatively-good Argumentative Practice and Persuasive Success: Evidence from Persuasion-Effects Research. In F.H. van Eemeren, J.A. Blair, C.A. Willard and A.F. Snoeck Henkemans (Eds.), Anyone Who Has a View: Theoretical Contributions to the Study of Argumentation (pp. 309318). Dordrecht: Kluwer Academic Publishers

Peirce, C.S. (1940). The Philosophy of Peirce: Selected Writings. London: Routledge and Kegan Paul (Republished as Philosophical Writings of Peirce. New York: Dover Publications, 1955.)

Perelman, Ch., and L. Olbrechts-Tyteca (1958). La Nouvelle Rhétorique: Traité de l'Argumentation. Paris: Presses Universitaires de France.

Perelman, Ch. (1982). The Realm of Rhetoric. W. Klubank (Tr.). Notre Dame / London: University of Notre Dame Press. (L'Empire rhétorique: rhétorique et argumentation. Paris: Vrin, 1977.)

Pollock, J.L. (2008). Defeasible Reasoning. In J.E. Adler and L.J. Rips (Eds.), Reasoning: Studies in Human Inference and Its Foundations (pp. 45I-470). Cambridge: Cambridge University Press.

Reboul, O. (1991). Introduction à la Rhétorique. Paris: Presses Universitaires de France. Rescher, N. (1976). Plausible Reasoning: An Introduction to the Theory and Practice of Plausible Inference. Assen: Van Gorcum.

Rieke, R.D. and M.O. Sillars (200I). Argumentation and Critical Decision Making, $5^{\text {th }}$ ed. New York: Longman.

Roojen, M. van (2008). Moral Cognitivism vs. Non-Cognitivism. In E.N. Zalta (Ed.), The Stanford Encyclopedia of Philosophy. <http://plato.stanford.edu/archives/ fall2oo8/entries/moral-cognitivism/> 
Ryle, G. (1960). “Formal and Informal Logic.” In G. Ryle, Dilemmas (Ch. VIII). Cambridge: Cambridge University Press.

Stevenson, C.L. (1944). Ethics and Language. New Haven: Yale University Press.

Stevenson, C.L. (1963). Facts and Values. New Haven: Yale University Press.

Tindale, C.W. (1999). Acts of Arguing: A Rhetorical Model of Argument. Albany: State University of New York Press.

Tindale, C.W. (2004). Rhetorical Argumentation: Principles of Theory and Practice. Thousand Oaks, CA: Sage Publications.

Walton, D.N. (1996). Argument Schemes for Presumptive Reasoning. Mahwah, NJ: Lawrence Erlbaum.

Walton, D. (2002). Legal Argumentation and Evidence. University Park, PA: The Pennsylvania State University Press.

Wellman, C. (1971). Challenge and Response: Justification in Ethics. Carbondale and Edwardsville, Southern Illinois University Press.

Wenzel, J.W. (1980). Perspectives on Argument. In J. Rhodes and S. Newell (Eds.), Proceedings of the Summer Conference on Argumentation (pp. II2-I33). Washington, DC: Speech Communication Association.

Wenzel, J.W. (1987). The Rhetorical Perspective on Argument. In F.H. van Eemeren, R. Grootendorst, J.A. Blair and C.A. Willard (Eds.), Argumentation: Across the Lines of Discipline (pp. IOI-Io9). Dordrecht: Foris.

Wenzel, J.W. (1990). Three Perspectives on Argument: Rhetoric, Dialectic, Logic. In R. Trapp and J. Schuetz (Eds.), Perspectives on Argumentation, Essays in Honor of Wayne Brockriede (pp. 9-26). Prospect Heights, IL: Waveland Press.

Willard, C.A. (1987). Valuing Dissensus. In F.H. van Eemeren, R. Grootendorst, J.A. Blair and C.A. Willard (Eds.), Argumentation: Across the Lines of Discipline (pp. 145-158). Dordrecht: Foris.

Woods, J. (2008). Beyond Reasonable Doubt: An Abductive Dilemma in Criminal Law. Informal Logic 28, I. <http://ojs.uwindsor.ca/ojs/leddy/index.php/informal_logic/ issue/view/76> 




\section{P A R T I I}

\section{The Rhetoric of Verbal}

Presentation

$\%$ 



\title{
6 Generalizing about the Persuasive Effects of Message Variations: The Case of Gain-Framed and Loss- Framed Appeals
}

\author{
DANIEL J O ' KEEFE
}

\section{I Introduction}

One recurring interest in rhetorical studies is the identification of useful general principles of effective message design - identifying what makes for more or less persuasive appeals. The most systematic way of gathering evidence on such questions is to conduct an experiment, in which (to take the simplest form) participants are exposed to one of two versions of a message, where the versions are identical except for the one particular feature of interest. For example, one might compare the persuasiveness of a message in which the advocate's overall conclusion is stated explicitly and that of the same message with the conclusion omitted. There is now quite an extensive empirical literature on such matters, examining a great many different message variations.

This chapter focuses on one such variation, the contrast between what are called "gain-framed" and "loss-framed" persuasive appeals. A gain-framed message emphasizes the advantages of compliance with the communicator's recommended action or viewpoint; a loss-framed message emphasizes the disadvantages of noncompliance. For example, "if you take your high blood pressure medication, you'll probably get to play with your grandchildren" is a gain-framed appeal, whereas "if you don't take your high blood pressure medication, you might not get to play with your grandchildren" is a lossframed appeal. The animating research question is: Which kind of appeal is more persuasive (generally, or in specified circumstances)?

The effects of this message variation are interesting enough in their own right, but I want to discuss this research also because the story of gain- 
loss message framing research speaks to some larger issues concerning this kind of research - experimental research aimed at producing dependable generalizations about the persuasive effects of message variations. So what follows is a rough narrative of gain-loss persuasive message framing research, concluding with some larger lessons that can be extracted from this case study.

\subsection{Gain-loss framing effects: Initial results}

The story begins over 20 years ago, in 1987, when one of the first studies of gain-loss message framing was published: Meyerowitz and Chaiken's article in the Journal of Personality and Social Psychology, a very well-regarded psychology journal. Meyerowitz and Chaiken compared the effectiveness of gainand loss-framed messages that were aimed at encouraging women to undertake breast self-examinations (for the early detection of breast cancer). They found a loss-framed appeal to be substantially more effective than a gainframed appeal (Meyerowitz and Chaiken 1987).

This was a really striking result. After all, the underlying argument is exactly the same in the two messages; the same underlying substantive consideration is invoked in the two appeals. Even so, this simple change of frame - emphasizing the disadvantages of noncompliance rather than the advantages of compliance - produced a large difference in persuasiveness.

So the question that naturally arises is: Why? Why this difference in persuasiveness, given substantive similarity in the arguments? As it happens, a good explanation of these results was ready to hand, in the form of the psychological phenomenon commonly called "negativity bias." Negativity bias is the heightened impact of, and sensitivity to, negative information (as opposed to otherwise-equivalent positive information; for a review, see Cacioppo, Gardner and Berntson 1997).

This "robust psychological phenomenon" (Cacioppo and Gardner I999, p. 206) has a variety of manifestations. For example, gains and losses are psychologically asymmetrical such that persons are generally more sensitive to losses than to otherwise-equivalent gains; specifically, people are more likely to prefer a risky (vs. less-risky) decision option if the option is presented in a way that emphasizes avoiding possible losses rather than obtaining possible gains (the classic study is Tversky and Kahneman 1981; for a review, see Kuhberger, Schulte-Mecklenbeck and Perner 1999). Negative information has a disproportionate impact on evaluations or decisions compared to otherwiseequivalent positive information (e.g., Hamilton and Zanna 1972; Lutz 1975; 
for reviews, see Kanouse 1984; Rozin and Royzman 200I; Skowronski and Carlston 1989). Negative stimuli are preferentially detected, that is, detected at lower levels of input or exposure than are positive stimuli (e.g., Dijksterhuis and Aarts 2003). Finally, negative events generally evoke stronger and more rapid reactions (of various sorts) than do positive events (for a review, see Taylor 199I); for instance, negative events evoke more cognitive work than do positive events (Peeters and Czapinski 1990).

Taken together, these findings indicate that negative information is more potent than positive information - which of course is a natural explanation for why a loss-framed message was more persuasive than a gain-framed message in Meyerowitz and Chaiken's study. And in fact, Meyerowitz and Chaiken (1987, pp. 50I, 507) invoked negativity bias as a plausible explanation of their results:

Theorizing associated with the negativity bias effect in person perception and decision-making research . . suggests that losses may be weighted more heavily than gains ... Thus it might be predicted that a pamphlet stressing the negative aspects of not doing BSE would have a greater persuasive impact than a pamphlet stressing the positive aspects of doing BSE.

Given the combination of Meyerowitz and Chaiken's finding and the accompanying negativity-bias explanation, the natural conclusion to draw is that loss-framed appeals are generally more persuasive than gain-framed appeals. And indeed that's a common-enough conclusion to see in the literature. For example: "Framing studies ... have generally shown that . . . loss frames are generally superior to gain frames" (Consedine, Horton, Magai and Kukafka 2007, p. 55I). Or: "Typically, loss frames are more persuasive than gain frames" (Johnson, Maio and Smith-McLallen 2005, p. 640).

\subsection{Synthesizing research results through meta-analysis}

But is it really true that loss-framed appeals are generally more persuasive than gain-framed appeals? Many subsequent studies have been conducted concerning the relative persuasiveness of gain- and loss-framed appeals, and in recent years Jakob Jensen and I have been engaged in an ongoing project in which we synthesize the results of these studies.

The traditional way of summarizing such studies has been the "narrative" review, in which studies are sorted on the basis of whether the message 
variation of interest made a statistically significant difference or not (and in what direction the difference occurred), where the reviewer searches for features that distinguish the significant and nonsignificant studies (or for features that distinguish the significant studies with one direction of effect from those with the opposite effect). But this way of synthesizing research is unsatisfactory for various reasons, and especially because of the role that statistical significance plays. As is now more widely appreciated, statistical significance is something different from the size of the effect of interest. To take a simple case, the correlation between two variables (X and $\mathrm{Y}$ ) might be statistically significant in one study and nonsignificant in another - even though the correlation was actually larger in the second (nonsignificant) study - because of differences in sample size (the number of participants) in the two studies.

In contrast to traditional narrative means of synthesis, meta-analysis focuses specifically on (what is called) the "effect size" in each study - the magnitude (size) of the effect or relationship of interest. Thus (crudely) a meta-analytic review involves three steps: (I) locating the studies of interest; (2) extracting the effect size (and related information, such as sample size) from each study; and (3) computing average effect sizes both across all the studies and within sub-categories of interest. Meta-analytic methods have replaced traditional narrative methods and indeed have become the standard for syntheses of this kind of research. (For useful general introductions to meta-analysis, see Borenstein, Hedges, Higgins and Rothstein 2009; Cooper 20IO; Cooper, Hedges and Valentine 2009.)

So we have been engaged in ongoing meta-analytic work to synthesize the results of existing research on gain-loss message framing effects. We search quite widely, across a number of databases with a variety of search terms, trying to find every relevant study we can: published articles, dissertations, conference papers, master's theses, and so on. Our interest, of course, is specifically in locating experimental studies comparing the persuasiveness of gain- and loss-framed messages.

For each such study, we convert its results into an effect size, which represents the size and direction of the difference in persuasiveness between the gain-framed appeal and the loss-framed appeal. Specifically, we use the correlation coefficient $(r)$ as our effect size index. A correlation is a value that can range from positive I to negative I. In this application, a correlation of zero indicates no difference in persuasiveness between the two appeals. A positive correlation (for a given study) indicates a persuasive advantage for the 
gain-framed appeal; a negative correlation indicates an advantage for the lossframed appeal. The larger the absolute value of the correlation, the larger the difference in persuasiveness between the two appeals.

Details of our methods are available in our published work (O'Keefe and Jensen 2006, 2007, 2008, 2009), so here I want only to specify how the present results are related to those previously reported. The cases analyzed here represent the cases initially analyzed by O'Keefe and Jensen (2006), with the addition of the subsequent studies concerning disease prevention behaviors that were included in the analyses of O'Keefe and Jensen (2007) and the subsequent studies concerning disease detection behaviors that were included in the analyses of O'Keefe and Jensen (2009).

\subsection{Initial meta-analytic findings: Are loss-framed appeals generally more persuasive?}

Even though persuasion effects research has been going on for quite some time, it's still rare to find more than Io or Is studies of any given message variable. Persuasion research, like many areas of social-scientific research, doesn't see replication as often as one might like. But gain-loss persuasive message framing has attracted a lot of research attention: over 200 studies, with over 60,000 participants.

If loss-framed appeals are generally more persuasive than gain-framed appeals, one would expect to find, on average, a negative correlation. Based on the effects observed for other persuasive message variations, one would not expect to see mean correlations as large as, say, .30 (or -.30). About the biggest mean effects one sees are in the .I5 to .20 range, and most mean effects are .Io or so - not large, but dependable (see O'Keefe 1999).

For the comparison of gain-framed and loss-framed appeals, the average effect size across all studies, expressed as a correlation, is actually only .oI (mean $r=.010, k=219, N=62,836$ ). And, unsurprisingly, that mean effect is not significantly different from zero (the $95 \%$ confidence interval limits are -.006 and .027 , that is, the confidence interval contains zero) - which is to say we cannot even be confident that the actual population effect is something other than zero. In short, there is no overall difference in persuasiveness between gain-framed and loss-framed appeals.

When statistically nonsignificant results are obtained, it is often useful to ask whether there were enough data in hand to detect some genuine effect if it exists. This is expressed as a matter of "statistical power," that is, the 
chances of finding a statistically significant effect (assuming, in the present case, that the actual [population] effect size was .Io [or -.Io]). Our analysis had excellent statistical power (.99, Hedges and Pigott 200I), which means it is correspondingly unlikely that the population effect size is indeed that large.

So Meyerowitz and Chaiken's initial study produced a striking experimental result (loss-framed appeals more persuasive than gain-framed appeals) and had a good explanation (negativity bias) - but that explanation turned out to be misplaced. Loss-framed appeals are not generally more persuasive than gain-framed appeals.

\subsection{Renewing the search for negativity bias effects}

The conclusion that loss-framed appeals are not generally any more persuasive than gain-framed appeals is, of course, a disappointing one - not least because of how Meyerowitz and Chaiken's initial finding fitted so nicely into the larger picture of negativity bias. So perhaps it is the case that loss-framed appeals really are more persuasive than gain-framed appeals, but that somehow that effect is being masked in these studies. After all, negativity bias is genuine, a very well-evidenced psychological phenomenon. So perhaps there is some factor at work that is preventing negativity bias from manifesting itself in these studies.

A little reflection on the nature of gain-framed and loss-framed appeals suggests a natural candidate for such a factor; namely, the linguistic representation of the "kernel state" of the consequence under discussion (O'Keefe and Jensen 2006). The kernel state is the basic, root state mentioned in the message's description of the consequence. A given framing form might mention either desirable or undesirable kernel states. For example, a gain-framed appeal might take the form "if you wear sunscreen, you'll increase your chances of having attractive skin" (where the kernel state, "attractive skin," is a desirable one) or the form "if you wear sunscreen, you'll reduce your risk of skin cancer" (where the kernel state, "skin cancer," is an undesirable one). Similarly, a loss-framed appeal might mention either desirable kernel states ("If you don't wear sunscreen, you'll reduce your chances of having attractive skin") or undesirable kernel states ("If you don't wear sunscreen, you'll increase your risk of skin cancer").

Notice, thus, that a gain-framed appeal might be phrased entirely in terms of undesirable kernel states ("skin cancer," "tumors," "premature death," etc.) that are avoided by compliance, and a loss-framed appeal might 
be phrased entirely in terms of desirable kernel states ("long life," "attractive skin," and so forth) that are foregone by virtue of noncompliance. Plainly, variations in kernel states might interfere with the appearance of the expected negativity bias effects.

To remove such interference and permit negativity bias to emerge, a more focused comparison is required. The comparison of interest is that between a gain-framed appeal that has exclusively desirable kernel states and a loss-framed appeal that has exclusively undesirable kernel states. Such a comparison pits a thoroughly "positive" message (gain-framed with desirable kernel states) against a thoroughly "negative" message (loss-framed with undesirable kernel states). If negativity bias is at work here, this comparison should yield a substantial negative mean effect, representing the expected persuasive advantage for loss-framed appeals.

Twenty different studies (with 2I,2I3 participants) have investigated such a comparison. The average effect size across these studies is -.or (actually, -.005 , that is, an effect that is almost literally zero). This effect is not statistically significantly different from zero (the $95 \%$ confidence interval limits are -.048 and .039; the statistical power was .99).

So not only do loss-framed appeals not enjoy any general persuasive advantage over gain-framed appeals, they are not more persuasive even under conditions in which negativity-bias effects would be expected to be maximized.

\subsection{Changing course: Disease detection and disease prevention}

Given the lack of any overall persuasive advantage for loss-framed appeals and given that the average difference in persuasiveness is statistically indistinguishable from zero - it naturally becomes attractive to consider the possibility that gain-framed appeals are more persuasive than loss-framed appeals under some (specifiable) circumstances, and loss-framed appeals have a persuasive advantage under other circumstances. (Notice that this might account for there not being any average difference overall.)

A 1999 study by Detweiler, Bedell, Salovey, Pronin and Rothman provides a convenient illustration of a study encouraging such a line of thinking. Detweiler et al. (1999) found that a gain-framed appeal was significantly more persuasive than a loss-framed appeal for encouraging people to use sunscreen (which prevents skin cancer). This study, in conjunction with several others, gave rise to the idea that, at least in the realm of health behavior, 
there might be a systematic difference in the relative persuasiveness of gainand loss-framed messages depending on whether the advocated action is a disease prevention behavior (like sunscreen use, the one Detweiler et al. studied) or a disease detection behavior (like breast self-examination, the one Meyerowitz and Chaiken studied). Here, for example, is a formulation of this idea:

The literature on framing and health promotion has yielded an interesting pattern of findings . . . Loss-framed messages have been effective in promoting mammography, BSE, and HIV testing, all early-detection behaviors. Conversely, gain-framed messages have been effective in promoting the use of infant car restraints and sunscreen, both prevention behaviors. (Salovey and Wegener 2003, p. 57)

So the suggestion is that for prevention behaviors, gain-framed messages will be more persuasive, but for disease detection behaviors, loss-framed appeals will be more persuasive. However interesting such a pattern of results might be, the natural question that arises is why such a difference should occur - that is, what would explain such a difference? The explanatory framework that is commonly offered derives from Kahneman and Tversky's prospect theory (1979) - and specifically from the finding that people are more likely to undertake risky behaviors when potential losses are salient but prefer risk-averse choices when gains are prominent (the classic study is Tversky and Kahneman 198I). As Rothman and Salovey (1997, p. 3) put it:

\footnotetext{
Prospect theory proposes that people are more willing to accept risks when they evaluate options in terms of associated costs but act to avoid risks when the same options are described in terms of associated benefits.
}

In the context of health behaviors, the supposition is that disease detection behaviors are riskier than disease prevention behaviors, because undertaking a disease detection behavior might uncover an abnormality. Hence as applied to gain-loss message framing, the reasoning is that the perceived riskiness of detection behaviors will make loss-framed messages more persuasive, whereas prevention behaviors will be more effectively promoted by gain-framed messages.

From a prospect theory point of view, the perceived risk (of finding an abnormality) could make loss-framed messages more persuasive in promoting the detection 
behaviors. However, ... gain-framed messages might be more likely to facilitate performing prevention behaviors. (Salovey and Wegener 2003, pp. 57-58)

This is now the overwhelmingly most common way of describing gain-loss message framing persuasive effects: that there's a difference between prevention and detection behaviors in the relative persuasiveness of these appeal variations, with the explanation derived from prospect-theoretic reasoning. For example:

A series of research studies converge on a single conclusion ... Gain-framed messages are more effective at encouraging prevention behaviors, but loss-framed appeals are more effective at fostering detection behaviors. (Dillard and Marshall 2003, p. 504)

There are a number of effects of message framing that have been consistently obtained. Detection behaviors generally are better promoted by loss-framed messages, but prevention behaviors seem better promoted by gain-framed messages. (Salovey and Wegener 2003, p. 70)

Gain-framed messages are more effective in promoting prevention behaviors . . . However, loss-framed messages are more effective in influencing early detection behaviors. (Perloff 2003, p. 196)

Research on changing general health behaviors shows that gain-framed messages are more effective when the advocated behavior is prevention-oriented. Prevention behaviors are viewed as low-risk behaviors . . . Loss-framed messages, on the other hand, appear to be more effective when the advocated behavior is detection-oriented. Detection behaviors . . are perceived as high-risk. (USDA 2007, p. 2)

And elements of this generalization have even entered the popular literature:

Framing matters: people are more likely to engage in self-examinations for skin and breast cancer if they are told not about the reduced risk if they do so but about the increased risk if they fail to do so. (Thaler and Sunstein 2009, p. 159) 


\subsection{Further meta-analytic findings: Disease prevention and disease detection}

This is a terrific explanation - but is there really that difference between prevention and detection behaviors with respect to the relative persuasiveness of gain- and loss-framed appeals? There are now many more studies of prevention and detection messages than the handful that initially encouraged this generalization, so those accumulated studies can be analyzed to address this question.

Concerning disease detection behaviors: Across 55 studies (with 9,247 participants), there is no statistically significant difference in the persuasiveness of gain-framed and loss-framed appeals. The mean effect size is -.03 (.029 ), with $95 \%$ confidence limits of -.066 and .008 (power $=.99$ ). So loss-framed appeals are not more persuasive than gain-framed appeals concerning disease detection behaviors.

Concerning disease prevention behaviors: There is a statistically significant difference such that gain-framed appeals are more persuasive than loss-framed appeals - but the difference is so small as to be trivial: Across IO3 studies $(N=22,652)$, the mean effect size is .04 (.038), with $95 \%$ confidence interval limits of .oI2 and .064. Thus there is no substantively important difference in the persuasiveness of gain- and loss-framed messages concerning disease prevention behaviors.

And, just to round out the picture, there are no significant differences on other message topics. For other health-related behaviors (e.g., getting hearing aids), the mean effect (across I3 studies with 4,702 participants) is -.02 ($.021 ; 95 \%$ confidence interval limits of -.073 and .031 ; power $=.99$ ). For advertising of non-health-related consumer products and services (ads for laundry detergent, insurance, etc.), the mean effect (across 25 studies with 3,805 participants) is $-.0 \mathrm{OI}$ (-.013; 95\% confidence interval limits of -.074 and .049 ; power $=.99$ ). For the remaining topics (a miscellaneous set including taxpayer compliance, recycling participation and public policy questions), the mean effect (across 23 studies with 22,430 participants) is .03 (.029; 95\% confidence interval limits of $-.02 \mathrm{I}$ and .079 ; power $=.99$ ).

Thus not only is there no overall difference in persuasiveness between gain-framed and loss-framed messages - even under conditions in which the effects of negativity-bias processes should be maximized - but the studies to date do not underwrite the suggestion that loss-framed appeals will have a substantial advantage concerning disease detection behaviors and gain-framed appeals a similarly large advantage concerning disease prevention behaviors. 
In short, the expected differences in persuasiveness between gain- and lossframed appeals do not obtain, despite the presence of attractive explanatory frameworks (negativity bias, prospect theory) that are ready to accommodate findings of such differences.

\subsection{Larger lessons}

I want to draw out three larger points here concerning how, as a research community, we should approach the task of generalizing about persuasive effects from research evidence of this sort. These are phrased as advice to consumers of this research - but of course those who produce such research should heed these lessons as well.

First: Pay attention to the size of an effect, not just whether the effect is statistically significant. Researchers are commonly focused on the question of whether a given message variation makes a statistically significant difference to persuasiveness. That's a natural and understandable focus. After all, a statistically significant difference means that the difference is probably genuine, that is, not zero - and knowing that an effect is not zero is valuable. But - as illustrated by the finding concerning disease prevention behaviors - it is possible for an effect to be statistically significant and yet trivially small. That is, there are some effects that, even though they are not actually zero, are sufficiently small that they might as well be zero.

I don't mean to say that it's always easy to decide just how small is "so small it might as well be zero" (see, e.g., Abelson 1985). But when a researcher reports that (for example) the difference in persuasiveness of two messages was statistically significant, it will be useful to ask "How big was that difference; that is, what was the size of the effect?"

Second: Don't put too much faith in the results of any single study. The early study by Meyerowitz and Chaiken (1987) found a loss-framed appeal to be more persuasive than a gain-framed appeal. And, as we have seen, some commentators have invoked that finding as evidence for the claim that generally loss-framed appeals are more persuasive. But there is no such general difference between gain- and loss-framed appeals. So obviously Meyerowitz and Chaiken's early result was in some sense unrepresentative, and hasty generalization from that finding was inappropriate.

Another way of expressing this second point is: Ask for replications. The results of any single study are all very nice, but the results of any one study cannot speak to questions of generalization in the way that is wanted. 
Messages are like most other things: Generalizations about a category require examining more than one instance of the category. A study that compares one gain-framed appeal against one loss-framed appeal may yield very useful information about the relative persuasiveness of those two particular messages, but it cannot provide good evidence for claims about any general differences in persuasiveness between gain-framed and loss-framed messages.

Notably, studies of the persuasive effects of message variations quite commonly display considerable variation in effects from one study to the next (see O'Keefe 1999). The plain implication is that the results of any one study are not necessarily an indication of the overall pattern of results across studies. That is to say, there is good empirical evidence that in this research domain, the results from any single study cannot be depended on to be representative of the picture that will emerge once a number of replications have been performed.

Third: Be wary of the combination of limited evidence and a good explanation. That is, be especially alert when presented with the combination of (a) a small number of statistically significant effects (or just one such effect) and (b) a good explanatory story.

Consider that early study by Meyerowitz and Chaiken, which found a significant advantage for loss-framed appeals. There was a compelling explanation for that result, in the form of negativity bias. This combination, I think, encouraged people to draw those broad conclusions about the greater persuasiveness of loss-framed messages.

Or consider the small number of studies that seemed to fit a pattern in which loss-framed appeals were more persuasive for disease detection behaviors (such as breast self-examination, the behavior studied by Meyerowitz and Chaiken), whereas gain-framed appeals were more persuasive for disease prevention behaviors (such as sunscreen use). The combination of these few studies and a prospect-theory explanation is apparently almost irresistible; that's the story one commonly sees told nowadays about message framing effects even though it's not true. So: Don't be seduced by limited evidence, no matter how good the explanation seems to be. In fact, don't be seduced by limited evidence especially when accompanied by a good explanation.

I am happy to acknowledge that resisting this temptation will be difficult. Given some research finding - and especially some unusual or striking finding - our natural inclination is to ask "what's the explanation?" But bear in mind the previous point: Don't put too much faith in the results of any sin- 
gle study. Another way of putting that might be: No single study yields something to be explained (i.e., some genuine phenomenon). With a number of successful replications in hand, we might be confident in concluding that the phenomenon is genuine (and so would be confident in considering possible explanations) - but without more extensive evidence, we cannot be sure there is anything to explain. Briefly put, the motto should be: No explanans without an explanandum. When faced with a singular finding, don't ask "What's the explanation?" Ask "Where are the replications?"

\section{References}

Abelson, R.P. (1985). A Variance Explanation Paradox: When a Little is a Lot. Psychological Bulletin 97, I29-133.

Borenstein, M., L.V. Hedges, J.P.T. Higgins and H.R. Rothstein (2009). Introduction to Meta-analysis. Chichester: Wiley.

Cacioppo, J.T. and W.L. Gardner (1999). Emotion. Annual Review of Psychology 50, 19I-2I4. Cacioppo, J.T., W.L.Gardner and G.G. Berntson (1997). Beyond Bipolar Conceptualizations and Measures: The Case of Attitudes and Evaluative Space. Personality and Social Psychology Review I, 3-25.

Consedine, N.S., D. Horton, C. Magai and R. Kukafka (2007). Breast Screening in Response to Gain, Loss, and Empowerment Framed Messages Among Diverse, Low-income Women. Journal of Health Care for the Poor and Underserved i8, 550-566.

Cooper, H. (20IO). Research Synthesis and Meta-analysis: A Step-by-step Approach (4th ed.). Los Angeles: Sage.

Cooper, H., L.V. Hedges and J.C.Valentine (Eds.) (2009). The Handbook of Research Synthesis and Meta-analysis (2nd ed.). New York: Russell Sage Foundation.

Detweiler, J.B., B.T. Bedell, P. Salovey, E. Pronin and A.J. Rothman (1999). Message Framing and Sunscreen Use: Gain-framed Messages Motivate Beach-goers. Health Psychology 18, I89-196.

Dijksterhuis, A. and H. Aarts (2003). On Wildebeests and Humans: The Preferential Detection of Negative Stimuli. Psychological Science I4, I4-I8.

Dillard, J.P. and L.J. Marshall (2003). Persuasion as a Social Skill. In J.O. Greene and B.R. Burleson (Eds.), Handbook of Communication and Social interaction Skills (pp. 4795I3). Mahwah, NJ: Lawrence Erlbaum.

Hamilton, D.L. and M.P. Zanna (1972). Differential Weighting of Favorable and Unfavorable Attributes in Impressions of Personality. Journal of Experimental Research in Personality 6, 204-2I2. 
Hedges, L. V. and T.D. Pigott (200I). The Power of Statistical Tests in Meta-analysis. Psychological Methods 6, 203-217.

Johnson, B.T., G.R. Maio and A. Smith-McLallen (2005). Communication and Attitude Change: Causes, Processes, and Effects. In D. Albarracin, B.T. Johnson and M.P. Zanna (Eds.), The Handbook of Attitudes (pp. 617-669). Mahwah, NJ: Lawrence Erlbaum.

Kahneman, D. and A. Tversky (1979). Prospect Theory: An Analysis of Decision Under Risk. Econometrica 47, 263-29I.

Kanouse, D.E. (1984). Explaining Negativity Biases in Evaluation and Choice Behavior: Theory and Research. Advances in Consumer Research II, 703-708.

Kuhberger, A., M. Schulte-Mecklenbeck and J. Perner (1999). The Effects of Framing, Reflection, Probability, and Payoff on Risk Preference in Choice Tasks. Organizational Behavior and Human Decision Processes 78, 204-23I.

Lutz, R.J. (1975). Changing Brand Attitudes Through Modification of Cognitive Structure. Journal of Consumer Research I(4), 49-59.

Meyerowitz, B.E. and S. Chaiken (1987). The Effect of Message Framing on Breast Self-ex amination Attitudes, Intentions, and Behavior. Journal of Personality and Social Psychology 52, 500-510.

O’Keefe, D.J. (1999). Variability of Persuasive Message Effects: Meta-analytic Evidence and Implications. Document Design I, 87-97.

O'Keefe, D.J. and J.D. Jensen (2006). The Advantages of Compliance or the Disadvantages of Noncompliance? A Meta-analytic Review of the Relative Persuasive Effectiveness of Gain-framed and Loss-framed Messages. Communication Yearbook 30, I-43.

O'Keefe, D.J. and J.D. Jensen (2007). The Relative Persuasiveness of Gain-framed and Loss-framed Messages for Encouraging Disease Prevention Behaviors: A metaanalytic Review. Journal of Health Communication I2, 623-644.

O'Keefe, D.J. and J.D. Jensen (2008). Do Loss-framed Persuasive Messages Engender Greater Message Processing Than do Gain-framed Messages? A Meta-analytic Review. Communication Studies 59, 5I-67.

O'Keefe, D.J. and J.D. Jensen (2009). The Relative Persuasiveness of Gain-framed and Loss-framed Messages for Encouraging Disease Detection Behaviors: A Metaanalytic Review. Journal of Communication 59, 296-316.

Peeters, G. and J. Czapinski (1990). Positive-negative Asymmetry in Evaluations: The Distinction Between Affective and Informational Negativity Effects. In W. Stroebe and M. Hewstone (Eds.) European review of social psychology (Vol. I, pp. 33-60). Chichester: John Wiley.

Perloff, R.M. (2003). The Dynamics of Persuasion (2nd ed.). Mahwah, NJ: Lawrence Erlbaum. 
Rothman, A.J. and P. Salovey (1997). Shaping Perceptions to Motivate Healthy Behavior: The Role of Message Framing. Psychological Bulletin 121, 3-19.

Rozin, P. and E.B. Royzman (200I). Negativity Bias, Negativity Dominance, and Contagion. Personality and Social Psychology Review 5, 296-320.

Salovey, P. and D.T. Wegener (2003). Communicating About Health: Message Framing, Persuasion, and Health Behavior. In J. Suls and K. Wallston (Eds.), Social Psychology Foundations of Health and Illness (pp. 54-8I). Oxford, UK: Blackwell.

Skowronski, J. J. and D.E. Carlston (1989). Negativity and Extremity Biases in Impression Formation: A Review of Explanations. Psychological Bulletin I05, I3I-I42.

Taylor, S. E. (199I). Asymmetrical Effects of Positive and Negative Events: The Mobilizationminimization Hypothesis. Psychological Bulletin IIO, 67-85.

Thaler, R. H. and C.R. Sunstein (2009). Nudge: Improving Decisions about Health, Wealth, and Happiness (rev. ed.). London: Penguin.

Tversky, A. and D. Kahneman (198I). The Framing of Decisions and the Psychology of Choice. Science 2II, 453-458.

U. S. Department of Agriculture (USDA) (2007). Nutrition Education Research Brief: Message Framing, Use of Interactive Technology to Tailor Messages, and Intervention Intensity. Alexandria, VA: U. S. Department of Agriculture, Food and Nutrition Service. 



\title{
7 The Contribution of Praeteritio to Arguers' Strategic Maneuvering in the Argumentation Stage of a Discussion
}

\author{
A. FRANCISCA SNOECK HENKEMANS
}

\section{I Introduction}

Deputy Prime Minister Bos was some time ago reported by the Dutch newspaper NRC Handelsblad to have made the following announcement on television about the possibility of a recession in the Netherlands:

As long as there are no concrete indications that we are heading for a recession,

I shall not utter that word. (Deputy Prime Minister Bos, October 25, 2008)

For all sorts of reasons it is unlikely that this message will have reassured the general public in the Netherlands that there was no danger of a recession in the near future. One of them could certainly be that Minister Bos made use of the rhetorical technique of praeteritio in the presentation of his announcement. Characteristic of praeteritio is the self-defeating character of this figure of thought: by making use of a praeteritio, speakers announce that they will not say something or not speak of something, which they say or mention nonetheless.

In classical and modern rhetorical studies, praeteritio has mainly been described as a device that can be of use in the presentation of arguments. ${ }^{I}$ In an earlier publication, I showed that praeteritio may have a strategic function not just in the argumentation stage, but in each of the stages of an argumentative discussion as a means to further both the arguers' dialectical and their rhetorical aims (see Snoeck Henkemans 2009). In this chapter, I want to look more closely at the role that has traditionally been ascribed to the sty-

${ }^{\text {I }}$ This is, for instance, how the Ad Herennium, Usher (1965) and Perelman and OlbrechtsTyteca (1969) describe this figure. 
listic device of praeteritio. I shall do this by investigating what role praeteritio can play in arguers' strategic maneuvers in the presentation of their arguments. I shall first give an analysis of the general effects the use of praeteritio may have due to the presentational means that are employed. Then I shall focus on how the device of praeteritio may contribute to arguers' dialectical and rhetorical aims in the presentation of their arguments. Finally, I shall pay attention to the ways in which the use of praeteritio for presenting moves that form part of the argumentation stage may derail and thus become fallacious.

\subsection{General effects of praeteritio}

According to the Ad Herennium, an important reason for using praeteritio is to get some information or evidence across without drawing attention to the fact that one is giving this information or presenting this evidence:

This figure is useful if employed in a matter which it is not pertinent to call specifically to the attention of others, because there is advantage in making only an indirect reference to it, or because the direct reference would be tedious or undignified, or cannot be made clear, or can easily be refuted. As a result, it is of greater advantage to create a suspicion by Paralipsis [praeteritio] than to insist directly on a statement that is refutable. (IV, 27.37)

Other authors see praeteritio first and foremost as a way of emphasizing the allegedly omitted material. Lanham, for instance, defines praeteritio as a way of "emphasizing something by pointedly passing it over" (I99I, p. IO4). And Dupriez makes a distinction between "semi-preteritions which hardly emphasize an utterance" and "true preterition" which "is a form of pseudosimulation, concealing the better to display" (I99I, p. 354).

I have argued that praeteritio can best be analyzed as a combination of emphasizing and hiding (Snoeck Henkemans 2009). Instead of just keeping silent about something or refraining from performing a particular speech act, speakers or writers who use praeteritio explicitly deny that they are committed to a certain proposition or explicitly announce that they will not speak of something. By denying their commitment to a proposition, the proposition in question becomes more prominent in the consciousness of the audience. ${ }^{2}$ If a speaker explicitly announces that he will not bring up a certain subject instead of just remaining silent about it, he thereby also draws attention to the speech act he claims not to perform, since this explicit announcement fo- 
cuses the audience's attention on the fact that he could have brought up the subject or that it may have been expected that he would do so. Denying a commitment or denying that one is going to perform a certain speech act therefore draws the attention of the audience to the information speakers or writers claim that they will not provide or the speech act they announce that they will not perform. If this refusal to commit oneself or to talk about something is a case of praeteritio and not just of reticence, the information is given nonetheless, but it is generally presented in such a way that the contradiction between what speakers claim to be doing and what they do in reality is camouflaged. ${ }^{3}$ It is in this way that praeteritio can be seen both as a form of emphasizing and of hiding.

In some cases it may become more difficult to establish what the commitments of speakers exactly are, as in example (I) where the arguer attempts to cancel an implicature by means of a praeteritio. In other cases it is not so much unclear what speakers are saying, but the use of particular techniques in presenting the praeteritio makes it less easy to hold them accountable for what they have said. Examples (2) to (4) seem to have this effect. In these examples, by way of the praeteritio, a distinction is brought about between what is said "on record" and what is said "off the record". In this way, speakers can avoid responsibilities that they would have had if they had not used the praeteritio.

(I) I am not anti-Obama. I am pro-America. And I am not saying being pro-Obama is anti-American.

(www.democraticunderground.com/discuss/duboard.php?az=viewa\&address=132)

(2) Dan: Saw "the Big Bite" sketch show on tv last night. How lame. How Unoriginal.

Joe M.: uh, Dan, it would be too easy to say "You do better" but a few people around here make their living from helping comedians get their stuff to air.

\footnotetext{
${ }^{2}$ As Clark (1975) observes with respect to Richard Nixon's famous "I am not a crook"statement, denials presuppose that the audience does or could believe what is being denied. A similar analysis is given by Ducrot (1984, pp. 216-217), who claims that sentences containing a (polemic) negation entail a dialogue with a (silent) second "voice" that maintains the opposite viewpoint.

${ }^{3}$ For a more detailed explanation of the types of presentation techniques that can be employed to mask the contradiction inherent in praeteritio, see Snoeck Henkemans (2009).
} 
I'd rather watch and support a local comedy for local people than any imported reality series. (www.phorums.com.aularchivelindex.php/t-33805.html-I2k)

(3) You're a smart person, so I don't have to tell you that the Internet is making a lot of people rich, you already know that. (www.makemoneyonline-now.com - 28k)

(4) If I didn't like you so much, I would say that I find your story crap. (www.dichttalent.nl/?nav =orthKsHrGmKhLkBgE\&gedsel=hgkruBsHrGmKhL Assxs UDKLuwB) [Author's own transl.]

\subsection{The contribution of praeteritio to strategic maneuvers in the ar- gumentation stage}

In order to determine in what way using praeteritio could contribute to arguers' strategic maneuvers in presenting their arguments, the question has to be answered why it would be to the advantage of arguers not to officially assert the content of their arguments but to make sure that these arguments are noticed by the audience nonetheless.

According to Van Eemeren and Houtlosser, the arguers' rhetorical objective in advancing their argumentation is to make the strongest case (2002, p. 139). In order to achieve this aim, arguers may formulate their arguments in such a way that they are less likely to raise particular criticisms, that they seem as strong as possible or are most likely to appeal to their audience. It is in all these respects, I think, that making use of praeteritio can help to make a strong case and thus make the argumentation potentially more effective.

That praeteritio may be a means of making an argument more difficult to criticize was already pointed out in the Ad Herennium, where this device is seen as a means for presenting weak evidence. ${ }^{4}$ Usher (1965) takes this analysis as a starting point and claims that the device of praeteritio can be used "as

${ }^{4}$ According to Lausberg (1998, p. 393), the announcement of the intention to leave out certain things implies the mentioning of those things, but "what is being dispensed with is the specification of these things." Lausberg mentions as an important motive for the use of praeteritio "that the things left out are unfavorable to one's cause [...], the effect on the audience is such that the things retreat to a secondary, less important level”. 
a medium for presenting evidence in such a way that it may be accepted by the audience in spite of its doubtful veracity or value." (1965, p. 175). He gives the following description of how praeteritio might work:

Occultatio [praeteritio] is thus used to present material which would, if critically examined by an alert jury, be found false or refutable. It enables a statement to be made and mentally noted by the jury in the speaker's favour; but because he seems to regard it as unnecessary for his argument or irrelevant, they do not examine it too closely. By this means, weak arguments and false evidence could be introduced with confidence under the pretence of omitting them. (ibid. p. 176)

In a similar vein, Perelman and Olbrechts-Tyteca (1969, p. 487) emphasize that praeteritio may be a useful technique for arguers who are afraid to use a certain argument, albeit that these authors do not mention the weakness of the argument as a reason for this fear, but its inappropriateness or illegitimacy:

The specific remedy open to a speaker who is afraid to use a particular argument is to hint at it. Too explicit use of some arguments is contrary to good taste, dangerous or even prohibited. There are arguments that can be referred to only by insinuation or allusion, or by a threat to use them. (ibid. p. 487)

Praeteritio is seen by Perelman and Olbrechts-Tyteca as a type of "semi-renunciation" or "pretended sacrifice" of an argument (ibid. p. 487).

In addition to the advantage of being able to put forward an argument in an unobtrusive way, thereby avoiding the negative consequences that presenting the argument in a more open and direct manner might have, the use of praeteritio may also have a positive effect on other arguments an arguer has advanced. According to Perelman and Olbrechts-Tyteca, "the sacrifice of the argument satisfies the proprieties, while it suggests also that the other arguments are sufficiently strong to make this one unnecessary" (ibid. p. 487).

In the classical and modern rhetorical literature the main advantage mentioned is thus the possibility of putting forward weak or otherwise problematic arguments without having to take the consequences. In view of the additional effect mentioned by Perelman and Olbrechts-Tyteca of reinforcing the other arguments the arguer has advanced, I think that presenting a strong and acceptable argument by means of a praeteritio could also be to the 
advantage of the arguer. If the arguer can supposedly do without a strong, maybe even the strongest argument, this may make the rest of the argumentation seem even stronger. Praeteritio can then, in other words, also be instrumental in presenting the arguments in such a way that they seem as strong as possible.

In example (5) the arguer seems to use the praeteritio for exactly this purpose. The standpoint that the arguer's family does not give her Christmas gifts that are personal or appropriate is first defended by a number of examples of ill-chosen bath products:

(5) Despite my best attempts to familiarize my family with me, their gifts always seem to be the results of a last-minute dash to Walmart where the first thing falling under the theme 'girl, age I0-76' was purchased and labeled with my name [...] So, I get crap for Christmas. [...] Mostly I receive junk I'm pretty sure comes form the dusty shelves of the dollar store. And sometimes a capful of the dollar store junk is missing because someone in the family has bought it, ran a bath for themselves, discovered that it smells suspiciously like burnt hair, and pawned the remains on me. [...] The very family who ostensibly know me to be the most sensitive-skinned person in the world, and yet gift me with cheap-ass bubble bath because nothing says I love you like a bottle of crap so drying that my skin will flake off and I will be unable to selflubricate for weeks on end! Oh the joy! And I won't even mention the fact that I don't have a bathtub.

(saintvodkaofthemartini.blogspot.com/2006/I2/im-getting-crap-for-hristmas.html)

The final argument that is introduced by means of a praeteritio makes the unsuitability of the gifts even more apparent: the receiver of the inappropriate bath products does not even have a bathtub. By presenting this very strong example of the inappropriateness of the gifts her family buys for her as if it is not necessary to mention it, the impression is given that the other arguments that have been advanced are more than strong enough.

Unlike in example (5), in example (6) the argument that the arguer supposedly does not mention is not a very strong argument, since the fact that one did not get a job at a certain magazine does in itself not say anything about the quality of the magazine. This might thus be an example of the arguer using a praeteritio in order to advance an argument that is too weak to withstand criticism and that is therefore best presented off the record. I think, 
however, that in this case the argument is so weak, that we should probably take it as a form of irony: the reader is supposed to understand that the reason that the arguer pretends not to mention is in fact the main reason (or motive) for her not to buy the magazine People, and that the arguments presented before are just arguments from convenience:

(6) I never buy People. I never even leaf through it at the doctor's office; I'd rather read a four-month-old issue of Parenting. Even an unapologetic pop-cultivore like me has to draw the line somewhere, and I like a trashy celebrity exposé as much as the next girl, but People's so-called exposés never really expose anything, except, of course, for the peppy unctuousness and terminal lack of writing flair of the staff. I won't even mention the fact that I auditioned for a job there and got turned down.

(tomatonation.com/? $p=392-I 6 k-$ )

In example (7) a member of the organization Tusiad (Turkish Industrialists' and Businessmen's Association) is defending the standpoint that there is no need to criticize the Report made by the European commission in which an assessment is made of Turkey's progress in fulfilling the Copenhagen criteria. There is no need to dwell on the mistakes of the report, because, according to the arguer, the audience already knows that the assessment made in the report is irrelevant for the judgment of whether Turkey should be admitted to the screening process for potential Eu members. Also, the author claims, his audience already knows or recognizes that for most of the lack of progress it is the Eu that is to blame. And finally, the author believes that there are more important things to do than advance criticisms against a report made by people who are against Turkey becoming a member of the Eu:

(7) I am sure that in Ankara you will hear aplenty about what the Report got wrong both on technical grounds and in its approach. I will not dwell in these. For you already know that the Copenhagen criteria do not constitute a precondition for the screening process to begin. You already recognize that the $\mathrm{EU}$ is at fault in terms of the assistance it provides to Turkey. You know that in the negotiations over the inclusion of services in the Customs Union, it is Brussels and not Ankara that drags its feet. It is on your records that Turkey has not received the financial assistance that was promised to her under the Customs Union agreement and is not getting its fair share for the efforts it is 
currently undertaking. And only part of the reason for this lag is attributable to Ankara's lethargy. I will not dwell on these matters for I believe we must rise above the trees and look at the whole forest that constitutes Turkey-EU relations. For us membership in the EU is the culmination of the civilizational project first undertaken over two hundred years ago. A process that was given a radical boost by the founding fathers of our Republic. We will not be deterred or sidetracked in this goal either by the enemies of the EU in this country or the Turcophobes in Europe.

(www.tusiad.org/.../dooI27d66cagc239c225679fo02765I2/ffafcf97cfce9408c22 s6brooo43d6a9 /\$FILE/duyurunos2.pdf)

By using the device of praeteritio several times in the presentation of his arguments, the speaker attempts to give the impression that his case in favor of Turkey joining the EU is stronger than that of those opposing Turkey's EU membership, and also that he is morally superior to others who find it necessary to criticize the Eu report. Of course, he manages to get his criticisms across all the same. The flaws signaled in the report are irrelevant, or cannot be blamed on Turkey. That the criticisms in the report are irrelevant or unjustified, is presented by the arguer as a common starting point about which no further discussion is possible or necessary. The repeated use of praeteritio thus allows the arguer to present the arguments for his standpoint that the report is not worth criticizing as indisputable and at the same time strengthen his own ethos by giving the impression that he is a morally high standing person who is above the petty squabbles. In this way, he can attempt to make a favorable impression on the audience.

\subsection{Conclusion}

As we have seen, using praeteritio when putting forward arguments in defense of a standpoint can contribute to the arguers' rhetorical aim of making their case seem as strong as possible. When the argument is weak, presenting it by means of a praeteritio can be a way of protecting oneself against criticism, since it then becomes more difficult for an opponent to hold the arguer accountable for any flaws in the argument. If the argument is strong, the pretended sacrifice of the argument may make the remaining arguments seem even stronger. Apart from this effect, especially if the sacrifice supposedly concerns refraining from being critical about someone else's position, the arguer may give the impression of being benevolent or 
morally superior to his opponent. At the same time, the praeteritio allows him to let his criticisms of the other party reach the audience. And finally, as we have seen in example (7), where the praeteritio was justified by referring to the superfluity of mentioning the criticisms, this device may make it possible for an arguer to present those criticisms as if they already belong to the common ground.

Making use of a praeteritio does not necessarily result in a fallacy. There is nothing fallacious about example (5) for instance, and example (7) would be an evasion of the burden of proof only if what is presented as a common starting point by means of the praeteritio was in fact not an agreed upon starting point. Although making use of a praeteritio does not by definition result in a fallacy, there is a real possibility that strategic maneuvers involving praeteritios may derail. In the argumentation stage, the use of praeteritio can typically result in evasions of the burden of proof, since this figure makes it possible for arguers to present their arguments in such a way that they are able to avoid the responsibilities that they would otherwise have taken upon themselves.

\section{References}

Clark, H.H. (1975). Bridging. Theoretical Issues in Natural Language Processing. Proceedings of the 1975 workshop on Theoretical issues in natural language processing.

Ducrot, O. (1984). Le dire et le dit. Paris: Minuit.

Dupriez, B. (199I). A dictionary of Literary Devices. Translated and adapted by A.W. Halsall. New York/London etc.: Harvester Wheatsheaf.

Eemeren, F.H. van and P. Houtlosser (2002). Strategic Maneuvering: Maintaining a Delicate Balance. In F.H. van Eemeren and P. Houtlosser (Eds.), Dialectic and Rhetoric: The Warp and Woof of Argumentation Analysis, (pp. II9-130), Dordrecht/ Boston/London: Kluwer Academic Publishers.

Lanham, R.A. (199I). A Handlist of Rhetorical Terms ( $2^{\text {nd }}$ ed.) Berkeley/Los Angeles/ Oxford: University of California Press.

Lausberg, H. (1998). Handbook of Literary Rhetoric. A Foundation for Literary Study. Leiden/Boston/Köln: Brill.

Perelman, Ch. and L. Olbrechts-Tyteca (1969). The New Rhetoric. A Treatise on Argumentation (Translation of La nouvelle rhétorique. Traité de l'argumentation. Paris: Presses Universitaires de France, 1958). Notre Dame/London: University of Notre Dame Press.

Rhetorica ad Herennium (H. Caplan, Trans.) (1954). Cambridge: Harvard University Press. 
Snoeck Henkemans, A.F. (2009). Manoeuvering Strategically with Praeteritio. Argumentation 23 (3), 339-350.

Usher, S. (1965). Occultatio in Cicero's Speeches. The American Journal of Philology 85 (2), I75-I92. 


\title{
8 Limits and Effects of Reductio ad Absurdum Argumentation
}

\author{
HENRIKE JANSEN, MARIANNE DINGEMANSE \\ AND INGRID PERSOON
}

\section{I Introduction ${ }^{1}$}

A few years ago the documentary First Kill was reviewed in the NRC Handelsblad, a Dutch newspaper. According to the reviewer, the documentary, presenting soldiers in wartime, supported the view that people actually like killing. The reviewer opposed this view. He wrote: "Everyone knows instinctively that the claim that people - men in particular - like killing, as they can do unpunished in wartime, is not true. If it were true, most of us would be serial killers." What strikes one in this argument is that the standpoint is supported by an If...then sentence: If people liked killing [If it were true], [then] most of us would be serial killers. This is striking because, in argumentation text books, an If...then sentence is most often the implicit element of an argument; after all, an If...then sentence expresses the inference license between the argumentation (the premise) and the standpoint (the conclusion). The element that has remained implicit in the reviewer's argument is not an If...then sentence, but has to be reconstructed as: Most of us are not serial killers. A pragma-dialectical analysis of the argument reads as follows:

I. Standpoint: The claim that people like killing is not true.

I.I Explicit premise: If people liked killing ['If it were true'], [then] most of us would be serial killers.

I.I' Implicit premise: Most people are not serial killers.

I This chapter is an adapted version of: Jansen, H., M. Dingemanse and I. Persoon (2009). Raadsels voor de argumentatietheorie. Het belang van de volgorde in de presentatie van enkelvoude argumentatie. In: W. Spooren, M. Onrust and J. Sanders (Eds.), Studies in Taalbeheersing 3 (pp. 163-174). Assen: Van Gorcum. We thank Ton van Haaften for his lucid comments. 
It should also be noted that the If...then sentence in this example is formulated in the subjunctive mood. Argumentation with an explicit If...then sentence in the subjunctive mood has the structure of reductio ad absurdum argumentation. ${ }^{2}$ Jansen (2007) has argued that reductio ad absurdum argumentation cannot be characterized on the basis of the inference license's specific pragmatic content (e.g., causality, analogy, sign - the pragmadialectical threefold), but has to be regarded as an argument's presentation mode. Arguments can also be presented in another mode, such as the one discussed earlier, in which the If...then sentence is an implicit premise (and is reconstructed in the indicative mood). Such an argument reads as follows:

I. Standpoint: The claim that people like killing is not true.

I.I Explicit premise: Most people are not serial killers.

I.I' Implicit premise: If most people are not serial killers, then it is not true that people like killing.

We will call this latter presentation mode 'standard presentation', which is merely meant to indicate that this is the usual way in which argumentation is presented in text books.

Of course, other presentation modes exist, but in this chapter we concentrate on the two modes discussed above. ${ }^{3}$ In particular we will discuss the problem that argumentation that appears causal in the presentation mode of reductio ad absurdum, appears symptomatic in the standard presentation (see also Jansen 2008, pp. 50-5I). Consider the previous example:

\section{Reductio ad absurdum presentation:}

I. The claim that people like killing is not true.

2 Jansen's collection of reductio ad absurdum arguments shows that when such an argument contains a descriptive/factual standpoint (as all the examples presented in this chapter do) it always has an If...then sentence with a subjunctive mood. Reductio ad absurdum arguments with normative standpoints can also have an If...then sentence with an indicative mood (van Wijk, 2008).

${ }^{3}$ Another way of presenting, for example, is leaving the standpoint implicit. Arguments can also be presented with various stylistic particulars, such as a reversed order of antecedent and consequent or a contraction of the antecedent by 'then' or 'otherwise'. 
I.I If people liked killing, then, as a causal consequence, most of us would be serial killers.

I.I $\quad$ Most people are not serial killers.

Standard presentation:

I. The claim that people like killing is not true.

I.I Most people are not serial killers.

I.I' If most people are not serial killers, then this indicates that it is not true that people like killing.

The central question of this chapter is: Why does the argumentation scheme of an argument seem to change when the argument's presentation mode is replaced by another mode? That is, how can it be possible that the argumentation scheme which an argument is based on is perceived differently when another presentation mode is used? With "perception of an argumentation scheme" we mean the impression that the argument conveys at first sight. We do not mean the qualifying of a scheme after careful analysis. To provide an answer to our question, we will first take a closer look at how the argumentation schemes of the causal and symptomatic types are described in pragma-dialectics, which is our theoretical framework. Next, we will try to explain why the type of argumentation scheme seems to change when a change in the presentation mode of an argument is made. Then we will examine the implications of our explanation and illustrate how this explanation is also applicable to other phenomena connected with the altering of an argument's presentation mode.

\subsection{Causal vs. symptomatic argumentation}

\subsection{Pragma-dialectical definitions}

Van Eemeren, Grootendorst and Snoeck Henkemans (2002, pp. 96 ff.) and Van Eemeren, Houtlosser and Snoeck Henkemans (2007) define argumentation which is based on a symptomatic relationship as argumentation that expresses a sign, a symptom or a distinguishing mark of what is claimed in the standpoint. An example is (Van Eemeren, Houtlosser and Snoeck Henkemans 2007, p. 154):

Bill must be an only child, because he is egocentric. (And egocentrism is characteristic of people who are an only child.) 
A 'reversed' variant of symptomatic argumentation also exists, in which the standpoint expresses a sign of what is stated in the argument:

Bill is very egocentric, because he is an only child.

It is the first variant, in which the argumentation expresses a sign of the standpoint that is regarded as the prototypical format of symptomatic argumentation.

In causal argumentation, a cause (means, instrument, etc.) is expressed as a reason based on which an effect is concluded in the standpoint. The standpoint is made acceptable by presenting the cause as a self-evident fact and the effect as inevitable (Garssen 1997, p. 19). An example is (Van Eemeren, Grootendorst and Snoeck Henkemans 2002, p. IOO):

Lydia must have weak eyes, because she is always reading in poor light. (And reading in poor light gives you weak eyes.)

Reading in poor light is the cause based on which a conclusion is made as to the effect of weak eyes. There is also a reversed, abductive, variant of causal argumentation, in which the standpoint expresses the cause and the argumentation the effect (ibid. p. IOI):

Lydia must have read a lot in poor light, because she has weak eyes.

In neither Van Eemeren, Grootendorst and Snoeck Henkemans (2002) nor Van Eemeren, Houtlosser and Snoeck Henkemans (2007) do we find any discussion about prototypical or non-prototypical variants of causal argumentation. Nevertheless, following the distinction that we have made with regard to symptomatic argumentation, we will consider causal argumentation in which the argumentation expresses the cause and the standpoint the effect, as the prototypical variant. The reversed variant we will call the non-prototypical one.

To sum up, in the pragma-dialectical theory, the causal and the symptomatic argumentation schemes are distinguished by their content. In a causal argumentation scheme a cause-effect connection between the argumentation and the standpoint is expressed. An arguer who makes such a connection in his argument suggests inevitability; namely that, in the event of the cause, the effect will automatically happen. In a symptomatic argumentation 
scheme, a connection of sign between the argumentation and the standpoint is expressed. In an argument such as this, an arguer suggests that if the sign is true, then the standpoint is true as well.

\subsubsection{A difficult distinction}

In the argumentation "Lydia must have weak eyes, because she is always reading in poor light" a causal connection is made between reading in poor light and eyes becoming weak. On the basis of this connection, the effect of weak eyes can be deduced from the cause, reading in poor light. But where does this causal relationship actually come from? After all, a causal relationship is not perceptible in itself. When we see that it is raining (cause) and we notice that the streets get wet (effect), we only see that one event or state of affairs is followed by another. The two events are perceived separately and the causal relationship between them is precisely that which is not visible. Apart from the fact that it is not visible, it is not a necessary relationship either, because it can easily be conceived that an event or state of affairs may be followed by an event other than expected. If it is raining the streets may very well stay dry, for instance if the rain is blocked by a shop's awning. Establishing a causal relationship is, therefore, not a matter of the senses. Language users merely possess inductively gathered knowledge that says that the one event is most often followed by the other event. On the basis of such knowledge it is expected that when one thing happens, another will happen too.

If causal relations are described as a regular correspondence between the occurrence of a cause and the occurrence of an effect, they resemble symptomatic relations. That is, the two events co-occur and belong together and, therefore, the occurrence of the one event can be regarded as a sign of the other, and vice versa. Rain often goes with wet streets and reading in poor light with weak eyes. In other words, it is a symptom of rain that it makes streets wet and it is a symptom of reading in poor light that it makes one's eyes weak. So, if there is a causal connection there is also a symptomatic connection, because of the regular co-occurrence of the two events.

Not only do causal relationships possess symptomatic characteristics but, turning it around, you can also say that (at least some) symptomatic relationships possess some kind of causality. Take Van Eemeren, Houtlosser and Snoeck Henkeman's (2007) example that Bill is very egocentric, because he is an only child. In the argument it is stated that Bill belongs to a class of people who are only children and will, therefore, possess the characteristic of ego- 
centrism. Why do we think that egocentrism is symptomatic of people who are only children? We do so because they do not have to share their toys with siblings and get all of their parent's attention, etc. Simply because there is a causal relationship between being an only child and having an egocentric character, egocentrism can be regarded as symptomatic of only children.

Having a closer look at the Bill example may cause severe doubt as to whether the relationship between standpoint and argumentation is of a symptomatic nature at all. However, we are not interested in deciding which argumentation scheme underlies an argument in essence. We are concerned with the affinity between causal and symptomatic argumentation schemes and with the fact that it appears to depend on an argument's presentation as to which scheme is prominent. We will argue that it is probably the argument's presentation mode that puts one scheme or the other to the fore and thereby influences the listener/reader's perception of it.

\subsection{The order of elements in the argument structure}

\subsection{Does the argument structure reflect the order of events in reality?}

In the introduction two presentation modes were distinguished: the standard presentation and the presentation mode of a reductio ad absurdum argument. An important difference between these two modes is that they present the order of events which are expressed in an argument - the order of cause and effect, or of the symptom and what it is a symptom of - in a different way. As a result, from the perspective of information structuring, the inference licenses expressed in both modes are opposite to each other. This is due to the fact that, from a logical point of view, both presentation modes are each other's counterpart. If the inference license in the standard presentation mode reads If $X$, then $Y$, it reads If $-Y$, then $-X$ in the reductio ad absurdum presentation mode. In our view, this is the reason why an argumentation scheme is perceived differently in another presentation mode. (It is true that the issue of whether the inference license contains negations or not may play a part as well, but that is subject to further research.)

Pander Maat and Degand (200I) concentrate on the order of the information in an inference. In causal argumentation, the order can either literally reflect the causal order in reality, or it can present it in a reversed way. The argument below (Pander Maat and Degand 200I, p. 222) describes causality in reality: 
It has rained continuously for two days. The tennis court will probably be unplayable.

The inference license of the argument reads: "If it has rained continuously for two days, the tennis court will probably be unplayable"; in other words: If [cause], then [effect]. Pander Maat and Degand consider this a "causality based epistemic relation" (an epistemic relation is, for example, the connection between argumentation and standpoint, as it is here). Because the causal order in the inference license (which they call "assumption") corresponds to the cause>effect order in reality, causality plays a role both in the 'real-world' domain and in the argumentative domain: "Causality-based inferences simply transpose a real world link into the inferential domain" (ibid.p. 224).

Pander Maat and Degand also distinguish "noncausal epistemic relations". In such relations, real-world causality is opposite to the causality as it is expressed in the inference license (as in an abductive argument) or is irrelevant (as in an argument based on a comparison):

the assumption behind abductive and other types of noncausal inference $\mathrm{i}[\mathrm{s}]$ no longer modeled on real-world causal links, although it may sometimes be based on real-world regularities. (ibid. p. 224)

In an abductive argument, a cause is deduced from an effect. The inference license that underlies such an argument reads If effect, then cause. Such an inference is 'non-iconic'; that is, it does not reflect the real-world causal pattern and, therefore, only exists through the speaker's mental activity. From this Pander Maat and Degand (ibid.) conclude that noncausal inferences exhibit a larger degree of speaker involvement than causality-based epistemic relations. Since our perspective is directed by a listener/reader's perception of an argument, we want to add that noncausal inferences require a larger degree of listener involvement as well. After all, the listener has to identify the underlying real-world causality herself. (This is something that Pander Maat and Degand do not say explicitly, but they may nevertheless have had this in mind as well.)

What does the foregoing imply for the If...then sentence in both the standard presentation mode and the reductio ad absurdum mode? It implies that if the If $X$, then $Y$ sentence reflects real-world causality, the If $-Y$, then $X$ sentence gives an abductive representation of causality, and vice versa. The reductio ad absurdum presentation of our example about serial killers in the 
introduction contains an If...then sentence that reflects real-world causality: liking killing causes killing. Therefore the argument is perceived as a causal one. The reformulated argument as an argument in the standard presentation contains an abductive inference license: being a serial killer is symptomatic of liking killing. In a presentation such as this there is no prominent causal relationship which immediately strikes the eye and the argument is perceived as a symptomatic one instead. But this may not be the whole story. In the next section we will discuss in more detail the influence that the order of information in an argument has.

\subsubsection{A further examination of argument structure}

In this section we demonstrate what the other consequences of altering the order of information presented in the antecedent and consequent of an inference license are. We do so by systematically reformulating instances of an argument expressed in the standard presentation mode as an argument in the reductio ad absurdum mode. (The preceding sections reflect the research outcome of working in the other direction, which was reformulating instances of arguments presented in the reductio ad absurdum mode as arguments in the standard presentation.) The following consequences were found: In some cases there was an altered argumentation scheme as well, but in others the argumentation became nonsensical. Our findings are presented below.

\section{Causal argumentation}

Causal argumentation in the standard presentation mode, with a standpoint in which the effect is expressed and an argumentation in which the cause is expressed, cannot be reformulated as reductio ad absurdum argumentation. This will be shown on the basis of the following example. The first item presents the argument in the standard presentation mode; the second (with an apostrophe) contains the reductio ad absurdum version:

(I) Eric will probably be fired, because he has been too late several times. (Garssen 1997, p. 209 [Our translation])

(') \# Eric will probably be fired, because if he were not fired, he would not have been too late several times.

The argument in the reductio ad absurdum presentation is confusing, because it is hard to work out the line of its reasoning. It seems to suggest that Eric 
has been too late deliberately, because he already knew that he was going to be fired, which does not make sense. The same effect is created by rewriting argument (2):

(2) I assume that Bert will not be fully compensated, because he was underinsured. (Garssen 1997, p. I72 [Our translation])

(2') \# I assume that Bert will not be fully compensated, because if he were fully compensated, he would not have been underinsured.

When presented as a reductio ad absurdum, the argument seems to suggest that Bert was underinsured on purpose, because he would not get full compensation anyway. The line of reasoning in the original presentation is, as it were, reversed in the reductio ad absurdum presentation mode, and this makes the argument nonsensical.

In our view, the reformulation problems discussed above are caused by the fact that the order of antecedent and consequent in the inference license of the standard presentation is opposite to the order in the reductio ad absurdum presentation. The order changes from real-world causality in the standard presentation to an abductive order in the reductio ad absurdum presentation mode. An abductive order does not seem natural in an If...then sentence; this may be because a sentence such as this suggests a causal order. The word 'antecedent' indicates that it presents the preceding element, whereas the word 'consequent' indicates that it presents the event that follows from the event which is presented in the antecedent: first the cause, then the effect. In the examples (I') and $\left(2^{\prime}\right)$ the order is from effect to cause, which obviously clashes with the suggested order of the If .. then formulation. However, this cannot be the entire explanation; the subjunctive mood also has something to do with it. After all, an indicative If...then sentence can indeed contain an abductive order, as is shown by "If the tennis court is unusable, it must have rained for two days". Nonetheless, since a modal element had to be added to this sentence (must have), it demonstrates that a causal order is preferable in such an If...then sentence. Why an abductive order is not only not favored but even impossible in a subjunctive If...then sentence, we have not examined yet.

To sum up, we conclude that the order of the elements in the inference license explains the nonsensicality of causal arguments that are reformulated as reductio ad absurdum arguments. An objection to this view could be that both examples ( $\left.\mathrm{I}^{\prime}\right)$ and ( $\left.\mathrm{2}^{\prime}\right)$ contain a prediction, and that this property might 
explain the observed phenomenon. However, the following example demonstrates that the problem of nonsensicality also arises when we reformulate an argument from a standpoint in which something is assumed. Such an argument can be nonsensical in the reductio ad absurdum presentation as well:

(3) Lydia must have weak eyes, because she is always reading in poor light. (Van Eemeren, Grootendorst and Snoeck Henkemans 2002, p. IOO)

(3') \# Lydia must have weak eyes, because if she did not have weak eyes, she would not always be reading in poor light.

The words "must have" indicate an assumption. The speaker assumes something about the present, namely that Lydia has weak eyes. In (3) it is argued that the cause "reading in poor light" entails the effect "weak eyes", but in (3) it seems as if Lydia is always reading in poor light for the simple reason that she has bad eyes.

It is also not true that standpoints in which an assumption is expressed cause the problem of nonsensicality. Other arguments with similar standpoints can yield an entirely normal argument in a reductio ad absurdum presentation, as is shown in example (4'):

(4) I assume that Frank has been ill, because he has lost weight substantially. (Garssen 1997, p. 209 [Our translation])

(4') I assume that Frank has been ill, because if he had not been ill, he would not have lost weight substantially.

This argument is completely acceptable in the reductio ad absurdum presentation. It perfectly fits in the following conversation:

A: I assume that Frank has been ill.

B: Why do you think that?

A: Well, otherwise he would not have lost weight so considerably.

We conclude that it is not the type of standpoint that explains the problem of nonsensicality, but the order of information which is presented in the antecedent and consequent of an If...then sentence. Example (4) represents the 'reversed' variant of causal argumentation described in section 2.I, which is the non-prototypical variant of causal argumentation. This variant has an abduc- 
tive structure: its line of reasoning goes from an observed effect, expressed in the argumentation, to a deduced cause, expressed in the standpoint. As we discussed in 3.I, the inference license of an abductive argument formulated in the standard presentation does not reflect real-world causality. However, if such an argument is reformulated as a reductio ad absurdum argument, the inference license takes on the cause>effect order, and thus expresses causality very clearly. After all, the If [effect: losing weight], then [cause: being ill] sentence in the argument presented in the standard way, changes into an If [non-cause: not being ill], then [non-effect: not losing weight] sentence in the reductio ad absurdum presentation. Therefore the reformulation of example (4) as (4') sounds completely normal. The same can be shown by reformulating the prototypical causal argument in (3) as an abductive (non-prototypical causal) argument in (3a) (by changing the premise and the standpoint). The reductio ad absurdum presentation of this argument also sounds perfectly normal:

(3a) Lydia must have read a lot with poor light, because she has weak eyes.

(3a') Lydia must have read a lot with poor light, because if she had not read a lot with poor light, she would not have weak eyes.

Since the If...then sentence of the reductio ad absurdum presentation in (3a') represents real-world order causality (not reading in poor light prevents one from getting weak eyes), it is a perfectly sensible argument.

The issue of the order of information presented in the inference license of an argument explains why causal argumentation with a standpoint containing a prediction becomes nonsensical when it is presented as a reductio ad absurdum argument. In a causal argument with a standpoint containing a prediction, the standpoint always expresses the effect and the argumentation the cause. "Eric will probably be fired" is an effect that is predicted on the basis of the cause of having been too late several times. In a reductio ad absurdum the effect is repeated in the antecedent of the If...then sentence. Although it is true that the effect is put in the negative in the antecedent - "Eric will probably be fired" is repeated in the antecedent as "If Eric were not fired" - that is not relevant to the claim that we want to make. That is, if the effect that is expressed in the standpoint is repeated in the antecedent of the inference license, the If...then sentence takes on an effect>cause structure. As we have shown in this section, such a structure makes a reductio ad absurdum argument nonsensical. 


\section{Symptomatic argumentation}

With regard to one of the subtypes of symptomatic argumentation, i.e. argumentation that is based on a definition, there is no problem in reformulating it as a reductio ad absurdum argument. Consider example (5'):

(5) Chickens are not birds, because they don't fly south in winter.

(5') Chickens are not birds, because if they were birds, they would fly south in winter. (Example based on Fogelin and Sinnott-Armstrong 199I, p. 132)

Taking into account the explanation of the reformulation problems argued for in the preceding section, it is not very surprising that $\left(5^{\prime}\right)$ is not problematic. In argumentation that is based on a definition, the time aspect that is needed for the suggestion of causality, however little it may be, is absent. As a consequence, a reformulation of the argument does not yield a reversed temporal order that clashes with the suggested If [cause: earlier event], then [effect: later event] order in a reductio ad absurdum argument.

Reformulation of common symptomatic argumentation, based on a sign, is also unproblematic. Illustrative is $\left(6^{\prime}\right)$ :

(6) Carla likes traveling, because she is a travel guide. (Garssen I997, p. 206 [Our translation])

(6') Carla likes traveling, because if she did not like traveling, she would not be a travel guide.

However, example ( 7 ') proves to be problematic:

(7) Our car is really solid, because it is French-made. (Garssen 1997, p. 206 [Our translation])

(7') \# Our car is really solid, because if it were not, it would not be Frenchmade.

( $\left.7^{\prime}\right)$ poses a problem because the characteristic of solidness now seems to imply the brand, instead of the other way around, as is meant in the argument. This problem can again be explained on the basis of the issue of the order of information presented in the If...then sentence. In the symptomatic argumentation in (7) an underlying causality can be observed: a French make brings about solid cars. If symptomatic argumentation with underlying causality has 
a standpoint in which the effect is expressed, it conveys the structure of causal argumentation which has a standpoint in which the effect is expressed and an argument in which the cause is expressed (prototypical causal argumentation). Therefore, this kind of symptomatic argumentation becomes nonsensical in the reductio ad absurdum presentation mode, in the same way as prototypical causal argumentation does. After all, in such an argument the standpoint expresses the later event and the argumentation the earlier event, and this provides the If... then sentence of the reductio ad absurdum argument with a 'later event>earlier event' structure (because the antecedent repeats the standpoint).

On closer inspection causality underlies example (6) as well, as we can see by making a reversed version of it. If we do this, the abductive structure (effect>cause) of the original argument's If...then sentence will be changed into a causal structure (cause $\mathrm{effect}$ ) in the new argument's If... then sentence. The original argument runs: "Carla likes traveling, because she is a travel guide", which makes the inference license: Being a travel guide points to liking traveling. The reformulated reversed argument runs the other way around: "Carla must be a travel guide, because she likes traveling", which transforms the inference license into a causal structure: Liking to travel causes a desire to become a travel guide. The argument now behaves as a prototypical causal argument, which means a reductio ad absurdum presentation of the argument is problematic:

(6a) Carla must be a travel guide, because she likes traveling.

(6a') \# Carla must be a travel guide, because if she were not, she would not like traveling.

Now the reductio ad absurdum argument suggests that Carla likes traveling because she is a travel guide, which is opposite to what is meant in the original argument (that Carla is a travel guide because of her liking of traveling). This can be explained by the fact that a symptomatic argument with an underlying causality and a standpoint in which the later event - the effect - is expressed, has the structure of a prototypical causal argument. Both cannot be presented as reductio ad absurdum arguments. ${ }^{4}$

${ }^{4}$ Jansen (2007b) discusses the role of the order with regard to symptomatic argumentation that is based on a counterexample. 


\subsection{Conclusion}

We have argued that the order of the elements in the inference license (the implicit or explicit - If...then sentence) of an argument influences (I) the perception of the argumentation scheme that is expressed in an argument and (2) whether or not it is possible to present such an argument in the presentation mode of reductio ad absurdum. The two presentation modes discussed in this chapter, the standard presentation and the presentation as a reductio ad absurdum argument, contain inference licenses that are each other's counterpart. An If $X$, then $Y$ inference license in an argument in a standard presentation mode, takes on an If $-Y$, then $-X$ structure when the argument is reformulated as a reductio ad absurdum argument.

The difference with regard to the order of events expressed in the If...then sentence explains the phenomenon that a reductio ad absurdum argument which looks causal, seems to be symptomatic when it is reformulated as an argument with a standard presentation. Causal reductio ad absurdum arguments have an inference license that reads: If [cause], then [effect]. The inference license takes on an abductive structures when such an argument is reformulated as an argument in a standard presentation, and that is why the impression of a symptomatic argument is created.

The altered argumentation scheme is not an isolated phenomenon; this has been demonstrated by reformulating arguments and, in that way, changing their presentation mode the other way around. When causal arguments presented in a standard mode which have an abductive inference license (non-prototypical causal arguments) are reformulated as reductio ad absurdum arguments, their causality becomes much more apparent; after all, an abductive inference license with an If [effect], then [cause] structure, takes on an If [non-cause], then [non-effect] structure in the other presentation mode. That a reductio ad absurdum presentation conveys causality better than the standard presentation also holds for symptomatic arguments in the standard presentation which possess an underlying causality and a standpoint in which the earlier event is expressed. Since these arguments contain an abductive inference license in the standard presentation,

\footnotetext{
${ }^{5}$ The abductive variant of a causal argument is always the non-prototypical version of a causal argument. With regard to symptomatic argumentation with an underlying causality, the way the causality is structured (in a cause effect or an abductive way) bears no relation as to whether the argument is the prototypical version or not.
} 
they behave in the same way as causal arguments which have an abductive structure.

The difference with regard to the order of events expressed in the If...then sentence also explains the following phenomenon. This phenomenon concerns arguments in the standard presentation mode that are either prototypically causal or that are symptomatic with an underlying causal structure and a standpoint that expresses the effect. Since these arguments have a standpoint that expresses an event or state of affairs that is preceded by the event or state of affairs mentioned in the argumentation (standpoint: 'later event', premise: 'earlier event'), they become nonsensical when they are reformulated as reductio ad absurdum arguments. The reason is that the realworld order of cause>effect, which is the order of the inference license in the standard presentation, changes into an abductive order in the reductio ad absurdum presentation, and thus clashes with the suggested causal interpretation of an If...then sentence in a subjunctive mood. Presumably such an If...then sentence suggests an order that follows the structure of causality in the real world: If [earlier event], then [later event].

In our view, our findings have the following implications. Apparently, both causal arguments on the one hand, and symptomatic arguments with underlying causality and a standpoint that expresses the later event on the other, have an abductive variant. On which argumentation scheme an argument is based in essence is a question that we do not find very interesting. What we do find interesting is that a speaker/writer can influence her listener/reader's perception of the type of argument that she makes use of. As a causal argument is more compelling than an argument based on a symptomatic relationship, the speaker/writer should choose the presentation mode for her argument that presents it as a causal one. The speaker/writer has this choice between the two presentation modes when the standpoint expresses an earlier event (that precedes the event mentioned in the argumentation). In that case, the reductio ad absurdum presentation mode is the preferred choice. Be that as it may, if an argument appeals to a well-known causality, such as frost causing a frozen pool, the choice for the one or the other presentation mode is less pressing. However, if the causality is less striking, a presentation mode with an inference license presenting 'earlier event>later event' enhances an argument's causality. 


\section{References}

Eemeren, F.H. van, R. Grootendorst and A.F. Snoeck Henkemans (2002). Argumentation. Analysis, Evaluation, Presentation. Mahwah, NJ: Erlbaum.

Eemeren, F.H. van, P. Houtlosser and A.F. Snoeck Henkemans (2007). Argumentative Indicators in Discourse. A Pragma-Dialectical Study. Dordrecht: Springer.

Fogelin, R. J. and W. Sinnott-Armstrong (199I). Understanding Arguments. An Introduction to Informal Logic. ( ${ }^{\text {th }}$ ed.) San Diego etc.: Harcourt Brace Jovanovich.

Garssen, B.J. (1997). Argumentatieschema's in pragma-dialectisch perspectief. Een theoretisch en empirisch onderzoek. Dordrecht: Foris Publications.

Jansen, H. (2007a). Refuting a Standpoint by Appealing to its Outcomes: Reductio ad absurdum vs. Argument from Consequences. Informal Logic 27 (3), 249-266.

Jansen, H. (2007b). Strategic Use of Reductio ad absurdum. In: F.H. van Eemeren, J.A. Blair, C.A. Willard and B. Garssen (Eds.), Proceedings of the sixth ISSA Conference on Argumentation, Amsterdam 27-30 June 2006 (pp. 70I-704). Amsterdam: Sic Sat.

Jansen, H. (2008). Argument Form and Rhetorical Effectiveness: the Presentation of Refutational Analogy. In: F.H. van Eemeren, D.C. Williams and I.Z. Zagar (Eds.), Understanding Argumentation. Work in Progress (pp. 47-54). Amsterdam: Sic Sat Rozenberg.

Pander Maat, H. and L. Degand (200I). Scaling Causal Relations and Connectives in Terms of Speaker Involvement. Cognitive Linguistics I2 (3), 2II-245.

Van Wijk, E. (2008). En dat is absurd! Een corpusonderzoek naar de vorm-en formuleringskenmerken van de reductio ad absurdum. Undergraduate Thesis Leiden. 


\title{
9 Professionalizing Speech Production Changes in 15 Years of Ministerial Speeches
}

\author{
JAAP DE JONG AND BAS ANDEWEG
}

\section{I Introduction}

"Yes, I agree with that" Ien Dales (Dutch Minister of the Interior, 1989-1994) said just after citing a passage from her speech text thus insinuating the text was not her own. Such slip-ups illustrate the distance between the speaker and the speechwriter in those times. Such a slip is rare nowadays. ${ }^{\mathrm{I}}$

Every Minister, State Secretary or other high official in the Netherlands delivers dozens of speeches a year. By making these speeches, they are out to establish a base for their policies and to improve their relations with the electorate. The past few years ministerial speechwriting has shown significant changes. Some fifteen years ago most speeches were written by government employees, or policy advisors - experts in the policy field. However ten years ago a new profession entered the offices of the departments: the speechwriter (Andeweg and De Jong 2003, 2004; Snoek 200I). This change can be characterized as a form of professionalization. The speechwriters themselves have described this development based on both their personal experiences and on the stories that circulated around the various departments (Snoek 200I). There was also some interest in the ministerial changes from academia; especially interest in the introduction (Andeweg and De Jong 2003, 2004) and the closing of these new speeches (De Jong and Andeweg 2008).

I The authors thank their students Marissa Driesprong, Eva Helder, Mieke Pulles and Martijn Wackers for their useful analyses and interviews and inspiring cooperation in this project. With many thanks to speechwriter Suzanne Levy and colleague Maarten van Leeuwen for their useful comments on an earlier version of this article that was published in Tijdschrift voor Taalbeheersing 4 (2008). 
Recently both the Dutch ministerial organizations and the (informal) speechwriting association expressed the need for an evaluation of the quality of the contemporary ministerial speeches. One way to assess the quality of the speeches is by looking back. Such a historical analysis can illuminate our perspective on the existing properties of modern speeches. What is still lacking however is a factual comparison of recent speech texts with the texts that originated in the eighties written by civil servants.

Therefore the main question in this research deals with the main textual differences between speeches of fifteen years ago and those written today. The manner in which these speeches are presented, the actio, will be left out of consideration.

\subsection{Speechwriting in The Hague}

In the I980s, speeches were not written by specially appointed speechwriters, but by the civil servants themselves. ${ }^{2}$ The assumption that it was often the youngest staff member that had to perform this task (Geel 2002) is refuted by the civil servants involved "it was part of the duties of a civil servant." From the beginning of the I990s men and women were appointed with the explicit task to write speeches. Besides their speechwriting task they also performed other duties like writing columns, prefaces and introductions. In 200I, almost all (95\%) governmental speechwriters in The Hague had a University Masters degree (Andeweg and De Jong 2004). Only fifteen percent had done a special communications major in Rhetoric or Journalism; most speechwriters (55\%) had some journalistic experience although four had no such experience at all. Currently there is no speechwriting training in the Netherlands. Most speechwriters said that they learned their skills from their more experienced colleagues or the head of the communication department. From the beginning of the nineties special courses are offered to newly appointed speechworkers.

\footnotetext{
${ }^{2}$ Much of the historical information stems from interviews we held in summer 2008 amongst civil servants who wrote speeches in the eighties and nineties of the last century. The structured interviews were organized with a fixed set of questions. With many thanks to the civil servants of ecs: Ype Akkerman, Roelco Offerein, R. Tiggelman, Frank Willemsen and the present speechwriter Suzanne Levy, and the civil servants of the Dutch Ministry of the Interior Renée Broekmeulen, Auke de Vries and the present speechwriters Luc van Koppen and Bauco van der Wal.
} 
There are many accounts of how speeches were written. Some of the civil servants involved say that sometimes the opening and closing phrases "Ladies and gentlemen" and "Thank you" were added to an existing document and then sent to the minister as a formal speech (Mulder 1995). The interviewees in our research could not really corroborate that image of the situation. They found it somewhat exaggerated but not completely beside the truth. They perceived it as a 'safe' way of speechwriting; that way the speeches would not contain incorrect information.

This view on the process of speechmaking was reinforced by the custom of finalizing a document by putting one's initials ('paraaf') on it ('a culture of parafen'): every supervisor in the organization had to finalize the document themselves. "At the Dutch Ministry of the Interior this bureaucratic process was maintained very strictly; every supervisor had their own color for writing their initials on the document" often demanding supplementary information or comments that sometimes were inconsistent with former comments (see also Janssen I99I; Van der Mast 1999). The result was - according the civil servants involved - a very long and frustrating writing process: "it did not contribute to the quality of the speeches. The speeches became dry because so many people wanted their own opinions reflected in it". In other words: "Until the last possible moment work was done on the document; sometimes even till the essence of the message was lost" (Kagie 1992, p. 9).

Officially the same culture of finalizing documents exists today. The difference between then (the end of the 1980s) and now is that speechwriters today - especially in the case of occasional speeches - employ 'backdoor methods' to discuss speech drafts with the speaker at an earlier stage, resulting in a kind of official approval before all the other supervisors in the organizational line approve the document. In practice, the level of contact between speechwriters and speakers varies according to the speaker.

\subsection{Plan of research}

Every year hundreds of speeches are delivered by Dutch officials. Whether those speeches are different from those fifteen years ago is the question in this chapter. Analysis of the speeches is a way to answer that question. In this chapter, we will first discuss the way the speeches were selected, after which the analyzing method is described. 


\subsection{Assembling the speech corpora}

Two ministries were selected from the thirteen ministries that make up Dutch government: the Ministry of Education, Culture and Science (ECS) and the Ministry of the Interior (MI). By doing so, we could profit from speech analysis done in earlier research commissioned by these ministries (see for the ECS research De Jong et al. 2003; and for the MI research De Jong et al. 2004). The selection of speeches in this earlier research was a blueprint for the selection of older speeches of fifteen years ago. The result was that there would be a small difference in the number of speeches selected for each ministry (see table 9.I), but that small difference was outweighed by the advantage of using earlier analysis work. The selection of the fifteen-year period was pragmatic as well: (easy) access to speech archives only dates back to 1988. In the selection of the speeches, we allowed for the difference in policy and occasional speeches. ${ }^{3}$ Working this way, comparable sets of speeches were selected for the 1988-1989 period and the 20032004 period (see table 9.I).

TABLE 9.I SELECTION OF SPEECHES

\begin{tabular}{l|cc|cc} 
& \multicolumn{2}{|c|}{ Policy speeches } & \multicolumn{2}{c}{ Occasional speeches } \\
\hline & ECS & MI & ECS & MI \\
$1988 / 9[\mathrm{~N}=33]$ & {$[\mathrm{N}=9]$} & {$[\mathrm{N}=\mathrm{II}]$} & {$[\mathrm{N}=8]$} & {$[\mathrm{N}=5]$} \\
$2003 / 4[\mathrm{~N}=33]$ & {$[\mathrm{N}=9]$} & {$[\mathrm{N}=\mathrm{II}]$} & {$[\mathrm{N}=8]$} & {$[\mathrm{N}=5]$}
\end{tabular}

ECS: Ministry of Education, Culture and Science

MI: Ministry of the Interior

3 The 'Culture' sub department was an addition (reorganization) to the Ecs department in 1994, so the 1988/9 Culture speeches were not present in the ECs archives. To obtain a representative corpus, the $1988 / 9$ Culture speeches were selected from the Staatscourant (Government Gazette, the formal communication medium of the Dutch Government) of 1988. 


\subsubsection{Rhetorical analysis}

How different are speeches written in the eighties from contemporary speeches? A plethora of topical and textual elements presents itself. Our approach was threefold:

I. Which text characteristics are considered to be important by the speechwriters?

2. Which models of analysis are available?

3. Which methods are at our disposal to quantify text differences?

\section{What are important speech characteristics?}

Andeweg and De Jong (2004) report that speechwriters consider the introduction and closing essential and important parts of the speech, in which they can excel. That research shows that speechwriters perceive style characteristics such as extracts quoted by the press (soundbites) and concrete examples as important but difficult writing techniques. Also textual aspects like speech length, sentence length, humour, anecdotes and the appropriate addressing of the target audience are named as important factors to be considered by the speechwriter. A good message is considered to be of the utmost importance; speechwriters complain that it is often missing in the input they get from the policy departments. "Without proper message, no proper speech" (Levy 2008, p. 4). Unfortunately, content qualities could not be studied within the context of the present research.

\section{Rhetorical analysis of ministerial speeches}

To study the differences between the introductions and closings of speeches, we made use of earlier developed analysis models: the exordium model (Andeweg and De Jong 2004; Van de Mieroop, De Jong and Andeweg, 2008; see table 9.2) and the peroration model (Andeweg and De Jong 2006, see table 9.3). Both models are based on advice literature from classical heritage and modern writings. ${ }^{4}$

The summarized techniques from these literature studies are classified by the classic-rhetorical function model of attentum parare (making the audience attentive), benevolum parare (making the audience benevolent) and

${ }^{4}$ The empirical basis of the models is an object of research: Andeweg, De Jong and Hoeken (1998); Andeweg, De Jong and Wackers (2008). 
TABLE 9.2 SIMPLIFIED DESCRIPTIVE EXORDIUM MODEL (ANDEWEG AND DE JONG 2OO3), OVERVIEW OF FUNCTIONS AND SUPPORTING TECHNIQUES IN THE INTRODUCTION OF THE SPEECH

Function - making attentive (attentum parare): [classical techniques] Stress the importance of the subject for the audience; Literally ask for attention; Promise to be brief; Humor (Present something wittily); Apostrophe (Address third parties); Introduce imaginary person; Historic example; Comparison and metaphor; Irony; Puns; [modern techniques] Anecdote; Make a challenging statement; Quote; Question; Current point of view; Salutation; Riddle and paradox; Example; Proverb

Function - making benevolent (benevolum parare): [classical techniques] Present oneself as credible; Praise one's own side; Make the impression to be improvising; Take away prejudices against speaker; Take the underdog position; Depreciate one's opponent; Praise suspect characteristics; Praising and making compliments; Stress common points; Alarm or reassure the audience; Mention positive sides to the subject; Shift responsibility for unfavourable matter onto someone else; Ask for understanding for inadequate speech; Praise a praiseworthy person; [modern techniques] Thank introductory speaker

Function - making understanding possible (docilem parare): [classical techniques] Present the essence of the matter (propositio); Announce the main points (partitio); Briefly present historical background of the matter (narratio). [modern techniques] Mention the subject; Present definition; Speech routine statements; From general to specific (funnel opening); transition to kernel of speech (bridge)

docilem parare (enabling the audience to follow, or understand, the key points of the presentation). The models contain a large number of classical and modern techniques that are at the disposal of the speaker; classified by the rhetorical function of the technique. These techniques can represent for instance a conceptual move (topical techniques like the Appeal to Pity in the closing) or a figure of speech (e.g., a metaphor; a question; a repetition). The original models have been simplified in order to apply them to this large speech corpus. Some of the techniques that did not seem to be applicable were discarded (e.g., the introduction techniques Pantomime, Image and sound effects). 
TABLE 9.3 SIMPLIFIED DESCRIPTIVE PERORATIO MODEL (ANDEWEG AND DE JONG 2006:I59), OVERVIEW OF FUNCTIONS AND SUPPORTING TECHNIQUES IN THE CLOSING OF THE SPEECH*

Function - getting attention (attentum parare): [no classical technique advised]; [Modern techniques] Announcing the close.

Function - evoking emotions (affectus; benevolum parare): [classical techniques]Appeal to pity (commiseratio); Praising one's own side; Anticipating the opponent's moves; Arousing negative feelings (indignatio); Suppressing positive feelings towards the opponent; Extenuating circumstances/excuses; Alarming the audience; [Modern techniques] Inciting audience to action; Word of thanks; Congratulations; Encouragement; Flattering, Praising and thanking; Cooperation/feeling of togetherness

Function - going back over main issues (recapitulatio; docilem parare): [classical techniques] Summary [Modern techniques] Circular technique; Closing speech

* The stylistic devices that are commonly used to excite the audience are not treated as part of the closing but as figures of speech of the whole text.

Finally, the figures of speech are analysed in the complete speech text (not only those in the introduction and closing). These figures of speech are part of the former models or are mentioned by the speechwriters as having a rhetorical effect. The starting point of the current list of figures of speech was the publication of Braet (2007). Table 9.4 gives an overview of the thirty-six figures of speech that were included in the research.

\section{TABLE 9.4 OVERVIEW FIGURES OF STYLE IN ANALYSIS}

Addressing; Amplification; Anecdote; Antitheses; Anticipation; Chiasm; Quotation; Climax; Complex sentence; Contrast; Dubitation; Ellipsis; Enumeration; Euphemism; Exclamation; Repetition figure; Humor; Hyperbole; Inversion; Irony; Litotes; Metaphor; Metonymy; Paradox; Preterition; Rhyme; Soundbite; Proverb; Synonym; Expression/saying; Understatement; Example; Prophesy; Question; Pun; Self correction. 


\section{Methods: tagging and counting}

The selected speeches in the corpus - only available on paper - were scanned and through optical text recognition software and transformed into digital text files. Next, the speeches were divided amongst four trained analysts, who, independently from each other, read a part of the total number of speeches; they searched for occurrences of rhetorical techniques described in the three models. The speeches were divided evenly between the analysts on the basis of period (old-new) and genre (occasional-policy). The analysts were divided into two teams, corresponding with the two ministries involved. Every occurrence of a technique was tagged by using ATLAS.ti software. In total 5500 text fragments were tagged. The purpose of dividing the speeches evenly was to reinforce the reliability of the research: the speeches within each sub corpus (1988/9 vs. 2003/4; occasional vs. policy) were analysed by four researchers. That way the idiosyncrasies of the individual analysts were distributed evenly. This distribution was not completely achieved in the third division (Ministry of ECS vs. Ministry of the Interior), because the teams were split between those ministries. So the speeches of ministries were only analysed by two instead of four researchers. ${ }^{5}$

First, the frequency of the observed rhetorical techniques was computed. In the analysis of the techniques in the introduction the relative frequency was computed, instead of the absolute frequency: a rhetorical technique that was used more than once in the introduction or the closing was counted as one occurrence. This way the resulting figures provide a better answer to the question of how common the use of a technique is in a speech introduction or closing (see also Andeweg and De Jong 2006).

The whole speech text (including introduction and closing) was examined for occurrences of the relevant figures of speech (see table 9.4). Here too the frequency was established and related to the length of the speech (total number of words). That way we computed the occurrence of a particular figure of speech per IOoo words. Through statistical procedures (ANOVA - SPSS) we ascertained whether or not the difference in occurrence between the sub corpora was significant.

5 A repeated analysis of (part of) the speeches to compute reliability figures (Cohen's Kappa) was unfeasible due to time constraints. 


\subsection{Results}

What are the textual characteristics of the ministerial speeches from the nineteen eighties and those today? In this section we present the characteristics quantitatively. The techniques that stand out because they are substantially differently deployed or elaborated will be described in more detail.

\subsection{The length of the speech}

The total corpus consists of 66 speeches. Table 9.5 presents an overview of the average length of the speeches in the corpus. Policy speeches (mean 2058 words; sd IOO5) are substantially longer $(\mathrm{F}(\mathrm{I}, 64)=2 \mathrm{I} .220 \mathrm{p}<$.0OI) than the occasional speeches (II2O words; sd 313).

TABLE 9.5 MEAN LENGTH OF THE SPEECHES (IN WORDS) AND INTRODUCTION/CLOSING (PERCENTAGE)

\begin{tabular}{l|cc|lc|ll} 
& \multicolumn{2}{|c|}{ Speech length (words) } & \multicolumn{2}{c}{ Length intro (\%)* } & \multicolumn{2}{c}{ Length closing (\%)* } \\
\hline & I988/9 & $2003 / 4$ & I988/9 & $2003 / 4$ & I988/9 & $2003 / 4$ \\
\hline All speeches & I870 & I5O7 & I5.9 & 22.2 & I2.3 & I0.0 \\
Policy speeches & 2384 & I732 & I4.0 & I9.4 & II.7 & 8.9 \\
Occasional speeches & IO79 & II6I & I8.8 & 26.6 & I3.3 & II.7
\end{tabular}

* Length intro/closing: percentage of length total speech

The numbers in the table suggest that in general the length of the speech decreases through time. That difference is statistically speaking non-significant $\left(\mathrm{F}(\mathrm{I}, 64)=2.589 \mathrm{p}=. \mathrm{I} \mathrm{I}_{3}\right)$. However, when we analyse the results per speech category the difference in length between the old and new policy speeches is found to be substantial $(\mathrm{F}(\mathrm{I}, 38)=4.583 \mathrm{p}<.05)$ : generally speaking, the more recent policy speeches are shorter; this difference is not observable in the occasional speech sub corpus. ${ }^{6}$

A similar difference can be found when we look at the (relative)

\footnotetext{
${ }^{6}$ The differences between the individual ministries with regard to the introduction of the speeches are substantial $(\mathrm{F}(\mathrm{I}, 64)=35.777 \mathrm{p}<$.00I $)$ : the average introduction at the MI speeches is II.7 \% of the total speech (sd 8.8) whereas those of the Ministry of ECS were $26 \%$ (sd I0.5). Apparently the idea on how such an element of a speech should be defined differs between the ministries.
} 
length of the introduction and closing in the speeches in table 9.5. Here too the differences between the policy speeches ( $\mathrm{m} \mathrm{I6.7 \%}$; sd II.I) and the occasional speeches (m 22.7\%; sd I2.6\%) are substantial $(\mathrm{F}(\mathrm{I}, 64)=4.133$ $\mathrm{p}<.05)$. Generally the relative length of the introduction is longer in the newer speeches $(\mathrm{F}(\mathrm{I}, 64)=4.827 \mathrm{p}<.05)$. The relative length of the closing stayed approximately the same. It was $12.3 \%$ of the total length of the speech falling to $10 \%$ in the new millennium; the difference is non significant $(\mathrm{F}(\mathrm{I}, 64)=\mathrm{I}, 84 \mathrm{O} \mathrm{P}=. \mathrm{I} 8 \mathrm{O})$.

\section{Sentence length}

The average sentence length in the speeches varies form Io words per sentence to 29 words per sentence per speech. ${ }^{7}$ The sentences in the $1988 / 9$ corpus (I8.7 words) are on average substantially longer $(\mathrm{F}(\mathrm{I}, 64)=\mathrm{I} 4.92 \mathrm{I} \mathrm{p}<. .00 \mathrm{I})$ than those in the 2003/4 corpus (I5.8 words). The same holds true for the period differences between the genres. In general there is no difference in sentence length between policy speeches and occasional speeches. It appears that sentence length and speech length are related $(\mathrm{r} .27 \mathrm{p}<.05)$ : longer speeches often have a longer average sentence length.

\subsubsection{The introductions of ministerial speeches}

Which functions are realized in the introduction of the speeches? We interpret the occurrence of rhetorical techniques as a sign of realizing one of the central introduction functions (Attentum parare, Benevolum parare and Docilem parare). Table 9.6 presents an overview of the functions that were realised in the speeches. ${ }^{8}$

\footnotetext{
${ }^{7}$ The average sentence length was computed using the program Text Analyser 2.0 www.writeitpro.co.uk.

${ }^{8}$ When more of the same introduction techniques were observed in the same speech introduction, they were counted only once in the function overview. The reasoning for this was that a single occurrence of an attention technique (e.g., Pun) in a speech introduction implicates that the corresponding (attentum parare) function is realised.
} 
TABLE 9.6 FUNCTIONS IN THE INTRODUCTION

\begin{tabular}{l|l|l|l|l|l} 
& & N & <2 functions & 2 functions & 3 functions \\
\hline All speeches & I988/9 & 33 & 5 & I2 & I6 \\
& $2003 / 4$ & 33 & 2 & I6 & I5 \\
\hline Policy speeches & $1988 / 9$ & 20 & I & 7 & I2 \\
& $2003 / 4$ & 20 & 0 & 9 & II \\
\hline Occasional speeches & $1983 / 4$ & I3 & 4 & 5 & 4 \\
& $2003 / 4$ & I3 & 2 & 7 & 4
\end{tabular}

$<2$ functions: no functions or only $\mathrm{A}$ (ttentum) or $\mathrm{B}$ (enevolum) or $\mathrm{D}$ (ocilem)

2 functions: $\mathrm{AB} ; \mathrm{AD} ; \mathrm{BD}$

3 functions: $\mathrm{ABD}$

The analysis of the data in table 9.6 shows that in the introduction of the 1988/9 speeches a comparable number of functions were realized as in the $2003 / 4$ corpus $\left.\left(\mathrm{F}_{\mathrm{I}}, 62\right)=0.266 \mathrm{p}=.608\right)$. No substantial period differences are evident in the individual genres. ${ }^{9}$ In general it appears that there are more functions realized in the introduction of policy speeches than in occasional speeches $(\mathrm{F}(\mathrm{I}, 64)=9 . \mathrm{I} 43 \mathrm{P}<.05)$. Which techniques are used to realize those principle functions of the introduction?

\section{Attentum techniques}

Table 9.7 presents an overview of the observed attentum techniques in the introduction (organized by frequency in the $1988 / 9$ corpus). A speech introduction contains nearly always a Salutation. The other introduction techniques are less frequent. Metaphor and Question can be observed in well over $40 \%$ of the $2003 / 4$ speeches; the other techniques are only found in I out of 4 speeches (or even fewer).

Table 9.7 shows that some of the introduction techniques occurred significantly more often in the 2003/4 corpus than in the 1988/9 corpus: Example, Anecdote and Irony. We will discuss the first two techniques.

\footnotetext{
${ }^{9}$ In the introductions of the ECS speeches more rhetorical functions are realized than in the MI speeches $(\mathrm{F}(\mathrm{I}, 64)=\mathrm{I} 4.966 \mathrm{p}<.00 \mathrm{I})$.
} 
TABLE 9.7 ATTENTUM TECHNIQUES IN INTRODUCTION (PERCENTAGE SPEECHES IN WHICH THE TECHNIQUE OCCURS)

\begin{tabular}{|c|c|c|c|c|c|c|}
\hline \multirow[b]{2}{*}{ Period } & \multicolumn{2}{|c|}{ All speeches } & \multicolumn{2}{|c|}{ Policy } & \multicolumn{2}{|c|}{ Occasional } \\
\hline & $1988 / 9$ & $2003 / 4$ & $1988 / 9$ & $2003 / 4$ & $1988 / 9$ & $2003 / 4$ \\
\hline $\mathrm{N}$ & 33 & 33 & 20 & 20 & $\mathrm{I} 3$ & $\mathrm{I} 3$ \\
\hline Salutation & 9I & 9I & 90 & 90 & 92 & 92 \\
\hline Current point of view & 24 & 24 & 30 & 20 & I5 & $3 \mathrm{I}$ \\
\hline Metaphor & $2 \mathrm{I}$ & 42 & 25 & 50 & 15 & $3 \mathrm{I}$ \\
\hline Question & $2 \mathrm{I}$ & 42 & 30 & 45 & 8 & 38 \\
\hline Pun & 15 & 6 & IO & 5 & 23 & 8 \\
\hline Humor & $\mathrm{I} 2$ & 15 & 5 & IO & 23 & 23 \\
\hline Quote & 12 & 24 & IO & 15 & 15 & 38 \\
\hline Example & $6 \mathrm{x}$ & $27 y$ & IO & 20 & ox & $38 y$ \\
\hline Anecdote & ox & $27 y$ & ox & $30 y$ & o & 23 \\
\hline Irony & ox & I5y & $\mathrm{O}$ & I5 & $\mathrm{o}$ & 15 \\
\hline
\end{tabular}

* $x y$ : row difference within one category is significant $\mathrm{p}<.05(\mathrm{~F}>5)$

* introduction techniques which occurred in less than $3 \%$ of the old or new speeches are omitted from this overview

Example. An example (exemplum) is a topical, often narrative technique which can be used to concretize an abstract concept. It can also be used to rhetorically enlarge parts of the message (amplification): to put them more in the centre of the attention of the listener. Examples in the introductions of the 1988/9 corpus were only observed in two policy speeches; the language is noticeably formal and not very inspiring. In the 2003/4 corpus there are more and more elaborated instances of this style technique:

If a butcher wants his customers to return to his shop, then he has to be able to answer the question whether his meat is BSE free and how he can guarantee that. And for those of us who do not cook: when we buy a new product at the butcher's we want to know from him how to prepare it. [Speech 28; npi ${ }^{\mathrm{IO}}$ ]

Io We use two characters and one digit to refer to the specific speech sub corpus. First character: $\mathrm{N}(\mathrm{ew} ; 2003 / 4)$ or $\mathrm{O}(\mathrm{ld} ; \mathrm{19} 88 / 9)$; second character concerns the genre: $\mathrm{P}($ olicy) or $\mathrm{O}$ (occasional); the digit refers to the department: $\mathrm{I}=\mathrm{ECS}, 2=\mathrm{MI}$. 
Anecdote. The anecdote is a short, witty and complete story that is presented in a lively and appealing way (Andeweg and De Jong 2006). The speechwriters of the 1988/9 corpus did not appear to use this rhetorical technique. In the introductions of the 2003/4 corpus there is more to enjoy. The anecdotes often have a fresh quality and a personal quality both in occasional speeches and in policy speeches:

Moving to a new home is always a case of selection. What do you take with you and what stays behind. But I did not hesitate for a moment about the necessity of one particular item when I moved to the new office in Zoetermeer: my card-index box had to come! In my former job I was often laughed at: an old-fashioned card box. All addresses where at that time already - up to date - in a database. I had a bet with a colleague: who could find an address faster: he, using the database or I with my card-index box. You can guess who won! [Speech 32; npI]

\section{Benevolum techniques}

Table 9.8 presents an overview of the benevolence techniques which occurred in the introduction of the speeches. The differences between the (sub) corpora are statistically non-significant: the number of observed benevolence techniques stays approximately the same.

TABLE 9.8 BENEVOLUM TECHNIQUES IN THE INTRODUCTION (PERCENTAGE SPEECHES IN WHICH THE TECHNIQUE OCCURS)*

\begin{tabular}{l|ll|ll|ll} 
& \multicolumn{2}{|c|}{ All speeches } & \multicolumn{2}{c|}{ Policy } & \multicolumn{2}{c}{ Occasional } \\
\hline Period & I988/9 & $2003 / 4$ & I988/9 & $2003 / 4$ & $1988 / 9$ & $2003 / 4$ \\
$\mathrm{~N}$ & 33 & 33 & 20 & 20 & I3 & 13 \\
\hline Present oneself as credible & 73 & 73 & 80 & 80 & 62 & 62 \\
Compliments and praise & 58 & 52 & 45 & 50 & 77 & 54 \\
Stress common points & I8 & 36 & 20 & 35 & I5 & 38 \\
Alarm or reassure the audience & 9 & 9 & I5 & I5 & 0 & 0 \\
Praise a praiseworthy person & 9 & 9 & IO & 0 & 8 & 23 \\
Take the underdog position & 6 & 0 & 5 & 0 & 8 & 0
\end{tabular}

* Benevolum techniques which occurred in less than $5 \%$ of the old or new speeches are omitted from this overview. 
Table 9.8 shows that ministerial speeches generally use two benevolum techniques: Presenting the credibility of the speaker (or their organization) and Praising and giving compliments (Flattering and praising).

Presenting one as credible. The presentation of oneself or the organization as credible is often achieved in a simple and indirect way. The member of government says for instance "it was with great pleasure that I accepted the invitation to address you today". In doing so they state that in their opinion the inviting party (the attendees) is credible and trustworthy (praise). At times a member of government might even pride himself on his own qualities.

Praising and making compliments. This ancient rhetorical technique occurs in over fifty percent of the speeches. Sometimes in a limited form like: "In a pleasant meeting like this ..." [speech 36; op2] or "The platform does a fantastic job, already for years, and it does this concerning an incredibly tough subject"

\section{Docilem techniques}

The third main function of the introduction - making it possible to understand the speech (docilem parare) - does not seem to concern the speechwriters any differently now than it did in earlier days. Table 9.9 suggests that the application of docilem techniques somewhat decreases, but the difference between the $1988 / 9$ corpus and the $2003 / 4$ corpus is non-significant.

TABLE 9.9 DOCILEM TECHNIQUES IN INTRODUCTION (PERCENTAGE SPEECHES IN WHICH THE TECHNIQUE OCCURS)

\begin{tabular}{l|ll|ll|ll} 
Techniques & \multicolumn{2}{|c|}{ All speeches } & \multicolumn{2}{c|}{ Policy } & \multicolumn{2}{l}{ Occasional } \\
\hline Period & I988/9 & $2003 / 4$ & I988/9 & $2003 / 4$ & I988/9 & $2003 / 4$ \\
N & 33 & 33 & 20 & 20 & I3 & I3 \\
\hline Announce the main points (partitio) & 33 & I8 & 40 & 30 & 23 & O \\
Transition to kernel of speech (bridge) & 27 & 2I & 35 & 20 & I5 & 23 \\
Brief background of the matter (narration) & I8 & I2 & I5 & IO & 23 & I5 \\
Mention the subject & I2 & I2 & IO & 20 & I5 & O \\
Essence of the matter (propositio) & 9 & I5 & IO & 20 & 8 & 8 \\
Present definition & 9 & 3 & IO & 5 & 8 & O
\end{tabular}


Table 9.9 shows that generally two docilem techniques can be observed: the partition and the bridge.

Partitio. The partition is an announcement of the main points (of a part) of the speech. The partitios in the 2003/4 corpus seem to be slightly more explicit in the phrasing of the announcement: they contain more meta-communication like: "I will discuss the following points", while for instance in the I988/9 speeches a number of questions are posed without mentioning that those are the questions which will be answered in the speech.

Transition to the middle of the speech (bridge). On occasions where there was no partitio in the introduction, there was often a Transition to the kernel of the speech, an announcement of only the next topic; an overview of the rest of the speech remains unmentioned:

I will primarily discuss the policy perspective: a much-published topic under heavy debate. (Speech II, OPI)

\subsubsection{The closing of ministerial speeches}

In the closing of a speech, speakers have to realise three functions.

I. Speakers have to gain refreshed attention for the last part of their speech (attentum parare).

2. Speakers have to reinforce the understanding of the listeners by summarizing the gist of their message (docilem parare).

3. Speakers have to use those last moments to positively influence the feelings of the audience towards them and the message (benevolum parare).

The rhetorical functions of the closing of a speech mirror those in the introduction of the speech (Braet 2003; Andeweg and De Jong 2006). Which functions are realized in the closing of these ministerial speeches? We interpret the occurrence of a rhetoric technique as a sign for the realizing of a specific function. Table 9.IO presents an overview of the realised functions. ${ }^{\text {II }}$ In the $2003 / 4$ speech corpus, the functions are realized substantially more often. 
TABLE 9.IO FUNCTIONS IN THE CLOSING OF THE SPEECH

\begin{tabular}{|c|c|c|c|c|c|}
\hline & & $\mathrm{N}$ & $<2$ functions & 2 functions & 3 functions \\
\hline All speeches & $1988 / 9$ & 33 & II & 16 & 6 \\
\hline Policy speeches & $\begin{array}{l}2003 / 4 \\
1988 / 9\end{array}$ & $\begin{array}{l}33 \\
20 \\
\end{array}$ & $\begin{array}{l}7 \\
5 \\
\end{array}$ & $\begin{array}{l}9 \\
\text { II }\end{array}$ & $\begin{array}{l}17 \\
4 \\
\end{array}$ \\
\hline \multirow[t]{2}{*}{ Occasional speeches } & $\begin{array}{l}2003 / 4 \\
1983 / 4\end{array}$ & $\begin{array}{l}20 \\
13\end{array}$ & $\begin{array}{l}3 \\
6 \\
\end{array}$ & $\begin{array}{l}6 \\
5\end{array}$ & $\begin{array}{l}\text { II } \\
2 \\
\end{array}$ \\
\hline & $2003 / 4$ & I3 & 4 & 3 & 6 \\
\hline
\end{tabular}

$<2$ functions: no functions or only $\mathrm{A}$ (ttentum) or $\mathrm{B}$ (enevolum) or $\mathrm{D}$ (ocilem)

2 functions: $\mathrm{AB} ; \mathrm{AD} ; \mathrm{BD}$

3 functions: $\mathrm{ABD}$

Which rhetorical techniques are applied in the closing?

\section{Attentum techniques}

Announcing the close. The attentum parare - refreshing the attention of the listeners in the last part of the speech - is a function that is not explicitly mentioned by classical authors like Quintilian or Cicero. It is a modern function of the closing of the speech. The Announcement of the close can be made explicitly by saying something like "I come to a close", or "To summarize", or "Before I formally open this meeting I would like to say ...", or the somewhat blunt phrase "This is the end of my speech". The announcement can also be made more implicit by using a Salutation "Ladies and Gentlemen", provided that the Salutation has not already been used too much during the speech as a continually returning attention refresher. Generally speaking, there are no differences between the 1988/9 corpus and the 2003/4 corpus (table 9.II). If we omit the category of implicit Salutations from the statistical analysis then a difference surfaces: modern speechwriters are less inclined to announce the closing explicitly $(\mathrm{F}(\mathrm{I}, 64)=4.000 \mathrm{p}=.05)$.

\footnotetext{
${ }^{\text {II }}$ When more occurrences of the same closing technique are observed in the same closing part of the speech then they are only counted once in the overview (table 9.I0; see also note 8).
} 
TABLE 9.II ATTENTUM TECHNIQUES IN THE CLOSING (PERCENTAGE SPEECHES IN WHICH THE TECHNIQUE OCCURS)

\begin{tabular}{l|ll|ll|ll} 
& \multicolumn{2}{|c|}{ All speeches } & \multicolumn{2}{c|}{ Policy } & \multicolumn{2}{c}{ Occasional } \\
\hline Period & $1988 / 9$ & $2003 / 4$ & $1988 / 9$ & $2003 / 4$ & $1988 / 9$ & $2003 / 4$ \\
$\mathrm{~N}$ & 33 & 33 & 20 & 20 & 13 & 13 \\
\hline Announcing the close & 52 & 42 & 50 & 50 & 52 & 48
\end{tabular}

\section{Benevolum techniques}

Table 9.I2 presents an overview of the topical benevolence techniques that are meant to manipulate the emotions of the listeners in those last moments of the speech. The figures of speech that are also recommended for use (for the same reason) in the closing of the speech are taken together in the present research with the number of occurrences of figures of speech in the complete speech text (see section 4.4). Overall, there are no differences between the two time periods in the use of benevolum techniques. The differences in the technique Cooperation/feeling of togetherness, however, are significant $(\mathrm{F}(\mathrm{I}, 64)=4.53 \mathrm{I} \mathrm{p}<.05)$.

TABLE 9.I2 BENEVOLUM TECHNIQUES IN THE CLOSING (PERCENTAGE SPEECHES IN WHICH THE TECHNIQUE OCCURS)

\begin{tabular}{|c|c|c|c|c|c|c|}
\hline & \multicolumn{2}{|c|}{ All speeches } & \multicolumn{2}{|c|}{ Policy } & \multicolumn{2}{|c|}{ Occasional } \\
\hline Period & $1988 / 9$ & $2003 / 4$ & $1988 / 9$ & $2003 / 4$ & $1988 / 9$ & $2003 / 4$ \\
\hline $\mathrm{N}$ & 33 & 33 & 20 & 20 & $\mathrm{I} 3$ & $\mathrm{I} 3$ \\
\hline Flattering, praising and thanking & 48 & 36 & 35 & 20 & 69 & 62 \\
\hline Congratulations & 45 & 39 & 35 & 35 & 62 & 46 \\
\hline Cooperation/feeling of togetherness & $2 \mathrm{IX}$ & $45 y$ & $25 \mathrm{x}$ & 6oy & I5 & 23 \\
\hline Inciting audience to action & I8 & I2 & 30 & 15 & o & 8 \\
\hline Word of thanks & $\mathrm{I} 2$ & 3 & 5 & o & 23 & 8 \\
\hline Alarming the audience & 9 & 6 & 15 & IO & o & o \\
\hline Encouragement & 9 & 9 & 15 & IO & o & 8 \\
\hline Anticipating the opponent's moves & 3 & $\mathrm{I} 2$ & 5 & 15 & o & 8 \\
\hline Extenuating circumstances/excuses & o & 9 & 0 & IO & o & 8 \\
\hline
\end{tabular}

* $x y$ : row difference within a category is significant $\mathrm{p}<.05(\mathrm{~F}>5)$ 
The classical rhetorical techniques Appeal to pity (commiseratio), Arousing negative feelings (indignatio) and Suppressing positive feelings towards the opponent were not observed in the corpus. In general, the closings were particularly characterized by the presence of the rhetorical techniques of Flattering, praising and thanking and Congratulations.

\section{Docilem techniques}

The docilem techniques are traditionally the most important techniques for a speaker to employ in the last part of the speech. The techniques Summary and Circle technique are regularly observed (see table 9.I3). The Summary is applied in a quarter of all cases; it seems to be a trend that the Summary occurs in policy speeches more often than in occasional speeches $(\mathrm{F}(\mathrm{I}, 64)=3 . \mathrm{IIO} \mathrm{p}=.08)$. The Circle technique is deployed substantially more often in the $2003 / 4$ corpus than in the $1988 / 9$ corpus $(F(I, 64)=13.938$ $\mathrm{p}<. \mathrm{OOI})$.

TABLE 9.I3 DOCILEM TECHNIQUES IN THE CLOSING (PERCENTAGE SPEECHES IN WHICH THE TECHNIQUE OCCURS)

\begin{tabular}{l|ll|ll|ll} 
Closing techniques & \multicolumn{2}{|c|}{ All speeches } & \multicolumn{2}{c|}{ Policy } & \multicolumn{2}{c}{ Occasional } \\
\hline Period & $1988 / 9$ & $2003 / 4$ & $1988 / 9$ & $2003 / 4$ & $1988 / 9$ & $2003 / 4$ \\
N & 33 & 33 & 20 & 20 & 13 & 13 \\
\hline Summary & $27 \%$ & $18 \%$ & $35 \%$ & $25 \%$ & $15 \%$ & $8 \%$ \\
Circle technique & I2\%x & $52 \% y$ & $10 \% x$ & $50 \% y$ & $15 \% x$ & $54 \% y$
\end{tabular}

${ }^{*} \mathrm{xy}$ : difference is significant $\mathrm{p}<.05(\mathrm{~F}>5)$

Summary (recapitulatio): Quintilian (6.I.3) distinguishes two functions for the Summary: remembrance and making an impression. He writes: "[it] is intended both to refresh the memory of the judge, to place the whole of the case before his eyes, and, even although the fact may have made little impression on him in detail, their cumulative effect is considerable." He warns to be brief. A speaker should not make a new "second speech" in the closing. Long summaries can be observed incidentally in the corpus (lists of more than ten points). Normally, the observed summaries were shorter and thereby had more possibilities for remembrance and impact. Most of the times, however, a form of recapitulation was missing - a missed opportunity. 
Circle technique: "It can be nice and still functional (...) when the closing and especially the last closing sentence has a relation in one way or the other to the opening statement of introduction" states Korswagen (1976, p. 34). De Jong and Van der Spek (1996, p. 2I) describe the effect of this technique as an enhancement of the cohesiveness of the speech: "it is the last piece of the jigsaw puzzle that falls rightly in place." For example:

Coming back to the beginning of my speech I again state that a review of the history yields lessons to be learned and pleasures to be enjoyed. [Speech 38; ob2]

\subsubsection{Figures of speech}

"Style is like a magic wand: all it touches changes into gold" said Logan P. Smith in 1865 . A way of giving a speech text more impact is the deployment of figures of speech: special examples of language use. Figures of speech are not only particularly suitable to catch and hold the attention of the audience, but are also good for making a text more acceptable or persuasive (Braet 2007). Did speeches become richer in figures of speech in the last decade or did they lose some of that magic? A prudent use of figures of speech could improve the listening experience of the audience. In total 3300 text passages in the corpus were tagged as figure of speech. A rough comparison between the use of figures of speech in the 1980 os and now - adding all the thirty-six figures of speech (per Iooo words) - shows $(\mathrm{F}(\mathrm{I}, 64)=6 \mathrm{I} .755 \mathrm{p}<.00 \mathrm{I})$ that in the $2003 / 4$ speeches figures of speech were used significantly more $(35.5$ style figures / I000 words) than in the 1988/9 speeches (17.2 style figures / I000 words). Overall, the policy speeches did not distinguish themselves from the occasional speeches in this respect $(\mathrm{F}(\mathrm{I}, 64)=.655 \mathrm{p}=.42 \mathrm{I})$.

The, statistically speaking, most important quantitative differences are observed in the use of the techniques Expression/saying, Soundbites, Repetition figures and Metaphors. Table 9.I4 presents an overview of the thirteen figures of speech that are used considerably more often than in the eighties. The other twenty-three figures of speech (not mentioned in the table) are found equally frequently at that time as nowadays. 
TABLE 9.I4 SIGNIFICANT PERIOD CHANGES IN THE NUMBER OF FIGURES OF SPEECH (PER IOOO WORDS)

\begin{tabular}{|c|c|c|c|c|c|c|c|}
\hline \multirow[t]{2}{*}{ Figure of Style } & \multicolumn{3}{|c|}{ All speeches } & \multicolumn{2}{|c|}{ Policy } & \multicolumn{2}{|c|}{ Occasional } \\
\hline & Period & M & sd & M & sd & M & $\mathrm{Sd}$ \\
\hline \multirow[t]{2}{*}{ Expression/saying } & $1988 / 9$ & $0.64 \mathrm{a}$ & 0.70 & $0.57 \mathrm{a}$ & $0.5 \mathrm{I}$ & 0.75 & 0.94 \\
\hline & $2003 / 4$ & $2.46 \mathrm{~b}$ & 2.04 & $2.27 \mathrm{~b}$ & I. 72 & 2.75 & 2.49 \\
\hline \multirow[t]{2}{*}{ Soundbite } & 1988/9 & $0.04 \mathrm{a}$ & 0.14 & 0.07 & 0.18 & $0.00 \mathrm{a}$ & 0.00 \\
\hline & $2003 / 4$ & $0.75 \mathrm{~b}$ & 0.85 & 0.55 & 0.75 & I. $07 \mathrm{~b}$ & 0.93 \\
\hline \multirow[t]{2}{*}{ Repetition figure } & $1988 / 9$ & $0.60 \mathrm{a}$ & 0.92 & 0.62 & 0.79 & 0.58 & I.I2 \\
\hline & $2003 / 4$ & $2.6 \mathrm{ob}$ & 2.39 & 2.47 & 2.12 & $2.8 \mathrm{I}$ & 2.84 \\
\hline \multirow[t]{2}{*}{ Metaphor } & $1988 / 9$ & $0.76 \mathrm{a}$ & 0.93 & 0.6ra & 0.73 & 0.98 & I.I8 \\
\hline & $2003 / 4$ & $2.57 \mathrm{~b}$ & 2.17 & $2.42 b$ & I. 89 & 2.80 & 2.60 \\
\hline \multirow[t]{2}{*}{ Example } & 1988/9 & 0.76 & I.I9 & 0.78 & 0.83 & & \\
\hline & $2003 / 4$ & 2.04 & I.67 & 2.02 & I. 73 & & \\
\hline \multirow[t]{2}{*}{ Antithesis } & $1988 / 9$ & 0.92 & I.09 & 0.73 & 0.82 & & \\
\hline & $2003 / 4$ & 2.03 & I. 45 & I.99 & 1.56 & & \\
\hline \multirow[t]{2}{*}{ Ellipsis } & $1988 / 9$ & $0.7 \mathrm{I}$ & I.I2 & 0.90 & I. 32 & $0.4 \mathrm{I}$ & 0.68 \\
\hline & $2003 / 4$ & I. 74 & I. 34 & 2.00 & I. 42 & I. 35 & I.I6 \\
\hline \multirow[t]{2}{*}{ Humor } & $1988 / 9$ & 0.16 & $0.4 \mathrm{I}$ & 0.03 & O.IO & & \\
\hline & $2003 / 4$ & 0.83 & I.I7 & 0.50 & 0.62 & & \\
\hline \multirow[t]{2}{*}{ Metonymy } & $1988 / 9$ & 0.08 & 0.23 & 0.06 & 0.24 & & \\
\hline & $2003 / 4$ & 0.37 & 0.62 & 0.40 & $0.6 \mathrm{I}$ & & \\
\hline \multirow[t]{2}{*}{ Questions } & 1988/9 & 0.92 & 0.88 & & & & \\
\hline & $2003 / 4$ & I.7O & I. 52 & & & & \\
\hline \multirow[t]{2}{*}{ Climax } & $1988 / 9$ & 0.13 & 0.34 & & & & \\
\hline & $2003 / 4$ & 0.42 & 0.57 & & & & \\
\hline \multirow[t]{2}{*}{ Irony } & $1988 / 9$ & 0.12 & 0.33 & 0.09 & 0.26 & & \\
\hline & $2003 / 4$ & 0.44 & 0.74 & 0.45 & 0.60 & & \\
\hline \multirow[t]{2}{*}{ Self correction } & $1988 / 9$ & 0.09 & 0.29 & 0.04 & O.II & & \\
\hline & $2003 / 4$ & 0.39 & 0.70 & 0.44 & $0.8 \mathrm{I}$ & & \\
\hline
\end{tabular}

\# All values are significantly different $\mathrm{p}<.05(\mathrm{~F}>5)$

$\mathrm{ab}$ : the difference are greater than $\mathrm{p}<.00 \mathrm{I}(\mathrm{F}>\mathrm{I} 5)$ 


\subsection{Conclusion}

What are the most important differences between ministerial speeches from the 1980 and those from the beginning of the new millennium? Before we draw our conclusions it is advisable to consider the choices made in this research and the subsequent limitations. First, the corpus we assembled came from only two of the thirteen Dutch ministries. Maybe the differences between the ministries exceed the resemblances. All kinds of (sub)cultural differences exist between the individual ministries, often relating to the societal role they fulfil (e.g., the Finance Department, where most of the employees wear three-piece suits in contrast with the more informal dress code at the Ministry of Social Services and Employment). Furthermore, the speakers ministers and state secretaries put their individual stamp on the speech style of a ministry. Our analysis shows that there are in fact significant textual differences evident between the ministries. The introductions of speeches by the Ministry of Education, Culture and Science (ECS) for instance, are substantially longer than those of the Ministry of the Interior (MI). In those ECs introductions we find a greater variety of rhetorical techniques, and on average more of the three central rhetorical functions are achieved. ${ }^{12}$ However, the observed change over time appears similar in both ministries. By assembling a relatively large corpus of speeches we believe to have produced a reliable reflection of the changes that took place between the chosen periods; a reflection that also shows the changes in the other eleven ministries. It is very likely that the tendency to produce shorter speeches, shorter sentences and more figures of speech is a typical development for Dutch ministerial speeches. ${ }^{13}$

Secondly, in this part of the article we also should consider our method of analyzing. After all, the selection of text passages from the larger speech texts, the naming and classifying of those fragments in terms of the three rhetorical models is a rather subjective analyzing activity. By training the analysts, by using teams of analysts and by systematically dividing the texts between the analysts, we aimed to control the idiosyncrasies of the individual analysts. Furthermore, we are convinced that the combination of a quantita-

\footnotetext{
${ }^{\text {I2 }}$ The differences between the two ministries must be regarded with some extra reserve. Every ministerial sub corpus was analysed by only two of the four analysts, in contrast to the situation with the other sub corpora (fours analysts per sub corpus, see section 9.3).

${ }^{13}$ A similar trend towards shorter sentences is apparent in American governmental speeches (Lim 2008).
} 
tive and qualitative analysis produces a reasonable inter-subjective description of the textual phenomena.

By way of a conclusion, choosing the perspective of a seasoned listener from the I980s may provide some insight. What would catch the ear of such a man or woman at a speech from the new millennium (2003/4)? The first thing they would notice is the little time reserved in the official program for a speech of an important government official. The minister's speech would be shorter than in former days. Speech text, written by the newly appointed speechwriters, shrank from on average 1870 words (almost twenty minutes of speaking time) to 1507 words (approximately a quarter of an hour).

The speech begins, as in the past, with a salutation of the present audience. Often some flattering compliments will be made. The modern speaker will appear somewhat more informal, more amiable. Such a concrete example or anecdote in the introduction of the speech to get the attention of the listeners, was usually absent in the earlier days; and what to think of a minister making - in a humorous fashion - some amusing, self-deprecating remarks? No, unthinkable. It is not always clear what point the speaker wants to make. In former days the speaker would have helped the listeners by listing the points he would cover in the speech. Also transitions to the next sub topic in the speech are rarely made. There is little explicit structure to keep the listeners on track. The introduction takes longer, but still not all central functions are realised.

The middle of the speech contains less very long sentences and more figures of speech are deployed. And with those ellipses and direct addressing techniques it appears like a real speech, made and improvised by the speaker. Policy is still presented in the $2003 / 4$ speech; also policy that is not always directly linked to the occasion for which the people in the audience are assembled. However, there are more examples, metaphors and commonplace expressions. There is more to enjoy; there can be even some laughter. Also soundbites like "Safety is more than catching criminals" [Speech 56; np2] and the use of repetition techniques amount to a more catchy phrasing of the policy statements.

Fortunately, in the closing of the speech the speaker comes back to the example in the introduction (a circle technique) or one would nearly have missed the end of the speech. In former days the speaker usually announced explicitly the last part of his or her speech; this maybe somewhat bookish, but it was an effective wake up call (as confirmed in experimental research, see Andeweg, De Jong and Wackers 2008). Considering the bookish style, summa- 
rizing the main point of the speech is something that speakers - in those days and today - often refrain from. Wasn't there just one point important enough to repeat? It appears that nowadays speakers use those last moments of the speech to seize the opportunity to stress the Cooperation/feeling of togetherness: "That is your job - that is my job - that is our mission" [Speech 26; npI]. Metaphors and Soundbites are more often evident in the closing of the speech, but they seldom become emotional. The closing is as long as in the older days, but often more complete (more central functions realized).

All that shines in the 2003/4 speeches is not all rhetorical silver, but the average quality of 2003/4 ministerial speeches is substantially better than the quality of the 1988/9 speeches. In the older speech corpus some good speeches can be found, but most of them consisted of formal language and were less audience oriented (few examples, anecdotes, comparisons; lots of abstract passages). Although not every 2003/4 speech surprises with fresh metaphors and convincing examples - humor is still very scarce and memorable soundbites are conspicuous by their absence, the craftsmanship of the speechwriters yields a rather stylistically satisfying speech text. However, the question whether the modern speech also has a clearer message, demands another kind of research.

The more central position of the speech in government communication, and the changing place of the speechwriters in the ministry (closer to their clients: the minister or state secretary) makes it less likely that a minister would let the remark "Yes, I agree with that" slip publically. Or even - and this really did happen - "This must be spelled correctly, speechwriter!"

\section{References}

Andeweg, B. and J. de Jong (2004). De eerste minuten. Attentum, benevolum en docilem parare in de inleiding van toespraken [The First Minutes. Attentum, Benevolum and Docilem Parare in the introductions of speeches]. PhD dissertation. [www.deeersteminuten.tudelft.nl/ with an extensive summary in English]

Andeweg, B. and J. de Jong (2003). Inleidingstechnieken van ministeriële speechschrijvers. Een onderzoek naar werkopvattingen. In: L. van Waes, P. Cuvelier, G. Jacobs and I. De Ridder (Eds.). Studies in Taalbeheersing I (pp. 7-I9). Assen: Van Gorcum. Andeweg, B.A., and J. de Jong (2006). Start With a Story: Theory Versus Practice of the Anecdote as Speech Introduction Technique. In P. Gillaerts and P. Shaw (Eds.), The Map and the Landscape: Norms and Practices in Genre (pp. I69-196). Bern: Lang. 
Andeweg, B.A., J. de Jong and H. Hoeken (1998). "May I Have your Attention?” Exordial Techniques in Informative Oral Presentations. Technical Communication Quarterly 7, 27I-284.

Andeweg, B.A., J. de Jong and M. Wackers (2008). 'The End is Near': Effects of Announcing the Closure of a Speech. Professional Communication Conference, 2008. IPCC 2008. IEEE International, Montreal, I3-I6 July 2008, I-9.

Braet, A.C. (2003). Exordiale en peroratieve argumentaties in de klassieke retorica en de moderne praktijk. In: Studies in taalbeheersing I (pp. 83-9I). Assen: Van Gorcum.

Braet, A.C. (2007). Retorische kritiek. Overtuigingskracht van Cicero tot Balkenende. The Hague: Sdu Uitgevers.

Geel, R. (2002). Toespraken bij de Nederlandse overheid: Ervaringen van een speechschrijver. Lezing gehouden op het negende vioT-congres te Antwerpen.

Janssen, D. (199I). Schrijven aan beleidsnota's. Schrijfprocessen van beleidsambtenaren empirisch - kwalitatief onderzocht. PhD dissertation. Rijksuniversiteit Utrecht. Groningen: Wolters-Noordhoff.

Jong, J, de and B. Andeweg et al. (2005). De speeches van BZK. Een retorische tekstanalyse van zestien speeches. Interne uitgave Directie Communicatie en Informatie Ministerie van Binnenlandse Zaken en Koninkrijkrelaties.

Jong, J. de and B. Andeweg et al. (2004). Speeches van OCenW. Retorische analyse en ontvangst bij publiek en pers. Interne uitgave Ministerie Onderwijs, Cultuur en Wetenschap.

Jong, J. de and B. Andeweg (2008). All's Well That Ends Well. The Problem of Peroratio in Ministerial Speeches. In: L. Dam, L. Holmgreen and J. Strunck (Eds.) Rhetorical Aspects of Discourses in Present-day Society. London: Cambridge Scholars Press.

Kagie, R. (1992). Schuren en schaven. De souffleurs van de nieuwjaarstoespraken. Vrij Nederland II januari, 8-II.

Korswagen, C.J.J. (1976). Mondelinge communicatie in theorie en praktijk. Groningen: Tjeenk Willink.

Levy, S. (2008). Speeches maken voor de overheid. Een vak apart. [Publicatie van de Directie Communicatie van het Ministerie van Onderwijs, Cultuur en Wetenschap]. The Hague: Xerox.

Lim, E.T. (2008). The Anti-Intellectual Presidency. The Decline of Presidential Rhetoric from George Washington to George W. Bush. Oxford: Oxford University Press.

Mast, N. van der (1999). Woordenwisselingen. Een onderzoek naar de manier waarop schrijvers consensus over beleidsteksten bewerkstelligen. $\mathrm{PhD}$ dissertation. Universiteit Utrecht. Amsterdam: Thesis.

Mulder, J. (1995). Het anonieme schrijverschap: ghostwriting. [Tekst]blad 2, I6-20. 
Quintilian. (2006). Institutes of Oratory. L. Honeycutt (Ed.) transl. by J.S. Watson (Original work published I856) http://honeyl.public.iastate.edu/quintilian/ (accessed 2009-OI-I2).

Quote (1995). Spreken. November, 83-9I.

Snoek, J. (200I). Speechen met beleid. In: Overheidscommunicatie. De nieuwe wereld achter Postbus 5I (pp. 156-169). Amsterdam: Boom.

Van De Mieroop, D., J. de Jong and B. Andeweg (2008). "I Want to Talk About..." A Rhetorical Analysis of the Introductions of 40 Speeches About Engineering. Journal of Business and Technical Communication 22, 186-210. 



\title{
Io The Correlation between Style and Argument in Newspaper Columns
}

\author{
HILDE VAN BELLE
}

\section{IO.I Introduction}

A column doesn't have any characteristics, because a column doesn't exist. A series of columns does. And even then, it's difficult to define specific characteristics. For the time being only this one: they all should have the same length.

This is how Willem Bekius, in his manual for journalists, starts off the chapter on columns. As the Dutch author goes on, nothing very specific is added. "A column holds opinion and entertainment", he claims, and, for a checklist, three very concise items of advice are presented: the day-after-test, the right amount of words, and the unity of style (Bekius 2003, p. I43). Bekius ironically suggests that there isn't much to be said about columns.

Of course, other manuals do give a better introduction and more useful instructions. They mention the well-known formal features, like the fixed regularity of author, amount of words or place in the paper. They try to pin down the functions a column can have: opinion, entertainment, aesthetic pleasure. All of them stress the style element: a compact style is the rule. In general, columns are listed in the category of persuasive articles, but invariably the style element is stressed as well. Asbreuk and De Moor admit: "columns are complicated genres where style and argument are intrinsically interwoven" (Asbreuk and De Moor 2007, p. 415). Apparently, columns should be well written in the first place; they function as exercises in style. As for the form, there are almost no limits. Columns come in the form of anecdotes, comments, letters, dialogues, interviews, essays, poems, aphorisms, book reviews, caricatures, portraits, news stories, art criticism, satire, nonsense.

Some authors speak condemningly about columns, like William Metz, who enthusiastically lists and explores a range of "genres", like crime report- 
ing, interviewing, fire reporting, sexism, sports and so on, but doesn't spend much time on (editorial) columns. The only thing we can read about them goes as follows:

But editorials are recognised as expressing a particular point of view. As such, they are not given the credence that is accorded to news accounts that are written to inform, not to sway. Many students of the press doubt that the editorial page has much clout anymore. (Metz 1985, p. II)

In his 1922 textbook on journalistic writing, Grant Milnor Hyde does discuss columns. He claims that the chief purpose of the (editorial) column is to interpret the news, and he adds an interesting note about the historical context of column writing:

In general, during wars and other periods of national stress, the editorial has wide influence; then it is likely to be argumentative. In periods of calm and quiet industry, its importance subsides, and it becomes a thoughtful expository interpretation of events. However much it may rise and fall, it is likely to continue to be an essential part of every newspaper. (Hyde 1922, p. 269)

Also the Dutch authors Kussendrager and Van der Lugt (1992) are not very clear about the genre: they sum up four features, "short, well written, surprising perspective, polemic", and they continue with a discussion of funny and shocking cases where "the limit of freedom of expression" is at stake. They end with the claim that our western column writing is a less exciting matter than in less tolerant societies: another historical note (ibid. pp. 294295). In the 2007 version of their manual, we find a new chapter on columns, but now it's indulging into a wide but not very clear range of examples, aims, possible themes, opinions, etc. The literary techniques that columnists can use come down to: hyperbole, fallacies [!], absurd reasoning [!], lies [!], and archaisms (Kussendrager 2007, pp. 338-342).

In many manuals, column writing simply is not mentioned (e.g., Fox I977, Epstein 1967) or only sporadically mentioned. Donkers and Willems just name the column, put it in the class of opinion articles (Donkers et al. 1999, p. 313) and connect it to the registers of amusement and/or shock (Donkers and Willems 2005, p. 70). Obviously, it is not easy to categorize columns or pin them down to something. They can handle any theme, in any form, and ful- 
fil any function. Often, they're considered to be too superficial to be called literature, and too frivolous to be called real journalism (Gijselhart 1986, p.II).

As columns are very closely linked to a specific author, one could ask whether this ethos element plays a major role in the understanding of the phenomenon. For one thing, columns are places where the public space moves very close to the personal, and the personal involvement of the author is part of this. Columnists apparently want to write down their daily observations and critique in an attractive and moving way. But it is difficult to point out what their aim is. They might be motivated by pigheaded obstructionist contrariness, morality, individualism, exhibitionism, idealism, liberalism or cynicism. To some, columnists are annoying egos, giving superficial comment on anything imaginable, chasing the ephemera of the day, changing their opinions and moods every once in a while, as well as the targets of their praise or attacks. To others, they are really involved in the core business of democracy, keeping up the spirit of enlightenment, challenging the powers and modes of the day (Gijselhart 1986). Or are they rather the fools, saying what everybody thinks, occasionally getting blamed for their impudence, but at the same time symbolically contributing to the greater power and glory of their masters?

The personal aspect of columns also holds for us, their readers. Maybe we are looking for news, knowledge, inspiration, wisdom, ideas, approval, controversy; but we might also be looking for emotion, beauty, shock, laughter, entertainment; and some of us might even be driven by a touch of malicious pleasure or voyeurism. And who else is reading with us? Not only our bosses and colleagues, our neighbours, friends and families, but also socially and politically engaged people, like judges or politicians.

The great variety of forms and functions that columns can display could indeed make one ironically decide that they really "don't exist", that it is impossible to define their features and their function. Their scope might be too wide, their functions too diffuse, their appreciation too personal. On the other hand, they are a popular phenomenon, even in this digital age, and one could ask what it is that makes them particular. Is it just the simple ritual regularity of a fixed time and space, together with the ethos of the author that makes up for the otherwise indecision of the phenomenon?

Columns used to be the place where opinions could be uttered under the shelter of style devices like irony, metaphor, satire, hyperbole and so on. Nowadays, in our western world, the press is supposedly free to utter any 
opinion, and columns are not the outspoken places for opinion anymore. But then what are their new functions? Readers find an article on the same place, at the same time, of the same length, by the same author. Newspaper editors know how important it is to create and encourage daily habits and rituals for their readers. Yet, my suggestion is that this is not the only reason why column writing has survived in time. I want to explore this phenomenon from another angle. I argue that the main function has changed from a free space for opinion into a free space for style.

In this chapter, I will track down the intense correlation between style and argument in the history of columns (section I0.2). Second, I will look at old and new theories about rhetorical figures and their argumentative function (sections I0.3 and I0.4). Finally, I will bring together these lines in a proposal about the actual function of columns.

\section{I0.2 Columns and reasoning}

The early history of the column shows how, from the start, they were spaces where literature and opinion, or style and argument, somehow were closely intertwined. Political comment, and artful and witty satire: they are inherent to our modern democracy; they played a basic role in the growth and evolution of our actual democratic society (see also Gijselhart 1986). They were printed and published in the form of pamphlets, brochures, books, weeklies, etc. They stood apart from $I 7^{\text {th }}$-century and $I 8^{\text {th }}$-century newspapers because those were strictly restricted to the publication of plain news, to facts and messages both local and international. Sentimental and sensational facts were to be found in separate sections, along with advertizements; but no opinion or critique whatsoever.

The reason for this very strict attitude is obvious: censorship. Every now and then, an occasional uprising simply wasn't mentioned in the paper, as if it hadn't happened at all. All over Europe, rulers were very sensitive to criticism, or libel, and they all tried out their own methods for minimizing or silencing critique, by different regulations and restrictions and other systems of suppression and prohibition. Newspapers had to work under special licenses, and apply for monopolies and privileges. In France, for example, the Gazette de France (licensed in I63I) was to speak in favour of the absolute monarchy. And Elizabeth I simply prohibited news pamphlets in England, except those published by ... Elizabeth I. In general, analysis, comment or reasoning, as it was called, was forbidden. 
The public space for reasoning was to be found elsewhere. The more rigid the laws and prohibitions of censorship became, the more creative writers and commentators grew. For comment did flourish, indeed. Great $18^{\text {th }}-$ century writers like Voltaire, Diderot, La Fontaine, Swift, Defoe, Fielding, Addison and Steele found ways of bypassing censors and governors. In this age of satire, critique was abundantly alive in papers and periodicals, in books and pamphlets. When reasoning was presented anonymously or under pseudonym, or in literary forms where it could sail safely under the flag of fiction, the rulers couldn't do very much.

This doesn't mean that writers did not disappear in jail or were banned once in a while - with or without any form of trial. Voltaire, one of the many darling gens de lettres in the Parisian salons travelled all over Europe, often looking for shelter and protection. Many rich and famous people protected him, while others were after him. Daniel Defoe, the founding father of English journalism, spent some time in jail; but then, he did have this bad habit of asking money for the opinion articles he wrote for very different parties. Rulers tried to silence the subversive voices by many means, like the enactment of libel laws in England as well as more undercover tricks. Yet, they found that it's not easy at all to trial anonymous or pseudonymous writers or to pin down the real meaning of their ambiguous allegories or satires, especially if the court decides to go along with the benefit of the doubt in the case of the so-called innuendos.

In the $19^{\text {th }}$ century, newspapers gradually attained more freedom and independence. They reserved more space for serious political comment and analysis. In I80o, in France under Napoleonic press censorship, the Parisian theatre critic Julien Louis Geoffroy created a space for his short, witty, lively, sharp and entertaining comments on everyday social and cultural life. He found room for his literary opinions and observations in the feuilleton, the paper's advertizing appendix. Due to their popularity, his columns moved to the pages of the actual paper, and even made it to the bottom (the rez-dechausséelthe ground floor) of the first page, separated from the real news by a thick black line. All over Europe, famous writers followed this example with great enthusiasm: Sainte Beuve, Victor Hugo, Heinrich Heine, Theodor Fontane, Pushkin, Dostoevsky, Turgenev, Tsjechov.

At first, the feuilletons were an innocent a-political playground for witty literary pieces with criticism on books and theatre, society gossip and nonsense stories; in short on a variety of themes, the big nothing - as it was oc- 
casionally called by some grudging critic. But gradually, and along with the many uprisings between 1830 and I 848 , the themes grew more serious, the critique sharper, the tone more grim. After all, the children of the enlightenment wanted to work towards the political and cultural awareness and education of the public. Newspaper editors remained cautious, however, and tried to find a balance between the safety of correct news reporting and the popularity of their all too witty enfants terribles.

In columns, opinion could find its way, thanks to the grey zone between form and idea, between language and meaning, between style and argument. This indecision was vital for the phenomenon. This is all the more fascinating, when we realize that it took well into the $20^{\text {th }}$ century before Perelman and Olbrechts-Tyteca (1958) took a position on the matter of style and argument. Their discussion on the argumentative value of style figures might shed some light on the phenomenon of columns.

\section{I0.3 Argument and rhetorical figures}

In their famous study 'The new rhetoric' Perelman and Olbrechts-Tyteca (1958) restored the link between style and argument and claimed that the study of rhetoric should not be reduced to stylistics or the superficial ornamental language of literature on the one hand, or to mere speech and argument exercises on the other. Rhetoric concerns the basic human activity of reasoning and logos is put back into its centre. Formal logic is no longer the exclusive domain for the development of human reasoning, since logic leaves out the domain of language. The quest for reasonable arguments and for acceptable compromises and solutions, within the plurality of opinions and interests that forms the basis of the democratic debate, that's what rhetoric is about.

According to Perelman and Olbrechts-Tyteca, the link between style and argument has been neglected or misunderstood all too often. From antiquity onwards, rhetoricians were too busy setting up elaborate classification systems for all kinds and modes of expressions that one way or another stood out from the normal language use. Once the argumentative role of rhetorical figures is disregarded, their study is reduced to a useless pastime, they claim, narrowing down into a search for strange names for affected turns of speech, put down in a classification system of rhetorical figures with no other function than the ornamental. Rhetorical figures can give an argument presence, they claim; this is what links rhetoric as art of persuasion and rhetoric as tech- 
nique of literary expression. And indeed, how could, e.g., a hypotyposis, which is a lively demonstration of a certain situation, not be part of an argumentative move, as it brings about a new presence in our minds? (Perelman and Olbrechts-Tyteca 1969, p. 167) To Perelman and Olbrechts-Tyteca, it is important to ask how and in what respect the use of particular rhetorical figures is explained by the requirements of argumentation.

Rhetorical figures need two necessary characteristics in order to be a figure, they claim, the first being a discernable structure, or a form; and the second a use that is different from the normal manner of expression, and in this way attracts attention. This means that, in the right circumstances, any structure could be considered a figure. On the other hand, not any uncommon structure can be called a figure. But in what respect exactly should a use be regarded as unusual? Perelman and Olbrechts-Tyteca suggest that this is the case when a distinction between form and substance is perceived, because the expression is recognized as not natural, not real, as a pretence.

The reader's perception of this distinction is basic, and this is the point where Perelman and Olbrechts-Tyteca let in the argumentative significance of rhetorical figures. A figure is argumentative when this distinction between form and substance is dissolved through the effect produced by the speech. This means that a change should be brought about: "Forms which seem at first to be used in an unusual manner may come to appear normal if their use is justified by the speech taken as a whole", they claim. A figure is argumentative if it brings about a change of perspective, and its use seems normal in relation to this new situation. So, only if the speech does not bring about the possibility of adherence to the argumentative form, the figure will be perceived as a mere figure of style: nice, original, poetic, but no part of the argument (Perelman and Olbrechts-Tyteca 1969, p. 169).

It is important to notice that Perelman and Olbrechts-Tyteca stress the dynamic aspect and the change of perspective that rhetorical figures can bring about. This is why rhetorical figures should never be studied in isolation or separately, as if they were convertible elements, since this is precisely how they lose their argumentative value, which makes it impossible to conceive of "a step from the common to the uncommon, and a return to another order of commonness, that created by the argument at the moment of its completion”. When rhetorical figures are put in a vertical, paradigmatic and static contrast to some so-called normal or neutral expression, they are studied separately from the argument construction in a text (ibid. p. I7I). 
In the second half of the $20^{\text {th }}$ century, the rhetorical turn took place, and many scholars (re)discovered rhetoric as a basis not only for speech production, but also for text analysis, evaluation and discourse theories in general. The persuasive aspect of rhetorical figures has been recognised by many rhetoricians, like, e.g., Olivier Reboul, who, unlike Perelman and Olbrechts-Tyteca, is especially concerned about both the aesthetic and persuasive aspect of rhetorical figures. Reboul doesn't completely agree with Perelman and OlbrechtsTyteca's suggestion that rhetorical figures are condensed arguments. To him, this theory is too intellectualistic, as it forgets the pleasure rhetorical figures generally generate, either emotional or entertaining, but always in the range of pathos (Reboul I999, p. I22).

Perelman and Olbrechts-Tyteca make a distinction between effective argumentative rhetorical figures and mere ornamental, literary rhetorical figures, leaving literature a very marginal position. Reboul does not follow them here, claiming that the main function of rhetoric is the creation of literary prose and the study of functional aesthetics (Reboul 1999, pp. 72-73). How could figuration be explained in terms of "écart"/"deviation", Reboul wonders, since it is impossible to determine the norm, or to indicate normality in a text. One shouldn't appear at a wedding party in a bathing suit, he explains, but neither should one appear on the beach in a tuxedo. The norm is a relative phenomenon. Reboul dismisses the popular idea of some zero degree, the possibility to track down a rhetorical figure to its proper sense. A figure does add sense to what is said; so if you do away with the figure, you lose sense as well, he claims. A figure can't be reduced to a useless or superficial language game with convertible elements. Moreover, in what way could this idea of "deviation" explain the persuasiveness of an expression? Not when the hearers distinctly appreciate it as a deviation, because precisely in that situation an expression is not persuasive. A figure should be richer, more expressive, even more exact and right than the so-called plain or zero degree or neutral way of saying. Paradoxically, this way, the figure could be called the norm, because it is the best way of putting something (ibid. pp. 74-77).

Perelman and Olbrechts-Tyteca restored the link between style and argument, stressing the persuasive aspect and the dynamic power of rhetorical figures. They refuse to treat rhetorical figures as if they were a collection of extra's one can add to a text. Reboul picks up their ideas on style and argument, but, in an answer to their struggle with the perception of the (un)common, claims that rhetorical figures are most persuasive when they're not 
perceived as such. This basic idea of functionality is what Jeanne Fahnestock (I999) tracks down in the earliest works on rhetoric.

\section{IO.4 The constitutive power of rhetorical figures}

\section{IO.4.I Rhetorical figures as extra value}

Theories of figuration in the first place try to explain and categorize individual rhetorical figures, Fahnestock argues, but when it comes to figuration in general and the notion that rhetorical figures form a departure from normal language, we find a long history of theories.

As a whole, value-added theories of the rhetorical figures have dominated in the rhetorical tradition ${ }^{1}$, Fahnestock explains. The rhetorical figures are considered to be sources of emotion, charm, vividness, force or elegance ${ }^{2}$. The overall problem with value-added theories is that they often impose a distinction between figurative and non-figurative language. This supposed difference between unmarked and marked language has pushed the rhetorical figures to the exclusive field of markers of the literary text, and made us forget about any possible other function (ibid. p. 20).

Indeed, what could the norm for normal language be? And what does it mean to claim that rhetorical figures are not typical? Fahnestock is sceptical about the possibility of providing statistic evidence of typical (literal) versus not typical (figurative) language without taking its context into consideration. Most definitions carry an implicit division of language in them: literal language on the one hand and figurative language on the other hand, as if one can switch back and forth between two levels of reading and understanding. This either/or-state theory isn't very fruitful. Even ancient biblical hermeneutics, with their simultaneous fourfold senses, did better (ibid.).

As for the added value of emotion, it is impossible to set an exclusive figure/emotion connection, not only because emotion is very much a func-

\footnotetext{
${ }^{\text {I }}$ Fahnestock also refers to the discussion about the Latin ornamentum that also means furniture, equipment, which would bring ornament closer to the notion of essential gear and armament than it is to adornment. Both interpretations keep the rhetorical figures on the surface of language, though, as if they could easily be removed.

${ }^{2}$ See also the traditional medieval icon for rhetoric as a woman whose dress is decorated with flowers. Language is supposed to be the dress of thought, and the rhetorical figures are the added embroidery (Fahnestock 1999, p. I8).
} 
tion of the larger rhetorical situation of an utterance, but also because it is unlikely that anything at all could be said or heard without involving more or less remarkable emotion. How could an emotional dimension be factored out of an expression leaving a content behind? How could in the aposiopesis figure, for instance, where the speaker stops in mid-sentence, the emotional and argumentative value be separated? The suggested inexpressibility works both on the emotional and material level.

\title{
I0.4.2 Rhetorical figures as epitomes
}

All the work on added values reveals important functions of the rhetorical figures, but none of them is exclusively constitutive of a text's many meanings. Rather, Fahnestock proposes, figure functions can be considered to exist within a continuum of expressive possibilities. The figures of speech hold a central position in rhetorical theory, she claims. It's her point to study the constitutive power of rhetorical figures and see how they are epitomized in various lines of argument. All along, writers in the rhetorical tradition have provided important "taxonomies of naturally occurring verbal devices and of lines and methods of argument, and, more important, of the connection between or even identity of these two" (ibid. p. 7).

So, rhetorical figures can also be understood as epitomes of lines of reasoning, as the formal embodiments of certain ideational or persuasive functions.

\begin{abstract}
Associating certain verbal rhetorical figures with general lines of reasoning, called 'topics' in the rhetorical tradition, also assumes that it is possible to define these lines or arguments in the first place, a notion that for contemporary readers with no exposure to rhetoric may seem as odd as the rhetorical figures themselves.
\end{abstract}

(ibid. p. 23)

A traditional lexicon for lines of argument disappeared together with the cognate notion of the rhetorical figures as epitomes of those lines. This notion of the generic skills of rhetoric conflicts with our ideas of spontaneity of invention based on complicated cognitive processes, and with the confinement of procedures of method and argument to the specific disciplines or professions. But the popularity of the metaphor to generate analogical reasoning could be a starting point for the assumption that human reasoning can follow many more lines than analogy alone. 
Arguments that link form and function of the rhetorical figures can be found all the way back to Aristotle, who in Rhetoric, Book III, nowhere claims the rhetorical figures to be emotional, ornamental or epiphenomenal in any other way. On the contrary, he "suggests that certain devices are compelling because they map function onto form or perfectly epitomize certain patterns of thought or argument" (ibid.p. 26). In his comments on the function of asyndeton and polysyndeton, both adding meaning to a text, but also on metaphor, antithesis and energeia he points out the functionality of those devices, as they are perfect embodiments of the speaker's intentions.

\section{I0.4.3 The role of history}

The reason for the gradual separation of the two functions is the confusion caused by the sequences of the rhetorical system, she claims, as if the different aspects of speech construction represented chronological steps in composition. Also, certain subject matters grew more and more apart, locked up in traditional methods and systems of teaching. Fahnestock mentions scholarly restorations that took place in the twentieth century: Kenneth Burke,

saw to the heart of the ability of the rhetorical figures to express a particular line of argument and simultaneously to induce an audience to participate in that argument simply by virtue of their form. (ibid. p. 34)

And of course, also Chaïm Perelman and Lucie Olbrechts-Tyteca claimed the argumentative role of rhetorical figures and re-established the link between the rhetorical figures and argumentation by dispersing the rhetorical figures among the techniques of argumentation, thus confirming a view of the rhetorical figures as the epitomes of certain durable lines of argument (ibid. p. 36).

By showing the conceptual or heuristic aspects of rhetorical figures, Fahnestock aims at restoring their full rhetorical function. When studied in their specific context and dynamism, style and argument elements prove to be interdependent and inseparable in many ways. The notion that style argues opens up possibilities for careful rhetorical analysis of texts or genres.

\section{I0.5 Columns and style}

Both argument and style are basic features of newspaper columns. New studies on rhetoric reveal how style figures are not just to be seen as surplus fea- 
tures one can add to argument. Columns are not only interesting places to discover how the rhetorical means of persuasion work, how logos, ethos and pathos are intertwined in the structure of the argument; but they also show how rhetorical figures cannot be locked up safely in an elaborate classification system, ready to be fetched down from the shelves to serve as extras that add aspects like pathos. On the contrary, they take part in the creation and expression of the argument itself. Consider this specific example, from a Flemish columnist who is retorting someone's attack on some local poetry project, claiming it's far too expensive and as such it is a waste of community money; money that should better go to old and needy people.
The artist as a parasite:
[...]
Every single time an artist receives a little money, handicapped and retired people are dragged into the picture. Why is that? In matters of waste, fraud, and inequal- ity, is it really the artists that should be the first logical target? Are they the big spenders with their millions hidden abroad? Or are they an easy target for pop- ulists? The artist as a parasite, enemy of the people. Abolish art, pensions will rise. [...]
(Tom Naegels, Spijkerschrift/De artiest als parasiet. The Standaard 09/30/2004 [transl. HvB])

An experienced reader at once detects an interesting set of rhetorical figures in this passage: rhetorical question, comparison, hyperbole, allusion, sarcasm and antithesis. They all serve in the line of argument that tries to lay bare and counter the all too easy opposition between public well-being and art, and to replace it by the new opposition between public well-being and the big spenders with their millions hidden abroad. In the last sentence, the presentation of the argument in the antithetical construction is a convincing move, not in the least made possible by the creation of what Reboul would call aesthetic functionality. It would be impossible and destructive to try to break down this text into separate sets of rhetorical figures, or to try to peel off the layers of pathos or ethos in order to end up with some basic or neutral or zero-degree content or argument. Breaking down the text into the different style figures and studying them apart from one another and from the line of argument would be a kind of analysis that totally misses the core aspect of columns: the match between style and argument. 
Is this match typical for columns? Of course not. Style and rhetorical figures are not restricted to literature or columns whatsoever. But columns are the only places in the media where this correlation between the what and the how of an argument is explicitly recognized and encouraged. They are typically well-demarcated places where the mere existence of style is explicitly allowed, where ideas and arguments are not explicitly separated from ethos and pathos, where aesthetic pleasure can be part of the persuasion.

Opinion and analysis have become respectable activities in our western world. Our columnists no longer need a grey zone of double-speak to protect themselves from revenge. For the time being, this kind of indecision seems to have disappeared more or less from our range of vision - although it should be kept alive without any doubt. Clearly, the taboo on reasoning and argument has lost ground. I suggest that the matter of style is another kind of indecision that has come into play.

News media go by the traditional understanding of literary style and style figures as an extra value that can be added to a neutral text. As the suggestion of clear and transparent representation of facts and ideas is crucial in the production of news and opinion, any suggestion of a gap between form and content raises suspicion. The quality newspaper is a place for plain facts and clear opinions; newspaper articles obey to strict rules and style prescriptions, rules that have to safeguard the quality of information and opinion. The suggestion of direct transmission from an event to the reporting of it is crucial; and the elements of choice and language are hidden under the suggestion of total transparence. This so-called neutral reporting of facts that can safeguard the idea of transparency is only possible in a form of writing that is dominated by well defined traditions. In this kind of journalism, any risk of too high a style level is carefully avoided. The element of style and the creative power of language are taboo in traditional journalism.

This might be a contemporary function of columns: they make up for the (necessary) blind spot in journalism; i.e., the fact that transparency (neutrality, normality) is the effect of a very strict and traditional low style of writing. This way, columns are not so much free spaces for political ideas, but rather free spaces away from the very strict style prescriptions and traditions in the rest of the paper. They are places of real human creativity, playful or grim exercises in thinking and writing, and in that way, they're always places of risk. 


\section{I0.6 Conclusion}

Two final conclusions I want to draw: the first is pedagogical, the second is of a more theoretical kind. As for the pedagogical consequences of my findings, I want to stress the hermeneutic aspect of text analysis. To read and interpret texts as a whole often seems to come down to an old fashioned, scholastic, "passive" way of analysis. Yet, looking for the (in)coherence between context, argument, structure, formulation and presentation of a text is an essential aspect of analysis and this art should not be minimized or neglected.

And here is where the theoretical aspect comes in. The most interesting aspect of this "Rhetoric in society" question to me is the correlation between empirical sciences and hermeneutic praxis. A scientific analysis of texts always aims at abstraction from the actual written or spoken form, in order to look for general rules. The rhetorical praxis is different, since the focus lies on the appreciation and evaluation of the text as a whole. Rhetorical analysis is a specific activity, a kind of praxis. And columns provide an exemplary invitation to this kind of praxis.

\section{References}

Asbreuk, H. and A. de Moor (2007). Basisboek journalistiek schrijven. Voor krant, tijdschrift en web. Groningen: Wolters-Noordhoff.

Bekius, W. (2003). Werkboek journalistieke genres. Bussum: Coutinho.

Braet, A. (2007). Retorische kritiek. Overtuigingskracht van Cicero tot Balkenende. The Hague: Sdu Uitgevers.

Donkers, H. and J. Willems (2005). Journalistiek schrijven voor krant en vakblad. Bussum: Coutinho.

Epstein, E.J. (1967). Between Fact and Fiction. The Problem of Journalism. New York: Vintage.

Fahnestock, J. (1999). Rhetorical figures in science. New York/Oxford: Oxford University Press.

Fox, W. (1977). Writing the News. Print Journalism in the Electronic Age. New York: Hastings House Publishers.

Gijselhart, A. (1986). De column als vrijplaats. Amsterdam: Sijthoff. Hyde, G.M. (1946 /4). Journalistic writing. Textbook for Classes and Handbook for Staff of Student Newspapers, Magazine and Yearbook. New York: Appleton-Century Comp. Kussendrager, N. and D. van der Lugt (1992, 2007). Basisboek journalistiek. Achtergronden, genres, vaardigheden. Groningen: Wolters-Noordhoff. 
Metz, W. (1985). Newswriting from Lead to “30". Englewood Cliffs N.J.: Prentice-Hall, Inc.

Perelman, C. and L. Olbrechts-Tyteca (1969). The New Rhetoric. A Treatise on Argumentation. [Trans. by John Wilkinson and Purcell Weaver] London/Notre Dame: University of Notre Dame Press.

Reboul, O. (1991). Introduction à la rhétorique. Théorie et pratique. Paris: Presses Universitaires de France. 

P A R T I I I

Rhetoric and the Media \% 



\title{
II If This Goes On ...: The Rhetorical Construction of Future Problems
}

\author{
JOEL BEST
}

\section{II.I Introduction}

People who hope to draw attention to social problems find themselves competing in a sort of social problems marketplace (Hilgartner and Bosk 1988, Best 2008). Rhetoric is central to this process; the most compelling claims attract concern from the press, the public and policymakers. Most often, sociologists study claims that depict problems of the present, arguments that some contemporary condition causes harm, that this is intolerable, and that something ought to be done to solve the problem. Such claims address the question: "What's wrong?" Less common are claims that construct past problems, what we might characterize as postmortem attempts to answer "What went wrong?" (Lewis 2003).

This chapter focuses on a third type of social problems claim: predictive claims about the future, claims about what could - or will - go wrong unless action is taken. History - and literature - is filled with prophets, seers and other people foretelling the future or warning about impending crises. In many cases, we can compare their predictions with what actually happened; so we can say that some of those predictions proved to be accurate, while others turned out to be misguided. It is more difficult to assess today's claims about tomorrow's problems. At any given moment, there are plenty of folks telling us that trouble lies ahead. They compete in a social problems "futures market", each trying to convince us to worry about their vision of what is to come. Of course, we may give more credence to some predictive claims, and less to others. When large numbers of scientists argue that global temperatures are likely to rise during the coming century, they are making a predictive claim, but then so are the people warning that the Mayan calendar indicates the world will end in 20I2. Still, few people give these two forecasts equal weight. 


\section{II.2 The rhetoric of future claims}

Future claims are rhetorically interesting. They vary of course. They evoke a wide range of rationales and authorities, including divine revelation, prognostications of soothsayers, models derived from natural or social science, speculation about possible worst-case scenarios, etc. Their intended audiences may range from small groups of true believers, to powerful policymakers, to the general - even global - public. But all predictive claims have one important feature in common: they are always subject to challenge and dispute. Critics, skeptics, and in fact pretty much anyone can question how - or whether - one can actually know what the future holds, and it is always possible to cast doubt on a particular forecast. Future claims lead to debates between prophets and skeptics, between urgent calls for action and doubts about the very reality of the threat. Thus, there is rhetoric that predicts future problems, and counter-rhetoric that calls those claims into question.

Of course, claims about the problems of the present and the past are also subject to dispute, but the inherent uncertainty regarding what the future holds makes the rhetoric of predictive claims particularly interesting. This is a topic of more than academic interest. In the aftermath of catastrophe, we may puzzle over why people failed to heed the warnings they were given. Explaining why some claims or counterclaims succeed or fail is central to the study of rhetoric. In particular, debates over future claims tend to revolve around four issues of uncertainty - prediction, magnitude, probability, and timing. This chapter begins by considering each of these issues in turn.

\section{II.2.I Prediction: What's going to be the problem?}

By definition, every predictive claim forecasts what the future holds. Many predictions are grounded in measurements; they envision that an observable trend will continue, or perhaps that it will change in some predictable way, for instance, grow at some increasing rate. Such predictions extrapolate from data about the past and present them as a basis for forecasting the future: things used to be not so bad, but today they are worse, and we can project that they will continue to get worse into the future. We are all familiar with such data-based projections: forecasts that the world population could reach 7.4 or 8.9 or even I0.6 billion by the middle of this century; that the world's oil production will peak within the next ten years; that average global temperature will increase between I.I and $6.4^{\circ} \mathrm{C}$ by century's end. These arguments use the language of trends and data as rhetoric. They often invoke scientists and other 
experts, people who are understood to be capable, not just of accurately measuring the trends that led to today's situation, but of being qualified to project those trends into the future. We live in an era - and in a part of the world - when scientists' judgments tend to be considered authoritative, as our most reliable means of predicting the future. In turn, experts trade on this authority, using their professional credentials to bolster their predictions.

However, even apparently authoritative data-based claims are subject to dispute. Counterclaims may challenge the data, and argue that the way the trend is being measured or projected isn't all that accurate. Or they may suggest that the experts disagree, that not all scientists are convinced that the predictions are correct. Or they may point to embarrassing instances when supposedly data-based predictions proved to be wildly off the mark (such as some climate scientists' well-publicized warnings during the I970s about global cooling). If experts' trend-based predictions have been erroneous in the past, why should we believe them this time? In some cases, a discipline's track record in making predictions may be spotty enough to warrant reservations about its authority to accurately forecast what will come (here, economics comes to mind). And, of course, it is always possible for some critics to dismiss the very authority of science, to argue that we need to turn to other guides (such as holy texts) to understand the future.

Trend-based claims invite relatively open debate centered on issues of evidence. Being able to measure something over time, to say that the problem was at Level A ten years ago, and at Level B five years ago, and at Level $\mathrm{C}$ today, suggests that it may reach Level $\mathrm{D}$ in five more years. We assume that there is some factor or set of factors that causes this trend, and that the processes that have produced change in the past will continue to work, leading to a foreseeable outcome. While critics may challenge these measurements and assumptions, there is at least some agreement about what is at issue.

Arguments over global warming - at least in my country - illustrate arguments over data-based predictions. Over the years, skeptics have argued that the evidence regarding global warming was ambiguous, that not all scientists agreed that global warming was occurring, that some of those experts who concurred that temperatures were increasing were unconvinced that this was caused by humans' activities, and so on. In response, those most active in warning about global warming emphasized that increasing evidence that supported their claims, that there was growing consensus among experts that the threat was real, and so on (McCright and Dunlap 2003; Spencer 2007). 
These are fundamentally arguments rooted in a rhetoric of authority. Most of us - and this includes most policymakers - are utterly unqualified to assess the evidence presented by scientific authorities; in fact, few scientists are well qualified to evaluate evidence produced by colleagues in other specialities, let alone disciplines. Thus, the issue becomes, not just should we believe - and act upon - forecasts made by people with scientific authority, but should we believe the reports we are given that claim to represent what those authorities are saying?

Of course, not all predictions rely on trends. In some cases there are forecasts of very rare, or unprecedented, or even unique events, so that it is impossible to construct a credible trend. Here, claims argue that something - the Second Coming, a terrible disaster, a new discovery, whatever - will change the world in ways that make current trends irrelevant. Such predictive claims are much harder to assess: What is the reasoning that justifies this prediction? What authority do those making this claim have? It is easier to construct such claims, but also easier to dispute them. In most of these cases, the rhetorics of both claims and counterclaims focus, not on the nature of problem, but on other key questions.

\section{II.2.2 Magnitude: How big will the problem be?}

Claiming that things will get worse is just the first element in predictive rhetoric. A second concerns the scope, or magnitude of the problem. Just how bad will things get? Because future claims must compete for our attention with one another (and with all of the present claims about today's problems), the most compelling claims tend to predict that things will get very, very bad. The more ghastly the forecast, the more likely people will listen.

The twentieth century raised our threshold for what constitutes a really bad problem. Improved communication and transportation linked people around the globe, enabling bad news to travel farther and faster. Looking back, we see an impressive array of catastrophes: a global influenza epidemic (more than 20 million deaths); a worldwide economic depression; two world wars and dozens of lesser conflicts (accounting for perhaps ioo million deaths); highly rationalized systems of political repression (that killed tens of millions more); the emergence of vastly more efficient, more lethal weapons (with previously unimaginable killing capacity); a sudden leap in overall population; and so on. The collective sense of just how bad things could get would never be the same. 
In response, during the second half of the twentieth century, people increasingly worried that the future might hold really big problems. Dystopian literature and popular culture flourished, but so did frightening projections by sober, expert authorities. For more than sixty years, for instance, the logo for the Bulletin of the Atomic Scientists has been a "doomsday clock" that attempts to assess the precarious state of humankind. The clock is periodically reset, as current events make the world's prospects seem somewhat better or worse, but the hands have always shown just a few minutes until midnight. We have become aware of a variety of doomsday scenarios:

- The first, of course, involves the threat of a nuclear world war - horrific explosions killing hundreds of millions, followed by radiation poisoning killing hundreds of millions more. In the I990s, there were arguments that the greatest danger might come from nuclear winter - dust clouds caused by explosions blocking sunlight, suddenly lowering global temperatures, wiping out most plant life, and leading to the starvation of most of those who survived the explosions and the radiation.

- There were also the various ecological threats associated with population, resources and environment. There was a choice of mechanisms that could cause it all to end. Overpopulation? Depletion of vital resources? Pollution? The current concern with climate change is just one scenario within this variety of doomsday thinking.

- There were new medical menaces - the possibilities of horrific, untreatable diseases spreading by air travel into sudden, global pandemics. HIV/AIDS made the threat seem plausible and invited the most dramatic projections. For instance, one book devoted to warning about the 2005-06 avian flu suggested that "the true worst-case scenario ... [is] in the range of 1 billion deaths" (Davis 2005, p. 126 - emphasis in original). Even if the losses from that year's bird flu - and from Ebola, sARS, and West Nile virus - failed to live up to the most frightening forecasts, it is easy to claim that the next epidemic (such as the form of swine flu that began spreading in 2009) might prove much worse.

- There was the prospect of an economic collapse. Could an increasingly interconnected world economy remain stable? In a densely populated, interdependent world, a failing economy could in turn unleash all four horsemen of the apocalypse - famine, disease, war and death. 
- And there were fears that our reliance on increasingly sophisticated technology might lead to ruin. Innovations such as cell phones or Frankenfoods might have devastating consequences. The world may have circumvented to the world-ending threats posed by $\mathrm{Y}_{2} \mathrm{~K}$ or CERN's Large Haldron Collider, but what of a robot uprising? Or of nanotechnology producing "gray goo" that would envelope the entire planet?

- Finally, in recent years, there has been increasing attention to the possibilities of huge natural disasters. Forget hurricanes and tsunamis. Think big. Do you realize that a major collision with a large meteor or asteroid - or an eruption of, say, the super-volcano beneath Wyoming - have the power to kill off most species? Again, these are scenarios that emphasize the possibility that dust or ash filling the atmosphere could block sunlight and thereby lead to the extinction of most plant and animal species. The growing scientific consensus that a wayward asteroid killed off the dinosaurs has attracted considerable attention to this possibility.

This is rhetoric to reckon with. These are predictive claims that warn of "an end to civilization," "an end to life as we know it," "an end to life itself." In a world that now holds about seven billion people who are increasingly dependent on technology and interlocking political and economic systems, the possibility that trouble could spread and, in the process, topple one key element in the social system after another allows us to envision horrific possibilities.

Counterclaims often focus on the sophistication and resilience of modern social systems, on their capacity to keep small problems from growing out of control. Our knowledge of medicine or economics is greater than in the past, giving us the capacity to minimize the damage caused - or even, in some cases, to prevent the problem from occurring. Pandemic influenza may have killed tens of millions in the aftermath of the Great War, but modern medicine is more sophisticated, and probably able to avoid a repetition of that catastrophe. Or is it?

\section{II.2.3 Probability: How likely is it that the problem will occur?}

Future claims depict possibilities, things that might happen. But, skeptics may counter, what about probabilities? What is the likelihood that some scenario will occur? Is it worth worrying about something that is extremely unlikely to happen? 
The most compelling response to such doubts is to argue that a projected future is certain - or nearly certain - to occur. Perhaps the forecast comes from an arguably unimpeachable authority - holy writ, or people whose expertise is generally accepted. In some cases, claims insist that some outcome is inevitable over the long haul - at some point, Earth will surely collide with another wayward asteroid - although advocates concede they cannot predict just when the problem will occur.

Where a threat cannot be depicted as certain - at least not in the short run - advocates may try to estimate the chances of the problem occurring. Obviously, the better the chances, the more forceful the claim:

The odds that a potentially devastating space rock will hit Earth this century may be as high as one in IO. (Easterbrook 2008, p. 74)

California has more than a $99 \%$ chance of having a magnitude 6.7 or larger earthquake within the next 30 years. . . (ScienceDaily 2008)

Such efforts to quantify probability often may be found in scientific modeling, where experts present calculations suggesting a range of likely outcomes, based on different assumptions about what might occur. Thus, we have already noted that projections for future world population growth or global warming are often presented as ranges - with the understanding that the future is likely to produce something between the highest and lowest estimates considered plausible.

Questions of probability also figure into counterclaims. One obvious critique of predictions of extremely rare threats, such as asteroid strikes or super-volcano eruptions, is to simply agree: yes, these things happen, but they don't happen very often, the next event might be thousands, or tens of thousands of years in the future, and there isn't a whole lot we could do about it in any case, so let's not worry about it. In other words, the probability of the problem occurring within the reasonably near future is so small that, critics argue, the risk can be ignored.

A common response to such criticism is to argue that, even if the prospect is remote, the downside risk is too great to ignore. The chance of some outcome occurring may be very small, but so long as the threat is sufficiently grave, it cannot be ignored. Perhaps, if disaster arrives sufficiently far in the future, we can find ways to circumvent it; science fiction has long imag- 
ined that humans will seek to spread beyond the solar system, if only to escape their dependence on an aging Sun. In the shorter run, we should seek to minimize our risks. Although most scientists agreed that operating the Large Haldron Collider would not cause a mini-black hole that would destroy the planet, the project's critics insisted that, so long as there was even a tiny, remote possibility that a world-ending catastrophe might result, we could ill afford to take that chance. Such rhetoric demands that we take every doomsday prediction - even the most unlikely - seriously.

\section{II.2.4 Timing: When will the problem occur?}

Perhaps the most impressive formulation for a predictive claim is to argue, not just that a big problem will inevitably occur, but that it will take place on a particular date. Thus, according to some interpretations, the Mayan calendar forecasts the end of the world on December 2I, 20I2. This is an impressive variety of claim, in that it argues that (I) a very big problem (such as the end of the world) is (2) certain to occur and (3) on a specified date (4) in the near future. Of course, the Mayan prediction is hardly unique. There have been any number of time-certain, end-of-the-world predictions over the years; most often, these have been associated with particular religious beliefs, but secular versions are possible (as evidenced by $\mathrm{Y}_{2} \mathrm{~K}$ fears). Such predictions are the subject of a sociological literature, where observers study the reactions of the faithful when the world does not end on schedule; it turns out the true believers have little difficulty adjusting to the world's continued existence while maintaining their beliefs. The Jehovah's Witnesses, for instance, rallied around five specific predictions that the world would end in I878, I88I, I9I4, I9I8, and I925, yet managed to endure when each forecast proved mistaken (Zygmunt 1970).

A slightly different set of future claims insists that catastrophe is inevitable, although it acknowledges that the precise date cannot be known. Often, these claims feature rhetoric that suggests that the big problem is due, perhaps even overdue:

[According to] Nature, perhaps the world's most respected science journal ... at least three-quarters of Earth's species are wiped out every 62 to 65 million years. It has been 65 million years since the Cretaceous-Tertiary disaster extinguished the dinosaurs, meaning that we are now overdue for a cataclysm that will without doubt reduce our population by at least half ... (Joseph 2007, p. I2) 
Similarly, there were major eruptions of the super-volcano beneath Yellowstone National Park about 2 million, I.3 million and 630,000 years ago, so the next event might occur any time now.

The problem with such formulations is that threats that occur on a schedule that can only be measured on a geological time scale lack a certain urgency. More pressing are future claims that depict threats that occur far more frequently, such as severe flu epidemics, or earthquakes on major fault lines. Here, claims tend to emphasize the near-certainty that there will be a problem in the not-too-distant future; there may be attempts to quantify the risk, preferably in seemingly urgent terms: "Seismic experts say a quake this size [7.8 on the Richter Scale] thumps the [Los Angeles] area every I5O years - and the last one occurred I5I years ago," (Los Angeles Times 2008, CII). Such claims warn that a problem is not just predictable, but inevitable, and that it can be expected to emerge in the near future.

Alternative quantitative formulations adopt a slightly longer view. At least in the United States, flood-control engineers speak of Ioo-year floods, meaning water levels likely to be attained on average once per century; there may be calculations that it makes economic sense to build flood-control structures designed to contain a Ioo-year flood, while the costs of building to withstand a 500-year flood are considered prohibitive.

Yet another way to address the question of timing is to check off warning signs. Evangelical Christians, for instance, have long sought to interpret real-world events as the signs of Christ's imminent return, as forecast in the somewhat oblique language of the Book of Revelations. The appearance of the anti-Christ, for instance, has been heralded in the rise of such figures as John Lennon, Mick Jagger, Bill Clinton and, of course, Barack Obama. To the degree that some predictions in Revelations seem to have been borne out, then surely the remaining forecasts must also be true, and can be expected to be fulfilled very soon. (Similarly, followers of other seers, such as Nostradamus, point to their uncanny records of accurate predictions [when properly interpreted].)

In sum, warnings about future problems - and resistance to those warnings - revolve around issues of what is being predicted, the prospective magnitude of the problem, its probability of occurring, and the timing of its arrival. Advocates argue there are reasons to be concerned - to anticipate certain problems, to worry that they will be large, that they are quite likely to occur, and this will happen soon. Skeptics doubt that the predictions will be 
fulfilled - the projected problem may not emerge, or if it does develop, it won't be as severe or happen as soon as forecast. As forms of rhetoric, debates over what might seem to be very different issues - warnings grounded in, say, climate science and interpretations of the Mayan calendar - are actually fairly similar.

\section{II.3 The consequences of rhetoric about future problems}

The fact that there are so many predictions of future problems, and that they must compete for the attention of the public, the press and policymakers, means that that competition pits rival future claims against not only one another, but also the many claims about pressing present problems. This competition encourages alarmist rhetoric. With so many claims clamoring to be treated as priorities, advocates need to frame issues in the most dramatic terms: this is what is going to happen; it will be a very big problem; it is very likely to occur; and it will happen in the very near future. Such a threat arguably demands quick action. Inaction or delay will have catastrophic consequences. Half-measures won't work. The only salvation lies in an immediate, fully committed response.

These arguments often draw lessons from history. Look what happened to those who ignored predictions that came true. Look at the fates of those who assumed that the future would be no different from the past, who didn't understand the need to confront the impending danger. Their failures, the disasters that overtook them, offer proof that not heeding warnings whether through arrogance or indifference or ignorance or whatever - can be catastrophic. We cannot afford not to act. This rhetoric always seems quite compelling to those who accept the arguments, and the authority of those making the claims. They believe the warning, and probably view the source as authoritative, the evidence as compelling, the logic as convincing. They support taking action.

On the other hand, not everyone will be so receptive. There will almost certainly be counterclaims promoted by critics and skeptics, people who remain un-persuaded by the claim's rhetoric, who discount the source or the evidence. This reaction may take the form of wholesale rejection: probably most people who receive the news that the Mayan calendar forecasts big - and probably really bad - things for 2012 simply shrug and ignore the warning. More interesting are those folks who concede that a prediction may be valid, but don't get caught up in the urgency. 
Consider, for example, earthquake preparedness. Los Angeles and San Francisco are major cities built on major seismic fault lines. Both have experienced devastating quakes in the past, and all of the seismological authorities agree that there are other jolts in both cities' futures. For decades, authorities have been distributing advice on how to be prepared for an earthquake; in particular, they urge citizens to have emergency kits in their homes and cars - packs stocked with flashlights, bottled water, and so on. Now virtually everyone who lives in those cities knows that there is a real earthquake danger; they talk about "The Big One", and make jokes about California falling into the ocean. This is not a matter of debate; I don't know of any earthquake skeptics. Yet only a small fraction of the citizens in these cities actually have earthquake kits. I have a colleague, a world-renowned sociologist who specializes in the study of disasters, the co-author of an important book on the challenges earthquake preparedness poses for Los Angeles policymakers, who lived in LA for years; she did not have an earthquake emergency kit. If asked, most Southern Californians will concede that a major quake could occur at any time, but they also know that the odds are it won't happen today or tomorrow. There's plenty of time to get prepared - someday.

We might dismiss this as the foolhardiness of an ill-informed public. But policymakers sometimes adopt an analogous sort of reasoning. Consider all of the criticism after Hurricane Katrina flooded New Orleans in 2005. It turned out there was a lengthy history of people warning that the city's levees needed attention; there were repeated warnings that, when a major hurricane next struck the New Orleans area, the levees would likely fail, and those making the warnings noted that, sooner or later, such a hurricane would certainly arrive. And yet, levee maintenance was not policymakers' top priority. Fixing levees is an expensive business; it costs a lot of money, and there is stiff competition for those dollars, with lots of other claims arguing that there are more urgent needs for that money. It is easy to imagine policymakers thinking that, while we'll certainly need those levees someday, they're not unlike earthquake kits, in that we probably won't need them this year, because there's only a tiny chance that there'll be a major, levee-threatening hurricane this season. Why not spend that money on this year's most pressing needs, and turn our attention to the levees next year? And the next year, of course, they could make the same calculations; year after year they gambled (always with the short-run odds in their favor), until they finally suffered a spectacular loss. 
Obviously, it is easy to view this as a rather blatant policy failure, but it is hardly unique, at least in the United States. My parents married immediately after the Second World War ended, and I showed up 5I weeks later. I was, then, a first-year Baby Boomer, one of 3.47 million American infants born in 1946. Just a few months before I'm told the Mayan calendar forecasts the end of the world, I will be eligible for Social Security. For more than sixty years, policymakers have known with considerable accuracy how many boomers are out there, and when they will be able to collect Social Security. This is not very speculative: the demographic information is readily available and generally accepted; simple arithmetic can estimate how much money will be needed. Yet, over the years, in spite of numerous warnings, my country's policymakers have chosen to address more urgent problems first, and thereby allowed the Social Security system to develop serious problems. The failures to convince ordinary Angelenos to assemble earthquake preparedness kits, like the failures of policymakers to maintain the levees in New Orleans and the Social Security Trust Fund, suggest a first problem with future claims: they describe the future - a future that isn't here, that may not arrive anytime soon, and that seems less pressing than other, immediate claims on our attention and resources. Even when everyone accepts a bleak forecast, unless the threat seems immediate, it is hard to get people to take action.

Precisely because it is difficult to mobilize people to address the problems of the future, those who make predictive claims find themselves looking for ways to make their warnings more competitive in the social problems marketplace, more likely to attract attention, arouse concern and move more people to take action. Karen Cerulo speaks of "caldrons" - "a context in which competition is always bubbling; alliances are fluid; social bonds are constantly forming and reforming in accord with groups' and individuals' current interests and goals" (2006, p. 156). The public sphere is one such caldron. In such circumstances, it's hard to get people to pay attention and stay focused on your predictive claims. The obvious solution is to devise more compelling rhetoric, to create dramatic arguments that will frighten the audience into taking action. Thus, advocates - who, after all, may be perfectly sincere in their belief that they have identified an important future problem - find it useful to emphasize the problem's magnitude (that is, to suggest that it will be very large), its likelihood (that is, to claim that it is very likely to occur), and its proximity (that is, to suggest that it will arrive sooner, rather than later). It is easier to convince people to worry about a giant problem that is 
certain to appear in the immediate future, than to get them concerned about a problem of uncertain size, that is more-or-less likely to occur sometime (who knows when) in the future.

There are, then, powerful incentives to ramp up the rhetoric, to start talking about doomsday scenarios in order to grab people's attention. This may help explain why history is littered with apocalyptic predictions that never came true. But, of course, the memory of those erroneous forecasts can be used to construct counterclaims. If there have been many mistaken warnings in the past, why shouldn't we suspect that today's warnings will also prove to be exaggerated? Moreover, the more powerful the rhetoric, the more likely it will be disconfirmed. Forecasting a huge problem means that the occurrence of even a somewhat smaller problem serves to discredit the claim. Assigning a high probability to catastrophe casts doubt on the claim so long as the event does not occur. Predicting that a problem will arrive on a particular date - or within the very near future - makes it easier to disconfirm the prediction. In other words, the more powerful the rhetoric, the less credible the claim is likely to seem so long as the prediction is unfulfilled. In the face of those doubts, there is a powerful temptation to overcome the resistance by devising even more powerful rhetoric, launching a new cycle of even more extreme predictions that, in turn, inspire further doubt.

In recent years, scholars have tried to better understand the dynamics of failing social systems. History offers us plenty of examples of collapse, of political empires or religious beliefs that succeeded, expanded across continents and endured over centuries, their successes embodied in great palaces and splendid temples, only to wither. Recently, Jared Diamond published Collapse (2005), a thick volume that examines the failure of nearly a dozen social systems (including the Mayans) that endured for at least four hundred years (that is, they lasted at least as long as English speakers have inhabited North America). Diamond is most interested in accounts of collapse caused by ecological crises, by civilizations that exhausted their resources or found themselves constrained by climate change. For example, he argues that the global cooling cycle that began around $\mathbf{3} 300$ (the onset of what is now recognized as the Little Ice Age), eventually forced Norse settlers to abandon their colony on Greenland. The cooler weather caused other, less dramatic, but arguably more consequential changes in Europe and Asia. Philip Jenkins (2008) notes how colder temperatures reduced harvests, which prompted famine and plague: "Whatever the religious coloring of particu- 
lar societies, this was a world that directly attributed changes in weather or harvest to divine will, and it seemed natural to blame catastrophes on the misdeeds of religious deviant minorities who angered God" (pp. 136-37). Thus, the cooler weather led to Western European pogroms that decimated the Jewish population, while Christian minorities in several Muslim societies suffered severe losses. The link between climate change and religious persecution - hardly self-evident - illustrates that future problems may take unpredictable forms.

In fact, Diamond argues that history shows elites often being oblivious to warnings - whether in the form of predictive claims or empirical evidence that a society is becoming hard-pressed. Often short-run advantages to ignoring the danger seem more pressing than forecasts of doom to come. Add the fact that predictions are often exaggerated, imperfect, or incomplete, and it is not difficult to justify ignoring the rhetoric of warning.

Postmortem analyses of what went wrong often address whether anyone predicted that the problem would come to pass and it is easy to point to cases when the danger was anticipated in at least some quarters, yet action was not taken. In retrospect, it seems natural to criticize these failures to ward off the impending threat. Most critiques tend to blame policymakers for failing to act in the face of warnings. However, focusing on the rhetoric of future claims invites us to consider why some claims inspire action, while others are dismissed. What is it about the ways claims are presented, and about the ways that their audiences interpret these messages that leads to different outcomes? Understanding how we assess the risks of the future may help us avoid having regrets about the past.

\section{References}

Best, J. (2008). Social Problems. New York: Norton.

Cerulo, K.A. (2006). Never Saw It Coming: Cultural Challenges to Envisioning the Worst.

Chicago: University of Chicago Press.

Davis, M. (2005). The Monster at Our Door: The Global Threat of Avian Flu. New York:

New Press.

Diamond, J. (2005). Collapse: How Societies Choose to Fail or Succeed. New York: Viking.

Easterbrook, G. (2008). The Sky is Falling. Atlantic 30I (June), 74-84.

Hilgartner, S. and C.L. Bosk (1988). The Rise and Fall of Social Problems. American

Journal of Sociology 94, 53-78.

Jenkins, P. (2008). The Lost History of Christianity: The Thousand-Year Golden Age of the 
Church in the Middle East, Africa, and Asia - and How It Died. New York: HarperCollins.

Joseph, L.E. (2007). Apocalypse 20I2: An Optimist Investigates the End of Civilization. New York: Morgan Road.

Lewis, B. (200I). What Went Wrong? Western Impact and Middle Eastern Response. New York: Oxford University Press.

Los Angeles Times (2008). Prepare for a Quake? L.A.’s Too Busy. (September I4): Cir. McCright, A.M. and R. E. Dunlap (2003). Defeating Kyoto: The Conservative Movement's Impact on U.S. Climate Change Policy. Social Problems 50, 348-73.

ScienceDaily (2008). California has More than 99\% Chance of a Big Earthquake Within 30 Years, Report Shows. (April I5). http//www.sciencedaily.com

Spencer, R.W. (2007). How Serious is the Global Warming Threat? Society 44 (July), 45-50. Zygmunt, J.F. (1970). Prophetic Failure and Chiliastic Identity: The case of Jehovah's Witnesses. American Journal of Sociology 75, 926-48. 



\title{
I2 Exploring Everyday Ethos \\ Ethos Techniques in Online Discussions about Extraordinary Experiences
}

\author{
PETER BURGER AND LOTTE ANEMAET
}

\section{I2.I Introduction: Bianca's story}

One Saturday night in May 2004, Bianca, a Dutch teenager, had a frightening experience at a dance party. Although she had had no drinks beyond the usual ("five Vodka Red Bull cocktails"), ${ }^{2}$ she suddenly started to shake all over, her vision blurred and her heart raced. She suspected that someone had drugged her drink, but she could not be sure. Sharing her worries with the crowd at Partyflock, a thriving Dutch Internet community for dance party enthusiasts, she ends her first message: "Does anyone know what could have caused this?"

Bianca knew in advance that she would meet with both sympathy and a fair amount of skepticism, since drink spiking is a controversial issue among Dutch adolescents: some are convinced that it is a genuine crime problem, others that it is a combination of urban legend and hysteria (Hulsebosch et al. 2008). Bianca's audience was not present at the party, so they have to take her words on faith - as do we. In order to elicit sympathy, Bianca has to convince others that she is a reasonable, likeable person, and a trustworthy witness to that night's events. To pre-empt the argument that she must have been drunk, she volunteers information about her alcohol intake, which does not exceed the limits deemed acceptable among Partyflock visitors. She also states her suspicions with caution: "I'm certainly not the one to jump to the conclusion that drugs were slipped into my drink, but I was just sooo scared." In rhetorical terms, Bianca has to establish ethos to convince her audience that something extraordinary has happened to her.

\footnotetext{
${ }^{\text {I }}$ Thanks to Jaap de Jong for his contribution to this chapter.

${ }^{2}$ All translations from the Dutch are by the authors.
} 
Like Bianca, millions of people use the Internet to share experiences and debate all sorts of issues. Whether or not this constitutes an extension of the public sphere (Habermas 1989) is itself a matter of debate (Dahlberg 200I; Pappacharissi 2002; Warnick 2007, pp. I-23; Witschge 2007). Some have welcomed newsgroups, blogs and web-based discussion boards as new public arenas, offering universal access and a more level playing field, others doubt the Internet's democratic potential and possibilities for deliberative discourse.

Perhaps topic starters like Bianca are not looking for debate. The very first thing they crave for is a reply. Getting a reply, let alone generate a discussion is quite an achievement in itself: in a study of 40,93I messages in 99 Usenet newsgroups it was found that 43 percent of the topic starters never received a reply; similar percentages were found in other studies (Burke et al. 2007). Using introductions and making requests raised the likelihood of receiving replies. This in turn has important group cohesion effects: posters who received a reply, particularly if they were newbies, were more likely to post again (Burke et al. 2007).

Although Burke et al. label these introductions and requests as rhetorical strategies, they eschew the framework of classical rhetoric. This is symptomatic for the study of online rhetoric: although this topic has come in for some scholarly attention (Enos and Borrowman 200I; Warnick 2007), the rhetoricians in this field are few and far between. However, given the prominence of the online world as an arena for public rhetoric, and, as we will argue, the abundance and ready availability of excellent research materials it offers, this promising topic is well worth the consideration of rhetoricians.

The present study explores the use of ethos in online discussions. To justify our focus on ethos, we might call to mind Aristotle's view that this is the most persuasive of the three modes of persuasion (Aristotle 1974, pp. IOO-IOI; Braet 2007, p. 50). Hence our research questions: What model can be used to study the ethos aspects of online discussions? What ethos techniques are used in the present sample of online discussions about drink spiking? And finally, do ethos techniques described in the classical literature possess real life - or rather, virtual life - validity?

\section{I2.2 Drink spiking as crime legend}

Discussions about drink spiking among Dutch adolescents offer a convenient point of entry into the study of online ethos. Drink spiking and drug rape emerged during the I990s as an international crime problem. In bars and at dance parties, young women are allegedly drugged and subsequently abused. The so-called 
rape drugs or date rape drugs mentioned most frequently are GHB and Rohypnol (or "roofies"). In spite of widespread concerns among adolescents and dire warnings by prevention agencies and police forces, however, forensic experts and a number of police officials remain unconvinced (Beynon et al. 2008; Burgess, Donovan and Moore 2009). The alleged effects of rape drugs, they claim, are merely the mistaken symptoms of unacknowledged alcohol abuse. This controversy also exists at the popular level of blogs and digital discussion boards.

The present study is part of a larger research project concerning the social construction of new crimes in various media and the relations between crime news and folklore (e.g., Burger 2009). Why folklore? Folklore is the realm of unofficial knowledge and informal stories. Stories and discussions about instances of drink spiking can be studied as belonging to the genre of legend. Traditionally viewed as narratives about man meeting the Other World, e.g., ghosts, vampires and aliens, in the opinion of a number of scholars (e.g., Best and Horiuchi 1984; Best and Hutchinson 1996; Donovan 2002) legend also encompasses stories about ordinary people meeting the Underworld.

In these crime legends, ordinary persons experience the extraordinary in the shape of organ thieves, hook-handed maniacs, or drug rapists. These narratives may be told as personal experience stories or as second-hand or thirdhand tales, attributed to the proverbial 'friend of a friend', hence 'FOAF tales' (Dale 1978). Legends are truth claims in narrative form, which typically engender debate. As such, these legends provide ample opportunity for studying ethos in action.

The online sample used in this study was assembled for a previous study of logos in drink spiking discussions that sought to answer the question what arguments discussion participants used to argue their belief, disbelief or partial belief in the threat of drink spiking (Hulsebosch et al. 2008). A threefold typology of crime legend belief and disbelief was used (Donovan 2002, 2004), that distinguishes between debunking ("It's a hoax / an urban legend / a case of hysteria"), fervent belief ("It's true! This is just the tip the iceberg!") and socalled instrumental or conditional belief ("Given the state of the world, it could be true, and even if it isn't, one can never be too careful"). From the quantitative content analysis of frequently used arguments, a fourth type emerged: experiential belief ("I know it's true, because it happened to me").

A breakdown of the arguments into the broad categories of those for and those against belief in the reality of drink spiking allegations, shows a neat, almost even distribution (figure I2.I). A closer look at the arguments on the 
FIGURE I2.I ARGUMENTS ( $\mathrm{N}=503)$ USED IN ONLINE DISCUSSIONS ABOUT DRINK SPIKING ( 54 THREADS)

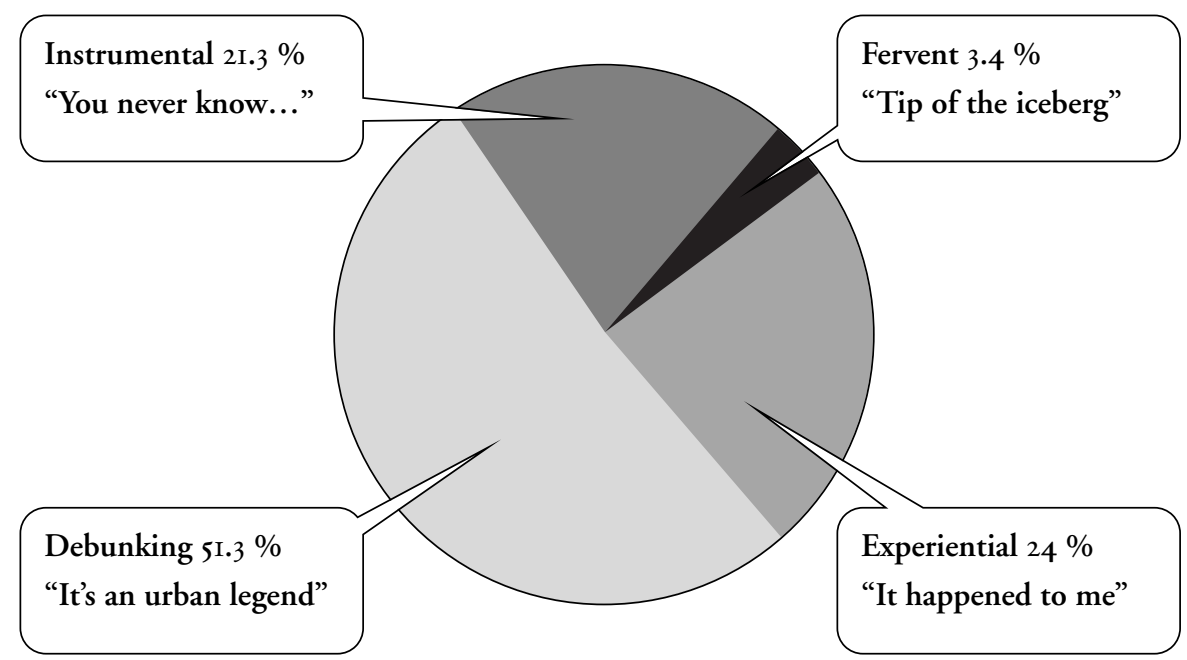

believing side shows them to be an uneven mix, in which those expressing fervent belief were negligible, whereas those expressing instrumental and experiential belief accounted for the majority of arguments.

From the study of logos in drink spiking discussions we can deduce that Bianca, and other believers, could expect strong opposition to their claims of having been spiked. Before we can answer the question how they established ethos, and how their adversaries tried to bolster their own ethos as they were trying to undermine the believers' ethos, we turn to the insights of the scholars who tilled this field before us.

\section{I2.3 Studying ethos: Aristotle and beyond}

In order to study the ethos techniques used in the discussions under consideration, we did not have to start from scratch. Both classical authors and contemporary academic literature offer a number of perspectives on the study of ethos. Our main sources of inspiration were Aristotle's rhetoric (2004) and the 'rhetoric of truth' model devised by folklorist Elliott Oring (2008), but we also drew on discursive psychology and social-psychological research into computermediated communication.

The terms used in these disciplines are not exact matches. The Aristotelian notion of ethos overlaps social psychology's source credibility (McCroskey 200I, 
pp. 83-85; McCroskey and Young 198I). Then again, Potter's discursive psychology offers terms like entitlement (Potter 1996, Ch. 5). Since the more recent psychological approaches address parts of the rhetorical whole, which is covered in its completeness by the Aristotelian model, we will stick to the classical terminology.

In the following overview, techniques that we incorporated in our integrated ethos model (see section I2.4) are tagged with bracketed numbers.

\subsection{The Aristotelian tradition}

According to Aristotle, a speaker's ethos is construed by the audience as it listens to his speech (Johnson I996, p. 243). The audience judges three dimen-

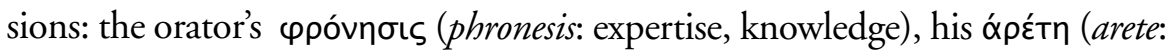
virtue), and his euvoí $\alpha$ (eunoia: goodwill) (Aristotle 2004, p. IOI) ${ }^{3}$.

An orator displays expertise by demonstrating an understanding of the topic at hand, and insight into the issues it raises, e.g., by offering details and numbers. Another way of showing expertise is by referring to one's experience and education (Braet 2007, p. 5I) (4).

Orators make a virtuous impression when they appear to speak the truth. One way of achieving this is by simply claiming to be a truthful person (9). Another, more roundabout way of reaching the same goal is by disclosing information that could be harmful to one's ethos, e.g., by admitting ignorance or minor sins (8).

Orators are judged to be persons of good will when they appear to share the characteristics of their audience. One can search for common ground by emphasizing personal or issue characteristics (IO). One's political affiliation or religious orientation may be an ethos booster, as can be the choice of issue, e.g., addressing environmental aspects when discussing the proposed expansion of an airport will be more likely to win the sympathy of a left-leaning audience than addressing economic interests (Braet 2007, p. 52). Other techniques that establish goodwill are vilifying common enemies (I2): doing this enhances the speaker's own ethos (Andeweg and De Jong 2004, p. 54), and praising and thanking the audience (ibid. p. 55) (II).

Although the classical tradition remains of paramount importance for the present-day study of rhetoric, the Aristotelian model was tailored to the

\footnotetext{
3 The literature offers various translations. McCroskey and Young (I98I, p. 24) summarize Aristotle's dimensions as “intelligence, character, and good will”.
} 
analysis of public monologues on matters juridical, political or ceremonial, which is a far cry from the free-for-all polylogues on discussion boards like Partyflock.nl. In order to study these informal discussions, however, we can draw on three further research traditions, those of computer-mediated communication (CMC) studies, discursive psychology and folklore studies.

\subsubsection{Computer-mediated communication studies: Burke et al. (2007)}

Burke et al. (2007) identified two successful rhetorical strategies for topic starters: introductions referencing lurking ("I have been reading here a while and wanted to ask") or a personal connection to the topic ("I was recently diagnosed with Epilepsy", in alt.support.epilepsy); and questions and requests ("What can I expect from chemotherapy?"; "Wondering the best way to dissolve chocolate, besides eating it."). We focus on the introductions, in which topic starters search for common ground by emphasizing personal or issue characteristics (Io). Requests, although they are rhetorical strategies, are indirectly related to the poster's ethos. As such, they need not concern us here.

The introductions clearly relate to the Aristotelian dimensions of ethos: "Including a self-disclosing introduction demonstrates legitimacy and commitment to the group [...]" (Burke et al. 2007, p. I6) Introducing yourself as a former lurker means disclosing information that could be mildly harmful to one's ethos (8): "I'm not one of the regulars, until now I have not made any contribution to the community." In effect, this strategy turns out to be beneficent: instead of being chastised for previous freeloading behavior, the poster is rewarded with a reply. Topic introductions establish common ground: the newbie shares the disease, music taste or cultural background of the community.

Although the number of techniques analyzed by Burke et al. (ibid.) is limited, the paper stands out for its strong empirical and experimental design. Correlation between these techniques and the number of replies was established by automatic content analysis of a Usenet sample consisting of almost 4I,O0O messages. The extent to which the response rate was caused by these techniques was investigated by tweaking and reposting a number of messages, systematically varying the presence of introductions and requests.

Group introductions ("I've been lurking here a while") double the number of replies. Topic introductions ("I was diagnosed with Epilepsy") did not have a significant effect, however. Requests did increase the number of replies, but their effect was less pronounced than that of the group introductions. 


\subsubsection{Discursive psychology}

Discursive psychology is part of the wider field of inquiry of discursive constructionism (Potter and Hepburn 2008). Its aim is the analysis of the discursive practices that are used to construct facts in various kinds of discourse. Building on ethnomethodology and conversation analysis, discursive psychologists have analyzed marriage counseling sessions, informal conversations between television documentary makers, talk show interviews and other forms of discourse to study the way talk constructs social reality (Potter 1996). Particularly relevant to our drink spiking case is Wooffitt's (1992) study of accounts of the paranormal. Wooffitt shows how speakers construct their extraordinary experiences as real by employing discursive practices a rhetorician would recognize as ethos techniques.

From this literature, we considered five techniques as potentially relevant for our model.

\section{A. Present oneself as an ordinary person}

The person relating the extraordinary experience may volunteer information as to his condition at the time: e.g., sitting upright in bed, wide awake and consequently fully conscious of what went on around him (Wooffitt I992, p. I52). To stress one's rationality, one may report a reality check (I), testing the extraordinary explanation, e.g.: "When I thought I heard the voice of my deceased mother, I first made sure that the radio was off, to exclude that as an explanation" (Wooffitt I992, p. 83). To show that they possess their critical faculties, people may also correct themselves (Wooffitt I992, p. IIO):

\footnotetext{
$\mathrm{H}$ : John, you told me about an experience that happened to you, repeatedly I take it, as a child. Would you give the details?

J: It wasn't exactly as a child.

I was a teenager at the time, you know.

Well, fifteen, sixteen years of age.
}

In this example, John does not want to label his younger self as a 'child', rather than a teenager or better still, a fifteen or sixteen year old, meaning that he was old enough to understand the experience correctly.

\section{B. Stressing the ordinariness of the situation}

A technique frequently employed is describing the situation just before the extraordinary event took place: "I was just doing X, when Y" (Wooffitt I992, p. 
II8). Typically, ' $\mathrm{X}$ ' is a mundane activity like doing the dishes; its very everyday quality means that what follows ("when I heard a voice in my head") could happen to anybody. Since this technique pertains to logos rather than ethos, we did not incorporate it in our model.

\section{Referring to authorities or other witnesses}

Appeals to authority (2) may make a story appear more credible. One may refer to others who concur that somebody really had an extraordinary experience or was acting or looking different. This is someone talking about a girl who was found to be mentally ill:

[...] I was actually the last of her close friends who was openly willing to admit that she was becoming mentally ill.

The person talking enlists the opinion of other 'close friends' to shore up her own conclusion that the girl was becoming mentally ill. This objectivates the extraordinary (Potter 1996, pp. I27-I28; Wooffitt I992, p. IOI). Speakers may also try to construct the phenomenon as a generally acknowledged one by pointing out others who have experienced it and who have expressed belief in it. One way of doing this is by quoting those people:

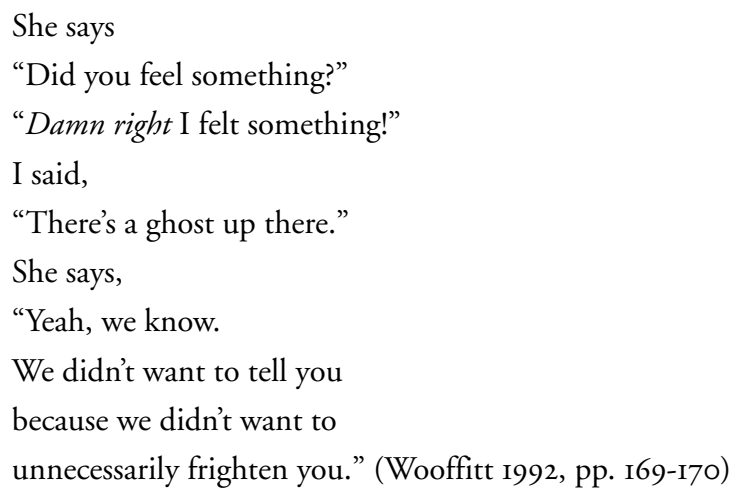

In this example a third party vouches for the correctness of the extraordinary experience. 


\section{Footing}

The experience under discussion may be one's own, a second-hand account or it may be even further removed from the speaker. Potter dubs this speaker-source relationship footing, a term coined by Goffman: "the range of relationships that speakers and writers have to the descriptions they report" (Potter 1996, p. I22). We will use the term distancing $(5,6,7)$, developed by Oring (2008) as an addition to the classical ethos devices (see below).

Since we are dealing with legends or urban myths, often characterized as 'friend-of-a-friend stories' or 'FOAF tales' (Dale 1978), it is worth repeating Potter's analysis of this formula (1996, pp. I34-I35). 'Friend', Potter observes, serves as an epistemic term, a warrant for factuality: "a friend told me" sounds more credible than "somebody told me". The 'friend of a friend' formula partakes of the epistemic authority of 'a friend', but avoids the danger of claiming a close relationship with the protagonist of an extraordinary event. Potter:

The 'friend of a friend' construction, then, provides some category entitlement but, at the same time, means the teller is not accountable for gaps, questions and issues with respect to the story: it was just what they heard. What it provides is a trade-off between factuality and deniability. (1996, p. 135)

\section{E. Reluctance}

A final ethos technique from the discursive psychology literature worth mentioning is the avowal of prior disbelief or skepticism: "I used to think that $\mathrm{x}$ was utter nonsense, but a recent experience has convinced me that it is, after all, for real." (Lamont 2007, Potter 1996, pp. I25-I26, Wooffitt 1992, pp. 7879). Conversely, skeptics may try to bolster their ethos by claiming that they were initially believers. In Potter's terms, this ploy belongs to the category of stake inoculation: the speaker pre-empts the counter-argument that he is merely holding a certain position because he has a stake in the argument. Since the initial qualitative analysis of the drink spiking discussions did not yield instances of this particular technique, however, it was not incorporated in our model.

Summing up: the discursive psychology literature offers a number of concepts and techniques that are relevant to our study of ethos in online discussions. The above examples show that storytellers tend to be prepared for attacks on their ethos. This literature also contains discussions of subjects pertinent to our inquiry into crime legends. Methodologically, these authors favor qualitative content analysis: the techniques they distinguish are based on 
the micro-analysis of spoken dialogues and other forms of discourse; they do not attempt to assess their frequency or test their effect. Neither have these concepts been applied to online discussions.

\subsubsection{Folklore studies}

Although folklore scholars have been studying folktales since the early nineteenth century, efforts to apply the framework of rhetoric to the telling of folktales are scarce indeed. Rhetoric features in a number of studies (e.g., Bennett I988, 1989, 1999; Correll 2005; Hill and Irvine 1993), but the first full-scale attempt to apply the Aristotelian framework to legend studies is a recent paper by Elliott Oring (2008). Oring's model covers all three modes of persuasion: logos, pathos and ethos. In the ethos category, it distinguishes four topo $i^{4}$ : the authority of the source, risk to the narrator, distancing and judgment.

\section{A. The authority of the source}

"The authority of a source depends, to some extent, upon the social position of the narrator and/or the reputed source of the narrative" (Oring 2008, p. 13I). Using Aristotle's distinction, this status can be entechnic or atechnic, i.e., embodied in the discourse or known beforehand. Narrators may construct their authority within the narrative, and besides they may be known as, say, a physician, an adventurer or, for that matter, the village fool. Since our study focuses on the construction of ethos in discourse, we will leave the atechnic part aside.

\section{B. Risk to the narrator}

Disclosing information that could be harmful to one's ethos (8) features in Oring's model as 'risk to the narrator': "The more risk a narrator takes in telling a tale, the more likely a story would be perceived as true" (2008, p.I33). A physician telling a ghost story risks his reputation as a man of science, but this, paradoxically, lends plausibility to his narrative.

\section{Distancing}

Oring uses the term distancing (2008, pp. 133-I35) to describe the relationship between the teller and the alleged source of the narrative (cf. Potter's concept of footing). Following Georgina Smith (I98I, p. I69), he discerns three degrees of separation:

${ }^{4}$ Oring applies the term tropes here, which many scholars will interpret as a form of 'figurative language'. 
I) 'Incorporated', i.e., first-hand, personal experience stories;

2) 'Semi-incorporated', i.e., second-hand, events allegedly experienced by an acquaintance, a named friend or a local character;

3) 'Detached', i.e., third-hand, without source attribution or identification of the protagonists.

The more unambiguous the source, and the closer to the narrator, the more believable the story. It is important to realize that distancing is to a certain extent a rhetorical choice: narrators may choose not to name a source when this is to their advantage, or they may even tell personal experience stories as third-person narratives or vice versa. Oring refers to an example in Slotkin (I988), of a person telling a ghost story in the third person, and, a month later, as a personal experience story.

More examples can be found in the literature on legends. The British writer Roald Dahl used to entertain guests at dinner parties with his repertoire of urban legends and his own short stories, told as personal experiences (Burger 2002, pp. 137-139).5

Like Potter, Oring points out the advantages of the 'friend-of-a-friend' formula: "[...] a brilliant compromise in that the narrator can establish a relation to a potentially credible source without being held accountable for it" (2008, p. 135).

\section{Judgment}

Oring states that discernment and judgment are the most important character traits a narrator must display to appear believable (2008, p. I35). In this respect, he lists five basic techniques: reflexivity, considering alternative explanations, showing reluctance, professing ignorance and reporting tests.

\section{I) Reflexivity}

Narrators may evaluate their stories from their audience's perspective and preempt counter-arguments reflecting on their reliability (3), e.g., "You may think I'm crazy, but..." (Correll 2005, pp. 3-4; Oring 2008, p. 136).

\footnotetext{
${ }^{5}$ Other examples can be found in Wachs (1988, pp. 3I-38), who came across a number of urban legends told as personal experiences when collecting New York crime victim stories; Bennett collected a story told by a relative as a dream, and later as an actual experience (I999, p. I6).
} 


\section{2) Alternative explanations}

In order to make their judgment appear more sound, narrators may offer alternative explanations for their anomalous experience, only to discard them after due consideration (Oring 2008. p. 136). Since this technique pertains to logos rather than ethos, we did not incorporate it in our model.

\section{3) Reluctance}

The narrator presents himself as a reluctant witness: "prior to the alleged event, he did not believe in ghosts, but now..." This avowal of prior skepticism heightens the story's credibility.

\section{4) Ignorance}

Narrators may profess ignorance of the facts, presenting themselves as cautious witnesses who do not jump to conclusions.

\section{5) Testing}

Narrators may report reality checks (I), e.g., in a story about a ghost encounter, the teller might say that he waved his arms to make sure he was not watching his own reflection in the mirror (Oring 2008, p. 137).

Although Oring's bid to match legend studies with classical rhetoric proved seminal for our study, it has certain limitations. His examples, taken from an unspecified sample of legend texts, illustrate his rhetorical model of legend telling, but he does not assess their relative frequency. The legend texts are monologues, whereas legends in the wild typically appear in the context of dialogues or polylogues. Unlike the text samples used in the discursive psychology literature, Oring's examples are reconstructed speech, based on research interviews, not spontaneous discourse. Finally, Oring's rhetoric is a 'rhetoric of truth', which omits the part of the debunkers. It should be augmented by a rhetoric of disbelief (Bennett 1999; Dégh 200I; Donovan 2002; Hufford 1982). All in all, the literature on ethos (however it is labeled) offered a number of rhetorical devices we could apply to the case in hand.

\section{I2.4 The integrated ethos model}

Based on the literature review and on a qualitative pilot study of our online discussions sample, we drew up the following model. We stick to the Aristotelian dimensions of expertise, virtue, and good will, the validity of which has been 
confirmed by social psychologists (McCroskey 200I, pp. 85-87; McCroskey and Young 198I). Because of space constraints, we refer to the literature review for descriptions and examples of these devices.

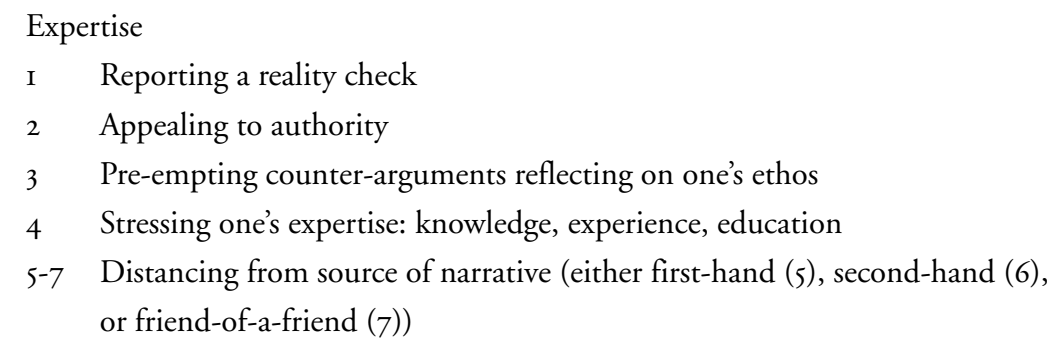

Virtue

8 Disclosing information that could harm one's ethos

9 Referring to one's honesty

IO Searching for common ground by emphasizing personal or issue characteristics

Good will

II Complimenting and thanking the audience

I2 Vilifying a common enemy

The model combines devices described in classical and in modern literature. Note that all techniques could be used by both proponents and debunkers of the claim that drink spiking is for real. By assessing the frequency with which these techniques are used by both parties, we try to improve on Oring's 'rhetoric of truth' (2008).

\subsection{Method}

\subsection{Sample}

Our sample consists of 25 discussions about drink spiking, published on Dutch web-based discussion boards during the years 2000-2008. These discussions were randomly chosen from a larger sample consisting of 54 discussions constructed for a study of argumentation about drink spiking (Hulsebosch et al. 2008). Most of the participants are adolescents who have an interest in dance parties and/or drugs. Typically, the discussion boards belong to communitytype websites; a minority of four discussions were found on news sites, where participants do not belong to one subcultural community. 


\subsubsection{Method of analysis}

A quantitative content analysis was carried out by two coders. The methodological choices involved in the content analysis of online discussions have been discussed before, although most of the literature deals exclusively with computer conferencing in closed educational environments (Marra et al. 2004; Murphy et al. 2006; Rourke et al. 2000; Strijbos et al. 2006; De Wever et al. 2006; Whittaker et al. 1998). The sticking points identified in these papers are unitization, coding manifest versus latent content and reliability. Briefly, the choices we made were as follows.

Unitization: the unit of analysis may be as small as the individual sentence, or as large as the entire discourse. The literature offers various classifications: Rourke et al. (200I) distinguish sentence, paragraph, message, thematic unit and the illocutionary unit; whereas Strijbosch et al. (2006) enumerate discourse, message, meaning, argument and proposition. In order to study ethos techniques, we opted for the message as the unit of analysis, since this is objectively identifiable and produces a manageable set of cases (Rourke et al. 2000).

During pilot analyses, however, it was found that the majority of messages consisted of bursts of invective or (to a lesser extent) approval. Initially we coded these as 'vilifying a common enemy' or 'praising and thanking the audience', but then we realized that these messages did contain argumentative moves, but did not use ethos as a means of persuasion. To cut out the jeering and cheering, we chose the formal criterion of message length, putting aside all messages of 50 words or less. This left 234 relevant messages.

Coding manifest versus latent content: manifest content, such as sentence length, word frequency and other easily observable phenomena, is suited for machine analysis. Analyzing rhetorical devices requires interpretative efforts by human coders, but the inherent subjectivity this entails is held in check by the assessment of inter-coder reliability.

Reliability: various practices are described in the literature to ensure inter-coder reliability. Not uncommonly, one coder identifies segments in which the sought-for phenomenon is present; the second coder then has to identify the phenomenon (Pander Maat 2004). Since this comes down to the second coder second-guessing the first one, we opted for the more severe design of two coders independently analyzing pre-defined units, i.e., the relevant messages.

A number of indexes are used to report inter-coder agreement. Percent agreement is a common measure, but in our view this is too liberal, since this 
fails to account for agreement by chance (Lombard et al. 2002). We used the more conservative Cohen's Kappa instead. Values above 0.75 are generally considered to be good to excellent, those below 0.40 poor and those in between fair to good (Neuendorf 2002; De Weever et al. 2005). One of the drawbacks of Cohen's Kappa is that it fails to compute when both coders do not use the same range of codes (for instance, when coder I uses I, 2, 3 and 4, and coder 2 uses I, 3 and 4 ).

A final problem common to this type of content analysis is that the sought-for phenomena are typically scarce. In the latest pilot test we conducted, half of the variables were not found in the test sample (table I2.I).

TABLE I2.I LATEST PILOT TEST

Ethos technique

Reporting a reality check

Appealing to authority

Pre-empting ethos attacks

Stressing one's expertise

Distancing (first-hand)

Distancing (second-hand)

Distancing (third-hand)

Disclosing harmful information

Referring to one's honesty

Searching for common ground

Complimenting \& thanking

Vilifying common enemies

* = Cohen's Kappa failed to compute

\section{Cohen's Kappa}

Believers

Debunkers

Not found

Not found

Not found

.464

.527

I.OO

I.OO

Not found

Not found

Not found

Not found

Not found

Not found

Not found

\subsection{Results}

The 234 relevant messages were found to contain 217 instances of ethos techniques, i.e., a mean score of 0.93 per message. 173 were used by believers, 44 by debunkers. $\mathrm{Al}$ in all, believers used more, and more varied, ethos techniques than debunkers (but the same amount of arguments (figure I2.I)). 
FIGURE I2.2 THE FIVE MOST FREQUENTLY USED ETHOS TECHNIQUES (PERCENTAGES) (BOTH GROUPS)

Appealing to authority Vilifying common enemies Pre-empting ethos attacks Stressing one's expertise Distancing (first-hand) Other

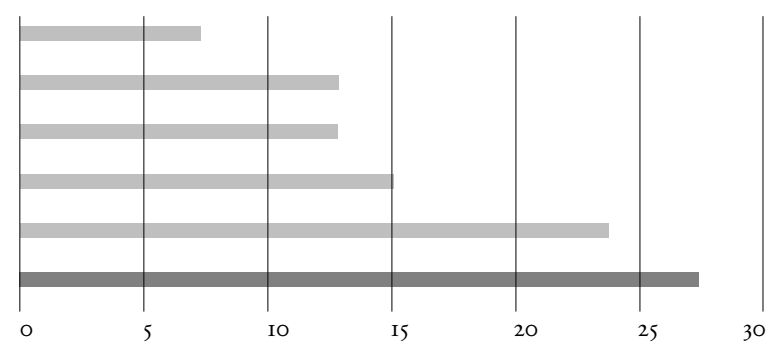

The most common technique in our sample was telling first-hand stories, which was used 52 times (24\%). Stressing one's expertise was used 33 times (I5.2\%), pre-empting arguments reflecting on one's ethos 28 times (I2.9\%) (figure I2.2).

FIGURE I2.3 THE FIVE ETHOS TECHNIQUES MOST COMMONLY USED BY BELIEVERS (PERCENTAGES) ( $\mathrm{N}=\mathrm{I} 73$ )

Distancing (second-hand) Pre-empting ethos attacks Stressing one's expertise Vilifying common enemies Distancing (first-hand) Other

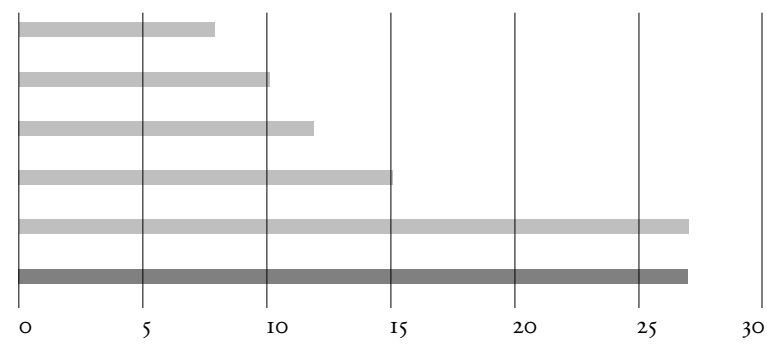

Proponents of drink spiking as a genuine threat never explicitly referred to their honesty, but they did use all the remaining eleven techniques. Most common were first-hand stories (46 times, $26.6 \%$ ), vilifying common enemies comes second (26 times, $15 \%$ ), stressing one's expertise third (22 times, 12.7\%) (figure I2.3). Debunkers used ethos techniques less often than believers (44 versus I73 times). Moreover, their repertoire is less varied (9 different techniques versus II). Reporting a reality check, telling second-hand stories and complimenting and thanking the audience were not found in debunking messages. Of the 44 instances of ethos techniques used by debunkers, stressing one's expertise was most common (II times, 25\%). Pre-empting attacks on one's ethos was used IO times (22.7\%), appealing to authority 7 times (I5.9\%) (figure I2.4). 
FIGURE I2.4 THE FIVE MOST COMMONLY USED ETHOS TECHNIQUES BY DEBUNKERS (PERCENTAGES) $(\mathrm{N}=44)$

\author{
Searching for common ground \\ Distancing (first-hand) \\ Appealing for authority \\ Pre-empting ethos attacks \\ Stressing one's expertise \\ Other
}

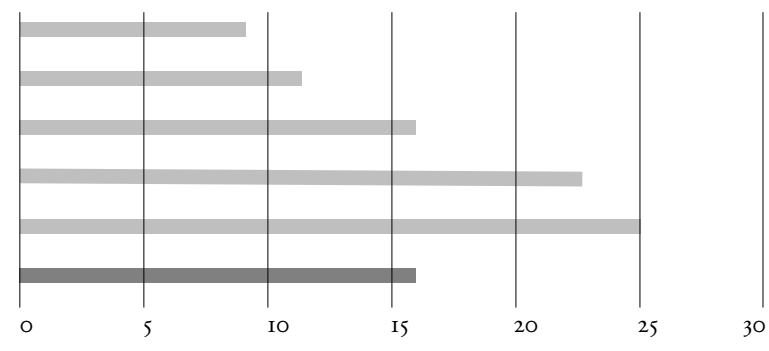

TABLE I2.2 ETHOS TECHNIQUES IN DISCUSSIONS ABOUT DRINK SPIKING (25 DISCUSSIONS, 234 RELEVANT MESSAGES)

\begin{tabular}{|c|c|c|c|c|c|}
\hline Believers & $\mathrm{N}$ & $\%$ & Debunkers & $\mathrm{N}$ & $\%$ \\
\hline I) Reporting a reality check & I & 0.4 & I3) Reporting a reality check & o & o \\
\hline 2) Appealing to authority & 9 & $4 \cdot 14$ & I4) Appealing to authority & 7 & 3.22 \\
\hline $\begin{array}{l}\text { 3) Pre-empting counter-arguments } \\
\text { reflecting on one's ethos }\end{array}$ & I8 & 8.2 & $\begin{array}{l}\text { I5) Pre-empting counter-arguments } \\
\text { reflecting on one's ethos }\end{array}$ & IO & 4.6 \\
\hline $\begin{array}{l}\text { 4) Stressing one's expertise: } \\
\text { knowledge, experience, education }\end{array}$ & 22 & IO.13 & $\begin{array}{l}\text { I6) Stressing one's expertise: } \\
\text { knowledge, experience, education }\end{array}$ & II & 5.06 \\
\hline $\begin{array}{l}\text { 5) Distancing from source of narrative, } \\
\text { category I: first-hand }\end{array}$ & 47 & 21.65 & $\begin{array}{l}\text { I7) Distancing from source of narrative, } \\
\text { category I: first-hand }\end{array}$ & 5 & 2.3 \\
\hline $\begin{array}{l}\text { 6) Distancing from source of narrative, } \\
\text { category 2: second-hand }\end{array}$ & I4 & 6.45 & $\begin{array}{l}\text { I8) Distancing from source of narrative, } \\
\text { category 2: second-hand }\end{array}$ & o & o \\
\hline $\begin{array}{l}\text { 7) Distancing from source of narrative, } \\
\text { category 3: third-hand }\end{array}$ & IO & 4.6 & $\begin{array}{l}\text { I9) Distancing from source of narrative, } \\
\text { category 3: third-hand }\end{array}$ & 2 & 0.92 \\
\hline $\begin{array}{l}\text { 8) Disclosing information that could } \\
\text { harm one's ethos }\end{array}$ & I4 & 6.45 & $\begin{array}{l}\text { 20) Disclosing information that could } \\
\text { harm one's ethos }\end{array}$ & 2 & 0.92 \\
\hline 9) Referring to one's honesty & o & o & 2I) Referring to one's honesty & I & 0.4 \\
\hline $\begin{array}{l}\text { Io) Searching for common ground by } \\
\text { emphasizing personal or issue characteristics }\end{array}$ & 9 & 4.14 & $\begin{array}{l}\text { 22) Searching for common ground by } \\
\text { emphasizing personal or issue characteristics }\end{array}$ & 4 & I. 84 \\
\hline $\begin{array}{l}\text { II) Complimenting and thanking } \\
\text { the audience }\end{array}$ & 3 & I. 38 & $\begin{array}{l}\text { 23) Complimenting and thanking } \\
\text { the audience }\end{array}$ & o & o \\
\hline I2) Vilifying a common enemy & 26 & 22.22 & 24) Vilifying a common enemy & 2 & 0.92 \\
\hline Total & I73 & 79.7 & Total & 44 & 20.3 \\
\hline
\end{tabular}




\section{I2.7 Conclusion}

Our integrated ethos model is based on Oring's (2008) application of classical rhetoric to folk legends (the 'rhetoric of truth'). We improved on this model by adding techniques from other sources and by applying the model to believers and disbelievers alike.

One of the aims of this study was to assess the validity of the ethos techniques described in the literature. Of the classical techniques, explicit references to one's honesty and complimenting and thanking the audience were hardly found at all. The others, however, were. Classical techniques were augmented by devices identified in more recent studies. For instance, the concept of distancing (or footing) proved a useful modern addition to Aristotle.

Both parties participating in the discussions about drink spiking use ethos as a means of persuasion, but believers use more and more varied ethos techniques. Apparently, the burden of proof is on them - they have to work harder to appear sensible and reliable persons. They stand to lose more than their opponents when their personal stories are dismissed as urban legends and their requests for advice remain unanswered.

Of the three Aristotelian ethos dimensions experience, virtue and good will, the first is used the most by both parties. Believers often refer to specific personal experiences, i.e., they claim to be the victims of drink spiking. Disbelievers typically do not counter these claims with their own personal experience stories, but rather stress their experience as party-goers or drug users. Appeal to external authorities plays a minor role for both parties, as does an appeal to their own formal education and position. For the last point, we have to rely on the coders' personal impressions, since we did not distinguish between references to informal experiences and formal education.

Although the discussions can be quite uncivil (as witnessed by the large number of messages consisting of invective), there is a discussion going on. In fact, both parties attempt to bolster their ethos by searching for common ground and pre-empting counter-arguments: they don't want to appear too dismissive or gullible, too distrustful, too much in favor of or against drug use. They generally agree that it is good to be careful and that drug use should be a free choice. The character of these discussions supports the view of the internet as an extension of the public sphere. 


\section{I2.8 Discussion}

The present study has attempted to assess empirically and quantitatively what ethos techniques are used in online discussions about drink spiking, in order to add to the knowledge base about online rhetoric. It remains to be seen to what extent the findings based on this sample can be generalized to other online discussions. The discussions in our sample probably differ from others in which personal experiences are not as centrally important. In the end, the drink spiking discussions are about making sense of personal experiences, not about making claims about public policy.

Political discussions may differ in the role they accord to education and external authority. We expect discussions in this genre to contain more appeals to the authority of experts, news media or other cultural authorities.

More research is needed, but those who want to try this should be forewarned that content analysis of online discussions is a trying and often frustrating procedure. Still, rhetorical research stands to win by collecting and analyzing internet discussions: the Web is full of massive amounts of raw and juicy, largely un-moderated rhetorical material that can be collected unobtrusively.

\section{References}

Andeweg, B.A. and J.C. de Jong (2004). De eerste minuten: Attentum, benevolum en docilem parare in de inleiding in toespraken. The Hague: Sdu.

Aristoteles (2004). Retorica. Transl. and intr. by Marc Huys. Groningen: Historische Uitgeverij. Bennett, G. (1988). Legend: Performance and Truth. In: G. Bennett and P. Smith (Eds.), Monsters with iron teeth. Perspectives on Contemporary Legend vol. 3 (pp. 13-36). Sheffield: Sheffield Academic Press.

Bennett, G. (1989). Playful Chaos: Anatomy of a Storytelling Session. In: G. Bennett and P. Smith (Eds.), The questing beast. Perspectives on Contemporary Legend vol. 4 (pp. 193-2I2). Sheffield: Sheffield Academic Press.

Bennett, G. (1999). Alas, poor ghost! Traditions of belief in story and discourse. Logan: Utah State University Press.

Best, J. and M.M. Hutchinson (1996). The gang initiation rite as a motif in contemporary crime discourse. Justice Quarterly 13, 383-404.

Beynon, Caryl M., C. McVeigh, J. McVeigh, C. Leavey and M. Bellis (2008). The Involvement of drugs and alcohol in drug-facilitated sexual assault: A systematic review of the evidence. Trauma, Violence \& Abuse 9, I78-188.

Braet, A. (2007). Retorische kritiek: Overtuigingskracht van Cicero tot Balkenende. The Hague: Sdu. 
Burger, P. (2002). Contemporary legends in the short stories of Roald Dahl. Contemporary Legend new series 5, $136-158$.

Burger, P. (2009). The Smiley Gang panic. Ethnic legends about gang rape in the Netherlands in the wake of 9/II. Western Folklore 68, 275-295.

Burgess, Adam, P. Donovan and S. Moore (2008). Embodying uncertainty? Understanding heightened risk perception of drink 'spiking'. British Journal of Criminology 49, 848-862.

Burke, M., E. Joyce, T. Kim, V. Anand and R. Kraut (2007). Introductions and requests: Rhetorical strategies that elicit response in online communities. In: C. Steinfield et al. (Eds.), Communities and Technologies 2007 (pp. 2I-39). Proceedings of the third Communities and Technologies conference, Michigan State University.

Capozzoli, M., L. McSweeney and D. Sinha (1999). Beyond kappa: A review of interrater agreement measures. Canadian Journal of Statistics 27, 3-23.

Correll, T.C. (2005). Believers, sceptics, and charlatans: evidential rhetoric, the fairies, and fairy healers in Irish oral narrative and belief. Folklore II6, I-I8. Available: http://findarticles.com/p/articles/mi_m2386/is_I_II6/ai_nI4726805

Dahlberg, L. (200I). The Internet and democratic discourse: Exploring the prospects of online deliberative forums extending the public sphere. Information, Communication \& Society 4, 615-633.

Dale, R. (1978). The tumor in the whale: A collection of modern myths. London: Duckworth.

Dégh, L. (200I). Legend and belief: Dialectics of a folklore genre. Bloomington: Indiana University Press.

Donovan, P. (2002). Crime legends in a new medium: Fact, fiction and loss of authority. Theoretical Criminology 6, I89-215.

Eemeren, F. H. van, R. Grootendorst, A. Francisca Snoeck Henkemans [et al.] (1997). Handboek Argumentatietheorie: Historische achtergronden en hedendaagse ontwikkelingen. Groningen: Martinus Nijhoff.

Ellis, B. (200I). Aliens, ghosts, and cults: Legends we live. Jackson: University Press of Mississippi. Enos, T. and S. Borrowman (200I). Authority and credibility: Classical rhetoric, the Internet, and the teaching of techno-ethos. In: L.G. Rosendale and S. Gruber (Eds.), Alternative rhetorics: challenges to the rhetorical tradition (pp. 93-I09). Albany: State University of New York Press.

Habermas, J. (1989). The structural transformation of the public sphere: An inquiry into a category of bourgeois society. Transl. Thomas Burger. Cambridge: Polity.

Hauser, G.A. (2002). Introduction to rhetorical theory. 2nd ed. Long Grove (Ill.): Waveland Press.

Hill, J.H. and J.T. Irvine (Eds.) (1993). Responsibility and evidence in oral discourse. 
Cambridge [etc.]: Cambridge University Press. (Studies in the social and cultural foundations of language 15 )

Hufford, D. (1982). Traditions of disbelief. New York Folklore 8, 47-55.

Hulsebosch, J.E.R., C.A.W. Pellemans and J. Sajtos [et al.] (2008). "Iemand moet iets in mijn drankje hebben gedaan". Een inhoudsanalyse van discussies over verkrachtingsdrugs binnen diverse communicatiemiddelen. Leiden.

Johnson, N. (1996). Ethos. In: T. Enos (Ed.), Encyclopedia of rhetoric and composition: Communication from ancient times to the information age (pp. 243-245). New York and London: Garland.

Korf, D.J., T. Nabben, F. Leenders [et al.] (2002). GHB: Tussen extase en narcose. Amsterdam: Rozenberg.

Lamont, P. (2007). Paranormal belief and the avowal of prior scepticism. Theory \& Psychology 17 (5), 68I-696.

Lombard, M., J. Snyder-Duch and C.C. Bracken (2002). Content analysis in mass communication: Assessment and reporting of intercoder reliability. Human communication research 28, 587-604.

Marra, R.M., J.L. Moore and A.K. Klimczak (2004). Content analysis of online discussion forums: A comparative analysis of protocols. Educational Technology Research and Development 52, 23-40.

McCroskey, J.C. and T.J. Young (198I). Ethos and credibility: The construct and its measurement after three decades. Central States Speech Journal 32, 24-34. Available: www.jamescmccroskey.com/publications/o96.pdf

McCroskey, J.C. (200I). An introduction to rhetorical communication. 8th ed. Boston [etc.]: Allyn and Bacon.

Murphy, E., J. Ciszewska-Carr and M. A. Rodriguez Manzanares (2006). Methodological issues in the content analysis of online asynchronous discussions: Unitizing, reliability, and latent content. Journal of the Research Center for Educational Technology 2, nr. 2. http://www.rcetj.org/?type=art\&id=79597\&

Neuendorf, K.A. (2002). The content analysis guidebook. Thousand Oaks: Sage.

Oring, E. (2008). Legendry and the rhetoric of truth. Journal of American Folklore I2I, I27-I66.

Pander Maat, E. (2004). Wervend taalgebruik in persberichten - werkt het? Hoe journalisten omgaan met persberichten in de luchtvaartsector. Tijdschrift voor Taalbeheersing 26, 209-225.

Pappacharissi, Z. (2002). The virtual sphere: The internet as a public sphere. New Media \& Society 4, 9-27.

Potter, J. (1996). Representing reality: Discourse, rhetoric and social construction. London [etc.]: Sage. Potter, J. and A. Hepburn (2008). Discursive constructionism. In: J.A. Holstein and J.F. 
Gubrium (Eds.), Handbook of constructionist research (pp. 275-293). New York and London: Guilford Press.

Potter, W. and D. Levine-Donnerstein (1999). Rethinking validity and reliability in content analysis. Journal of Applied Communication Research 27, 258-284.

Rourke, L., T. Anderson, D.R. Garrison and W. Archer (2000) Methodological issues in the content analysis of computer conference transcripts. International Journal of the Artificial Intelligence in Education 12, 8-22. Available: http://hal.archives-ouvertes.fr/docs/oo/19/73/19/PDF/rourkeoI.pdf

Slotkin, E.M. (1988). Legend genre as a function of audience. In: G. Bennett and P. Smith (Eds), Monsters with Iron Teeth. Perspectives on Contemporary Legend vol. 3 (pp. 9I-IoI). Sheffield: Sheffield Academic Press.

Smith, G. (198I). Urban legend, personal experience narrative, and oral history. ARV: Scandinavian Yearbook of Folklore 37, I67-I73.

Strijbos, J.-W., R.L. Martens, F.J. Prins and W.M.G. Jochems (2006). Content analysis: what are they talking about? Computers and Education 46, 29-48.

Ueding, G. (Ed.) (1994). Historisches Wörterbuch der Rhetorik. Darmstadt: Wissenschaftliche Buchgesellschaft.

Wachs, E. (1988). Crime-victim stories. New York's urban folklore. Bloomington/ Indianapolis: Indiana University Press.

De Wever, B., T. Schellens, M. Valcke and H. Van Keer (2006). Content analysis schemes to analyze transcripts of online asynchronous discussion groups: A review. Computers and Education 46, 6-28.

Warnick, B. (2007). Rhetoric online: Persuasion and politics on the World Wide Web. New York: Peter Lang.

Whittaker, S., L. Terveen, W. Hill and L. Cherny (1998). The dynamics of mass interaction. Proceedings of the 1998 ACM conference on computer supported cooperative work, Seattle (pp. 257-264). New York: ACM.

Witschge, T. (2007). (In)difference online: The openness of public discussion on immigration. Unpublished Doctoral dissertation. Amsterdam: Universiteit van Amsterdam.

Wooffitt, R. (1992). Telling tales of the unexpected: The organization of factual discourse. Hemel Hempstead: Harvester Wheatsheaf. 


\title{
I3 The Popular Virgin and the Wolf in Sheep's Clothing: A Case Study of the Imaging of Victims and Offenders
}

\author{
WILLEM KOETSENRUIJTER AND \\ GABRY VANDERVEEN
}

\section{I3.I Introduction}

Crime is popular and this popularity has a long-standing tradition. Most people like to read news about crime, watch crime series on television, read books about crime, and a large number of movies are about crime. Evidently, we have a 'pleasurable fascination with crime' (Katz 1987, p. 57). Crime is probably one of the most popular subjects in the stories people tell each other, including news stories.

Stories such as these do not only provide information about (specific types and incidents of) crime and the criminal justice system, but they also give information about the cultural and social rules of living and provide an explanatory framework of how to make sense of everyday life. Since it is easier to make sense of a world in which everything is either black or white, without any nuances, it might come as no surprise that (news) media tend to focus on the stereotypical crimes and the stereotypical actors: victims and offenders. By using specific rhetorical devices (frames) we are encouraged to interpret words, phrases, or visual images, as well as stories in general, in a specific way. In this chapter, we examine how the Dutch media constructed stereotypical images of the victim and the alleged offender by using these frames or rhetorical devices in a particular case; the case of Holloway/Van der Sloot. By making content analyses of newspaper and magazine accounts, photographs and television programs, it becomes clear how the Dutch media convinced the public of Holloway's innocence, and Van der Sloot's guilt. We will describe how the Dutch media presented the Van der Sloot/Holloway case, both visually and verbally, and what means were used to construct guilt and innocence. 
Our general question in the project is: How do media construct frames of victims and offenders? More specifically for this chapter the question is: What rhetorical means have the media used to construct guilt and innocence by portraying Joran van der Sloot as an ideal offender and Natalee Holloway as an ideal victim? In this chapter, we look at news as a narrative, which has specific social functions that we will discuss. Also, news stories selectively depict reality and play a major role in the construction of social problems. This selective depiction of reality is demonstrated overwhelmingly by empirical studies that illustrate the stereotypes of victims and offenders which are common in (news) stories. These stereotypes are partly created by rhetorical devices which we will elaborate on. The following section describes the method we used to study the cases and the various instruments used in different content analyses. When presenting the results, we focus on the photographs published in tabloids, magazines, newspapers and on the Internet.

Finally, the chapter ends with a discussion of the main implications of this study, which suggest that Holloway can be presented as a stereotypical victim with features that fit the stereotype. Van der Sloot, on the other hand, is a more round and complex character and not a stereotypical offender. A methodological point is made about the limits of a quantitative content analysis of the photographs. We found that the quantitative instruments were not able to fully grasp the meaning of the images and we make a case for using a mixed methods research design (Cresswell and Plano Clark 2007). Our analysis shows that some media - like the Peter R. de Vries Tv program - use several rhetorical devices to present the distinction between victim and offender in as clear a manner as possible. Yet, in cases like the Holloway/Van der Sloot case, when the stereotypes can be challenged, the just world is challenged too and the rhetoric of victims and offenders is less simple and clear-cut, enabling discussion and different scenarios about who is good and evil to exist. But, first we will begin by broadly describing the Van der Sloot/Holloway case. ${ }^{1}$

\subsection{The case: Van der Sloot/Holloway}

The case which we have focused on involves the disappearance of the American high school student Natalee Holloway, who spent her holidays with her classmates on the Dutch Caribbean island of Aruba.

\footnotetext{
${ }^{\text {I }}$ With thanks to our students L. van Dijk, D. Guldemond, M. Lammers, V.B.M. Nistro, N.J.K.J. Raats and C.W. Wong, who, among other things, collected and coded the data.
} 
Natalee Holloway disappears after a night of dancing and drinking. Two Surinam brothers - Deepak and Satish Kalpoe - and a Dutch adolescent named Joran van der Sloot are arrested as suspects, but are released a few months later because of a lack of evidence. Almost a year after the disappearance of Holloway, Dutch and Aruban television broadcast a reconstruction in the program Opsporing verzocht (comparable to America's Most Wanted). When Van der Sloot, the son of a Dutch judge, returns to the Netherlands, he is arrested again. Once again, he is released because of a lack of evidence. The Dutch crime reporter Peter R. de Vries concentrates on the case in his TV program The Peter $R$. de Vries Show and presents footage filmed using a hidden camera. De Vries puts the hidden camera in a car, and uses an accomplice, Patrick van der Eem, to find out what happened. Van der Sloot thinks of Van der Eem as his friend, not knowing that he is, in fact, working for De Vries, and he talks with Van der Eem in the car.

Caught on camera, Van der Sloot tells Van der Eem that he and Natalee were making out at the beach, when all of a sudden she started having convulsions. Not knowing what to do, he phones a friend, some people guess that this friend is in fact his father, who helps him to put her in a boat. He states that she was dumped in the sea. The body is never found. This episode of The Peter R. de Vries Show, trailed as "the confession", received a lot of media attention. The week after the broadcast, Van der Sloot appears on television and says that he made the whole story up. He is not arrested because legal evidence is still lacking. Currently, Van der Sloot is still a free man. ${ }^{2}$

The case generated a huge amount of media exposure, not only in the Netherlands, but also in the rest of Europe, and - because Holloway was American - in the United States as well. Baynes (2008) gives an overview of the amount of media coverage of the case. According to Google Trends, during the month after Holloway's disappearance, the story generated thirty times the number of Google searches as the American Secretary of State, Condoleezza Rice. During the month of June 2005, Google searches for Holloway were more than double the number of Iraq war searches. Holloway's disappearance was one of the top ten stories on network and cable television and it made the top ten stories list for the week of February 4-IO 2008. According to a Lexis Nexis Report, the story was at the top of the most talked about

\footnotetext{
${ }^{2}$ Since June 20IO, Van der Sloot is locked up in a Peruvian jail, charged with murdering a Peruvian girl.
} 
news stories in 2005 (Baynes 2008). The interest in this particular case, that media and the public shared alike, is also reflected in the publications about the death of Van der Sloot's father on sale in February 2oro. In these recent publications, De Vries is interviewed again and argues that the case will never be solved, since the father's knowledge and role will now never be known.

The Van der Sloot/Holloway case is a typical high-profile crime (Chancer 2005), receiving a lot of attention in the media. These media, including the footage from the hidden camera interviews with De Vries, from Van der Sloot and his parents, Holloway's mother Beth, websites and books written by the main characters (i.e., books by Van der Sloot, the accomplice Van der Eem, Holloway's mother, Holloway's father), two Dutch plays, and a movie broadcast by Lifetime in the USA, all provide information on this case. All these media are the main sources of information; this is elaborated in the following section.

\section{I3.3 Theoretical framework: Media as sources of information}

Media are usually the most important source of information about crime. Most people have no direct experience and hence no knowledge of (specific types of) crime and the criminal justice system. Therefore, people obtain their knowledge, ideas and attitudes from other people and from the (news) media. Yet, the information which people get from the media does not necessarily reflect reality. On the contrary, numerous studies have found that a variety of media, such as movies, cartoons and newspaper accounts, tend to focus on the more sensational, unusual and stereotypical crimes (Vanderveen 2006). All these media, these kinds of sources of information, provide the social context and the material and ideological constraints that act on individuals.

In general, the way a society gives meaning to social phenomena such as crime and specific incidents thereof, and the way news media use rhetorical devices to depict these phenomena, can be described in terms of framing. Though the definition of framing is still under discussion (e.g., Scheufele 2008), in this study the concept contributes to an understanding of how a frame, consisting of a set of characteristics - or rhetorical devices - works to picture or to frame a social phenomenon. Framing concerns the inevitable process of selective influence over the individual's perception of the meanings attributed to words, phrases, or visuals. A frame - the set of characteristics used to frame a phenomenon - defines the packaging of elements of rhetoric in such a way as to encourage particular interpretations and to dis- 
courage others. Ervin Goffman (1974, p. 2I), one of the founding fathers of framing theory, suggests that the idea of frames can be used to label the "schemata of interpretation" that allow individuals or groups "to locate, perceive, identify, and label" events and occurrences, thus rendering meaning, organizing experiences and guiding actions. In our study, frames are considered the means that media use to construct the picture of victims and offenders.

Similar to Gamson and Lasch (1983), our analysis focuses on the elements in visuals that make them persuasive. These framing devices are part of the rhetorical structure of visuals (photographs, info-graphics), like metaphors, stereotypes and particular features of the image. Thus, in our study about the guilt or innocence of the leading actors of the assumed murder of the American high school student Natalee Holloway, certain aspects of the visuals function as rhetorical devices to convince the public. All sorts of media, as sources of information about crime and criminal incidents, employ frames or rhetorical devices to construct a story or narrative. As we will discuss belowbelow, whether the source of information is fiction or news is, in line with narrative theory, irrelevant.

\section{I3.4 Media as social context}

Stories from various sources provide information about cultural and social rules for living and offer an explanatory framework of how to make sense of everyday (urban) life. According to Wachs (1988, p. 32), the purpose of a lot of stories that people tell one another is to address human predicaments by showing how people act in times of crisis and danger; they provide models for the reconstruction of everyday experience. Wachs (1988) suggests the stories stress street smarts; the importance of being on one's guard, being aware of the environment, following one's intuition and being suspicious, as part of sensible (urban) behaviour, since it increases the ability to act in case of danger:

Street smarts were developed by the American National Crime Prevention Council for policy purposes and are propagated by American city councils and police departments. These street smarts portray the popular images of crime as well. "Wherever you are - on the street, in an office building or shopping mall, driving, waiting for a bus or subway - stay alert and tuned in to your surroundings", "Trust your instincts. If something or someone makes you uneasy, avoid the person or leave". The popular image of the offender as a stranger instead of an acquaintance is reflected by, for example: "Have to work late? Make sure there are 
others in the building, and ask someone - a colleague or security guard - to walk you to your car or transit stop"; "Never hitchhike or accept rides from strangers"; "If you have to walk in the street, walk facing traffic. A person walking with traffic can be followed, forced into a car, and abducted more easily than a person walking against traffic" and "Walk confidently, directly, and at a steady pace. Don't stop to talk to strangers." (NCPC, n.d.)

Stories have an important function in warning people, especially women, about dangers and threats. Stories tell them how to protect themselves in cases of danger. The more frightening stories, in particular, serve as cautionary tales (Wachs 1988, p. 6I). Obviously, several sources reinforce each other; they result from and further shape the shared assumptions about the appropriate behaviour for people and victims and set the limits of this appropriate behaviour (e.g., Green, Hebron and Woodward 1987). Sometimes, the warnings are very explicit. For example, immediately after the Lifetime movie on Holloway/Van der Sloot, Beth Holloway (Natalee's mother) was screened in a public service announcement, in which she encouraged (young) people to take the proper precautions before traveling abroad (mylifetime.com, n.d.).

In addition to the social function that stories have, teaching people "what crimes to fear, where and when to be afraid, who is dangerous and who is safe" (Madriz 1997, p. 343), there are other consequences as well. Indeed, the information the public gets from the media about crime, victims, offenders and the criminal justice system can have several other consequences. For example, people may become more afraid of crime and of becoming a victim of crime (Heath and Gilbert 1996). Also, the overrepresentation of African-Americans in offender statistics leads to the development of stereotypical notions of the relationship between race and violent behavior (e.g., Dixon 2007, 2008). Besides the effect on perceptions and attitudes, information portrayed in the media on particular cases can have direct, behavioral consequences in real life as well. For example, high-profile cases, cases that get an extraordinary amount of attention from the media, can lead to public hatred, loathing and the commission of vigilante actions (see Jones and Wardle 2008). As noted previously, the case in this current study is such a high-profile case. The Van der Sloot/Holloway case received extensive (news) media coverage in the Netherlands, Aruba and the Netherlands Antilles as well as in the United States. 


\section{I3.5 News as narrative}

In this study, the question as to whether the source of people's information is fiction or news, is irrelevant. The media are usually the most important source of information about crime, and what specific type or background the media have is of little interest here. In other words: this study is in line with narrative theory. Narrative Theory, developed in the seventies and the eighties (Fisher 1987) changed the idea that news is objective, that it is about the truth and nothing but the truth. Narrative theory created a new perspective on news and the function of news in society. Ettema and Glasser (1988) set out this perspective in their article called 'Narrative Form and Moral Force'. They point out that - referring to Tuchman (1976, p. 97) - news is a selective reality with its own internal validity, with particular forms and themes. The writers suggest that our fascination with crime can be explained because of the way crime news helps us to establish our ideas about good and evil, about normal and deviant. Every time we read or see news about crime we establish our norms; thus, crime news also functions as a mean of establishing coherence in society or within groups in that society. Similarly, Kellner (I995, p. 24) states: "Media images help shape our view of the world and our deepest values; what we consider good or bad, positive or negative, moral or evil". Other researchers follow this line of reasoning. For example Grabe et al. (2006), who describe a number of studies (Erikson 1966; Grabe 1999; Schattenburg 198I; Stevens 1985) which have examined the potential of crime news to serve social functions and found patterned evidence that journalistic narratives support social control, the construction of morality and social integration. With what is called by Durkheim and Mead "episodes of shared outrage", individuals reaffirm their membership of society (Durkheim I933; Mead 1918). Thus, news, like any other source of information, provides narratives or stories that contain information about cultural and social rules for living. This holds for several types of news programmes which we describe in the following section.

\subsection{News as entertainment}

Analogous to Ettema and Glasser (1988) who suggest looking at news as narratives, Surette and Otto (2002) state that news and entertainment cannot be clearly distinguished; this is reflected in the term infotainment. Infotainment refers to the blurred boundaries between fact and fiction in media depictions. News media, or other predominantly factual programs, use dramatic, recon- 
structive elements (Mason 2002). Besides news and news magazines as common types of infotainment, reality-based crime shows and co-opted courtroom dramas and media trials can also be distinguished (Craig and Newcomb 2003; Surette 1989; Surette and Otto 2002). For example, a violent incident can be presented as news with "story lines, plot and character development, victims, villains, and dramatic endings" (Surette and Otto 2002,p. 445). Gilliam and Iyengar (2000) also found that (local) news stories follow a 'narrative script' that contains two essential elements, namely that the crime is violent and the perpetrator is a non-white male.

Reality-based crime shows broadcast on television, like COPS, Real Stories of the Highway Patrol and America's Most Wanted (see Eschholz et al. 2002) typically employ dramatizations of actual crimes, police narratives and interviews or actual video footage (Surette and Otto 2002). The format that is often used by these shows and news media is a secular version of a morality play, building on the audience's familiarity with narratives that spell out simple and clear truths (Altheide 1997, 2002). The Dutch crime reporter, Peter R. de Vries, has a television show which is of special interest to this study as it complies with the format of such a morality play; the program adheres to existing traditions and morality in the history of popular culture and fulfils a traditional need for a sense of justice (Reijnders 2005).

\section{Peter $R$. de Vries}

Peter R. de Vries is the presenter of a non-fiction (Dutch) crime television program, in the tradition of America's Most Wanted or Crime Watch UK. Reijnders (2005) studied sixteen episodes of The Peter R. de Vries Show, in which 2I murder cases were featured. In 14 of the $2 \mathrm{I}$ cases, the murder victim was female; in four cases the victim was a child and in only three cases was the murder victim a man. The victim is presented as innocent and helpless, by highlighting characteristics that contribute to such an image. According to Reijnders, any information that contradicts the stereotypical representation of the victim and offender is ignored. The show uses rhetorical devices to convince the public of the proposed scenario, including the alleged innocence and guilt of the victim and offender. For example, the mourning family of the victim is shown extensively. A lot of information, in the form of photographs and TV footage, is given about the offender too. This information focuses on personal details, like dress, appearance and life style, which reinforce the idea that the person is indeed an offender. Reijnders states Peter 
R. de Vries "commits character assassination of suspects before they have been tried and convicted." (Reijnders 2005, p. 644). As we will see, the characteristics of The Peter $R$. de Vries Show outlined by Reijnders appear to be applicable to the reports on the Van der Sloot/Holloway case as well. The main episode was highly successful and De Vries got an Emmy for it; the episode also appeared to exert a strong influence on public opinion. This episode presented Joran van der Sloot as an offender without a conscience, and Natalee Holloway as his innocent victim: two stereotypes that were convincingly presented to the public by using rhetorical means.

\section{Stereotypes of crimes, victims and offenders}

We have already referred to stereotypes in the media presentations of crimes, victims and offenders. The mere classification as offenders and victims gives meaning to the reality depicted by our media. These kinds of simple contrasts - victim and offender, good and evil - make a storyline clear. This arrangement, the classification of offenders and victims, helps media consumers to give meaning to their reality and define our general ideas about good and evil. Also, these stereotypes conform to our belief in a just world: people deserve what they get (Lerner 1980). The stereotypical victim has a set of typical characteristics. Vanderveen (2006) analyses the literature on media representations of offenders and victims and presents the characteristics that are perceived to be essential for a victim (see table I3.I). A victim can be perceived (and represented) as having all these characteristics. Christie (1986, p. I8) refers to this as the 'ideal victim': "a person or a category of individuals who - when hit by crime - most readily are given the complete and legitimate status of being a victim". An ideal victim behaves in a manner which conforms to this specific social role; any role inconsistencies make the victim less ideal and less stereotypical, which leads to the attribution of more responsibility (i.e., "she shouldn't have been drinking"). Information about inconsistencies with the stereotype can be ignored by media representations, which, according to Reijnders (2005) is what The Peter R. de Vries Show does. Also, media consumers, people themselves, can discredit information that is inconsistent with their concept of the ideal victim by for example, giving these pieces of information less weight or reinterpreting them. The same holds for the 'ideal offender': the more stereotypical a suspect is, the easier people find it to acknowledge that the suspect is indeed the offender and attribute full responsibility to him. 
TABLE I3.I ESSENTIAL CHARACTERISTICS (VANDERVEEN 2006)

\begin{tabular}{|c|c|}
\hline & Essential characteristics of ideal victim/ideal victimization \\
\hline Victim & Weak, vulnerable, innocent \\
\hline Offender & Evil, cruel and bad \\
\hline Activities victim & Respectable (e.g., going to school, getting groceries for sick friend) \\
\hline Relationship & Stranger, unknown offender, no relationship between victim-offender \\
\hline Incident & Physical force/violence, deliberately \\
\hline & Victim protests and resists (physically) \\
\hline & Offender is brutal, cruel, violent \\
\hline & $\begin{array}{l}\text { Random \& senseless (random violence) or specific selection (e.g., series } \\
\text { of eroticized murder) }\end{array}$ \\
\hline Protection & Victim has made a reasonable effort to protect him/herself \\
\hline Location & $\begin{array}{l}\text { Somewhere where s/he cannot possibly be blamed for being, somewhere } \\
\text { s/he was supposed to be (e.g., home) }\end{array}$ \\
\hline Time & $\begin{array}{l}\text { Somewhere where s/he cannot possibly be blamed for being at that } \\
\text { particular time, somewhere s/he was supposed to be at that time } \\
\text { (e.g., during the day) }\end{array}$ \\
\hline
\end{tabular}

As is overwhelmingly reported in the literature, the two powerful stereotypes designate the victim as a young, weak, vulnerable, beautiful and innocent woman, who lives a peaceful life and is loved by family and friends (Vanderveen 2006). The offender is constructed as evil, cruel, cold-blooded - or hot-headed as Reijnders (2005) states. The crime incident involves a victim who is doing something respectable: she is working, going to school. When the offender, unknown to her, brutally and violently attacks her, the victim protests and resists so that she can protect herself. The location of the crime is somewhere where she cannot possibly be blamed for being at that particular time. Stories in the (news) media comment on these different aspects, socially constructing a more or less stereotypical offender and victim. In some cases, for example, when (very) young children are involved, the information fits the stereotypes more easily: the rhetorical devices are clear. For example, in the case of the young girl Madeleine McCann, who disappeared in the south of Portugal. Clearly, this girl has the characteristics of an ideal victim: a three-year old blond girl, sleeping in the hotel room of her parents. Yet, in this particular case, the role of the offender is not clear. Are the parents victims of a lost child or were they involved in her disappearance (Machado and 
Santos 2009)? These less clear-cut cases elicit a lot of discussion: people don't know how to make sense of them, but nonetheless want to. The discussion on responsibility, guilt and innocence increases, especially in more complex cases where a victim and an offender do not entirely conform to their stereotypical formats. Vanderveen (2006) argues that this is because, in cases such as these, one can identify with both the victim and the offender, as well as contrast oneself with them.

\section{Stereotypes in a just world: identification and contrast}

Cases including an ideal victim and an ideal offender are clear: we can identify with the victim (or the mourning family) and contrast ourselves with the offender. In general, people's reactions can take different forms when they are faced with visual and verbal information about victims, offenders and the reactions of law enforcement officials and actors within the criminal justice system. Four reactions are distinguished here, based on the possibility of identification or contrast with the victim and/or offender (see Vanderveen 2006). The elicited identification or contrast with the victim and/or offender influences people's reactions, such as attributions of responsibility and culpability, and penal attitudes, attitudes to punishment and sentencing decisions.

Starting from a social comparison perspective, which suggests that people relate and compare themselves to others, two comparison targets can be identified: the victim or the offender. People can engage in downward comparisons with the victim and offender, considering the role of victim or offender as not being desirable (see Wills I98I). Next, people can identify with the target, or contrast themselves, as is suggested by the identificationcontrast model (Buunk and Ybema 1997). Identification has been considered to be closeness to the target, forming a bond with the target, being similar in personality to the target or viewing the situation of the target as a similar potential future for oneself (see Carmona et al. 2008). Identification with the offender involves interpreting the offender as less stereotypical. For example, identification with both victim and offender refers to a tragedy (see table 13.2); in this situation the individual offender has not acted in a voluntarily capacity under the given circumstances (Fletcher 1974, p. 1306). These 'excusing conditions' make the offender less culpable, responsible and blameworthy, causing less punitive reactions and encouraging empathy with offender and victim. 
TABLE I3.2 IDENTIFICATION AND CONTRAST WITH VICTIM AND OFFENDER: FOUR TYPES OF REACTIONS (BASED ON VANDERVEEN 2006)

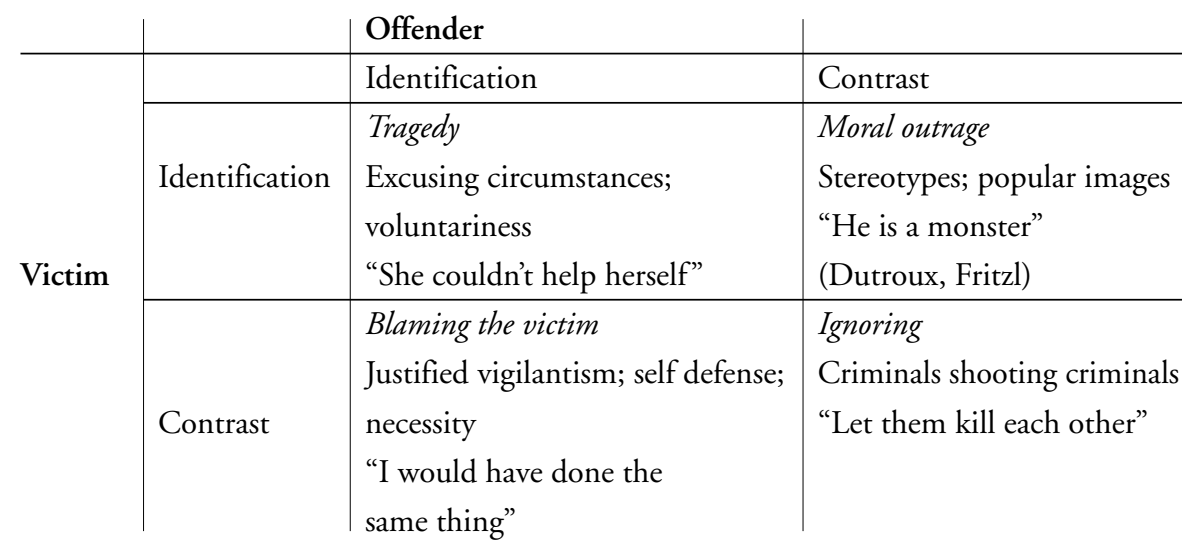

In cases with an 'ideal' victim and an 'ideal' offender, in which victim and offender are presented in a stereotypical manner, people will contrast themselves with the offender, thinking he is entirely different, or not even human: a monster or beast. Blaming the victim occurs when people contrast themselves with the victim, for example, because s/he acted in ways that are disapproved of, accompanied by identification with the offender. Another typical case would be a father taking the law into his own hands by killing the brutal rapist of his young child (see Neapolitan 1987).

The likelihood of identification or contrast can be experimentally manipulated (e.g., Aguiar et al. 2008), and is also manipulated by the (news) media. In the case of the disappearance of Holloway, The Peter $R$. de Vries Show used particular rhetorical means: framing devices in order to make Joran van der Sloot a more stereotypical (ideal) offender, encouraging the public to contrast with him. Also, the rhetorical means showed Natalee Holloway as a stereotypical (ideal) victim, encouraging the public to identify with her (and her mother). The main episode of the show in which the footage from the hidden camera was shown, provided an apparently clear picture featuring an immoral offender and an innocent victim. If it were such a clear-cut, stereotypical case, moral outrage would prevail. Yet, in this case The Peter $R$. de Vries Show wasn't the only source of information. Other sources presented information which was less consistent with these stereotypes, showing a more complex narrative in which good and evil seem less clear. Because the stereo- 
types can be challenged and contested with other information, the public, and young people in particular, are able to both identify with Holloway and Van der Sloot, and contrast themselves with them. Thus, besides moral outrage (see table 13.2), other reactions are possible as well. The complexity of the narrative generates a lot of discussion, possibly because in a case that is less stereotypical, there is a stronger need to make sense: the just world is challenged. The narrative has generated a lot of discussion over a longer period of time, which is hardly surprising. The case involves (possibly) an accident (convulsions); before Holloway was missing, the victim and offender were young people having a good time; and last but not least, the story has an open ending: different scenarios are still possible. These elements enable (young) people to identify with both victim and offender.

\section{Method}

To investigate the rhetorical means that media employed to construct the guilt of Van der Sloot and the innocence of Holloway, we employed a quantitative and qualitative content analysis of text, photographs and footage from a variety of sources. In this chapter, we focus only on the photographs. We will briefly describe the two checklists we used to code the information derived from photographs published in tabloids, magazines, newspapers and on the Internet.

\section{Dataset}

All the material was published in the period from May 3I 2005 until March 3I 2008. Several archives were searched, including the archive of the public broadcasting company, archives of commercial television programs and Lexis Nexis. The photographs that provide the relevant cases for this chapter were collected from different databases. First, photographs from newspapers, including De Volkskrant (broadsheet), Telegraaf (middle market - tabloid) and three free Dutch newspapers (Spits, Metro and De Pers), were collected from the кв (National Library) and the online database archives of newspapers (Lexis Nexis). Photographs from magazines were collected from databases provided by the magazines. We chose three popular Dutch magazines: the popular men's magazine Panorama and two women's (gossip) magazines Privé and Story. These three could be seen as leading tabloids in the Netherlands and they paid a lot of attention to the case. Other photographs were collected on the internet using the website FlickR, an international social networking 
site based on sharing and exchanging amateur and professional photographs. Our collection amounted to a total of 283 photographs, I89 (66\%) of Joran van der Sloot and 94 (33\%) photographs of Natalee Holloway.

\section{Instruments}

As text, television programs and photographs were analyzed, a total of six instruments (A to F, see table 13.3) were developed to examine the content: one on Joran van der Sloot and one on Natalee Holloway, for the three different formats (television, photographs and texts). In part, the instruments or checklists are the same in the checklists for the different formats; other variables are specific for one of these formats.

TABLE I3.3 SIX INSTRUMENTS

\begin{tabular}{l|ll} 
& Van der Sloot & Holloway \\
\hline Text & A & B \\
Television & C & D \\
Photographs & E & F
\end{tabular}

Some variables were the same for both actors, for example, formal variables concerning the description of the size of the photograph, use of color, publishing date, caption used and the source. Other variables included in both checklists referred to, for example, the position of the body (i.e., standing, sitting), the relative size of the person depicted, facial expression, or where the photograph was taken (i.e., home setting, public setting).

From the literature and an exploratory qualitative analysis, we derived more than fifty variables of stereotypical features. To mention a few: the physical appearance of Van der Sloot included variables related to whether or not the photograph showed him unshaven, with cops, handcuffed, wearing jeans, wearing a baseball cap, wearing a t-shirt, sweating and so on. Physical features of Natalee Holloway that were coded included the use of make-up, whether or not she appeared to be sweating. Other variables included, for example, whether Van der Sloot or Holloway were depicted with friends, with a drink in their hands, a joint, in interaction with other persons, etc. Figures I3.I and I3.2 show a selection of the photographs found. 
FIGURE I3.I DEPICTING THE OFFENDER

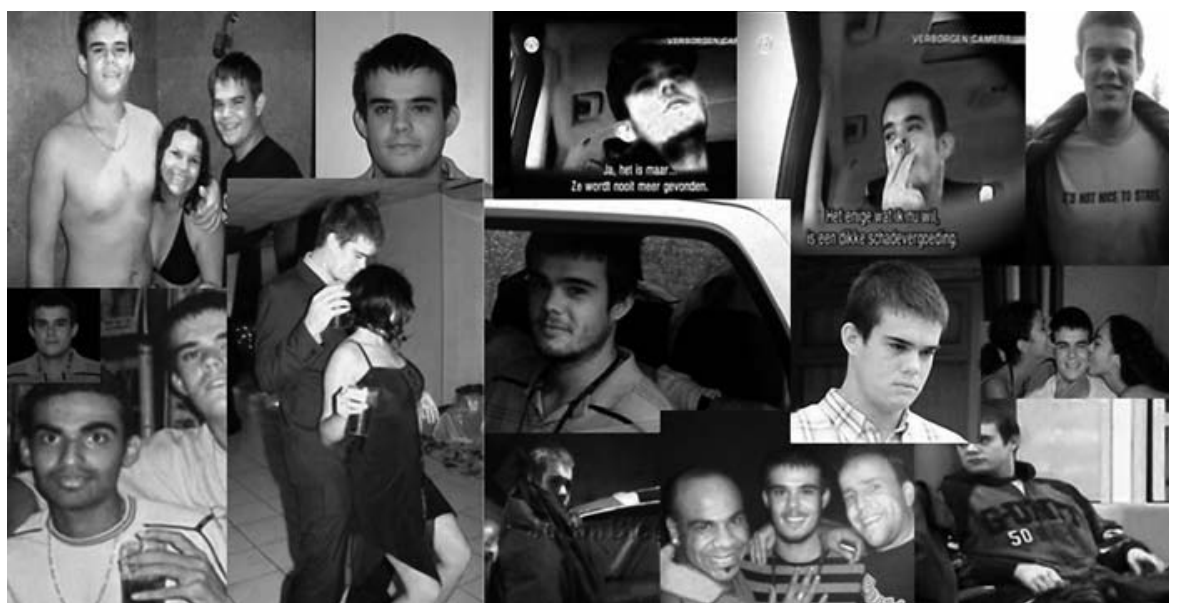

FIGURE I3.2 DEPICTING THE VICTIM

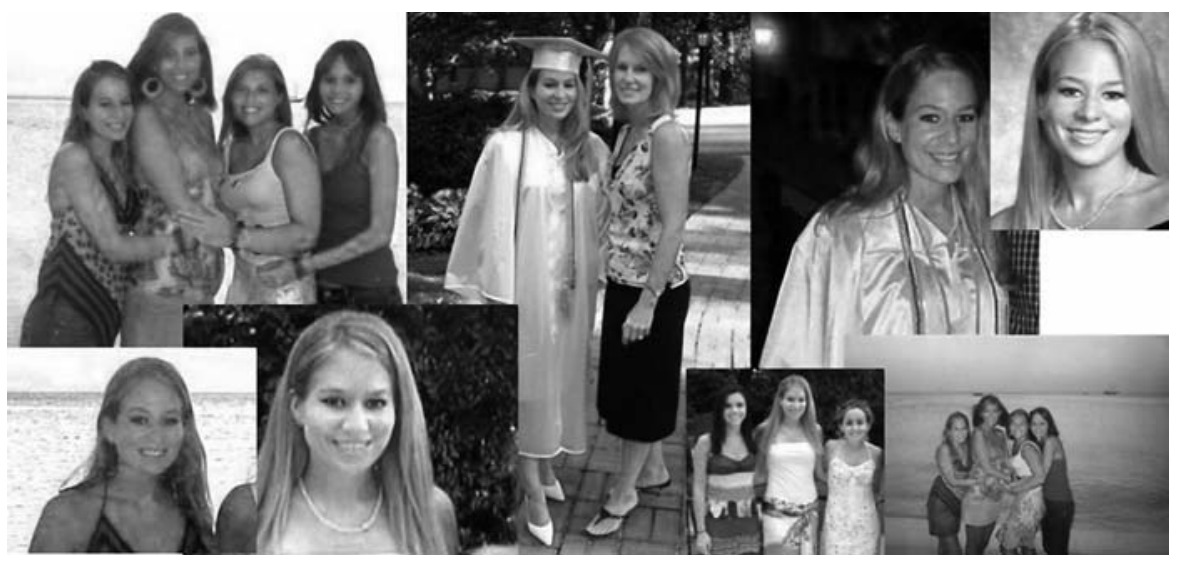

A content analysis gives quantitative characteristics of the collection of photographs in terms of the frequency with which the variables occurred. All the photographs were coded by two or more coders using the relevant checklist. In a pilot training session, the coders were trained and instructions were defined explicitly. The checklists were adjusted till inter-rater reliability was sufficient; for all the variables scored, Cohen's Kappa was at least .75. After coding the data from a total number of 283 photographs, checklists were entered in SPSs, a statistical software program. 


\section{Results}

Our main research question concerned the means that were used to construct the guilt of the offender and the innocence of the victim, in this particular case. We looked at these means in two ways: first we collected the frequencies of distinctive features and afterwards we combined these means in terms of frames: collections of variables that work together to portray the main characters.

The variables were aggregated by way of a qualitative analysis of the photo material and the literature. After the analysis it became clear that some variables gave almost no variance or just did not occur. We found, for example, almost no photographs with Joran and Natalee together and no photographs where Joran was smoking. The last finding was particularly remarkable, because the stills from the television show of Joran in the car, smoking pot presented a very strong, almost iconic image of him that lasted long after the television show. But indeed: on almost all of our photographs, he was NOT smoking. Table I3.4 summarizes the percentages of photographs that show these particular characteristics.

Table 13.4 shows that most of the variables were coded as binominal values: yes or no. So it is clear that when Natalee is depicted in $85 \%$ of the photos with others, in $15 \%$ she is alone. Most of the photos are taken from an eye-level perspective, looking right into the camera and most of the photographs are posed. On almost half of the photographs she is with other people, in most of them with known others like friends, parents, etc. She has interaction with the people in the photograph and if she is with others she has, in almost $70 \%$ of the cases, eye contact and physical contact. In almost all the photographs, coders judged the facial expression as happy; she has no exceptional make up ("natural" in $97.9 \%$ of the photographs) and her hair is always neat. She is not sweating, not smoking. Her position is judged as passive in $70 \%$ of the photographs.

In the photographs of Joran the overall image is somewhat different. Although most of the photographs are taken at eye level (60\%), a substantial number of them are taken from a bird's perspective $(20 \%)$ and from a frog's perspective $(20 \%)$. Joran does not look right into the camera in $46 \%$ of the photographs and in fewer photos than Natalee is he posing (in only $76 \%$ of them). There are some photographs ( $16 \%)$ where Joran is shown with police and in handcuffs. In $48 \%$ he is not with others in the photograph. And if he is with others, he is not making eye contact with anyone else in the photograph (97\%). In 50\% of the photographs his facial expression is judged neu- 
TABLE I3.4 RESULTS

\begin{tabular}{|c|c|c|}
\hline & $\begin{array}{l}\text { Holloway } \\
(\mathrm{n}=94)\end{array}$ & $\begin{array}{l}\text { Van der Sloot } \\
(\mathrm{n}=\mathrm{I} 89)\end{array}$ \\
\hline Camera perspective, eye level & 89.4 & $59 \cdot 3$ \\
\hline Camera bird perspective & 8.5 & 20.6 \\
\hline Camera frog perspective & 2.I & 20.1 \\
\hline Subject looks into camera & $94 \cdot 7$ & 54.5 \\
\hline Subject is unshaven & * & $39 \cdot 7$ \\
\hline Posed photograph & $94 \cdot 7$ & 42.9 \\
\hline Handcuffs & * & 6.3 \\
\hline With Peter R. de Vries & * & 8.2 \\
\hline With cops on photograph & * & I6.3 \\
\hline With others & 84.8 & 57.1 \\
\hline With mom on photograph & 15.2 & II. 2 \\
\hline With dad on photograph & 6.5 & 22.4 \\
\hline Interaction with people on photograph & 78.3 & 66.3 \\
\hline Eye contact & 66.7 & 3.0 \\
\hline Physical contact & 68.4 & 97.0 \\
\hline Happy face & 98.9 & $4 \mathrm{I} .8$ \\
\hline Natural make up & $97 \cdot 9$ & * \\
\hline Decent haircut & IOO & $57 \cdot 7$ \\
\hline Decent clothing & 83.0 & $*$ \\
\hline Alcohol & $4 \cdot 3$ & 4.8 \\
\hline First impression nice & 74.5 & 33.9 \\
\hline First impression innocent & 88.3 & 26.5 \\
\hline First impression passive & 84.0 & 24.9 \\
\hline
\end{tabular}

tral; in $49 \%$ as happy. In most of the photographs he is clean shaven with a fresh hair cut. In $60 \%$ of the photographs he is judged as active.

\section{Frames}

Can we set out these variables in terms of frames, as in "collections of variables that work together to portray the main characters"? A common technique of doing this is the homals analysis, or optimal scaling option which is available in spss, but the scores were too diverse and - because of the large number of variables - in many cases too few per variable to make an analy- 
sis that would make any sense. Nevertheless, by looking at the preliminary results of optimal scaling/HOMALs, as well as the frequencies of the main characteristics, we can distinguish two remarkable sets of variables: we called them the Popular Virgin and the Wolf in Sheep's Clothing.

\section{Popular Virgin}

The Popular Virgin frame can be characterized by the following features: a camera perspective at eye level, eye contact with the viewer of the photograph, posed, interaction with people in the photograph, eye contact with the other people in the photograph, a happy face, natural make up, combed hair, decent clothing (see figure 13.3). Coders characterized her at first sight as nice, innocent and passive in most of the photographs. More than $50 \%$ of the photographs represent these typical features.

\section{FIGURE I3.3 POPULAR VIRGIN}

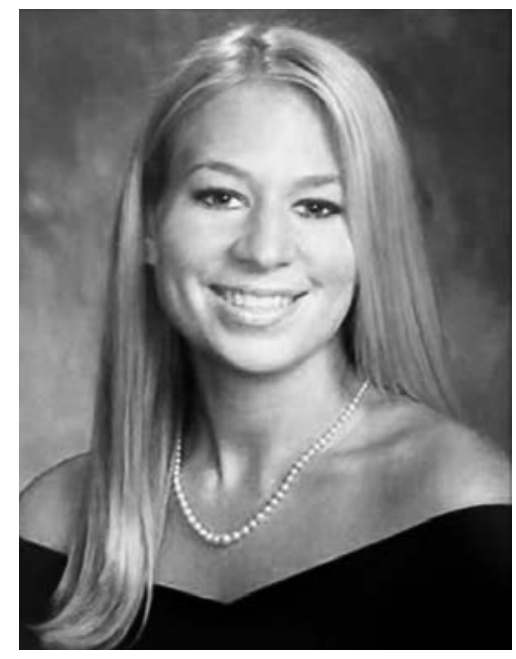

\section{Wolf in Sheep's Clothing}

The analysis of the photographic material on Van der Sloot shows more dimensions. The photographs are more diverse than those of Natalee (see figure I3.4). Obviously, this is because after the disappearance of Holloway, the development of visual material related to her stopped, yet the visual material depicting Van der Sloot could still be created and published. Besides that, the distribution of the features of the visual material depicting Van der Sloot is also 
more varied. On several photographs, the coders did not consider him to be obviously nice, or happy, but when he is with friends in a photograph, he makes eye contact and physical contact. Also, he is a character in more snap shots, in photographs which have not been posed: he has been in the news for longer than Natalee and became an important news topic after her disappearance. We called this frame The Wolf in Sheep's Clothing (also used in e.g., McIntyre 1988 and Sperber et al. 2009). A lot of the photographs are quite similar to photographs featuring Natalee, yet he is often framed as a criminal (e.g., figure 13.5, a screenshot from the website of Peter R. de Vries). This makes him a man with two faces.

FIGURE I3.4 WOLF IN SHEEP'S CLOTHING
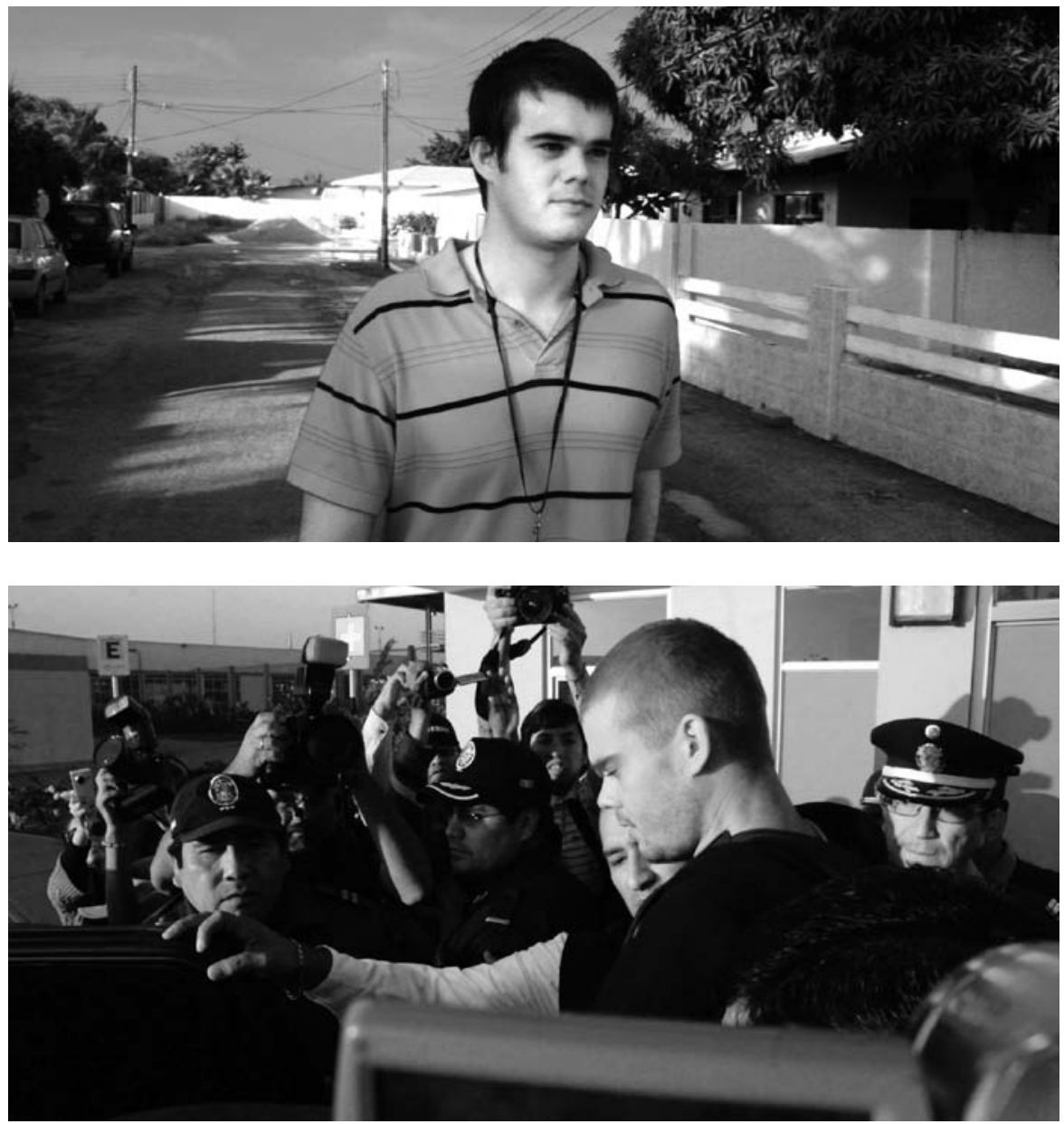
FIGURE I3.5 STEREOTYPICAL VICTIM AND OFFENDER: CASED SOLVED (“OPGELOST") I2 NOVEMBER 2009

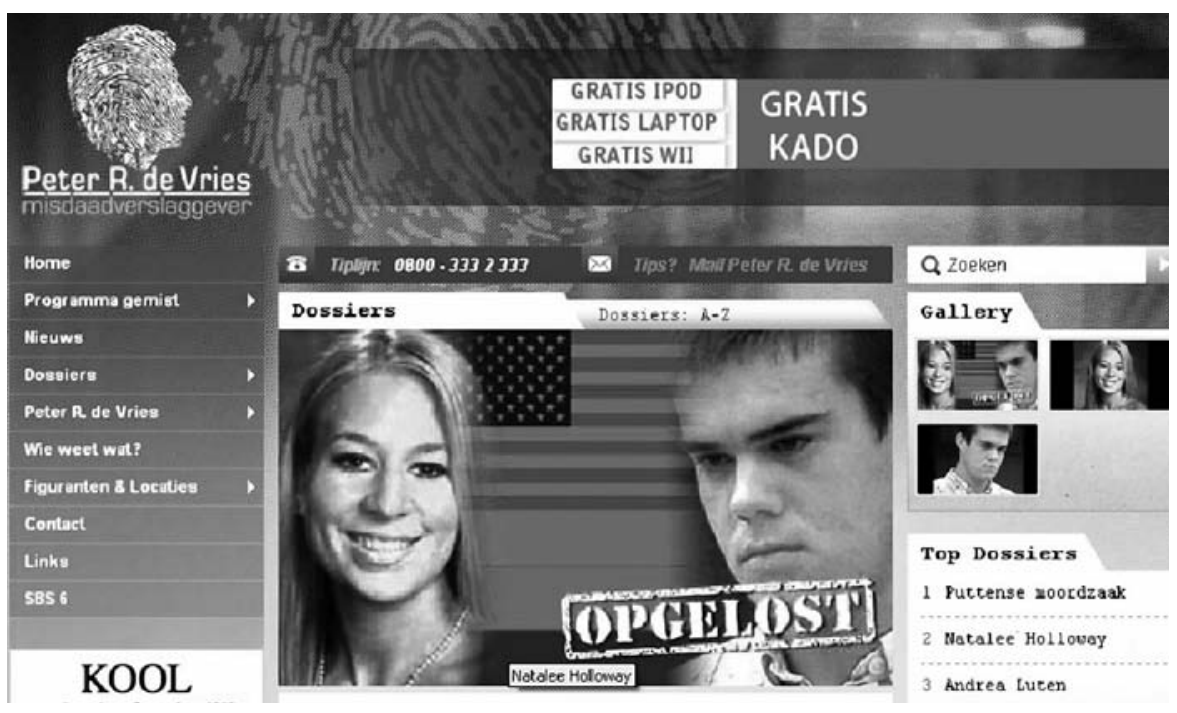

\section{I3.7 Conclusions and discussion}

Browsing through the collection of the 283 photographs from newspapers, magazines, websites and tabloids, one's intuitive impression is that the two main actors in this drama are two normal adolescents, from white middleclass families. Several photographs of the victim and offender show both of them with friends, obviously having fun, or with their family members. A quantitative analysis underpins this intuition.

Holloway can be presented, and she often is, as a stereotypical victim with features that fit the stereotype: decently posed photographs of a freshfaced, happy girl, looking straight at the camera, in the company of friends or her mother, graduated and easily perceived (and judged by our coders) as passive, nice and innocent. Her clothing, combed blond hair, her smile revealing healthy white teeth and her good-looking friends in the photograph support the impression of her innocence. These are the rhetorical means by which she is constructed. Information that contests this impression hasn't received a lot of attention - it is said, for example, that she was drunk and under influence of drugs before she died. This kind of information does not appear on these photographs and appeared rarely in the written press. She is the flat character in this morality play. 
In sum, Holloway is constructed as a normal female adolescent and this offers all the possibilities for identification: it could have happened to you.

Van der Sloot, on the other hand, is the round and more complex character. Based on this collection of photographs, Joran van der Sloot is not a stereotypical offender: we get a far more diffuse picture of him. In more than half of the photographs he is depicted as a normal adolescent with whom one can easily identify (see figure 13.6). These photographs are rather similar to the photographs of Holloway: socializing with friends and family. Yet, after Holloway's disappearance and his possible role in that incident, his 'confession' caught on hidden camera and his appearance in television, he can easily be perceived as a wolf in sheep's clothing. In more than $20 \%$ of the photographs, he is shown with police officers and/or in handcuffs.

\section{FIGURE I3.6 A NORMAL ADOLESCENT}

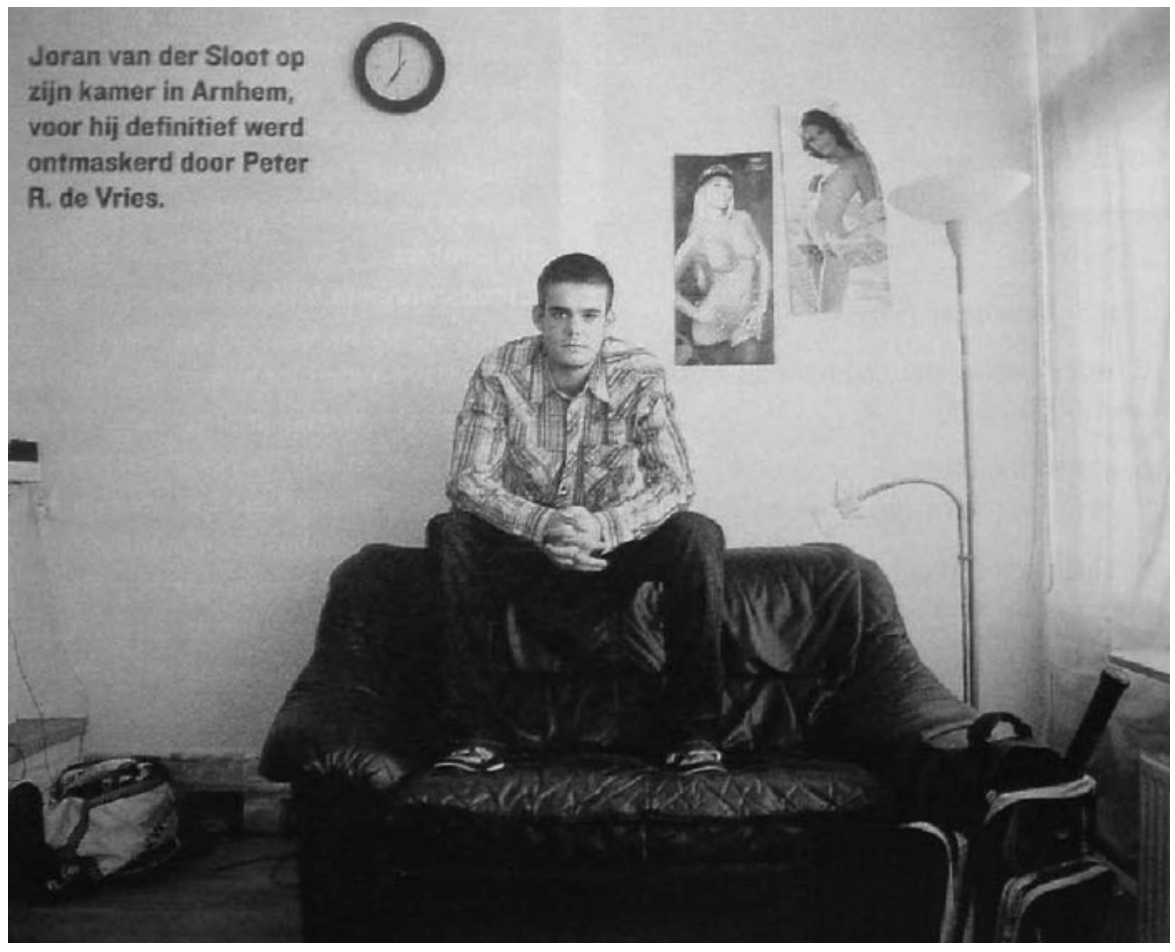

Anticipating the findings from the analyses of the television footage, it appears that the impression of deviance that we get from Van der Sloot comes from 
his appearance in television shows. There we can see and hear him lying and reacting short temperedly. Although the stills from these television shows, for example the stills from the footage from the hidden camera in The Peter $R$. de Vries Show (see figure 13.7), were not published very often in the print or news media, they established an extremely powerful, almost iconic picture of Van der Sloot.

FIGURE I3.7 STILL FROM HIDDEN CAMERA

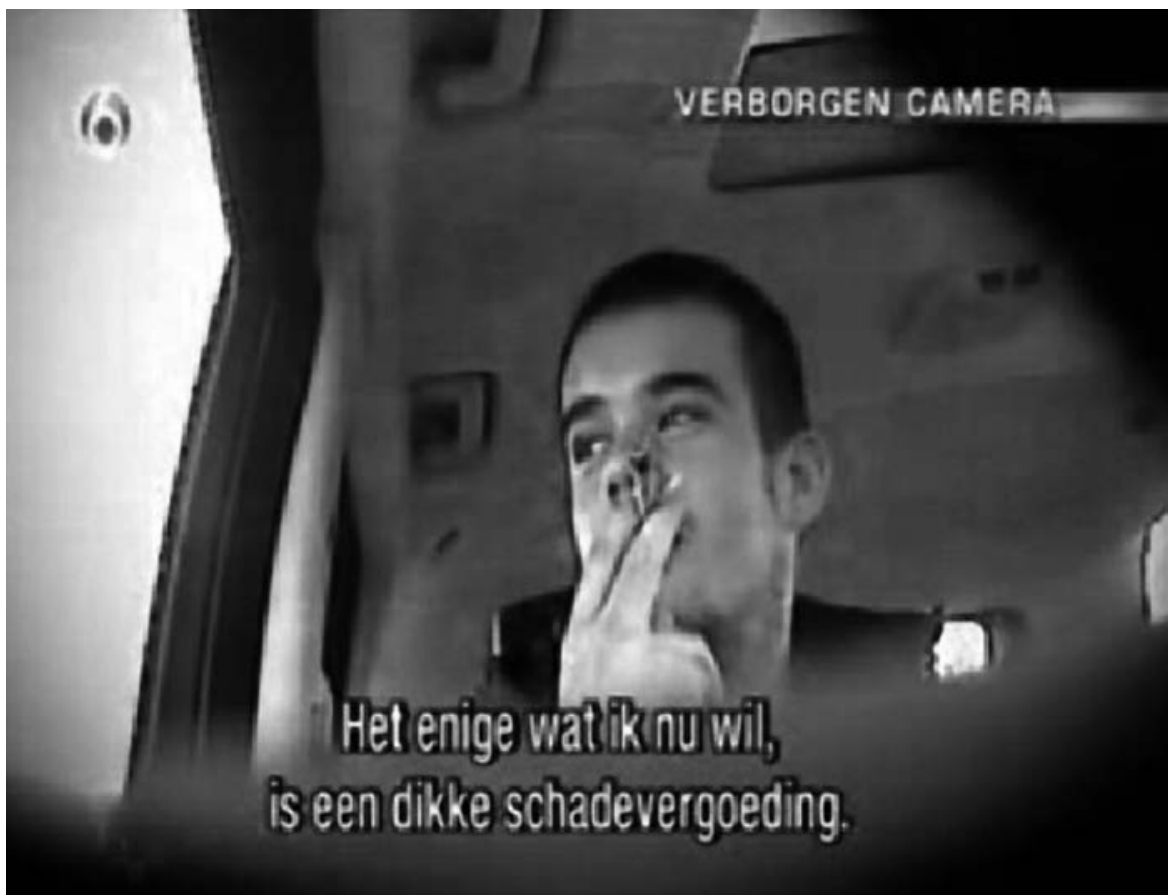

The narrative has generated a lot of discussion over a long period of time. In retrospect, this is not that surprising. The case involves (possibly) an accident, the main characters are young people having a good time before Natalee went missing; and the narrative has an open ending so different scenarios are still possible. These elements enable (young) people to identify with both victim and offender. There is hardly any discussion about Holloway's fate: she is dead, no one doubts that. This results in a mono-dimensional framing of her. In contrast with Holloway, Van der Sloot's role is, to a certain extent, questioned. Since nobody knows exactly what really happened that night, 
nobody knows whether he is really guilty or not. The incident could still have been an accident. The story leaves a lot of room for speculation, which enables the different media to portray his character in more than one way.

At the beginning of this chapter, we stated that the narrative of this particular case is more complex than the stereotypes we know from our reading of standard literature. The characters here are less stereotypical; at least Van der Sloot is. The interpretation of this character can be challenged and contested with other information. Thus, good and evil are less clear. This makes a wider variety of opinion possible: besides just contrasting with the offender and identifying with the victim (and her family), other reactions are possible. Thus, the narrative generates a lot of discussion; perhaps because, in a less stereotypical case, there is a stronger need to make sense: the just world is challenged.

In this discussion, a number of different issues are highlighted. The nature of the data and method used in these analyses are discussed. After that we will comment on the theoretical relevance of our research question with respect to stereotypical media portrayals. But first, the societal relevance is explored in more detail. During the development of this particular case, the two main reasons as to why the study of media portrayals is societally important were stressed several times. The first reason is that media portrayals reflect issues in (real) social life; that is, the media as a source of information tells us about society. Themes such as alcohol and drug use, international travel, rules of conduct among friends and female and male adolescents, responsibility of parents and media, dynamics between legal actors and the public and so forth were reported on. However, the disappearance of Holloway did not become a typical example of all the (female) adolescents who have disappeared; no claims were made about her disappearance being the tip of the iceberg. In that sense, the disappearance wasn't constructed as a social problem (Best 2007).

The second reason why the study of media portrayals is societally relevant is because these portrayals have (real) consequences in (real) social life. Immediately after the broadcasting of the epsiode of The Peter $R$. de Vries Show in which Van der Sloot 'confesses' on hidden camera, many people posted insults and threats on (what was supposedly) his social network site (Hyves). Direct responses included protests, discussions, letters to the editor of newspapers, comments on websites and disturbances at sites where Joran was assumed to be hiding himself. One of the newspapers we analyzed, $D e$ 
Volkskrant, suggested that if "Van der Sloot had been found, he would have been lynched by a furious crowd" (Giesen 2008).

One of the women's (gossip) magazines, similar to the magazines we analyzed (Privé and Story) had the headline "Kill the monster" (figure I3.8). In itself, the media exposure caused effects for all (family) members involved. Real consequences, not only for Van der Sloot, but also for legal actors working within the criminal justice system who had to defend the legal notions of a confession and explain why the "confession" on hidden camera did not constitute enough legal evidence to arrest and prosecute him.

\section{FIGURE I3.8 KILL THE MONSTER}

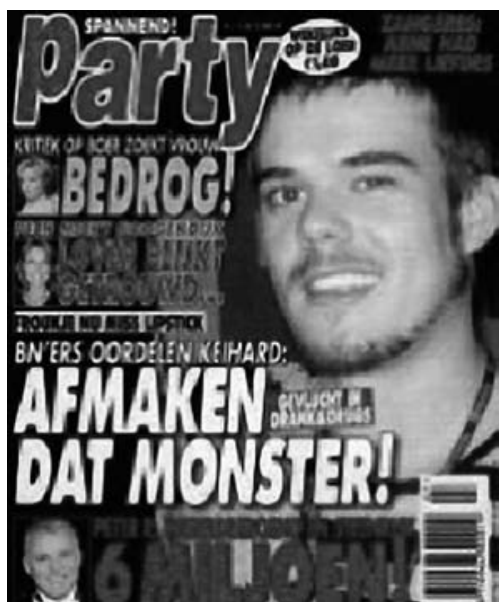

Most people do not have any direct experience with (specific types of) crime or with the criminal justice system, so they obtain their information, and form perceptions, ideas and attitudes, from other people and from the (news) media. As Forst (2004, pp. 213-219) describes, the public's perception that the criminal justice system is just and effective, its (perceived) legitimacy can be seriously flawed, yet this legitimacy "is essential to a well-functioning, citizensupported, criminal justice system” (Forst (2004:3). The public's (mis)perceptions are influenced by, among other things, high-profile media cases and miscarriages of justice. In the Van der Sloot/Holloway case, The Peter $R$. de Vries Show refers to the footage, in which Van der Sloot tells acquaintance Van der Eem what had happened, as 'the confession'. Several other (news) media report on the 'confession' and people perceive this confession to be 
valid, at least to a certain extent. Nonetheless, the confession is not a confession in any legal sense and provides no further evidence. This is difficult to explain to the general public. These kinds of developments, and other miscarriages of justice such as wrongful convictions, may undermine the legitimacy of the criminal justice system (Cole 2009). In short, these considerations illustrate the relevance of analyses of media portrayals. Another issue we would like to comment on in this discussion is the nature of the data and method we focused on in our analyses.

FIGURE I3.9 MORE EVIDENCE AGAINST JORAN

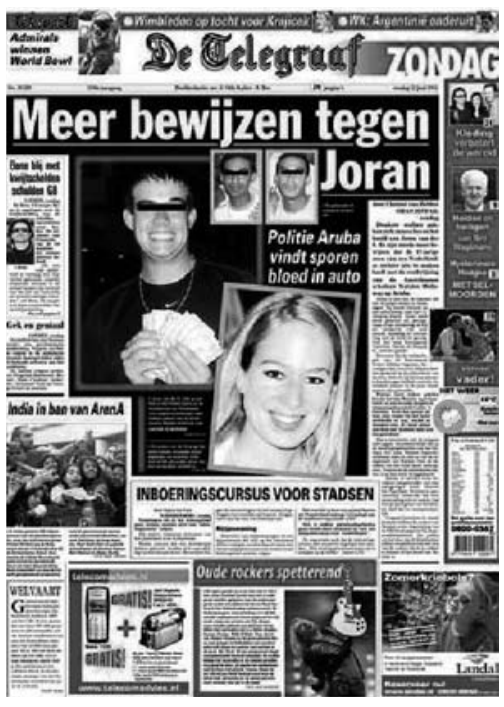

Figure 13.9 shows the front page of De Telegraaf (June 12, 2005) with the heading "Meer bewijzen tegen Joran"/ "More evidence against Joran". The article is illustrated with a well-known photograph of Holloway, a photograph of Van der Sloot, who holds money in his hands, and two smaller photographs of the two Surinam suspects. All three suspects have a black band covering their eyes. The smaller heading between the photographs reads: "Politie Aruba vindt sporen van bloed in auto"/ "Aruba police find blood in car". This front page is a good example of why a content analysis focused on the characteristics of the individual characters in crime news stories, or focused on other substantial research questions, cannot limit itself to a content analysis of text alone. The same article in LexisNexis Academic NL News, which contains the 
complete texts of several Dutch newspapers, informs us that the article consists of 335 words. In this chapter, we focused on photographs, not text, because previous research has shown that visual material is far more important in establishing, for example, the guilt and innocence of persons (Dubelaar and Vanderveen 2009). While most content analyses of news media are limited to textual data, we believe this will only produce valid and relevant findings if the research question is extremely limited.

However, the richness of the visual data is challenging when one is using a quantitative content analysis. During our analyses of the visual data derived from (print) media and television shows, we found that the quantitative instruments were not able to fully grasp the meaning of the images: by breaking up a photograph into smaller, different pieces, the overall picture can be easily missed. By splitting the visuals up into more than fifty variables, the whole image was covered ... yet it wasn't. What is important is the way in which all these features work together. While some statistical tools to correlate (certain) features do exist, in our analyses, other issues arose because of missing data and the huge variety of material. In many cases, visual data such as photographs are analyzed in a rather exploratory or qualitative manner, often missing the preciseness, the controllability and strictness of quantitative analytical methods. Yet, these qualitative approaches offer the possibility of analyzing the image as a whole, and analyzing the image in depth. Recapitulating our experiences briefly, we would plead for a mixed methods research design (Cresswell and Plano Clark 2007). The main advantages of using such a design are triangulation, complementarity and development (see Greene, Caracelli and Graham 1989). Our future analyses of the data will use a mixed methods approach such as this; preliminary findings already indicate, for example, that the visual material accompanying text (in the print media) and the visual material broadcast on television highlight other aspects of the characters, or highlight them in different ways.

The last issue we would like to discuss here concerns the theoretical relevance of our research question with respect to stereotypical media portrayals. We have examined the way in which media construct stereotypical images of victims and offenders by using established sets of characteristics (frames). These frames act as rhetorical devices to convince their public of the guilt and innocence of the parties involved. Although we have found many cases in which these frames are stereotypical, featuring Holloway as innocent victim and Van der Sloot as brutal offender, this is not the whole story. 
Though the literature is consistent in stating that disproportional attention is paid to narratives featuring stereotypes as main characters, both in news media and fiction, this portrayal of stereotypes is a stereotype in itself as well (Vanderveen and Koetsenruijter 2009). In many cases, such as the Holloway/Van der Sloot case, the narrative is more complex. When characters are less stereotypical, good and evil are less clear. Such narratives elicit a wider variety of opinion and more discussion because these types of narratives fuel the need that we have to make sense of a situation. The simple classification of persons into either offenders or victims helps media consumers to give meaning to their reality and define our general ideas about good and evil. Media sources like The Peter $R$. de Vries Show use several rhetorical devices to present the distinction between victim and offender in as clear a way as possible. Yet, in some cases, when the stereotypes can be challenged, the just world itself is challenged. The rhetoric of victims and offenders is less simple and clear-cut; this enables discussion and a variety of scenarios about who is good and evil to coexist.

\section{References}

Aguiar, P., J. Vala, I. Correia and C. Pereira (2008). Justice in our world and in that of others: Belief in a just world and reactions to victims. Social Justice Research 2I(I), 50-68.

Altheide, D.L. (1997). The news media, the problem frame and the production of fear. The Sociological Quarterly 38(4), 647-668.

Altheide, D.L. (2002). Children and the discourse of fear. Symbolic Interaction 25(2), 229-250.

Baynes, L.M. (2008). White Women in Peril on Broadcast and Cable Television News. Available at: http://works.bepress.com/prof_leonard_baynes/2

Best, J. (2007). Social problems. London: W.W. Norton and Company.

Buunk, B.P., and J.F. Ybema (1997). Social comparisons and occupational stress: The identification-contrast model. In F.X. Gibbons (Ed.), Health, coping, and wellbeing: Perspectives from social comparison theory (pp. 359-388). Mahwah, New Jersey: Lawrence Erlbaum.

Carmona, C., A.P. Buunk, A. Dijkstra and J.M. Peiro (2008). The Relationship Between Goal Orientation, Social Comparison Responses, Self-Efficacy, and Performance. European Psychologist 13(3), I88-196.

Chancer, L. (2005). High Profile Crimes. When legal causes become social causes. Chicago, University of Chicago Press. 
Christie, N. (1986). The Ideal Victim. In: E.A. Fattah (Ed.), From Crime Policy to Victim Policy (pp. 17-30). London: Macmillan.

Craig, R. and H. Newcomb (Eds.) (2003). Courtroom Television: The Encyclopedia of Television. Retrieved from http://www.museum.tv/archives/etv/C/htmlC/court roomtel/ courtroomtel.htm [February 5 20I0]

Creswell, J. W., and V.L. Plano Clark (2007). Designing and conducting mixed methods research. Thousand Oaks: Sage Publications.

Cole, S. A. (2009). Cultural Consequences of Miscarriages of Justice. Behavioral Sciences and the Law 27(3), 43I-449.

Dixon, T.L. (2007). Current issues and developments in race hate crime. Probation Journal 54(2), IO9-I24.

Dixon, T.L. (2008). Network News and Racial Beliefs: Exploring the Connection Between National Television News Exposure and Stereotypical Perceptions of African Americans. Journal of Communication 58, 321-337.

Dubelaar, M.J. and G.N.G. Vanderveen (2009). Beeld en geluid in het strafproces; implicaties van de opkomst van (audio)visuele technieken en materialen voor communicatie en besluitvorming in de strafrechtspraktijk. Nederlands Juristenblad 84 (30), pp. 1954-1960.

Durkheim, E. (1933). The division of labor in society. New York: Free Press.

Erikson, K.T. (1966). Wayward puritans. New York: Macmillan.

Eschholz, S. (2002). Racial Composition of television offenders and viewers' fear of crime. Journal of Criminal Justice 30(4), 327-34I.

Ettema, J.S. and T.L. Glasser (1988). Narrative Form and Moral Force: The Realization of Innocence and Guilt Through Investigative Journalism. Journal of Communication 38 (3), 8-26.

Fisher, W.R. (1987). Human Communication as Narration: Toward a Philosophy of Reason, Value, and Action. Columbia: University of South Carolina Press.

Fletcher, G.P. (1974). The Individualization of Excusing Conditions. Southern California Law Review 47(4), I269-I309.

Forst, B. (2004). Errors of justice: nature, sources, and remedies. Cambridge/New York: Cambridge University Press.

Gamson, W.A and K.E. Lasch (1983). The Political Culture of Social Welfare policy. In: S.E. Spiro and E. Yuchtman-Yaar (Eds.), Evaluating the Welfare State. Social and Political Perspectives. (p. 424). New York, Academic Press.

Gilliam, F.D. and S. Iyengar. (2000). Prime Suspects: The Influence of Local Television on the Viewing Public. American Journal of Political Science 44(3), 560-573.

Giessen, P. (February 9 2008). Kermis van de Moraal. De Volkskrant, page 2I. 
Goffman, E. (1974). Frame Analysis: An essay on the organization of experience. Cambridge: Harvard University Press.

Grabe, M.E. (1999). A functionalist perspective on television news magazine stories. Critical Studies in Mass Communication I6, I55-17I.

Grabe, M.E., K.D. Trager, M. Lear and J. Rauch (2006). Gender in Crime News: A Case Study Test of the Chivalry Hypothesis. Mass Communication and Society 9(2), I37-163.

Green, E., S. Hebron and D. Woodward (1987). Women, leisure and social control. In: J. Hanmer and M. Maynard (Eds.), Women, Violence and Social Control (pp. 75-92). Atlantic Highlands, NJ: Humanities Press International.

Greene, J.C., V.J. Caracelli and W.F. Graham (1989). Toward a conceptual framework for mixed-method evaluation design. Educational Evaluation and Policy Analysis II(3), 255-274.

Heath, L. and K. Gilbert (1996). Mass Media and Fear of Crime. American Behavioral Scientist 39(4), 379-386.

Jones, P. J. and C. Wardle (2008). 'No emotion, no sympathy': The visual construction of Maxine Carr. Crime Media Culture 4(I), 53-7I.

Katz, J. (1987). What makes crime 'news'. Media, Culture and Society 9, 47-75.

Kellner, D. (1995). Cultural studies, multiculturalism and media culture. In: G. Dines and J.M. Humez (Eds.), Gender, Race and Class in Media: A Text Reader. Thousand Oaks, CA: Sage Publications.

Lerner, M.J. (1980). The belief in a just world: a fundamental delusion. New York: Plenum Press.

Machado, H., and F. Santos (2009). The disappearance of Madeleine McCann: Public drama and trial by media in the Portuguese press. Crime Media Culture 5(2), I46-I67.

Madriz, E.I. (1997). Images of criminals and victims - A study on women's fear and social control. Gender and Society II(3), 342-356.

Mason, P. (2002). The Thin Blurred Line: Reality Television and Policing. Paper presented at The British Criminology Conference: Selected Proceedings, Keele.

McIntyre, T. (1988). A Wolf in sheep's clothing. The search for a child killer. Detroit Michigan: Great Lake books.

Mead, G.H. (1918). The psychology of punitive justice. The American Journal of Sociology 23, 577-602.

Mylifetime.com (n.d.). Retrieved from http://www.mylifetime.com/on-tv/lmn/nataleeholloway-movie/extras/video/beth-holloways-public-service-announcement.

Neapolitan, J. (1987). Vigilante Behavior and Attribution Bias. Criminal justice and behavior I4(2), I23-137. 
NCPC , National Crime Prevention Council (n.d.). Streetwise, the Way to Be. Retrieved from www.ncpc.org/resources/files/pdf/neighborhood-safety/streetwise.pdf

Reijnders, S. (2005). The people's detective: true crime in Dutch folklore and popular television. Media, Culture and Society 27(5), 635-65I.

Schattenburg, G. (198I). Social control functions of mass media depictions of crime. Sociological Inquiry 51, 7I-77.

Scheufele, D.A. Framing Effects. The International Encyclopedia of Communication. Donsbach, Wolfgang (Ed.). Blackwell Publishing, 2008. Blackwell Reference Online. 22 January 20I0. Retrieved from http://www.communicationencyclopedia. com/subscriber/tocnode?

Sperber, K.G., C.T. Lowenkamp, D.E. Carter and R.A. Allman (2009). Sheep in Wolf's Clothing or a Wolf in Sheep's Clothing? Ohio Sex Offender Registration and the Role of Science. Criminal Justice Policy Review. o: o887403409350909vi.

Stevens, J.D. (1985). Sensationalism in perspective. Journalism History I2(3and4), 78-79.

Surette, R. (1989). Media Trials. Journal of Criminal Justice 17 (4), 293-308.

Surette, R., and C. Otto (2002). A test of a crime and justice infotainment measure. Journal of Criminal Justice 30(5), 443-453.

Tuchman, G. (1976). Telling Stories. Journal of Communication 26(4), 93-97.

Vanderveen, G. (2006). Interpreting Fear, Crime, Risk and Unsafety; Conceptualisation and measurement. The Hague: Boom. [Internationally distributed by Willan Publishing]

Vanderveen, G. and A.W.M. Koetsenruijter (2009). Guilt and innocence: how Dutch media presented the Van der Sloot/ Holloway case visually and verbally. Paper presented at the Annual Meeting of the American Society of Criminology, Philadelphia, UsA (4-7 November 2008).

Wachs, E. (1988). Crime Victims'Stories: New York City's Urban Folklore. Bloomington: Indiana University Press.

Wills, T.A. (198I). Downward comparison principles in social psychology. Psychological Bulletin 90(2), 245-27I. 


\section{I4 "Conceptual and Fanciful" or}

"A Depiction of Reality": Exploiting
Visual Modality to Claim Environmental Ethos in UK Advertizements for Automotive and Energy Companies (2007-2008)

SUSAN HOGBEN

\section{I4.I Introduction}

The business benefits that can be accrued through association with and actual sound environmental practices cannot be understated (Bortree 2009; Grant 2007). Indeed, stakeholder support for organizations is increasingly dependent on evidence of a commitment to the growing political and public interest in social and environmental responsibility (Livesey and Kearins 2002). Moreover, automotive and energy companies typically considered responsible for detrimental environmental effects can especially benefit from associating themselves with pro-environmental activities through sponsorship of social and environmental organizations and especially by advertising the positive environmental impacts of their products and production processes (Fombrun and Rindova 2000; Beder 2002; Coupland 2004).

These kinds of environmental claims in advertizements, however, do not go without scrutiny. UK governmental bodies (DEFRA 2006) and industry watchdogs (ISBA 2007) offer guidelines for sound practice and, in the UK, the Advertising Standards Authority (ASA) is charged with investigating and adjudicating on any complaints made about the legitimacy of environmental claims. In recent years objections to the environmental benefits asserted in corporate advertizements in the UK have risen substantially (ASA 2008). 
This chapter examines how corporations generate green capital by exploiting the difference in truth claims attributed to visual modality in advertisements. Analysis of a corpus of UK advertizements produced by automotive and energy companies finds that adjudications about the truth values attributed to images or visual argument are treated differently to similar linguistic claims.

Firstly, the chapter summarizes the relationship between ancient ethos and modern corporate image maintenance by making apparent the shared need to demonstrate strength of character, virtuousness and an appreciation of an audience's values and concerns. Following the explanation of modality as a means of distinguishing truth claims in text and image, the chapter turns its attention to the adjudications regarding environmental claims in text and image. This piece concludes with a call for greater visual literacy and a more consistent consideration of the impact of images in environmental claims that are used to add to a corporation's reputation.

\section{I4.2 Ancient ethos and modern corporate image: Rhetorical connections}

For Aristotle (I99I, p. 38) "the controlling factor in persuasion" is the development of ethos or a credible and trustworthy character. Constructing and maintaining credibility relies on three complementary constituents: using practical wisdom (phronesis), displaying virtue (arête) or moral character and demonstrating goodwill (euonia) towards the audience (Waerass and Ihlen 2009):

Practical wisdom means using knowledge accurately to impress an audience. This can be accomplished by using reliable evidence of sound provenance in, for example, the form of logical and well-founded argument, the accurate use of statistics or in the convincing application of technical expressions. (Ihlen 2009)

The display of virtue refers to the "all-round personal excellence ... in service of the larger community" (Solomon 2004, p. I023).

In this respect displaying virtue involves both character and behaviour; that is, virtue is a disposition to act in a morally laudable fashion that serves more than the self but also some common good.

The third factor influencing the development of ethos is the demonstration of goodwill towards the audience. This is less about displaying personal affiliation but rather about demonstrating a shared affective concern for common goals or an appreciation of the audience's needs or interests. In 
other words, the credible persuader should "somehow identify with the audience, by for instance holding some of their basic aspirations [or] speaking their language" (Kinneavy and Warshauer 1994, p. I77). This is likely to rely on sharing an appreciation of similar virtues and, as Ihlen (2009, p. 364) points out, could be "indirectly supported by pathos" or arousing an emotional response.

These ancient principles for constructing credibility have been routinely applied to individual orators but in more recent times the tenets have been deployed as a means of explaining the construction of a credible corporate image or reputation. Whilst applying the bases of individual ethos to organizational credibility is not without its opponents (see for example Gowri 2007 for a critical distinction between human and corporate virtues), contemporary understandings of corporate image construction are indeed being understood through the lens of these ancient rhetorical techniques (Wei 2002; Solomon 2004; Ihlen 2009).

Consequently, it seems wholly appropriate to pay critical attention to the ways that corporations aim to be "thought to be sensible and morally good" or to "look right" (Aristotle I954, I356aI-3); that is, to identify the means through which an organization demonstrates strength of corporate character in terms of: phronesis, the judicious reporting of evidence; arête, the display of shared virtues; and euonia an appreciation of "characteristics and qualities that are valued by an audience and community" (Beason I99I, p. 330) which includes internal and "external stakeholders, especially ... customers" (Davies, Chun and Da Silva 200I, p. II3).

As Ihlen (2009) acknowledges, the virtues and characteristics valued by modern audiences will differ to ancient audiences. Indeed, recent research reveals that $\frac{4}{5}$ of UK consumers are likely to use a product because of its association with a good and especially an environmentally oriented cause (Theaker 2004; Bortree 2009). Whilst there are principles that connect between ancient and modern rhetoricians the specific means available to persuaders are greatly extended. The contemporary corporate communicator has innumerable media outlets and platforms through which to meet these "greener" goals.

\section{I4.2 "Greening" the corporate image: Claims and concerns}

Companies "will not shy away from spending millions on environmental improvements if there is reputational capital in it" (Beder 2002). These im- 
provements may be actual investment in changes to production and manufacturing but often this level of investment includes self-promotion in the form of internal strategy documents (Pedersen and Neergaard 2009), annual reports (Neu, Warsame and Pedwell I998), corporate social responsibility reports (Ihlen 2009; Ocler 2009), corporate websites (Adams and Frost 2006; Coupland 2006) and advertorials (Livesey 2002). Whilst these practices are often for restricted stakeholders the vehicle through which corporations assert their good environmental citizenship is nowhere more publicly apparent than brand and product promotion in mass media advertising.

The rise in environmental claims in advertising has also seen a sharp rise in concerns that these claims may be overstated (вт, 2007). As Ashforth and Gibbs (I990, p. I80) appreciate, an organization may "espous[e] socially acceptable goals while actually pursuing less acceptable ones". Indeed, corporations have been advised to ensure that any advertising claims should make accurate reference to legitimate environmental action (Grant 2007) in order to avoid allegations of "green spin" (Magee 2008), "greenwashing" or, in its extreme, "ecopornography" (CIPR 2007).

Despite this laudable counsel, complaints to the UK's Advertising Standards Authority (ASA) about environmental claims in advertising rose from II7 objections to 83 advertizements in 2006 to 56I complaints about $4 \mathrm{IO}$ advertizements in 2007 and beyond.

Contemporary advertising affords the corporate communicator a near open-ended set of multimodal resources from which to craft messages designed to persuade. As a result, the potential to combine text, image and sound means that especially close attention to complaints made about any or all these semiotic resources is required. This brings me to the analytic and interpretative issues central to this chapter: the truth-values attributed to text and image or linguistic and visual argument and especially to the resulting adjudications based on these values.

\section{I4.3 Visual argument and linguistic argument: Modality and truth- values}

Following Barthes (1972) it is widely acknowledged that texts and images have differing meaning-making capacities or "individual functions and strengths" (Lemke 1998, p. 38). For Lemke this means that language is adept at encapsulating typological meaning by categorizing whereas the visual can make meanings topologically or by degree. As a result, language is interpreted as 
having more fixed, or closed, meanings whereas images are deemed to be more polysemous, open to interpretation and often (although not exclusively) subordinate to the text (Van Leeuwen 2006).

That said, there is also much competing evidence to support the equal treatment of text and image. Mitchell (I994, p. I6I) maintains that "semantically speaking there is no essential difference between texts and images". Van Leeuwen (2006, p. I79) similarly argues that just as other semiotic resources operate in collaboration to generate implicatures, visual analysis should focus "not only the image as representation but also on the image as an 'inter'act"; that is, analysis should address how the reader/viewer interprets and deduces meanings from the collage of signs present in, for example, an advertizement. There is also some support to move beyond this perceptual equity. Blair (1994, p. 54) emphasizes the "power of visual imagery to evoke involuntary reactions" and exceed linguistic argument. Further research suggests that the visual (in, but not limited to, metaphor) can be more influential than linguistic (either literal or figurative) arguments (Blair 2004). McQuarrie and Philips (2005) argue that the juxtaposition, replacement or fusion of images to exploit figurative interpretations can generate a range of meanings that require complex processing. This increased effort in the comprehension process can result in an enhanced memory trace of the message and more permanent impact (Petty and Cacioppo 1986). This scope for multiple interpretations means that it is also true that "not all assumptions in a message can be taken as communicated with equal force, nor with the same degree of strength to different people" (Forceville 1996, p. I77). Such a position is important when understanding which aspects of an advertizement attract complaints and how these complaints are upheld or rejected by the ASA.

Before I go on to discuss the complaints and adjudications in detail, I briefly want to foreground another key aspect of linguistic and visual argumentation: truth claims and modality. Modality refers to the status, authority and reliability of a message, to its ontological status, or to its value as truth or fact (Hodge and Kress I988, p. I24) and marks out certainty, possibility and necessity. Lexical choice can impose a view of truth that is difficult to challenge or truth claims may be more qualified or weakly asserted. As a result, "truth is ... a matter of degree" (Van Leeuwen 2006, p. I62).

Visual expression similarly construes different truth-values by degree often depending on combinations of gradable differences available in terms of saturation, differentiation and modulation (Van Leeuwen 2006). Images 
can be produced using fully saturated color, pastel or muted tones, or with the complete absence of color. The communicative potential of saturation is ambiguous: "high saturation may be positive, exuberant, adventurous, but also vulgar or garish. Low saturation may be subtle and tender, but also cold and repressed, or brooding and moody" (Kress and Van Leeuwen 2007, p. 233). Whilst there are important distinctions in terms of light and shadow, depth of field and degrees of detail, there are also, as we shall see, competing interpretations regarding color saturation and realism. Differentiation marks out a scale ranging from monochrome to a diverse and complex color palette. Color can also be deployed from a flat to a fully modulated scale. Flat modulation offers a general impression or generic characteristics of an entity and produces a more abstract representation whereas fully modulated color with concomitant grading of nuances realises a stronger perceptual truth or carries greater "epistemic force" (Hill 2004, p. 29). With this in mind, Hill (2004) further argues that realism depends on vivid information using "concrete and imagistic language, personal narratives, pictures, or first-hand experience". Vivid information draws on representations that are more "realistic". For example, in table I4.I, a photograph is considered more true to life than a line drawing.

TABLE I4.I

Most vivid information

actual experience

moving images with sound

static photograph

realistic photograph

line drawing

narrative, descriptive accounts

abstract, impersonal analysis

Least vivid information

statistics

The relative verisimilitude of an image is based on combinations of these modalities and the viewer's own judgments. Realism, it seems, is judged on dimensions such as color, degree of contextualization, comprehensiveness of representation, nature of the perspective, sources of illumination and degree of brightness. However, how each of these factors influences the interpretation of an image's veracity are not insignificant matters. Kress and Hodge 
(1988, p. I47) make the importance of modality plain when they assert that "social control rests on control over the representation of reality which is accepted as the basis for judgment and action... whoever controls modality can control which version of reality will be selected out as the valid version in that semiotic process."

These kinds of judgments about what sorts of images are more representative versions of reality can be explored in the following: a color photograph, a black and white photograph with increased background saturation, a colored pencil sketch and a black pencil line drawing. ${ }^{.}$

FIGURE I4.I

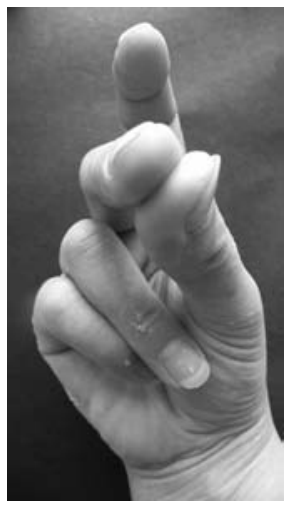

FIGURE 14.2

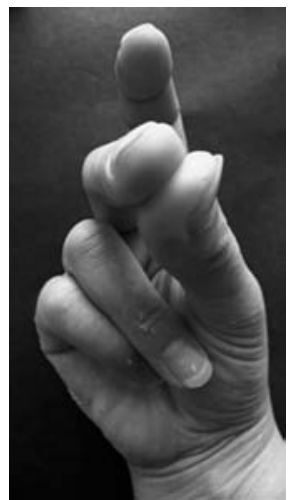

FIGURE I4.3

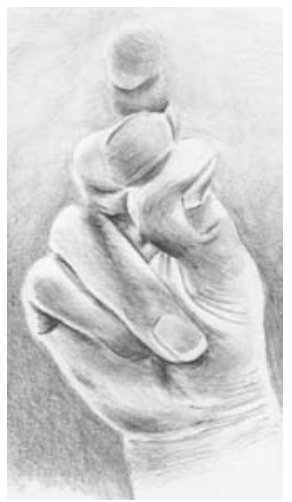

FIGURE I4.4

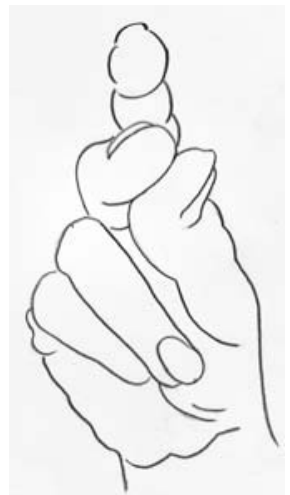

These images demonstrate the tension between representation, resemblance and reality (Lopes 1996) and how form, communicative function and cultural interpretations influence judgments about which is the more accurate version of reality. The color photograph (figure I4.I) in contrast to the black pencil line drawing (figure I4.4) following Hall's (2004) criteria is likely (under some conditions) to be judged as more 'realistic'. The corollary is that the black pencil line drawing could be considered to be "visual 'opinion' and less factual than a ... photograph which is held to provide reliable documentary information" (Van Leeuwen 2006, p. I67). This overlooks, however, the powerful communicative function of a line drawing or densely saturated cartoon.

People can identify an image more quickly when it is drawn as a cartoon than when they are shown a photograph of a hand (Lopes 1996). Addi-

${ }^{\text {I }}$ My thanks go to Suzanne Curran for producing these images. 
tionally, such simplified and decontextualized images can, like gesture, acquire symbolic meaning that makes it possible "to form generalised images that reflect the facts of real life correctly and in depth" (Meshcheryakov I979, p. 189). Moreover, diagrams, line drawings and illustrations also have the potential to be read as images with "high truth-values and not as fictions or fantasies" (Van Leeuwen 2006, p. I67).

There are, of course, far more meaning-making mechanisms at work in print advertising including, not least, the role of semiotic space and how different information values pertain to the different placement of materials on a page. Figure I4.5 demonstrates how the location of image or text also carries different information values.

FIGURE I4.5

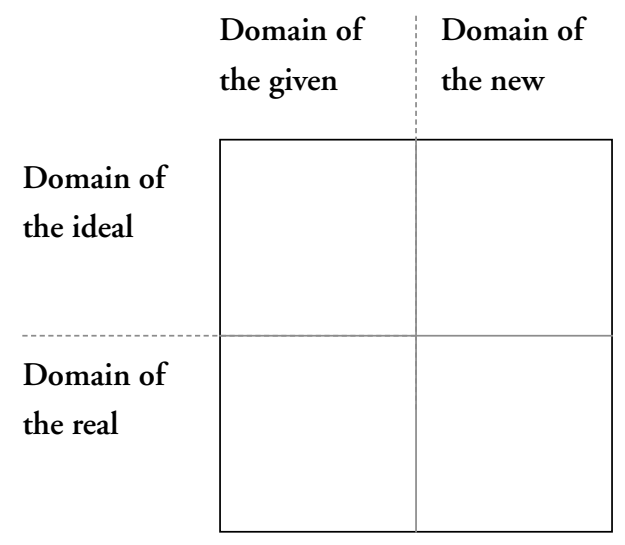

When a page is spatially polarized, information on the left inhabits the given domain: the already known or predictable. Material located on the right, in the new domain, displays original, modified or unexpected information which, according to Kress and Van Leeuwen (1998, p. I89), can be treated as "problematic, contestable [or] the information at issue". In the vertical plane, material located in the upper part is presented as the generalized or idealized essence of the information. In the lower part, the information is valued as more specific, more practical or more "down-to-earth" (Van Leeuwen 2006).

To interpret meanings and attribute truth-values, Chandler (2002) explains, readers must draw on all their "knowledge of the world and of the medium. For instance, they assign it to fact or fiction, actuality or acting, live 
or recorded, and they assess the possibility or plausibility of the events depicted or the claims made in it". These issues of realism, the credibility of the image and the legitimacy of linguistic claims are at the heart of the data under discussion to which our attention now turns. The data consists of the complaints and adjudications about five advertizements produced by car manufacturers and energy companies during 2007-2008 in the UK.

\section{I4.4 The complaints and adjudications: Textual claims versus image representation}

The first text is a UK magazine advertizement and poster campaign (May 2007) for a Lexus RX 400 hybrid fuel car. Its headline states "High performance. Low emissions. Zero guilt". Visually the advertizement presents a highly decontextualized, intensely lit, minimally differentiated photograph containing a richly refracted reflection of the car. Accompanying the image the body copy states: " $\mathrm{RX} 400 \mathrm{~h}$. The world's first high performance hybrid suv ... category-leading low $\mathrm{CO}_{2}$ emissions. A combination without equal. Or compromise".

The complaints addressed the accuracy of the headline claims "low emissions" and "zero guilt" suggesting that they misrepresented the environmental impact of the sports utility vehicle. The ASA concluded that the complaints about the unqualified use of the ambiguous category term 'low' implied the vehicle's emission rate was negligible and readers would infer that it had less detrimental emissions in comparison with all cars. The attempt to use the technique of phronesis and boost ethos using albeit unqualified evidence was deemed to be unsubstantiated and misleading.

In terms of absolute truth claims, the ASA additionally decided that the term 'zero' (unsubstantiated by the body copy and additional evidence submitted) would (mis)lead readers to infer that the car caused little or no harm to the environment which, the ASA concluded, was not the case. Of note, however, is that no complaints made by members of the public or comments by the ASA questioned the highly stylized, decontextualized, pristine setting and unrealistic representation of the vehicle. The lack of attention to the image in meaning-making is also evident in the next text.

A UK national press advertizement (January 2007) for the Golf GT TSI uses a triptych. It shows a centrally-positioned image of the car on a split background. The left hand side of the advertizement pictures a dimly lit forest with wolves and the text "High performance". The right hand side of the 
advertizement shows a brightly lit meadow with a deer and the text "Low emissions". The body copy states: "It also does over $38 \mathrm{mpg}$, and emits just I75g of $\mathrm{CO}_{2}$ per kilometre. More power, less pollution. Better to drive. Better for the planet". The text at the bottom of advertizement states: " $\mathrm{CO}_{2}$ emissions for the Golf GT TSI are lower than other engines with similar power outputs". The complainants challenged the assertion "low emissions".

The ASA, in line with the previous adjudication, maintained that readers would be likely to understand the weak modality of the linguistic claim "low emissions" to mean the car had less damaging emissions than all cars and upheld the complaint. What is of interest, again, is the lack of mention of the content or modality of the images.

The image on the left, in the given semiotic space, is more fully saturated and the lighting adds to its near photographic quality. The image on the right, presenting new information, uses low saturation, pastel shades, graininess and an evaporating perspective along with more fanciful sources of illumination resulting in a more visibly cartoon or sketch-like resonance. The reader should take the lupine performance of the car as given, as "commonsense and self-evident and as established" (Kress and Van Leeuwen 1998, p. I89). The new material, a deer grazing in a tranquil meadow, should be treated analytically; "problematic, contestable, the information at issue" (ibid.). Apart from not being scrutinized as contestable, the lack of reference also ignores the potential implicatures generated by the low modality of the sketch. That is, of an inescapable intertextual reference to Disney's Bambi grazing in idyllic rural pastures. This image is undoubtedly being used to underscore and extend the textual claim that has been deemed to be inaccurate and misrepresentative. However, the evocative pastoral associations of the image available to a viewer along with their location in a contestable space are allowed to stand without scrutiny or critical evaluation. The car company has evoked pastoral virtues and has produced a form of identification with an uncomplaining audience by representing basic aspirations without criticism. As a result, this particular form of image has allowed the company enhance its image through association with environmental capital.

The third text, a national print advertizement (March 2008) for the Renault Twingo Dynamique uses a photographic image of the car against a pale green background and presents illustrations or sketches of differently sized drawings of oversized leaves apparently emanating from the car's exhaust.

The text on the largest leaf reads "eco ${ }_{2}$ economical ecological". One 
complaint challenged whether the textual claim "ultra low" in the body copy was misleading. Another complaint argued that the claims "ecological" and "eCO 2 " were misleading because the terms exaggerated, without evidence, the environmental credentials of the car. The ASA concluded that the unqualified use of the terms "ecological" and the "eco ${ }_{2}$ " logo could lead readers to infer that the vehicle caused relatively little harm to the environment and had low emissions compared with other similar cars. Whilst the ASA noted the use of large (certainly not to scale) illustrations of leaves in place of exhaust emissions. However, they did not ask for them to be removed in any amended advertisements. The presence of oversized environmental "goods" metaphorically replacing an environmental "bad" clearly warranted but did not receive adequate critical attention.

Having foregrounded the lack of attention being paid to the visual in complaints to the ASA, the next two advertizements have images at the centre of both the complaint and the subsequent adjudications.

Example 4 is a direct mailing circular (February 2008) produced by an energy company. It has a black print headline "Wind Power News" and shows a monochrome photograph of four wind turbines in the mid and background. Alongside hedge-bounded fields there are four horses grazing in the foreground. There is a web link to an update about the proposed Nun Wood wind farm.

The complaints addressed the veracity of the image suggesting it gave a misleading impression of the visual impact of the wind turbines for the proposed Nun Wood wind farm. The photograph uses perspective, articulation of background, saturated color and tonal shades to produce a relatively highly modulated realization. The ASA (2007a) concluded that, given the nature of the image, readers were "likely to believe the photograph represented" how the Nun Wood wind farm would look if it were to be built. The ASA noted the image was of an already operational wind farm where the turbines appeared to be smaller than those proposed for the Nun Wood site. The photograph is treated as presenting "more vivid information" (Hall 2004) and thus is attributed greater "plausibility of the events depicted or the claims made in it" (Chandler 2002). The company was asked to withdraw the flyer.

In the fifth example, the data example, the complaints addressed both the environmental claims in the image and in the text. A national press advertisement (November 2007) for an energy company was headlined "Don't 
throw anything away there is no away" and shows a generic silhouette of an oil refinery which has four chimneys producing clouds of colorful flower heads. The body copy states:

If only we had a magic bin that we could throw stuff in and make it disappear forever. What we can do is find creative ways to recycle. We use our waste $\mathrm{CO}_{2}$ to grow flowers, and our waste sulphur to make super-strong concrete. Real energy solutions for the real world.

The complainants maintained that the image of industrial chimneys emitting flowers misrepresented the environmental impact of company's refineries. The objections also addressed the textual assertion "We use our waste $\mathrm{CO}_{2}$ to grow flowers" suggesting it implied that the company used all of its waste $\mathrm{CO}_{2}$ to grow flowers. The complainants offered evidence that less than $0.5 \%$ of carbon dioxide emissions were used by local greenhouse growers to produce plants. In its adjudication, The ASA upheld the complaints regarding the unqualified assertion of waste carbon dioxide use that invited the inference that the company used all, or at least the majority, of their waste carbon dioxide to grow flowers. However, the ASA did not uphold the complaint about the potential inferences prompted by the incongruent metaphorical image that suggests that one direct consequence of the industrial oil refining process is the immediate production of flowers. In drawing up its decision, the ASA concluded that the image was "conceptual and fanciful" (ASA 2007b) and that "most readers were unlikely to interpret it as a depiction of reality." It seems that because the image is a flatly modulated, impressionistic or generic silhouette with a highly simplified visual metaphor using images akin to a child's rudimentary drawing of flowers and not a photograph that it is not considered to constitute a direct or vivid reference to reality (Hall 2004). Its influence on viewers is deemed to be minimal. Analytically, the judgement overlooks the powerful effect of "generalised images" that can "reflect the facts of real life correctly and in depth" (Meshcheryakov 1979) and, as Van Leeuwen (2006, p.167) maintains, can carry "high truth values" and not be treated as "fictions or fantasies".

This conclusion neglects recent research exploring the potency of visual metaphor to influence readers/viewers (Lagerwerf and Meijers 2008). It also ignores the powerful connotations encoded in the typeface redolent of I960s pro-environmental "flower power" drawing on the densely satu- 
rated hybrid color palette associated with that period. The combination of image and typeface are used, it seems, to express a commitment to goodwill required to build ethos. The opening line of the body copy also seems to demonstrate an appreciation of and alignment with the concerns of the public. That is, the general wish to find a solution to produce a better world. The connotations available in the image also seem to express respect for a value system desired by some, if not all, potential readers. Certainly, as Kinneavy and Warshauer (1994, p. I77) suggest, demonstrating goodwill can mean that persuaders "share or affirm the prejudices of their audience." By drawing the graphic outline of the emission-producing refinery on the horizon goes someway to show some identification with the audience. The image acknowledges that the refinery does produce waste but not of the order presumed by the audience. That the complaints about the image are rejected allows the company to accrue much green capital and concomitant environmental ethos.

These two adjudications address visual representations and truth-values in important but different ways. The image in the oil company's advertisement is treated as "visual opinion" (Van Leeuwen 2006, p. 167). The photograph of wind turbines is deemed to provide "reliable documentary information" (ibid.). It seems when images are recognisable because of their geographic, historical or socially specific identity they are treated as arguments and engaged with the same degree of critique as linguistic claims. When they are decreed to be of a fictional or fanciful form they are treated as peripheral and of minimal importance.

Overall, in these five advertizements (despite the perspectives outlined previously that image and text should receive, at least, perceptual equity) it seems that the word is mightier than the image or rather truth claims asserted in linguistic argument are given greater attention and critical treatment. So whilst The ASA demonstrates a laudable capacity to tackle low modality linguistic claims about environmental impacts they dismiss the persuasive value in low modality images. So, when assertions are made that use the notion of practical wisdom inaccurately they engage critically with the implicatures arising from the unqualified or unsubstantiated use of such terms yet only high modality images, deemed to represent reality, attract critical re-appraisal. The potential benefits for the production of corporate environmental ethos are profound. 


\section{I4.5 Building environmental ethos, exploiting visual modality, en- hancing corporate image}

Regardless of the industry sector a company inhabits, any corporation will have "its virtues - or morally desirable habits, its vices - or morally undesirable habits" (Gowri 2007, p. 39I). However, for organizations considered especially responsible for detrimental environmental effects reducing attention to these undesirable practices can reap significant financial benefits. Consequently, many companies are keen to market themselves by aligning themselves with the virtue $d u$ jour; currently conceived in terms of environmentally responsible activities.

The data has demonstrated how organizations attempt to develop positive relationships and generate goodwill (eunoia) with a range of stakeholders including their customers. The use of knowledge (phronesis) in the low modality linguistic claims of environmental goods and reduced environmental impacts are identified to be overstated and less than judicious. However, it seems that the use of low modality images, images that are deemed to be "fanciful" and non-realistic, allows corporations to display a commitment to the "service of the larger community" (Solomon 2004, p. IO23) or planet by "wishing good for others" (Ihlen 2009, p. 364) with the aim, undoubtedly of benefiting themselves.

I conclude this chapter using two examples from an IвM (2008) television advertizement from the unashamedly titled Go Green campaign to demonstrate the extent of this strategy. Seated behind a desk, in an office, a male executive is considering an "eco-friendly" plan to reduce energy consumption. He is ultimately convinced of its worth because of its significant reduction in costs. Previously in black and white, letterboxed in corporate blue, following the executive's decision to accept the plan to cut energy use/save money/increase profit the screen surround turns a vibrant green. The formerly monochrome executive is elevated to full color and his office becomes inhabited by cartoon rabbits, squirrels, birds and plants with accompanying music redolent of a saccharine animated film soundtrack. The environmental consequences or, more accurately, the economic benefits of energy reduction are realized visually and acoustically in the reductive form of a "Disneyfied" (Bauman 2004) version of "real" nature reduced to a highly restricted code of animals and plants.

Whilst it is encouraging that nearly $33 \%$ of uk consumers recognize that corporations are exaggerating their environmentally beneficial activities 
(вт, 2008). Corporate image marketing already seems wise to the different degrees of scrutiny paid to textual claims and visual representations about environmental goods. Corporate rhetoricians already appreciate that a persuader "must disguise his art and give the impression of speaking naturally and not artificially" (Aristotle 1954, I404b I8). However, it seems this is done by exploiting images of nature itself. Corporations demonstrably eager to accrue environmental ethos can accomplish this, it seems, with ease by hoodwinking a visually illiterate public and a rhetorically inconsistent regulatory body.

\section{References}

Aristotle (1954). The Rhetoric and the Poetics of Aristotle. New York: Random House.

Aristotle (1991). On Rhetoric: A Theory of Civic Discourse. Oxford: Oxford University Press. ASA - Advertising Standards Authority (2006). Non-broadcast adjudications.

Available at http://tinyurl.com/yjv77v4 Accessed 28 October 2009.

ASA - Advertising Standards Authority (2007a). Non-broadcast adjudications. Available at http://tinyurl.com/yglpjxz Accessed 28 October 2009.

ASA - Advertising Standards Authority (2007b). Non-broadcast adjudications. Available at http://tinyurl.com/yj39kgx Accessed 28 October 2009.

ASA - Advertising Standards Authority (2008). Environmental Claims in Advertising. Is

Green a Grey Area? London: Advertising Standards Authority.

Ashforth, B.E. and B.W. Gibbs (1990). The Double-edge of Organizational Legitimation.

Organization Science: A Journal of the Institute of Management Sciences I, I77-94.

Barthes, R. (1972). Mythologies. London: Paladin.

Bauman, A. (2004). The Disneyization of Society. London: Sage.

Beason, L. (199I). Strategies for Establishing an Effective Persona: An Analysis of Appeals to Ethos in Business Speeches. Journal of Business Communication 28(4), 326-346.

Beder, S. (2002). Environmentalists Help Manage Corporate Reputation, Changing

Perceptions not Behaviour. Ecopolitics, Thought and Action I, 60-72.

Blair, J.A. (1994). The Rhetoric of Visual Arguments. In: C. A. Hill and M. Helmers (Eds.), Defining Visual Rhetorics (pp. 4I-62). Mahwah NJ: Lawrence Erlbaum.

Blair, J.A. (2004). The Possibility and Actuality of Visual Arguments In: C Handa (Ed.), Visual Rhetoric in a Digital World (pp. 344-363). Boston: Bedford/St. Martin's.

Bortree, D.S. (2009). The Impact of Green Initiatives on Environmental Legitimacy and Admiration of the Organization. Public Relations Review 35, I33-135.

British Telecom (2007). Consumers Sceptical of Corporate Commitment to Sustainability. Available at http://tinyurl.com/yz346w4. Accessed 28 October 2009. 
Chartered Institute of Public Relations (2007). CIPR Best Practice Guidelines for Environmental Sustainability Communications. London: CIPR.

Coupland, C. (2004). Corporate Identities on the Web: An Exercise in the Construction and Deployment of 'Morality'. Nottingham: International Centre for Corporate Social Responsibility Research Paper Series.

Coupland, C. (2006). Corporate Social and Environmental Responsibility in Web-based reports: Currency in the Banking Sector. Critical Perspectives on Accounting 17,865-8I. DEFRA - Department for Environment, Farming and Rural Affairs (2006). Green Claims Code. London: Defre Publications.

Davies, G., R. Chun and R. da Silva (200I). The Personification Metaphor as a Measurement Approach for Corporate Reputation. Corporate Reputation Review 4, II3-I27.

Forceville, C. (1996). Pictorial Metaphor in Advertising. London: Routledge.

Fombrun, C.J. and V.P. Rindova (200o). The Road to Transparency: Reputation Management at Royal Dutch/Shell. In: M. Schultz, M.J. Hatch and M. Holten Larsen (Eds.), The Expressive Organization (pp. 77-96). Oxford: Oxford University Press. Grant, J. (2007). The Green Marketing Manifesto. Chichester: Wiley.

Gowri, A. (2007). On Corporate Virtue. Journal of Business Ethics 70, 391-400.

Hill, C.A. (2004). The Psychology of Rhetorical Images. In: C.A. Hill and M. Helmers (Eds), Defining Visual Rhetorics (pp. 25-40). Mahwah NJ: Lawrence Erlbaum.

Hansen, A. and D. Machin (2008). Visually Branding the Environment. Discourse Studies I0, 777-794.

IBM (2008). Go Green: Tree huggers Available at http://tinyurl.com/6y8h7a. Accessed 28 October 2009.

Hodge, R. and G. Kress (1988). Social Semiotics. Cambridge: Polity.

Ihlen, Ø. (2009). Good Environmental Citizens? The Green Rhetoric of Corporate Social Responsibility. In: R.L. Heath, E.L. Toth and D. Waymer (Eds.), Rhetorical and Critical Approaches to Public Relations II (pp. 360-274). New York: Routledge. ISBA (2007). Environmental Claims in Advertising: A Guide for Advertisers. London: ISBA. Kinneavy, J.L. and S.C. Warshauer (1994). From Aristotle to Madison Avenue: Ethos and the Ethics of Argument. In: Baumlin, J.S. and T.F. Baumlin (Eds.), Ethos: New Essays in Rhetorical and Critical Theory (pp. I7I-190). Dallas, Texas: Southern Methodist University Press.

Kress, G. and T. van Leeuwen (1996). Reading Images: The Grammar of Visual Design. London: Routledge.

Kress, G. and T. van Leeuwen (1998). Front Pages: (The Critical) Analysis of Newspaper Layout. In: A. Bell and P. Garrett (Eds.), Approaches to Media Discourse (pp. I86219). Oxford: Blackwell. 
Lemke, J.L. (1998). Resources for Attitudinal Meaning: Evaluative Orientations in Text Semantics. Functions of Language 5, 33-56.

Livesey, S.M. (2002). Global Warming Wars: Rhetorical and Discourse Analytic

Approaches to Exxonmobil's corporate public discourse. Journal of Business Communication 29, II7-I46.

Livesey, S.M. and K. Kearins (2002). Transparent and Caring Corporations? A Study of Sustainability Reports by The Body Shop and Royal Dutch Shell. Organization and Environment 15, 229-254.

Lopes, D. (1996). Understanding Pictures. Oxford: Oxford University Press.

McQuarrie, E.F. and B.J. Phillips (2005). Indirect Persuasion in Advertising: How Consumers Process Metaphors in Pictures and Words. Journal of Advertising 34, 7-2I.

Magee, K. (2008). Firms warned over 'greenwash'. PR Week April I7 2008.

Meshcheryakov, A.N. (1979). Awakening to Life: Forming Behaviour and the Mind in DeafBlind Children. Moscow: Progress Publishers

Mitchell, T. (1994). Picture Theory: Essays on Verbal and Visual Representation. Chicago: University of Chicago Press.

Neu, D., H. Warsame and K Pedwell, K. (1998). Managing Public Impressions: Environmental Disclosures in Annual Reports. Accounting, Organisations and Society 23(3), $265-282$.

Petty, R.E. and J.T. Cacioppo (1986). Communication and Persuasion: Central and Peripheral Routes to Attitude Change. New York: Springer-Verlag.

Solomon, R. (2004). Aristotle, Ethics, and Business Organizations. Organization Studies 25, IO2I-IO43.

Theaker A. (2004). The Public Relations Handbook. (2nd ed.) London: Routledge.

Urry, J. (1992). The Tourist Gaze and the Environment. Theory, Culture and Society 9, I-26.

Van Leeuwen, T. (2006). Introducing Social Semiotics: An Introductory Textbook. London: Routledge.

Wæraas, A. and Ø. Ihlen (2009). ‘Green' Legitimation: The Construction of an Environmental Ethos. International Journal of Organizational Analysis I7(2), 84-IO2.

Wei, Y.K. (2002). Corporate Image as Collective Ethos: a Poststructuralist Approach. Corporate Communications: An International Journal 7, 269-276. 



\author{
PART I V \\ Rhetoric \\ and Politics
}

\% 



\section{I5 Rhetoric and the ( $\mathrm{Re})$ Constitution of Collective Identity: The Example of Poland}

CEZAR M. ORNATOWSKI

\section{I5.I Introduction}

Concern with "identity" has become increasingly salient lately, in academic as well as in public discourse. The wave of democratic transformations in Central/Eastern Europe and Eurasia following the dissolution of the Soviet Union, combined with the ethnic violence in the former Yugoslavia and evidence of a resurgence of xenophobia and nationalism in many areas of the former Soviet Block, foregrounded issues of collective identity. In the wake of these transformations, scholars such as Noemi Marin and Vladimir Tismaneanu noted that in post-1989 Central/Eastern Europe the problematic of "democracy" has to a large extent been coextensive with the problematic of identity. The problematic of collective identity has also been central to the transformation in South Africa from an apartheid (racialist) state to a multiethnic and democratic "rainbow nation" (Salazar 2002). Finally, the current global situation related to the "war on terror" in the Middle East and elsewhere involves collective identity construction on the part of the various contesting religious, political and nationalist movements and in the context of the various "nation building" projects (for instance, in Iraq, Afghanistan, Chechnya and elsewhere). Construction of collective identities - whether racial, class, religious, group, national or transnational, has been central to ideological projects such as fascism, National Socialism or communism or to political projects such as the European Union or Islamic extremism.

Clearly, the problem of collective identity has not - as some had hoped in the 1950 and 1960s - disappeared with the retreat of colonialism, spread of democracy, development of technologies of communication, spread of "global culture", regionalization or the creation of trans-national institutions. Rather the reverse. Just as in transformational contexts, the problematic iden- 
tity seems to have moved to the forefront of political debates, the pressures of globalization, immigration, cultural diffusion and struggle over resources appear to lead to a resurgence of identity-dominated movements and discourses (witness the current debate over immigration in the us).

Although much work in political science, sociology, anthropology, history, cultural studies, and from other perspectives has focused on various aspects of collective identity construction, from national to social and ideological (Anderson 1991; Cohen 1985; Gillis 1994; Guibernau 2007; Hastings 1997; Laclau 1994; Llobera 2004; Smith 199I; Radcliffe and Westwood 1996; Rowland and Frank 2002; Taylor 2009; Verdery 199I), the problematic of collective identity has not been explored in a systematic way by rhetoricians, although it is taken up in various ways, explicitly or implicitly, in work concerned with post-colonialism, public memory or political transformation (for more explicit discussion of various rhetorical aspects of collective identity construction, see, for instance, Bruner 2002; Hauser 1999; Salazar 2002; White 1984). In all of this work, collective identity emerges as a rhetorical project, bearing out Kenneth Burke's insight that "identification" is one of the primary mechanisms of rhetoric.

There is no room here for a review of relevant contemporary perspectives on collective identity. Suffice to say that collective identities are generally approached as "imaginary constructions" (Anderson 1991; Bowman 1994), "countries of words," in so far as "the rituals of inscribing borders, picturing territories and populations, and thematizing issues salient to those terrains and the communities believed to occupy them occur within discourse" (Bowman I994, p. I40). Anthony Cohen has agued that community "exists in the minds of its members, and should not be confused with geographic or sociographic assertions of 'fact'" (Cohen 1985, p. 98).

It is also widely accepted that identity is negative and relational. Identity is "negative" because it does not inhere in some intrinsic essence or positive "inner" core but rather depends on an establishment of contrasts and differences. Bowman, for instance, suggests that collective identity is "not a 'thing' in itself but a way of speaking, and thinking, about others who are 'like us.' People create communities rhetorically through thinking that some people are 'like' themselves while others are 'unlike' them" (Bowman I994, p. I40). Similarly, according to Cohen the "quintessential referent of community is that its members make, or believe they make, a similar sense of things either generally, or with respect to specific and significant interests, and, further, 
that they think that that sense may differ from one made elsewhere" (Cohen I985, p. I6). Identity, as both Cohen and, more recently, Noelle McAfee (2002) point out, is thus relational, because it emerges as a function of relationships of affiliation and disaffiliation. If I were the only human left alive after a nuclear holocaust, my "identity" as I understand it now would cease to be functional; the fact of my being American, Catholic or a Democrat would be irrelevant in my relations with animals and rocks. If all other life forms were gone and I was surrounded only by the inorganic, my identity would probably boil down to simply being the only living being in my environment. It may even be that, as McAfee suggests in her concept of "relational subjectivity", "individual" identity is a function of "community," of a "congregation," to use Kenneth Burke's term (Burke 1984), rather than the other way around. In fact, Aristotle seems to suggest just that in the Politics:

the state is by nature prior to the family and the individual, since the whole is necessarily prior to the part; for example, if the whole body be destroyed, there will be no foot or hand, except in an equivocal sense, as we might speak of a stone hand ... But things are defined by their working and power ... The proof that the state ... is prior to the individual is that the individual, when isolated, is not self-sufficing; and therefore he is like a part in relation to the whole. (I253a, pp. 19-30)

"All identities emerge within a system of social relations and representations," argues Montserrat Guibernau (Guibernau 2007, p. IO). To the extent that identity is a function of relationships, it potentially gets richer, more "dense", the more relationships there are and thus the more salient distinctions (in terms of similarities and contrasts) can be drawn and the more potential choices are available in terms of affiliations, disaffiliations, positionalities and attitudes.

The distinctions and relationships that define collective identity are vested largely in symbols (Cohen 1985; McGee 1980). Cohen characterizes communities as "symbolic" because they cohere around networks of relevant symbols. "The reality of community in people's experience," Cohen suggests, "thus inheres in their attachment or commitment to a common body of symbols" (Cohen 1985, p. 16). Symbols, however, "do not tell us what to mean, but give us the capacity to make meaning" (ibid.). Thus, individuals may differ in their specific interpretations of the meaning of the symbols. In fact, arguments about the meanings vested in symbols are, as I will argue below, one 
of the major rhetorical mechanisms of collective identity formation and transformation.

In this chapter, I propose a rhetorical framework for looking at collective identity in terms of its major constitutive dimensions. I identify the constitutive dimensions of collective identity using, as my representative anecdote (in Kenneth Burke's sense, see Burke 1969), two versions of the Constitution of the Republic of Poland. These dimensions represent topoi of collective identity in the rhetorical sense of locis communis, places of argument concerning such questions as who "we" are, where we are, where we come from, how we relate to each other and to our others, what values, and what purposes we share. 'These topoi, analogous to Burke's Pentad of Act, Agent, Agency, Scene, and Purpose, which represent a framework for analyzing human motives in discourse and symbolic action, offer, I suggest, a rhetorically productive way of examining the rhetorical mechanisms of collective identity formation and transformation (Burke 1969).

\subsection{Topoi of identity in the political transformation of Poland}

Let me now move to my representative anecdote, which, in the Burkean spirit, represents a reduction of complex subject matter, but which will allow me, within limited space, to evolve a "terminological structure" that represents a rhetorically productive perspective on collective identity formation and transformation (Burke 1969, p. 60). Following Burke, I begin this brief foray into the rhetorical nature of collective identity with constitutional relations (ibid. p. 323).

Kenneth Burke has referred to constitutions as proclaiming the "common substance" of community (ibid. p. 343). Let us examine the nature of this "common substance" as it was articulated in the Preamble to the 1952 socalled 'Stalinist' Constitution of the Polish People's Republic (the name of the polity erased in the wake of the 1989 transformation). The Preamble states:

The Polish People's Republic is a republic of working folk.

The Polish People's Republic harks back to the most progressive traditions of the Polish Nation and realizes the liberatory ideas of the Polish working masses. The Polish working folk, under the leadership of the heroic working class, basing on the worker-peasant alliance, has struggled for decades for liberation from national en-

\footnotetext{
${ }^{\text {I }}$ An earlier version of this proposal appears in Ornatowski (2008).
} 
slavement imposed by Prussian, Austrian, and Russian conquerors-colonizers, just as it has struggled for the abolition of the exploitation of Polish capitalists and landowners.

During the period of [Nazi] occupation the Polish Nation waged an unyielding, heroic struggle with a bloody Hitlerite invasion. The historic victory of the Union of Soviet Socialist Republics over fascism liberated Polish lands, enabled the Polish working folk to win power and created the conditions for the national revival of Poland within new, just borders. The Recovered Territories returned to Poland for all time.

Realizing in practice the historic directives of the Declaration of the Polish Committee of National Liberation on July 22, 1944 and extending its programmatic principles, the people's government - thanks to the self-sacrificing and creative efforts of the Polish working folk, through struggle against the bitter resistance of the stragglers of the old capitalist-landowner system - achieved great social transformations. As a result of revolutionary struggles and transformations the government of capitalists and landowners has been overthrown, the state of people's democracy has been consolidated, a new social system is taking shape and solidifying, one that corresponds to the interests and aspirations of broad masses. (...)

The foundation of the current people's government in Poland is the alliance of the working class with working peasantry. In this alliance, the leading role belongs to the working class as the vanguard social class, based on the revolutionary achievements of the Polish and international workers' movement, on the historic experiences of socialist construction in the Union of the Soviet Socialist Republics, the first state of workers and peasants. (...) (Preamble to the Constitution of the Polish People's Republic of July 22, 1952, author's translation)

As the Preamble articulates it, the Polish People's Republic was primarily a community of "working folk". The origins of this community are traced to the "most progressive traditions of the Polish nation," the "liberatory ideas of the Polish working masses," the "achievements of the Polish and international workers' movement" and the "experiences of socialist construction" in the Soviet Union, as represented in the programmatic principles set out in the Declaration of the Polish Committee of National Liberation of July 22, I944; the latter, in effect, becomes the "constitutive" (I'm using the word in Maurice Charland's sense) text of the new Polish republic (Charland 200I). The Preamble also offers a highly selective historical narrative of the emergence of this community, which connects in one chain of equivalencies the liberation 
from national enslavement by Prussian, Austrian and Russian conquerorscolonizers, the abolition of the exploitation by Polish capitalists and landowners, the struggle against the Nazi occupation and the struggle against the "resistance of the stragglers of the old system." It locates the community within "new, just borders" that include the Recovered Territories (the euphemism for lands taken from Germany and given to Poland in exchange for the eastern provinces taken from Poland by the Soviet Union). The foundation of the agreement, or social contract, that underpins this community is the "worker-peasant alliance", subordinated to the principle of the "leadership of the heroic working class." Finally, the Preamble names the "others", the enemies, of the community (Prussian, Austrian and Russian "conquerors-colonizers" and Polish "capitalists and landowners") as well as its affiliations, its allies (the Soviet Union and - in a paragraph omitted for the sake of space other "peace-loving nations").

Let me suggest that what we have here are the "constitutive" (in the sense developed by Maurice Charland) dimensions of the collective identity of the "community" of People's Poland as it was officially articulated during the period of "real socialism": membership (who belongs), origin and history (a narrative of the community's genesis and provenience), location (both in a geographic and geopolitical, as well as symbolic sense) and key relationships, including relations between members (internal social and political relations) as well as relations with others (external relations, patterns of affiliation and disaffiliation, including the positing of the community's "other" or "others").

In social practice, each of these dimensions of collective identity was inscribed in and articulated through multiple symbols. According to Radcliffe and Westwood, "imaginary and embodied nations are lived through the discursive practices of everyday life." (Radcliffe and Westwood I996, p. 7) A denizen of People's Poland in the I970s, for example, experienced her membership in this "republic of working folk" through forced participation in organizations, ceremonies, outings or events such as the May Day parade or rituals such as the Harvest Festival, official observance of Miners' or Steelworkers' Days or hearing official rhetoric in which the expression "working people of towns and villages" functioned as the ritual invocation of the Polish people. Origin and history were figured forth through narratives, histories, films, portraits of leaders (including the ever-present duo of Marx and Lenin, typically flanking the current party general secretary), epics depicting the struggle for social and national liberation, and so on. Internal relations 
were symbolized through portraits and statues of leaders. Artwork depicting social transactions in which those in uniform or wearing red ties (indicating party or Communist Youth League membership) were shown in positions of authority or leadership as were films depicting the socialist way of life and of dealing with people and situations.

Guibernau suggests that the two fundamental elements of national identity are continuity over time and differentiation from others. Historical continuity of People's Poland was symbolized through working class and revolutionary heroes, the official calendar of state holidays commemorating occasions important to the regime and commemorating the "achievements of the Polish and international workers' movement" and the "experiences of socialist construction" in Poland and elsewhere, as well as through histories of liberatory struggles against various external and internal enemies. Of course, another history existed side-by-side in private memory (see Hauser 1999) as well as in the various symbols extent in the urban and symbolic landscape, but not emphasized in official discourse. During his history-making visits to Poland between 1979 and 1987, Pope John Paul II successfully deployed such symbols to activate a different narrative of national history and a different sense of collective identity (see Ornatowski 2008). Communist Poland's "others" included the "West", especially "Western imperialism", most prominently represented by the U.S. and West Germany and their allies, as well as spies, saboteurs and various "criminals," such as, for instance, possessors or traders of western currencies or gold, as well as ideological enemies. These were depicted through a variety of images, narratives and discourses.

The dimensions of membership (who are "we"?), origin and history (how did we become who we are?), location (where are "we"? what is the "scene" to use Kenneth Burke's generative term - on which we are constituted as agents?), internal relations (how are we organized? how do we relate to each other?), and external relations (who are our others? What are our relations of affiliation and disaffiliation?) are topo $i$ in a rhetorical sense; they represent constitutive and "strategic" dimensions of collective identity (locis communis) within which collective identities are articulated, debated and transformed.

As an example of such a re-articulation, consider the Preamble to the Constitution of the Polish Republic of April 2, 1997 (the post-transitional constitution that replaced the 1952 constitution). The Preamble states: 
Having regard for the existence and future of our Homeland, Which recovered, in 1989, the possibility of a sovereign and democratic determination of its fate, We, the Polish Nation - all citizens of the Republic, Both those who believe in God as the source of truth, justice, good and beauty, As well as those not sharing such faith but respecting those universal values as arising from other sources, Equal in rights and obligations towards the common good - Poland, Beholden to our ancestors for their labours, their struggle for independence achieved at great sacrifice, for our culture rooted in the Christian heritage of the Nation and in universal human values, Recalling the best traditions of the First and the Second Republic, Obliged to bequeath to future generations all that is valuable from our over one thousand years' heritage, Bound in community with our compatriots dispersed throughout the world, Aware of the need for cooperation with all countries for the good of the Human Family, Mindful of the bitter experiences of the times when fundamental freedoms and human rights were violated in our Homeland, desiring to guarantee the rights of the citizens for all time, and to ensure diligence and efficiency in the work of public bodies, Recognizing our responsibility before God or our own consciences, Hereby establish this Constitution of the Republic of Poland as the basic law for the State, based on respect for freedom and justice, cooperation between the public powers, social dialogue as well as on the principle of subsidiarity in the strengthening the powers of citizens and their communities.

We call upon all those who will apply this Constitution for the good of the Third Republic to do so paying respect to the inherent dignity of the person, his or her right to freedom, the obligation of solidarity with others, and respect for these principles as the unshakeable foundation of the Republic of Poland. (Preamble to the Constitution of the Polish Republic of April 2, 1997)

One can readily identify the same general dimensions of collective identity as in the Preamble to the 1952 Constitution, except articulated differently. In terms of the topos of membership, the community of the Republic of Poland includes "all citizens of the Republic." In addition, in deliberate contrast to the 1952 text, the Preamble opens with the plural pronoun "we", symbolizing the "authentic" voice of the political community (the 1952 constitution was written in Moscow and, following a review in Warsaw, was hand-edited by Stalin and handed to the Polish parliament for endorsement). The community of the new Republic further characterizes its members as both believers and non-believers, although the former appear to be privileged, at least by syntax. Membership is also extended to Poles living 
elsewhere (who were not considered legitimate members under the previous dispensation).

In terms of origin and history, the new Republic traces its origins to the Christian tradition and the thousand-year history of Poland (the coming of Christianity in the $\mathrm{IO}^{\text {th }}$ century coincided with the appearance of Poland as a recognizable geopolitical entity). It also pointedly erases the communist republic from its antecedents. The Preamble posits internal relations based on human dignity, solidarity, social dialog, freedom, justice, and subsidiarity. "Solidarity" implies a fundamental "horizontality" of the national community in contrast to the class-based foundations of the socialist republic, while subsidiarity contrasts with the former centralization and hierarchization of political authority. In terms of the community's external relations, the 1997 text refrains from naming its political "others" (although it may be read as implying moral "others", those who do not share the "universal human values"). By explicitly calling for the "cooperation of all countries", the text distances itself from the affiliations and divisions (symbolized most emphatically by the Iron Curtain) that defined the geo-political positioning and thus collective identity of socialist People's Poland.

Both preambles "constitute" the collective identity of (the two different Republics of) Poland along the same five fundamental dimensions. These dimensions functioned (and some of them continue to function) as major "places" of argument during the political transition.

As one example, one may consider the debates concerning Poland's geopolitical "location": whether Poland after 1989 was part of "Eastern" or "Central" Europe, whether it should be closer - politically and economically - to Russia or the West, or whether it should form a "bridge" between "East" and "West." Unlike the debates on "location" after 1945, when Poland was literally shifted territorially to the West and lost territory in the East, the transition after 1989 did not involve territorial changes; still, the memories of the "lost lands" in the East constituted a part of the discussions of post-1989 collective identity.

The symbolic resources of the topos of "location" are revealed especially clearly in the strategic deployments of rival symbolic geographies over the period of the political transition. During communist times, the ritual peregrinations of the First Secretary of the ruling party (and sometimes other officials) to key industrial enterprises, collective farms, and "great construction sites of socialism" mapped out a specific symbolic geography of Poland. Each newly 
appointed First Secretary, along with other major officials, also made a routine pilgrimage to Moscow to "confer" with Soviet leaders, along with periodic visits to "fraternal parties." These peregrinations, like medieval religious pilgrimages, endowed space with meaning by mapping its symbolic center, its key compass points and axis. The peregrinations of the First Secretary (which involved the key "building sites" and symbolic places of socialism) contrasted with Pope John Paul II's peregrinations around the country during the latter's dramatic visits between 1979 and 1987, which mapped out an alternative symbolic geography: a spiritual one (involving a variety of historical and religious sites associated with Poland's pre-socialist and non-socialist existence) (see Ornatowski 2009). The two itineraries, the First Secretary's and the Pope's, activated two visions of collective identity implicit in the symbolic resources of the topos of "location". I want to emphasize three important moments here. One is that these alternative versions of collective identity existed, as it were, side by side as interpretive possibilities implicit in the resources of place. Another is that these possibilities existed in a dialectical tension, which enhanced their dramatic and transformative potential. Still another is that these symbolic geographies continue to be implicit in the political "landscape" (a uniquely appropriate metaphor) in Poland today and continue to be activated, as rhetorical needs dictate, by various political a actors and parties, especially in regard to Poland's presumed "subservience" to the European Union; in the discourse of the populist right wing, "Brussels" had taken the former place of "Moscow" as a symbolic compass point and place of political "pilgrimage", a symbol of Poland being subsumed in a larger, and alien, collective identity.

As a final example, one may consider the post-1989 debates within the topos of "membership". During the I970s and I980s, Polish society was basically divided, in popular perception and discourse, between "us" (ordinary people) and "them" (the rulers). When Poland started to change toward the end of the I980s, the identity of the "we" became an issue. Once the transition returned the country to "us," made the country "our own", it turned out that "we" are no longer monolithic, since the "other" that united and defined "us" had disappeared. That is why the political scene quickly fragmented after the June 4, 1989 transitional parliamentary elections. In fact, both the opposition and the heretofore ruling party quickly differentiated along a range of new dividing lines in respect to the problems facing the changing country.

The two constitutional Preambles cited here in effect mark out a space of transformation of the collective identity of the Republic of Poland. In so- 
cial practice, this space was, and continues to be, elaborated and mediated through a multitude of discourses and symbolic practices: changes in national and local symbols, signs, place names, monuments, spatial and architectural designs (i.e., taking down border posts, extending streets), and even rerouting the entire national communication grid: from the East-West orientation - the primary orientation of all major routes and rail lines during communist times, when Poland was regarded as the route of possible Soviet attack against Western Europe - to the North-South orientation, the orientation conducive to Poland's new economic orientation. Collective identity is a space of contestation and such contestation forms the constant undercurrent of public discourse. For instance, the current anxieties about immigration in the US imply the topos of "membership": who, or what, is an "American" and what it means to be "American."

What I called here "topoi of identity" represent constitutive dimensions of collective identity; their rhetorical sense lies in the fact that they are, to adapt Sarah Radcliffe and Sallie Westwood's words, "key sites" in which collective identities are "generated and sustained," as well as transformed. The list of such topoi may be extended through further examination of how various kinds of collective identities are rhetorically and symbolically constituted, debated, and transformed. For instance, in the case of the United States, the dimension of "shared purpose" or "shared fate" was an important constitutive dimension of collective identity from the beginning of the Republic (since the new Republic did not have much historical continuity behind it and since it was, and continues to be, a community of immigrants with diverse histories and points of origin). Part I of the Constitution of the European Union, a transnational collective identity, also contains the dimension of shared objectives, in addition to another constitutive dimension: shared values (http:// www.europeanconstitution.ie/constitution/en/parti_en.asp).

The "topoi of identity" are analogous to Kenneth Burke's Pentad (Act, Agent, Agency, Scene and Purpose) (Burke 1969). However, whereas Burke's Pentad enables a "dramatistic" analysis of human motives and actions, the topoi of membership, origin and history, location, internal relations, external relations, shared values, and shared purpose offer a framework for examining how collective identities are constituted and reconstituted in a variety of discourses and practices, from public rhetoric to films, rituals, events, and other communicative activities. I have found them useful in examining the practices of identity-building in the case of various political or religious groups or move- 
ments (for instance, www.palestine-info.co.uk or www.kavkaz.org.uk/eng) or virtual "nations" such as the Kingdom of Talossa www.kingdomoftalossa. net/index.cgi) or the Republic of Talossa (www.talossa.com).

As in the case of Burke's Pentad, what is most important analytically are not so much the topoi themselves, but their "ratios": the shifts in relative emphases within and between them. For instance, while possession and justification for newly acquired territories (taken from Germany after world War II in lieu of territories lost to the Soviet Union in the east) constituted an important aspect of the topos of "location" in communist post-war Polish propaganda (according to which Poland had "returned" to ancient Polish lands in the west), and an important constituent in national and ideological "identification", after 1989 the topos of location was dominated by the shift in geopolitical affiliation (articulated as Poland's "return" to its "European home" and to Western civilization, symbolized by membership in NATO and the European Union - themselves "imaginary" communities). In the speeches of Polish prime ministers between 1989 and 1990 one can see the shift in emphasis toward relations with the West (with the addition of the United States as a major "partner" - a new "imaginary" relationship) as opposed to communist-era primary emphasis on relations with the Soviet Union and other "socialist" countries. In terms of rhetorical arrangement, this shift was accompanied by a switch in order (relations with the West began to be mentioned before relations with Russia and the "East").

\subsection{Conclusion: Communication as the making of community}

In biological terms, a community is a group of interacting organisms sharing an environment (http://en.wikipedia.org/wiki/Community). In human communities, both "interacting" and "sharing" may take a wide variety of forms and meanings, some of which are implicit in the etymology of "common" and "community".

According to the Oxford English Dictionary, the term "community" derives from Latin communis: $\mathrm{com}=$ together, munis = bound, under obligation, also in early Latin "ready to serve" (thus Lat. immunis, English immunity = under no obligation, not bound) ("Common"). The second element (munis) is also the source of Latin munia, "duties, public duties, functions" related to munia, "office." One early meaning of the root "com" in English was "public," "shared," "belonging to more than one" (the Cursor Mundi of I300 speaks of the "commun pasture"). Another early meaning was "belonging to humankind 
alike," a possession of the human race as a possession or attribute (for instance, death as our "common" fate). The sense of "common" as "belonging to humankind alike" contains an implicit contrast with non-humans, as well as with those considered not fully "human". The latter underlies the expression "common sense," which originated in the $14^{\text {th }}$ century to designate the ordinary power of uniting mentally the impressions conveyed by the five senses, which became synonymous with ordinary understanding, without which one is foolish or insane. Still other historical senses of "common" included "belonging to the community at large" (thus something shared by all members of a community as opposed to those who are non-members) and something "general," shared by all, with an attached implication of lowliness (as in "a common" man, or "common intelligence"). This last meaning included connotations of lack of distinction, secularity (as opposed to holiness), and membership in the general populace, the "commons"; it is these connotations that underwrote the political sense of the British "House of Commons" ("Common").

An important distinction that emerges from the foregoing is that between "commonness" as vested in something "given" (such as land, pasture, or mental or physical attributes), as opposed to something that represents a more "abstract" achievement, a result of cooperation, action, or decision (such as arriving at an agreement or "making common cause"). We see here that the etymological senses of "community" suggest a spectrum of potential foundations for human association, from a shared possession or attribute (territory, mental attribute, or a marker such as skin color - all of which, in social and political practice, may be, and usually are, heavily over-interpreted), to more specifically "rhetorical" products of deliberation, negotiation, or agreement (such as "common" fate, understanding, values, or cause). Hence, "communing," or the making of community, involves both putative "givens" (i.e., possession of shared territory) along with acts of interpretation and "making" that together constitute what Kenneth Burke has referred to as a "congregation" (1984).

These are not merely philological exercises. "Community," we are reminded by such reflections, is implicit in "com-muni-cation," which denotes, literally, the "making of the common." Such making implies both com (that which is shared, whether a thing, property, attribute, symbol, interpretation, understanding, or agreement) and munia (obligations, thus some form of reciprocity, if only "symbolic", as, for instance, being part of the Catholic Church involves periodic acts of confession and participation in "holy com- 
munion", or begin part of a terrorist organization involves committing act of violence). We arrive here, albeit by a somewhat roundabout route, at fundamentally rhetorical territory.

A "community" may be based on a shared attribute or territory (although both may, and usually are, heavily over-interpreted), but it has to reach an agreement; in this sense, the "makedness" of community implies a range of "com-muni-cative" actions, from creation and/or representation of the putative givens (territory, attribute) to creation of relatively more abstract and "imaginary" outcomes and (sometimes enforced) rituals of participation. For instance, the "volkisch" community of German National Socialism was based on a (heavily mediated and over-interpreted) "natural" attribute ("Aryan" racial origin) and possession, or conquest, of a territory (both invoked in the Nazi slogan of "blood and soil"), along with a specific interpretation of shared fate (defeat in World War I, economic misery presumably caused by the Treaty of Versailles, and so on). The obligations of participation for the ordinary German involved donating to the "Winter Aid" and joining one of innumerable official organizations for every profession and age group. More symbolic rituals of participation were also represented in propaganda films such as Leni Riefenstahl's famous Triumph of the Will.

Topoi of identity such as of membership (who are we?), origin and history (how did we become who we are?), location (where are we?), internal relations (how are we organized? how do we relate to each other?), external relations (who are our others?), shared values (what things do we hold in common?), and shared purpose (what are we striving for?) are loci of invention of collective identity, in effect, of community. Together, they offer a productive lens for analysis of how human communities are constituted and reconstituted through a variety of "com-muni-cative" activities.

\section{References}

Anderson, B. (1991). Imagined Communities: Reflections on the Origins and Spread of Nationalism. London: Verso.

Aristotle. Politics. (1943). Trans. Benjamin Jowett. New York: Random House.

Bowman, G. (1994). A Country of Words: Conceiving the Palestinian Nation from the Position of Exile. In: E. Laclau (Ed.), The Making of Political Identities (pp. 138170). London: Verso.

Bruner, M.L. (2002). Strategies of Remembrance: The Rhetorical Dimensions of National Identity Construction. Columbia, SC: University of South Carolina Press. 
Burke, K. (1969). A Grammar of Motives. Berkeley and Los Angeles: Univ. of California Press. Burke, K. (1984). Attitudes Toward History. Berkeley and Los Angeles: Univ. of California Press.

Charland, M. (200I). Constitutive Rhetoric. In: T.O. Sloan (Ed.), Encyclopedia of Rhetoric (pp. 616-619). New York: Oxford University Press.

Cohen, A.P. (1985). The Symbolic Construction of Community. London and New York: Routledge.

"Common." (1985). Oxford English Dictionary, The Compact Edition (pp. 482-3). Oxford, uk: Oxford University Press.

Gillis, J.R. (1994). Commemorations: The Politics of National Identity. Princeton: Princeton University Press.

Guibernau, M. (2007). The Identity of Nations. Cambridge, uk: Polity Press.

Hastings, A. (1997). The Construction of Nationhood. Ethnicity, Religion and Nationalism. Cambridge: Cambridge University Press.

Hauser, G.A. (1999). Vernacular Voices: The Rhetoric of Publics and Public Spheres.

Columbia, SC: University of South Carolina Press.

Laclau, E. (Ed.) (1994). The Making of Political Identities. London: Verso.

Llobera, J.R. (2004). Foundations of National Identity: From Catalonia to Europe. New York and Oxford: Berghahn.

Marin, N. (2007). After the Fall: Rhetoric in the Aftermath of Dissent in Post-Communist Times. New York: Peter Lang.

McAfee, N. (200o). Relational Subjectivity. In: N. McAfee (Ed.), Habermas, Kristeva, and Citizenship (pp. I29-150). Ithaca and London: Cornell University Press.

McGee, M.C. (1980). The 'Ideograph': A Link Between Rhetoric and Ideology. Quarterly Journal of Speech 66, I-I6.

Ornatowski, C.M. (2008). Topoi of Identity: Rhetorical Practices in the Political Reconstruction of Poland. In: D. Zarefsky and E.A. Benacka (Eds.), Sizing up Rhetoric (pp. 355-365). Long Grove, IL: Waveland Press.

Ornatowski, C.M. (2009). The Rhetoric of Pope John Paul II's Visits to Poland, 1979-2002. In: J.R. Blaney and J. P. Zompetti (Eds.), The Rhetoric of Pope John Paul II (pp. I03I50). New York: Lexington.

Preamble to the Constitution of the Polish People's Republic of July 22, 1952, Dziennik Ustaw 33, item 232 (www.trybunal.gov.pl/wszechnica/akty/konstytucja_prl.htm).

Preamble to the Constitution of the Polish Republic of April 2, 1997, Dziennik Ustaw 78, item 483 (http://www.sejm.gov.pl/prawo/konst/angielski/kont.htm).

Radcliffe, S. and S. Westwood, (Eds.) (1996). Remaking the Nation: Place, Identity, and Politics in Latin America. London and New York: Routledge. 
Rowland, R.C. and D.A. Frank (2002). Shared Land/Conflicting Identity: Trajectories of Israeli and Palestinian Symbol Use. East Lansing, MI: Michigan State University Press.

Salazar, P-J. (2002). An African Athens: Rhetoric and the Shaping of Democracy in South Africa. Mahwah, NJ: Erlbaum.

Smith, A.D. (1991). National Identity. London: Penguin.

Taylor, S. (2009). Narratives of Identity and Place. London: Routledge.

Tismaneanu, V. (1998). Fantasies of Salvation: Democracy, Nationalism, and Myth in Post-Communist Europe. Princeton, NJ: Princeton University Press.

Verdery, K. (199I). National Identity Under Socialism: Identity and Cultural Politics in Ceausescu's Romania. Berkeley, CA: University of California Press.

White, J.B. (1984). When Words Lose Their Meaning: Constitutions and Reconstitutions of Language, Character, and Community. Chicago and London: The University of Chicago Press. 


\title{
I6 Symbolic Power: Political Rhetoric in a State of Exception
}

\author{
BART VAN KLINK, OLIVER LEMBCKE AND \\ PABLO LEANDRO CIOCCHINI
}

\section{I6.I Introduction}

The so-called "war on terror" is being waged not only with weapons and intelligence but (and perhaps to an even greater extent) with words. Political leaders who are successful at manipulating linguistic symbols are able to mobilize popular support for their cause and to legitimize their actions (Edelman 1967). Pursuing a war requires some sort of shared understanding of who is to be considered a friend and who is to be considered an enemy and how the war should be waged. Generally speaking, the "war on terror" is being fought on behalf of "us" - people living in the "free world" - and directed against "them" - an unspecified group of "terrorists", presumably of a fundamentalist Islamic persuasion. Because states belonging to the "free world" in general are dedicated to the Rule of Law in one way or another, they are not completely free in their selection of means. Unlike "terrorists" who may do whatever they like to spread terror on a global scale, political leaders in the West can act and react only with caution, as if their hands were tied (as the popular comparison goes). Nonetheless, they are increasingly resorting to measures that their critics (such as Chomsky 2006) consider to be at odds with fundamental principles of the Rule of Law. Here lies the greatest challenge for political rhetoric in our times: how is it possible to justify measures that apparently contradict everything "we" stand for and believe in?

In their fight against terrorism, modern states seem to install a permanent state of exception. Special competencies are being created that allow the authorities involved to violate fundamental rights, such as habeas corpus and the freedom of speech, for an unspecified period of time. Agamben (2005, pp. 6 and 50-5I) denies that the state of exception is a "state of law"; instead it is an "emptiness of law", a space "without" or "devoid of law", in which nothing but a fictitious relation with the previously existing legal order can be es- 
tablished. Whereas, in the past, the state of exception was intended to restore normalcy, governments currently seem to be maintaining a state of exception on a permanent basis. Especially with the institutionalization of abortion and euthanasia and the declaration of a global war on terrorism, the "juridically empty" space of the state of exception threatens to "coincide with the normal order." The state of exception has been permanently institutionalized; the exception becomes the rule.

In our chapter, we will examine the role that notions connected to the Rule of Law play in key speeches delivered by two political leaders who had to defend exceptional measures in reaction to terrorist actions and threats: the former British Prime Minister Tony Blair and the current Prime Minister of Spain, Jose Luis Rodríguez Zapatero. We have chosen to focus on these two political leaders, because they both represent countries with longtime experiences with terrorism - IRA and ETA - and, moreover, they employ in their speeches two opposing rhetorical strategies: while Blair argues that exceptional times call for exceptional measures, Zapatero denies that there is anything extraordinary about his anti-terrorism approach. ${ }^{1}$ In the speeches selected, ${ }^{2}$ the two leaders react on crucial political events during their leadership: the terrorist attacks on the World Trade Center in New York on II September 20oI, the attack on a train station in Madrid on II March 2004, and the London bombings on 7 July 2005. Our central research questions are as follows: How are the anti-terror measures taken justified in the speeches at hand? Are they, legally speaking, created "from nowhere", as Agamben (following Schmitt 1996a) would claim, or are they still related in some way to positive law? In section I6.2 and I6.3 we will analyze the rhetorical devices that Blair and Zapatero respectively use in order to justify exceptional measures that seem at odds with the Rule of Law. In this rhetorical analysis we explore two questions: How are "friends" differentiated from "enemies"? And, what role, if any, do notions related to the Rule of Law play in defending the measures at hand? In section I6.4 the two opposing rhetorical strategies will be compared and evaluated.

\footnotetext{
I This chapter is part of a series of articles on the rhetoric of exception. In subsequent articles we will analyze other political leaders, including former us President George W. Bush and current us President Barack Obama.

${ }^{2} \mathrm{~A}$ list of the speeches can be found in the appendix. We have also used a number of statements and interviews as an additional source of information (although we do not refer to them as such in the text). We have translated Zapatero's statements into English.
} 


\section{I6.2 Blair's rhetoric of exception}

For Blair, 9/II was a turning point both in the history of humanity and in his personal history as a leader. In a religious vein, he acknowledges that this attack, "without parallel in the bloody history of terrorism," made him see his true vocation: "September II $^{\text {th }}$ was for me a revelation" (Speech 4). What was revealed to him, was his political mission as a world leader: "I feel a most urgent sense of mission about today's world" (Speech 3). His mission is to "reorder this world around us" (Speech I) or, more precisely, to restore the world's order: "The global threat to our security was clear. So was our duty: to act to eliminate it" (Speech 4). The world's security is at stake, "our" life as well as "our" way of life.

Blair, a true champion of inclusive speech, frequently invokes a "we". In different contexts this sign may denote different entities. As the Prime Minister of the UK at the time representing the country he was obviously authorized to speak on behalf of the British people and he often did so. In speeches delivered after the London bombings, "we" refers in particular to the authorities involved in tracking down and prosecuting the offenders: "We will pursue those responsible, not just the perpetrators but the planners of this outrage, wherever they are, and we will not rest until they are identified, and as far is humanly possible, brought to justice" (Speech 5). In his speech to the US Congress, the word "we" functions as a sign of solidarity with the American people after 9/Ir: "And our job, my nation that watched you grow, that you fought alongside and now fights alongside you, that takes enormous pride in our alliance and great affection in our common bond, our job is to be there with you" (Speech 3; italics added). Here, "we" obviously refers to the alliance of British and American people who stand united in their fight against terrorism (as they once stood united against fascism).

In many cases, "we" is used to denote an even wider circle of people: nothing less than "the entire international community" (Speech $7 \mathrm{C}$ ). People building this "we" are not restricted to a certain space (e.g., the Western part of the world); they are defined by the sharing of a particular set of convictions: "We is not the West. 'We' are as much Muslim as Christian or Jew or Hindu. 'We' are those who believe in religious tolerance, openness to others, to democracy, liberty and human rights administered by secular courts" (Speech $7 \mathrm{~A})$; "We" cherish freedom and democracy. Moreover, "we" are tolerant toward people who think differently: "We are open societies. We feel enriched by diversity. We welcome dynamism and are tolerant of difference" (Speech 
$7 B)$. "We" are not aggressive at all: "We are peaceful people" (Speech 2). People like "us" can also be found in the Arab and Muslim world:

Across the Arab and Muslim world such a struggle for democracy and liberty continues. ... [We must] stand up for and not walk away from those engaged in a life or death battle for freedom ... many Muslims, millions of them the world over, including Europe, who want what we all want: to be ourselves free and for others to be free also; who regard tolerance as a virtue and respect for faith of others as part of our own faith. (Speech $7 \mathrm{~A}$ )

According to Blair: "these are the true voices of Muslims and Arab people" (Speech $7 \mathrm{C}$ ). "They" are not our enemy but our friend in the fight for freedom and democracy.

However, as inclusion always implies exclusion (see Lindahl 2004), not everyone in the "the entire international community" is "our" friend. Just as there are friends outside the international community stricto sensu - "they" who are like "us", "our" peers in the Arab and Muslim world - there are people who support the enemy inside this community by defending a "policy of benign inactivity" (Speech $7 \mathrm{~A}$ ): "It is a posture of weakness, defeatism and most of all, deeply insulting to every Muslim who believes in freedom of the majority. Instead of challenging the extremism, this attitude panders to it and therefore instead of choking it, feeds its growth" (Speech 7A). Fellow-citizens, who are critical of the current American and European approach to terrorism, are (perhaps willy-nilly) contributing to the country's destruction: "[Anti-Americanism or Euro-scepticism] are the surest route to the destruction of our true national interest" (Speech 8). According to Blair, these "false friends" are siding with the enemy: "The problem we have is that a part of opinion in our own countries agrees with them" (Speech $7 \mathrm{~B}$ ). "They", the "real" enemy, are the "terrorists", also referred to as "religious fanatics" (e.g., in Speech I) or "extremists" (Speech 3). "They" are a new kind of enemy without precedent in history: "In this century, a new and unconventional enemy has appeared: a global terrorism, based on a thoroughly warped misinterpretation of Islam, which is fanatical and deadly" (Speech 8). In apparent contrast to conventional terrorist groups in Europe such as the IRA or ETA, new Islamic terrorist groups not only aim at spreading insecurity but also in killing people for its own sake (see Mendes 2008, p. I7). This "new and unconventional" enemy is described as bloodthirsty, barbarous and boundless: "These 
fanatics who will stop at absolutely nothing to cause death and destruction on a mass scale" (Speech 4). "They" hate "us" and everything "we" and "our" peers stand for: "They disagree with our way of life, our values and in particular our tolerance. They hate us but probably hate those Muslims who believe in tolerance, even more, as apostates betraying the true faith," (Speech $\left.{ }_{7} \mathrm{C}\right)$. The terrorist's aim is to spread discord and destruction: "Its purpose is now plain: to provoke civil war" (Speech 8). In short, the enemy endorses an "evil ideology" (Speech 6) and is prepared "to bring about Armageddon" (Speech 4). Therefore, the possibility of compromise or communication between "us" and "them" is excluded altogether: "There is no compromise possible with such people, no meeting of minds, no point of understanding with such terror" (Speech I).

In Blair's view, the differentiation between friends and enemies ultimately boils down less to a clash of civilisations than to a "clash about civilisation" (Speech $7 \mathrm{~A}$; italics added). It is a "clash between extremism and progress", "a life and death battle for freedom", "a battle about modernity" and "a battle of values and progress" (Speech $7 \mathrm{~A}$ ). Terrorism is perceived as an existential threat to the modern way of life and its liberal and hedonistic values. According to Blair: "all civilised people, Muslim or other, feel revulsion at it" (Speech 6). By implication, terrorists are banned from civilization, the "entire international community" and probably - as agents of "evil" from humanity as well. ${ }^{4}$

In order to justify the extraordinary measures to be taken against terrorism, Blair resorts to roughly two different types of discourse: on the one hand a discourse of exception in which he argues that an exceptional threat requires an exceptional response, and a discourse of normalcy in which he states that, although the threat is exceptional, the response remains safely within the 'ordinary' boundaries of custom, morality and the Rule of Law (and, if it does not, these boundaries must be stretched somewhat to make it fit). Drawing on the discourse of exception, Blair claims that "we" are facing a "new type of war"s that "will rest on intelligence to a greater degree than ever before. It

\footnotetext{
${ }^{3}$ The theme of "evil" is even more present in speeches by US President Bush (see Mral 2004, pp. 20-22).

${ }^{4}$ As Schmitt (1996a, p. 37) notices, an intensification of the friend-enemy distinction may lead to pleas for the "endgültig letzten Krieg der Menschheit" (that is, the "absolute last war of humanity", Schmitt I996b, p. 36).
} 
will rest on intelligence to a greater degree than ever before. It demands a different attitude to our own interests. It forces us to act even when so many comforts seem unaffected, and the threat so far off, if not illusory" (Speech 4). The exceptional threat - apparently distant but nevertheless "real and existential" (ibid.) - requires "us" "to be prepared to think sooner and act quicker" if "we" want to defend "our" values. What is needed is "progressive pre-emption" (Speech $7 \mathrm{C}$ ). "We" have no other choice than to fight: "We can no more opt out of this struggle than we can opt out of the climate changing around us," (Speech $7 \mathrm{~A}$ ). "If we want to secure our way of life, there is no alternative but to fight for it" (Speech $7 \mathrm{~B}$ ). Blair compares terrorism to a virus: "The virus is terrorism whose intent to inflict destruction is unconstrained by human feeling and whose capacity to inflict it is enlarged by technology" (Speech 3). If "we" do not stop this virus, the result will be disorder: "Our new world rests on order. The danger is disorder. And in today's world, it can now spread like contagion" (Speech 3). It is "our" duty to act: "The global threat to our security was clear. So was our duty: to act to eliminate it" (Speech 4). Everything "we" can do to avert the threat, "we" must do: "We should take what security measures we can" (Speech 6).

Despite his frequent invocations of a "we", it is clear that, in crucial moments, Blair is primarily thinking of himself - in his capacity as Prime Minister of the UK and one of the world's leaders - as the one who must act, while others may "err on the side of caution" (Speech 4). In defence of his decision to go to war in Iraq, Blair argues that it is the task of leadership to expose and fight the global threat of terrorism. He acknowledges that the invasion in Iraq stirs "bitter emotions" in his own country and may be "illfitting the pre-occupations of the man and woman on the street" (ibid.). This does not, however, prevent him from taking the measures he deems necessary, building on his own judgment. By taking the decision to participate in Iraq's invasion, Blair puts an end to a potential endless deliberation in an authoritarian and authoritative manner:

Prime Ministers don't have the luxury of maintaining both sides of the argument. They can see both sides. But, ultimately, leadership is about deciding . . . Do we

\footnotetext{
5 In contrast to Bush (see Mral 2004, pp. 17-20), Blair rarely uses the expression "war" and never speaks of a "war on terror", but prefers seemingly softer notions like a "battle" or a "fight" against terrorism.
} 
want to take the risk? That is the judgment. And my judgment then and now is that the risk of this new global terrorism and its interaction with states or organisations or individuals proliferating WMD [Weapons of Mass Destruction], is one I simply am not prepared to run. (ibid.)

In addition to appealing to his leadership and personal judgment as a last resort ("ultimately"), Blair persistently tries to gain a broad support for his decisions by using the discourse of normalcy. In defending his anti-terror approach, he draws his main arguments from both shared ideals and shared interests, in order to create "a happy marriage of conviction and Realpolitik" (Speech 8). As a matter of fact, Blair states that "we" have a shared interest in the world's orderliness in particular for economic reasons: "All of us have an interest in stability and a fear of chaos. That's the impact of interdependence," (Speech $7 \mathrm{C}$ ). Here, British self-interest collides with the world's general interest. Therefore, "we" have to fight terrorism collectively on a global scale and take away the causes of its growth, such as poverty and inequality. Moreover, as Blair would argue soon after 9/II (Speech I), it is "our" "moral duty" to fight for the values in which "we" believe, especially freedom and justice: "So I believe this is a fight for freedom. And I want to make it a fight for justice too. Justice not only to punish the guilty; but justice to bring those same values of democracy and freedom to people round the world". In a communitarian vein, ${ }^{6}$ Blair argues that the "power of community" should be combined with justice in order to become a "moral power". In his view, justice consists of "fairness and people of equal worth . . . but also reason and tolerance". These values are not specifically Western as some opponents have claimed, but are endorsed by the whole of humanity: "Ours are not Western values, they are universal values of the human spirit. And anywhere . . . the choice is the same: freedom not tyranny; democracy, not dictatorship; the rule of law; not the secret police" (Speech 3). The best way to defend "our" security is to spread these universal values all over the world (Speech 4). "The only way to win is: (...) to defeat it by values and ideas set in opposition to those of the terrorists" (Speech $7 \mathrm{~A})$. In other words:

\footnotetext{
${ }^{6}$ Whether New Labour under Blair really reflected, or was influenced by, communitarian thought is debatable (see MacMillan 2007).
} 
To win, we have to win the battle of values, as much as arms. We have to show these are not Western still less American or Anglo-Saxon values but values in the common ownership of humanity, universal values that should be the right of the global citizen. (Speech 7 B)

The quotation above marks the transition from the moral to the legal sphere: universal values, such as freedom and justice, should be "the right of the global citizen" (italics added). By using a normative phrase ("should be"), Blair acknowledges explicitly that citizens worldwide are not, or not yet, legally entitled to these fundamental values. In other passages, however, he makes it appear as if these values are already law: "We are fighting for the inalienable right of humankind - black or white, Christian or not, left, right or a million different - to be free (...)" (Speech 3). Particularly in his defence of the invasion of Iraq, Blair displays an ambivalent stance towards the law. On the one hand, he claims that the invasion is in full accordance with the right of selfdefence, as granted by international law:

The best defence of our security lies in the spread of our values. But we cannot advance these values except within a framework that recognizes their universality. If it is a global threat, it needs a global response, based on global rules. The essence of a community is common rights and responsibilities. If we are threatened, we have a right to act. And we do not accept in a community that others have a right to oppress and brutalise their people. We value the freedom and dignity of the human race and each individual in it. (...) Emphatically I am not saying that every situation leads to military action. But we surely have a duty and a right to prevent the threat materialising; and we surely have a responsibility to act when a nation's people are subjected to a regime such as Saddam's. (Speech 4 )

Blair further argues that Iraq contravened UN resolution no. I44I. It was, therefore, the UK's duty to intervene: "We had to force conformity with international obligations that for years had been breached with the world turning a blind eye" (ibid.). "Our primary purpose was to enforce un resolutions over Iraq and wMD” (ibid.).

On the other hand, Blair pleas for amending the existing international law in order to provide for a legal justification of interventions like this. $\mathrm{He}$ claims that "the rule book of international politics has been torn up": 
Interdependence - the fact of a crisis somewhere becoming a crisis everywhere makes a mockery of traditional views of national interest. (...) [These challenges] can only be effectively tackled together. And they require a pre-emptive and not simply reactive response. (...) What is more such action will often require intervention, far beyond our own boundaries. (...) What this means is that we have to act, not react; we have to do so on the basis of prediction not certainty (...). And what all that means is: that this can't be done easily unless it is done on an agreed basis of principle, of values that are shared and fair. (Speech ${ }_{7} \mathrm{C}$ )

According to Blair, the basic problem of existing international law is that it does not sanction a pre-emptive response:

It may well be that under international law as presently constituted, a regime can systematically brutalise and oppress its people and there is nothing anyone can do, when dialogue, diplomacy and even sanctions fail, unless it comes within the definition of a humanitarian catastrophe (though the 300,000 remains in mass graves already found in Iraq might be thought by some to be something of a catastrophe). This may be the law, but should it be? (Speech 4; italics added.)

In his view, therefore, the United Nations has to be reformed: "It means reforming the UN so its Security Council represents $2 \mathrm{I}^{\text {st }}$ century reality; and giving the un the capability to act effectively as well as debate" (ibid.). "The Security Council should be reformed. We need a new international regime on the non-proliferation of WMD" (Speech 3).

When confronted with legal objections to his course of action, Blair responds by referring to the allegedly political bias of his critics: "The lawyers continue to divide over it - with their legal opinions bearing a remarkable similarity to their political view of the war" (Speech 4 ). The cause seems to justify the means: "It is a cause that has none of the debatable nature of the decisions to go for regime change; it is an entirely noble one to help people in need of our help in pursuit of liberty; and a self-interested one, since in their salvation lies our own security" (Speech 7). Here we find again (as earlier in this section) an allusion to "a happy marriage of conviction and Realpolitik": by liberating other people, "we" protect "our" own security. 


\section{I6.3 Zapatero's rhetoric of normalcy}

In contrast to Blair, Zapatero was not in charge when the 9/II terrorist attacks took place. At that time he was leader of the Partido Socialista Obrero Español (PSOE), the main party of the opposition, while José María Aznar was Prime Minister of the Spanish government. Zapatero took office after (and to some extent because of) the terrorist attacks in 2004. He benefited from his promise of ending Spain's support for Bush's "war on terror" and withdrawing Spanish troops from Iraq.

Like Blair, Zapatero often makes use of inclusive speech. He uses a collective "we" to refer to the government over which he presides: the people of Spain, the democratic western citizens, all the civilized people (in contrast to terrorist and terrorist supporters). When addressing the Spanish people, Zapatero portrays his government as one in which "no one feels excluded":

[A government that] listens to and pays attention to [citizens]; that always explains the reason of every decision adopted. It will be a Government who respects citizens, listens to their voices and criticisms no matter how hard they are. (Speech I3)

This openness to dialogue exists only among "us", the Spanish society, "a tolerant, non-clerical, educated and developed society as it should be ours" (ibid.). Whereas "we" are "civilized", "they", the terrorists, represent the negation of everything we stand for:

$[T]$ errorism is, in my opinion, the negation of democracy, terrorism is the negation of progress, terrorism is the negation of freedom, terrorism is the negation of speech which has made human beings, society and civilization stronger. (Speech I4)

Terrorists are thus excluded from the "we", as it is not possible to reach a consensus with "them". "They" are not rational:

[T] here is no reason in terrorism; there is no sense in terrorism; there is no politics in terrorism. There is only terror, death, blackmail. There is only the will to control, to subjugate, to destroy the morality of men, to eliminate their convictions. (Speech I3)

The open dialogue for which Zapatero pleads is meant to take place only among "us", the democratic people seeking unity. According to him, "the 
unity of democrats is the fundamental element in the fight against terrorism" (ibid.). As a member of the opposition, he tried to achieve this when he proposed the "Pact of freedoms and against terrorism" on the following ground: "United, we can beat terrorism. And that union is one of the most efficient weapons for achieving that goal" (Speech 17 ).

From the very beginning, Zapatero has tried to face international terrorist issues with this strategy of dialogue. Zapatero's "major" project was thus the "Alliance of Civilizations": a "forum" inside the un structure to promote a dialogue among different civilizations opposed to the "clash of civilizations" announced by some American intellectuals. This forum allowed drawing a new line between the "civilized" Arab world and Islamic terrorist groups (e.g., Al Qaeda) and governments who supported them. According to Zapatero, these terrorist groups represent "international" instead of "Islamic terrorism". He considers it to be a "great mistake" towards people of the Muslim faith that the adjective "Islamic" is used to refer to a kind of terrorism (Speech I4). Terrorist groups "do neither deserve to be recognized as followers of either a religion (...), a nation or the people" (ibid.). They are nothing but a group of "fanatics who are prepared to kill in order to impose their madness through force, ready to disseminate the seed of evil" (Speech 15 ).

Despite his exclusionary rhetoric, Zapatero did occasionally open the dialogue with the armed Basque separatist movement ETA. From the very beginning of his presidency he was engaged in an ambivalent process of negotiation. While the Spanish judiciary power had banned several political parties, NGOs and other social organizations that had ties with the Basque Separatists, a group of international negotiators tried to reach a peaceful solution with Zapatero's approval. After ETA broke the cease-fire period in December 2006, however, Zapatero declared that "there will be no dialogue" (Speech 20), thus definitively excluding ETA from the possibility of becoming a part of "us".

After having won the elections in 2004, Zapatero offered a speech of rational dialogue in reaction against his predecessor Aznar, who had supported Bush's military interventions. Zapatero argued for counter-terrorism policies with respect for the Rule of Law and human rights. This respect is unconditional because:

no democratic conviction will be put under question by terrorism actions, nor democratic law will be changed because of terrorist actions, no democratic practice will be altered because we are in combat against terrorism. (Speech I4) 
In the international sphere this commitment to legality implies that

Spain will assume the international obligations that correspond to it in the defence of peace and security. Spain will always have one simple requirement: a previous decision of the United Nations or from any other organisation with multinational character. (Speech I3)

Despite his retirement of Spanish troops from Iraq, Zapatero has kept Spanish troops in Afghanistan, and he has even increased the amount of military power.

In the domestic sphere, Basque terrorism is being fought through "the activity of State Security Forces and Justice and (...) by the loss of social support to violence" (Speech 20). An important consequence of this strategy is that since 2002 five Basque political parties - supposed to be linked with ETA - have been banned. ${ }^{7}$

One major feature of Zapatero's anti-terrorism policy is his belief in its legal foundation. He points out that "the response can come only from the law; that is to say, the response can come only from democracy" (Speech I4). However, despite Zapatero's repeated references to the Rule of Law in Spain, denouncements of human-rights violations in the fight against terrorism have been launched by Basque human rights NGOs as well as by such prestigious international NGOs as Amnesty International ${ }^{8}$ and Human Rights Watch, ${ }^{9}$ in addition to the United Nations Special Rapporteurs on Torture, Theo Van Boven and Manfred Nowak. ${ }^{\text {. }}$

7 These parties represent $15 \%$ of the electorate, with approximately 150,000 votes. If the assumption that those parties "are" part of ETA is correct, this organization has an important base of support among the Basque population.

${ }^{8}$ See Amnesty International Report 2008 available at: http://thereport.amnesty.org/ document/IOI.

${ }^{9}$ Human Rights Watch report "Setting an Example? Counter-Terrorism Measures in Spain”, available at: http://www.hrw.org/en/reports/2005/oI/26/setting-example.

Io United Nations Special Report on Torture after visiting Spain in October 2003, available at: http://daccessdds.un.org/doc/UnDoc/GEN/Go4/IO7/I6/PDF/Go4IO7I6.pdf?Open Element. Follow-up report 2006 by Special Rapporteur Manfred Nowak, available at: http://daccessdds.un.org/doc/Undoc/GEN/Go6/II9/I2/PDF/Go6II9I2.pdf?Open Element. 
At first glance, Zapatero's claim to act in accordance with the Rule of Law seems to contradict the reports on human rights violations by the Spanish government. In addition to recognizing the state of exception as most constitutions do, however, the Spanish Constitution also regulates a permanent exception with regard to terrorism issues in Article 55 II. This article regulates limitations to fundamental rights (e.g., longer periods of arrest, incommunicado detentions, the possibility of intercepting a suspect's correspondence or any other communication and entering in any building without a search warrant in the prosecution of individuals in relation to investigations of terrorist crimes). From the very beginning of its democracy, Spain made provisions that allowed for exceptional measures and these constitutional restrictions were regulated in special anti-terrorism acts. In the process of normalizing the exception in 1988, anti-terrorism acts were promulgated and their provisions were included in the "normal" legislation, the Criminal Code and Procedure Criminal Law. The rulings of judges applying legal norms which were originally exceptional measures are now regarded as "normal".

Furthermore, the exception is institutionalized by the modification of the law and its interpretation. A paradigmatic example is the banning of political parties linked with terrorist organization ETA. The Spanish Constitution allows the banning of organizations - and political parties fall into this category - only when they are catalysts of criminal activities. So, the law which regulated political parties required a criminal sentence previous to the banning. Since 1998, there was an ongoing criminal investigation on the links between Batasuna - a Basque radical separatist political party - and ETA. However, the investigation advanced slowly. As a consequence of $\mathrm{Za}$ patero's Pact of freedoms and against terrorism (see above), a new Act for regulating political parties was accepted. The Act introduced several new grounds on which political parties could be banned. It contravened the Spanish constitution, because it made it possible to ban a political party on the sheer basis of a "suspicion" that the party at hand supports terrorist groups. The Act also introduced a new procedure for the banning of political parties with fewer legal safeguards. For instance, a previous criminal sentence was no longer required.

In 2002, after the promulgation of the Act, the judge responsible for the old ongoing criminal investigation finally decided to suspend all Batasuna activities. This clearly demonstrates the political dimension of law enforcement. About this process of banning Basque political parties, Zapatero 
says that " $[t]$ he prosecutors present their accusations based on their opinion, their legal understanding and their professionalism" (Speech I8). Moreover, he claims that his government is only responsible to "appoint the State General Prosecutor and to indicate a criminal policy to follow. What are the basic objectives of that criminal policy? Evidently: to fight against terrorism" (ibid.). Although Zapatero tried to present counter-terrorism measures as objective law enforcement with a minimum of political influence, under his leadership legislation has been introduced that contravenes fundamental constitutional rights. Consequently, even when formal rule of law is maintained, the substance of law is modified or re-interpreted according to political needs.

Zapatero's rhetoric based on the rule of law is reinforced with militant arguments based on democracy. As a result, it is not only the rule of law but in fact democracy itself what is at stake in the fight against terrorism: " $[\mathrm{N}]$ obody in a democracy can engage in the political life and the institutions representing acronyms [implying ETA] that imply a lack of respect to democratic values"(Speech 2I). And people who do not respect that are banned "in defence of a democratically ordered system of values such as freedom and security" (ibid.).

Another example that shows the underlying political interests of $\mathrm{Za}$ patero's "legal" strategy is his response to the criticism he received due to the treatment of a former Basque terrorist leader De Juana Chaos. De Juana Chaos was found guilty of various terrorist crimes and condemned to prison. According to the Spanish Prison Law, in 2006 he had the right to finish the rest of his sentence under the regime of parole. However, a powerful NGO, named Asociación Victimas del Terrorismo (Terrorism Victims Association), and the Partido Popular (pp) pressured the government to keep De Juana Chaos in prison on the ground that he had not publicly expressed repentance. Pushed by public opinion, Zapatero's government solved the problem by presenting new accusations against him in the same month he was meant to leave prison on parole. The State prosecutor accused De Juana Chaos of committing apology of terrorism in two articles which he had written a month before in a Basque newspaper. Facing a possible new sentence of 96 years of prison, De Juana Chaos started a hunger strike in protest against these accusations. At that time, ETA was under the cease-fire and in negotiations with the Spanish Government. Within this political context the accusation of the Prosecutor changed from 96 to 3 years. De Juana Chaos 
remained at the centre of the polemics between the government and the opposition party, since his hunger strike forced the government to let him recover in a hospital in the Basque Country against the policy of preventing Basque terrorist criminals from serving their sentences in Basque territory.

Zapatero was severely criticized because these measures were considered a surrender to terrorist demands. He defended himself by saying that this was just the "enforcement of the law". However, being tired of the criticism he received by the PP he said that during the "former Government they reduced his sentence with one year for writing a book that glorifies terrorism" (Speech I8). During his government Zapatero nonetheless claims: "for writing one or two articles where he does the same he receives three years of prison" (ibid.).

As a result, Zapatero's overall rhetorical strategy aims to portray the fight against terrorism as nothing else than "just" law enforcement. However, exceptional measures normalized in the Spanish Constitution including incommunicado detentions, the banning of Basque political parties and the treatment of De Juana Chaos' hunger strike contradict Zapatero's normalcy portrayal of the Spanish fight against terrorism.

\section{I6.4 Words don't come easy}

Both Spain and the UK have a long time experience with terror originating from inside of their own political systems. Under Zapatero, however, Spain took another route than the one taken by the British government under Blair. Zapatero departed from Aznar's and Blair's course of following the United States and their "coalition of the willing" in fighting international forms of terrorism. In response to the growing criticism of the us anti-terrorism policy, Zapatero altered his stance and adapted his rhetoric accordingly, and he became a "strong" defender of the Rule of Law. This obviously had to do with the mandate that he received in the 2004 election. Apparently of even greater importance is the change of perspective: Zapatero took the opportunity to combine the problems of national and international terrorism and focused on the first. In this respect, he did not need to declare the "state of exception" like Blair in order to execute special measures, simply because Spain has preserved the exception in terrorist issues since the time of Franco.

Whereas Blair used the rhetoric of exception sustained by moral and political arguments in order to justify his policy while mobilizing consent and support for it at the same time, Zapatero normalized the exception by paying respect to internationally acknowledged standards of the Rule of 
Law. Both political leaders were masterful in managing the discourse of inclusive speech, albeit for different purposes: Blair tried to build a consensus for a state of exception allowing the introduction of a just cause reasoning into the international law. Zapatero used an existing consensus (about the Rule of Law) to broaden the consensus for his way of dealing with the problem of national terrorism in Spain.

In hindsight, these rhetorical strategies ultimately proved unpersuasive: the British people were growing increasingly dissatisfied with Blair's agenda of supporting the United States in their fight against terrorism (as clearly demonstrated by his steady decline in popularity), ${ }^{\mathrm{II}}$ and there was a increasing lack of support in Spain (with the exception of the Basque country) for re-opening negotiations with ETA, after Zapatero's earlier attempts failed. ${ }^{12}$ These rhetorical failures were primarily due to the "logic" of symbolic power. If the inclusive speech that both leaders used in the wake of terrorist attacks is contradicted by an eroding consensus, the weakness of symbolic power becomes apparent. To be sure, inclusive speech is an essential element of political rhetoric in general. Its exploitation by Blair and Zapatero was therefore nothing exceptional. Instead, it was the exception the exceptional threat of terrorism - that enabled both leaders to use the anti-terror consent of the people for their own purposes, to fight terrorism either on a global scale (Blair) or at home (Zapatero). Nonetheless, this process of consensus-building proved fragile. Critics soon reclaimed the stage and redefined the battle field: in Blair's case they demanded a return to a state of normalcy where the Rule of Law holds sway. In Zapatero's case, however, they dismantled his attempt to normalize the exception. It seems that, whenever there is a critical auditorium, symbolic power based on inclusive speech is itself an exception. Although it may be persuasive for a while, it will never last.

\footnotetext{
${ }^{\text {II }}$ For some statistics, see The Long Decline: Tony Blair's popularity, Guardian, 25 April 2007, http://politics. guardian.co.uk/flash/page/o,,2065152,00.html/.

${ }^{12}$ In February $200677 \%$ of the Spanish people supported negotiations with ETA. See: http://www.elpais.com/ elpaismedia/ultimahora/media/200602/20/espana/2006022 opepunac_I_Pes_otr.mht. In March 2007, two months after the end of the cease fire by ETA and a month before the general elections only $48 \%$ of the Spanish people supported to open new negotiations with ETA. See: http://www.opina.es/web/pdfs/90070\%2 oE.pdf.
} 


\section{Appendix: Speeches, interviews, statements}

\section{Tony Blair}

I. Speech delivered at the Labour Party Conference, 2 October 200I, available at: http://www.guardian.co.uk/politics/200I/oct/o2/ labourconference.labour6

2. Statement on military action in Afghanistan, 7 October 200I, available at: www.guardian.co.uk/world/20oi/oct/o7/afghanistan. terrorismiI

3. Speech delivered at the US Congress, I7 July 2003, available at: http://edition.cnn.com/2003/US/o7/I7/blair.transcript/

4. Speech delivered in Blair's Sedgefield constituency, 5 March 2004, available at: www.guardian.co.uk/politics/2004/mar/os/iraq.iraq

5. Statement to UK Parliament on the London bombings, II July 2005, available at: www.numberı.gov.uk/Page7903

6. Speech delivered at the Labour Party national conference, I6 July 2005, available at: http://news.bbc.co.uk/I/hi/uk/4689363.stm

7. A: Foreign Policy Speech I, London, 2I March 2006, available at: http://www.numberIo.gov.uk/Page9224

B: Foreign Policy Speech II, London, 27 March 2006, available at: www.numberio.gov.uk/Page9245

C: Foreign Policy Speech III, London, 26 May 2006, available at: www.numberio.gov.uk/Page9549

8. Speech delivered at the Lord Mayor's Banquet, London, I3 November 2006, available at: http://www.numberio.gov.uk/ PageI0407

\section{José María Aznar}

9. Delivered at Palacio de la Moncloa, I2 September 200I, available at: http://www.maec.es/SiteCollectionDocuments/Fotos_Actualidad_ Prensa_y_Documentacion/PDF/revistas/200I/C2.pdf 8 (pp. 2I2-2I3)

\section{José Luis Rodríguez Zapatero}

Io. Congress of Deputies, 26 September 200I, available at: http://www.congreso.es/public_oficiales/L7/CONG/DS/PL/PL_IO7.PDF

II. Congress of Deputies, 5 February 2003, available at: http://www.congreso.es/public_oficiales/L7/CONG/DS/PL/PL_222.PDF 
I2. Congress of Deputies, 5 March 2003, available at: http://www.congreso.es/public_oficiales/L7/CONG/DS/PL/PL_23I.PDF

13. Assumption speech as President of the Government, Congress of Deputies, I5-04-2004, available at: http://www.congreso.es/ public_oficiales/L8/CONG/DS/PL/PL_OO2.PDF

I4. Speech delivered in a summer course on "The fight against terrorism and its limits" of the Complutense University at San Lorenzo del Escorial, I6 July 2004, available at: http://www.la-moncloa.es/ Presidente/Intervenciones/Discursos/pi6o7040.htm

15. Statement to the general debate of the United Nations General Assembly, 2I September 2004, available at: http://www.lamoncloa.es/Presidente/Intervenciones/Discursos/p2I0904I.htm

16. Press conference, Palacio de La Moncloa, io February 2006, available at: http://www.la-moncloa.es/Presidente/Intervenciones/ ConferenciasdePrensa/Rdez. +Zapatero+Rueda+Moncloa+ I00206.htm

17. Speech given at the Congress of Deputies, I5 January 2007, available at: http://www.congreso.es/public_oficiales/L8/conG/DS/ PL/PL_227.PDF

I8. Interview by Carlos Herrera from Onda Cero radio, I5 March 2007, available at: http://www.la-moncloa.es/Presidente/Intervenciones/ Entrevistas/pren20070315.htm

19. Statement to the press, Palacio de La Moncloa, 7 March 2008, available at: http://www.la-moncloa.es/Presidente/Intervenciones/ Discursos/prdi20080307.htm

20. Interview by El Pais, 29 June 2008, available at: http://www. psoe.es/ambito/saladeprensa/docs/index.do?action=View\&id $=203885$

2I. Press conference at the Congress of Deputies, I6 September 2008, available at: http://www.la-moncloa.es/Presidente/Intervenciones/ ConferenciasdePrensa/ prrp200809i6.htm

22. Statement to the press, Palacio de La Moncloa, 3 December 2008, available at: http://www.la-moncloa.es/Presidente/Intervenciones/ Otros/prot20081203.htm 


\section{References}

Agamben, G. (2005). State of Exception, trans. K. Attell. Chicago: University of Chicago Press.

Bulley, D. (2008). "Foreign” Terror? London Bombings, Resistance and the Failing State, British Journal of Politics and International Relations io, 379-94.

Chomsky, N. (2006). Failed States. The Abuse of Power and the Assault on Democracy. London: Hamish Hamilton.

Edelman, M. (1967). The Symbolic Uses of Politics. Urbana: University of Illinois Press. Lindahl, H.K. (2004). Inside and Outside the EU's "Area of Freedom, Security and Justice." Reflexive Identity and the Unity of Legal Space, Archiv für Rechts- und Sozialphilosophie 4, 478-97.

MacMillan, S. (2007). Blair's Community. Communitarian Thought and New Labour. Manchester: Manchester University Press.

Mendes, C. (2008). The Speeches of Tony Blair. The Concept of Terrorism and the Stability of its Structures, paper presented at the annual meeting of the ISA's 49th Annual Convention Bridging Multiple Divides. Hilton San Francisco, San Francisco, California, USA, 26 March 2008, <www.allacademic.com/meta/p253729_ index.html>.

Mral, B. (2004). “Wére a Peaceful Nation.” War Rhetoric After September II. Stockholm: Swedish Emergency Management Agency, Special feature 2004: 5.

Schmitt, C. (1996a). Der Begriff des Politischen. Text von 1932 mit einem Vorwort und drei Collarien (6th edition). Berlin: Duncker \& Humblot: Berlin.

Schmitt, C. (1996b). The Concept of the Political, trans. by G. Schwab. Chicago: University of Chicago Press. 



\title{
17 Do New Parties Bring Personalization, a Narrow Issue Agenda and Populist Rhetoric?
}

\section{Evidence from Dutch Election \\ Campaign Coverage from 1998 to 2006}

\author{
JANET TAKENS, ANITA VAN HOOF, JAN \\ KLEINNIJENHUIS AND WOUTER VAN ATTEVELDT
}

\section{I7.I Introduction}

In Western Europe an increasing number of new political parties have recently gained extensive popular support at the expense of established parties. These parties employ a communication style that attracts media attention. This chapter focuses on three of the characteristics of this communication style, namely an emphasis on party leaders (personalization), a narrow issue agenda, and the use of populist rhetoric. We study the rhetoric used by new political parties, while taking into account who is voicing this rhetoric, and which issues they are discussing.

New parties use these three elements of this communication style to persuade the public. Communication starts with an actor (a person or organization) who chooses to make a statement. In ancient times rhetoric was perceived as an art that was practised by powerful political leaders (Witteveen I988, p. 42). Nowadays political stances are voiced by a large number of politicians. At the same time, political stances are often attributed to political institutions, such as political parties while new parties are usually personified by their political leaders.

The second element refers to the issues on which the public has to be persuaded. Scholars of rhetoric focus on the use of language to persuade the public, while limited attention is paid to the issues being talked about. However, the persuasive power of politicians does not only depend on their rhet- 
oric quality, but also on the issues they discuss. A discourse is easier to understand when a limited number of issues are adressed. New parties are often founded to advocate a specific interest, which existing parties ignored according to these parties, and they emphasise this unique selling point by reinforcing their stances with regard to these issues, while disregarding other issues.

The third element of new parties' communication style regards the use of populist rhetoric, consisting of criticism of the political elite, and positive statements about "the people". Populist rhetoric can be used as a rhetorical technique to create sympathy for a party, and since new and unknown parties lack a stable core of constituency, they will have a stronger incentive to create sympathy.

Political parties are constantly competing for media attention, since for most voters the media are the most important source of political information. Given that recently established parties are still unknown to the public, media attention is even more important for new parties. We argue that the three characteristics of the communication style of new political parties attract media attention because they correspond to certain journalistic schemata. Prime examples are the inclination to cover individual politicians rather than political institutions (e.g., Kleinnijenhuis et al. 2003; Rahat and Schaefer 2007) and the tendency to cover negative news in general (e.g., Patterson I993; Pfau et al. 1998; Semetko and Schönbach 2003) and conflict in particular (Kepplinger 2000; Paletz and Entman 198I). Furthermore, the media aim to decrease the complexity of the news by paying attention to a limited number of issues, and by covering the simple divide between "the people" and the political elite. This study examines media coverage of different categories of political parties by focusing on the relative attention given to party leaders, the breadth of the issue agenda, and the attention given to populist rhetoric. The present study examines these three core concepts in the media coverage of different party categories during four Dutch national election campaigns between 1998 and 2006.

\subsection{Personalization, a narrow issue agenda and populist rhetoric}

This section elaborates on personalization, a narrow issue agenda, and populist rhetoric as characteristics of the communication style of new parties. Furthermore, we will address the question as to why new parties, other parties, and the media might be attracted to these three core concepts. 


\subsection{Personalization}

In ancient times politics was conducted by powerful political leaders. Political rhetoric was perceived as an art that was reserved for those powerful men (Witteveen 1988, p. 42). In recent times, however, the prominence of individual politicians, labelled personalization, has a rather negative connotation. Personalization in politics is defined as "creating and using the prominence of leaders" (Schönbach 1996, p. 94). New parties might employ a personalized communication style, because they depend more strongly on their party leader than established parties. They have no party history and lack a recognisable party image. Since new parties cannot depend on the fame of administrators representing their party, a new and unknown political party needs an inspiring and well-known party leader to gain media attention and to reach the voter (Van Stipdonk and Van Holsteyn 1996, p. I3I). Consequently, new parties will use the prominence of their party leaders to project a distinctive image of the party.

The question arises then as to whether the use of the prominence of a party leader is specific to new parties. All parties will try to project a distinctive party image, and personalization has been found to be present in different, interdependent contexts (Rahat and Schaefer 2007). In response to the prominence of successful leaders of new parties, other parties might be inclined to push their party leaders to the fore. For this reason, we expect that the coverage of established parties is more personalized in the years in which new parties were most successful.

The present chapter focuses on personalization in the news, which is defined as "a heightened focus on individual politicians and a diminished focus on parties, organisations, and institutions" in the media (Rahat and Sheafer 2007, p. 67). The media favour news about actors above issues (e.g., Kleinnijenhuis, et al. 2003). When covering political actors, the media prefer news about individual politicians above abstract political institutions, such as political parties (e.g., Rahat and Sheafer 2007). Wattenberg (I984, p. 9I) argues that one of the main causes of the media's preference for personalized news is the changing role of the media from "the prime reinforcers of partisanship", covering parties and their stances, to more independent outlets (Wattenberg 1984, p. 9I). The introduction and distribution of television news has accelerated this change "as acquaintance with personalities is much easier to convey through the visual media than knowledge about abstractions such as political parties" (Wattenberg 1984, p. 9I). Stewart, Mazzoleni and 
Horsfield (2003, p. 227) showed that the expectation that media prefer personalized coverage especially holds true for new parties. In most of the eight countries under study: "much of the media coverage of the neo-populist movements was expressed via reporting on the person of the movement's leader(s)".

Because new parties depend more strongly on their party leaders than other parties, we test whether the party leaders of new parties receive relatively more attention. We additionally study whether the salience of party leaders is especially high in the news coverage of the elections in which new parties made an upsurge.

H ıа: New parties are more often depicted as employing a personalized style than other parties.

$\mathrm{H} \mathrm{ib}$ : Party leaders are more often covered in the news in the elections in which new parties made an upsurge.

\subsubsection{The breadth of the issue agenda}

A discourse containing a limited number of issues is less complex, and therefore more easily understandable, than a discourse containing a larger number of issues. According to issue ownership theory, it is beneficial for political parties if the issues that they "own" receive media attention (e.g., Budge and Farlie 1983; Petrocik 1996). Consequently, it is important that they reinforce their stances on the issues they are associated with by the public. New parties are often founded to advocate a certain interest (e.g., Krouwel and Lucardie 2008). Therefore, new parties often have a narrow issue agenda. One-issue parties, such as anti-immigration parties and parties for the elderly, form the clearest example. However, new parties that split from an established party also did so because of disagreement on one or a limited number of issues. To position themselves in the political field, new parties emphasize their unique selling points, which results in a narrow issue agenda.

Then the question arises as to whether this narrow issue agenda of new parties also affects the agenda of other parties. Existing parties usually have a broad issue-agenda because they are expected to express their opinion on a large number of issues in Parliament or Government. Previous studies have shown that the political policy agenda consists of a stable set of issues, which only changes under influence of certain events called "policy punctuations" (Baumgartner and Jones 1993). Established parties are responsive to the agen- 
das of new parties when these new parties are doing well (Krouwel and Lucardie 2008), which indicates that the upsurge of new parties can form a policy punctuating event: "When established parties face electoral decline they tend to mimic new parties in issue emphasis patterns" (Krouwel and Lucardie 2008, p. 297). In other words, established parties narrow their issue agenda when put under pressure by the popularity of successful new parties.

Politics and the media both have their own issue agenda, which are interconnected according to agenda-setting theory (e.g., McCombs and Shaw 1972). The breadth of the media agenda refers to the number of issues that receive a substantial amount of attention in the news. Previous studies have shown that during election campaigns the media focuses on a limited number of issues (e.g., Kleinnijenhuis et al. 2007), as a low number of different issues makes the news easier to understand (Kleinnijenhuis 2003). The tendency to cover a limited number of issues might be amplified by the upsurge of new parties because of the news value of controversial issues introduced by these parties. Stewart, Mazzoleni and Horsfield (2003, p. 226) state that "the media, by virtue of their espousal of news values - such as timelines, proximity, and prominence - tend to focus upon dramatic and transitory issues rather than on a prolonged analysis of social or political phenomena". When the media intensively cover a limited number of controversial issues, the attention given to other issues decreases and the issue agenda narrows.

Based on the assumption that new parties emphasize a limited number of controversial issues, new parties are expected to appear in the news with a narrower issue agenda than existing parties. We additionally test whether the depiction of the issue agenda of other parties in the news narrowed in the years in which new parties made an upsurge.

$\mathrm{H}$ 2a: New parties are more often depicted as having a narrow issue agenda than other parties.

$\mathrm{H} 2 \mathrm{~b}$ : The issue agenda of established parties in the news is smaller in the election years in which new parties made an upsurge.

\subsubsection{Populist rhetoric}

Populism is an essentially contested concept (e.g., Taggart 2000; Canovan 1999). The discussion about populism centres on the question as to whether populism is a political ideology or a communication style. Some scholars argue that populist parties aspire to restoring the power of "the people", while 
others argue that it is a "normal communication style" (e.g., Jagers and Walgrave 2007), which is used instrumentally to gain political power. Agreement seems to exist on the defining elements of populist rhetoric: positive references to "the people", and criticism of the political elite (Jagers and Walgrave 2006). The defining components of populist statements coincide with rhetorical techniques to garner the public's sympathy. One of the techniques to create goodwill, distinguished by Andeweg and De Jong (2004, p. 54), is to discredit opponents. Cicero argued that the arousal of aversion, jealousy or contempt of opponents by a speaker would create sympathy for the speaker himself (Andeweg and De Jong 2004, p. 54). This technique corresponds with criticism of the political elite as a characteristic of populist rhetoric. A second technique for creating goodwill, praising the public (Andeweg and De Jong 2004), corresponds with the second element of populist rhetoric; i.e., positive statements towards the public. In conclusion, although populism might be an ideology, populist rhetoric can also be used as a technique to create sympathy with the own party.

New parties might use populist rhetoric for both instrumental and ideological reasons. Since new - and consequently unknown - parties lack supporters who sympathise with them, populist rhetoric, i.e., criticism of their opponents and praising the public, can be used to create sympathy. The use of populist rhetoric also stems from the self-assigned role of new parties as the defenders of neglected interests of the public. To emphasize that they defend the interests of "the people", they refer positively to the public, and to call attention to those who should be blamed for the neglect of these issues they criticise the political elite. Populist rhetoric could also serve an ideological goal. Some new parties are formed because of their will to reform the political system or culture (Krouwel and Lucardie 2008), and they can use populist rhetoric to support their argument that certain powers should shift from "the corrupted political elite" to "the good people".

The question then arises as to whether populist rhetoric is employed exclusively by new parties. Established parties might also use populist rhetoric to create sympathy. Since in democracies politicians are expected to represent "the people", all politicians can be expected to refer positively to the public to some degree. The use of populist rhetoric by existing parties might increase under pressure of the electoral success of new parties, since the creation of sympathy becomes more urgent. Furthermore, it is inherent to politics that political parties disagree with each other, and therefore criticise other 
parties in general and governing parties in particular. Different scholars have argued that politicians use criticism of other politicians instrumentally to increase politicians' media presence (Kepplinger, Brosius and Staab I99I; Bennett 2007; Kepplinger 2000). The introduction of new and controversial issues by new parties could catalyse the instrumental use of criticism on the deliverers of these issues.

Populist rhetoric in the news also consists of references to "the people" and criticism of the political elite, which either stem from journalists themselves or from sources like political or societal actors. Populist rhetoric corresponds with different schemata that are used by the media to cover politics. With its focus on the political elite and the public, populist rhetoric coincides with the focus of the media on actors instead of issues (Kleinnijenhuis et al. 2003, 2007). Contrasting opinions with regard to complex issues are difficult to convey, while the simple clash between the political elite and "the people" is much easier to get across. What is more, criticism of the elite is in line with the inclination of the media to cover negativity in general (e.g., Patterson 1993; Pfau et al. 1998; Semetko and Schönbach 2003) and conflict in particular (Kepplinger 2000; Paletz and Entman 198I). Stewart, Mazzoleni and Horsfield (2003) argue that in the insurgent phase of new parties, the media are attracted by the novelty of their communication style. In the insurgent phase, "charismatic leaders stage events appealing to the news media, engage in verbal extremism, and bluntly attack established parties and government policies". Media are attracted by these "newsworthy realities" that they "cover comprehensively in their pursuit of editorial goals" (Stewart, Mazzoleni and Horsfield 2003, p. 22I).

Because new parties are inclined to employ populist rhetoric, we test whether the media covered populist rhetoric more frequently in the news about new political parties than in the news about other parties. We additionally test whether populist rhetoric is in general used more often in the years in which new parties made an upsurge.

H za: New parties are more often depicted as referring positively to "the people" than other parties.

$\mathrm{H}_{3}$ b: Positive references to "the people" are more often covered in the news in the election years in which new parties made an upsurge.

$\mathrm{H}$ 4a: New parties are more often depicted as criticising the political elite than other parties. 
$\mathrm{H} 4 \mathrm{~b}$ : Criticism of the political elite is more often covered in the news in the election years in which new parties made an upsurge.

\subsubsection{The Dutch case}

Personalization, the breadth of the issue agenda and populist rhetoric will be studied in the context of the coverage of four successive Dutch national election campaigns held between 1998 and 2006. The Netherlands is an appealing context for studying personalization, the breadth of the issue agenda and populist rhetoric because of the recent upsurge of new political parties in that country. Since 1945, the Netherlands has witnessed an increase of electoral support for structural opposition and new parties at the expense of established parties. The success of new and structural opposition parties was most pronounced in the last fifteen years.

\section{FIGURE I7.I DISTRIBUTION OF THE VOTE}

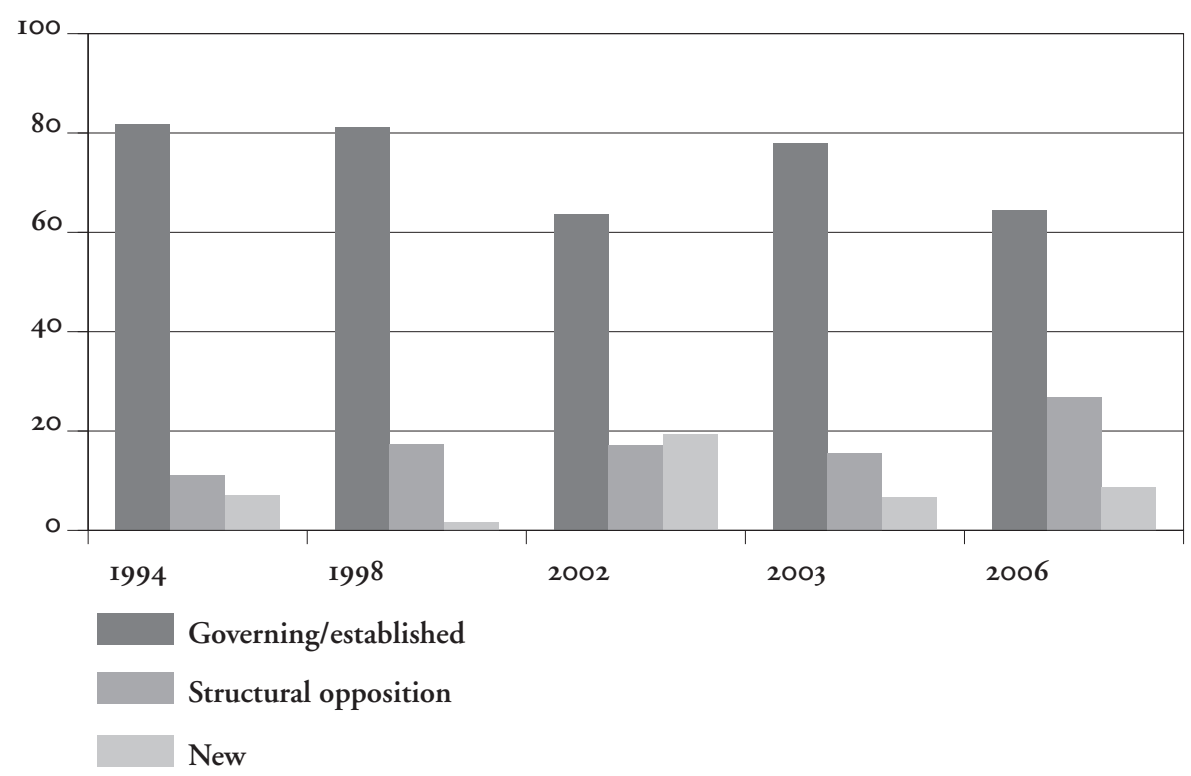

Throughout this chapter we will make a distinction between governing parties, non-governing established parties, structural opposition parties and new parties. ${ }^{I}$ Figure 17.I represents the percentage of votes that the four party categories received in the last five elections. In the 1998 election, none of the new parties was able to gain any parliamentary seats. In 2002, the new 
anti-immigration party LPF, whose leader Pim Fortuyn was assassinated a few days before the election, made the largest upsurge ever witnessed in the Netherlands. Out of nothing, the party gained 26 out of 150 parliamentary seats. The party entered the coalition. The new conservative liberal party Leefbaar Nederland also won two seats. In the 2003 election the LPF lost I8 seats. Of the four contending new anti-immigration parties in 2006 only the anti-immigration party PVV of Geert Wilders was successful. The PVV gained nine seats. The Party for Animals gained two parliamentary seats. We will consider 2002 as the prime example of an election year in which new parties made an upsurge (28 seats). 2006 is also an election year in which new parties were successful (II seats). Although in 2003 the new LPF was still quite successful (8 seats), in comparison with 2002, new parties were unsuccessful (-20 seats). In 1998, new parties were not successful at all (o seats). In short, we consider 2006 and especially 2002 as years in which new parties made an upsurge.

\section{I7.3 Method}

For this study, election coverage of two Dutch news broadcasts (the prime time news bulletins of public broadcaster NOS and commercial broadcaster $R T L$ ) and all subscription-based national newspapers (De Telegraaf, de Volkskrant, NRC Handelsblad, Het Algemeen Dagblad and Trouw) in the three months preceding the 1998, 2002, 2003 and 2006 Dutch national elections were analyzed. All articles in which either a political actor or a political issue was mentioned were included in the study. ${ }^{2}$ This resulted in 19,196 included

\footnotetext{
${ }^{\text {I }}$ Governing parties are parties that governed at the time of the election. Established parties are parties that have been part of the coalition at least twice in the last 8 years, but that are currently not in Government. Structural opposition parties are parties that are represented in Parliament and which participated in the elections for the first time over four years ago. Finally, a new party is a party that is either not represented yet, or participated for the first time in the elections less than four years ago. This category contains parties such as the Party for Animals in 2003 and 2006, the anti-immigration party LPF in 2002 and 2003, and the anti-immigration party PVV in 2006.

${ }^{2}$ We defined a political actor as a political party, a member of Government, a Member of Parliament or a national political institution. A political issue is an article with one of the predefined political issues as the main subject of the article (e.g., unemployment and state finances).
} 
articles and news items. The headline and lead of these newspaper articles, and the television news items were manually coded by teams of intensively trained coders using Semantic Network Analysis.

\subsection{Semantic Network Analysis}

The content of political news coverage was analysed by means of Semantic Network Analysis (SNA). With SNA, a network of relations between objects can be extracted from a text. SNA has important advantages over thematical content analysis, which consists of unitising a message and coding each of the units on one or more variables (Van Atteveldt 2008, p. 22). One of the main advantages of sNA is its flexibility. The method of analysis can be used to simultaneously study different elements of media coverage, such as the breadth of the issue agenda, populistic rhetoric and personalization. A second advantage is that SNA results in network representations that represent the text as closely as possible (ibid. p.i88). Due to the detailed coding, the coded units are semantically close to the original news coverage, which makes sNA a useful means of studying subtle elements of texts, such as the use of populist rhetoric. ${ }^{3}$

The coding of the newspaper articles and news bulletins was conducted using the Network of Evaluative Texts method (NET method) (e.g., Krippendorf 2008; Van Atteveldt 2008), a semantic network analysis method. The NET method divides a text into a number of so-called elementary statements that describe the relations between objects such as actors and issues in the form of source: subject / predicate / direction of the predicate / object. The subject refers to the actor or issue from which the energy in a sentence stems, while the object is the actor or issue at which the energy is directed. The predicate connects the subject and the object by association or disassociation. The quality quantifies the connection, ranging from -I (maximal disassociation)

\footnotetext{
${ }^{3}$ Semantic Network Analysis could have been used to detect even more detailed characteristics of a text. The coded network of relations enables an analysis of the chains of reasoning in a text, by analyzing the coded elementary statements in conjunction. SNA also makes it possible to detect the modalities of the relations in a text. However, in the current study no distinction has been made between the modalities of the relations. Although news coverage of actual actions taken in favour or against the public might have an even bigger impact on the public than expressions of affection or disaffection, the exclusion of actions would provide a measure of populist rhetoric that better conforms to populist rhetoric as a rhetorical technique.
} 
to $+\mathrm{I}$ (maximal association). For example, in "Pim Fortuyn ridicules the socialist party", the subject Pim Fortuyn is disassociated from the object socialist party. This results in the following elementary statement: Pim Fortuyn / ridicules / I / socialist party. The coding starts from an ontology, a predefined list of "knowledge objects", from which coders draw the sources, objects, and subjects. The term "knowledge objects" is used as an overarching concept for political and societal actors and issues frequently found in the news. At the aggregate level, the elementary statements form a network of relations from which the presence of different elements of news coverage can be deduced.

\section{Personalization}

Personalization in the news was measured by calculating the percentage of statements in the news in which a political party or a politician representing that party was mentioned containing a reference to the party leader. We compared the number of occurrences of the party leader with the occurrence of other individual politicians and the party itself. The number of occurrences of political actors was measured by counting the number of elementary statements with a political actor in the source, subject or object position. ${ }^{4}$

\section{The breadth of the media agenda}

The breadth of the media agenda was measured by measuring the distribution of the attention paid to different main issues. We are interested in the differences in the diversity of the issues with which the different party groups are associated in the news. Therefore, we counted the number of relations in the network of coded sentences in which a party group was associated with each of the different main issues. We included all elementary statements containing an issue statement; i.e., statements in which a political party in the subject position was associated with an issue in the object position. All issues that appeared in the news were categorized in thirteen issue categories. ${ }^{5}$ The

${ }^{4}$ If an elementary statement contained a political actor on the source, object and the subject position, only the actor on the source position was included in this study. Likewise, if the elementary statement only contains a political actor at the subject and object position, the subject is included in this study. Notice that a sentence can contain more than one elementary sentence. The sentence "Party A disapproves of Party B's support of measure C", for example, contains two elementary statements. Therefore both party A and party B would be included in our analysis. 
breadth was measured by calculating the perplexity, a measure indicating the number of issues which receive a substantive and equivalent amount of attention (De Ridder 1984; Kleinnijenhuis et al. 2003). ${ }^{6}$

\section{Populist rhetoric}

Populist rhetoric consists of positive references to "the people" and criticism of the political elite by a political party. The presence of populist rhetoric is measured by calculating the percentage of all statements in the news in which a political party in the object position is related to either "the people" or the political elite (a political institution, a governing party or a politician representing a governing party) in the subject position. In other words, we measured the number of statements in which a political party or one of its members associated or disassociated itself with either "the people" or the public. No distinction has been made between different modalities of the relation; i.e., both actions and affections are included in the analyses. Note that both associating and disassociating statements are taken into account. The tone of parties' references to the public and the political elite was measured by calculating the mean direction of the relations expressed in the statements. The following examples illustrate the coding of populist rhetoric:

Examples of positive references to "the people":

"Geert Wilders claims to solve the problems of the people."

Geert Wilders / claims to solve problems / $+I$ / people

Example of criticism of the political elite:

"Pim Fortuyn attacks political culture of the Cabinet."

Pim Fortuyn / attacks / - I Cabinet Kok II

\footnotetext{
${ }^{5}$ The main issues are: Valence issues (e.g., the economy), financial issues, social security, health care, education, crime and national security, environment, administrative reform, infrastructure, Christian values, new left/progressive issues and European integration.

${ }^{6}$ The perplexity can be calculated using the following formula: diversity $=\prod_{\text {ieissues }} p_{i}{ }^{-p_{i}}$ where $p_{i}$ is the proportion of the attention devoted to an issue category in a certain news outlet. We calculated the perplexity rather than the commonly used entropy (which can be derived by taking the $\log$ of the perplexity) because the perplexity can be interpreted more intuitively. It represents the number of issues which received a substantive and equivalent amount of attention from a newspaper or broadcaster.
} 


\section{I7.4 Results}

Before we turn to personalization, the breadth of the issue agenda and populist rhetoric, we will give a brief overview of the amount of attention given to the four party types. Figure 17.2 shows the relative attention paid to the four different party categories in the news coverage of the four elections under study. Governing parties dominated the news, although the amount of attention given to these parties strongly fluctuates. Both the established parties and the structural opposition parties received relatively much attention during the last two elections. New parties were almost absent in the coverage of the 1998 elections (0.68\%), whereas in 2002 they received almost one third of all the attention $(30.70 \%)$. Notwithstanding their electoral decline, new parties still received a considerable amount of attention in $2003(25.6 \mathrm{I} \%)$. While in 2006 the new parties were successful in gaining votes, the attention that the media paid to the new parties was relatively limited (5.94\%). Since in 1998 less than 50 statements of the new parties were covered in the news, the coverage of new parties in 1998 is excluded from the analyses presented in table I7.I, table 17.2, and table I7.3.

\section{FIGURE I7.2 ATTENTION FOR DIFFERENT PARTY GROUPS}

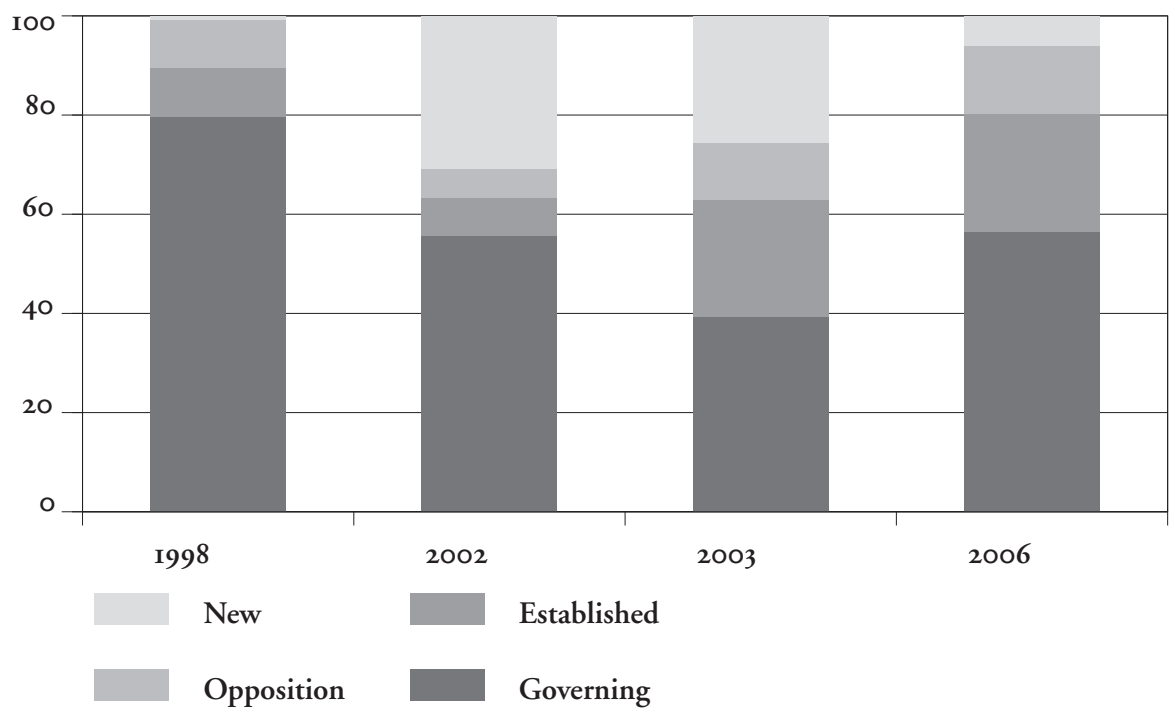




\subsection{Personalization}

Table I7.I shows the relative attention given to party leaders in comparison to the attention given to other individual politicians representing the same party and the party itself. The percentages for the attention paid to individual politicians and the name of the party itself (not represented in this table) and the percentage of the attention given to party leaders would add up to Ioo percent (column percentages). Hypothesis Ia is confirmed by the data represented in table 17.4. In the coverage of each of the elections under study, new parties' leaders appear the most often in the news (47.78\%). The party leaders of governing parties appear the least often in the news (18.90\%), which can be explained by the fact that many individual politicians representing governing parties are Ministers, and therefore draw a lot of attention. Hypothesis $\mathrm{Ib}$ also is confirmed. The election campaigns in which new parties were the most successful, 2002 and 2006, were the most personalized campaigns (respectively $27.13 \%$ and $27.12 \%$ attention paid to party leaders). The high average attention given to party leaders in 2002 is, however, exclusively caused by the prominence of new party leader Pim Fortuyn (6r.98\%). The party leaders of all other party groups received relatively less attention in 2002 than in other years. Especially governing parties' leaders were pushed to the background (II.00\%). In 2006 the news coverage was truly more personalized. The relative attention paid to party leaders of all party groups was above average.

TABLE I7.I RELATIVE ATTENTION GIVEN TO PARTY LEADERS COMPARED WITH OTHER INDIVIDUAL POLITICIANS AND THE PARTY NAME

\begin{tabular}{l|lllll} 
& $\mathbf{1 9 9 8}$ & $\mathbf{2 0 0 2}$ & $\mathbf{2 0 0 3}$ & $\mathbf{2 0 0 6}$ & Average \\
\hline Governing parties & $2 \mathrm{I}, 49$ & $\mathrm{II}, \mathrm{OO}$ & $2 \mathrm{I}, 93$ & $2 \mathrm{I}, \mathrm{I} 7$ & $\mathrm{I} 8,90$ \\
Established parties & $\mathrm{I} 8,27$ & 23,77 & 27,24 & 35,35 & $26, \mathrm{I} 6$ \\
Structural opposition parties & $2 \mathrm{I}, 72$ & $2 \mathrm{O}, \mathrm{O} 3$ & $\mathrm{I} 2,2 \mathrm{O}$ & $3 \mathrm{O}, 33$ & $2 \mathrm{I}, \mathrm{O} 7$ \\
New parties & $45, \mathrm{IO}$ & $6 \mathrm{I}, 98$ & 32,40 & $5 \mathrm{I}, 64$ & 47,78 \\
Average & $2 \mathrm{I}, 43$ & $27, \mathrm{I} 3$ & 20,74 & $27, \mathrm{I2}$ & $24, \mathrm{IO}$
\end{tabular}

Reading example: In 1998 the leaders of the governing parties received 2I.49 percent of the attention paid to governing parties in that year, implying that other individual politicians and the party itself received $78.5 \mathrm{I}$ percent of the attention. 


\subsubsection{The breadth of the issue agenda}

Table I7.2 shows the perplexity of the issue agenda, which represents the number of issues receiving a substantive and equivalent amount of attention in the news. We make a distinction between general news about issues (all issue news, top row), and issue statements of political actors (issue statements, bottom rows). The data presented in table I7.I confirm hypothesis 2 a. In each of the election years under study, new parties are represented as disseminating stances on the smallest number of issues (averagely 8.63 issues). In 1998 - the year in which new parties were the least successful - the overall media agenda was the most diverse (I2.09 issues), while in 2002, the year in which the new anti-immigration party LPF made an upsurge, the media agenda was the least diverse (Io.6 issues). These results seem to confirm hypothesis $2 \mathrm{~b}$. However, the breadth of the media agenda in 2003 was smaller than in 2006 , while in 2003 new parties were less successful. Hence, these results are not in line with hypothesis $2 b$. The number of issues that the established parties and especially the governing parties covered in 2002 was lower than in other election years (respectively 9.79 and 9.82 issues). These results suggest that in 2002 the governing and established parties adjusted their issue agenda to the agenda of new parties.

TABLE I7.2 BREADTH OF THE POLICY AGENDA (PERPLEXITY)

\begin{tabular}{|c|c|c|c|c|c|c|}
\hline & & 1998 & 2002 & 2003 & 2006 & Average \\
\hline All issue news & $\begin{array}{l}\text { Governing } \\
\text { parties }\end{array}$ & 12,09 & Io,6o & $\mathrm{II}, \mathrm{I} 2$ & II, 53 & $\mathrm{II}, 33$ \\
\hline \multirow{5}{*}{$\begin{array}{l}\text { Issue statements of } \\
\text { political parties }\end{array}$} & $\begin{array}{l}\text { Governing } \\
\text { parties }\end{array}$ & $\mathrm{II}, 58$ & 9,79 & 10,99 & $\mathrm{II}, 37$ & 10,93 \\
\hline & $\begin{array}{l}\text { Established } \\
\text { parties }\end{array}$ & IO,24 & 9,82 & 9,65 & IO,I7 & 9,97 \\
\hline & $\begin{array}{l}\text { Structural oppo- } \\
\text { sition parties }\end{array}$ & 9,83 & $\mathrm{II}, 22$ & 10,52 & I0,87 & IO,6I \\
\hline & New parties & & 8,49 & 9,04 & 8,37 & 8,63 \\
\hline & Average & $\mathrm{II}, 73$ & $\mathrm{IO}, 4 \mathrm{I}$ & II,IO & 11,35 & II,IS \\
\hline
\end{tabular}

Reading example: The distribution of the attention given to different issues in 1998 correspondents with a perplexity of 12.09 , which means that 12.09 issues received a substantive and equivalent amount of attention in the news in 1998. 


\subsubsection{Populist rhetoric}

Table I7.3 shows the percentage of political parties' statements containing the first element of populist rhetoric - references to people - and the average tone of these statements. References to "the people" only are an indication of populist rhetoric if they are positive. In each of the election years, all parties expressed themselves in a positive way about "the people" (+ 0.44$)$. On average, the established parties referred the most often to "the people" (2.74\%). Hypothesis 3 a, stating that new parties are depicted more often as referring positively to "the people" than other parties, is confirmed only for 2002, the year in which new parties were the most successful (3.28\%). In the two subsequent election years, all other party groups referred more often to "the people" than did the new parties. Hypothesis $3 b$ is not confirmed either. Although the attention given to references to "the people" increased sharply in 2002, when the new party LPF made an upsurge (2.86\%), the salience of references to "the people" was even higher in 2003 , when the new party LPF was far less successful (3.10\%).

TABLE I7.3 PERCENTAGE OF STATEMENTS CONTAINING REFERENCES TO THE PEOPLE

\begin{tabular}{l|lllllllllll} 
& \multicolumn{3}{|c}{1998} & \multicolumn{3}{c}{2002} & 2003 & \multicolumn{2}{c}{2006} & \multicolumn{3}{c}{ Average } \\
& $\%$ & tone & $\%$ & tone & $\%$ & tone & $\%$ & tone & $\%$ & tone \\
\hline Governing parties & 0,57 & 0,60 & 3,02 & $0,5 \mathrm{I}$ & 2,98 & 0,04 & 2,15 & $0,2 \mathrm{I}$ & 2,18 & 0,34 \\
Established parties & $\mathrm{I}, 70$ & 0,95 & $\mathrm{I}, 95$ & 0,60 & 3,97 & 0,63 & 3,33 & 0,19 & 2,74 & 0,59 \\
Structural opposition parties & 0,38 & $\mathrm{I}, 00$ & $\mathrm{I}, 45$ & 0,78 & 3,20 & 0,47 & $\mathrm{I}, 44$ & 0,40 & $\mathrm{I}, 62$ & 0,66 \\
New parties & & & 3,28 & $0,4 \mathrm{I}$ & 2,49 & 0,44 & 0,94 & 0,40 & 2,24 & 0,42 \\
Average & 0,67 & $0,7 \mathrm{I}$ & 2,86 & 0,50 & $3, \mathrm{IO}$ & 0,32 & 2,23 & 0,23 & 2,22 & 0,44
\end{tabular}

Reading example: In 1998 the governing parties referred in 0.57 percent of their statements in the news to people. The average tone of these statements is +0.60 on a scale from $-\mathrm{I}$ to $+\mathrm{I}$.

The second element of populist rhetoric - criticism of the political elite - is represented in table 17.4. The table contains the percentage of party statements containing criticism of the political elite, and the average tone of these statements. The established parties criticized the political elite the most often $(29.48 \%)$, while the structural opposition parties did so least often (17.70\%). 
It is striking that the governing parties referred to the political elite in 25.82 percent of all their statements, and that they did so with a negative tone (o.Io). The data represented in table 17.4 confirm hypothesis $4 \mathrm{a}$, stating that new parties criticized the political elite most often, only for 2003. In 2003, more than half of the statements of new parties dealt with the political elite. Hypothesis $4 \mathrm{~b}$ is not confirmed. In the election year in which the new parties were least successful, 1998, the news contained relatively the most references to the political elite $(32.23 \%)$, while in one of the election years in which new parties were the most successful, 2006, the news contained relatively the least criticism on the elite (20.52\%).

TABLE I7.4 PERCENTAGE OF STATEMENTS CONTAINING CRTICISM OF THE POLITICAL ELITE

\begin{tabular}{l|lllllllllll} 
& \multicolumn{3}{|c}{1998} & \multicolumn{2}{c}{2002} & 2003 & \multicolumn{2}{c}{2006} & \multicolumn{2}{c}{ Average } \\
& $\%$ & tone & $\%$ & tone & $\%$ & tone & $\%$ & tone & $\%$ & tone \\
\hline Governing parties & 33,94 & $-0,22$ & $3 \mathrm{I}, \mathrm{I} 7$ & $-0,2 \mathrm{I}$ & $\mathrm{I} 8,70$ & 0,08 & $\mathrm{I} 9,46$ & $-0,06$ & 25,82 & $-0,10$ \\
Established parties & 32,60 & $-0,65$ & 32,04 & $-0,25$ & 23,42 & $-0,36$ & 29,89 & $-0,60$ & 29,48 & $-0,46$ \\
Structural opposition parties & $\mathrm{I}, 900$ & $-0,54$ & $24, \mathrm{I} 2$ & $-0,40$ & $\mathrm{I} 3,42$ & $-0,82$ & $\mathrm{I} 4,36$ & $-0,6 \mathrm{I}$ & 17,70 & $-0,59$ \\
New parties & $5,7 \mathrm{I}$ & $-\mathrm{I}, 00$ & 26,67 & $-0,46$ & $5 \mathrm{I}, 35$ & $-0,20$ & $\mathrm{I} 2,22$ & $-0,3 \mathrm{I}$ & 23,99 & $-0,49$ \\
Average & 32,23 & $-0,28$ & 29,77 & $-0,27$ & $2 \mathrm{I}, 35$ & $-0, \mathrm{I} 7$ & 20,52 & $-0,29$ & 25,97 & $-0,25$
\end{tabular}

Reading example: In 1998 the governing parties referred in 33.94 percent of their statements to either the governing parties or political institutions. The average tone of these statements is -0.22 on a scale from $-\mathrm{I}$ to $+\mathrm{I}$.

\section{I7.5 Conclusion}

This study analyzed the rhetoric of new parties in political news coverage. We focused on the source of the rhetoric, the number of issues that were adressed and the use of populist rhetoric. First, we tested whether new parties used the prominence of their party leaders more frequently, whether they had a narrower issue agenda than other parties and whether they employed populist rhetoric more often than other parties. Second, we examined whether the media covered these three elements of the communication style of new parties more frequently in the election years in which new parties made an upsurge. 
Two of the three hypotheses with regard to the use of this communication style in the coverage of new parties were confirmed. As expected, the news about new parties was more personalized: the party leaders of new parties appeared relatively more often in the news. New parties were also portrayed as having a narrower issue agenda than other parties. However, our hypothesis with regard to the use of populist rhetoric by new parties was not confirmed. Only in 2002 did new parties refer most often positively to the public, and only in 2003 did they criticize the political elite most often. The first outcome can be explained by the introduction of populist rhetoric by Pim Fortuyn in 2006, and the latter by the criticism of the new LPF on its former coalition partners. We have to conclude that new parties use populist rhetoric only in specific circumstances.

Only some of our hypotheses with regard to the presence of the three characteristics of new parties' communication style in general news coverage were confirmed. The campaigns in which new parties made an upsurge were indeed the most personalized. Although the prominence of party leaders in 2002 can be explained by the omnipresence of Pim Fortuyn, in 2006 party leaders of all party types received relatively much attention. As expected, the general media agenda was the narrowest in 2002 and the broadest in 1998, but our hypothesis with regard to the breadth of the issue agenda was not confirmed because of the unexpectedly narrow issue agenda in 2003 and the relatively broad issue agenda in 2006. The relatively unsuccessful LPF was still omnipresent in the news in 2003, while in 2006 the new parties received little media attention in comparison with their electoral success. So, the mere presence of new parties in the news seems a better explanation for a narrow issue agenda than their electoral success. Our hypothesis with regard to populist rhetoric was not confirmed. Although the coverage of positive references to "the people", the first characteristic of populist rhetoric, increased in 2002, when the LPF made an upsurge, populist rhetoric remained present in the subsequent campaigns, especially in the coverage of other parties. The introduction of populist rhetoric by new parties appears to have legitimized the future use of populist rhetoric by other parties as well.

The results suggest that political parties reacted to the entrance of new parties in the political arena by adjusting to their communication style. The communication style of the LPF had the most noticeable impact on the communication style of other parties. Fortuyn managed to change political news coverage by gaining extensive media attention, by directing attention towards 
a limited number of issues, and by introducing populist rhetoric. In 2002, even the governing parties referred in three out of ten statements to the performance of the political elite, with a mostly negative tone. This indicates that the upsurge of the LPF caused internal turmoil within the governing parties. Contrary to our expectations, they furthermore reacted by putting politicians other than their party leaders to the fore. This reaction might be caused by the failure of the heavily criticized political leaders to respond to the upsurge of the LPF. Finally, other parties made statements about a smaller number of issues in those years in which new parties were most successful. It would seem that the electoral success of new parties compels other parties to put emphasis on new parties' issues. The salience of new parties' issues forces their opponents to respond, making these issues even more salient.

Further research should answer the question as to whether parties actually did employ a communication style characterized by these elements or whether the media portrayed them as doing so. Although the portrayal of politics arguably has a larger impact on political attitudes than politicians' actual political behaviour, it would be interesting to know where the communication style originates. An analysis of political rhetoric during election campaigns in other forums, such as party manifestos, by means of content analysis or interviews with politicians, journalists and spokespersons could shed light on this question. Furthermore, it would be interesting to examine whether the media in other multi-party democracies in which new parties made an upsurge, such as Austria and Belgium, also adjusted to the communication style of new parties. Semantic Network Analysis enables an even more detailed analysis of texts by taking the chains of reasoning and the modalities of relations into account. A more elaborate use of Semantic Network Analysis could provide additional insights in the use of populist rhetoric.

In conclusion, this study indicates that the media depict new parties as voicing rhetoric through their party leaders, while employing a narrow issue agenda, and the established parties as adjusting to that communication style when new parties gain popularity. A charismatic leader of a new party appeared to be able to influence political news coverage.

\section{References}

Baumgartner, F.R. and B.D. Jones (1993). Agendas and instability in American Politics.

Chicago: University of Chicago Press.

Bennett, W.L. (2007). News, the politics of illusion. New York: Longman. 
Budge, I. and D.J. Farlie (1983). Explaining and Predicting Elections: Issue Effects and Party Strategies in Twenty-three Democracies. London: Allen \& Unwin.

Canovan, M. (1999). Trust the People! Populism and the Two Faces of Democracy. Political Studies 47, 2-I6.

Andeweg, B. and J. de Jong (2004). De eerste minuten. Attentum, docilem en benevolum in de inleiding van toespraken. Dissertation Radboud University Nijmegen. The Hague: Sdu Uitgevers.

Jagers, J. and S. Walgrave (2007). Populism as Political Communication Style: An Empirical Study of Political Parties' Discourse in Belgium. European Journal of Political Research 46, 319-345.

Kepplinger, H.M. (2000). The Declining Image of the German Political Elite. The Harvard nternational Journal of Press/Politics 5, 71-80.

Kepplinger, H.M., H-B. Brosius and J. Staab. (I99I). Instrumental Actualization: A Theory of Mediated Conflicts. European Journal of Communication 6, 263-290.

Kleinnijenhuis, J. (2003). Het publiek volgt media die de politiek volgen. In: Raad voor Maatschappelijke Ontwikkeling, Medialogica. Over het krachtenveld tussen burgers, media en politiek (pp. I5I-2I2). The Hague: Sdu Uitgevers.

Kleinnijenhuis, J., D. Oegema, J.A. de Ridder, A.M.J. van Hoof and R. Vliegenthart (2003). De puinhopen in het nieuws. Alphen aan de Rijn: Kluwer.

Kleinnijenhuis, J., O. Scholten, W. van Atteveldt, A.M.J. van Hoof, A.P. Krouwel, D. Oegema, J.A. de Ridder, N. Ruigrok and J. Takens (2007). Nederland Vijfstromenland. Amsterdam: Bert Bakker.

Krouwel, A.P. and P. Lucardie (2008). Waiting in the Wings: New Parties in the Netherlands. Acta Politica 43, 278-306.

Krippendorff, K. and M. Bock (2008). The Content Analysis Reader. Thousand Oaks: New York.

McCombs, M.E. and D.L. Shaw (1972). The Agenda-setting Function of Mass Media. Public Opinion Quarterly 36, 176-187.

Paletz, D. and R. Entman (198I). Media power politics. New York: The Free Press.

Patterson, T. (1993). Out of order. New York: Alfred A. Knopf.

Petrocik, J.R. (1996). Issue Ownership in Presidential Elections, with a 1980 Case Study. American Journal of Political Science 40, 825-850.

Pfau, M. and P. Moy (1998). The Influence of Individual Communication Media on Public Confidence in Democratic Institutions. The Southern Communication Journal 2, 9I-II2.

Rahat, G. and T. Sheafer (2007). The Personalization(s) of Politics: Israel, I949-2003. Political Communication 24, 65-80. 
Ridder, J.A. de (1994). Van Tekst naar informatie: ontwikkeling en toetsing van een inhoudsanalyse-instrument. Dissertation University of Amsterdam.

Stewart, S., G. Mazzoleni and B. Horsfield (2003). Conclusion: Power to the Media Managers. In: G. Mazzoleni, J. Stewart and B. Horsfield (Eds.), The Media and Neo-Populism. A Contemporary Comparative Analysis (pp. 217-238). Westport: Praeger Publishers.

Schönbach, K. (1996). The "Americanization" of German Election Campaigns: Any Impact on the Voters? In: D. Swanson and P. Mancini (Eds.), Politics, Media, and Modern Democracy (pp. 9I-I04). London: Praeger.

Semetko, H. and K. Schönbach. (2003). German Bundestag Campaigns in the Bild, 19902002. The Harvard International Journal of Press/Politics 8, 54-69.

Stipdonk, V. van and J. van Holsteyn (1996). Wat ouderen verbond: verklaringen van het ontstaan en succes van een nieuwe partij. In: G. Voerman (Ed.), Jaarboek I995 (pp. I27-I48). Groningen: Documentatiecentrum Nederlandse Politieke Partijen.

Taggart, P.A. (2000). Populism. Buckingham, Pa.: Open University Press.

Van Atteveldt, W. (2008). Semantic Network Analysis. Techniques for Extracting, Representing and Querying Media Content. Charleston: Booksurge Publishing.

Wattenberg, M. (1984). The Decline of American Political Parties. Cambridge: Harvard University Press.

Witteveen, W.J. (1988). De retoriek in het recht. Zwolle: W.E.J. Tjeenk Willink. 



\title{
I8 Parliamentary Debate and Political Culture: The Dutch Case
}

\author{
TON VAN HAAFTEN
}

\section{I8.I Introduction}

Contrary to what one sees in, for example, the British or French parliaments, the debate in the Dutch parliament can be characterized as a rather formal and clinical discussion, which only uses rhetorical techniques in great moderation. It can be argued that this way of debating, and the do's and don't's of it, originate from the shaping of the modern Dutch parliament during the second half of the $19^{\text {th }}$ century. Historical analyses of the origins and development of the modern Dutch parliament, and its culture, have shown how much their $19^{\text {th }}$-century liberal founding fathers, under the leadership of the much respected politician J.R. Thorbecke, aimed at a dialectical ideal when shaping the new parliament (Turpijn 2008; Te Velde 2003, 20I0). In their ideal parliament, the members of the Chamber would attain the 'truth' via worthy, free and rational debate (Turpijn 2008, p. 79). It is with this perspective in mind that the formal and informal rules for the conduct of debate were shaped and it has remained basically unchanged to this very day, notwithstanding the great societal and political changes that have taken place since.

At several points in history, this dominant culture of Dutch parliamentary debate has been challenged by left and right-wing political parties as a whole, and by individual members of parliament. These parties, or individual representatives, make a substantial and often purposive use of rhetorical techniques and, in doing so, often exasperate and confuse many Dutch members of parliament. Currently, for example, the dominant debate culture in the Dutch Parliament is undergoing a challenge from the Partij voor de Vrijheid (PVv, Party for Freedom), a political party on the extreme right which focuses on a single issue in its political program: the danger of the Islamization of Dutch society. In the elections for the Dutch Parliament, held on June $9^{\text {th }}$ 20IO, this political party was the big winner: it gained twenty four of the hundred and fifty parliamentary seats and became the third largest po- 
litical party in the Netherlands. It is generally assumed that this enormous election success is a direct consequence of the way in which the leader of this party, Mr. Geert Wilders, conducts himself in Dutch parliamentary debates. Mr. Wilders is not just well-known for what he says, he also attracts a lot of attention because of the way he puts his message into words. On the one hand, he is criticized for using words like "bonkers", "insane" or "completely nuts" to characterize his opponents in parliamentary debates but, on the other, he is able to formulate his standpoints very clearly, illustrated, for example, by the fact that he won a Plain Language Award in 2007 from the Dutch National Youth Council.

So, the way that Mr. Wilders debates has aroused a lot of questions and meta-political and meta-communicative discussions amongst citizens, journalists, opinion makers and members of parliament, about the nature of the debate in the Lower Chamber of Dutch Parliament, and about what contributions to a parliamentary debate are admissible or reasonable in the very broadest sense. These two questions are also central to the project which is currently being undertaken by the Dutch political historian Henk te Velde and myself: a project which investigates the development of the rules governing Dutch parliamentary debate since the middle of the $19^{\text {th }}$ century from both a rhetorical and argumentation-theoretical perspective, and a politicalhistorical perspective.

The project focuses on the historical development of conventions and norms which govern parliamentary debate, including those which govern parliamentary language-use. As is the case with many other activities, a lot of these rules and conventions are implicit and are not all articulated in, for example, the Code of Order of the Dutch Parliament. Besides, these implicit rules and conventions are often highly culturally biased and have been developed over a long period of time. This means that a long-term empirical and praxeological analysis of parliamentary debates needs to be made to establish what these rules and conventions are.

As this investigation continues to be a work in progress, concrete results from the research will not be included in this chapter, but I will deal with some of the basic argumentation-theoretical assumptions that the project makes. More specifically I would like to discuss one fundamental aspect of this project; namely, the characterization of Dutch parliamentary debate as a "communicative activity type", a concept recently discussed by Van Eemeren (20I0). I will do so on the basis of a case study. ${ }^{\mathrm{I}}$ 


\title{
18.2 A case study: A sub-discussion in Dutch parliament
}

In a speech during a debate on "Islamic activism" which was held in the Dutch Lower Chamber on 6 September 2007, Mr. Wilders called for a ban on the Koran and argued that what he described as "the Islamization of the Netherlands" had to be stopped. ${ }^{2}$ The speech caused quite a stir, in particular, because Wilders called the current Minister of Integration and Social Democrat, Ella Vogelaar, "crackers", see the excerpt below:

\section{(I) Mr. Wilders (PVv):}

\begin{abstract}
Minister Vogelaar kwekt dat Nederland in de toekomst een joods-christelijkeislamitische traditie zal kennen, en dat zij de islam wil helpen te wortelen in de $\mathrm{Ne}$ derlandse samenleving. Zij toont daarmee wat mij betreft aan dat zij knettergek is geworden. $\mathrm{Zij}$ toont daarmee aan dat zij de Nederlandse cultuur verraadt. $\mathrm{Zij}$ toont daarmee aan dat zij niet begrijpt dat veel Nederlanders de islamisering en de islamitische traditie niet willen. Ik vind dat verschrikkelijk, en ik vraag haar dan ook om die woorden terug te nemen. Ik vraag haar, zich te verzetten tegen de islamisering en terug te nemen dat Nederland, al is het over een aantal eeuwen, ook een islamitische traditie kent. Als zij dat niet doet - dat is haar goede recht - zullen wij het vertrouwen in haar moeten opzeggen.
\end{abstract}

Minister Vogelaar babbles on about the Netherlands having a Jewish-ChristianIslamic tradition in the future, and that she wants to help Islam take root in Dutch society. She thus shows, for me, that she is going crackers. She thus shows that she is betraying Dutch culture. She thus shows that she does not understand that a lot of Dutch people do not want the Islamization (of the Netherlands) and the Islamic tradition. I find this terrible and so I ask her now to take back these words. I ask her to oppose Islamization and to retract her statement that the Netherlands will have an Islamic tradition, albeit within a few centuries. If she does not comply with this - which is her right - we will be obliged to withdraw our confidence in her.

${ }^{\mathrm{I}}$ I would like to thank Henrike Jansen and Henk te Velde for their valuable comments on an earlier version of this chapter.

${ }^{2}$ The excerpts (I) - (I4) are taken from this debate; see: Handelingen voor de Tweede Kamer (Proceedings of the Lower Chamber), 6 September 2007 (тK 93-5268) [translation $\mathrm{TvH}]$. 
The speech is quite representative of the way in which Wilders presents himself in his addresses and for the way in which he operates in a parliamentary debate: adopting radical standpoints, breaking through political etiquette and using language which can impressionistically be described as "clear" (see Van Leeuwen 2009).

After his speech, a sub-discussion or, as others would say, "a meta-discussion" (see Van Eemeren 20IO, pp. 257-26I), was initiated by some of his fellow-representatives; this is illustrative of the unease that his style of debating had created. The participants in this sub-discussion, besides Mr. Wilders, were: Mr. Slob, a member of the Christen Unie (cu, the Christian Union), a small, more progressive Christian party; Mr. Van der Staaij, a member of the Staatkundig Gereformeerde Partij (sGP, the Calvinist Party), a small conservative Christian party, and Mr. De Wit, a member of the Socialistische Partij (sp, the Socialist Party), a left-wing party. This sub-discussion went as follows:

\section{(2) Mr. Slob (cu):}

$\mathrm{U}$ heeft het over waarden en normen. $\mathrm{U}$ wilt hier een debat voeren en dat zet $\mathrm{u}$ scherp in. Dat is uw goed recht. Dat moeten wij als parlementariërs ook doen, maar dat doen wij wel met respect voor anderen. Wij proberen altijd het goede en de vrede te zoeken in de samenleving en in onze onderlinge verhoudingen. In dat opzicht vind ik het zeer ongepast dat u "aan de verstandelijke vermogens van de minister twijfelt", terwijl u met haar over de inhoud moet spreken. Dat geldt ook voor alles wat $\mathrm{u}$ zegt tegen de islamieten. $U$ legt bij tijd en wijle de vinger op gevoelige plekken. Dat mag, maar wij moeten er altijd voor zorgen dat wij de Nederlandse samenleving bij elkaar houden in al haar diversiteit. Wij moeten het goede zoeken voor de samenleving. Dat zijn waarden en normen. Daar wil ik u op aanspreken. De wijze waarop u opereert, zich tot collega's verhoudt - u noemt ons lafaards - en zich op de samenleving richt, werkt alleen maar splijtend. Dan schieten wij ons doel voorbij.

You are talking about values and norms. You want to lead a debate and start off in a very acute manner. That is your right. It is our duty as representatives to do this, but when we do it, we are supposed to show respect for others. We should always strive for goodness and peace in society, as well as in our mutual relationships. It is in this respect that I consider it very inappropriate of you "to contest the intellectual capacities of the minister", instead of discussing the contents with her. This ap- 
plies to everything you say to Islamic people as well. You do sometimes point out sensitive issues. One may do this, but one always has to make sure that we keep Dutch society together in all its diversity. We ought to strive for the good things for society. These are the values and norms. This is what I want you to account for. The way you operate, the way you relate to colleagues - you call us cowards - and your attitude to society, only results in division. This is overshooting the goal.

\section{(3) Mr. Wilders (Pvv):}

Ik werk niet splijtend. Ik zeg gewoon de waarheid. Als ik vind dat hier veel lafaards zitten omdat zij het niet aandurven als ik vanwege een inhoudelijke voorstel vind dat een minister knettergek is geworden, dan zeg ik dat gewoon. Dat heeft niks met splijten te maken. Zeiden maar meer mensen wat zij op hun hart hadden. Zeiden maar meer mensen dat zij het spuugzat zijn dat het kabinet iedere keer de andere kant op kijkt als zich problemen voordoen met moslims en de islam. Zeiden maar meer mensen dat de grenzen eindelijk een keer dicht moeten omdat het immigratiebeleid er al sinds de jaren zestig voor zorgt dat Nederland Nederland niet meer blijft. Zeiden maar meer mensen dat!

I am not being divisive. I am simply saying the truth. If I want to say a lot of you are cowards because you daren't say that the minister has gone crackers because of the contents of a proposal, then I will say so. It's nothing to do with creating divisions. If only more people would say what bothers them. If only more people would say that they are fed up with the cabinet looking in the other direction when problems arise with Muslims and Islam. If only more people would say that the borders have to finally be closed because immigration policy, since the sixties, is responsible for the fact that the Netherlands has not stayed the Netherlands. More people should say that!

\section{(4) Mr. Van der Staaij (sGP):}

Ik heb u positieve opmerkingen horen maken over de joods-christelijke traditie. Dat is een goede zaak, maar volgens de joods-christelijke traditie, in welke interpretatie dan ook, staat het volgens mij buiten kijf dat wij een minister nooit maar dan ook nooit, en zeker niet in een parlementair debat, voor knettergek uitmaken. Wilt $\mathrm{u}$ terugkeren naar de fatsoensnormen uit de joods-christelijke traditie en die kwalificatie terugnemen? 
I have heard you make positive comments about the Jewish-Christian tradition. That is a good thing but, according to the Jewish-Christian tradition, in whatever interpretation, it is obvious that one should never, ever characterize a minister as having gone crackers, and certainly not in a parliamentary debate. Would you go back to the norms of decency of the Jewish-Christian tradition and retract that characterization?

(5) Mr. Wilders (PVV):

Traditie of geen traditie, de minister is in mijn ogen, doordat zij praat over een toekomstige christelijke, joodse en islamitische traditie knettergek geworden. Ik ga het niet terugnemen, ik ga het nog herhalen.

Tradition or not, the minister has, in my view, by mentioning a future Christian, Jewish and Islamic tradition, gone crackers. I am not going to take that back, I am going to repeat it.

(6) Speaker:

U hebt dat punt nu gemaakt. (...) U handhaaft dit woord. Dat hebben wij nu een aantal malen gehoord. U hebt de reactie van de collega's daarop gehoord en ik stel voor dat u dit woord niet verder gebruikt.

You have made that point. (...) You are standing by that word. We have heard it several times now. You have listened to the reactions of your colleagues, and I propose that you do not use this word anymore.

(7) Mr. Wilders (PVV):

Als ik erom word gevraagd, noem ik het, zo simpel is het.

When I'm asked, I speak as I find, it's as simple as that.

(8) Speaker:

Dat hebt u nu een aantal keren gedaan.

You have done so a number of times now. 
(9) Mr. De Wit (sp):

Wat denkt de heer Wilders dat het effect is van zijn toespraak tot nu toe in de samenleving? Hij maakt zich net als ik druk over de tegenstellingen in de gewone buurten en wijken, waar wij allemaal mee te maken hebben. Wat is het effect van zijn toespraak en de kwalificaties die hij allemaal gebruikt over de islam?

What does Mr. Wilders think the effect of his speech on society will be? Like me, he is concerned by the divisions affecting ordinary neighbourhoods and districts which we are all familiar with. What is the effect of his speech and the characterizations he uses when he addresses Islam?

(Io) Mr. Wilders (PvV):

Ik hoop dat ik hier het geluid vertolk, en dat weet ik eigenlijk wel zeker, van heel veel Nederlanders, die vinden dat het genoeg is met de islam in Nederland, die vinden dat wij genoeg problemen hebben met moslims in Nederland, die vinden dat het niet onder het tapijt moet worden geschoven en dat je bijna voor racist wordt uitgemaakt, als je daar wat over durft te zeggen. Mijnheer De Wit, die mensen zijn geen racisten, het zijn nette, keurige mensen, die problemen hebben, dat zij in elkaar worden geslagen op straat, dat zij zien dat hun land hun land niet meer is, dat hun wijk hun wijk niet meer is, dat hun straat hun straat niet meer is. Ik ben er trots op om dat geluid en de ergernis van die mensen hier te mogen vertolken.

I hope that I express the opinion here, and in fact I am quite sure of it, of very many Dutch people, who feel that we have had enough Islam in the Netherlands, who feel that we have enough problems with Islam in the Netherlands, who feel that we should not brush these problems aside, and that one is almost called a racist when one dares to comment on this. Mr. de Wit, these people are not racists, they are decent, good people who find it a problem to be beaten up on the streets, who find it a problem that their country isn't their country anymore, that their neighbourhood isn't their neighbourhood anymore, that their street isn't their street anymore. I am proud to express this view and to interpret the anger of these people here. 


\section{(II) Mr. De Wit (sp):}

Ik onderken het probleem dat u schetst, dat heb ik daarnet ook gezegd, maar het gaat mij om het effect van uw toespraak en van de kwalificaties die u geeft over de islam en over al die mensen die dit geloof aanhangen. Daarbij maakt u wel onderscheid tussen gematigd en niet-gematigd, maar in de praktijk blijkt uit uw verhaal dat dit toch een heel moeilijk probleem is. Al die mensen hebt $\mathrm{u}$ in het diepst van hun hart gegriefd. Denkt u dat wordt bevorderd dat de problemen in die buurten, die ik nogmaals erken, door uw toespraak en door uw kwalificaties worden opgelost of enigszins worden verbeterd? Zou het niet zo zijn dat dit juist tegen al die mensen werkt? Het leidt tot een verharding van de tegenstellingen, waardoor mensen inderdaad nog meer radicaliseren, onder invloed van uw woorden.

I recognize the problem that you outline, I said so just now, but I am concerned about the effect of your speech and the way that you characterize Islam and all the people who follow this religion. You do make a distinction between moderate and not-moderate, but in practice your story seems to illustrate just how difficult a problem this is. You have hurt these people to the bottom of their hearts. Do you think that the problems in these neighbourhoods, which I do recognize - again will be solved in any way, or even partially, by your speech or your characterizations? It will lead to a hardening of the divisions, causing people to become even more radicalized under the influence of your words.

\section{(I2) Mr. Wilders (PVV):}

De bedoeling is dat mensen na gaan denken en dat ook moslims na gaan denken. Verdorie, wat is dat met die Koran? Klopt dat inderdaad? Wat staat erin? Wat wordt er gezegd? Hoe gaan wij daarmee om? Het heeft zeker effect als u en anderen mijn voorstel zouden steunen om de Koran te verbieden en te zeggen dat er allerlei verschrikkelijke dingen in staan. Ik weet zeker dat de heer De Wit die ook afschuwelijk vindt. Dat moet gewoon niet meer bespreekbaar zijn als het woord van God en als iets wat men dus moet gaan doen; oproepen tot moord, aanzetten tot haat. Als je daarvoor strijd[t] en daarvoor je best doet, kan dat toch alleen maar een positief effect hebben? Mocht dat niet zo zijn, dan toont dat eens te meer aan hoezeer sommige mensen daar niet deugen. 
The purpose is that people are going to think and that Muslims as well are going to think: Darn it, what is it with the Koran? Does it make sense? What's in it? What's being said in it? How do we deal with it? It would definitely help if you and others would support my proposal to ban the Koran and assert that horrible things are said in it. I am quite sure that Mr. De Wit finds these things awful too. So these things should not be open to discussion as if they were the word of God and as possible incentives for action, calling for murder, inciting hatred. If one fights against these things, and does one's best, this can only have a very positive effect. If this weren't the case, then it shows once again the extent to which people there are in the wrong.

(13) Mr. De Wit (sp):

$\mathrm{U}$ weet dat $\mathrm{u}$ te maken hebt met een grote groep van mensen die juist aan het radicaliseren zijn en die ook door dit soort toespraken van u nog verder aangezet worden om een verkeerde weg te volgen. Dat zou tot nadenken moeten stemmen over de toon die $\mathrm{u}$ aanslaat in het debat en over de manier waarop $\mathrm{u}$ iedereen kwalificeert.

You know that you are also dealing with a large group of people who are turning to radicalism and who will be incited by this type of speech to follow the wrong course. That should make you reflect on the tone that you use in debate and on the way that you characterize everyone.

(I4) Mr. Wilders (Pvv):

Voorzitter. Ik heb een fantastische toon, dus ik ga daar niets aan veranderen.

Speaker, I do have a fantastic tone, so I will do nothing to alter it.

From Mr. Wilder's quotations, it is clear that he is making use of discussion strategies such as: (a) putting pressure on an opponent by threatening sanctions,

${ }^{3}$ In the Pragma-Dialectical Argumentation Theory these discussion strategies are analyzed as potentially fallacious; see Van Eemeren and Grootendorst (1992, pp. 107-2I7) for an overview of these types of discussion strategies. See Tonnard (2009) for a pragma-dialectical analysis of some of the discussion strategies used by Mr. Wilders. 
see especially excerpt (I); (b) attacking the other party in the debate directly and personally, see excerpts (I), (3) and (5); (c) distorting the other party's standpoint by taking utterances out of context, oversimplification or exaggeration, see excerpts (I) and (Io); (d) presenting a premise as self-evident, see especially excerpts (3) and (I2); (e) parading one's own qualities, see excerpts (3), (IO) and (I4); (f) polarising the difference of opinion, see especially, of course, excerpt (I) although this strategy is employed in almost all the quoted contributions that Mr. Wilders made to this debate.

It is not only his abundant use of these discussion strategies which is remarkable, but it is the way Mr. Wilders puts his message into words that attracts such attention. He often, for example, uses verbs, nouns, adjectives and adverbs which denote an endpoint on a semantic scale: going crackers, betray, terrible, to oppose, excerpt (I); simply, the truth, are fed up, to be closed, finally, excerpt (3); as simple as that, excerpt (7); very many, had enough, racists, beaten up, the anger, excerpt (Iо); horrible, quite sure, awful, fight, very positive, excerpt (I2); fantastic, excerpt (I4). In this sense Mr. Wilders often makes use of hyperbole, especially when he wants to amplify the danger of the Islamization of Dutch society and the lax attitude of the political elite in the face of it. Using all kinds of parallelisms and figures of repetition, which give his contributions to the debate a clear structure, is also characteristic of Mr. Wilders' speeches, see excerpts (I), (3), (IO) and (I2), as is his use of exclamation, see excerpts (I) and (3). ${ }^{4}$

The way in which Mr. Slob, Mr. van der Staaij and Mr. de Wit react to the statements of Mr Wilders in this sub-discussion makes clear that they consider his way of debating to be at odds with the norms and conventions which hold for Dutch parliamentary debate in general. In large part, their critique seems to address his purposive use of discussion strategies and rhetorical techniques. But then one could ask: what norms and conventions do they believe are being violated in the specific context of Dutch parliamentary debate?

\section{I8.3 Parliamentary debate as a communicative activity type}

The framework adopted here, the Extended Pragma-Dialectical Argumentation Theory (see Van Eemeren 20I0), assumes that people who are engaged in argumentative discourse are maneuvering strategically. 'Strategic maneu-

\footnotetext{
4 See Kuitenbrouwer (2010) and Van Leeuwen (2009) for specific analyses of Mr. Wilders' language-use in political debates.
} 
vering' refers to the efforts that arguers make in argumentative discourse to reconcile rhetorical effectiveness with the maintenance of dialectical standards of reasonableness. To prevent one objective from prevailing over another, the parties try to strike a balance between them at every stage of resolving their differences of opinion. Strategic maneuvering manifests itself in argumentative discourse in: (a) the choices that are made from the topical potential available at a certain stage in the discourse; (b) the audience-directed framing of argumentative moves; and (c) the purposive use of presentational devices. Although these three aspects of strategic manoeuvring can be distinguished analytically, in actual argumentative practice they will usually be hard to disentangle (Van Eemeren 20I0, pp. 93-I27).

In this chapter, it is assumed that, in most cases, a parliamentary debate is an example of an argumentative discourse, and that the members of parliament who are engaged in such a debate are maneuvering strategically. In this sense then, in the sub-discussion described above, we could say that the critique of the statements made by Mr. Wilders which Mr. Slob, Mr. Van der Staaij and Mr. De Wit put forward, seems to address a lot of the choices which Mr Wilders makes from the topical potential and his audience-directed framing of argumentative moves but, most of all, they address his (purposive) use of presentational devices. According to these critics, the strategic choices that Mr. Wilders makes in his contributions to the debate are not admissible.

As Van Eemeren (2010) points out, in practice, argumentative discourse takes place in different kinds of communicative activity types which are, to a greater or lesser degree, institutionalized so that certain practices have become conventionalized. The concept 'communicative activity type' is intended to contribute to a better grasp of argumentative reality in the analysis of argumentative discourse. In the various communicative activity types that can be distinguished in argumentative practice, the conventional preconditions for argumentative discourse differ to some extent, and these differences have an effect on the strategic maneuvering that is admissible.

So, in order to answer the question: What strategic choices are admissible in a debate in Dutch parliament? it is necessary to determine what the characteristics of this specific communicative activity are. To do that, we will first have to discover what the specific institutional goal, or goals, of a parliamentary debate are. This specific institutional goal affects the participant's pursuit of both dialectical and rhetorical aims in a communicative activity 
type by imposing constraints but also by providing opportunities for them to be effective - to win the discussion - while maintaining certain standards of reasonableness (see Mohammed 2008).

Crucial to the characterization of Dutch parliamentary debate as a communicative activity type, is the concept of representative or indirect democracy, a form of government in which the population chooses representatives to execute political ideas. The aim of indirect democracy is to achieve compromises between several civil groups which have opposing interests. In this system, the majority will be able to impose its views, but not without taking good care of the interests of the minorities. It is generally assumed in political theory that (free) representation consists of two layers: one of them being the representative's responsibility or autonomy, the other the formulation of problems which exist in society. In this sense, a parliament of representatives can be characterized in one way as an organization with rules and rituals which enable its members to formulate civil questions in a way which is acceptable to the public and, in another way, as a public discussion arena which opens up opportunities for engaging with the public and bridging the gap between themselves and the voters (Te Velde 2003, p. 18). This involves representatives having to keep a balance between their independence (but not isolation), and their focus on the public (but not surrendering to them) (Te Velde 2003, p. 28). This duality inherent in representation affects the institutional goals of parliamentary debate in a representative democracy: such a debate does not only strive to reach decisions independently within the prevailing rules and procedures, an aim that is connected with the autonomous position of the representative, but it also strives to give an account to the public, to legitimize politics and formulate the civil or societal problems which deserve political priority, goals which are linked to the representative's relationship with the public or the voters (Te Velde 2003, pp. 26-27), see (I5).

(I5) Institutional goals of parliamentary debate:

(a) reaching decisions within the prevailing rules and procedures (the goal connected to the autonomous position of the representative);

(b) being accountable to the public, legitimizing politics, formulating and selecting civil problems which deserve political priority (the goals connected to the representative's relationship with society or voters). 
Following the sociological analysis of the political field completed by the French sociologist Bourdieu (I99I), one could say that a representative plays a "double game": the representative is simultaneously playing a game against the government or his fellow representatives in the political field of the parliament, and a game in which he represents his electorate in the social field. Developing this line of reasoning a little further, one could argue that the dualistic institutional goal of parliamentary debate in a representative democracy, and the ensuing role and task of a representative, means that when he is participating in such a debate, he will always have to deal with two audiences at the same time: parliament, which he is a part of himself, and society, which he represents. It may be assumed that this duality is reflected in the strategic design of his argumentative moves - that is: in the choices he makes from the topical potential, in his audience-directed framing of argumentative moves, and in his purposive use of presentational devices. 5

Following this line of reasoning, one might say that, in a parliamentary debate, the orientation to reaching a decision, goal (I5a), represents the dialectical aspect of the debate, while the orientation to society, goal (I5b), represents the rhetorical aspect of the debate. If one looks at it this way, strategic manoeuvring in the context of a parliamentary debate boils down to keeping a balance between one's independence, on the one hand, and one's focus on the public, on the other. A representative who focuses too much on his relationship with society or his voters, goal ( $15 \mathrm{~b}$ ), in his contribution to a parliamentary debate risks losing sight of his role in parliament and, concomitantly, the reasonableness of the debate, while a representative who is fully focused on achieving results with his fellow representatives in a parliamentary debate, risks committing a rhetorical blunder.

This approach, however, as an analysis of parliamentary debate seems to me to be too simple; it considers the discussion with fellow representatives as too dialectical, and the one with society as too rhetorical. What would be more in the spirit of the theory of strategic manoeuvring, so it seems to me,

\footnotetext{
${ }^{5}$ In the literature about political language in general, it is usually assumed that a politician is always dealing with a complex audience (see, e.g., Zarefsky 2008). What is meant by this is that the public targeted by the politician is very heterogeneous in their social and religious opinions, value systems, social status, level of education, etcetera. That is not the sort of heterogeneity that I have in mind here but, rather, two functionally distinct types of public, each of which can be of a very heterogeneous composition.
} 
would be an approach in which a representative, in the strategic design of his argumentative moves, has to take the requirements of reasonableness as well as considerations of effectiveness into account, both as regards his orientation to his fellow representatives and in his orientation to society and his voters. Or, to borrow from Bourdieu's game terminology: in both games which the representative is playing, he must try to maintain the balance between the effectiveness and reasonableness of his argumentative moves. ${ }^{6}$

This line of reasoning implies that a participant in a parliamentary debate has to maneuver strategically in a more complex way than a participant does in most of the other communicative activity types; he should not only make efforts to reconcile his aim for rhetorical effectiveness while maintaining dialectical standards of reasonableness in each game he has to play, but he should also perform this, given the functional complexity of his public, while sharply observing his own double task and role, the latter being perceived as a specific constraint within this communicative activity type. In principle then, a representative can lose his balance in a contribution to a debate in two possible ways: he can disturb the balance between the dialectical standards of reasonableness and the rhetorical effectiveness, and the balance between his independence and his public focus in either game. This means that parliamentary debate contributions, in general, can derail in a more complex way than contributions to another kind of communicative activity type. ${ }^{7}$

\section{I8.4 Dutch parliamentary culture}

The general characterization of parliamentary debate as a communicative activity type in a representative democracy given in the preceding section,

${ }^{6}$ In a very interesting paper on 'Legitimation and Strategic Maneuvering in the Political Field' Ietcu-Fairclough relates the theory of Bourdieu to the theory about strategic maneuvering. According to her, there is a "homology" between the two games of Bourdieu, in the sense that a (un)successful move in one game is also a (un)successful move in the other game. For example: if a politician allows himself to be discredited by a political opponent, he is at the same time doing a disservice to his own electorate (Ietcu-Fairclough 2008, p. 4II). I am not sure that this homology always holds, but it is a thought which is worthy of further research, in my opinion.

${ }^{7}$ Because the purpose of this chapter is to give a general characterization of parliamentary debate, I am abstracting here from the differences which exist between various types of parliamentary debate. But such differences should be investigated in any further research, of course. 
also applies to the Dutch parliamentary debate, needless to say. And the sub-discussion between Mr. Wilders and his fellow representatives quoted above shows that they are well aware of the dual institutional goals of parliamentary debate described under (I5) and of the constraints on parliamentary argumentative discourse that are associated with them. The core of the reproach made against $\mathrm{Mr}$. Wilders seems to be that his strategic choices in parliamentary debates, in general, have negative consequences for society as a whole. In this line of reasoning, stating that Minister Vogelaar is going crackers, for example, is not only a personal attack on an opponent in a specific speech event, but it is also an attack on the wellbeing of society as a whole. ${ }^{8}$ According to his fellow representatives, by using this language, Mr. Wilders threatens the parliamentary goal of arriving at socially acceptable solutions and the goal of achieving stability in society. This becomes clear, in particular, in the following contributions to the sub-discussion referred to above.

(2) Mr. Slob (cu):

You are talking about values and norms. You want to lead a debate and start off in a very acute manner. That is your right. It is our duty as representatives to do this, but when we do it, we are supposed to show respect for others. We should always strive for goodness and peace in society, as well as in our mutual relationships. It is in this respect that I consider it very inappropriate of you "to contest the intellectual capacities of the minister", instead of discussing the contents with her. This applies to everything you say to Islamic people as well. You do sometimes point out sensitive issues. One may do this, but one always has to make sure that we keep Dutch society together in all its diversity. We ought to strive for the good things for society. These are the values and norms. This is what I want you to account for. The way you operate, the way you relate to colleagues - you call us cowards - and your attitude to society, only results in division. This is overshooting the goal.

(9) Mr. De Wit (sp):

What does Mr. Wilders think the effect of his speech on society will be? Like me, he is concerned by the divisions affecting ordinary neighbourhoods and

${ }^{8}$ See Plug (20IO) on ad hominem argument in parliamentary debates in general. 
districts which we are all familiar with. What is the effect of his speech and the characterizations he uses when he addresses Islam?

(II) Mr. De Wit (sp):

I recognize the problem that you outline, I said so just now, but I am concerned about the effect of your speech and the way that you characterize Islam and all the people who follow this religion. You do make a distinction between moderate and not-moderate, but in practice your story seems to illustrate just how difficult a problem this is. You have hurt these people to the bottom of their hearts. Do you think that the problems in these neighbourhoods, which I do recognize - again will be solved in any way, or even partially, by your speech or your characterizations? It will lead to a hardening of the divisions, causing people to become even more radicalized under the influence of your words.

(13) Mr. De Wit (sp):

You know that you are also dealing with a large group of people who are turning to radicalism and who will be incited by this type of speech to follow the wrong course. That should make you reflect on the tone that you use in debate and on the way that you characterize everyone.

According to his fellow representatives, Mr. Wilders' contributions to the debate are not admissible because they endanger both the objectives of a parliamentary debate and violate the constraints which are associated with them. ${ }^{9}$ In this sense, excerpts (2), (9), (II) and (I3) seem to support the general characterization of parliamentary debate as a communicative activity type in a representative democracy, as described above.

But these excerpts also give us an insight into the opinion within the dominant Dutch political culture about how parliamentary debate should be conducted, that is, as a reasoned and temperate discussion, as that is also best for society. This opinion about parliamentary debate dates back to the $19^{\text {th }}$ century - as shown by Te Velde (2010, pp. 97-I2I) - and essentially has not changed since. Te Velde writes:

${ }^{9}$ Note that this view seems to agree strongly with the idea of homology developed by Ietcu-Fairclough (2008), see Footnote 6. 
Generally, Dutch parliaments had little regard for attempts to impress the members by emotional or grandiloquent language. Many of the orators who were held in high esteem in Great Britain or France would not have made much of an impression in the Dutch Lower Chamber. There, what counted (...) was the force of legal arguments and authority based on restrained superiority. When great orators made their appearance in the last quarter of the nineteenth century, it was not in the houses of parliament but at party assemblies held in meeting halls or in the open air. A phenomenon such as William Gladstone, who could captivate the public in Great Britain at mass meetings, as well as in the House of Commons, was unthinkable in the Netherlands. The Lower Chamber of Parliament was a place for doing business, preferably with a minimum of fuss. This attitude continued in the twentieth century. (Te Velde 20Io, p. Io8 [translation TvH])

In Dutch political culture, the emphasis in parliamentary debate on argumentation and persuasion rather than rhetorical effectiveness is, therefore, based on a preference for pragmatism, but Te Velde (2OIO, pp. III-II2) points out that other cultural factors also play a role. In the $19^{\text {th }}$ century this was, above all, decency: one ought to conduct oneself with restraint and politeness in debate. During the Interbellum period, when communists and national socialists made their appearance in parliament and wanted to make propaganda for their causes by behaving raucously and over-stepping the rules, an overly rhetorical presentation was considered to be anti-parliamentary and uncivilized and, after the Second World War, it was particularly associated with having an undemocratic attitude. For this reason, making an overly rhetorical presentation was usually taboo. The underlying idea was that it was incompatible with the dignity of parliament. The importance attached to the dignity of parliament within the dominant political culture, therefore, also determines to a large extent the way in which a representative is supposed to maneuver strategically within a Dutch parliamentary debate. ${ }^{\text {Io }}$

It is clear from the case study that Mr. Wilders and his fellow-representatives have a difference of opinion about how the two games should be played. According to the dominant norms, a moderate discussion in parliament is best if one wants to achieve the two objectives of a parliamentary debate, whereas Mr. Wilders seeks polarization, both in parliament and society.

Io We also see this in the case study, in particular, in the contribution of Mr. Van der Staaij (sGP), see excerpt (4). 
In this sense, Mr. Wilders seems to challenge the dominant debating culture in Dutch parliament; i.e., the norms and conventions for Dutch parliamentary debate held valid by the majority of the representatives. ${ }^{\text {II }}$

\section{I8.5 Concluding remarks}

In this chapter, on the basis of a case study, I have characterized Dutch parliamentary debate as a culturally determined, specific type of communicative activity and I have done this in two stages.

In the first place, I have pointed out the two institutional goals of a parliamentary debate in a representative democracy in general: such a debate does not only attempt to reach decisions independently according to prevailing rules and procedures, an aim which is connected to the autonomous position of the representative, but it also attempts to give an account to the public, to legitimize politics and formulate which civil or societal problems deserve political priority, goals which are linked to the representative's relationship to the public or the voters. This involves a participant in a parliamentary debate having to strategically maneuver in a more complex way than a participant would in most other communicative activity types: a representative in a parliamentary debate should ideally not only make efforts to reconcile the attempt to be rhetorically effective whilst maintaining dialectical standards of reasonableness in the two games, but should also perform this, given the complexity of his public, while keenly observing his own two tasks and roles.

${ }^{\text {II }}$ For this majority, however, it is more or less impossible to sanction Mr. Wilders for violating these norms. Because of a representative's relationship with his voters and his obligations to them, it is very difficult to forbid him the choice of his own topics, or his ways of adapting to his audience or the ways he chooses his words within a parliamentary debate. The detached way in which the speaker reacts to Mr. Wilders' argumentative strategies, illustrates this, see the excerpts under (6) and (8) in the main text. The Code of Order of the Dutch Parliament gives the Speaker the formal authority to interrupt the debate and to sanction a politician if he or she uses offensive language. But nowadays the Speaker in the Dutch parliament seldom uses this authority. And - as Plug (20IO, p. 313) correctly points out - from a study of the contributions made to parliamentary debates which were considered inadmissible by the Speaker over the period 1934-200I (see Bootsma and Hoetink 2006), it is clear that there are no unambiguous norms indicating what should be considered offensive or un-parliamentary language. 
In the second place, I have tried to demonstrate that the opinions about the way in which a parliamentary debate ought to be conducted and, in particular, what the ideal relationship should be between the argumentative-dialectical and the rhetorical-effective strategies in a parliamentary debate is determined to a high degree by the dominant political culture. Further research has to prove whether this is a fruitful approach for the analysis of Dutch parliamentary debates and the use of political language.

\section{References}

Bootsma, P \& C. Hoetink (2006). Over lijken. Ontoelaatbaar taalgebruik in de Tweede Kamer. Amsterdam: Boom.

Bourdieu, P. (1991). Language and Symbolic Power. London: MacMillam.

Eemeren, F.H. van (Ed.) (20Io). Strategic Maneuvering in Argumentative Discourse.

Amsterdam/Philadelphia: John Benjamins Publishing Company.

Eemeren, F.H. van \& R. Grootendorst (1992). Argumentation, Communication and Fallacies. A Pragma-Dialectical Perspective. Hillsdale, NJ: Lawrence Erlbaum Associates.

Fahnestock, J. (2009). Quid Pro Nobis. Rhetorical Stylistics for Argument Analysis. In: F.H. van Eemeren (Ed.), Examining Argumentation in Context. Fifteen Studies on Strategic Maneuvering (pp. 19I-220). Amsterdam/Philadelphia: John Benjamins Publishing Company.

Ietcu-Fairclough, I. (2008). Legitimation and Strategic Maneuvering in the Political Field. Argumentation 22, 399-4I7

Kuitenbrouwer, J. (2010). De woorden van Wilders \& hoe ze werken. Amsterdam: De Bezige Bij.

Leeuwen, M. van (2009). 'Clear' vs. 'Woolly' Language Use in Political Speeches: The Case of the Controversial Dutch Politician Geert Wilders. In: Online Proceedings of the Annual Conference of the Poetics and Linguistics Association (PALA). http//www.pala. ac.uk/resources/proceedings/2009/vanleeuwen2009.pdf

Mohammed, D. (2008). Argumentative Activity Types: Tracing the Influence of Institutional Settings on Arguers' Strategic Manoeuvring. In: F.H. van Eemeren, D.C. Williams and I.Z. Zagar (Eds.), Understanding Argumentation. Work in Progress (pp. 55-67). Amsterdam: Sic Sat - Rozenberg.

Plug, H.J. (20IO). Ad-hominem Arguments in the Dutch and European Parliaments: Strategic Manoeuvring in an Institutional Context. In: C. Ilie (Ed.), European Parliaments under Scrutiny (pp. 305-328). Amsterdam/Philadelphia: John Benjamins Publishing Company. 
Tonnard, Y. (2009). Shifting the Topic in Dutch Parliament: How Presentational Choices Can be Instrumental in Strategic Manoeuvring. In: F.H. van Eemeren (Ed.), Examining Argumentation in Context. Fifteen Studies on Strategic Maneuvering (pp. 22I- 240). Amsterdam/Philadelphia: John Benjamins Publishing Company. Turpijn, J. (2008). Mannen van Gezag. De uitvinding van de Tweede Kamer I848-I888.

Amsterdam: Wereldbibliotheek.

Velde, H. te (2003). Het Theater van de Politiek. Amsterdam: Wereldbibliotheek.

Velde, H. te (20Io). Van Regentenmentaliteit tot Populisme. Politieke tradities in Nederland. Amsterdam: Bert Bakker Publishing Company.

Zarefsky, D. (1998). Strategic Maneuvering in Political Argumentation. Argumentation 22, 317-330. 


PART V

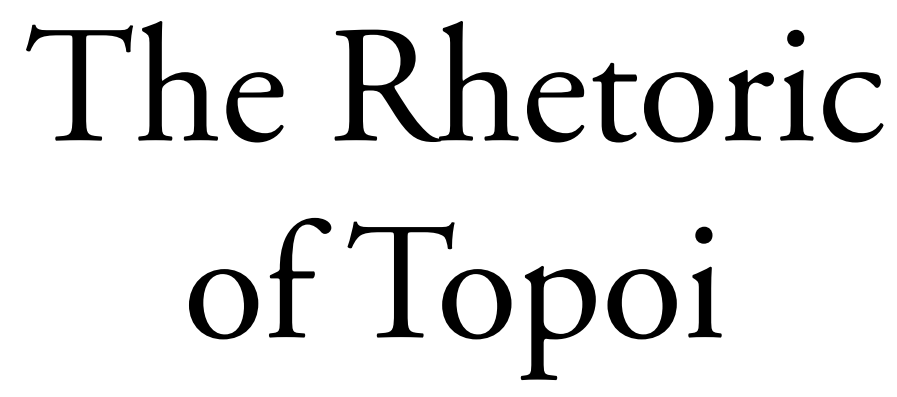

\% 



\title{
19 Talking about Sustainability: Responses to Frames in Persuasive Messages about Sustainable Agriculture and Food
}

\author{
BALDWIN VAN GORP AND MARGOT VAN DER GOOT
}

\section{I9.I Introduction}

Sustainability refers to the solution for a range of issues relating to the impact of human activity on the environment. In 1987, the UN's World Commission on the Environment and Development published the report Our Common Future, also known as the Brundtland Report. Ever since, the notion of 'sustainable development' is steadily in use in public speech: sustainable tourism, sustainable entrepreneurship, sustainable agriculture, etc. The Brundtland Report defined sustainable development as "development that meets the needs of the present without compromising the ability of future generations to meet their own needs." According to Elkington (1997), sustainability is essentially a matter of the present generation striving for a balance between social justice, economic progress and ecological interests. Almost any stakeholder, such as policy makers, various industries and interest groups, adheres to these basic assumptions. However, it remains subject for debate which path one should take to move towards a sustainable society.

Consequently, the notion of sustainability gives rise to contradictions and debate. As an example: proponents of organic farming claim that this way of farming ties in most closely with the notion of sustainability, for instance because all genetically modified organisms (GMOs) are banned. On the other hand, producers of GMOs in farming claim that precisely GMOs offer sustainable solutions to current issues in agriculture (e.g., www.monsanto. com). Thus sustainability is an abstract, complex and even contradictory notion that does not clearly result in one particular type of agriculture or food production. 
Because there is no practical link between sustainability and certain ways of agriculture or food production, stakeholders in the field have room to claim that particularly their methods are contributing to sustainable development. Consequently, they need to look for the most effective arguments to communicate to their target groups and the general public that their ways of growing or making food are sustainable. To communicate this conclusion, they need to select a topos, or line of argument (e.g., Herrick 2005). Rhetoric studies these argumentative schemes, and how they contribute to the acceptance of the conclusion. In the present study, we make use of the framing perspective, because frames could be seen as rhetorical devices that can activate specific images in the receivers' minds, increase salience of an argument, or, more in general, increase the appealing power of a message (Pan and Kosicki 1993).

Frames can be defined as "organizing principles that are socially shared and persistent over time, that work symbolically to meaningfully structure the social world" (Reese 200I, p. II). We situate frames at the cultural level and conceptualize frames as a "tool kit" from which people select to communicate about issues (cf. Gamson 1992; Swidler 1986) and which help people to understand topics. Simply put, stakeholders can use frames, embedded in a culture, to communicate about the complex and abstract topic of sustainability and the audience subsequently responds to these messages based on their own stock of knowledge.

In the present chapter, we focus on how citizens respond to persuasive messages about sustainable food and agriculture. Because sustainability is a social construction we opt for a research design that allows for social interaction and debate. In an earlier study (Van Gorp and Van der Goot 2009), we described frames that stakeholders in the farming and food industry use to communicate about sustainability. In the current study we asked the audience how they perceive such messages, in order to gain insight in how these frames work in communicating such complex topics to the general public.

\subsection{Framing and the construction of reality}

\subsection{How framing works}

The theoretical approach we use is framing from a constructionist perspective, because especially the constructionist school of thought within framing research devotes attention to how frames can contribute to defining a given situation (Gamson and Modigliani 1989; Van Gorp 2007; for an 
overview of approaches see D'Angelo 2002). Social constructionism deals with the interactive process in which individuals and groups actively construct social reality by means of a variety of information sources, such as the mass media (Neuman, Just and Crigler 1992; Price, Nir and Cappella 2005; Wicks 2005).

Bateson (1955, 1972) was the first to argue that each frame functions as a meta-communicative message that guides the audience interpretation of a message to a particular definition of a situation. Consequently, frames are underlying meaning structures in communications that imply to the receiver how the message possibly could be understood. The main functions of framing are defining problems, diagnosing causes and consequences, making moral judgments and suggesting solutions (Entman 1993). This line of reasoning, however, does not need to be explicitly included in a message. One of the main assumptions of framing theory is that the receivers come up with a chain of causal inferences when they follow the suggestion to make an association between the discussion at hand and the applied frame.

The specificity of the approach applied here is the perceived location of frames, that is, at the macro level. Each culture possesses a repertoire of possible frames for its members to use in attributing meaning to the various events and issues with which they are confronted. When an author 'frames' a message, the topic discussed is connected with a notion that is already present within the culture and hence is familiar to its members. In order to emphasize the dynamics unfolding between culturally embedded frames and individual cognitive constructs, frames are considered to exist beyond people's minds, precisely as culture is not just in the individual's head (cf. Polletta 2004). Mental constructs are individual, specific and subject to constant change as they are reviewed and adjusted on the basis of experiences and newly acquired knowledge (Van Gorp 2007). Frames are much more stable, and perhaps also more persistent, than such individual schemata.

Because culturally embedded frames are ideas the receiver is already familiar with, they can be easily introduced in communication. In sum, frames form universally understood codes that implicitly influence the receiver's message interpretation, and lend coherence, meaning and ready explanations for complex issues. If receivers define and interpret an issue in correspondence with the preferences of the sender, they follow the preferred meaning (Hall 1980). In the end, however, the framing process is interactive, vulnerable and in all its phases prone to counter-framing, since the audience actively inter- 
prets messages. That is why frames can have effects that are hard to predict (Scheufele 1999).

\subsubsection{Frame packages}

In framing research, in the constructionist tradition, content analysis is often conducted to reconstruct the frames that are used in mediated messages (Van Gorp 2007). As frames constitute a latent meaning structure in a message, analyzing them is not straightforward (Van Gorp 2009). However, by accepting the heuristic principle that a series of manifest variables can represent a latent concept, it is possible to follow an inductive approach to reconstruct an inventory of frames. One can start with the analysis of a strategically chosen set of texts, and determine for each text which elements possess persuasive power; as formulated in Aristotle's definition of rhetoric (Garver 1994). Then, the frame analyst can identify the logical chains of elements across the separate texts. In accordance with the principle of constant comparison, the most representative devices can be identified and, finally, integrated in frame packages that are presented in a frame matrix. Therefore, the main result of an inductive framing analysis is an overview of frame packages (cf. Gamson and Modigliani 1992; Gamson and Lasch 1983; Van den Bulck, Simons and Van Gorp 2008; Van Gorp 2005).

Each frame package is an integrated structure of a core frame, framing devices, and reasoning devices. The core frame is the implicit cultural phenomenon that defines the package as a whole. The framing devices are manifest elements in a message that form the rhetorical structure of the message, such as lexical choices, catchphrases, depictions, figures of speech, and visual images (Gamson and Modigliani 1989; Kitzinger 2007; Pan and Kosicki 1993, pp. 6I-62; Plett 200I; Tankard 200I). As such, the framing devices function as the demonstrable indicators of the frame. Reasoning devices on the other hand refer to the frame's capacity to define issues. They form a route of causal reasoning which may be evoked when, in this case, food production and consumption are associated with a particular culturally embedded frame. The most important difference between framing devices and reasoning devices is that the reasoning devices do not need to be explicitly included in a mediated message. During the interpretation of the message, when a mental connection is made between the message, the cultural frame, and individual schemata, the receiver may come up with causal inferences that are in line with the reasoning devices. 


\subsection{Communicating about sustainable agriculture and food}

In an earlier study (Van Gorp and Van der Goot 2009) we conducted an inductive framing analysis to investigate which frames principal stakeholders use in their public communications about sustainable food and agriculture. We analyzed a diverse sample of communications $(n=578)$ including advertizements, and brochures of farming federations, the food industry, consumer organizations and interest groups in Flanders and French-speaking Belgium. The analysis resulted in an inventory of six frame packages, each with a core frame, the framing devices and the reasoning devices. In that study we also analyzed the relations between the frames. Here we only briefly summarize the six frames in order to provide background information for the reception study as presented in this chapter.

Responsibility. The first frame ties in with the notion of legacy (Frameworks Institute, 2009) and the value that humans are responsible for children, and finally for all living creatures on earth. The prominent framing devices are vulnerability and accountability. Children, who represent future generations, are vulnerable, while their parents, representing the present generation, are accountable. Social justice towards those future generations is the central reasoning device.

Undermining-of-foundations. The second frame relies on the metaphor of supporting walls that are gradually destabilized (Aubrun and Grady 2006; Jaspaert, Geeraerts and Feyaerts 2008). The effectiveness of the frame relies on the image of the structural soundness of a building being undermined, so that it is in danger of collapsing. It suggests that the underlying structure of the global ecosystem is gradually and stealthily being compromised. Textual framing devices are "(delicate) balance", "foundations", "base" and any expression of the "intricate relationships" within the ecosystem.

Frankenstein. The third frame stresses the urgency of sustainable food production, even more so than in the undermining-of-foundations frame, making ample use of superlatives. There obviously is the link with the story of Doctor Frankenstein, whose creature turned out to be an uncontrollable, unwieldy abomination. This frame has many variants, all of which have in common that they refer to a series of related narratives that are generally founded on (the Christian) faith, such as Judgment Day, the Apocalypse or Doomsday. Characteristic for this frame is that messages in which the frame has been applied contain direct references to the underlying narratives, for instance "Frankenfood". The vocabulary refers to "risks", "pollution", "poison- 
ing" and "contamination" on the one hand and to irreversibility on the other: "the fences are down", "there is no way back" or "the snowball is rolling" (De Morgen, 8 April 2005).

Natural goodness. A dominant frame in the material studied is constructed around the myth that nature is inherently good. Natural products are attributed exceptional properties: they are by definition good for you, they taste better, and they are pure and authentic. By contrast, anything produced by humans is presented as artificial and therefore lacking these essential qualities. The apparent relationship between "biological" and "logical" and between "nature" and "naturally" are conducive to puns that suggest that the choice for organic is self-evident.

Progress. The myth of progress provides a fifth frame for communicating about sustainable agriculture and food. The underlying notion is that the constant quest for technological and scientific progress in food production must on no account be impeded. While the Frankenstein frame assumes uncontrolled scientific progress will inevitably result in the demise of humankind, the myth of progress suggests that life on Earth has a purpose, namely to strive for the ultimate good through modernization and progress (Troester Nunez 2008).

The Good Mother. The archetype of the feeding and caring mother suggests that the young child should be grateful for the food that its mother unselfishly provides, which is seen as a sign of love, sacrifice and service (Aubrun, Brown and Grady 2006; Lule 2005). This sixth frame is the most ambiguous of all. On the one hand, the frame is combinable with the natural goodness frame: "Mother Earth" and "Mother Nature" are well-established mythical symbols of fertility and creative force. On the other hand, the frame can also be used to argue that sustainable food production is unnecessary, because food is available in the stores in unlimited supplies and in an unprecedented range of varieties. In this case, stores and shopping malls are presented as good mothers that feed their children. The public is then addressed as consumers who should be thankful, whereas in most of the other frames the receivers are addressed as responsible citizens.

In order to explore how these frames work, we studied how the general audience responds to these frames. Therefore the research question in the present chapter is: How do citizens respond to and appreciate messages that use these six frames to communicate about sustainable food and agriculture? 


\section{I9.4 Method}

We conducted four focus groups, because focus groups are useful for stimulating new ideas and learning about how respondents talk about the phenomenon of interest. Moreover, the open response format of a focus group provides an opportunity to obtain large and rich amounts of data in respondents' own words (Stewart, Shamdasani and Rook 2007, pp. 4I-42). Two focus groups were held in Flanders and two in French-speaking Belgium, because cultural differences may play a part in people's responses to messages about sustainability. Stakeholders in the French-speaking part of Belgium tend to argue more in favor of organic food and against genetically modified organisms than stakeholders in Flanders (Van Gorp and Van der Goot 2009). Also, two groups consisted of persons from the lower middle-class ( 8 men and 8 women; average age $=36$ ) and two groups contained persons from the higher middle-class ( 7 men and 8 women; average age $=38$ ), because social class may influence how people respond to a complex and abstract issue such as sustainable agriculture. Each focus group was composed of seven or eight unrelated people that were selected on the basis of sex, age, place of residents and profession. Each group discussion lasted two hours.

Central in the group discussions were six texts that we constructed to represent as clearly as possible the six frames that we had found in our inductive frame analysis (table 19.I). Each text consisted of about I25 words, divided in a few paragraphs without a title or image, and was printed on a plain white page. Because many studies demonstrated that ethos, the receiver's assessment of the moral character and competence of the source of communication, has a significant effect upon the persuasiveness of messages (e.g., McCroskey 2006; O'Keefe 2002), we decided not to mention explicitly who the source of the arguments was. Prior to the actual focus groups, six lay-persons and nine experts were asked to respond to the six texts in order to ensure the texts were as understandable and as univocal as possible.

After a short introductory round, each group discussion started with the moderator reading the first text out loud and participants were invited to read the text on paper at the same time. They were asked to write down their thoughts individually and to indicate on five-point scales how understandable they thought the text was and the extent to which they agreed with the text. The group discussion started with open-ended questions; participants were asked about their reactions to the text. After that, the group read the text sentence by sentence in order to invoke even more remarks. Participants were en- 
TABLE I9.I SUMMARY OF THE SIX TEXTS USED IN THE FOCUS GROUPS

\begin{tabular}{|c|c|c|c|}
\hline Frame & Problem definition & Cause & Solution \\
\hline I. Frankenstein & $\begin{array}{l}\text { Malpractices in } \\
\text { agriculture and the } \\
\text { food industry lead } \\
\text { the world to doom }\end{array}$ & $\begin{array}{l}\text { Humans acting } \\
\text { as God }\end{array}$ & $\begin{array}{l}\text { Looking for alterna- } \\
\text { tives for practices } \\
\text { such as GMOs and } \\
\text { hormone injections }\end{array}$ \\
\hline 2. Responsibility & $\begin{array}{l}\text { Current generations } \\
\text { pass on problems to } \\
\text { future generations }\end{array}$ & $\begin{array}{l}\text { Human beings } \\
\text { see the earth as } \\
\text { their property }\end{array}$ & $\begin{array}{l}\text { Producing food while } \\
\text { taking responsibility } \\
\text { for future generations }\end{array}$ \\
\hline 3. The Good Mother & $\begin{array}{l}\text { Biological food is } \\
\text { only affordable for a } \\
\text { imited part of the } \\
\text { population and there } \\
\text { is not enough for } \\
\text { everyone }\end{array}$ & $\begin{array}{l}\text { Limited spending } \\
\text { power of average } \\
\text { consumer }\end{array}$ & $\begin{array}{l}\text { Going to super- } \\
\text { markets that provide } \\
\text { a rich supply of } \\
\text { affordable products }\end{array}$ \\
\hline $\begin{array}{l}\text { 4. Undermining of } \\
\text { foundations }\end{array}$ & $\begin{array}{l}\text { The fragile eco- } \\
\text { system is about } \\
\text { to collapse }\end{array}$ & $\begin{array}{l}\text { There is a mosaic } \\
\text { of problems, such } \\
\text { as the intensive use } \\
\text { of pesticides, that } \\
\text { harms the eco-system }\end{array}$ & $\begin{array}{l}\text { Avoiding practices } \\
\text { that disturb the } \\
\text { ecological equilibrium }\end{array}$ \\
\hline 5. Natural goodness & $\begin{array}{l}\text { Large-scale and } \\
\text { intensive forms of } \\
\text { agriculture are harm- } \\
\text { ful for nature }\end{array}$ & $\begin{array}{l}\text { Humans lost their } \\
\text { connection with } \\
\text { nature }\end{array}$ & $\begin{array}{l}\text { Respecting nature, } \\
\text { consuming local } \\
\text { and seasonal products }\end{array}$ \\
\hline 6. Progress & $\begin{array}{l}\text { It is ridiculous to } \\
\text { slow down scientific } \\
\text { progress }\end{array}$ & $\begin{array}{l}\text { There are ever more } \\
\text { mouths to be fed }\end{array}$ & $\begin{array}{l}\text { Believing in scientific } \\
\text { progress, because it } \\
\text { helps to produce } \\
\text { more and better food }\end{array}$ \\
\hline
\end{tabular}

couraged to express spontaneous reactions, to talk about their experiences, and to discuss the issues with each other. In this manner the six texts were discussed, in every group in the same order. At the end of the sessions, participants were asked to rank the six texts in terms of their persuasiveness.

We conducted the analysis on the basis of the transcripts, the video recordings of the discussions, and the individual rankings. We derived guidelines for the analysis from methodological literature on qualitative analysis 
(e.g., Charmaz 2006; Strauss and Corbin 1998). Next, we conducted open coding (Strauss and Corbin 1998) or initial coding (Charmaz 2006), which means that we read the transcripts line-by-line, being open to respondents' interpretations, and making notes about our observations. We focused on what was salient in how the participants responded to the texts, and on what this said about the six frames, in order to identify the underlying mechanisms that offer insight into how framed messages are conceived in an interactive context.

\subsection{Findings}

\subsection{Simplification}

The first of five findings is that frames are useful as simplifying models. The focus groups suggest that the use of frames helped to make the complex issue of sustainable agriculture and food simpler and better understandable. Earlier focus groups around these themes were held in 2005, and there it turned out that especially the group discussion with people from the lower middle class was extremely difficult (King Baudouin Foundation 2005, p. 6). There were long silences, and the moderator had to probe intensively in order to get useful answers. In the current focus groups on the other hand, there were no long silences and the answers came easily. The group discussions were lively, and a large share of the participants turned out to be interested in the topic. The frames stimulated the discussion because they connected the topic with images and values that participants were familiar with. For instance, the participants understood the notions of the monster of Frankenstein (text I) or responsibility for children and grandchildren (text 2). Thus the frames provided images that people recognized and that made it possible for them to talk about this topic; the frames enabled dialogue and debate.

With respect to the mechanism of simplification it is also relevant to note that the participants saw the texts as understandable. They gave scores from 4.2 to 4.6 on a scale of $\mathrm{I}$ to 5 ( $\mathrm{I}=$ absolutely not understandable, $5=a b$ solutely understandable). Only a few times the discussion showed that certain terms, such as 'intensive agriculture', were misunderstood. In the four groups, there was one person who indicated that she was not interested in the topic and that she did not understand notions such as 'sustainability' and 'ecosystem'. In other words, the inherent complexity and the abstract character of the notion of sustainability imply that also the use of simplifying models is not sufficient to make to the topic understandable for everyone. 
Although the use of frames as simplifying models turned out to be useful, some respondents thought it went too far to reduce a complex topic to such simplified images.

They warned of oversimplification. They did not appreciate certain texts, because they saw them as too one-sided and simplistic. In other words, a danger of using a frame as a simplifying model is that it is conceived as a biased portrayal of a more complex issue, as illustrated in the next discussion of the text with the Frankenstein frame (taken from the higher middle class group in the French-speaking part of Belgium):

\footnotetext{
"The text is rather childish. It is good for twelve-year-old children, but not for adults, except when they are not that smart [laughs]." (Participant 6, female, 50 years old, small business owner)
}

Moderator: "What is the main message?"

"One has to be careful with what they are doing, otherwise the evil will turn against humanity." (Participant 3, male, 42 years old, accountant)

"Well, first you see a man, the creator, and then you recognize Frankenstein's monster. So, I think it is like they play in a children's movie." (Participant I, male, 39 years old, photographer)

“[...] It is a little bit simplistic." (Participant 6)

\subsubsection{Figurative analogy}

Figurative analogy (e.g., McCroskey 2006) refers to the idea that drawing a relationship between a complex issue (sustainability in the context of agriculture and food) and a culturally shared idea (e.g., Frankenstein) helps to clarify the meaning of the issue. Once integrated in the vocabulary a newly constructed term such as "Frankenfood" can immediately evoke a thrilling doom scenario.

Interesting is that at first glance the frame and the issue may not be related. However, one aspect that connects the frame with the issue can be sufficient to suggest that many more aspects are alike. For instance, most people agree that Dr. Frankenstein and the scientist involved in genetic engineering have in common that they try to create new forms of life. By making this as- 
sociation, more connections are suggested, such as that when scientists start to play God, bad things will happen.

The focus groups showed that figurative analogy helped the participants to incorporate the frames into their vocabulary and to use them to express their point of view. We saw that some respondents used framing devices that were presented in earlier texts later on during the discussion of other texts. Other participants, however, experienced difficulties in seeing the figurative analogies. An example comes from a metaphor we included in one of the texts: the metaphor of a "mosaic of related problems that slowly destroy the foundations of the complex ecological structure" (text 4). Some participants were immediately able to use the image of a mosaic, whereas others did not find it a useful image in the beginning. This following fragment was part of the discussion of text 4 , in the lower middle class group in Flanders, and illustrates the inability to work with the metaphor:

"I find the text rather negative and dramatic. Yeah, such big words. 'A mosaic of related problems,' what does that mean? I have mosaic tiles in my bathroom; that is my mosaic. 'A mosaic of related problems' and the text indeed points the finger very negatively at citizens, but I think that we all, at this table, understand that it is the people in Brussels who have to decide. I think they have to search for solutions that the people are satisfied with as well. The text presents it as if it is our fault and that those people in Brussels are innocent." (Participant 8, male, 30 years old, policeman)

Although this participant was not able to work with the metaphor of a mosaic, another participant in the same group used that notion later when discussing the text about progress (text 6). This fragment illustrates how simplifying models work. First, a certain image has to become part of the discourse regarding sustainable agriculture, and when it has acquired a shared meaning for the participants, they can use it to clarify their own points of view in the discussion:

"It seems, especially in the third paragraph, that we all need to contribute. But not as individuals, because that would not work out. It seems useless if you want to do something about it as an individual, but the point of a mosaic is that it works when everybody does their part." (Participant 4 , female, 39 years old, worker) 


\subsubsection{Causation}

A next step in the potential persuasiveness of frames is that the figurative analogy between, on the one hand, the issue of agriculture and food production and, on the other hand, the frame as a simplifying model leads to a causal relation which is specific for the applied frame. When frames are used, only some reasoning devices are explicit. The idea is that the receiver of the message completes this line of reasoning. For example, when food is connected to the notion of Frankenstein, the audience is supposed to infer that consuming such food can have disastrous consequences.

The focus groups indicated that frames stimulated thoughts about relations, in some cases causal ones, and contributed to a better understanding of the mutual relations within an ecosystem. An excerpt from the discussion (in the lower middle class group in Flanders) following the text about progress (text 6) shows how a participant points at the consequences of certain actions. It seems plausible that this participant would not have pointed specifically at the consequences, if she had not discussed the other five texts beforehand.

\footnotetext{
"It does not take into account the consequences. Here [in the Western world] we indeed have food for everybody, but what consequences does it have for our world, all those chemicals, for example to grow fresh potatoes? I don't know. That is not the solution. You always have to take into account the consequences of what you are doing." (Participant 7, female, 25 years old, employee)
}

For persuasive communication about sustainability, an essential element is whether individuals hold themselves or somebody else responsible. The focus groups show two positions on this matter. The first is a fatalistic attitude, in which case participants claimed that it is impossible for individuals to change the system. They argued that it is all about money and making profit, and that the government should help, but neglects to do so. Moreover, they said that it does not help when individuals in, for example, Belgium take initiatives to improve the environment, because the actions of countries such as India and China have much more influence. This stance is visible in the following interaction (in the lower middle class group in Flanders):

"In Hoboken [in Flanders] there are children with toxic lead in their blood. The company that caused all this is summoned to get rid of that polluted ground, 
which costs a lot of money, and they start with that. But when you see that in India for example, they just burn ships, children need to work there, and for dozens of kilometers that sea is polluted. [...] Then I say: Several thousands kilometers from here they burn anything you can imagine, while here they have to clean the ground. As long as they do not do anything there, cleaning that ground here does not make much sense." (Participant 3, male, 42 years old, clerk)

"When everybody reasons like that, nothing will get better." (Participant 2, female, 42 years old, worker/decorator)

"Here we need to do the best we can, and over there they have to do the best they can too." (Participant 7 , female, 25 years old, clerk)

"But well, those people do not have a brain. You can not beat some sense into them. They are a different type." (Participant 2)

The second position is a hurt attitude. In this case participants were prepared to take responsibility, but they felt that someone pointed a finger at them. Individuals can contribute, they said, even it consists of just small things. They sorted out their garbage, used low-energy light bulbs, looked at where vegetables and fruits originated from, but they never heard what the results were of these small efforts. They thought the texts were too negative, and they missed a positive note or a perspective of action, particularly regarding their own efforts.

\subsubsection{Cultural resonance}

In order to find out whether some of the defined frames would only be effective in a specific culture, we made a comparison between the French-speaking and the Dutch-speaking groups, and a comparison between the lower middle class and the higher middle class group. Yet we did not find any clear differences between the Dutch-speaking groups and the groups in Frenchspeaking Belgium. It seemed that the defined frames, such as Frankenstein, responsibility and progress resonated across the different cultural groups in the study. There were, however, some differences between the lower and the higher middle class groups in how they dealt with the frames.

First, participants from the lower middle class group related the topic more to personal experiences in their everyday lives. They made a connection 
between the topic and their occupation, family situation, health, travel experiences, etc. They also frequently referred to media content, such as television programs and newspaper articles. The constructionist approach to framing sees this media influence predominantly in terms of the media providing information, arguments and frames that the audience actively interprets on the basis of their own stock of knowledge.

Second, the higher middle class group talked about the topic with more distance, and members of this social stratum were also more capable of taking the underlying system into account when discussing agriculture and food. This could be the reason why they saw the undermining of the foundations frame as more persuasive than the lower class group did. Their ways of arguing, taking the underlying system into account, also made them stress that it is important to present both pros and cons. Their discussions included meta-communication: they discussed how the text was structured and formulated. By taking a distant approach they were even able to recognize that certain frames were used in the line of reasoning. For instance, they tried to assess who the source of the message was. The following citations, from the higher middle class group in Flanders, show how participants critically assessed the texts.

"[...] The text [text I] could be rephrased so it would be less extreme. For instance: What will happen if men play with nature?" (Participant 8 , female, 37 years old, independent translator)

"One loses sight of one aspect here [in text 4]: One criticizes agriculture and the way agriculture works, but at the same time we should not forget that there is still not enough food for everyone. That is not mentioned here, but it is of course the other side of the coin. To produce a lot of food, which is necessary, we need the upto-date techniques. I mean, with cultivating biologically we will not be able to feed everybody." (Participant 4, male, 47 years old, middle management)

"[...] It is a fluently written text, but I think it is a bit idyllic and a bit unrealistic. Someone who argued radically against all these things wrote text $\mathrm{I}$, and this author [of text 5] argues radically against organic food." (Participant I, male, 26 years old, middle management pharmaceutical company) 


\subsubsection{Ranking the frames}

After the discussion participants were asked to individually rank the six texts in order of persuasiveness. We present an overview of the ranking, in order to give an illustration of how the respondents perceived the messages. In these four focus groups, two texts were seen as most persuasive: the text about the foundations of the ecosystem (text 4 ) and the text that refers to the responsibility for children and grandchildren (text 2). The text about the foundations (text 4) was appreciated because it presented a real and complex problem in a clear way. What participants did not like about this text was that it used rather difficult terminology, and that its tone was pessimistic. The text that focused on responsibility for children and grandchildren (text 2) was seen as persuasive because it presented a tangible and understandable explanation of what 'sustainability' is. A flaw of the text was that some participants who did make efforts felt that they were accused of not doing anything and they missed a perspective on what they were supposed to do. Possibly, people without children find a text using this frame less appealing.

Two texts took a middle position: the text that described that all good comes from nature (text 5 ) and the text that presented supermarkets as ultimate Good Mothers (text 3). Strong points of the text about nature were that it was positively formulated and presented tangible solutions. Participants also agreed that natural products taste better. However, participants did not like the woolly language, and they pointed out that nature does not give enough to provide food for everybody. The text that presented supermarkets as Good Mothers was appreciated because it came across as a balanced story that included both positive and negative elements.

The two texts that were seen as least persuasive were the text about Frankenstein food (text I) and especially the one that presented the progress frame (text 6). Participants saw the text about Frankenstein food as too pessimistic and too simplistic. Referring to Frankenstein and to God made the text less trustworthy. The text seemed to aim to invoke guild and fear, but did not present solutions. And the text about progress was not seen as persuasive because it suggested that individuals do not need to do anything, because science will solve all problems.

\subsection{Conclusion}

The aim of this chapter was to investigate how citizens respond to persuasive messages about sustainability. Sustainable agriculture and food production 
present a complex field in which stakeholders need to look for the most effective arguments to communicate that especially their ways of agriculture or food production are sustainable. It is of both scholarly and societal interest to study the argumentative schemes used regarding this hotly debated topic, and we studied this persuasive communication by using framing theory from a constructionist perspective. In a previous study we identified six frames that are used in communication about sustainable food and agriculture (Van Gorp and Van der Goot 2009), and the current focus group study helps to identify how these frames contribute to communicating such abstract issue. The analysis leads to four main findings about how frames work with respect to the issue of sustainability in the agriculture and food system: simplification, figurative analogy, causation and cultural resonance.

First, frames can reduce a complex, abstract, and probably even chaotic issue to something simple. In this simplified version of our agricultural and food system it is easier to draw conclusions that seem logical, natural and obvious. As such, frames are simplifying models (Aubrun, Brown and Grady 2006; Nall, Bales and O'Neil 2008). For instance, the focus groups show that the use of the monster of Frankenstein makes it simpler to talk about the issue of genetically modified food.

Second, framing draws on figurative analogy by making a connection between a complex issue such as sustainable agriculture and food, and a culturally shared idea. The focus groups show that because of the figurative analogy a frame indirectly can cause an effect in that receivers pick up a frame as a simplifying model and use it in the discussion as mental shortcuts. This observation does not mean that the texts affect the audience in the sense of changing their attitudes. Our research design was not meant to measure framing effects. What we saw is that the participants had their opinions, defended their positions when necessary, and listened to other participants, without copying these other opinions, and that during this process they adopted the presented frames in their vocabulary.

Third, focus groups indicate that the framed messages help people to understand relations within an ecosystem and to stimulate their thoughts about relations, including causal ones. The frame's capacity to define and to suggest causal relations is an important one, because these lines of reasoning do not have to be included explicitly in a text. It is, however, difficult to predict whether the individual holds oneself responsible for achieving a more sustainable society. 
Fourth, we presume that cultural resonance is the conditio sine qua non in the framing process as sketched here. The defined frames are imbedded in a culture and that is why they would resonate with the individual cognitive schemes. Although cultural differences between the Dutch-speaking and the French-speaking parts of Belgium may be expected, we did not find differences between these cultures. There were, however, some differences between the lower and the higher middle class groups. Participants from the lower middle class tend to refer more frequently to their private lives, whereas participants of the higher middle class discussed the topic with more distance.

The research design indicates that in framing research it is insightful to extend an analysis of media content with a reception study. The 'art' of framing is to identify cultural phenomena that are appropriate to get a grip on new challenges society is confronted with. And although content analysis is helpful in identifying the frames that stakeholders use in their communications, reception research is necessary in order to see how these frames work with an actual audience. For instance, the focus groups lead to a nuanced view on how simplifying models work. Although some people point out that simplifying models make a text appear biased and untrustworthy, these models appear to be useful in making a complex and abstract topic tangible. In addition, we saw that frames stimulate thinking in terms of relationships and cause and effect. Moreover, more than a content analysis alone, reception research is able to generate practical recommendations for stakeholders. The findings about simplification, figurative analogy, causation and cultural resonance are useful in that respect.

All in all, the present focus group study provides a glimpse into how frames work in communicating about such a debated and chaotic topic as sustainable agriculture and food. The study, however, has some limitations.

First, we developed the texts ourselves; they were meant to represent six persuasive messages each relying on one of the six frames. Logically, the group discussions did not focus only on the content of the texts, but also on the use of particular phrases and words. One recommendation for future research is to deliberately make use of rhetorical insights in constructing the texts. Another way of generating material for future reception research is to employ actual material as developed by the stakeholders, especially material that includes both verbal and visual information. For example, responses to the Frankenstein-frame will probably alter when visual fear appeals are included.

Second, we organized only four focus groups. This is sufficient to ob- 
tain some input for theory development about how frames work, but especially the findings about cultural differences and the ranking should be interpreted with restraint and as only an indication. To gain more insight into the differences between groups, large-scale research needs to be conducted. Especially research into cultural differences is promising, because culture is such a central element in this line of framing research. The current smallscale study did not show differences between Dutch-speaking and Frenchspeaking cultures, but other research (Debomy 2005) suggests that there are profound differences between cultures. For example, inhabitants from Eastern European countries perceive the economic dimensions of sustainable food largely from the perspective of keeping traditions and the rural fabric alive, whereas inhabitants from countries with a culinary tradition such as Belgium, France and the Mediterranean countries stress the hedonistic and affective dimension of sustainable food. In sum, both quantitative and qualitative audience research is needed to study how frames resonate differently with people from different cultures and different social classes.

\section{References}

Aubrun, A., A. Brown and J.E. Grady (2006). Conceptualizing US Food Systems With Simplifying Models: Findings from TalkBack Testing. Washington, DC: The FrameWorks Institute.

Aubrun, A. and J.E. Grady (2006, October). Towards a Cross-cultural Simplifying Model for Food Systems: Findings from French TalkBack Research. Brussels: King Baudouin Foundation.

Charmaz, K. (2006). Constructing Grounded Theory: A Practical Guide Through Qualitative Analysis. London: Sage.

D’Angelo, P. (2002). News Framing as a Multiparadigmatic Research Program: A Response to Entman. Journal of Communication 52, 870-888.

Debomy, D. (2005). The Europeans and Sustainable Food: Qualitative Study in Is European Countries, Pan-European Report. Brussels: King Baudouin Foundation.

Elkington, J. (1997). Cannibals with Forks: The Triple Bottom Line of $2 I^{\text {st }}$ Century Business. Oxford: Capstone.

Entman, R.M. (1993). Framing: Toward Clarification of a Fractured Paradigm. Journal of Communication 43(4), 5I-58.

Frameworks Institute (2009). Foodsystems (online). Retrieved February 16, 2009, from Frameworks Institute, Washington, DC http://www.frameworksinstitute.org/ foodsystems.html 
Gamson, W.A. (1992). Talking Politics. Cambridge, uk: Cambridge University Press.

Gamson, W.A., and K.E. Lasch (1983). The Political Culture of Social Welfare Policy. In S.E. Spiro and E. Yuchtman-Yaar (Eds.), Evaluating the Welfare State: Social and Political Perspectives (pp. 397-415). New York: Academic Press.

Gamson, W.A. and A. Modigliani (1989). Media Discourse and Public Opinion on Nuclear Power: A Constructionist Approach. Amer. Journal of Sociology 95, I-37.

Garver, E. (1994). Aristotle's Rhetoric: An Art of Character. Chicago, Il: The University of Chicago Press.

Hall, S. (1980). Encoding/Decoding. In S. Hall, D. Hobson, A. Lowe, and P. Willis. (Eds.), Culture, Media, Language: Working Papers in Cultural Studies, I972-1979 (pp. I28I38).London: Hutchinson.

Herrick, J.A. (2005). The History and Theory of Rhetoric: An Introduction (3rd edition). Boston, MA: Allyn and Bacon.

Jaspaert, K., D. Geeraerts and K. Feyaerts (2008). Op zoek naar een Simplifying Model voor duurzame voedselproductie [In search of a Simplifying Model for sustainable food production]. Brussels: King Baudouin Foundation.

King Baudouin Foundation (2005). The Europeans and Sustainable Food: Country Report Belgium. Brussels: King Baudouin Foundation.

Kitzinger, J. (2007). Framing and Frame Analysis. In E. Devereux (Ed.), Media Studies: Key Issues and Debates. Los Angeles: Sage.

Lule, J. (2005). News as Myth: Daily News and Eternal Stories. In E.W. Rothenbuhler and M. Coman (Eds.), Media Anthropology (pp. IoI-IIo). Thousand Oaks, CA: Sage.

McCroskey, J.C. (2006). An Introduction to Rhetorical Communication: A Western Rhetorical Perspective (9th edition). Boston, MA: Allyn and Bacon.

Nall Bales, S. and M. O’Neil (2008). Gaining Support for Teen Families: Mapping the Perceptual Hurdles (Research report). Washington, DC: FrameWorks Institute. Neuman, W.R., M.R. Just and A.A. Crigler (1992). Common Knowledge: News and the Construction of Political Meaning. Chicago: The University of Chicago Press.

O'Keefe, D.J. (2002). Persuasion: Theory and research ( $2^{\text {nd }}$ edition). Thousand Oaks, CA: Sage.

Pan, Z.P. and G.M. Kosicki (1993). Framing Analysis: An Approach to News Discourse. Political Communication I0, 55-75.

Plett, H.F. (200I). Figures of Speech. In T. O. Sloane (Ed.), Encyclopedia of Rhetoric (pp. 309-314). New York: Oxford University Press.

Polletta, F. (2004). Culture is Not Just in Your Head. In J. Goodwin and J.M. Jasper (Eds.), Rethinking Social Movements: Structure, Meaning, and Emotion (pp. 97-IIO). New York: Rowman and Littlefield. 
Price, V., L. Nir and J.N. Cappella (2005). Framing Public Discussion of Gay Civil Unions. Public Opinion Quarterly 69(2), I79-212.

Reese, S.D. (200I). Introduction. In S.D. Reese, O.H. Gandy, and A.E. Grant (Eds.). Framing Public Life: Perspectives on Media and Our Understanding of The Social World (pp. I-3I). Mahwah, NJ: Erlbaum.

Scheufele, D.A. (1999). Framing as a Theory of Media Effects. Journal of Communication 49(I), IO3-I22.

Stewart, D.W., P.N. Shamdasani and D.W. Rook (2007). Focus Groups: Theory and Practice (2nd ed.). Thousand Oaks: Sage.

Strauss, A. and J. Corbin (1998). Basics of Qualitative Research: Techniques and Procedures for Developing Grounded Theory (2nd ed.). Thousand Oaks: Sage.

Swidler, A. (1986). Culture in Action: Symbols and strategies. American Sociological Review SI (2), 273-286.

Tankard, J.W. (200I). The Empirical Approach to the Study of Media Framing. In S.D. Reese, O.H. Gandy and A.E. Grant (Eds.), Framing Public Life: Perspectives on Media and our Understanding of the Social World (pp. 95-I06). Mahwah, NJ: Lawrence Erlbaum.

Troester Nunez, M. (2008, November). The Motivational Power of Metaphors in the US Debate over Genetically Modified Foods. Paper presented at the $2^{\text {nd }}$ ECREA European communication conference, Barcelona, Spain.

Van den Bulck, H., N. Simons and B. Van Gorp (2008). Let's Drink and be Merry: The Framing of Alcohol in the Prime Time American Youth Series The OC. Journal of Studies on Alcohol and Drugs 69(6), 933-940.

Van Gorp, B. (2005). Where is the Frame? Victims and Intruders in the Belgian Press Coverage of the Asylum Issue. European Journal of Communication 20, 485-508.

Van Gorp, B. (2007). The Constructionist Approach to Framing: Bringing Culture Back In. Journal of Communication 57, 60-78.

Van Gorp, B. (2009). Strategies to Take Subjectivity out of Framing Analysis. In P. D’Angelo and J. Kuypers (Eds.), Doing News Framing Analysis: Empirical, Theoretical, and Normative Perspectives. New York: Routledge.

Van Gorp, B. and M. Van der Goot (2009). Van Frankenstein tot de Goede Moeder: De inzet van frames in de strategische communicatie over duurzaamheid [From Frankenstein to the Good Mother: The use of frames in the strategic communication about sustainability]. Tijdschrift voor Communicatiewetenschap 37, 303-316.

Wicks, R.H. (2005). Message Framing and Constructing Meaning: An Emerging Paradigm in Mass Communication Research. In P. Kalbfleisch (Ed.), Communication Yearbook 29 (pp. 333-360). Mahwah, NJ: Erlbaum. 
TALKING ABOUT SUSTAINABILITY

World Commission on Environment and Development (1987). Our Common Future. New York: United Nations. Dec 5, 2008, http://www.un-documents.net/wced-ocf.htm 



\section{Responding to Expert Arguments Emerging Lay Topoi in Focus Group Interviews on GM Crops}

ANDERS HORSBØL

\section{I Introduction}

An important feature of modern societies is the exchange between academic expert and lay knowledge, the "interface between science and society" as Horst puts it (Horst 2005, p. 197). Since the equation between scientific development and societal progress has been problematized, the exchange between scientific expertise and everyday knowledge has led to several controversies. A recent controversy is the debate on genetically modified organisms (GMO) and their potential use within agriculture. In Europe, in particular, the introduction of GMO in agriculture has been met with widespread public scepticism and protest actions from NGOs (see Bauer and Gaskell 2002 and Scholderer 2005 for an overview).

The Eurobarometer study of public opinion in different European countries concludes that " $\mathrm{t}]$ here is widespread support for medical [...] and industrial [...] biotechnologies, but apparently significant opposition to agricultural [...] biotechnologies in all but a few countries" (Eurobarometer survey $244 \mathrm{~b}, 2006$ ). Within studies of consumer behaviour, Scholderer humorously suggests that "[...] attitudes towards GM foods appear to be utterly resistant to persuasion. Not a single study reported in the literature has ever been able to change consumer attitudes through communication" (Scholderer 2005, p. 270). The term "communication" in the above quote refers to mediated communication, not to face-to-face or interpersonal communication.

The current study differs from the above mentioned by being a qualitative study based on focus group interviews. As such, it resembles interview studies of opinions on GM crops held by laypersons (Myers 2004) or by scientific GM experts (Cook 2004). Furthermore, and in line with Myers' study, the object of analysis is not opinions per se, but opinions as they emerge within a 
situation; i.e., "how opinions are generated and negotiated in interaction with other people" (Myers 2004). It is important to add, however, that the current study differs from the studies of Myers and Cook by focusing on exchange between lay and expert knowledge in interpersonal communication, in this case between biotech experts and laypersons (with respect to biotechnology).

In order to analyse the interpersonal exchange between lay and expert knowledge, a series of focus group interviews were carried out. Each interview included two biotech experts and four or five 'ordinary citizens' (with respect to knowledge on biotechnology). The interviews were led by two moderators, drawing on an interview guide. The participants had been chosen according to criteria of demographic stratification and had agreed to join a focus group interview on food in general. Each interview lasted two to two and a half hours.

The following analysis will concentrate on two of these interviews and will focus on one aspect of the interactional dynamic of the discussion; namely, on the laypersons, responses to (persuasive) utterances from biotechnologists, who are mainly in favour of the use of GM crops and argue their case during the interview. I shall ask how, in the course of the interaction, the lay participants refer back to and make relevant earlier expert utterances, and how they reconstruct and respond to the expert talk. Of particular relevance is the way in which the lay participants try to manage the obvious knowledge gap between them and the experts without restraining from making argumentative contributions to the discussion. In that sense, the lay responses are not seen as simply reactive, but as rhetorically inventive contributions in an already populated argumentative space (Billig 1996). For this aim, I shall employ the concept of topos and analyse the different topoi which are put forward by the lay participants as they respond to the (persuasive) utterances from the biotechnologists.

Topoi are 'places' of arguments, i.e., places from which something can be argued. A topos may be understood formally as a certain argumentative form or structure, such as argumentation by definition, contrast, comparison, causality or authority (which are all listed as general or "koinoi" topoi by Aristotle in his Rhetorics, Aristotle 2007). Or, on a lower level of abstraction, a topos may be understood materially as the premises on which a concrete argument is based. Crossing the distinction between formal and material, a topos may be (rather) field dependent, as in scientific argumentation, or (rather) common-sensical, as in lay argumentation. In line with the latter 
meaning, a topos may take the form of a commonplace (literally a translation of the Latin "loci communes", Cicero 198I), thereby being reduced to a rhetorical cliché. In all cases, a topos has a certain level of generality, making it applicable in different concrete situations, a characteristic termed "potentiality" by Bornscheuer (German: "Potentialität", Bornscheuer 1976, p. 99). At the same time, the available topoi represent a culturally specific reservoir of argumentation (ibid.p. 34), in which arguments for specific situations and problems may be sought (Kienpointer 1997; Gabrielsen 2009). This culturally specific reservoir is often not harmonious, but "composed of contraries", as argued by Billig (Billig 1996, p. 235).

In the following analysis, I shall take a material approach to the concept of topos and analyze, in the laypersons' responses, the general principles according to which controversial GM food issues are 'located' argumentatively. Some of the topoi in the laypersons' responses are modifications of topoi used by the experts earlier in the interview, whereas other topoi have not been previously employed in the interview.

\subsection{Analysis}

The use of topoi in the laypersons' responses to expert arguments has been summed up in table 20.I. For means of clarity, the list is divided into approaching and distancing responses, where the former leans towards agreement with the expert argument, and the latter leans towards disagreement. The list points to the diverse and multiple argumentative resources of 'ordinary citizens', which is often overlooked in media representations, where emphasis tends to be on pronounced views with clear conflicts.

\section{TABLE 2O.I OVERVIEW OF TOPOI IN THE LAY RESPONSES}

\begin{tabular}{l|l} 
Approaching responses & Distancing responses \\
\hline Topos of utility & Topos of contrast between impartiality and bias \\
Topos of security & Topos of (self-) contradiction \\
Topos of moral necessity & Topos of ability \\
Topos of contrast between feelings and facts & Topos of risk and preciousness \\
Topos of personal authority & Topos of the natural
\end{tabular}

In the following, I shall give examples and elaborate on the employed topoi individually, commenting also on their placement in the interaction and their 
relation to the preceding expert arguments. The analysis starts with the approaching responses and then moves on to the distancing responses.

\subsection{Approaching responses}

(I) Topos of utility: Well, I didn't know very much before, but I have found out in this focus group that sort of for environmental reasons, it could possibly be an advantage. ${ }^{\mathrm{I}}$ (Speaker 2)

A reoccurring topos in the focus group interviews is the topos of utility, as represented in the example above. In this example, the lay speaker explicitly states her own lack of knowledge prior to the interview, and acknowledges the contributions by the experts as valid and relevant new knowledge. She points to the benefit for the common good, in particular the environment, as a possible advantage of GM foods. This is done in a very low modality ("could possibly be"), which is a change in 'tone' from the expert utterances to which she is referring. In that sense, the lay speaker does not simply duplicate an expert argument, but represents it as a legitimate argument worthy of consideration.

(2) Topos of security and (3) topos of moral necessity: Yes, that he said that it took place in a closed environment, I hadn't really thought about that, or that it is being said that this is the only way to produce superior insulin [...]

Interviewer: You mean, what Carsten said about saving human lives?

Yes, exactly. So in that way I am influenced by the things I hear, but I still don't like it.

(Speaker 22)

Whereas the topos of utility makes the argument for a positive impact of GM crops, the topos of security makes the argument that a potentially negative impact of GM crops can be prevented. As such, it is a defensive rhetoric which counters the topos of risk, which generally has been highly prevalent in the debate on GM crops. In the example above, the topos of security is not applied to GM crops as such, but only to GM crops grown under certain circumstances, more precisely in a "closed environment". Thus, it is based on a

${ }^{\text {I }}$ The quotations are all my own translations from Danish into English. They have been checked and corrected by a speaker with excellent competence in both English and Danish. 
distinction which leaves most uses of GM crops as insecure. This application of the topos of security had been put forward in passing by one of the biotech experts earlier in the discussion, and in this passage the lay speaker makes it relevant as an example of a new distinction which has influenced her during the discussion. However, she does not represent the new information as leading to a complete change in her view on GM crops, not even on those GM crops which can be sealed off. Instead, she represents the new distinction as putting her in a dilemma where she is influenced by the expert utterance but still does not like the whole thing. The outcome of that dilemma is not settled in the discussion.

In the same quoted passage, the lay speaker employs what may be termed a topos of moral necessity. In referring to an expert utterance about GMO as "the only way to produce superior insulin", the speaker indicates that if a potentially lifesaving process can be achieved only through GMO, it may be acceptable. As with the topos of security, this application of the topos of moral necessity represents an exception to the layperson's general non-acceptance of GMO. And, similarly, saying that she is influenced by the expert argumentation does not imply that the lay speaker says she is convinced by it, only that she finds it worthy of consideration, and apparently has moved from a rather unitary to a more dilemmatic attitude towards certain forms of GMO.

(4) Topos of facts vs. feelings: It is quite clear that what we get to know, the facts we get, that is what we just happen to hear when we watch television or read about it. The facts we get are many times represented in an emotional way [....] And it is the same with the debate on dairies. Many people buy Hirtshals Milk [small diary in Northern Jutland] because they want to support the small dairy. But it hasn't anything to do with the quality, right, it's attitude value and sympathy and such things. (Speaker I)

In the above example, the lay speaker represents the knowledge of the laypersons (the first "we") as accidental, mass media based, and, due to the media representation, mainly emotional. This is later elaborated and said to be equivalent with the speaker's own example, the popular support for a small local diary, where the emotionality is implied to be equivalent to "attitude value" and "sympathy" as opposed to the "quality" (of the milk). The speaker thus picks up and elaborates on the topos of factual vs. emotional argumentation, which had been put forward by one of the experts earlier in the discussion. And, importantly, the speaker applies the topos to the knowledge 
base of the laypersons in general, thereby writing them off any substantial argumentative legitimacy. ${ }^{2}$

(5) Topos of personal authority: It does [make a difference] every time Marianne [one of the biotech experts] says something. I don't know why, but she seems very trustworthy to me. And it's being said in a way so that I can follow many of the things she says. (Speaker 2I)

Asked about whether the discussion has changed her mind, the lay speaker employs a topos of personal authority, referring to the credible and understandable way of arguing by one the biotech experts in the discussion. It is worth noticing, though, that this is not the classical topos of authority of the expert as such, but a topos of an authority which is achieved and performed by a specific individual in a specific situation.

\subsubsection{Distancing responses}

(6) Topos of risk \& preciousness: It could of course be that in I0-IS years time when this area has been researched a bit more and the information has reached a higher level, maybe then I may acknowledge that it [GM crops] can be used in some areas. But as it looks now, no, we only have the very same earth and the same environment, and then I do not dare to run the risk. (Speaker 25)

Moving to the distancing responses, the topos of risk plays an important role in the focus group interviews. In the example above, where the speaker sums up his view on GM crops after a good deal of the discussion, the topos of risk is linked to a topos of preciousness. By asserting the fact that "we only have the very same earth and the same environment" the speaker indicates at the same time the global reach ("earth"), and the preciousness ("only the very same") of what is at stake. This assertion, though, is preceded by a concession with regard to future knowledge. The speaker rejects GM crops for the present time, but explicitly opens a possibility of partial acceptance in the future - though highly modalized ("maybe then I may") - depending on the

\footnotetext{
${ }^{2}$ This use of the topos of facts vs. feelings resonates with Cook's studies on attitudes among scientist on the GMO debate, where the attitude that "scientists think" whereas "the public feels" is reported to be widespread (Cook 2004).
} 
development in knowledge about GM crops. As such, the response is not only a distancing response, but also has an approaching quality.

(7) Topos of naturalness: I also have a lot of respect for the things you [the experts] are saying, right, because you are a bit different from us, because you have another background, right. But the one with the tomatoes, I won't go for that one, because I still think it is disgusting, that it should be that way because they should be able to last longer. I still think it is chemical, in my world it will remain so, but I have a lot of respect for it, and I also listen a lot to what you are saying, and I think much of it sounds sensible, but you haven't convinced me. And then you can call me stubborn or whatever I am, I don't know. (Speaker 24)

The topos of nature or naturalness also occurs several times in the focus group interviews. In the example above, the natural is assumed to be the positive alternative to the "chemical" quality of the long-life GM tomato. The speaker stresses his own subjectivity by the frequent use of " $P$ ", especially in combination with mental processes such as "I think", and uses the emotional term "disgusting" to underline his rejection of GM crops. But, on the other hand, the rejection is framed by a lot of defensive and interpersonal rhetorical (face) work, where the speaker takes great pains to express his respect for the experts present in the discussion, and even anticipates self-criticism at the end of his turn.

(8) Topos of impartiality vs. bias: That's the problem, it's when do you have a trustworthy expert? What is his agenda? That's where the problem is, right, because experts who are employed by Novo Nordisk [Danish medical company] I may doubt, but an expert within a public institution I will probably side with a bit more. (Speaker 25)

Whereas the topoi of risk and naturalness both address the content or issue qualities of GM crops, the topos of impartiality vs. bias addresses qualities of the debate, more precisely the conditions of the debate. Without mentioning the specific experts in the focus group, the lay speaker challenges the credibility of experts in general. He does so by raising the question of cui bono ("What is his agenda?"); also experts may be led by interests which are not purely scientific. This question is followed by a distinction between privately and publicly employed experts, the latter being described as more trustworthy, though in a modalized form expressing uncertainty or caution. 
(9) Topos of (self-) contradiction: I read all the time that now it's healthy to eat something, and then suddenly you find out, then, suddenly, some experts find out that it's not healthy after all. And then, suddenly, some experts find out that it is healthy after all. You get so much misleading information. (Speaker 24)

Another topos which addresses the quality of the debate and indirectly the credibility of expert utterances is the topos of (self-)contradiction. Here, the lay speaker points to contradictory expert information on healthy food, which by analogy may question expert information on GM foods as well. As with the topos of impartiality, the topos of (self-)contradiction denies the application of the classical topos of authority in relation to experts on foods.

(Io) Topos of ability: I can easily understand what you're saying, but I try to see it from the other side as well. I also think, just how much reflection are you allowed to have when you live on less than a dollar a day? How much room is there to reflect on what you put into your mouth? There's probably not very much room for that. (Speaker 2)

Finally, the topos of ability in the above example also addresses the conditions of the debate, but now in relation to the attitudes of poor inhabitants in developing countries where GM crops may be used - and welcomed - to remedy famine. After having expressed full understanding for the view put forward by one of the participating experts (that one should give developing countries the choice of using GM crops), the lay speaker claims to add "the other said'; i.e., the perspective of distant others, to the debate. She problematizes whether the willingness to use GM crops by people living at a subsistence level can be seen as a true approval, given the limited "reflection" which can be expected in such cases of necessity. The speaker does not, in the example or elsewhere in the focus group interview, state exactly how this problematization should affect the stance on GM crops in developing countries. Her contribution adds a new perspective, rather than presents a definite attitude.

\subsection{Discussion and conclusion}

The analysis clearly shows that the laypersons in the interviews do not dismiss the expert arguments straightaway but reflect upon and 'negotiate' several of these. In that sense, the laypersons' views on GM crops do not appear to be "resistant to persuasion" as Scholderer (2005) has suggested. Since Scholderer's 
suggestion was based on a review of the literature on how mediated communication may change attitudes on GM crops, the striking difference between the results in the current study and in the studies referred to by Scholderer suggests significant differences between the persuasive influence of mediated communication on the one hand and interpersonal communication on the other, at least in settings similar to the lengthy focus group interviews in the current study. This is not a new finding to communication studies, at least since Katz and Lazersfeld formulated their "two-step flow" theory based on the role of "opinion leaders" (Katz/Lazersfeld 1955), but it is worth noticing that the current study indicates that also interpersonal communication with strangers, in this case academic experts, may be influential. It is an open question how this applies to contexts other than the focus group interviews here examined.

Equally important, the analysis shows that the laypersons typically do not change their views in the sense that they simply take over the expert view. Instead, a wide variety of modifications can be observed. The laypersons express interest in arguments or information put forward by the experts, they recognize an expert style of communicating, or articulate dilemmas between different perspectives. Related to this, the use of modality, which expresses doubt, reservations or caution, is quite frequent in the laypersons' responses. Differentiations between different kinds of GM crops also play an important role, especially in the approaching responses. Again, these differentiations do not simply imply acceptance of certain forms GM crops, rather they imply an acceptance that certain arguments are worthy of consideration.

Several of the topoi in the lay responses, especially among the distancing responses, concern the conditions for discussing GM crops rather than the issue itself. Far from appearing as flat refusals to accept expert arguments, these meta-communicative topoi are inventive contributions to the interview discussion which display a reflexive relation to expert argumentation in society. The use of these topoi also represent a strategy which lay persons may employ in order to simultaneously appear as rational individuals and recognize the gap of field-specific knowledge between them and the experts.

This strategy enacts one of the predominant situational identities (Billig 1996, p. 264) which can be observed among the lay persons in the focus groups. It is an identity as a critical or reflective citizen, who questions the scope of scientific expertise and the role of science in the societal deliberation. Another predominant identity enacted by the laypersons, is the learning citi- 
$z e n$, who positions herself as being educated by science. Thirdly, a less predominant situational identity is the stubborn or isolated citizen, who positions himself as essentially unaffected by science, insisting on keeping his own view, though not insisting on it as the view for anybody else. When the laypersons in the focus groups enact one of these identities, and they may enact more than one in the course of events, they all appear to be concerned about showing open-mindedness and recognizing the value of scientific knowledge, also in the case of disagreement and problematization. Whether this is the case in more informal and backstage interactions would make an interesting study. Finally, a word on the absent topoi in the focus group interviews. Although a major point of the current chapter has been to give an impression of the diversity of everyday argumentation in dealing with complex issues and expert argumentation, this diversity is not unlimited. An interesting absence, in my view, is that topoi of pleasure, personal convenience and aesthetics play almost no role in the discussion. These topoi do indeed play a role in the discourses surrounding many other technologies and knowledge saturated products, and they form part of everyday dilemmas for many users when it comes to considering for example personal convenience against environmental concerns. However, they do not, as yet, seem to be associated with GM crops.

\section{References}

Aristotle (2007). Retorik. Odense: Museum Tusculanum.

Bauer, M.W. \& G. Gaskell (Eds.) (2002). Biotechnology. The Making of a Global Controversy. Cambridge: Cambridge University Press.

Billig, M. (1996). Arguing and Thinking: a rhetorical approach to social psychology. Cambridge: Cambridge University Press.

Bornscheuer, L. (1976). Topik. Zur Struktur der gesellschaftlichen Einbildungskraft. Frankfurt a.M.: Suhrkamp.

Cicero, M.T. (198I). Retoriske skrifter. De oratore. Odense: Odense Universitetsforlag.

Cook, G. (2004). Genetically Modified Language. The discourse of arguments for GM crops and food. London: Routledge.

Gabrielsen, J. (2009). Topisk kritik. In: M.L. Klujeff and H. Roer (Eds.) Retorikkens aktualitet (pp. 14I-165). København: Hans Reitzels Forlag.

Horst, M. (2005). Cloning Sensations: Mass Mediated Articulation of Social Responses to Controversial Biotechnology. Public Understanding of Science 14 (2), 185-200.

Katz, E. and P.F. Lazersfeld (1955). Personal Influence. The Part Played by People in the Flow of Mass Communication. Glencoe, Ill.: The Free Press. 
Kienpointner, M. (1997). On the Art of Finding Arguments. What Ancient and Modern Masters of Invention Have to Tell Us about the 'Ars Inveniendi'. Argumentation II (2), 225-236.

Lassen, I. (2008). Matters of Uncertainty: Negotiating Public Opinion. In: Journal of Risk Research II (8), I025-I045.

Myers, G. (2004). Matters of Opinion. Talking about Public Issues. Cambridge: Cambridge University Press.

Scholderer, J. (2005). The GM Foods Debate in Europe: History, Regulatory Solutions, and Consumer Response Research. Journal of Public Affairs 5 (3-4), 263-274.

Zompetti, J.P. (2006). The Value of Topoi. Argumentation 20 (I), I5-28. 



\title{
2I Speaking of Terror: Challenging Norms of Rhetorical Citizenship in Danish Public Discourse
}

\author{
LISA STORM VILLADSEN
}

\section{I.I Introduction}

Rhetorical citizenship as an area of research includes inquiries into social and institutional deliberative practices and norms and issues of access, scope and strength of individual or group discursive initiatives in the public realm. The notion is new. It was created as a frame for examining the role of rhetoric on a societal plane, based on an understanding of rhetoric as not just a tool for individuals to wield, but rather as a medium for, or a mode of, being a citizen. Theoretically, the concept of rhetorical citizenship springs from two particular strands of research: deliberative democracy and rhetorical agency. There is already an established body of literature on deliberative democracy which deals with the challenges of citizen participation in the political life of representative democracies, e.g., discussing in what ways actual deliberation among the citizenry constitutes a more valuable form of participation than merely voting and how this could be realized and brought to bear on lawmakers (Rawls 1987; Gutman and Johnson 2004; Dryzek 2002; Benhabib 1996). The concept of rhetorical agency is newer and still subject to definitional variation (Geisler 2004; Hauser 2004; Lundberg and Gunn 2005; Rand 2008).

My case material - public political commentaries on statements made by two individuals in reaction to a terrorist attack against a Danish embassy - serves to illustrate the connection between theory on deliberative democracy and the concept of rhetorical agency. It illustrates how notions of rhetorical citizenship are informed by implicit social and discursive norms: the statements were interpreted not "merely" as discursive acts but also as breaches of proper civic responsibility. One way to analyze the interaction between the two statements and the reactions to them is to regard the episode as a case of negotiating rhetorical agency and the norms that are seen as appropriate as 
guidelines in this context. A brief overview on scholarship on rhetorical agency is therefore in order.

\section{I.2 Rhetorical agency}

In recent years, the concept of rhetorical agency has inspired scholars from a range of theoretical backgrounds. A 2004 special issue of the journal Philosophy and Rhetoric illustrates the diversity of scholarly interest in the concept, and while the editor does not offer a definition of the concept in his foreword, he does point to the dual concerns associated with it: on the one hand, rhetoric's constitutive powers as implicated "in the ongoing construction of a human world and the consequences of symbolic choice, or questions of responsibility" and, on the other, the way the concept of agency "raises questions of voice, power, and rights", which places the concept "at the centre of this era's major social, political, economic, and cultural issues" (Hauser 2004, p. I83). The notion thus concerns the fact that we cannot account for rhetorical action merely by referring to the rhetor's intention, but neither can we completely abandon the significance of the individual in particular rhetorical utterances. The concept of rhetorical agency provides a vocabulary for describing the ways in which rhetors are both makers of rhetoric (through skill, inventio, etc.) and made by rhetoric (as well as by circumstance, position in society and other institutional or social conditions) as they address audiences.

Cheryl Geisler identifies the core of the concept to be concerned with the capacity to act. She traces three main strands of research stemming from this: one concerned with critique of the ideology of agency, that is, the link between rhetorical action and social change, one concerned with the more instrumental aspect of rhetoric understood as the rhetor's skill and ability to respond to shifting circumstances and finally, one which is concerned with the conditions for agency, in other words, studying the means or resources characterizing the conditions under which a rhetor is able to act, and not least, the accessibility of such a position: who even gets a chance to be heard? (Geisler 2004, p. I2-I4) The approach here is most akin to the discussion of the alleged illusion of agency. But, whereas this discussion is inspired by what Gaonkar (1997) labelled the "ideology of agency" and focuses on what Gunn and Lundberg (2005) might call the vain ("ontotheological") notion that rhetors can both will and do things with their words, this chapter deals more with the ideological underpinnings of the general, public expectations vis-à-vis rhetorical agency in a particular context. 
Several significant contributions to current theory on rhetorical agency have given special attention to the opportunities and means that marginalized or otherwise underrepresented groups have to enter and influence public political debate (Asen and Brouwer 200I; Welsh 2002; Asen 2004). This scholarly work is highly important and promises to yield new and constructive perspectives on nurturing a more inclusive and constructive political culture. However, the case in question here seems to suggest that rhetorical agency can be contested even when it concerns individuals and institutions that are usually considered 'mainstream'. In fact, the speakers in question belong to the elite: one, Margrethe Vestager, is an elected member of the Danish Parliament and a party leader, and the other, Niels Due Jensen, is a CEO. In spite of their otherwise privileged positions in society in general and as commentators on public affairs, both found their individual rhetorical agencies impugned when commenting in unexpected ways on a controversial matter. It therefore seems that issues of rhetorical citizenship can be contested even for members of society who ordinarily enjoy easy access to the media and whose opinions on current politics are normally considered relevant. The case also illustrates how deeply conceptions of rhetorical agency are caught up in ideological assumptions that are highly contextual in nature. In my interpretation of the controversy, it seems that expectations of rhetorical agency in this context are informed by unexamined and unchallenged norms informed in turn by a dichotomous and, in Kenneth Burke's terminology, "tragic" frame of debate.

\section{I.3 Background: The attack in Islamabad and initial reactions}

On June 2, 2008 the Danish Embassy in Islamabad, Pakistan was the target of a terrorist attack. A car loaded with explosives slammed into the front wall of the embassy, killing between four and six people and wounding 20 to 30 others. No one took responsibility for the attack immediately afterwards, and the reason for the attack remained a matter of speculation for some time. ${ }^{1}$ The attack was, however, generally assumed to be a response to either the socalled "cartoon crisis" of 2005 and the more recent reprinting of the Mohammed cartoons in the spring of 2008. Another interpretation was that it

\footnotetext{
${ }^{\mathrm{I}}$ In July 2008, a representative of Al-Qaeda claimed responsibility for the attack and said it was an answer to the reprinting of Danish newspaper Jyllands-Posten's Mohammed cartoons in February 2006 and the presence of Danish troops in Afghanistan.
} 
was a protest against Denmark's participation in the war in Iraq and its current military presence in Afghanistan. ${ }^{2}$

As was to be expected, the event called for a response from Danish politicians about the interpretation and proper reaction to this violent act. The attack on the Danish embassy clearly represented a crisis of some significance - regardless of whether one subscribed to the Prime minister's view that it constituted "an attack on Denmark" or held a more limited view of it as a despicable, but isolated terrorist attack on Danish property, or 'simply' as a criminal act calling for police investigation and prosecution of the guilty individuals. Since there was no immediate indication as to who was responsible for the attack in Islamabad or what the reason for it was, comments by Danish politicians initially focused on denouncing the act and expressing sorrow over the loss of innocent human lives and the many injuries.

After the immediate expressions of shock, anger and empathy with the victims and their families, several political commentaries broached the question of how Denmark ought to react to the situation in order to prevent or defend itself from similar attacks in the future. The dominant reaction was to call for an investigation of the incident and a commitment to uphold Denmark's diplomatic and military presence in the Middle East and thus to continue the country's foreign policy and diplomatic procedures in general. In other words, the general view was that it was crucial to "stick to our guns", in order to signal Denmark's determination and commitment to the principles of free speech and democracy. Alternatives to this reaction were either ignored or denounced as "giving in" to the terrorists out of fear. There emerged, therefore, what seemed to be only two discursive options: either to show loyalty to Denmark by expressing steadfastness on the political and military fronts or be seen as disloyal to Denmark by not supporting the official policy. ${ }^{3}$

\footnotetext{
${ }^{2}$ Because Denmark, to many people in the world, is a country that is indistinguishable from other countries such as Sweden and the Netherlands some also speculated that the attack was a misdirected reaction to the Dutch anti-Islamic film Fitna which was released on the internet in March 2008.

${ }^{3}$ The discursive space was, in many ways, similar to the one characterizing the US during the aftermath of the events of Sept. II, 20oI when former us President George W. Bush gave succinct expression to a bifocal political and ethical logic when he declared: "Either you are with us, or you are with the terrorists" in his address to a joint session of Congress and the American People, Sept. 20, 200I.
} 


\section{I.4 Two non-conforming reactions}

In this rather restrictive discursive space, there were, however, two notable exceptions. One came from the leader of the Danish Social Liberal Party, Margrethe Vestager. In her first statements on June 2, she condemned the attack as inexcusable and "totally unacceptable" and expressed her "deepest sympathy" 4 with the wounded and their relatives. ${ }^{5}$ Later that day, in a TV interview with TV2 News, she stated that she thought the incident would lead to a discussion of Denmark's foreign policy line. Denmark ought to be more involved in solving conflicts, she added. ${ }^{6}$

In response to this statement, Vestager was met with aggressive criticism from a broad range of politicians for giving in to terror and for not displaying enough loyalty to Denmark at a moment of crisis. In reaction to Vestager's comment, the Prime Minister said that he was dismayed and considered Vestager's thinking to be "very, very dangerous" at the same time as he denied that terrorists would be allowed to determine Danish foreign policy.7 The Social Democratic leader, Helle Thorning-Schmidt, commented that a terrorist attack is an "infinitely ill-suited background against which to discuss changes in our foreign policy and our internal discussions at home such as the one about freedom of expression". Thorning-Schmidt concluded, "it is wrong to link a terror attack and our foreign policy" ${ }^{8}$ The Leader of the Danish People's Party, Pia Kjærsgaard, called Vestager's comment "pathetic", and also steered the problem toward domestic politics when she opined that Vestager was "abusing the situation to create division and - to put it nicely - [trying] to shift the blame to the parties supporting the foreign policy". Kjærsgaard thus saw Vestager's comment as primarily "an attempt at domestic politicking and trying to set people up against each other". ${ }^{9}$ Perhaps the most pointed cri-

\footnotetext{
${ }^{4}$ All translations of statements by politicians and Niels Due Jensen are the author's own.

5 "Vestager: Totalt uacceptabelt" Ritzau's Bureau, June 2, 2008.

${ }^{6}$ Vestager later explained that this comment was offered in response to a comparison between Denmark and Israel made by her political opponent, the Danish People's Party, calling Denmark "The Israel of the North" - the implication presumably being that both nations are surrounded by Islamic enemies to be combated at any price in order to secure survival.

7 "Sprækker i borgfreden" Jyllands-Posten, June 3, 2008.

8 "Hård kritik af Vestager" Politiken, June 3, 2008.

9 "Hård kritik af Vestager" Politiken, June 3, 2008.
} 
tique of Vestager came from various members of the governing Liberal Party. The party's political spokesperson, Inger Støjberg regretted on her blog that Vestager was getting "weak at the knees" ${ }^{\circ 0}$ and "giving in to the terrorists"." Both she and the Prime Minister were quoted several times charging Vestager with "playing into the terrorists' hands" ${ }^{22}$ A few days later, on June IO, the Liberal Secretary of Taxation, Kristian Jensen, criticized Vestager for yielding to the terrorists and deemed her statements "a dangerous signal" to terrorists, calling her and her party "unfit" to become a member of government. This opinion was backed later that day by the Prime Minister who said that one should never give terrorists the impression that one can be pressured.

Four days after the attack, on June 6, 2008, another critical voice that of Niels Due Jensen, CEO of the Grundfos Corporation (a large pump manufacturer) - also drew heavy criticism. In an interview in the financial newspaper Børsen he expressed concern over the current aggressive foreign policy. He saw it as inviting confrontation and as an unfortunate escalation in the relations between Denmark and the Muslim world. He also stated that he found this policy to be detrimental to Danish business interests and concluded that it certainly was detrimental to his own company's interests. ${ }^{13}$

Like Vestager's, Jensen's comments were also met with heavy criticism and he was all but accused of being a traitor to his country by several members of the Danish Parliament. Conservative party political spokesperson, Henriette Kjær, suggested that Jensen "think in a larger perspective than next year's bottom line for Grundfos". Naser Khader, leader of the libertarian party New Alliance, called Jensen's view a "disgrace" and speculated that he might feel more comfortable living under a dictatorship. Khader also dismissed what he called Jensen's "huckster attitude" and looked forward to the day when

\footnotetext{
${ }^{10}$ I will leave the sexual and sexist connotations of this comment unexamined but merely mention that Støjberg seems to merge two Danish idioms here: blive "blød om hjertet" og "svag i knæene" both of which are used to describe a particularly female version of infatuation and emotional weakness. In fairness, Danish also has at least one idiom about power issues mentioning the knees ("falde på knæene for"). Støjberg's neologism seems to connote a reaction based on emotional/sentimental and power-related submissiveness.

II "Vestager bliver blød i knæene” Inger Støjberg’s blog, June 3, 2008.

I2 Støjberg later said she had been misquoted as leaving out the word "involuntarily" in this context. "Er vi selv ude om det?" Jyllandsposten, June 3, 2008

I3 "Topchef træt af dansk udenrigspolitik" Viborg Folkeblad, June 5, 2008.
} 
Jensen chose to criticize the dictatorships that his corporation traded with instead of criticizing his own country. ${ }^{\mathrm{I}}$ Representatives from both the Danish Liberal Party and the Danish People's Party compared Due Jensen to the infamous so-called collaborators (businesspeople who during the wwir Nazi occupation of Denmark traded with the Germans and profited from it), and Tom Behnke, the Conservative Party's spokesperson on matters of national defense, compared Jensen with a character from a popular Danish television series who was a collaborator. Søren Espersen (Danish People’s Party) summed up his comparison of Jensen with the collaborators saying that Jensen "has chosen the wrong country to live in. It is a tragedy when businesspeople think like that". ${ }^{\text {Is }}$ Behnke (who two days earlier, on Denmark's Constitution Day June 5 , had spoken in praise of the nation's constitutionally sanctioned freedom of expression) explained:

It is sad that Niels Due Jensen questions the policy when we are under attack. Because it showcases that we do not stand together in Denmark, and that will make the terrorists applaud with their chubby little hands. ${ }^{16}$

Behnke also called Jensen "double dumb" because not only did he say controversial things, but also did so at a bad time. In fairness, Benkhe did recognize Jensen's right to say whatever he liked, but explained that the problem was the timing. Said Behnke: "It encourages the terrorists to more acts of terror." ${ }^{17}$

Behnke, of course, had a point, at least concerning the issue of timing. A key principle in rhetorical theory is that of kairos, saying the right thing at the right time. Clearly, the case could be made that the statements by Vestager and Jensen were ill-timed. When people are in a state of shock and fear, they are rarely as ready to engage in critical discussion as when things have settled down, so especially Vestager's comments could be said to be premature in so far as the Prime Minister's definition of the event in Islamabad as "an attack on Denmark" was accepted as correct. Obvious, too, is the presence of ad-

\footnotetext{
I4 "Khader raser over erhvervsboss" Jyllandsposten, June 6, 2008.

is "Profeten og profitten" Jyllandsposten, June 7, 2008.

${ }^{16}$ For reasons of space I have to leave the condescending and chauvinist nature of this statement uncommented upon.

17 "Holdkæftbolsjet: Tom Behnke: Grundfos' Niels Due er vor tids Viggo Skjold Hansen" Information June 7, 2008.
} 
hominem attacks and the general lack of sound argumentation in the various statements condemning Vestager and Due Jensen. However, setting these observations and more traditional rhetorical criticism of the statements, their background, and effect aside, the aim here is not to pronounce a verdict on the respective validity of the statements in the debate, but to examine the controversy from the viewpoint of rhetorical citizenship. The question here is what to make of Vestager's and Due Jensen's enactment of their rhetorical agency. I will argue that concepts of rhetorical agency and deliberative democracy facilitate an understanding of this particular case that speaks to the conditions of contemporary Danish political debate, forms a constructive ground for rhetorical criticism, and proves useful for theorizing further about public deliberation and debate.

\subsection{Challenged notions of rhetorical citizenship}

Viewing this case as an example of how citizenship can be enacted and how that enactment turns out to be controversial is in line with recent calls to make a change in scholarly focus from deciding what counts or doesn't count as citizenship to a concern with how people enact it. While seemingly narrow in scope and ephemeral in political significance, this type of quotidian political polemic is, by virtue of its "knee-jerk" quality, extremely telling of common political practice and the norms that inform it. A similar view of what constitutes rhetorically relevant case material can be found in research on public sphere issues and the theoretical and methodological assumptions that inform the scholarship on citizenship in his work (Asen and Brouwer 200I; Asen 2004). Asen asserts that whether optimistic or pessimistic about the health of civic life, commentators tend to regard citizenship as being "constituted in specific acts" even though the types of activities that are recognized as ways of engaging in citizenship differ. He argues that we must broaden our view of what constitutes civic engagement and recognize the significance of more fluid and quotidian forms of enactment of citizenship (Asen 2004, p. 190). Among the implications of Asen's suggestions is that it recognizes enactment of citizenship in non-traditional because such modes may serve to unsettle the takenfor-granted and challenge norms of propriety. Here, the focus is on public statements that apparently challenged norms of discursive propriety. Reactions to them were strong enough to suggest that they not only hit against notions of proper timing, but were essentially perceived as provocative in their alleged disregard for implicit norms of prudence and national solidarity. 
Thinking of citizenship in terms of mode highlights the manner by which something is done from what is done and it highlights agency (Asen 2005, p. 194). Placing manner and deed in relation to each other allows for consideration of intention and consequently for interpretation as well (ibid.p. 195). The focus here will be that the statements were interpreted not merely as discursive acts but also as manifestations or performances of proper civic responsibility (or rather: lack thereof). As a result, the real issue in the debate turns out to be not what Denmark's foreign policy should be, or when and how it should be discussed, but how a public person should properly perform his or her rhetorical citizenship. The case thus illustrates the highly symbolic significance associated with speaking publicly on matters of collective concern. As an opposition party leader, Vestager was a natural choice to be among the first individuals given the opportunity to comment on the terrorist attack in the media, and her right to speak on this issue went unquestioned. In her case, the issue of rhetorical agency is interesting in relation to the content of her statements and particularly with the reception of them. Rather than constraining herself to an expression of her immediate emotional and political reaction to the attack, she predicted a reconsideration of Denmark's foreign policy. As we have already seen, by so doing, she provoked a large number of negative reactions from politicians representing most of the spectrum. ${ }^{18}$ Vestager's political competence and even her patriotism were severely questioned because she was believed to be suggesting that the country's foreign policy itself might have led to the attack and that this policy perhaps needed to be re-examined in light of Denmark's overall foreign policy aims. This was interpreted as a criticism, even disavowal, of the current foreign policy and as a wish to change it in order to make it less offensive to militant Islamists and thus prevent future attacks against Danish citizens or property.

The vehemence and stridency of these reactions suggest that Vestager not only hit a nerve, but also challenged prevailing communicative norms. I read the attacks on Vestager as an indication that her realization of rhetorical agency in this case was deemed both inappropriate and dangerous, and I want to suggest that this reaction was informed by a particular climate of political debate that I will explore further in a moment. In the eyes of many politicians and the public, Vestager's rhetorical act of questioning current policies jeopardized her performance of political citizenship and national values. Robert-

${ }^{18}$ Excluding the two parties furthest to the left: Enhedslisten and SF. 
Millers discusses the rhetorical power of naïve realism and in-group identity and states: "Naïve realists [...] tend to see calls for deliberation, further research, more complicated descriptions, or scepticism as intentional attempts to obfuscate a situation that is clear to all right-thinking people". Since nuanced public debate is difficult, people tend to ground their response to political issues on group identification and, by the same logic, make an essentializing move that marginalizes people with differing view to an outgroup (Roberts-Miller 2009, p. I80). Vestager's statements challenged the dominant, rather simplified, perception of reality (the attack was a criminal act, not an act of war against Denmark; discussing means and end of the country's foreign policy at moments of crisis does not equal giving in to terrorists, much less treason) and were therefore associated with out-group viewpoints. The fact that she disagreed in turn led to the conclusion that she was being disloyal to her country. By questioning the government's foreign policy, this essentializing argumentative move resulted in the view that she was potentially putting the country at risk. She was, in other words, regarded as betraying her rhetorical citizenship: at a time when many people stuck to an in-group logic of not questioning a dichotomous position of being either against or with terrorists, Vestager, in their eyes, cast serious doubts on her patriotism and abused her rhetorical agency by not saying what they thought to be appropriate.

According to Hauser and Benoit-Barne, agency amplifies the element of risk inherent in any social interaction and, therefore, the need for trust emerges (Hauser and Benoit-Barne 2002, p. 27I). The reactions to Vestager illustrate the fragility of social, political trust in times of crisis. Vestager's political agency was questioned by her political opponents, partly by citing distrust of her judgment in foreign policy matters, partly by referring to her call for a discussion of contemporary Danish foreign policy, and partly by "guiltby-association", citing the foreign policy endorsed by her party during the I940s as evidence against her.

Much the same can be said about the reactions to Due Jensen's statements - the main difference being that, as a business leader, his own vested interests in the matter were more palpable rendering him more immediately subject to suspicion. He was almost universally criticized for feathering his own nest. Space does not permit me to develop this line of argument, but there is an interesting issue of rhetorical agency here. While statements regarding current policy made by leading industry spokespeople are usually readily used as warrants in political debate, especially by two of the Danish 
government parties, we see here an attempt to undermine Jensen's rhetorical agency by an unusual dichotomization of economy and politics.

One of the problems besetting the current discussion of deliberative democracy is that it is usually based on the interests of the individual. A richer understanding would re-conceive political relations as deliberation-based (Hauser and Benoit-Barne 2002, p. 263). Vestager's case brought to the fore some of the challenges inherent in the predominant understanding of political debate as being interest-based instead of being oriented toward inclusion and actual exchange of views and reasons. While Vestager did employ the language of serving one's political interests, her statement, nevertheless, might serve as an example of a different kind of political discourse, one more in line with Hauser and Benoit-Barne's ideal of deliberative democracy. From a rhetorical theory point of view, we might regard Vestager's statements as an attempt to translate "ordinary" speaking access to rhetorical agency. Her comments were not intended to provoke but to initiate a controversial discussion of Denmark's foreign policy. She was using her access to the media to bring to the public's attention a topic that, in her opinion, is too often ignored.

Assuming that Vestager's position is one that favours deliberate and deliberative formation of public opinion, we might see in it an alignment with Aristotelian thinking on phronesis: the cultivation and practice of (sound) political judgment. Hauser and Benoit-Barne contrast the concept of phronesis with the concept of doxa, stating that whereas the former springs out of a rhetorically-based conception of political deliberation, the latter is the assumed basis of conventional interest-based understanding of political action.

Democratic participation [...] is a vehicle for moving the 'will of the people' past its status as doxa (a strongly held but weakly grounded preference), as reflected in opinion polls, and return it to the status of civil judgment envisioned by Aristotle in the Rhetoric. (Hauser and Benoit-Barne 2002, p. 264)

Clearly such a move toward reflection and critical examination of the means and ends of Danish foreign policy felt like a threat in many political circles and was deemed unwise and almost treacherous to the nation's safety. ${ }^{19}$

${ }^{19}$ Later, as other politicians and media commentators reflected on it and found her statements to be in fact both legitimate and reasonable, the criticism was moderated to calling the statements ill-timed. 


\section{I.6 Deliberative democracy and rhetorical theory}

Drawing on the abundant literature on deliberative democracy, several rhetorical scholars have pointed to the dearth of a rhetorical perspective in this body of theory (e.g., Keith, Hauser and Benoit-Barne, Asen). In the article "Rhetorical Deliberation and Democratic Politics in the Here and Now", Robert Ivie makes the case for understanding democratic deliberation as primarily rhetorical. Unlike theorists of deliberative democracy such as Chantal Mouffe and Iris Young, the latter of whom suggests that an adequate understanding of political deliberation must include rhetoric, Ivie in other words turns the tables and claims that championing rhetoric as the basic principle holds more promise (Ivie 2002, p. 277). Ivie's point is that the rhetorical tradition offers constructive ways of understanding and dealing with disagreement both procedurally and substantively because it "promotes democratic practice immediately" (rather than postponing it to an ideal future where diversity and passionate disagreement have been replaced by consensus and universal reason). It also takes dissension as a natural condition not to be combated but rather embraced as a source of critique and thus potential improvement of the debate. Using the Burkean distinction between tragic and comic frames, Ivie points to the fundamentally comic nature of a rhetorical conception of democratic deliberation in virtue which puts into play ...

a potentially positive expectation of a political advocacy, dissent, and disagreement, conduct that otherwise is easily interpreted as a dysfunctional exercise in political wrangling that is wasteful, misguided, corrupt, and far removed from the daily lives of citizens

and thus displays attitudes of tolerance and contemplation (Ivie 2002, p. 278). Says Ivie:

[b]y maintaining a productive tension between cooperation and competition and not privileging any single perspective to the exclusion of all others, 'rowdy' rhetorical deliberation increases the potential of preventing adversaries from being transformed into scapegoats and enemies. Moreover, such robust give-and-take helps to overturn the debilitating assumption that democracy is inherently fragile, and thus risky in the here and now. (Ivie 2002, p. 279) 
While neither Vestager's nor Due Jensen's public statements could be considered unruly, the reactions to them clearly reflected an understanding of the statements as being improper and in violation of the norms of public commentary, both with regard to timing and message. Nothing indicates that they intended to unsettle or discount notions of propriety, but the reactions suggest that this was the effect. So in a sense, Vestager and Due Jensen were both chastised for bad behaviour, and Vestager - by calling into question the timeless wisdom of the nation's foreign policy - was perceived by many as calling into question, or rather, ignoring, common notions of propriety. Content, so to speak, spilled over onto procedure.

\section{I.7 Conclusion}

The uncritical adoption of the simplistic language of war which was invoked by the Danish Prime Minister's labelling of the violent incident in Islamabad as "an attack on Denmark" adopted by the political establishment and the media effectively framed the political commentary which immediately followed the event as dichotomous, intolerant of questioning or hesitation regarding what a wise reaction would be. The result was a debate climate that in Ivie's words added up to "an exclusionary aim for consensus and unity" as witnessed by reactions that reduced difference to total otherness (Ivie 2002, p. 278). The reactions to Vestager are illustrative of some of the problems besetting contemporary Danish public political culture: the criticism of Vestager's call for a reconsideration of Danish foreign policy at was perceived to be threatening, even destabilizing, to the credibility and security of Denmark at a time perceived by some to be a crisis.

The argument was that initiating a discussion of Denmark's foreign policy at that time was not in its interest because it would be perceived as a sign of weakness by the terrorists. In times of crisis, the underlying assumption went, the nation must stand together and not show any signs of internal disagreement or division. In a manner of speaking, the crisis paradoxically - closed the space for political deliberation, even for this leading politician. The reactions, in effect, curbed the possibility of testing competing interpretations and common perspectives of the events in Islamabad, as well as those of Danish foreign policy in the Middle East in general. It is especially remarkable that this was done in a manner that in Ivie's words "effortlessly and absolutely reduced [this issue] to a patriotic battle between the forces of good and evil". 
I have examined the controversy from the perspective of rhetorical citizenship primarily using theory on rhetorical agency and public deliberation. We have seen how unexamined norms of how a citizen may properly act rhetorically in public lead to strong personal attacks on individuals whose statements fall outside of a narrow frame of acceptable reactions. In this reading we observe an a-rhetorical debate culture where disagreement is troubling and deliberation dangerous. A more productive, and genuinely rhetorical, conception would embrace difference as a fact to be dealt with constructively. In the words of Hauser and Benoit-Barne:

A rhetorical reading of civil society returns us to its structure as a web of rhetorical arenas in which strangers encounter difference, learn of the other's interest, develop understanding of where there are common goals, and where they may develop the levels of trust necessary for them to function in a world of mutual dependency. (Hauser and Benoit-Barne 2002, p. 27I)

I suggest that cases such as this invite us to continue examining the norms spoken as well as unspoken - underlying notions of rhetorical citizenship in a given national or cultural context.

\section{References}

Asen, R. and D.C. Brouwer (200I). Counterpublics and the State. Albany: State University of New York Press.

Asen, R. (2004). A Discourse Theory of Citizenship. Quarterly Journal of Speech 90, I89-2II.

Benhabib, S. (1996). Democracy and Difference. Princeton: Princeton University Press.

Burke, K. (1984). Attitudes Towards History. (3rd ed.) Berkeley: University of California Press.

Dryzek, J. (2002). Deliberative Democracy and Beyond: Liberals, Critics, Contestations.

Oxford: Oxford University Press.

Hauser, G.A. (2004). Editor's Introduction. Philosophy and Rhetoric 37, I8I-I87.

Hauser, G.A. and C. Benoit-Barne (2002). Reflections on Rhetoric, Deliberative Democracy, Civil Society, and Trust. Rhetoric and Public Affairs 5, 26I-275.

Gaonkar, D.P.(1997). The Idea of Rhetoric of the Rhetoric of Science. In: Rhetorical Hermeneutics. Invention and Interpretation in the Age of Science. Alan G. Gross and William M. Keith (Eds.), (pp. 25-85). Albany: State University of New York Press. Geisler, C. (2004). How Ought We to Understand the Concept of Rhetorical Agency? Report from the ARs Rhetoric Society Quarterly 34, 9-I7. 
Gutman, A. and D. Thompson (2004). Why Deliberative Democracy? Princeton: Princeton University Press.

Ivie, R.L. (2002). Rhetorical Deliberation and Democratic Politics in the Here and Now. Rhetoric and Public Affairs 5, 277-285.

Keith, W.M. (2002). Introduction: Cultural Resources for Deliberative Democracy. Rhetoric and Public Affairs 5, 219-221.

Lundberg, C. and J. Gunn (2005). Ouija Board, Are There Any Communications? Agency, Ontotheology, and the Death of the Humanist Subject, or Continuing the ARS Conversation. Rhetoric Society Quarterly 35, 83-105.

Mouffe, C. (2000). The Democratic Paradox. London: Verso.

Rand, E.J. (2008). An Inflammatory Fag and a Queer Form: Larry Kramer, Polemics, and Rhetorical Agency. Quarterly Journal of Speech 94, 297-319.

Rawls, J. (1987). The Idea of an Overlapping Consensus. Oxford Journal for Legal Studies 7 (I), I-25.

Roberts-Miller, P. (2009). Dissent as "Aid and Comfort to the Enemy": The Rhetorical Power of Naïve Realism and Ingroup Identity. Rhetoric Society Quarterly 39, I70-188.

Welsh, S. (2002). Deliberative Democracy and the Rhetorical Production of Political Culture. Rhetoric and Public Affairs 5, 679-708.

Young, I.M. (2000). Inclusion and Democracy. Oxford: Oxford University Press. 



\title{
22 Strategic Maneuvering with Linguistic Arguments in the Justification of Judicial Decisions
}

\author{
EVELINE FETERIS
}

\section{I Introduction}

Participants in a legal process often use linguistic arguments to support their claim. In a linguistic argument it is shown that the proposed interpretation of a rule is based on the meaning of the words used in the rule in ordinary or technical language. The reason why a linguistic argument is chosen as a support for a legal claim is that linguistic arguments are considered to have a preferred status in justifying a legal decision, and for this reason, in rhetorical terms, constitute a topos in legal discourse. However, this preferred status can also be 'misused' for rhetorical reasons. A particular reading of the rule can be presented as the accepted standard reading, although other interpretations of the rule might be presented from a legal perspective. In addition, reference to the presupposed standard meaning of the rule can be presented as a sufficient justification, although it is not possible to establish the meaning on the basis of the formulation of the rule alone, because other considerations must also be taken into account. In such cases, if linguistic arguments as topoi are used incorrectly, higher judges criticize the linguistic argument. In the first case because it is based on "a disputable literal reading of statute law" and in the second case because it is based on "a misunderstanding of the law as the legislator had in mind when enacting it".

Although higher judges often give a negative evaluation of certain uses of linguistic arguments, in the literature on legal interpretation and the justification of legal decisions, no clear norms for the use of linguistic arguments are specified. The aim of my contribution is to develop an instrument to analyze and assess the use of linguistic arguments in legal discussions about the application of a legal rule from the perspective of the pragma-dialectical norms for the use of arguments in a critical discussion. I analyze the use of 
linguistic arguments in terms of the strategic maneuvering in the context of a critical discussion. I establish when the strategic maneuvering with linguistic arguments is acceptable from this perspective and when it derails.

In the analysis of the strategic maneuvering I make use of the insights developed by Van Eemeren and Houtlosser (2002a, 2002b, 2003, 2006) about strategic maneuvering in argumentative discourse. I consider strategic maneuvering with linguistic arguments as an attempt to convince a legal audience by showing that the decision is in accordance with accepted legal starting points without openly violating the dialectical norms of reasonableness. The strategic maneuvering implies that the parties try to reconcile two, often conflicting goals, the rhetorical reasonableness norm of convincing the audience and the dialectical reasonableness norm of resolving the difference of opinion in a critical discussion. The strategic maneuvering derails when the rhetorical norm to convince prevails over the dialectical reasonableness norm. If the dialectical reasonableness norm is violated, in pragma-dialectical terms the party commits a fallacy.

To be able to assess the strategic maneuvering with linguistic arguments first, in section 22.2, I specify the dialectical norms for the use of linguistic argumentation in the context of a critical legal discussion. I do this by specifying the conditions under which linguistic argumentation forms an adequate means of justifying a legal decision about the application of a legal rule in a concrete case. Then, in section 22.3, I analyze and evaluate a form of strategic maneuvering with linguistic arguments that often occurs in discussions about the application of legal rules, and I explain on the basis of the norms specified in section $\mathbf{2 2 . 2}$ how the strategic maneuvering derails. I explain that the strategic maneuvering with linguistic arguments in these cases consists of a complex form of strategic maneuvering that constitutes a combination of two maneuvers.

\subsection{Norms for the use of linguistic argumentation in a critical legal discussion}

If we look at the discussion about the use of linguistic arguments in the justification of legal decisions we find, generally speaking, a consensus about the functional use of linguistic arguments. In clear cases in which there is no difference of opinion about the interpretation of a legal rule, linguistic argumentation can function as a justification of the decision, although a justification is not necessary in such cases because there is no difference of 
opinion. ${ }^{\mathrm{I}}$ In hard cases in which there is a difference of opinion about the correct interpretation of the rule, a linguistic argument cannot function as a decisive argument because there are different views with respect to the exact meaning of the rule. ${ }^{2}$

The reason why a linguistic argument may suffice as a justification in an easy case is that, from the perspective of legal certainty, in principle reference to the clear intention of the legislator as it appears from the wordings of the law, must be taken as the starting point for the application of the law. In hard cases in which there is a difference of opinion about the meaning of the law for the concrete case because the intention of the legislator cannot be deduced from the wordings, other sources are necessary to establish the intention of the legislator. Linguistic arguments can have a 'demarcating' function by showing that the judge has remained within the latitude for interpretation he has on the basis of the formulation of the rule. ${ }^{3}$

The problem with the strategic use of linguistic arguments is that parties to a legal process often present a case as an easy case in which a linguistic argument suffices to justify the decision because a linguistic argument is supposed to have a 'presumptive' status from the perspective of legal certainty. However, if the case is a hard case such a presentation is misleading because other arguments based on the legal system, the intention of the legislator, the goal of the rule, etc. are required to give an adequate justification. If these arguments are not given, the justification is not sufficient and the party evades the burden of proof by not mentioning and substantiating these other considerations. ${ }^{4}$

Given the different functions of linguistic arguments in different legal discussion contexts, the question arises which uses of linguistic arguments can be distinguished and which norms apply for an acceptable use of linguistic arguments in the context of these clear and hard cases from the perspective of a rational critical legal discussion.

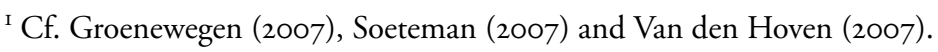

${ }^{2}$ Ibid.

${ }^{3}$ Judges often refer to linguistic arguments when they balance the requirements of legal certainty and the requirements of justice and fairness in a concrete case. See also Feteris (2005 and 2008a) on the balancing of legal certainty and fairness.

4 See also Vranken (2004) about the technique of "veiling argumentation" in legal decisions and the comments given by Feteris (2004). 
From an argumentative perspective we can distinguish between three forms of using linguistic arguments, based on the relationship between the linguistic argument and the standpoint. In what I call the first form, a linguistic argument is presented as an independent justification. In the second form, a linguistic argument is supplemented with other arguments. And in the third form, a linguistic argument is overruled by another argument.

To establish the norms for an acceptable use of linguistic arguments in these three forms, from a pragma-dialectical perspective a distinction can be made between two types of norms. The first type of norm concerns the adequacy of linguistic argumentation as a means to justify a legal decision: whether linguistic argumentation can, in a particular discussion context, constitute an adequate and sufficient justification. The second type of norm concerns the correctness of the application in the case at hand: whether the linguistic interpretation of the rule in a concrete case is correct.

For each form I specify under which conditions the linguistic argument is an adequate justification (condition a) and is used correctly (condition b).

(I) A linguistic argument is presented as an independent justification of the application of a legal rule

From a legal perspective, in an easy case where there is no difference of opinion about the interpretation of the rule and if the formulation of the rule can give a clear and uncontested indication for establishing the meaning of the rule in a concrete case, single argumentation consisting of a linguistic argument can constitute an independently sufficient justification. In such a case it is not necessary to mention that other arguments, such as a systematic arguments or teleological arguments, do not point to a different solution.

When a linguistic argument is presented as an independent justification it is acceptable if:

(Ia) The argumentation is put forward in a context of an easy case in which there is no difference of opinion with respect to the interpretation of the rule in relation to the facts of the concrete case

(ib) The linguistic argumentation refers to the accepted standard meaning of (a term used in) the rule 
Norm (Ia) concerns the adequacy of linguistic argumentation as an independently sufficient argumentation in a legal context and ( $\mathrm{Ib}$ ) concerns the acceptability of the propositional content of the argumentation.

This form of using linguistic argumentation does not occur very often in legal practice because judges do not tend to justify their interpretation if it concerns a clear and uncontested case. If it is used, judges tend to do this for strategic reasons to anticipate doubt that might arise with respect to the acceptability of the decision and use linguistic argumentation for rhetorical reasons to convince the audience that the decision is coherent with common legal starting points; i.e., the linguistic meaning of (a particular expression in) the rule. Sometimes a linguistic argument is supported with subordinative argumentation referring to the "common understanding of the term" or reference to the description in the dictionary.

Sometimes, for rhetorical reasons, the linguistic argumentation is supplemented with coordinative arguments such as systematic or teleological arguments to show that the decision is also in line with other rules of the relevant part of the legal system and/or the intention of the legislator. ${ }^{5}$

(2) A linguistic argument is presented as a supplementary argument in addition to other argumentation

In hard cases where there is a difference of opinion about the correct meaning of the rule and the formulation of the rule does not give a clear and uncontested indication for establishing the meaning of the rule in relation to the concrete case, linguistic argumentation cannot constitute a sufficient justification and must be supplemented by other forms of argumentation. In such cases systematic argumentation or teleological argumentation must form a necessary part of the argumentation, while linguistic argumentation can only function as a supplementary coordinative or subordinate argument.

${ }^{5}$ Van den Hoven (2007) considers this form of using linguistic arguments as the "positive form" of linguistic argumentation. In his view, by using linguistic argumentation in this way judges claim that no adaptations of the legal system are necessary to include the decision in a concrete case. From the perspective of strategic maneuvering you could say that in this form of using linguistic argumentation the judge puts forward the linguistic argument and sometimes supplementary arguments to take away doubt that might arise with respect to the acceptability of the decision from the perspective of the starting points of the legal system. 
When a linguistic argument is presented as a supplementary argument it is only acceptable if:

(2a) The linguistic argument constitutes a support for the same interpretation of (the term used in) the rule as the other arguments that are put forward as a justification

(2b) The linguistic argument is not inconsistent with the meaning of (a term used in) the rule

We find this form of using linguistic argumentation in cases where the legal rule contains a vague or evaluative term so that the rule must be interpreted to establish the meaning of the rule for the concrete case. In such a case linguistic argumentation can never constitute an independent justification because it is not possible to establish in abstracto what the meaning is by checking the literal meaning or the technical meaning of the term. The meaning will have to be established by looking at the legal system and/or goal of the rule. Systematic or teleological argumentation then forms a necessary part of the argumentation and the linguistic argumentation can only have the function as supplementary coordinative argumentation. Linguistic argumentation of this form is often presented in the form of a statement that the formulation of the rule also supports this interpretation or that the formulation of the rule does not form an objection to application in the proposed interpretation. ${ }^{6.7}$

Since linguistic arguments have a 'preferred' status, judges tend to use this form of argumentation as supplementary argumentation for rhetorical

${ }^{6}$ For example, if a judge argues for an a contrario application of a rule, he will put forward a linguistic argument if the formulation of the rule contains a verbal indicator that gives an uncontested indication that the rule is meant as a limitative enumeration of the conditions for applying the rule.

7 This form of linguistic argumentation may occur also in cases in which there is no discussion about the interpretation of a vague or evaluative term but there is still a difference of opinion about the exact interpretation that must be given of a rule on the basis of the question whether in the context of a specific case (and similar cases) a particular formulation used in the rule must be given a particular meaning or not. In such cases the same applies as in the case of a vague of evaluative term: the meaning must be established on the basis of systematic or teleological argumentation and cannot be based on linguistic considerations alone. 
reasons to increase the acceptability of their decision for the legal audience. The linguistic argument must increase the acceptability by showing that on other grounds it can also be asserted that the decision is coherent with common starting points. ${ }^{8}$

(3) A linguistic argument is presented in a context in which it is overruled by another argument

In hard cases linguistic arguments can be used also in a context in which it is asserted that the rule must not be applied in the literal meaning because such an application would be unacceptable from the perspective of the goal of the rule as intended by the legislator. ${ }^{9}$ In such a context the linguistic argument is used to show that the linguistic argument has been considered and could be an acceptable justification, but it is argued that this argument must be "overruled" by other arguments such as systematic arguments, teleological arguments, or arguments from reasonableness. These arguments are a necessary part of the argumentation as pro-arguments to justify that the rule must be applied in a broader or more restricted meaning in a particular case. Normally, if there would be no reason to question the applicability because the concrete case belongs to the standard range of application of the rule, the argumentation could consist of linguistic argumentation of (I). However, for the concrete case the judge may argue that there are overriding reasons not to apply the rule in the strict literal meaning but in another meaning including an exception for the concrete case.

When a linguistic argument is presented in a context in which it is overruled by another argument it is acceptable if:

\footnotetext{
${ }^{8}$ In terms of Van den Hoven (2007) who calls this use of linguistic arguments the "negative use" of linguistic argumentation the strategic maneuvering implies that the judge tries to show that it is not necessary to change the legal system for the concrete case but that the concrete decision was already (implicitly) included in the legal system.

${ }^{9}$ In Dutch civil law this use of linguistic arguments in a context in which the linguistic argument is overruled by other arguments often occurs when it is argued that a "billijkheidscorrectie", an exception for the concrete case on the basis of fairness, is necessary. See Feteris (2007).
} 
(3a) The linguistic argument is put forward in the context of a case in which there are other arguments that overrule the linguistic argument on the basis of the weight attached to them

(3b) The linguistic argumentation refers to the accepted standard meaning of (a term used in) the rule

This form of linguistic argumentation is often used when someone argues in favor of an exception to a rule about which there is no discussion about the correct interpretation of the rule, but where it is argued that on the basis of the unacceptable consequences of a literal interpretation from the perspective of justice and fairness an exception to the rule must be made for the concrete case. ${ }^{10}$

\subsection{Analysis and evaluation of strategic maneuvering with linguis- tic arguments}

In this section I discuss two examples of strategic maneuvering with linguistic arguments from Dutch civil law on the basis of the distinction between the different forms of using linguistic arguments in the different discussion con-

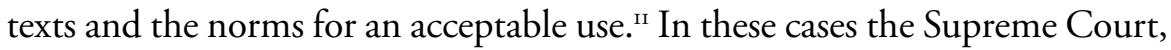
in pragma-dialectical terms, gave a negative evaluation of the strategic maneuvering of one of the parties with linguistic argumentation. ${ }^{12}$ I specify how the examples can be analyzed in terms of the first and second form of using linguistic argumentation and I explain how the norms specified in section 22.2 can be used to determine when the strategic maneuvering with linguistic argumentation is acceptable and when it derails. I do this by explaining how the evaluation of the Supreme Court can be translated in terms of derailing strategic maneuvering.

Parties in a legal dispute often present a linguistic argument as an independently sufficient justification. As we have seen, in easy cases if the conditions for the first form are met, it is a perfectly sound way of justifying a legal decision. However, the strategic maneuvering with linguistic argumentation may derail because one or more of the conditions for an acceptable

\footnotetext{
${ }^{\text {IO }}$ For a discussion of this form of complex argumentation see Feteris (2005, 2008).

${ }^{\text {II }}$ For the text of these examples in the original version in Dutch and in an English translation see the texts attached at the end of this chapter.

${ }^{12}$ Both examples are given by Smith (2007).
} 
use of a specific form of using linguistic argumentation is not met. Sometimes parties in a legal dispute present a particular interpretation of the rule as the accepted standard interpretation of the rule although this is not the case and condition $(\mathrm{Ib})$ of the first form is not met. In such a case the strategic maneuvering derails because in doing so the party violates the starting point rule because a particular meaning of the rule is wrongly presented as a common starting point in the legal community.

Starting with presenting a particular interpretation as the accepted standard interpretation, a party may claim that the linguistic argumentation based on the formulation of the rule may serve as an independent justification. As we have seen, in cases in which the conditions of the first form are met, this is a perfectly sound way of justifying a legal standpoint. However, if the interpretation of the formulation of the rule is not the accepted standard interpretation, the linguistic argumentation can never function as an independent justification and other arguments are required to justify the application of the rule. In such cases a linguistic argument cannot constitute an independently sufficient argument. For this reason, if a party or a judge presents the formulation of the rule as an independent justification in a case that does not meet condition (Ia) for the first form, the strategic maneuvering derails. In such a case the 'preferred' status of linguistic argumentation is misused by presenting the argumentation as an adequate justification whereas it does not meet condition (Ia) of the first form but must be reconstructed as argumentation of the second form which would have been the correct form. By doing so, someone evades the burden of proof for the necessary supplementing coordinative argumentation referring to the legal system and/or goal of the rule (that form a necessary supplement of the linguistic argumentation of the second form) and the strategic maneuvering constitutes a violation of the burden of proof rule.

In what follows I discuss two examples of this complex form of strategic maneuvering that both consist of a combination of these two forms of strategic maneuvering that both derail because two discussion rules are violated.

The first example is from a discussion in Dutch law about the correct interpretation of the term "finding". In the case of Hoge Raad 25 oktober 1996, $R v d W$ 1996, 207, the discussion was about the question whether the activities of a professional car hunter who had found a stolen car, entitled him to a reward for finding the car and to compensation for the costs he had 
incurred in taking care of the car on the basis of the legal regulation for finding lost and unattended objects of clause 5:5 of the Dutch Civil Code.

In this case the plaintiff, the owner of the car, denies the right of the defendant, the car hunter, to compensation for the costs he has made. The plaintiff is of the opinion that the rule does not apply to this case because the acts of the defendant cannot be considered as "finding". In his view, the term finding must be interpreted in the narrow sense, that is, excluding the activities of a professional car hunter. Here the plaintiff presents linguistic argumentation referring to the meaning of the word "finding" as independently sufficient justification.

However, the District Court, the High Court and the Supreme Court are of the opinion that the rule is applicable to the concrete case in the broad meaning of "finding". This broad meaning includes also the activities of a professional car hunter who has been looking for the car. The Supreme Court is of the opinion that the interpretation of the word "finding" must be based on a combination of teleological argumentation (supported by argumentation based on the discussion about the rule in parliament) and linguistic argumentation. The Supreme Court is of the opinion that the meaning of the rule (which is of a relative recent origin) must be established on the basis of the purpose, the legal ratio, of the rule that can be found in the parliamentary documents: "The purport of clause $5: 5 \mathrm{ff}$., as becomes clear from the history of the enactment of the rule, can be summarized as follows: the intention of the legislator was to promote that someone who has lost an object will, as much as possible, be capable of finding the object, and in case the person who has lost the object does not show up, to provide a solution that makes it possible to bring the object into circulation within the not too distant future or make it possible that the object can be used again" (see the text of the decision attached at the end of this chapter). The purpose was to promote that a lost object is returned to its rightful owner as soon as possible, in any case is brought back as soon as possible into circulation or is used again. According to the annotator, HJs, the idea of the Supreme Court is that the ratio of this rule is served by such a broad interpretation that is also linguistically correct. So, in this case, according to the Supreme Court the ratio of the rule must be considered as the main argument in support of the decision to apply the rule (in the broad meaning of "finding") in the case at hand. This argument is supplemented by the consideration that the linguistic meaning of find- 
ing does not form a counter-argument against application in this broad sense.

From our perspective this decision forms an example of a case in which the strategic maneuvering by the party derails. First, it constitutes an instantiation of derailing strategic maneuvering because condition $(\mathrm{Ib})$ is not met. The proposed literal meaning of "finding" in a narrow interpretation is wrongly presented as the accepted standard meaning of the term "finding" in clause 5:5, because the term must be interpreted in a broader sense that includes also the activities of a professional car hunter. Second, it constitutes an instantiation of derailing strategic maneuvering because condition (Ia) is not fulfilled. The linguistic argument in favor of a narrow interpretation of the term "finding" cannot constitute an independently sufficient justification. The Supreme Court argues that also the intention of the legislator (which supports a broad interpretation of "finding") must be taken into account. In the view of the Supreme Court the teleological argument referring to the goal of the rule constitutes a necessary element of the argumentation. The Court points to the fact that the intention of the legislator to promote that the object is brought back into circulation is also in accordance with the meaning of the term "finding" in the broad sense as used in the rule.

The second example of strategic maneuvering with linguistic argumentation can be found in the discussion in Dutch law in a case called "Samesex marriage" about the application of the old article i:33 of the Dutch Civil Code, that says that: "A man can, at the same time, be married only to one woman and a woman can, at the same time, be married only to one man" (in the Dutch text the expression "one" can mean "a" as well as "one", which is the basis of the discussion in this case). In this case a civil servant refused to marry a female homosexual couple on the basis of this article. However, the plaintiffs state that the text of this article does not forbid a marriage between two women because it only says that one man can only marry one woman with the stress on the formulation "a" interpreted as "one" and hence must be interpreted as a prohibition of polygamy. The judge of first instance, the judge in appeal and the Dutch Supreme Court (Hoge Raad I9 oktober 1990, RvdW I990, I76) decide that "the claim departs from a reading of various articles that is in itself already wrong and it ignores the purpose of the law the legislator had in mind when formulating the rules of Book I of the Civil Code, also in light of the preceding legislation" (see the text of the decision attached at the end of this chapter). ${ }^{13}$ 
From our perspective it is an interesting example of a case in which the strategic maneuvering by the party derails. First, as in the previous example, it constitutes an instantiation of derailing strategic maneuvering because condition ( $\mathrm{Ib}$ ) is not fulfilled. The proposed literal reading of "a man" and "a woman" in clause $\mathrm{I}: 33$ is wrongly presented as the only possible reading because there is also another reading; i.e., the accepted standard reading. The Supreme Court states that the other reading implies that the article must be read in the standard reading as forbidding a same-sex marriage so that the given interpretation is incorrect. Furthermore, it constitutes an instantiation of derailing strategic maneuvering because condition (Ia) is not fulfilled. The linguistic argument can never be the only argument because, according to the Supreme Court, in establishing the meaning of a rule the legislative history of the rule and the goal of the rule as intended by the legislator must also be taken into account, so the argument could never serve as an independent justification. With the formulation "miskent de strekking van de wet" (ignores the purpose of the rule) the Supreme Court indicates that the purpose of the rule as it is based on the legislative history is a necessary element of a justification of the interpretation of the meaning of a rule.

In both examples the combination of the violation of the starting point rule and the violation of the burden of proof rule can be considered as a specific form of derailing strategic maneuvering. The derailment consists of a combination of two violations. The first violation implies that a particular interpretation of the meaning of the rule is wrongly presented as the only correct interpretation. Starting from this incorrect interpretation the second violation implies that certain information (the goal of the rule as intended by the legislator) is wrongly ignored and is not included in the argumentation

13 In this case the lower judges and the Supreme Court put forward also additional argumentation in which they react to other arguments put forward by the plaintiff in which they discuss the argument by the plaintiff that the views in society about same-sex relations have changed since the enactment of the law. The courts make clear that in certain matters, such as the present one that concerns the public sphere where legal certainty plays an important role, it is not the task of the judge to change the meaning of a rule by departing from the goal of the rule as intended by the legislator on the basis of changing views in society. The Supreme Court argues that it is not the task of the judge to decide against the clear meaning of the rule about marriage, since abolition of the prohibition to marry for same-sex couples would have far-reaching consequences. 
so that the burden of proof for this information is evaded. In the evaluation of the Supreme Court we see that both mistakes are assessed individually as mistakes in the context of a rational discussion about the application of legal rules. The violation of the starting point rule is characterized as departing from a "disputable literal reading of statute law" (gaat uit van een aanvechtbare letterlijke lezing). The violation of the burden of proof rule is characterized as a "misunderstanding of the law as the legislator had in mind when enacting it" (miskent de strekking van de wet zoals men die bij haar totstandkoming voor ogen heeft gehad). ${ }^{14}$ The combination of the two forms of strategic maneuvering can be considered as a complex form of strategic maneuvering in which the second builds on the first form so that the combination can be considered as subordinate.

\subsection{Conclusion}

In my contribution I have made a first attempt to reconstruct the strategic maneuvering with linguistic arguments in a discussion about the application of a legal rule in a concrete case in the context of a court of law. I have explained how the legal norms can be translated in pragma-dialectical terms to explain why certain forms of strategic maneuvering with linguistic arguments in this activity type are acceptable and when the strategic maneuvering derails.

By distinguishing three forms of the use of linguistic argumentation I have tried to give a systematic and precise description of the various ways in which linguistic argumentation can be used and on the basis of the translation of the norms I have shown how it can be explained why certain forms of strategic maneuvering with a particular use are acceptable and other forms derail.

In the analysis of some examples from Dutch law I have demonstrated how the framework for evaluating the soundness of strategic maneuvering

${ }^{14}$ In the discussion about "finding" the Supreme Court claims that the High Court has not departed from a wrong conception of law ("heeft niet blijk gegeven van een onjuiste rechtsopvatting”). This is a specific legal expression used to indicate that a lower court has made a mistake in giving a wrong interpretation of the law. In this context the Supreme Court refers to this kind of mistake because the party that has asked the Supreme Court to correct the decision has put forward as a reason for the necessity of correcting the decision (the mistake presented as the "cassatiegrond") that the Court has departed from a wrong conception of the law in giving a broad interpretation of the term "finding". 
can be used in explaining why certain ways of using linguistic argumentation in a particular context are unacceptable and constitute a derailment of strategic maneuvering. I have explained that the strategic maneuvering with linguistic argumentation often takes the form of a complex of strategic maneuvers that are mutually dependent and each form a violation of a discussion rule.

\section{Example I}

Hoge Raad 25 oktober 1996, no. 16074 RvdW 1996, 207

(...) 3.3.I Bij de beoordeling van onderdeel I, dat de vraag aan de orde stelt wat moet worden verstaan onder "vinden" in art. 5:5 moet het volgende worden vooropgesteld. De strekking van art. 5:5 e.v., zoals deze uit de geschiedenis van de totstandkoming van deze bepalingen naar voren komt, laat zich aldus samenvatten dat daarmee beoogd is te bevorderen dat degene die de zaak verloren heeft, haar zo veel mogelijk zal kunnen terugvinden, en voor het geval de verliezer niet meer komt opdagen een oplossing te geven, welke mogelijk maakt dat de zaak binnen afzienbare tijd weer in het rechtsverkeer wordt gebracht of in gebruik genomen (Par. Gesch. Boek 5, Inv. 3, 5 en 6, p. I008). Met die strekking strookt het begrip vinden in art. 5:5 in overeenstemming met zijn taalkundige betekenis, in ruime zin uit te leggen. Daarmee zou slecht te verenigen zijn dat zou moeten worden aangenomen dat niet van vinden sprake is, indien de zaak niet bij toeval is ontdekt, maar daarnaar is gezocht en handelingen zijn verricht die als het opsporen daarvan kunnen worden beschouwd. (...)

\section{English translation:}

Supreme Court of the Netherlands October 25, 1996, no. I6074 RvdW I996, 207

(...) In the evaluation of part $\mathrm{I}$, which introduces the question of the exact meaning of "finding" in clause 5:5, the following must be assumed. The purport of clause 5:5 ff., as becomes clear from the history of the enactment of the rule, can be summarized as follows: the intention of the legislator was to promote that someone who has lost an object will, as much as possible, be capable of finding the object, and in case the person who has lost the object does not show up, to provide a solution that makes it possible to bring the object into circulation within the not too distant fu- 
ture or make it possible that the object can be used again (Parliamentary History, Book 5, 3, 5, 6, p. 1008). It is consistent with this purport to interpret the concept of finding in clause 5:5, in accordance with its linguistic meaning, in the broad sense. It would be inconsistent with this purport to assume that the rule would not be applicable if the object would not be discovered by accident, but when the person who has found the object would have been looking for it and would have developed actions which can be considered as tracing/hunting the object. (...)

\section{Example 2}

\section{Hoge Raad I9 oktober 1990, no. 7649 NJ 1992/129}

(...) Die stelling (de stelling dat de tekst van de Nederlandse wet een huwelijk tussen twee vrouwen niet verbiedt en dat die tekst in het licht van de maatschappelijke ontwikkelingen zo moet worden uitgelegd dat zo'n huwelijk toelaatbaar is $\mathrm{EF}$ ) kan niet als juist worden aanvaard. Zij gaat uit van een reeds op zichzelf aanvechtbare letterlijke lezing van een aantal wetsartikelen en miskent de strekking van de wet zoals men deze bij de totstandkoming van Boek I BW, mede in het licht van de daaraan voorafgaande wetgeving, voor ogen heeft gehad. Ook indien latere maatschappelijke ontwikkelingen steun zouden geven aan de opvatting dat het niet openstaan van de mogelijkheid van een wettelijk huwelijk tussen twee vrouwen of twee mannen niet langer gerechtvaardigd is, zou dit niet een van de onmiskenbare strekking van de wet afwijkende wetsuitlegging wettigen, te meer niet nu het hier gaat om een onderwerp dat de openbare orde raakt en waarbij de rechtszekerheid een belangrijke rol speelt. (...)

\section{English translation:}

Supreme Court of the Netherlands October 19, I990, no. 7649 NJ 1992/129

(...) This claim (the claim that the text of the Dutch law does not forbid a marriage between two women and that this text must be interpreted in the light of the developments in society that would support the view that such a marriage is allowed (EF) cannot be accepted as correct. This claim departs from a reading of various articles that is in itself already wrong and it ignores the purpose of the law the legislator had in mind when formulating the rules of Book I of the Civil Code, also in the light of the preceding legislation. If later developments in society would also support the opinion that the impossibility for two women or two men to marry is no 
longer justified, this would not justify an interpretation of the law that departs from the clear purpose of the law, because it concerns also a subject matter that concerns the public order where legal certainty plays an important role. (...)

\section{References}

Eemeren F.H. van and P. Houtlosser (2002a). Strategic Maneuvering: Maintaining a Delicate Balance. In: F.H. van Eemeren and P. Houtlosser (Eds.), Dialectic and rhetoric. The Warp and Woof of Argumentation Analysis (pp. I3I-I60). Dordrecht etc.: Kluwer. Eemeren F.H. van and P. Houtlosser (2002b). Strategic Maneuvering with the Burden of Proof. In: F.H. van Eemeren (Ed.), Advances in Pragma-dialectics. (pp. 13-28) Amsterdam: Sic Sat/Vale Press.

Eemeren F.H. van and P. Houtlosser (2003). A Pragmatic View of the Burden of Proof. In: F.H. van Eemeren et al. (Eds.), Anyone Who has a View. Theoretical Contributions to the Study of Argumentation (pp. I23-132). Dordrecht etc.: Kluwer.

Eemeren F.H. van and P. Houtlosser (2006). Strategic Manoeuvering: A Synthetic Recapitulation. Argumentation I6 (3), 349-367.

Feteris, E.T. (2002). A Pragma-dialectical Approach of the Analysis and Evaluation of Pragmatic Argumentation in a Legal Context. Argumentation I6 (3), 349-367.

Feteris, E.T. (2004). Zijn de onuitgesproken vooronderstellingen, uitgangspunten en vanzelfsprekendheden in het argumenteren in het burgerlijk recht het leem in de voeten van de reus? Nederlands Tijdschrift voor Rechtsfilosofie en Rechtstheorie 33 (I),43-46.

Feteris, E.T. (2005). The Rational Reconstruction of Argumentation Referring to Consequences and Purposes in the Application of Legal Rules: A Pragma-dialectical Perspective. Argumentation I9 (4), 459-470.

Feteris, E.T. (2007). A Normative Reconstruction of Arguments from Reasonableness in the Justification of Judicial Decisions. F.H. van Eemeren, J.A. Blair, C.A. Willard, B. Garssen (Eds.), Proceedings of the sixth conference of the International Society for the Study of Argumentation (pp. 393-398). Amsterdam: Sic Sat.

Feteris, E.T. (2008a). The Rational Reconstruction of Weighing and Balancing on the Basis of Teleological-evaluative Considerations in the Justification of Judicial Decisions. Ratio Juris 2I (4), 482-496.

Feteris, E.T. (2008b). Strategic Maneuvering with the intention of the Legislator in the Justification of Judicial Decisions. Argumentation 22 (3), 335-353.

Groenewegen, F.T. (2007). De relatieve waarde van de grammaticale interpretatiemethode. In: E.T. Feteris, H. Kloosterhuis, H.J. Plug and J.A. Pontier (Eds.), Alles afwegende ... Bijdragen aan het vijfde symposium juridische argumentatie (pp. 239-244). Nijmegen: Ars Aequi. 
Hoven, P.J. van den (2007). Commentaar bij F.T. Groenewegen. In: E.T. Feteris, H. Kloosterhuis, H.J. Plug and J.A. Pontier (Eds.), Alles afwegende ... Bijdragen aan het vijfde symposium juridische argumentatie (pp. 245-248). Nijmegen: Ars Aequi.

MacCormick, N. (2005). Rhetoric and the Rule of Law. A Theory of Legal Reasoning. Oxford: Oxford University Press.

Smith, C.E. (2007). Enkele varianten van taalkundige argumentatie. In: E.T. Feteris, H. Kloosterhuis, H.J. Plug and J.A. Pontier (Eds.), Alles afwegende ... Bijdragen aan het vijfde symposium juridische argumentatie (pp. 249-256). Nijmegen: Ars Aequi.

Soeteman, A. (2007). Commentaar bij C.E. Smith. In: E.T. Feteris, H. Kloosterhuis, H.J. Plug and J.A. Pontier (Eds.), Alles afwegende ... Bijdragen aan het vijfde symposium juridische argumentatie (pp. 257-260). Nijmegen: Ars Aequi.

Vranken, J.B.M. (2004). Verhullend argumenteren in het vermogensrecht. Nederlands Tijdschrift voor Rechtsfilosofie en Rechtstheorie 33 (I), 9-34. 



\section{Contributors}

Bas Andeweg, Delft University of Technology, the Netherlands

b.a.andeweg@tudelft.nl

Lotte Anemaet, Leiden University, the Netherlands

l.anemaet@umail.leidenuniv.nl

Wouter van Atteveldt, vu University Amsterdam, the Netherlands w.h.van.atteveldt@vu.nl

Hilde van Belle, Lessius University College, Belgium

hilde.vanbelle@lessius.eu

Joel Best, University of Delaware, Delaware, UsA

joelbest@udel.edu

J. Anthony Blair, University of Windsor, Ontario, Canada

tblair@uwindsor.ca

Peter Burger, Leiden University, the Netherlands

p.burger@hum.leidenuniv.nl

Pablo Leandro Ciocchini, University of the Basque Country, Spain ciocchini@gmail.com

Marianne Dingemanse mariannedingemanse@gmail.com

Eveline Feteris, University of Amsterdam, the Netherlands e.t.feteris@uva.nl

Marie Formarier, University of Lyon, France

formariermarie@gmail.com

Margot van der Goot, Radboud University Nijmegen, the Netherlands m.vandergoot@maw.ru.nl

Baldwin van Gorp, K.U.Leuven, Belgium baldwin.vangorp@soc.kuleuven.be

Ton van Haaften, Leiden University, the Netherlands t.van.haaften@hum.leidenuniv.nl

Susan Hogben, University of Ulster, Northern Ireland, UK sh.hogben@ulster.ac.uk

Anita van Hoof, vu University Amsterdam, the Netherlands a.m.j.van.hoof@vu.nl 
Anders Horsbøl, Aalborg University, Denmark

horsboel@hum.aau.dk

Henrike Jansen, Leiden University, the Netherlands

h.jansen@hum.leidenuniv.nl

Jaap de Jong, Leiden University, the Netherlands

j.c.de.jong@hum.leidenuniv.nl

Jan Kleinnijenhuis, vu University Amsterdam, the Netherlands

j.kleinnijenhuis@vu.nl

Bart van Klink, vu University Amsterdam, the Netherlands

b.vanklink@rechten.vu.nl

Christian Kock, University of Copenhagen, Denmark

kock@hum.ku.dk

Willem Koetsenruijter, Leiden University, the Netherlands koets@wxs.nl

Manfred Kraus, University of Tübingen, Germany manfred.kraus@uni-teubingen.de

Oliver Lembcke, Friedrich Schiller University of Jena, Germany oliver.lembcke@uni-jena.de

Daniel J. O’Keefe, Northwestern University, Illinois, UsA d-okeefe@northwestern.edu

Cezar M. Ornatowski, San Diego State University, California, UsA ornat@mail.sdsu.edu

Ingrid Persoon, Utrecht University, the Netherlands i.persoon@uu.nl

Ineke Sluiter, Leiden University, the Netherlands i.sluiter@hum.leidenuniv.nl

A. Francisca Snoeck Henkemans, University of Amsterdam, the Netherlands a.f.snoeckhenkemans@uva.nl

Janet Takens, vu University Amsterdam, the Netherlands jh.takens@fsw.vu.nl

Gabry Vanderveen, Leiden University, the Netherlands g.n.g.vanderveen@law.leidenuniv.nl

Lisa Storm Villadsen, University of Copenhagen, Denmark lisas@hum.ku.dk 


\section{Index}

abductive

argument I49, I53

inference license 150,156

order I5I, I57

representation of causality $\mathbf{I} 49$

reversed abductive variant of causal

argument I46

structure I53, I55-I57

Abrams v. United States 31, 32

actio 160

Ad Herennium $134, \mathrm{I} 36$

addressing technique, direct 180

ad-hominem attack 4I3, 4I4

Advertising Standards Authority 27I, 274,

$275,279-283$

aesthetic functionality 196

agora 27

allegory $\quad 189$

allusion 196

ambiguum 82

anacrusis 76

analogy IOI, IO7

figurative $382-384,388$

analysis

visual 275

anaphora 72,74

clause 73

ternary anaphoric pattern 73,75

Andeweg, B.A. I63, 332

anecdote I63, I69, I7I, I80, I8I

Angelo, F. D’ 58

announce

close $\quad \mathbf{I 7 4}$ explicitly last part of speech I8O

main points (of a part) of the speech

173

next topic 173

antecedent I5I-I53, I55

inference license I5O, I53

antiquity $6 \mathrm{I}, 72,77$

classical $26,39,40$

linguistic theories in 62

Roman 42

antiquity, late 5I, 53

antithesis 195, 196

Antonius 62, 70

Aphthonius 53-57

Progymnasmata 53, 55, 58

apodeixis 65, 66

aposiopesis 194

appeal

authority 226, 23I, 233-235, 237

external authority 236

gain-frame II7-I23, I26-I28

loss-frame II7-I28

variation $\mathrm{I} 25$

argument

abductive I49, I53

causal I44-I46, I48, I50, I5I, I53, I55-I57

coordinative $427,428,43 \mathrm{I}$

counter 433

data-based prediction 205

dialectical 99, , 08

defective IO2

dramatic $2 \mathrm{I} 4$

from reasonableness 429 
global warming 205

good 102

linguistic 423-426, 428-430, 435

rhetoric-argument relation 97, 98, 108

subordinative 427

supplementary 427,428

symptomatic I45, I46, I48, I5O, I54-I57

systematic $426,427,429$

teleological 426-429, 432, 433

valid IO4

argumentation

everyday 404

expert 397-399, 402-404

lay 396

scheme I45, I46, I48

visual 275

argumentative scheme 374,388

Aristotle 35, 50, 65-67, 69, 70, 77, 95, 96,

99, 100, 108, 195, 220, 222, 223, 230, 236,

272, 273, 285, 293, 4I7

definition of rhetoric 376

dimension of ethos 224, 236

distinction 228

frame 228

model 223

notion of ethos 222

Rhetoric 95, 195, 222, 396

asyndeton 195

attack

ad hominem 4I3, 4I 4

personal 420

attack, personal 358,363

attentum parare $\mathrm{I} 63, \mathrm{I} 68, \mathrm{I} 73, \mathrm{I} 74$

attentum technique I69, I7I, I74, I75

Attic

Atticism 52, 53

authors 52 democracy 55

style 52

Behnke, T., Danish Conservative Party's spokesperson on matters of national defense $4 \mathrm{I} 3$

Bekius, W. I85

benevolence technique. See benevolum technique

benevolum parare 163, I68, I73

benevolum technique I7I, I75, 332

Benoit-Barne, C. 416, 417, 420

Berlin, Isaiah

value pluralism 88

bias

negativity II8, II9, I22, I23, I26-I28

Blair, J.A. 275

Blair, T. 308-316, 32I-323

rhetoric of exception 309

blame the victim 252

Blocher, J. 38

Bos, W., Deputy Prime Minister 133

Bourdieu, P.

game terminology 362

sociological analysis of the political field 36I

Braet, A. 107, 165

Brandeis, J. 33, 39, 43

bridge $\mathrm{I} 73$

Brietzke, P. 34

burden of proof $236,425,43 \mathrm{I}$

evasion of I4I

violation 43I, 434, 435

Burke, M. et al. 220, 224

Burke, K. 95, 96, 99, 195, 292-294, 297, 303

distinction between tragic and comic

frame $4 \mathrm{I} 8$

Pentad of Act, Agent, Agency, Scene, 
and Purpose 294, 301, 302

terminology 409

cadence 77

caldron 2I4

Calvinist Party. See SGP

Campbell, G. 99

causal I44

effect I49, I53, I55, I57

argument I44-I46, I48, I50, I5I, I53,

I55-I 57

argumentation scheme I45, I46, I48

connection $\quad$ I47

noncausal inference I49

order $\mathrm{I} 48, \mathrm{I} 49, \mathrm{I} 5 \mathrm{I}$

real-world $149 \mathrm{ff}$.

reductio ad absurdum $\quad 156$

relation $\mathrm{I} 47, \mathrm{I} 48, \mathrm{I} 5 \mathrm{O}, 384,388,389$

reversed abductive variant of causal

argument I46

reversed variant of causal argument I52

structure I55, I57

censorship I88, I89

Cerulo, K.A. $2 \mathrm{I} 4$

Chaiken, S. II8, II9, I22, I24, I27, I28

Cicero 42, 62-64, 66, 68-72, 77, 95, I09,

174, 332, 397

De Inventione 66

De Oratore 62, 70

myth of origin 42

On invention 42

circle technique $176, \mathrm{I} 77, \mathrm{I} 8 \mathrm{O}$

claim

authoritative data-based 205

counter 204-206, 208, 209, 2I2, 2I5

future 204, 206, 208, 210-212, 214, 216

predictive 203, 204, 206, 208, 210, 2I4, $2 \mathrm{I} 6$ present 206

trend-based 205

claims

truth $272,275,279,283$

Clinton, B., former President 90

closing technique 165

смс. See computer-mediated

communication

cognitivism IO5

Cohen, A. 292, 293

collective identity 294

column I85-I88, I95, I96, I98

historical context of column writing

I86, I88, I89

newspaper 185 , 195

commonplace

expression $\mathrm{I} 8 \mathrm{O}$

communicative activity type 359,366

dialectical aim 359, 360

rhetorical aim 359

comparison 196

compliment I72, I80, 231, 233-236

computer-mediated communication 222 ,

224

confirmation 58

connotation 282,283

consequent I5I, I52

controversiae 53

conversation analysis 225

Dales, I., former Dutch Minister of the

Interior 159

De Juana Chaos 320, 321

debate

a-rhetorical debate culture 420

contemporary Danish political 4I4

dialectical aspect of $36 \mathrm{I}$

political 4I5-4I7 
public 4I4, $4 \mathrm{I} 6$

public political 409

tragic frame of 409

debate, Dutch parliament 349, 350, 358, $363,365,366$

as a communicative activity type 358 , $360,362,366$

polarisation 365

debate, parliament 359, 36I

as a communicative activity type 362 ,

364

institutional goal 360, 36I, 363

strategic maneuvering 362

declamation 49

judicial 53

deduction 96,97

formal deductive logic I04

formal deductive systems IO4

valid arguments IO4

validity IOS

Defoe, D. 189

Degand, L. I48, I49

deliberation

democracy $407,414,417,418$

public, 4I4, 420

Demosthenes 52,55

detection

behavior I24-I26

disease I23, I26

disease detection behavior I2I, I24, I26, I28

early detection behavior I25

message 126

dialectic 96, IOO-IO2, IO4, IO6-IO8

dialectical

aim 359,360

argument 99, IO2, IO4, I08 argumentation as a dialectical activity

IO3

aspect of the debate $36 \mathrm{I}$

constraint of being reasonable $\mathrm{IO} 3$

fallacy 107

ideal 349

norm 108

perspective 107

property 100

rationality IO4

reasonableness norm 424

standard of reasonableness 359,362 , 366

strategy 367

Diamond, J. 215

Dionysius of Halicarnassus 5I, 6I-63

discourse 225, 228, 230, 232

argumentative $358,359,363,424$

deliberative 220

ethos in 228

legal 423

meta- 40

political 37,417

psychology 222, 224, 225, 227, 230

public 40

public, Danish 407

discussion

critical legal 424, 425

legal 425

strategy 357,358

sub- $351,352,358,359,363$

discussion rule

violation of 436

discussion, online

drink spiking 220-222, 225, 227, 231,

234-237

ethos 220 
ethos aspect 220

ethos technique 220, 237

dispute

legal 430, 43I

docilem parare I63, I68, I72, I73

docilem technique 172,176

Donkers, H. $\quad$ I86

doxa $4 \mathrm{I} 7$

ecopornography 274

Eemeren, F.H. van IO2-IO4, I36, I45-I47, $350,359,424$

ellips I8o

eloquence $42,49,6$ I, 69

political 6I, 62

rhetoric and dramatic $7 \mathrm{I}$

energeia 195

epistemic

authority 227

causally based epistemic relation $\mathbf{I 4 9}$

force 276

noncausal epistemic relation I49

term 227

Espersen, S., member of the Danish People's

Party 4I3

ethnomethodology 225

ethos 65, 66, 68, 77, I40, 187, 196, 197, 219-

224, 226-228, 230, 232, 272, 273, 279,

283,379

ancient 272

arête 223, 272, 273

Aristotelian dimension of 224, 236

Aristotelian notion of 222

aspect of online discussion 220

device 227

element $\quad$ I87

environmental 27I, 283-285

eunoia 223, 272, 273 everyday 219

expertise 223, 230, 23I, 233-235

good will 223, 230, 23I, 236

goodwill 272, 283, 284

knowledge. See expertise

model 223, 230, 236

of the author $\quad$ I87

phronesis 223, 272, 273, 279, 284

practical wisdom 272, 283

technique 220, 222, 225, 227, 232-237

virtue 223, 230, 23I, 236, 272, 284

euboulia 30

example I77, I80, I8I

concrete $\mathrm{I} 63$

exclamation 358

exemplum. See example

exercises, rhetorical 54

chreia 54

commonplace 54

comparison 54,58

confirmation 54,56

description 54,56

encomium 54-56

ethopoeia 54

fable 54

maxim 54

narration 54,56

refutation 54

thesis 54

vituperation $54,55,58$

exordium

model I63

expression $\quad \mathbf{I} 77$

commonplace $\mathrm{I} 80$

visual 275

Fahnestock, J. I93-I95

fallacy I07, I34, I4I, I86, 424 
straw man $8 \mathrm{I}$

feuilleton $\quad 189$

First Amendment Theory 39

flatter $\mathrm{I} 72, \mathrm{I} 76$

FOAF. See friend-of-a-friend

folklore 22I, 228

legend 236

study 224,228

Forst, B. 264

Fortuyn, P., leader of LPF $335,337,338$, 340,344

frame 26, 33, 4I, II7, II8, I2O-I22, I24, I25, I28, 24I, 244, 245, 256, 257, 259, 266,

$374,375,388,407,419,420$

and figurative analogy $382-384,388,389$

as a meta-communicative message 375

as a simplifying model 384,388

as a tool kit 374

as simplifying model 382

audience-directed, of argumentative

move 359, 36I

Burkean distinction between tragic and

comic $4 \mathrm{I} 8$

change of $\mathrm{II} 8$

conceptual 3I

constructionist tradition $374,376,386$, 388

core 376,377

cultural resonance 376,385

culturally embedded 375

device $245,252,376,377,383$

economic 43

explanatory I24, I27, 24I, 245

free speech 42

gain- and loss-framed message II8, I2O,

I24, I26

gain-frame II7-I28 gain-loss message frame II8

gain-loss message framing research II7, II8

inductive analysis 376,377

loss-frame II7-I28

macro level 375

matrix 376

mono-dimensional 262

of the market 26

of the marketplace of ideas 34,37

of victims and offenders 242

package 376,377

Popular Virgin 24I, 258

process 375,389

research $374,376,389,390$

stereotype 266

sustainable agriculture and food 373 ,

$377,378,381,382,384,385,388,389$

textual device 377

traditional marketplace 37

Wolf in Sheep's Clothing 24I, 258, 259

framework 294, 30 I

rhetorical 294

Geisler, C. 408

Geoffroy, J.L. I89

Glasser, T.L. 247

Gorgias, theory of the dominance of the passive psychè by the active logos 70

green spin 274

greenwashing 274

Grootendorst, R. I45, I46

Guibernau, Montserrat 293, 297

Hauser, G.A. 99-IOI, 4I6, 4I7, 420

Hermogenes of Tarsus 52

Hill, C.A. 276

Hirsi Ali, A. 4I

Hodge, R. 276 
Holloway/Van der Sloot case 24I, 242, 244, Jensen, N.D., CEO of the Grundfos

$246,249,264,267$

Holloway, N. 242, 243, 245, 249, 252, 254

Sloot, van der, J. 24I-244, 249, 253, 254, 258, 26I-266

Holmes, O.W. 3I-33, 36, 39

Homer, epic 52

Horsfield, B. 330, 33I, 333

Houtlosser, P. IO2-IO4, I36, I45-I47, 424

Hyde, G.M. $\quad$ I86

hyperbole 196,358

hypotyposis I9I

identification 25I, 252

image

metaphor 282

vivid information $276,28 \mathrm{I}$

incantation 73

incommensurability 88

induction 96

inductive

frame analysis 376,377

inference license $150 \mathrm{ff}$.

infotainment 247,248

Ingber, S. 36, 37

innuendos 189

introduction

ministerial speech $159,163,168,169$,

I7I, I73, I79

speech I63-I66, I68, I73

technique I64, I66, I69, I7I

inventio 408

irony 139

Isocrates 52, I09

Ivie, R.L. 4I8, 4I9

Jansen, H. I44

Jenkins, P. 215
Corporation 409, 4I2-4I4, 4I6, 4I7,

4I9

Jensen, K., Danish Liberal Secretary of

Taxation $4 \mathrm{I} 2$

Jensen, J.D. II9, I2I, I22

Johnson, R.H. IO2-IO4

Jong, de J. I63, I77, 332

Kahneman, D. $\quad$ I24

kairos $4 \mathrm{I} 3$

Khader, N., leader of the Danish libertarian party New Alliance $4 \mathrm{I} 2$

Kjær, H., Danish Conservative party political spokesperson $4 \mathrm{I} 2$

Kjærsgaard, P., leader of the Danish People's Party 4II

Kock, C. 99, IOI, I05, I06

koiné, style 52

Kress, G. 276, 278

Kussendrager, N. I86

Leefbaar Nederland, Dutch conservative liberal party 335

Leff, M. I08, I09

legend 22I, 227-230

crime 220, 22I, 227

folk 236

urban 219, 221, 236

Lemke, J.L. 274

Libanius 53, 54, 56

literacy, visual 272

loci

of invention of collective identity 304

locis communis 294, 297

logic 97, I02, I04, I05, I07-109, 190

and dialectic 106-108

as a tool of rhetoric IOS

formal 190 
IN DEX

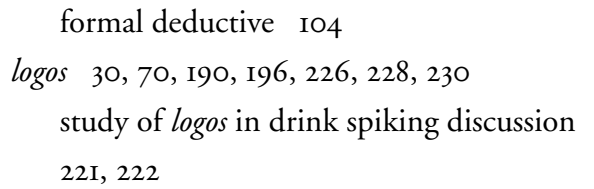

LPF, Dutch anti-immigration party 335, $341,342,344,345$

Lugt, D. van der 186

Lysias 52

marketplace of ideas 36

Mayan

calendar 203, 2IO, 2I2, 2I4

prediction 210

Mazzoleni, G. 329, 33I, 333

McQuarrie, E.F. 275

mental construct 375

meta-discussion. See sub-discussion

metaphor I64, I69, I77, I80, I8I, I94, I95,

$28 \mathrm{I}$

of the marketplace of ideas 3I, 33

Metz, W. I85

Meyer, M. 97, 98

Meyerowitz, B.E. II8, II9, I22, I24, I27, I28

Mill, J.S. 3I

mimesis $68,7 \mathrm{I}, 72$

$$
\text { emotional } 67,68,70
$$

Mitchell, T. 275

modality $272,275,277,280,283,284,398$, 403

monologue 230

public 224

myth, urban 227

myths, pagan 56

Napoleonic press 189

narrative 22I, 228, 23I, 235, 245, 247, 248,

$252,262,263,267,377$

construct authority within 228

historical 295 journalism 247

news as 242,247

of national history 297

police 248

script 248

technique 170

theory 245,247

third-person 229

non-cognitivism IO5

O'Keefe, D.J. I2I

Obama, B. 72-77

Victory Speech, 72, 77

voice 73,76

ocultatio $\quad \mathrm{I} 37$

offender 25I, 252, 263

Olbrechts-Tyteca, L. 89, 97, I00, I37, 190192, 195

Traité de l'Argumentation Ioo

Oring, E. 227-230, 236

Otto, C. 247

Pander Maat, H. I48, I49

paralipsis $\mathrm{I} 34$

parallelism 358

Partij voor de Vrijheid. See PvV

partitio $\quad \mathrm{I} 73$

partition 173

Party for Animals, The, Dutch party 335

Party for Freedom. See PvV

pathos 65, 66, 68, 77, 192, 196, 197, 228,

273

pattern

dactyl 76

moloss 77

of Latin 62

peon 76

rhythmic 76

spondee 76 
ternary anaphoric 73,75

trochee 76

Pechtold, A. 4I, 42

pedagogy 62

Perelman, Ch. 89, 97, I00, I04, I05, I37, 190-192, 195

Traité de l'Argumentation 100

peroratio

model 165

peroration

model. See peroratio model

Philips, B.J. 275

phronesis $4 \mathrm{I} 7$

Plain Language Award 350

Plato 27, 28, 30, 67

Protagoras 28

political

debate 409, 4I5-4I7

discourse $4 \mathrm{I} 7$

relation as deliberation-based $4 \mathrm{I} 7$

political, Dutch, culture $349,364,365$

polylogue 230

free-for-all 224

polysyndeton 195

populism $327,328,33 \mathrm{I}-334,336,338$,

$339,342-345$

as communication style $33 \mathrm{I}$

as political ideology 33I, 332

populist rhetoric

criticism of the political elite 328,332 ,

$333,338,342-344$

reference to "the people" $328,33 \mathrm{I}-333$,

$338,342,344$

Potter, J. 227, 229

praeteritio I33-I38, I4O, I4I

as a form of irony 139

pragma-dialectical I45, 423, 424, 426, 430,
435

analysis of the reductio ad absurdum I43

definitions I45

extended, argumentation theory 358

school 89

theory 146

threefold I44

praise 172,176

praxis 198

hermeneutic 198

presentation I44, I45, I48, I49, I5I-I53, I56,

I57

presentation mode 148 , I5I

presenting one as credible $\quad \mathrm{I} 72$

preterition. See praeteritio

prevention

behavior I24-I26

disease $\mathrm{I} 23, \mathrm{I} 26$

disease prevention behavior I2I, I24,

I26-I28

message $\quad$ I26

Prime Minister, Danish 4II-4I3, 4I9

Progymnasmata 49, 54

Aphthonius 53

prolepsis IOI

prooemium 54

prospect theory I24, I25, I27, I28

Protagoras 28-30, 42

myth about the origins of human

civilization 28, 29

PVV 349, 35I, 353-357

PVV, Dutch anti-immigration party 335

Quintilian 53, 62-64, I74, I76

pedagogy 62

Quintilianus, Aristides 67

Ramist

position IO2 
relegation 95

ratiocinatio 82

reason, device $376,377,384$

reasoning

absurd 186

conductive 88

Reboul, O. 97, 100, 192, 196

recapitulatio 176

recapitulation. See recapitulatio

reductio ad absurdum I43, I44, I48-I57

reference, intertextual 280

refutation 56,58

Reijnders, S. 248-250

remembrance 176

repetition $\quad \mathrm{I} 64$

figure of 358

figures $\quad$ I77

technique $\mathrm{I} 8 \mathrm{O}$

rhetoric 219, 223, 225, 228, 229

classical, 220, 230, 236

of embattled free speech $26,39,40,42$,

44

of exception $308,32 \mathrm{I}$

of free speech $4 \mathrm{O}, 4 \mathrm{I}$

of normalcy 316

of truth model 222, 228, 230, $23 \mathrm{I}$

of victims and offenders 242,267

of Zapatero 32I

interpersonal $4 \mathrm{OI}$

mechanisms of 292

meta- 45

rhetorical

agency 407-409, 4I4-4I7, 420

aim in a communicative activity type

359,360

alarmist 2I2

a-rhetorical debate culture 420 aspect of parliamentary debate 36I

authority 206

blunder 36I

citizenship 407, 409, 4I4-4I6, 420

cliché 397

constitutive power 408

construction of future problem 203

criticism 4I4

device 230, 232, 308

effectiveness $359,362,365$

evolutionary (theory of) 45

failure 322

figure 197

frame 25

intention 408

maneuvering 40

perspective 107

ploy 37

question 196

reasonableness norm 424

school 49, 52-54, 56-58

strategy $25,30,220,224,308,321,322$,

367

technique I66, I68, I7I-I74, I76, I79,

349, 358

training in the spirit of Aphthonius'

Progymnasmata 58

turn 192

Rhetoric to Alexander 95

rule, legal 423-426, 428, 435

salutation $169, \mathrm{I} 74, \mathrm{I} 8 \mathrm{O}$

sarcasm 196

satire $\quad$ 188, I89

saying $\quad$ I77

science, empirical $\quad$ I98

semiotic space 278,280

SGP $\quad 352,353$ 
Siedenfaden, T. 90, 9I

Sloan Wilson, D. 44

Slob, A., member of the CU $352,358,359$, 363

Snoeck Henkemans, A.F. 8I, I45-I47

Socialist Party. See SP

Socialistische Partij. See SP

Socrates $27-30$

solemnity $68,72,73,75$

sophist $28,30,52$

Second Sophistic movement 52

soundbite $163, \mathrm{I} 77$, I80, I8I

SP $352,355-357,363,364$

speech

inclusive $309,316,322$

ministerial I59, I60, I63, I67, 172, I73,

I79, I8I

occasional I6I, I62, I67-I69, I7I, I76,

I77

of rational dialogue 317

policy I62, I67-171, 176, I77, I80

Staaij, C.G. van der, member of the SGP $352,353,358,359$

Staatkundig Gereformeerde Partij. See SGP standpoint

legal 43I

radical 352

starting point rule

violation 43I, 434, 435

status

atechnic 228

entechnic 228

status legales $82,83,86,90$

stereotype 245,246

contrast $25 \mathrm{I}$

crime 24I, 244, 249

feature of offender 254 ideal offender 252

ideal victim 252

identification $25 \mathrm{I}$

image of victim and offender 266

innocent victim 249

media portrayal 263,266

offender 242, 249-252, 26I

offender without a conscience 249

suspect 249

victim 242, 249, 25I, 252, 260

victim and offender $242,248,260$

Stewart, S. 329, 33I, 333

Stjernfelt, F. 90, 9I

stock character 54

story 226,229

credibility 230

drink spiking 22I

first-hand 234

friend-of-a-friend 227

informal 22I

personal experience 22I, 229, 236

second-hand 234

storytellers 227

strategic maneuvering IO3, 358, 359, 424,

430, 43I, 433-436

argumentation stage $133, \mathrm{I} 34, \mathrm{I} 36$

derailment of 430,431, 433-436

in a parliamentary debate 362,365

involving praeteritio $\mathrm{I} 4 \mathrm{I}$

strategic maneuvering in parliamentary

debate 359,366

audience-directed 359, 36I

topical potential $359,36 \mathrm{I}$

presentational device $359,36 \mathrm{I}$

straw man $8 \mathrm{I}$

style I85, I88, I95, I97

and argument I85, I88, I90, I92, I95, 
196

Attic 52

bookish I8O

compact 185

device 187

exercises in 185

figure I9I, 195, 196, 197

koiné 52

literary 197

low 197

prescription 197

technique 170

style device 187

hyperbole 186,187

irony 187

metaphor 187

satire 185, I 87

style, communication, of new political

parties in Western Europe

breadth of the issue agenda 328,330 ,

334, 336, 339, 34I, 344

emphasis on party leaders. See personali-

sation

narrow issue agenda $327,328,330,33$,

344,345

personalisation $327-329,334,336,337$,

339, 340, 344

suasoriae 53

subjunctive If...then sentence I44, I5I, I57

summary 176

Sunstein, C. $34-36$

Surette, R. 247

symptomatic I44, I48, I5O

argument I45, I46, I48, I5O, I54-I57

argumentation scheme I45-I47

synthesis, study II9, I2O

meta-analysis review II9-I2I, I26 narrative review II8-I2O

Tacitus 53

tale

cautionary 246

folk 228

friend-of-a-friend 22I, 227, 229, 23I

second-hand 22I

third-hand 22I

Taylor, C. 26

Theodosius 53, 56

Thorning-Schmidt, H., Danish Social

Democratic leader 4II

Thucydides 55

Tindale, C.W. Ior

topoi 294, 297, 301, 302

topology 274

topos 39, 40, 228, 374

commonplace 397

free speech 39

legal discourse 423

meta-communicative 403

of location 299, 300, 302

of membership 298, 300, 301

topos, lay 395, 397, 403

(self-) contradiction 397,402

ability 397,402

contrast between feelings and facts 397 ,

399

contrast between impartiality and bias

397, 4OI

moral necessity 397-399

natural(-ness) 397, 40I

personal authority 397,400

risk and preciousness $397,398,400$,

4 I I

security 397-399

utility 397,398 
Toulmin, S.

warrant 83

transition

to the kernel of the speech $\quad$ I73

to the middle of the speech 173

to the next sub topic in the speech 180

triptych 279

Tversky, A. $\quad$ I24

typology, meaning 274

typology of crime legend belief and disbelief

$22 \mathrm{I}$

uncertainty, four issues of 204

magnitude 204, 206, 209, 2II, 2I4

prediction, 203-206, 209-2I2, 215, 216

probability 204, 208, 209, 2II, 2I5

timing 204, 2IO, 2II

Usher, S. 136

validity

deductive IOS

formal IOS

impersonal 97

Van Leeuwen, T. $275,277,278,280,282$, 283

Vanderveen, G. 25I

Velde, H. te $350,364,365$

Vestager, M., member of the Danish Social

Liberal Party 409, 4II-4I7, 4I9

victim 25I, 252

Vogelaar, E., former Minister of Integration

351,363

Voltaire $\quad 189$

Vries, P.R. de 243, 244, 248, 249, 259

The Peter R. de Vries Show 242, 243,

$248,249,252,262-264,267$

warrant 83

Wenzel, J.W. IOI, IO2

Wilders, G. 25, 26, 37, 38, 4I, 42, 335, 338,
$350-359,363-366$

polarisation 365

rhetorical strategy 25

Willems, J. I86

Wit, J. de, member of the SP 352, 355-359, 363,364

Woodruff, P. 30

Wooffitt, R. 225

Zapatero, J.L.R. 308, 316-324 
